Nina Seiler

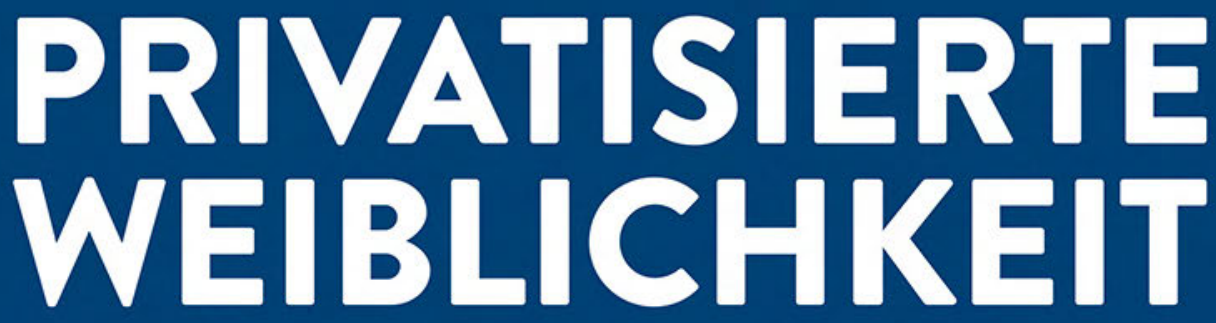

Genealogien und Einbettungsstrategien feministischer Kritik im postsozialistischen Polen

[transcript] Gender studies 
Nina Seiler

Privatisierte Weiblichkeit

Gender Studies 
Nina Seiler, geb. 1986, ist Slavistin und Kulturwissenschaftlerin mit Schwerpunkt Polen. Zu ihren Forschungsinteressen zählen die Dynamiken der (post-) sozialistischen polnischen Gesellschaft und Kultur, performative Praktiken von Körper und Geschlecht sowie Prozesse der Wissensgenerierung. Sie verfasste ihre Dissertation im Rahmen des Doktoratsprogramms »Gender Studies« der Universität Zürich und ist in ein Forschungsprojekt zu kommunitären Konzepten in der polnischen Kultur involviert. Sie lebt und arbeitet in Zürich und Warschau. 
NinA SEILER

\section{Privatisierte Weiblichkeit}

Genealogien und Einbettungsstrategien feministischer Kritik im postsozialistischen Polen 
Die vorliegende Arbeit wurde von der Philosophischen Fakultät der Universität Zürich im Frühjahrssemester 2017 auf Antrag der Promotionskommission, bestehend aus Prof. Dr. German Ritz (hauptverantwortliche Betreuungsperson) und Prof. Dr. Sylvia Sasse, als Dissertation angenommen.

Die Druckvorstufe dieser Publikation wurde vom Schweizerischen Nationalfonds zur Förderung der wissenschaftlichen Forschung sowie von der Gleichstellungskommission der Universität Zürich unterstützt.

\section{(9)(1) $\Theta \Theta$}

Dieses Werk ist lizenziert unter der Creative Commons Attribution-NonCommercial-NoDerivs 4.0 Lizenz (BY-NC-ND). Diese Lizenz erlaubt die private Nutzung, gestattet aber keine Bearbeitung und keine kommerzielle Nutzung. Weitere Informationen finden Sie unter https://creativecommons.org/licenses/by-nc-nd/4.o/deed.de Um Genehmigungen für Adaptionen, Übersetzungen, Derivate oder Wiederverwendung zu kommerziellen Zwecken einzuholen, wenden Sie sich bitte an rights@transcript-verlag.de

\section{(C) 2018 transcript Verlag, Bielefeld}

\section{Bibliografische Information der Deutschen Nationalbibliothek}

Die Deutsche Nationalbibliothek verzeichnet diese Publikation in der Deutschen Nationalbibliografie; detaillierte bibliografische Daten sind im Internet über http://dnb.d-nb.de abrufbar.

Umschlaggestaltung: Maria Arndt, Bielefeld

Satz: Andreas Bertschi

Druck: Majuskel Medienproduktion GmbH, Wetzlar

Print-ISBN 978-3-8376-4189-9

PDF-ISBN 978-3-8394-4189-3

Gedruckt auf alterungsbeständigem Papier mit chlorfrei gebleichtem Zellstoff. Besuchen Sie uns im Internet: http://www.transcript-verlag.de

Bitte fordern Sie unser Gesamtverzeichnis und andere Broschüren an unter: info@transcript-verlag.de 


\section{Inhalt}

\section{Vorwort | 9}

\section{Einleitung $\mid 11$}

1.1 Forschungsstand I 15

1.2 Die ,Klassiker feministischer Polonistik | 18

1.3 Intertextualität, Intonation, Ideologem I 24

1.4 Der Standpunkt als epistemologische Herausforderung | 34

1.5 Aufbau der Arbeit I 38

2. Geschlechtergeschichte Polens - Mythen, Fakten, Diskurse | 41

2.1 Adliger Geschlechtervertrag und Matka Polka | 42

2.2 Emanzipationsbestrebungen | 45

2.3 Gleichstellung in der Volksrepublik | 52

2.3.1 Rückkehr des Geschlechts I 55

2.4 Neuorientierung der 1990er Jahre I 60

2.4.1 Die Geschlechterfrage als Scheideweg I 63

2.4.2 Akademischer Feminismus | 70

\subsubsection{Feministische Polonistik | 81}

\section{Maria Janion - Wege zur feministischen Kritik | 89}

3.1 Romantik, Phantasma, Transgression I 90

3.1.1 Aufopferung und Emanzipation | 94

3.1.2 Maskerade, Mentalismus, Wahnsinn | 97

3.1.3 Jenseits geschlechtlicher Binarität | 103

3.2 »Hermeneutik der Verdachte«: Kritische Wissenschaft I 105

3.2.1 Transnationale Perspektiven I 108

3.2.2 Feministische Kritik als Notwendigkeit I 111 
3.3 /lkonen der feministischen Polonistik | 113

3.3.1 Die Kondition der Frauen I 116

3.3.2 Geschlecht und Identität | 119

3.3.3 Komornicka/Włast, Janion und die feministische Kritik | 122

4. Rezeptionslinien $\mid 129$

4.1 Geschichte(n) des Feminismus | 130

4.1.1 Erbfolgen. Zur Genealogie feministischer Kritik | 136

4.1.2 (In)Kongruenzen I 143

4.2 Die große Abwesende: Psychoanalyse I 147

4.2.1 Literatur als epistemologisches Medium I 149

4.2.2 Umgänge mit Freud - Freud umgehen? | 155

4.3 Grenzgehen. Liminale Figuren, liminale Texte | 164

4.3.1 Die Funktion liminaler Figuren I 165

4.3.2 Filtertexte | 169

4.3.3 Katalysatoren I 173

5. Literatur und Geschlecht $\mid 181$

5.1 Rezeptionskritik | 182

5.1.1 Den Zeitgeist dekonstruieren | 183

5.1.2 Reading among women | 189

5.1.3 Affektive Lektüren, vorgefertigte Urteile | 192

5.2 Weibliches Schreiben I 197

5.2.1 Definitions- und Kategorisierungsversuche | 199

5.2.2 Eine eigene Sprache I 206

5.2.3 Oberfläche und Spalten I 213

5.3 Tradierungen I 217

5.3.1 Archäologien am Text | 218

5.3.2 Matrilineare Genealogien | 223

6. Postsozialistische Abgrenzungen | 231

6.1 Die weibliche Sphäre | 232

6.1.1 Pathologische und phantasmatische Mütter | 236

6.1.2 Schwangerschaft, Geburt, Abort I 243

6.1.3 Krzątactwo und Klassenblindheit I 248

6.2 Politisches und Apolitisches I 253

6.2.1 Geschlechterordnung und (anti)politischer Diskurs | 256

6.2.2 Feministische Ideologie | 259

6.2.3 The Personal is (not) Political I 265

6.2.4 Abschied vom polnischen Gemeinschaftsnarrativ | 270 
6.3 Gemeinsam einsam I 278

6.3.1 Affektierte Körper | 282

6.3.2 Ausgrenzungen I 286

6.3.3 Geschlossene und offene Apelle | 289

7. Schlusswort | 297

7.1 Positionierungen feministischer Kritik der 1990er Jahre I 298

7.2 Von Spalten zu Spaltungen. Ausblick auf das 21. Jahrhundert I 302

Literaturverzeichnis | 311

Begriffs- und Titelverzeichnis $\mid 337$ 



\section{Vorwort}

Das vorliegende Buch stellt in nur leicht veränderter Form die Publikation meiner im Mai 2017 an der Universität Zürich verteidigten Doktorarbeit dar. Meine Forschungsarbeit im Bereich feministischer Kritik in der polnischen Literaturwissenschaft der 1990er Jahre hatte von Beginn an Patchworkcharakter, da sich mir im analysierten Material unterschiedlichste Narrationen in einem rhizomatischen Diskursfeld eröffneten. Im Prozess, in dem dieses fragmentarische Arbeiten schließlich in eine lineare verschriftlichte Form fand, konnte ich immer wieder auf die Unterstützung von Menschen und Institutionen zählen, denen ich hiermit danken möchte.

Seinen Ursprung nahm die unternommene Forschungsarbeit im Gespräch mit meinem Betreuer German Ritz, der mich nicht nur motivierte, das Projekt Doktorarbeit überhaupt anzugehen, sondern mit seinem enormen Vorwissen auch thematisch richtungsweisend war. Mit der Teilhabe an seinem Wissen und dem Eröffnen neuer Pfade sorgte er dafür, dass ich in der Entwicklung eigener Thesen den Rundumblick nicht verlor. Meine Zweitbetreuerin Sylvia Sasse steuerte eine genauso wertvolle Außenperspektive auf den polonistischen Kontext bei und leistete neben institutioneller Unterstützung pragmatische Hilfe bei Gedankenstaus. Die Umsetzung des Forschungsvorhabens und eine Zeit intensiver Auseinandersetzung mit dem Thema ermöglichte mir die Universität Zürich mit der Zusprache des Forschungskredits Candoc. Einen längeren Forschungsaufenthalt an der Polnischen Akademie der Wissenschaften in Warschau konnte ich dank der finanziellen Unterstützung des Förderprogramms Doc.Mobility des Schweizerischen Nationalfonds verwirklichen.

Das literaturwissenschaftliche Kolloquium am Slavischen Seminar der Universität Zürich, dessen Infrastruktur ich schon seit über zehn Jahren zu schätzen weiß, bot mir eine Diskussionsplattform im slavistischen Rahmen und trug entscheidend dazu bei, meine Gedanken zu schärfen und in die richtige Form zu bringen; außerdem haben mir Jelica Popović, Anne Krier, Sandra Frimmel, Matthias Meindl und Tatjana Hofmann in kritischen Momenten durch ihre Inputs weitergeholfen. Dem Kolloquium des Doktoratsprogramms Gender Studies der Universität Zürich und dessen Koordinatorin Therese Steffen verdanke ich eine 
feministische Horizonterweiterung und die Sensibilisierung für intersektionelle Denkansätze. Meine Ansprechpartnerinnen am Institut für Literaturforschung IBL PAN in Warschau waren Grażyna Borkowska sowie Monika Rudaś-Grodzka und der von ihr geleitete Arbeitszirkel, der sich damals noch als Arbeitszirkel »Literatur und Gender« regelmäßig traf. In diesen Treffen konnte ich meine Thesen vor einem informierten Publikum überprüfen, das konstruktive Kritik und weiterführende Ideen einbrachte. Außerdem danke ich Paulina Pilch, Dobrochna Kałwa und Agnieszka Mrozik für einführende Hinweise vor und zu Beginn meines Warschauer Forschungsaufenthalts.

Durch ihre kritischen Lektüren haben mich Selina Wenger, Ursula Weber, Conny Trümpi, Kathrin Seiler-Erb, Dorota Sajewska, Jürg Mühlemann, Gianna Frölicher, Isabelle Baume und Jovin Barrer enorm entlastet. Reto Plattner bildete mit seiner Korrekturarbeit die letzte Instanz vor der Abgabe der Dissertation und sorgte somit für das notwendige Setzen des Schlusspunkts. Nicht zuletzt gebührt auch der Röschi Dank für ihre Geduld und Unterstützung in der Abschlussphase.

Ich freue mich, dass das Manuskript der Arbeit auf Interesse beim transcript Verlag gestoßen ist und nun mit finanzieller Unterstützung des Schweizerischen Nationalfonds in der Reihe Gender Studies erscheint. Der Satz durch Andreas Bertschi wurde durch den ergänzenden Publikationszuschuss der Gleichstellungskommission der Universität Zürich ermöglicht.

Warschau, den 9. März 2018 


\section{Einleitung}

Polen und feministische Kritik - die Frage, wie dies zusammengeht, stellt sich gegen Ende der 2010er Jahre wieder mit zunehmender Dringlichkeit. In der sich spaltenden polnischen Gesellschaft, in der religiöse und säkulare, konservative und liberale Weltsichten immer stärker auseinanderdriften und zunehmend in Konflikt geraten, nimmt die Frage nach den Geschlechterrollen eine zentrale Funktion ein. Seit der Machtübernahme der katholisch-konservativen Partei Prawo i Sprawiedliwość (PiS, Recht und Gerechtigkeit) im Herbst 2015 versucht diese, der polnischen Gesellschaft eine immer restriktivere Geschlechterpolitik überzuwerfen, was zum Beispiel im Oktober 2016 zu der frauenrechtlichen Protest- und Streikwelle unter dem Schlagwort Czarny Protest (Schwarzer Protest) führte.

Doch die Frage nach der Geschlechterordnung bildete bereits vor wie auch nach dem Beginn der Transformation von 1989 einen Kernpunkt der gesellschaftspolitischen Aushandlungen. Die 1990er Jahre verzeichneten neben einer stärkeren geschlechtlichen Sphärenteilung auch einen Zuwachs feministischen Engagements in Politik und Wissenschaft, dessen Rolle in der polnischen Gesellschaft jedoch eher marginal blieb. Die feministische Kritik stellte sich den Naturalisierungsbestrebungen der katholischen Kirche und politisch konservativer Kreise entgegen und versuchte aufzuzeigen, dass die (neo)traditionellen Geschlechterrollen und -stereotypen kein unausweichliches Schicksal sein müssen. Als Reaktion auf feministische Argumentationen wurde 2013 schließlich medial Jagd auf das `Gender-Monster eröffnet, das dem katholischen Konservatismus als Sinnbild des westlichen, über Polen hereinbrechenden Sittenzerfalls gilt.

Die Kritik der polnisch-puristischen Konservativen steht in Zusammenhang mit der auch kulturellen und wissenschaftlichen Ost-West-Annäherung im Zuge der Transformation: Tatsächlich schöpfte die feministische Kritik und die Genderforschung große Inspiration aus den im Westen - in Frankreich, Deutschland oder den USA - konzipierten Theorien zur Kategorie des Geschlechts und deren methodischer Erforschung. Im 'Westen bildete sich mit den 1970er Jahren die 'Zweite Welle des Feminismus heraus, während der Geschlechterdiskurs in Polen und anderen Staaten des `Ostblocks $`$ zu dieser Zeit weitgehend brach lag oder gerade wieder stärker in ein binäres Rollenverständnis fand. Die 1989 einsetzende Sys- 
temtransformation machte vielen polnischen Frauenaktivistinnen bewusst, dass die Geschlechterungleichheit durch die demokratisch-kapitalistische Restrukturierung noch verstärkt wurde. Bei steigender Arbeitslosigkeit und destabilisierten Gesellschaftsmodellen sahen viele Polen und auch Polinnen feste Geschlechterrollen als einen Fixpunkt im sich zersetzenden System.

Vor diesem Hintergrund und gerade mit der Installierung eines Abtreibungsverbots im Jahre 1993 - dem ersten Sieg des katholisch geprägten Konservatismus - wuchsen latent bestehende Gleichstellungsbestrebungen zu einer wenn auch instabilen Frauenbewegung an. Mit dieser Entwicklung erwachte - so das Narrativ - die publizistische und wissenschaftliche Beschäftigung mit der Kategorie des Geschlechts und mit dem Feminismus aus dem Dornröschenschlaf. Aufgrund einer nur schmalen heimischen Tradition richteten Feministinnen und Geschlechterforscher/innen den Blick auf das feministische Schaffen im westlichen Ausland, von wo zunehmend nicht nur Ansätze und Methoden, sondern auch Übersetzungen feministischer Publikationen nach Polen kamen, sekundiert von Gastprofessor/innen und Mitarbeiter/innen westlicher NGOs. In Anbetracht dieses Phänomens ist es naheliegend, für die 1990er Jahre von einem Transfer feministischen Gedankenguts zu sprechen, das dem westlichen Kontext entlehnt und auf polnischem Grund implementiert wurde. An diesem Punkt setzt denn auch die vorliegende Arbeit an, deren vorläufiges Ziel es war, die Transferprozesse feministischer Theorie in der polnischen Literaturwissenschaft als gleichsam wissenschaftliches wie poetologisches Phänomen zu untersuchen und zu beschreiben.

Als Untersuchungsmaterial legte ich fünf polonistische Monographien der 1990er Jahre fest, die als `Klassiker ' dieser Zeit und als `Meilensteine ‘ für die Entwicklung feministischer Perspektiven in der polnischen Literaturwissenschaft gelten können und weiter unten vorgestellt werden. ${ }^{1}$ Ziel war es, die polnische literaturwissenschaftliche Rezeption von ‘westlichen`Geschlechtertheorien dahingehend $\mathrm{zu}$ untersuchen, mit welchen Argumenten bestimmte theoretische oder methodische Ansätze eingeführt und im polnischen Kontext eingebettet wurden. Dabei ging bereits aus anderen Metauntersuchungen hervor, dass es sich bei der

1 I Es handelt sich hierbei um die folgenden, hier chronologisch geordneten Texte: Iwasiów, Inga: Kresy w twórczości Włodzimierza Odojewskiego. Próba feministyczna [Die Kresy im Schaffen Włodzimierz Odojewskis. Ein feministischer Versuch], Szczecin 1994; Janion, Maria: Kobiety i duch inności [Frauen und der Geist des Andersseins], Warszawa 1996; Borkowska, Grażyna: Cudzoziemki. Studia o polskiej prozie kobiecej [Ausländerinnen. Studien zur polnischen weiblichen Prosa], Warszawa 1996; Kłosińska, Krystyna: Ciało, pożądanie, ubranie. 0 wczesnych powieściach Gabrieli Zapolskiej [Körper, Begehren, Kleidung. Zu den frühen Romanen Gabriela Zapolskas], Kraków 1999; Kraskowska, Ewa: Piórem niewieścim. Z problemów prozy kobiecej dwudziestolecia międzywojennego [Mit weiblicher Feder. Von den Problemen weiblicher Prosa der Zwischenkriegszeit], Poznań 1999. Bei Buchtiteln bedeutet eine kursive Übersetzung in Klammern, dass der Titel in Übersetzung vorliegt und als solcher übernommen wurde. Bei stark abweichenden Titelübersetzungen füge ich die wörtliche Übersetzung in eckigen Klammern hinzu. 
postsozialistischen Theorieentwicklung in den 1990er und 2000er Jahren, gerade auch in Bezug auf Geschlechtertheorien, um das Phänomen einer "Verknotung « ${ }^{2}$ handelte; die Ansätze verschiedener 'Wellen` der westlichen Geschlechterforschung wurden quasi zeitgleich und parallel rezipiert, womit eine Vermengung, Überlagerung oder eben Verknotung unterschiedlicher und sich mitunter widersprechender Theorien stattfand. Die Verknüpfung essentialisierend-abgrenzender und performativ-öffnender Sichtweisen auf die Kategorie des Geschlechts sollte den komplexen Herausforderungen der normativen postsozialistischen Gesellschaft wie auch den dekonstruktivistischen Tendenzen neuester Forschung im Westen gerecht werden. ${ }^{3}$

Solche strategischen Theorieverknüpfungen ließen sich in den Texten feministischer Polonistik der 1990er Jahre nur erst marginal erkennen. Performative und gender-orientierte Ansätze wurden kaum rezipiert; im Vordergrund standen feministische und mitunter weiblich-essentialistische Ansätze der französischen und US-amerikanischen 1970er und 1980er Jahre. Während dieser >Rückgriffs auf einen Feminismus, für den die weibliche Identität und Differenz im Vordergrund steht, durchaus kritisch betrachtet werden kann, steht diese Entwicklung im Lichte des gesellschaftlichen Kontexts im Polen der 1990er Jahre. Es ging den feministischen Polonistinnen vorerst darum, überhaupt ein Bewusstsein für vergeschlechtlichte Hierarchien in der Gesellschaft und im kulturellen Schaffen zu erzeugen, womit die Konstitution einer Kategorie der Frauen und der Weiblichkeit als Identitätsangebot zu einem zentralen Anliegen wurde.

Das Phänomen des Theorietransfers wies somit zwei Dimensionen auf: eine räumliche und eine zeitliche. Gleichzeitig fiel in meinen Untersuchungen auf, dass diese Dimensionen in den polonistischen Texten in der Regel nivelliert wurden. Die feministischen Forscherinnen in Polen stellten zwar fest, dass die polnische Wissenschaft und damit auch die Polonistik dem Aspekt des Geschlechts bislang wenig oder keine Beachtung geschenkt hatte; sie konstruierten jedoch keine grundlegende historische oder geographische (und damit auch kulturelle) Differenz zum Entstehungskontext der rezipierten feministischen Ansätze. Dies lässt sich damit erklären, dass feministische Theorien gerade der Zweiten Welle die symbolische Geschlechterordnung des abendländischen >Patriarchats` als sowohl historisch wie räumlich konstant und flächendeckend inszenieren und sich auf dieses als universale Ordnung beziehen. Der `Anschluss` der polnischen feministischen Kritik an ein gesamteuropäisches feministisches Bewusstsein ließ sich somit durch den gemeinsamen Bezugspunkt des omnipräsenten Patriarchats na-

2 I Robert Kulpa und Joanna Mizielińska nennen dies "a constant ’knotting ‘ and looping of time(s) after 1989«. Kulpa, Robert/Mizielińska, Joanna: »Contemporary Peripheries‘: Queer Studies, Circulation of Knowledge and East/West Divide«, in: dies., De-Centring Western Sexualities (2011), S. 11-26, hier S. 15.

3 I Vgl. Iwasiów, Inga: Gender dla średnio zaawansowanych. Wykłady szczecińskie, Warszawa 2004, S. 82. 
turalisieren. Die Dethematisierung kultureller und sozialer Differenzen zwischen dem 'Westen postsozialistische Assimilierungsstrategie an die ehemalige `Erste Welt ' gelesen werden.

Die spezifische Ausrichtung der untersuchten polonistischen Texte ließ mich die These des >Theorietransfers aus dem Westen hinterfragen. Es stellte sich heraus, dass die feministischen Kritikerinnen zwar durchaus Inspiration und mitunter auch Legitimation aus den westlichen Ansätzen schöpften; die Arbeit mit dem lokalen literarischen Material nahm jedoch eine mindestens ebenso wichtige Rolle ein. Einzelne Monographien der feministischen Polonistik waren bestrebt, die weibliche Literatur des 19. und frühen 20. Jahrhunderts aufzuarbeiten; besonders die flächendeckenden Arbeiten Grażyna Borkowskas zum 19. Jahrhundert und Ewa Kraskowskas zur polnischen Zwischenkriegszeit offenbaren diese Tendenz. Alle im Rahmen der vorliegenden Arbeit behandelten Texte verstehen die von ihnen untersuchten Schriften als weltanschaulich strukturiertes Material und als gewichtete Aussagen zur Geschlechterdebatte. Die Forscherinnen stellten fest, dass die Texte aus dem 19. Jahrhundert emanzipatorische, wenn nicht gar feministische Züge tragen, die zum Teil bis heute aktuell sind und als Gedankenanstöße in die wissenschaftlichen Überlegungen miteinbezogen werden können. Es handelte sich also in gewisser Weise auch um einen Ideentransfer aus der polnischen Literaturgeschichte. Damit musste die Analyseperspektive in der vorliegenden Arbeit geöffnet werden und nahm einen integrativeren, stärker am lokalen Kontext orientierten Charakter an.

Ziel der vorliegenden Arbeit ist somit die Beschreibung und Analyse der feministischen Kritik in der Polonistik der 1990er Jahre als ein multirelationales Diskursfeld. ${ }^{4}$ Als die drei Hauptvektoren der intertextuellen Bezüge meines Untersuchungsmaterials verstehe ich die westlichen Theorieansätze, die polnische Literatur- und Kulturgeschichte sowie die kontextuelle Einbettung in die gesellschaftlichen Prozesse der Transformationsjahre. Mit letzterer wird die Frage nach dem politischen Charakter der feministischen Kritik und ihrem Beitrag zur Formung der postsozialistischen Gesellschaft aufgeworfen. Entlang der drei Konzepte der Intertextualität, der Intonation und des Ideologems, die ich weiter unten bespreche, versuche ich den vielseitigen Bezügen der untersuchten Texte, ihren spezifischen Argumentationsstrategien sowie den Fragen nach der Kontextualisierung in der polnischen Wissenschaft und Gesellschaft der 1990er Jahre gerecht zu werden. Meine Analyse soll deshalb eine gleichsam poetologische wie politische sein und dabei wissenschaftliche Texte als eine Form intertextueller Bezug-

4 । Ein Diskursfeld oder diskursives Feld wird hier verstanden als der Rahmen, in dem unterschiedliche Diskurse sich auf ein bestimmtes Thema beziehen und somit eine Intersektion konkurrierender Narrative bilden. »Discursive fields consist of competing ways of giving meaning to the world and of organizing social institutions and processes." Weedon, Chris: Feminist Practice and Poststructuralist Theory. Second Edition, Oxford 1987 (1997), S. 34. 
und Stellungnahme verstehen. Somit werden die Texte polnischer feministischer Kritik zu Bausteinen einer postsozialistischen Gesellschaft, in denen rhetorische Brüche, Leerstellen und Ambivalenzen genauso Bedeutung erzeugen können wie explizit in den Vordergrund gekehrte Themen und Argumentationen.

\subsection{Forschungsstand}

Metaanalysen über die feministische Kritik in der Polonistik der 1990er Jahre gibt es bisher eher wenige. $\mathrm{Zu}$ nennen sind hier besonders zwei Dissertationen aus dem Jahr 2012. Katarzyna Majbroda untersucht in ihrer Arbeit Feministyczna krytyka literatury w Polsce po 1989 roku. Tekst, dyskurs, poznanie z odmiennej perspektywy (Feministische literarische Kritik in Polen nach 1989. Text, Diskurs, Erkenntnis aus anderer Perspektive) ${ }^{5}$ das lekturologische Projekt feministischer Kritik in Polen. Im Zentrum ihrer Analyse steht das vergeschlechtlichte Lesen »als Frau « (jako kobieta) ${ }^{6}$, das Majbroda detailliert anhand dreier auch in der vorliegenden Arbeit besprochener Polonistinnen (Ewa Kraskowska, Krystyna Kłosińska und Inga Iwasiów) diskutiert. Majbroda geht dabei eher am Rande auf den soziohistorischen Hintergrund ein und ordnet sich konzeptuell größtenteils der Perspektive der damaligen feministischen Kritik unter. Darin unterscheidet sie sich stark von der ebenfalls 2012 erschienenen Dissertation Agnieszka Mroziks unter dem Titel Akuszerki transformacji. Kobiety, literatura i władza w Polsce po 1989 roku (Hebammen der Transformation. Frauen, Literatur und Macht in Polen nach 1989). ${ }^{7}$ Mrozik bezieht in ihre Untersuchung vor allem literarische, aber auch wissenschaftliche Diskurse ein und analysiert diese im Kontext transformationaler soziopolitischer Prozesse kritisch. Hauptleistung ihrer Arbeit ist das Aufzeichnen der vielfältigen Narrative, denen sich die feministische Kritik und der weibliche literarische Diskurs nach 1989 implizit oft unterordnen, wodurch der feministische Diskurs zu einem der Motoren der (neo)liberalen Umformung der Gesellschaft wird - daher der Titel »Hebammen der Transformation«.

Bei beiden hier vorgestellten Publikationen ergeben sich Überschneidungen mit der vorliegenden Arbeit. Mit der Dissertation Mroziks verbindet meine Arbeit das kritische Moment und die Einbettung im soziopolitischen Kontext; mit der Dissertation Majbrodas hingegen die stärker lekturologische Ausrichtung und die Fokussierung auf den literaturwissenschaftlichen Kontext. In Abgrenzung zu Majbroda wie auch Mrozik konzentriert sich die vorliegende Arbeit aber stärker

5 I Vgl. Majbroda, Katarzyna: Feministyczna krytyka literatury w Polsce po 1989 roku. Tekst, dyskurs, poznanie z odmiennej perspektywy (= Modernizm w Polsce, Band 41), Kraków 2012.

6 । Alle Übersetzungen aus dem Polnischen stammen, wenn nicht anders angegeben, von der Verfasserin der vorliegenden Arbeit.

7 | Vgl. Mrozik, Agnieszka: Akuszerki transformacji. Kobiety, literatura i władza w Polsce po 1989 roku, Warszawa 2012. 
auf die poetologische Untersuchung wissenschaftlicher Texte. Neben dem Motiv feministischer Kritik rückt dabei die Frage nach der Position und Funktion wissenschaftlicher Rhetorik in den Vordergrund, womit ich eine Art transponierter Rezeptionsästhetik ${ }^{8}$ in die Analysen integriere. Hauptmerkmal meiner Arbeit ist zudem die Frage nach wissensgeschichtlichen Mechanismen, also die Untersuchung intertextueller Bezüge, die sich auf literarische wie (transnationale) theoretische Verknüpfungen erstrecken.

Eine ähnliche Perspektive nimmt die Diplomarbeit von Theresa Vatter, Die Rezeption der Gender Studies in der polnischen Literaturwissenschaft (2009), ${ }^{9}$ ein. Vatter untersucht anhand von in der polonistischen Zeitschrift Teksty Drugie (Zweite Texte) in den Jahren 1990-2008 veröffentlichten Artikeln mit breit verstandener Geschlechterthematik die transnationale Rezeption der Gender Studies. Das Untersuchungskorpus dieser Arbeit ermöglicht mir, mich in der vorliegenden Arbeit auf die feministischen Monographien zu konzentrieren und die für die Dynamik der feministischen Kritik in Polen relevanten Zeitschriftenartikel nur punktuell in die Analyse miteinzubeziehen.

Neben diesen drei Arbeiten lassen sich vereinzelte Artikel zum Theorietransfer in Polen und/oder der feministischen Kritik finden; besonders erwähnenswert ist der Sammelband De-Centring Western Sexualities. Central and Eastern European Perspectives (2011), ${ }^{10}$ herausgegeben von Robert Kulpa und Joanna Mizielińska, dessen Grundgedanke der »Verknotung “ postkommunistischer Zeitlichkeit mit der >westlichen $<$ Zeit ich implizit in der vorliegenden Arbeit (kritisch) mitdenke. Unter dieser Verknotung verstehen Kulpa und Mizielińska die simultane Rezeption verschiedener, im >Westen $`$ diachron abfolgender Strömungen der Auseinandersetzung mit Sexualität(en). ${ }^{11}$ Detailliertere Überlegungen zur transnationalen Rezeption von Theorien in einem diesbezüglich als >unbeschrieben verstandenen polnischen Kontext finden sich auch in Mizielińskas Monographie Płeć Ciało Seksualność. Od feminizmu do teorii queer (Geschlecht Körper Sexualität. Vom Feminismus zur queer theory) von 2006. ${ }^{12}$ Einen geschlechterfokussierten Ansatz wählt German Ritz in seinem kurzen Aufsatz Gender studies dziś. Budowanie teorii $i$ wędrowanie teorii (Gender Studies heute. Theoriebildung und das Wandern

8 | Zur Rezeptionsästhetik vgl. Iser, Wolfgang: »Die Appellstruktur der Texte«, in: Warning, Rainer (Hg.), Rezeptionsästhetik. Theorie und Praxis, München 1975, S. 228-252.

9 I Vgl. Vatter, Theresa: Die Rezeption der Gender Studies in der polnischen Literaturwissenschaft, Unveröffentlichte Diplomarbeit, Passau 2009.

10 I Vgl. Kulpa, Robert/Mizielińska, Joanna (Hg.), De-Centring Western Sexualities. Central and Eastern European Perspectives, Farnham 2011.

11 I Vgl. Kulpa/Mizielińska: 'Contemporary Peripheries‘, S. 15. Siehe auch Ritz, German: "Literatura w labiryncie pożądania. Homoseksualność a literatura polska«, in: Pogranicza 1 (1998), S. 92-99, hier S. 93, der dieselbe Diagnose bereits früher für die Geschlechter- resp. Frauenforschung stellt.

12 I Vgl. Mizielińska, Joanna: Płeć Ciało Seksualność. Od feminizmu do teorii queer, Kraków 2006. 
von Theorien), in dem er die Risiken von Theorietransfers, aber auch der Kategorie gender selbst in Bezug auf hegemoniale Tendenzen im gegenwärtigen Polen bespricht. ${ }^{13}$ Informativ und reflektiert präsentiert sich zudem Lena Magnones kürzlich erschienener Aufsatz Die polnischen Gender Studies (2016), in dem sie die feministische Kritik der 1990er Jahre in ihrer intertextuellen Bezugnahme skizziert. ${ }^{14}$ Eine spezifisch auf feministische Theorien zugeschnittene Metaanalyse (transnationaler) intertextueller Bezüge lässt sich außer bei den angesprochenen Fragmenten für den polonistischen Bereich jedoch noch nicht feststellen. Erwähnenswert ist an dieser Stelle letztlich der Sammelband Überbringen - Überformen - Überblenden. Theorietransfer im 20. Jahrhundert (2011), der mit dem Artikel Reflexionen zum Potential des Reisens feministisch motivierter Theoriebildung von Martina Kampichler Überlegungen anstellt, ${ }^{15}$ die ich ebenfalls als gedanklichen Bezugspunkt meiner eigenen Arbeit verstehe.

$\mathrm{Zu}$ erwähnen ist außerdem die starke Selbstreflexivität feministischer Überlegungen in Polen in den 1990er Jahren. In feministischen Zeitschriften der Zeit finden sich kontroverse Debatten über den Feminismus als solchen, besonders jedoch als Desiderat für die Frauenbewegung der 1990er Jahre. Es wird diskutiert, ob und inwiefern in Polen von einem >Feminismus ' gesprochen werden könne; diese Diskussion zieht sich jedoch nur am Rande in die explizit literaturwissenschaftliche Analyse hinein, die vor allem auf den bisher fehlenden Miteinbezug der Kategorie des Geschlechts in der Polonistik hinweist. Was auffällt, ist die sowohl in der politischen Feminismusdebatte wie auch in der literaturwissenschaftlichen feministischen Kritik der 1990er Jahre auftretende pauschale Umgehung oder Disqualifizierung des Geschlechterdiskurses in der Volksrepublik. Diese Auslassung möchte ich im ersten Teil der vorliegenden Arbeit (siehe Kapitel 2) aufzuarbeiten versuchen; dort diskutiere ich auch die Introspektion der feministischen Debatte der 1990er Jahre ausführlicher.

Den Zeitraum der 1990er Jahre und das Korpus an Monographien setze ich bewusst als relativ stark eingegrenzten Forschungsbereich. Dies hat zur Folge, dass hier von einem übersichtlicheren und homogeneren Feld der polonistischen feministischen Kritik gesprochen werden kann; trotz alledem divergiert in den untersuchten Arbeiten schon nur das Verständnis des `Feministischen stark. Doch ungeachtet deutlicher Differenzen im methodischen Ansatz und ideellen Hintergrund gelten die 1990er Jahre in der feministischen Polonistik und darüber hinaus als Zeitraum, in dem besonders die sweibliche Identität im Vordergrund stand.

13 I Vgl. Ritz, German: "Gender studies dziś. Budowanie teorii i wędrowanie teorii«, in: Teksty Drugie 113/5 (2008), S. 9-15.

14 I Vgl. Magnone, Lena: »Die polnischen Gender Studies«, in: Die Welt der Slaven. Internationale Halbjahresschrift für Slavistik 61/2 (2016), S. 371-398.

15 | Vgl. Kampichler, Martina: »Reflexionen zum Potential des >Reisens Theoriebildung«, in: Hüchtker, Dietlind/Kliems, Alfrun (Hg.), Überbringen - Überformen - Überblenden. Theorietransfer im 20. Jahrhundert, Köln 2011, S. 149-160. 
Diesen Befund diskutiere ich in der Arbeit und setze ihn in Verbindung mit postkommunistischen Diskursen. Besonders interessiert mich außerdem die Schwelle der Systemtransformation, weshalb ich auf eine Ausdehnung des Forschungsbereichs in die 2000er Jahre zugunsten eines stärkeren Miteinbezugs des Übergangs der 1980er zu den 1990er Jahre verzichte. Dennoch eröffnen sich an einzelnen Stellen der vorliegenden Arbeit auch Ausblicke auf die konzeptuelle Rekapitulierung und `Öffnung` der feministischen Kritik, die sich lose an den Umbruch zu den 2000er Jahren knüpfen lässt.

\subsection{Die ,Klassiker، feministischer Polonistik}

Obwohl in der Polonistik zunächst vor allem einzelne Artikel und Schwerpunkthefte zur feministischen Kritik erschienen, sind es die Monographien feministischer Ausrichtung, die das Bild dieser Strömung entscheidend prägten und in einer breiteren Öffentlichkeit wahrgenommen wurden. Ihre repräsentative Positionierung in der feministischen Kritik und die Versuche umfassender Skizzen $\mathrm{zu}$ bestimmten Themen/Epochen machen die im folgenden vorgestellten Werke $\mathrm{zu}$ hervorragendem Untersuchungsmaterial für die Prozesse zwischen diskursiver Einbettung und subversiver Lektüre im Kontext der Transformationsgesellschaft. An dieser Stelle fasse ich sowohl die Themenfelder der betreffenden Monographien sowie ansatzweise ihre jeweilige methodologische Ausrichtung kurz zusammen. Damit sollen erste Überschneidungen und Parallelitäten wie auch ebenso relevante Differenzen in der Methodik einführend skizziert werden.

Die erste explizit feministische Monographie in der Polonistik der 1990er Jahre war die Dissertation von Inga Iwasiów $\left({ }^{\star} 1963\right)$ an der Universität Szczecin, die 1994 als schmale Publikation unter dem Titel Kresy w twórczości Włodzimierza Odojewskiego. Próba feministyczna (Die Kresy im Schaffen Włodzimierz Odojewskis. Ein feministischer Versuch) erschien. Den feministischen Zugang bildet hier nicht primär der Blick auf die Geschlechterkonstellationen in den Texten - obwohl auch diese behandelt werden -, sondern vor allem das Einbringen einer subjektiven, subversiven Lesart, die bisherige Interpretationsparadigmen kontrastiert. ${ }^{16}$ "Ich will [den Expeditionen zum Podolen-Zyklus ${ }^{17}$ ] mein Geschlecht einhauchen, sie mit dem Raum der Weiblichkeit umgeben. Denn ich - eine Frau - lese und realisiere im Artikulieren der Interpretation meine ex definitione ideologischen Zie-

16 I Vgl. Iwasiów: Kresy, S. 13, wo sie nicht so sehr auf eine Dekonstruktion bisheriger Lesarten als auf eine abweichende, dezentralisierende Interpretation ihrerseits hinweist.

17 I Mit dem Podolen-Zyklus meint Iwasiów diejenigen Romane Odojewskis, deren Handlung in den ukrainischen Kresy angesiedelt ist und deren Figuren und Schauplätze sich überschneiden. Der Begriff Kresy (Grenzländer) bezeichnet die ehemaligen 0stgebiete der Republik Polen-Litauen, die heute in Litauen, Weißrussland und der Ukraine liegen. 
le. ${ }^{18}$ Das ambivalente Verfahren Iwasióws zeigt sich darin, dass sie einerseits eine Dezentralisierung patriarchaler Diskurse und somit eine Pluralität anstrebt, andererseits aber, wie das obige Zitat vermuten lässt, mitunter Versuchen der 'Wahrheitsfindung` und einer "Apotheose der Frau in der weiblichen Lektüre $~^{19}$ erliegt.

Iwasiów geht in ihrem dekonstruktivistischen Verfahren auf die Suche nach in den Text eingeschriebenen Archetypen. Sie trägt die »Schichten« (warstwy) der textuellen Kresy in einem zivilisationsarchäologischen Verfahren ab und versucht so, »die Figur zu finden, die im textuellen Gebirge am tiefsten liegt und dennoch Skizze der Substanz bleibt, nicht Substanz selbst. $\aleph^{20}$ Der Raum der ukrainischen Kresy funktioniert dabei als phantasmatisches Grenzland von Zivilisation und ,Wildnis` und als Gebiet des Aufeinanderprallens westlicher und östlicher Kulturen. In Bezug auf die auch in den Kresy greifende "patriarchale Unterwerfung" (opresja patriarchalna) zeichnet Iwasiów die Geschlechterkonstellation als ein ökonomisches Verhältnis auf, wobei die Frau im heiratsfähigen Alter als "Tauschmünze« (moneta wymienna) figuriere. ${ }^{21}$ Diese Auslegung ist bereits in den Texten Odojewskis deutlich angelegt. ${ }^{22}$

Insgesamt lässt sich über die Monographie Iwasióws sagen, dass sie kaum westliche feministische Ansätze einflicht, mit Ausnahme einzelner Verweise auf Kate Millett und Julia Kristeva. Vielmehr entwickelt Iwasiów ihren `Feminismus‘ anhand strukturalistischer, aber auch dekonstruktivistischer Richtungsweiser (v. a. Jacques Derrida) und entlang der jungschen Konzeption von Archetypen weitgehend eigenständig. Hinzu kommt, dass Iwasiów den Autor Odojewski $\left({ }^{\star} 1930\right)$ in ihre Analyse nicht miteinbezieht, ${ }^{23}$ womit sie eine stärker strukturalistisch ausgerichtete Lektüre vorschlägt als andere Arbeiten der feministischen Polonistik der 1990er Jahre. Iwasióws Dissertation nimmt in der feministischen Polonistik zwar eine Pionierrolle ein, bleibt aber relativ unbekannt und übernimmt nur schwerlich eine richtungsweisende Funktion. Dies lässt sich wohl primär auf die Besprechung von Texten eines männlichen Autors zurückführen, während andere `Klassiker der feministischen Polonistik expliziter auf die weibliche Erfahrung und das Schreiben aus weiblicher Perspektive ausgerichtet sind. Hinzu kommen die dem

18 | Ebd., S. 21: "Chcę natchnąć je [wyprawy ku cyklowi podolskiemu] swoją płcią, ogarnąć przestrzenią kobiecości. Czytam bowiem ja - kobieta - i realizuję poprzez artykułowanie interpretacji swoje, ideologiczne ex definitione, cele. Ufam jednak, że kobieca lektura zbliża tekst do ideału." 19 | Łebkowska, Anna: »Kobieta czytająca jak kobieta czytająca jak kobieta...«, in: Teksty Drugie, Feminizm po polsku (1995), S. 180-187, hier S. 186.

20 I Iwasiów: Kresy, S. 12: „odnalezienie figury, która - leżąc najgłębiej w tekstowym górotworze - wciąż pozostaje projektem substancji, nie zaś substancją samą."

21 । Vgl. ebd., S. 99.

22 | Vgl. Odojewski, Włodzimierz: Zasypie wszystko, zawieje..., Warszawa 1990, S. 45-49, $56,252 f$.

23 I Dies, obwohl oder gerade weil Iwasiów von einem Hybriden aus Autor, Erzähler und Figur spricht, vgl. Iwasiów: Kresy, S. 45. 
Text inhärente konzeptuelle Spannung und eine "metaphorische und vieldeutige $\aleph^{24}$ Sprache, die Iwasióws Dissertation zu keiner leichten Lektüre machen.

Thematisch breiter ist Maria Janions $\left.{ }^{*}{ }^{*} 1926\right)$ Kobiety $i$ duch inności (Frauen und der Geist des Andersseins), das 1996 erschien. Das Buch versammelt Artikel und Studien Janions aus den Jahren von 1979 bis $1996 \mathrm{zu}$ verschiedenen literarischen Epochen, Schriftsteller/innen und »Phantasmen«; mit dieser Spannbreite wird die reiche und mehrere Jahrzehnte umfassende Forschungstätigkeit der in Gdańsk und Warschau lehrenden Janion in den Bereichen der Romantik, Młoda Polska (Junges Polen) und allgemein des 19. und 20. Jahrhunderts ersichtlich, wobei Janion sich neben der Phantasma-Forschung besonders für die Transgression als Grenzüberschreitung und -verwischung sozialer und kultureller Normen interessierte und so quasi zwangsläufig auf die Geschlechterthematik als kulturelles Diskursfeld stieß.

Als Leitgedanke und roter Faden von Kobiety $i$ duch inności dient die Auseinandersetzung mit der diskursiven `Ent-fremdung` der Frau. Janion widmet sich dabei zunächst der Französischen Revolution und der weiblichen Allegorie der Liberté und der Revolution, wobei sie sich auf die Schriften Jules Michelets ${ }^{25}$ bezieht. So kommt sie auch auf die >Disqualifizierung〈 historischer wie literarischer Frauenfiguren durch die gesellschaftliche Zuschreibung des Wahnsinns zu sprechen, was eines der Hauptinteressen von Janions Forschung insgesamt bildet. Die Untersuchung diskursiver Prozesse der vergeschlechtlichten Pathologisierung und Marginalisierung in Literatur und Gesellschaft bildet denn auch den roten Faden der verschiedenen Studien in Kobiety i duch inności.

So diskutiert Janion u. a. die Ansichten des polnischen Romantikers Józef Ignacy Kraszewski (1812-1887) zu emanzipierten Frauen anhand dessen Romans Szalona (Auf Irrwegen [Die Wahnsinnige], 1882). Janion verweist auf die Faszination der Romantik am Zustand geistiger Entrückung und damit auf die dünne Linie zwischen sozialer Ächtung und genialer Exzentrik. ${ }^{26}$ Diese zeigt sich ebenso in den Studien zu Texten Adam Mickiewiczs (1798-1855), während die Analysen zu Nicole Müllers Denn das ist das Schreckliche an der Liebe (1992) und Günther Grass' Der Butt (1995) die Kategorie des Geschlechts an zeitgenössischen Beispielen thematisieren. Janion diskutiert auch Élisabeth Badinters Thesen zur "primären « Weiblichkeit und Androgynität der Menschen, die diese in XY - De l'identité masculine (1992) vorstellt. ${ }^{27}$ Anschließend finden sich zwei Studien (von 1979 und

24 | Łebkowska: Kobieta czytająca, S. 183.

25 I Jules Michelet, La Femme (1859) und La Sorcière (1862).

26 । Vgl. Janion: Kobiety, S. 68f. Eine detailliertere Besprechung der Verbindungen von Romantik und Geschlecht findet sich in Kapitel 3.1.

27 I Die polnische Übersetzung erschien 1993 unter dem Titel $X Y$ - tożsamość mężczyzny und wird von jenem Text Janions eingeführt, der auch in Kobiety $i$ duch inności abgedruckt ist. Vgl. Badinter, Elisabeth: XY - tożsamość mężczyzny, Warszawa 1993. 
1996) über die polnische Schriftstellerin Maria Komornicka (1876-1949), die 1907 beschloss, fortan als Mann unter dem Namen Piotr »Odmieniec« Włast zu leben (siehe Kapitel 3.3). Den Band Kobiety i duch inności schließt ein Artikel zu Izabela Filipiaks Roman Absolutna amnezja (Absolute Amnesie, 1995) ab.

Janions Schreibtechnik charakterisiert ein dialogisches Zusammenbringen von Primär- und Sekundärliteratur, wodurch "große Landschaften rund um bestimmte Probleme ${ }^{28}{ }^{8}$ entstehen, die jedoch selten direkte Rückschlüsse auf den subjektiven Standpunkt der Forscherin erlauben. Damit unterscheidet sich Janions Monographie methodisch von der zumindest postulierten Subjektivität der Arbeit Iwasióws und den deutlich zutage tretenden Sympathien im Text Borkowskas (s. u.). Auch Janion bezieht sich kaum auf feministische Theorien, sondern entwickelt in ihrer dialogischen Strategie eigene, wenn auch mit den Stoßrichtungen westlicher feministischer Kritik verwandte Fragestellungen (etwa Wahnsinn und Geschlecht ${ }^{29}$ ). Zugleich ist Kobiety $i$ duch inności aufgrund der facettenreichen Thematik und der historischen Distanzen zwischen den einzelnen Artikeln im Vergleich meines Untersuchungsmaterials die in sich widersprüchlichste Monographie, die sich als gesamte kaum als eindeutiges Ideologem lesen lässt.

Im selben Jahr wie Kobiety i duch inności erschien der Band Cudzoziemki. Studia o polskiej prozie kobiecej (Ausländerinnen. Studien zur polnischen weiblichen Prosa, 1996) von Grażyna Borkowska $\left({ }^{\star} 1956\right)$. Die Warschauer Literaturhistorikerin beschäftigte sich bereits zuvor mit der Literatur des Positivismus, wobei sie mit der Publikation Dialog powieściowy i jego konteksty (na podstawie twórczości Elizy Orzeszkowej) (Der Romandialog und seine Kontexte (anhand des Schaffens Eliza Orzeszkowas)) von 1988 den Fokus auf eine weibliche Autorin legte. ${ }^{30} \mathrm{Mit} \mathrm{Cudzo-}$ ziemki nimmt Borkowska diesen Faden erneut auf, öfnet jedoch die Perspektive auf mehrere Schriftstellerinnen des 19. Jahrhunderts und kehrt einer strukturalistischen Methodik ${ }^{31}$ zugunsten der Parallelisierung von Autorinnenbiographie und literarischem Werk den Rücken. Borkowska spannt den Bogen von der Mitte des 19. Jahrhunderts bis zum Beginn des ersten Weltkriegs und beschäftigt sich mit den Schriftstellerinnen Narcyza Żmichowska (1819-1876), Eliza Orzeszkowa (1841-1910), Zofia Nałkowska (1884-1954) und Maria Dąbrowska (1889-1965) sowie in geringerem Maße mit Maria Konopnicka (1842-1910) und Maria Jehanne

28 I Nasiłowska, Anna in: Janion, Maria: "Kuferek Harpagona. Z profesor Marią Janion rozmawiają Anna Nasiłowska i Marta Zielińska«, in: Teksty Drugie 43-44/1-2 (1997), S. 199-217, hier S. 201.

29 I Vgl. etwa das zeitgleiche Interesse Janions an dieser Thematik und die Publikation von Gilbert, Sandra M./Gubar, Susan: The Madwoman in the Attic. The Woman Writer and the Nineteenth-Century Literary Imagination, New Haven 1979.

30 | Vgl. Borkowska, Grażyna: Dialog powieściowy i jego konteksty (na podstawie twórczości Elizy Orzeszkowej) (= Z Dziejów Form Artystycznych w Literaturze Polskiej, Band 72), Wrocław 1988. 31 I Vgl. hierzu Borkowska, Grażyna: Interview [unveröffentlicht], Warszawa 2013. 
Wielopolska (1882-1940). Borkowska untersucht den Zusammenhang zwischen persönlichen Einstellungen der Schriftstellerinnen etwa zur Emanzipation mit ihrer kreativen Tätigkeit wie dem Schreibstil. Thema ist dabei immer auch wieder die Spezifik weiblichen Schreibens als Gegenkonvention zum männlichen Literaturparadigma. Borkowskas erklärtes Ziel ist es, mit ihrer Arbeit die Inanspruchnahme weiblicher (kreativer) Handlungsfähigkeit durch einen national-patriotischen Diskurs zu hinterfragen und als Wert an sich jenseits gesellschaftlicher Nutzbarmachung zu betrachten.

Borkowska verweist im Vorwort auf ihre feministische Methodik, trifft dabei aber keine »entschiedene Auswahl unter den präsentierten Vorschlägen « ${ }^{32}$ feministischer Theorien. Als feministische Herangehensweise versteht sie die Hinterfragung konventioneller Sichtweisen und den Fokus auf die weibliche Erfahrungswelt und Psychologie. Der literarische Text dient Borkowska als Ausdruck spezifischer Haltungen zum weiblichen Geschlecht und dessen Verortung in der Gesellschaft. ${ }^{33}$ Gleichzeitig baut Borkowska eine Art persönliches Verhältnis zu den von ihr behandelten Autorinnen auf. Diese biographistische Lektüre, die letztlich auf das Verständnis nicht des Texts, sondern der Autorin abzielt, soll in der vorliegenden Arbeit noch problematisiert werden (siehe Kapitel 6.3). ${ }^{34}$

1999 erschienen die beiden letzten in der vorliegenden Arbeit berücksichtigten Publikationen. Ewa Kraskowskas $\left({ }^{*} 1954\right)$ Piórem niewieścim. Z problemów prozy kobiecej dwudziestolecia międzywojennego (Mit weiblicher Feder. Problemstellungen der weiblichen Prosa der Zwischenkriegszeit) lässt sich als Produkt einer interkulturellen Inspiration beschreiben. Die Posener Literaturwissenschaftlerin, Autorin von Twórczość Stefana Themersona: dwujęzyczność a literatura (Das Werk Stefan Themersons: Zweisprachigkeit und Literatur, 1989), ${ }^{35}$ stellt aufgrund ihres eigenen Kontakts mit englischsprachiger sweiblicher Prosa die Frage nach der Existenz und Charakteristik eines polnischen Pendants. ${ }^{36}$ Kraskowska konzentriert sich auf die Texte mehrerer Schriftstellerinnen aus der Zwischenkriegszeit. Innerhalb der Arbeit widmet sich Kraskowska einzelnen Aspekten, die sich teilweise mit dem Schaffen einer oder mehrerer konkreter Autorinnen überschneiden; so diskutiert sie etwa erotische und familiäre Beziehungen am Beispiel der Texte Nałkowskas, die Relevanz der Alltagswelt bei Helena Boguszewska (1886-1978), Lesbianismus am Beispiel eines Romans von Aniela Gruszecka (1884-1976), die Thematik weiblicher Aufopferung im Schaffen Elżbieta Szemplińskas (1909-1991),

32 । Borkowska: Cudzoziemki, S. 20: "zdecydowanego wyboru spośród prezentowanych propozycji«.

33 । Vgl. ebd., S. 20.

34 I Siehe dazu auch Magnone: Die polnischen Gender Studies, S. 384.

35 । Vgl. Kraskowska, Ewa: Twórczość Stefana Themersona: dwujęzyczność a literatura (= Rozprawy literackie, Band 65), Wrocław 1989.

36 | Vgl. Kraskowska: Piórem niewieścim, S. 7. 
den Mutterschaftstopos bei Maria Kuncewiczowa (1895-1989) und Wanda Melcer (1896-1972) sowie das Genre der Reportage wiederum bei Melcer.

Kraskowskas Arbeit bietet einen umfangreichen Einblick in das weibliche literarische Schaffen der polnischen Zwischenkriegszeit. Dieses wandte sich besonders stark der Alltagsgeschichte zu und lieferte so Mikrostudien über verschiedene Milieus, soziale Schichten und Einrichtungen, widmete sich aber auch psychosozialen Prozessen. Kraskowska sieht das `Weibliche Set spezifischer Eigenschaften, die sich um die `weibliche` Erfahrungswelt als eine private, vom Alltag und seinen Details geprägte und weitgehend von der igroßen Geschichte der Gesellschaft isolierte Sphäre gruppieren. Insofern sieht Kraskowska in einer von Elaine Showalter adaptierten Kategorisierung der Literatur von Frauen das weibliche »integrale» Schreiben als Ideal. Dieses trete als nicht-konkurrierende Differenz zum >Männlichen` hervor und setze sich als solches von einer kämpferisch-»feministischen « Literatur und einer sich ins männliche Paradigma einschreibenden (»transgressiven«) Literatur weiblicher Autorschaft ab. ${ }^{37}$ Das Recht zur Weiblichkeit verteidigt Kraskowska gegen die literarische Kritik und Rezeption, die dem weiblichen Schreiben eine Unernsthaftigkeit vorwarf. Ziel Kraskowskas ist es somit, in ihrer Arbeit den wenn auch nicht immer literarischen, so doch sozialen und Geschlechtsidentität stiftenden Wert weiblicher Literatur zu demonstrieren. Wie auch Borkowska kann sie sich dabei einer gewissen Essentialisierung ihres Konzepts der Weiblichkeit nicht erwehren.

Krystyna Kłosińskas ( $\left.{ }^{\star} 1952\right)$ Ciało, pożądanie, ubranie. O wczesnych powieściach Gabrieli Zapolskiej (Körper, Begehren, Kleidung. Die frühen Romane Gabriela Zapolskas) erschien wie auch Kraskowskas Monographie 1999 und bildet somit mit dieser zusammen den Endpunkt meines Forschungsmaterials. Die Kattowitzer Literaturwissenschaftlerin Kłosińska veröffentlichte bereits 1988 mit Powieści $w$ swieku nerwowym (Romane im `nervösen Zeitalter`) eine Monographie, in der sie die Neurose anhand von Romanen von 1890 bis 1904 aus einer literarischen Perspektive untersuchte. ${ }^{38}$ Eine ähnliche Thematik bildet mit der Hysterie auch in Ciało, pożądanie, ubranie einen Teil des Forschungsinteresses. Kłosińska widmet sich in dieser Arbeit der Schriftstellerin Gabriela Zapolska (1857-1921) respektive deren frühen Romanen. Kłosińska führt zunächst - wie Kraskowska, Borkowska und in geringerem Maße Iwasiów - über eine kritische Auseinandersetzung mit

37 | Während Showalter, Elaine: »Toward a Feminist Poetics«, in: Jacobus, Mary (Hg.), Women Writing and Writing About Women (= The Oxford Women's Series, Band 3), London 1979, S. 22-41, hier S. 35f., die drei Kategorien feminine (transgressiv), feminist und female (integral) diachron als literaturhistorische Phasen anordnet, sieht Kraskowska diese als parallele Strömungen in der polnischen Literatur an (vgl. Kraskowska: Piórem niewieścim, S. 204).

38 I Vgl. Kłosińska, Krystyna: Powieści w »wieku nerwowym«, Katowice 1988 sowie Popiel, Magdalena: »Powieści w ’wieku nerwowym<, Krystyna Kłosińska, Katowice 1988: [recenzja]«, in: Pamiętnik Literacki 81/2 (1990), S. 388-392, hier S. 388. 
der Literaturkritik und der bisherigen Rezeption in das Thema ein. Wie Kraskowska und Borkowska stellt auch Kłosińska eine ungenügende, verdrehte oder ungerechtfertigt negative Rezeption des von ihr thematisierten weiblichen Schaffens fest. In ihrer Monographie untersucht sie die drei Romane Kaśka Kariatyda (Käthe, die Karyatide, 1888), Przedpiekle (Die Hölle der Jungfrauen [Vorhölle], 1889) und Fin-de-siècle'istka (Die Fin-de-Sièclerin, 1897) im Detail und mithilfe psychoanalytisch informierter feministischer Methodologie.

Stärker als bei Borkowska und Kraskowska, ähnlich aber wie bei Iwasiów, gräbt sich die Lektüre Kłosińskas in den literarischen Text hinein, den sie als einen »doppelten« versteht. Das weibliche Schreiben, so Kłosińska, sei eine weitere Form der weiblichen Mimikry als Resultat des gesellschaftlichen Zwangs zu Verhüllung und Verstellung. ${ }^{39}$ Dies sieht sie besonders im Roman Fin-de-siècle'istka anhand der hier untersuchten Maskerade durch Kleidung auf einer weiteren Ebene illustriert. Kłosińska versucht deshalb, mithilfe von im Text angelegten weiblichen Signaturen oder den ambiguen »Wort-Ächzern « (słowa-jęki), in denen sich Maskerade und der darunterliegende, nicht-artikulierte Schrei gleichsam äußern, ${ }^{40}$ unter die Textoberfläche zu gelangen.

Kłosińska beschäftigen in ihrer Analyse vor allem die Interessensbereiche feministischer Psychoanalyse: das Semiotische als Bereich des Weiblichen, das Begehren und die Hysterie als zweischneidiges Schwert des Umgangs mit weiblicher Sexualität in der modernen Gesellschaft, Mutterfiguren und die Mutterschaft als manifester Bereich der gesellschaftlichen Doppelmoral oder die bereits erwähnten Prozesse der Ver- und Enthüllung durch das Zeichenhafte der Kleidung. Kłosińska geht in ihren Analysen ausschließlich vom Text aus und referiert dabei auf Zapolska als Schreibende der Texte, nicht aber als biographische Person. Parallel dazu zieht sich Kłosińska stärker hinter diese aus dem Text konstruierte Instanz Zapolska zurück und beurteilt die diegetischen Geschehnisse entlang des im Text angelegten Ideologems, selten aber aus ihrer seigenen` Perspektive. Damit ist in Kłosińskas Monographie weniger deutlich von einer subjektiven Intonation zu sprechen, die Kraskowska und Borkowska vorexerzieren und die punktuell auch bei Iwasiów und Janion zu finden ist.

\subsection{Intertextualität, INTONATION, IdEOLOGEM}

Die Forschungsfrage der vorliegenden Arbeit konzentriert sich auf die intertextuellen Bezüge der feministischen Kritik der polnischen 1990er Jahre. Methodisch stütze ich mich auf die drei Konzepte der Intertextualität, der Intonation und des Ideologems, die sich gegenseitig durchdringen. Mit dem Konzept der Intertextualität möchte ich dem Phänomen des Transfers einen offeneren analytischen Cha-

39 । Vgl. Kłosińska: Ciało, S. 28.

40 । Vgl. ebd., S. 65f., $276 f$. 
rakter geben. Die untersuchten Monographien verstehe ich als Aktualisierungen in einem Textkontinuum, innerhalb dessen der Transfer von Theorien und das Hervorheben lokaler und historischer Spezifika nur eine Form der Dynamik darstellen. Der Text soll als Schnittstelle verschiedener Diskurse und Narrative verstanden werden, die sich nicht nur auf schriftlich fixierte literarische oder wissenschaftliche Texte reduzieren lassen. Damit versuche ich dem komplexen Diskursfeld der Geschlechterdebatte der polnischen 1990er Jahre gerecht zu werden. Die transnationale feministische Kritik, die polnischen literarischen Texte und der soziale und historische Kontext der 1990er Jahre bilden dabei die intertextuellen Referenzrahmen und widerspiegeln als solche lose den Aufbau der vorliegenden Arbeit (s. u.). ${ }^{41}$

Um die Intertextualität weiter aufschlüsseln zu können und dabei die Frage nach dem agens der Wissensproduktion nicht zu vernachlässigen, die gerade im feministischen Kontext als relevante Auseinandersetzung gelten kann, untersuche ich die Texte auch nach den beiden Konzepten der poetologisch-subjektiven Intonation und des Ideologems als eine Form ideellen Kommunikats. Die Intonation oder Gestimmtheit versuche ich zunächst als Stimme im Text zu fassen. Hier soll gewissermaßen die Frage nach der Erzählperspektive gestellt und der Raum im Text abgesteckt werden, in dem das schreibende Subjekt hervortritt. Diesen Raum versuche ich besonders durch eine poetologische Lektüre zu ergründen, wobei die Intonation an konkreten Textstellen aufgezeigt werden soll. Gleichzeitig sind diese Stellen nicht nur 'gestimmte die Frage nach einer Lektüre, die den Text innerhalb spezifischer Zeichensysteme unwillkürlich decodiert. Mit dem Begriff des Ideologems soll deshalb der feministische Text als ideelles Angebot verstanden werden, das im Kontext feministischer Argumentationen in den 1990er Jahren als (latent) politische Aussage aktiv wird. ${ }^{42}$ Auf die Spezifika und Verflechtungen der Konzepte von Intertextualität, Intonation und Ideologem gehe ich nun noch genauer ein.

Der Begriff der Intertextualität soll im Gegensatz und in Ergänzung zum Transferbegriff ein sowohl breiteres wie auch pluraler ausgelegtes Konzept von Rezeptionsprozessen umfassen. Zentral in meinem Verständnis von Intertextualität sind

41 I Aufgrund des eng ineinander verwobenen Geflechts des untersuchten Diskursfelds kann und soll jedoch keine strikte Trennung dieser drei Referenzrahmen vorgenommen werden. Sie interagieren und überschneiden sich deshalb auch innerhalb der einzelnen Untersuchungsschwerpunkte. In gewisser Weise lehnte ich die vorliegende Arbeit an den Begriff des Rhizoms von Gilles Deleuze und Félix Guattari an, dessen Motiv der Delinearisierung einerseits half, die Arbeit zu konzipieren und andererseits vielleicht für Überschneidungen oder ein »repetitives Erzählen« (nach Martinez, Matías/Scheffel, Michael: Einführung in die Erzähltheorie, München 2005, S. 46) verschiedener Aspekte verantwortlich zeichnet. Vgl. Deleuze, Gilles/Guattari, Félix: Rhizome, Paris 1976.

42 I Es soll jedoch in der konkreten Textanalyse nicht darum gehen, diese Begriffe/Konzepte abzufragen, weshalb sie in der Untersuchung oft eher mitgedacht als nominell erwähnt werden. 
die Konzeptionen Julia Kristevas zu dieser Thematik, die den Textbegriff über denjenigen des schriftlich fixierten, materiell vorhandenen Texts hinausdehnen. ${ }^{43}$ Kristeva versteht das »textuelle Umfeld « als eine Art »Kompetenz der Performanz« des »konkreten Texts $\aleph^{44}$, als prozessuale, nicht zwingend linguistische Umgebung des Texts $»$ in ephemeren [...] und nicht-bedeutungstragenden [non-signifiantes] Strukturen « ${ }^{45}$. Ein solches Verständnis von Intertextualität erscheint mir für mein Vorhaben hilfreich, da so überhaupt erst eine umfassendere Einbettung in den Diskurs der polnischen 1990er Jahre und darüber hinaus ermöglicht wird. Gleichzeitig befasse ich mich mit der Analyse der Rezeption wissenschaftlich-theoretischer Ansätze und der 'Verarbeitung` des jeweils untersuchten literarischen Texts im polonistischen Text sehr stark mit Prozessen, die sich auf spezifische, fixierte und benannte sprachliche Äußerungen (Texte) beziehen.

Kristevas Konzeption der Intertextualität oder der »Transposition eines Zeichensystems (oder mehrerer) in ein anderes $\aleph^{46}$ tendiert zwar zur Auflösung der Textgrenzen, macht aber auch auf die lokale Historizität der Zeichensysteme aufmerksam. Mit Michail Bachtin verweist Kristeva auf die Situierung des Texts »in der Geschichte und in der Gesellschaft « ${ }^{47}$. Konzepte des Transfers oder des Reisens von Theorien/Ideen bilden damit eine Form der intertextuellen Textbeschreibung, ${ }^{48}$ fokussieren aber stärker auf die Lokalität bestimmter Zeichensysteme und die zu überwindende Distanz bei der Transposition.

Edward Said schreibt in seinem Aufsatz Traveling Theory von einem "point of origin, or what seems like one, a set of initial circumstances in which the idea came to birth or entered discourse « ${ }^{49}$. Diesem stellt er die "new position in a new time and place«, ein Einfinden in "conditions of acceptance or, as an inevitable part of acceptance, resistances $\aleph^{50}$ als `Zielpunkt des Reisens von Theorien entgegen. Da-

43 I Vgl. Schahadat, Schamma: »Intertextualität: Lektüre - Text - Intertext«, in: Pechlivanos, Miltos et al. (Hg.), Einführung in die Literaturwissenschaft, Stuttgart, Weimar 1995, S. 366-377, hier S. 368.

44 I Kristeva, Julia: Le Texte du roman. Approche sémiologique d'une structure discursive transformationelle (= Approaches to Semiotics, Band 6), Den Haag, Paris 1970, S. 71f. Die Übersetzungen der Zitate Kristevas stammen hier und im Folgenden von der Verfasserin der vorliegenden Arbeit.

45 I Kristeva, Julia: Sèméiotikè. Recherches pour une sémanalyse. Essais (= Collection Tel Quel), Paris 1969, S. 83, Hervorh. i. 0.

46 I Kristeva, Julia: La Révolution du langage poétique. L'avant-garde à la fin du XIXe siècle: Lautréamont et Mallarmé, Paris 1974, S. 60. Vgl. auch Rajan, Tilottama: »Intertextuality and the Subject of Reading/Writing «, in: Clayton/Rothstein, Influence and Intertextuality (1991), S. 61-74, hier S. 63.

47 I Kristeva: Sèméiotikè, S. 144.

48 I Vgl. Rajan: Intertextuality, S. 61.

49 I Said, Edward W.: »Traveling Theory«, in: ders., The World, the Text and the Critic, Cambridge, Mass. 1983, S. 226-247, hier S. $226 f$.

50 । Ebd., S. 227. 
mit macht Said darauf aufmerksam, dass Texte auch in einem intertextuellen Kontinuum jeweils eine lokale Gewichtung und Verflechtung haben und sich derart in unterschiedlichen (kon)textuellen Räumen bewegen. ${ }^{51}$ Dieses Verständnis ist für die Untersuchung von Rezeptionsprozessen gerade über geographische und historische Distanzen unabdingbar. Gleichzeitig verweist Said auch auf den Prozess des Übertragens selbst, als »a passage through the pressure of various contexts as the idea moves ${ }^{52}$. Zentral an dieser Feststellung ist für die vorliegende Arbeit vor allem, das Interesse auch auf das Prozessuale und die Zwischenräume zu richten. ${ }^{53}$ Als solchen Zwischenraum könnte man die Schaltstelle der feministischen Kritikerin als `schreibendes Subjekt ` anführen, aber auch die aus dem wissenschaftlichen Text hervortretenden interpretativen >Leerstellen`, die die Leserin in den Prozess des Verstehens und Rezipierens einbinden. Mit diesen Aspekten befasse ich mich eingehender unter den Begriffen Intonation und Ideologem.

Der `Zielpunkt « der Rezeptionsprozesse von Theorien oder Ideen ist nicht klar zu bestimmen: liegt er im feministisch-polonistischen Text selbst, eher im den Text umgebenden Kontext oder ergibt er sich erst im Dialog dieser beiden Texte`? Eine Beschreibung von Rezeptions- und Transferprozessen lässt sich somit nie endgültig stabilisieren. Im Rahmen der vorliegenden Analysen gehe ich stets vom Untersuchungsmaterial, den polonistischen Texten aus, von wo aus Spuren intertextueller Bezüge nachverfolgt werden sollen. Die >Rezeptionslinien sich somit gleichwohl ‘rückwärts`, hin zu den vielschichtigen textuellen Bezügen, die im Text angesprochen werden, wie auch >vorwärts` im Sinne des Zusammendenkens von Text und Kontext im Prozess der Lektüre dieser Texte. ${ }^{54}$

Den Begriff des `Transfers` versuche ich in der Arbeit größtenteils zu vermeiden, da er im polnischen Kontext gewisses Unbehagen und das Bild einer binären

51 Siehe auch Homi K. Bhabhas Überlegungen, insbesondere zur Lokalität als »spatialization of historical time«: Bhabha, Homi K.: The Location of Culture, London, New York 1994, S. 143; außerdem MacIntyre, Alasdair: Whose Justice? Which Rationality? Notre Dame, Indiana 1988, S. 370-388, bes. S. 371f. zu »tradition and translation«.

52 । Said: Traveling Theory, S. 227.

53 I Vgl. dazu auch Bal, Mieke: Travelling concepts in the humanities. A rough guide, Toronto u.a. 2002, S. 11, die Konzepte als »dynamic in themselves « versteht. »While groping to define, provisionally and partly, what a particular concept may mean, we gain insight into what it can do. It is in the groping that the valuable work lies." Hervorh. i. 0.

$\mathbf{5 4}$ I Ritz macht auf die Notwendigkeit der Transgression der Textgrenzen in der kritischen Lektüre aufmerksam, ohne jedoch dabei den Text aus den Augen zu verlieren: »Das Überschreiten der Textimmanenz gehört zu jeder gender-Analyse. [...] Gleichzeitig ist es wesentlich, dass die Antworten das Medium des literarischen Texts nicht verlassen. "Ritz: Literatura w labiryncie pożądania, S. 98. Die kritische Lektüre oszilliert somit um die Grenzen des Textes, im Bereich intertextueller Transpositionen. Vgl. auch Bal: Travelling concepts, S. 8f. 
Hierarchie hervorruft. ${ }^{55}$ Zudem erscheint er mir tatsächlich wenig praktikabel, um detailliert die textuellen Prozesse analytisch zu verfolgen. Die zum Teil in den Texten beobachtbaren Grenzziehungen zwischen lokalem und >globalem`Kontext können dennoch thematisiert und untersucht werden, und so bleibt die Wahrnehmung offen für ebenso anzutreffende >Verwischungen` von Grenzen und Diskursfeldern. In gewisser Weise stehen deshalb postkoloniale Ansätze im Hintergrund meiner Arbeit. Homi K. Bhabha formuliert in der Einleitung zu The Location of Culture:

"What is theoretically innovative, and politically crucial, is the need to think beyond narratives of originary and initial subjectivities and to focus on those moments or processes that are produced in the articulation of cultural differences. These sin-between spaces provide the terrain for elaborating strategies of selfhood - singular or communal - that initiate new signs of identity, and innovative sites of collaboration, and contestation, in the act of defining the idea of society itself. It is in the emergence of the interstices - the overlap and displacement of domains of difference that the intersubjective and collective experiences of nationness, community interest, or cultural value are negotiated. ${ }^{56}$

In Anlehnung an Bhabhas Formulierung soll es deshalb in der vorliegenden Arbeit sowohl um die textuelle Herstellung von Differenz - kultureller, ideeller, geschlechtlicher - gehen, als auch um das textuelle Verwischen von Differenz, die Betonung des verbindenden »overlap« bestimmter Bereiche. Beide Prozesse können als Verfahren der Intertextualität verstanden werden und verschmelzen letztlich zusammen mit der Intonation zum Ideologem der untersuchten Arbeiten.

In meinen Analysen steht die Arbeit mit der konkreten Textstelle im Vordergrund, wobei ich das Augenmerk neben inhaltlichen Formulierungen und konkreten Textverweisen auch immer wieder auf die Form der Aussage lege. Wie in der Analyse eines literarischen Texts geht es hier darum, textuelle, rhetorische Verfahren in einer poetologischen Analyse aufzudecken. ${ }^{57}$ Wie ergiebig eine sol-

55 I Diese Ansicht kristallierte sich in der Diskussion im Kolloquium des Zespół Literatura i gender (Arbeitskreis Literatur und Gender) am Instytut Badań Literackich Polskiej Akademii Nauk (Institut für Literaturforschung der Polnischen Akademie der Wissenschaften, IBL PAN) heraus, 18. 6. 2015. 56 I Bhabha: Location of Culture, S. $1 f$.

57 | Vgl. dazu allgemein Kreiswirth, Martin: »Merely Telling Stories? Narrative and Knowledge in the Human Sciences«, in: Poetics Today 21/2 (2000), S. 293-318; Moser, Jeannie: »Poetologien I Rhetoriken des Wissens. Einleitung «, in: Höcker, Arne et al. (Hg.), Wissen. Erzählen. Narrative der Humanwissenschaften, Bielefeld 2006, S. 11-16; Vogl, Joseph: »Für eine Poetologie des Wissens «, in: Richter, Karl et al. (Hg.), Die Literatur und die Wissenschaften 1770 - 1930, Stuttgart 1997, S. 107-127; ders.: "Einleitung«, in: ders. (Hg.), Poetologien des Wissens um 1800, München 1999, S. 7-16; White, Hayden: Tropics of Discourse. Essays in Cultural Criticism, Baltimore, London 1978. 
che Untersuchung textueller Mechanismen auch am wissenschaftlichen Text sein kann, demonstrierte Clare Hemmings in Why Stories Matter. The Political Grammar of Feminist Theory eindrücklich. Hemmings fokussierte ausschließlich auf den textuellen Wortlaut feministischer Artikel, um darin »to uncover the political grammar through which we come to believe in narratives $\aleph^{58}$. Sie geht ähnlich wie Hayden White davon aus, dass auch nicht-literarische Texte >Geschichten erzählen und durch ihre spezifische Poetik eine bestimmte Sichtweise vermitteln, die nicht direkt in der inhaltlichen Argumentation des Textes ersichtlich sein muss. Damit wird, in Whites Worten, auch der falsche "belief in the transparency of language, its purely reflective, rather than constitutive nature $~^{59}$, freigelegt.

Die Frage nach den rhetorischen Verfahren eines Textes wirft gleichzeitig die Frage nach dessen Subjekt auf. Diese Überlegung steht zudem in Zusammenhang mit der intertextuellen Transposition von Zeichensystemen, die ebenfalls erst durch ein agens zustande kommt. Kristeva nennt einen "Schreiber" oder »Schriftsteller« (écrivain), der die historischen und sozialen Texte »liest und in die er sich durch ihr Wiederschreiben [en les récrivant] einfügt [s'insère] « ${ }^{60}$. Relevant wird hier jedoch die Bedeutung, die diesem »Schreiber« epistemologisch zugemessen wird. Während Kristevas Intertextualitätskonzept kaum auf diese Frage eingeht, betont etwa Nancy K. Miller, dass die konzeptuelle Erodierung des schreibenden Subjekts im intertextuellen Kontinuum aus einer feministischen Perspektive verfrüht wäre, da so die Untersuchung diskursiver Machtpositionen und des politischen Potentials von Textualität delegitimiert würde. ${ }^{61}$ Der Subjektbegriff als epistemologische Kategorie soll deshalb aufrechterhalten werden, um nach der Position eines agens (agency) fragen zu können und »to figure a writing identity as grounded and located in a scene of work, thus holding together representation and cultural production. ${ }^{62}$

Das schreibende Subjekt wird damit zur Schaltstelle von sozialem und historischem `Text und dem zu untersuchenden Text und baut in letzteren seine Sub-

58 I Hemmings, Clare: Why Stories Matter. The Political Grammar of Feminist Theory (= Next Wave: New Directions in Women's Studies), Durham, London 2011, S. 17.

59 I White: Tropics of Discourse, S. 21.

60 | Kristeva: Sèméiotikè, S. 144.

61 I Vgl. Miller, Nancy K.: Subject to Change. Reading Feminist Writing, New York 1988, S. 80ff., 104-107 sowie Friedrichsmeyer, Sara/Clausen, Jeanette: „What's Missing in New Historicism or the >Poetics of Feminist Literary Criticism «, in: Women in German Yearbook 9 (1993), S. 253-258, hier S. 257; Lennox, Sara: »Feminism and New Historicism«, in: Monatshefte 48/2 (1992), S. 159170, hier S. 159, 167f.; Newton, Judith: »History as Usual? Feminism and the 'New Historicism«, in: Cultural Critique 9 (1988), S. 87-121, hier S. 98f.; dies.: "Family Fortunes: >New History and 'New Historicism« «, in: Radical History Review 43 (1989), S. 5-22, hier S. 18; Stanford Friedman, Susan: »Weavings: Intertextuality and the (Re)Birth of the Author «, in: Clayton/Rothstein, Influence and Intertextuality (1991), S. 146-180, hier S. 146f., $157 f$.

62 । Miller: Subject to Change, S. 77. 
jektposition ein als »a certain reflexiveness that makes all writing the site of its own reading. ${ }^{63}$ Die Aufrechterhaltung einer handlungsfähigen Subjektposition (die "position of agency « ${ }^{64}$ ) in Bezug auf den Text befähigt dazu, die Prozesse der Transposition zwischen Zeichensystemen als historisch und sozial verortete zu verstehen, soll jedoch in der vorliegenden Arbeit nicht auf eine biographistische oder intentionalistische Lektüre zurückgeführt werden. ${ }^{65}$

Mich interessiert in den Analysen grundsätzlich diejenige Instanz, die in der Narratologie als Erzählinstanz oder Stimme bezeichnet wird: also das grundsätzlich als fiktiv zu erachtende Subjekt, das an der Grenze der Diegese anzusiedeln ist. ${ }^{66}$ In Bezug auf den wissenschaftlichen Text überlagern sich schreibende und erzählende Instanz deutlicher als im literarischen Text; ${ }^{67}$ und obwohl die schreibende/erzählende Instanz im literaturwissenschaftlichen Text zwar selten offen zutage tritt, bestimmt sie doch die Narration des Textes und ıäußert sich indirekt in der Intonation.

Unter der Intonation ${ }^{68}$ eines Textes versteht Bachtin die »Aktivität des Autors«, die sich in der »Aktivität der zum Ausdruck gebrachten Wertung« offenbart. Als

63 I Rajan: Intertextuality, S. 67.

64 I Stanford Friedman: Weavings, S. 146.

65। Relevanter wäre vielleicht die Kategorie einer sakademisch-biographischen Legende، als 'wissenschaftliche Funktion der untersuchten Texte, die sich aus der Zusammenschau des (bisherigen) wissenschaftlichen Schaffens einer `Forscher/innenpersönlichkeit ergibt. Dies ermöglicht gewisse Verbindungen über die Grenzen eines einzelnen Texts hinweg und somit die Frage nach der Stabilität bestimmter Konzepte im intertextuellen Vergleich (siehe bspw. Kapitel 3). Die Formulierungen von sakademisch-biographischer Legende und 'wissenschaftlicher Funktion entlehne und verfremde ich von Boris Tomaševskijs Überlegungen zum Zusammenhang von Autor und Literatur, vgl. Tomaševskij, Boris: »Literatur und Biographie«, in: Jannidis et al., Theorie der Autorschaft (2000), S. 49-61, hier S. 50ff.

66 | Vgl. Martinez/Scheffel: Einführung, S. 68f.; zu Fiktion/Fiktionalität vgl. Rühling, Lutz: »Fiktionalität und Poetizität«, in: Arnold, Heinz Ludwig/Detering, Heinrich (Hg.), Grundzüge der Literaturwissenschaft, München 1996 (2011), S. 25-51, hier S. $28 f$.

67 I Diesbezüglich meine ich mit der Bezeichnung bspw. >Janion` gleichzeitig das schreibende wie das erzählende Subjekt als Verbindung der intra- wie extradiegetischen Ebene; damit wird die Erzählinstanz von einer fiktiven zu einer fiktionalen, insofern man den wissenschaftlichen Text auch als eine Art der Erzählung betrachtet.

68 I Bachtin, Michail M.: Autor und Held in der ästhetischen Tätigkeit, Frankfurt a/M. 2008, S. 42 unterscheidet die "formale Intonation « des Autors von der »realistischen Intonation" des Protagonisten, wobei er letztere auch »ethische« (ders.: Sobranie sočinenij v semi tomach. Tom 1. Filosofskaja èstetika 1920-ch godov, Moskva 2003, S. 319, Übers. v. d. Verf.) nennt. Diese Differenzierung scheint mir am wissenschaftlichen Text im Hinblick auf das Zusammenfallen von schreibender und erzählender Instanz in gewisser Hinsicht unterwanderbar; Vorsicht ist jedoch geboten, da mit den untersuchten Schriftstellerinnen und deren Texten quasi eine Doppelung der Intonation stattfindet, die im Prozess des Schreibens wie der Lektüre auch zusammenfließen kann. 
»emotional-volitional[e] Reaktionen des Sprechers" führt sie dazu, dass im Text $» n i c h t$ einfach ein Laut erzeugt [wird], sondern ein bedeutungshaltiger Laut ${ }^{69}$; die ästhetische Intonation wird somit zu demjenigen Ort im Text, wo Bedeutung generiert wird und sich gleichzeitig der »Autor-Leser« (avtor-čitatel' $\left.{ }^{\prime}\right)^{70}$ manifestiert. Bachtins Formulierung des "Autors-Lesers" als Zusammenschluss zweier Textinstanzen weist auf die intertextuellen Bezüge des Lesens/Schreibens hin und schließt damit an die oben hervorgehobene »reflexiveness « des Texts an, wo das Schreiben zum Ort seines eigenen Lesens wird. Während diese Reflexivität gleichzeitig intendiert wie unbeabsichtigt ist, ${ }^{71}$ geschieht auch die Intonation, wie Bachtin schreibt, »erwünscht wie nicht erwünscht" (želatel'noe i ne želatel'noe). Das »ausgesprochene Wort kann sich nicht nicht intonieren, die Intonation entspringt [vytekaet] allein schon aus der Tatsache seiner Aussprache $\ll^{72}$. Die Intonation tritt als ambivalente hervor, als »Vielfalt von Wertbeziehungen der sprechenden Person zum Inhalt « ${ }^{73}$, nicht aber als direkte Aussage des "Autors-Lesers«.

Die Intonation schreibt sich somit durch die lesende/schreibende Instanz auf einer Art subrationalen Ebene in den Text ein. Sie ist der Ort, an dem sich das "subject of agency« im intertextuellen Geflecht offenbart, und entzieht sich doch der Kontrolle einer `Autorintention`. Die Intonation siedelt in den rhetorischen Figuren des Texts ${ }^{74}$ und den mikrotextuellen Strukturen, ist also eine Art poetologisches Ordnungsprinzip. Als solches wird sie auch zum Ansatzpunkt der Lektüre, die diese im Text angelegten 'Spuren die Verbindung zu den Affect Studies hilfreich. So beschreibt Eric Shouse die Prozesse der Affektierung am Beispiel der Musik, für ihn "perhaps the clearest example of how the intensity of the impingement of sensations « ${ }^{75}$ im Prozess des Hörens Bedeutung annimmt und den/die Hörer/in »bewegt" (move). Die Intonation bildet hier ein Bindeglied zum musikalischen Bereich und bezieht sich auch im textuellen Bereich auf eine Form der verbal/rational nicht endgültig greifbaren $>$ Übermittlung». Mit der deutschen `Gestimmtheit`spielen zudem psychologische Prozesse hinein, die ihrerseits Untersuchungsgegenstand der Affect Studies sind. Geht man nun davon aus, dass ein Text 'gestimmt Träger von Informationen, die jenseits der rationalen Ebene affektiv aktiv werden.

Da die Intonation die Frage sowohl nach dem Agens wie dem Patiens dieser 'Gestimmtheit stellt, erscheint mir dieses Konzept geeignet, die textuellen Me-

69 I Bachtin, Michail M.: Die Ästhetik des Wortes, Frankfurt a/M. 1979, S. 147f. Hervorh. i. 0.

70 I Bachtin: Sobranie sočinenij, S. 72. In ders.: Autor und Held, S. 39 wird diese Formulierung in »Autor und Leser« aufgelöst.

71 I Vgl. Rajan: Intertextuality, S. 67 sowie Stanford Friedmans (Weavings, S. 163) Formulierung des "grammar of the unconscious «.

72 I Bachtin: Sobranie sočinenij, S. 32. Übersetzung v. d. Verf.

73 I Bachtin: Ästhetik, S. $147 \mathrm{f}$.

74 | Vgl. White: Tropics of Discourse, der Tropen ins Zentrum seiner Analyse stellt.

75 I Shouse, Eric: »Feeling, Emotion, Affect«, in: M/C Journal 8/6 (2005), o. S. 
chanismen zu untersuchen, die "generate coherent meaning and allow for author, context, and reader agreement ${ }^{76}{ }^{76}$, wie Hemmings schreibt. Mit dieser Formulierung einer »kohärenten Bedeutung«, die im Lektüreprozess entsteht, ist nun bereits auch das Ideologem als letztes Element der Triade angesprochen.

Gemäß Kristeva, von der ich dieses Konzept entlehne, ist das Ideologem »der Abgleich einer gegebenen textuellen Organisation (einer semiotischen Praxis) mit Äußerungen (Sequenzen), die sie in ihren Raum aufnimmt oder denen sie im Raum externe Texte (semiotische Praktiken) erwidert ${ }^{77}$ und somit eine textinhärente Funktion, die gleichzeitig auf ein Textexternes verweist.

"Das Ideologem ist diejenige intertextuelle Funktion, die man auf verschiedenen Ebenen einer jeden Textstruktur als smaterialisiert lesen kann und die sich über die gesamte Entwicklung des Texts erstreckt, indem sie diesem seine historische und soziale Koordinaten verleiht. [...] Das Ideologem eines Textes ist der Brennpunkt [foyer], in dem die erkennende Rationalität die Transformation der Äußerungen (auf die der Text irreduzibel ist) in ein Ganzes (den Text) wie auch das Einbringen dieser Gesamtheit in den historischen und sozialen Text erfasst. « ${ }^{78}$

Das Ideologem kann somit nach Kristeva als diejenige Funktion des Textes verstanden werden, die ihm im Rahmen seines historischen und sozialen Eingebettetseins seine Einheit verleiht. Kristeva verweist darauf, dass das Verständnis des textuellen Ideologems nicht ein sekundärer, »ideologischer « Schritt der Textinterpretation sei; »linguistische« und »ideologische« Ebene greifen in Eins, sind untrennbar. ${ }^{79}$ Zudem umfasst das Ideologem nicht (nur) die inhaltlich-verbalisierte Aussage im Text, sondern wird wie die Intonation »als eine Gegebenheit-Vorgegebenheit [erlebt], [...] tritt in eine wirkungsvolle Beziehung zu mir in Einheit mit der uns umfangenden Ereignishaftigkeit. ${ }^{80}$ Das Ideologem ist also jener Wert, der durch die >Gestimmtheit eines Textes aktiv wird und den/die Leser/in sangeht oder, wie Shouse schreibt, »bewegt « oder »affektiert $« .{ }^{81}$ Es entsteht gleichsam

76 I Hemmings: Why Stories Matter, S. 17.

77 | Kristeva: Sèméiotikè, S. $113 \mathrm{f}$.

78 I Ebd., S. 114, Hervorh. i. 0. Siehe auch Jameson, Fredric: The Political Unconscious. Narrative as a Socially Symbolic Act, London 1981, S. 76, der das Ideologem als "the smallest intelligible unit of [...] collective discourses « beschreibt und ergänzt: "[t]he advantage of this formulation lies in its capacity to mediate between conceptions of ideology as abstract opinion, class value, and the like, and the narrative materials«(S. 87).

79 | Vgl. Kristeva: Sèméiotikè, S. $113 f$.

80 । Bachtin: Sobranie sočinenij, S. 32. Übers. v. d. Verf.

81 । Vgl. Shouse: Feeling, 0. S.; Massumi, Brian: »Notes on the Translation and Acknowledgements «, in: Deleuze, Gilles/Guattari, Félix, A Thousand Plateaus. Capitalism and Schizophrenia, Minneapolis, London 1987, S. xvi-xix, hier S. xvi. 
durch seine »ability to create affective resonances ${ }^{82}$. Im Zusammenspiel »rationaler« und "affektiver« Rezeption lässt sich überhaupt erst von einem Ideologem des Textes sprechen. ${ }^{83}$

Das Ideologem ist deshalb keine fixe Größe, sondern relational und wird im Prozess der Lektüre-als-Transposition performativ hergestellt: "That intertextuality produces the ideology of the text and that of its reading as a transformational surface is evident in Kristeva's definition of transposition as a process that brings about a new articulation of enunciative and denotative positionality. ${ }^{84}{ }^{84} \mathrm{Das}$ Ideologem kann also immer nur im intertextuellen Kontext gesehen werden, als ideell strukturierte Aussage im Dialog mit ihrem Kontext. Dieser Rahmen ${ }^{85}$ oder intertextuelle Kontext wird nicht nur im Schreibprozess, sondern ebenso in der Lektüre aktiv und macht diese »into a scene of self-reading the effect of which is also to inscribe us in our own history. ${ }^{86}$

Dies bedeutet, dass die Intonation als affektive `Gestimmtheit des Texts im intertextuellen Lektüreprozess zu einem "political unconscious ${ }^{87}$ wird, zu einem Wiedereinschreiben des Texts in den historischen und sozialen Kontext der Lektüre. Der Text ist in einer affektiven Sichtweise "what moves us, or what affects us such that we are no longer in the same place. Hence movement does not cut the body off from the swhere of its inhabitance, but connects bodies to other bodies - indeed, attachment takes place through movement ${ }^{88}$ Versteht man den Text als sich in der Lektüre aktualisierendes Ideologem, als Zusammenspiel multipler Transpositionen, die das lesende Subjekt in Bewegung setzen und gleichzeitig

82 | Vgl. Shouse: Feeling, 0. S.

83 I Vgl. auch Leys, Ruth: »The Turn to Affect. A Critique«, in: Critical Inquiry 37/3 (2011), S. 434472, hier S. 436, die schreibt, dass die Affekt-Theoretiker/innen "are gripped by the notion that most philosophers and critics in the past (Kantians, neo-Kantians, Habermasians) have overvalued the role of reason and rationality in politics, ethics, and aesthetics, with the result that they have given too flat or sunlayered or disembodied an account of the ways in which people actually form their political opinions and judgments."

84 I Rajan: Intertextuality, S. 65.

85 I Zum Begriff des Rahmens siehe auch Erving Goffmans Rahmenanalyse, auf die ich mich hier allerdings nicht konkret beziehe: Goffman, Erving: Frame Analysis. An Essay on the Organization of Experience, Cambridge, Mass. 1974. Interessant an Goffmans Vorschlag ist allerdings, dass sich seine Überlegungen in eine ähnliche Richtung bewegen wie das hier vorgeschlagene Konzept der Intonation. Den Rahmen (bspw. "primary frameworks", S. 21) definiert Goffman als ein "set of conventions « (S. 43) zur Decodierung von kulturellen Phänomenen oder Aussagen, wobei diese auch in einen anderen »key« (ebd.) transkribiert und ihre Bedeutung somit verändert werden können.

86 | Rajan: Intertextuality, S. 71.

87 I Ebd., S. 70. Siehe dazu auch Jameson: The Political Unconscious.

88 | Ahmed, Sara: "Collective Feelings. Or, The Impressions Left by Others«, in: Theory, Culture \& Society 21/2 (2004), S. 25-42, hier S. 27. 
`binden`, wird der Text unumgänglich als politischer aktiv, wird zu einer sozialen Intervention. ${ }^{89}$

Mit dem Begriff des Ideologems versuche ich deshalb, die Texte der polnischen feministischen Kritik als politische zu lesen. Dabei sollen auch ihre Selbstdefinitionen als un/politische hinterfragt werden. ${ }^{90}$ Ich verstehe den Text als Ganzes, der bestimmte Themen und Argumentationen in den Vordergrund stellt und andere durchstreicht oder verhüllt; diese Gesamtheit (tout) oszilliert zwischen intendierter und unintendierter Aussage der schreibenden Instanz, wird allerdings am wissenschaftlichen Text in der Regel als von der Autorin intendierte Aussage wahrgenommen. Den Lektüreprozess prägen aber auch Leerstellen und Ambivalenzen, implizite Distanzierungen und rhetorische Undurchdringlichkeiten. Einzelne Textstellen können sich affektiv auf den gesamten Lektüreprozess ausdehnen. Es gilt also, die nominelle Intention des Textes im gerahmten Lektüreprozess als dynamische zu verstehen und so nach einer politischen Bedeutung des Textes $\mathrm{zu}$ fragen, die sich erst im Wiedereinschreiben in den historischen und sozialen Kontext konstitutiert.

\subsection{Der Standpunkt als epistemologische Herausforderung}

Das Wiedereinschreiben des Texts in den historischen und sozialen Kontext möchte ich an dieser Stelle zum Anlass einiger metaanalytischer Überlegungen nehmen. Wenn ich nämlich vom spezifischen Zeichensystem spreche, in dem die Lektüre der untersuchten Texte stattfindet und die letztlich für deren Verständnis als Ideologem zentral ist, so muss ich im Besonderen auf meine eigene Lektüreposition eingehen. Diese ist spezifisch gewichtet, und mein Standpunkt ist durch eine historische wie kulturelle Außenperspektive auf die feministische Kritik im Polen der 1990er Jahre von Distanz gekennzeichnet. Diese Distanz unterlag im Verlauf des Forschungsprojekts verschiedenen Transformationen und hat sich durch Aufenthalte in Polen, Gespräche mit `Zeitzeug/innen` und die Lektüre entsprechender Primär- und Sekundärliteratur zweifellos verringert. Trotz der Rekonstruktion der >damaligen` soziopolitischen, wissenschaftlichen, ökonomischen Situation, auf die ich mich in der vorliegenden Arbeit auch beziehe und in die ich die Texte einbette, bleibt die Distanz jedoch bestehen. ${ }^{91}$ Dies hat neben einigen Nachteilen auch die Vorteile einer zumindest anfänglich unvoreingenommeneren Sichtweise

89 | Vgl. Miller: Subject to Change, S. 111, die sich hier auf Roland Barthes bezieht (siehe Barthes, Roland: »Der Tod des Autors«, in: Jannidis et al., Theorie der Autorschaft (2000), S. 185-193.

90 । Vgl. hierzu Kapitel 6.2.

91 I Darauf weist auch Ritz als nicht-polnischer Polonist hin: »Ein Leser von außerhalb kann jedoch nie völlig die Position eines verspäteten Lesers abwerfen«. Ritz, German: »Kanon i historia literatury widziane z zewnątrz«, in: Iwasiów, Inga/Czerska, Tatiana (Hg.), Kanon i obrzeża, Kraków 2005, S. $29-40$, hier S. 30. 
und der Möglichkeit, `naive` Fragen zu stellen und ungewohnte Rezeptionswege einzuschlagen..$^{92}$ Meine Position liegt zwischen der `Entdeckung`von im deutschsprachigen Raum wenig bekannten Diskursfeldern und wissenschaftlich-kulturellen Zusammenhängen einerseits und der Feststellung, dass viele Aspekte aus der sinformierteren wurden. ${ }^{93}$

Der Fokus auf die Situiertheit des wissenschaftlichen Subjekts in Bezug auf das Untersuchungsmaterial lenkt zudem den Blick auf die Tatsache, dass eine >unverortete Objektivität ‘ auch in der Wissenschaft nicht möglich ist. Feministische Ansätze haben aufgezeigt, dass Wissen stets als "situiertes Wissen " ${ }^{94}$ verstanden werden muss und somit bereits normativen Charakter hat, was jedoch oft durch einen $»$ veil of claimed neutrality ${ }^{95} \mathrm{zu}$ depolitisieren versucht werde. Die Theorie des epistemologischen Standpunkts bezieht intertextuelle Bezüge mit ein, indem sie davon ausgeht, dass eine Aussage immer von "particular, historically specific, social locations « und »historically distinctive institutional and cultural interests and concerns ${ }^{96}{ }^{96}$ geprägt ist.

Hinsichtlich meines eigenen "Standpunkts« droht aufgrund der historisch-kulturellen Distanz die Überstülpung einer ‘fremden` Sichtweise. Diese kann zudem in der europäischen (Wissenschafts)Landschaft als ızentralere gegenüber der polnischen »Semiperipherie« gelesen werden. ${ }^{97}$ Der Vorwurf von

92 I Insofern könnte man hier auch von einem millerschen »overreading « des »underread « sprechen, das den Lektüreprozess zu deautomatisieren versucht, vgl. Miller: Subject to Change, S. 83; auch Bal: Travelling concepts, S. 291. Haraway, Donna: "Situiertes Wissen. Die Wissenschaftsfrage im Feminismus und das Privileg einer partialen Perspektive«, in: dies., Die Neuerfindung der Natur. Primaten, Cyborgs und Frauen, Frankfurt a/M., New York 1995, S. 73-97, hier S. 84 verweist zudem auf die Relevanz einer "Vielfalt partialen, verortbaren, kritischen Wissens" und somit plurizentraler/dezentraler Diskurse.

93 I In gewissen Bereichen steht meine Position somit in einem Ähnlichkeitsverhältnis zu den in der Arbeit analysierten Positionen polnischer feministischer Kritik. Die von mir untersuchten intertextuellen Bezugnahmen der polnischen Wissenschaftlerinnen auf feministische Theorien sind ebenso von einer historischen Distanz geprägt, von einem 'Nach-Lesen und Aufbereiten westlicher Diskurse in einer zeitlichen Verschiebung.

94 I Haraway: Situiertes Wissen.

95 I Harding, Sandra: »Introduction: Standpoint Theory as a Site of Political, Philosophic, and Scientific Debate«, in: dies. (Hg.), The Feminist Standpoint Theory Reader. Intellectual and Political Controversies, New York, London 2004, S. 1-15, hier S. 2. Siehe auch Feyerabend, Paul: Wider den Methodenzwang. Skizze einer anarchistischen Erkenntnistheorie, Frankfurt a/M. 1976, S. 31f.; Newton: History as Usual, S. 98.

96 I Harding: Introduction, S. 4f.

97 | Vgl. Blagojevic, Marina: »Creators, Transmitters and Users: Women's Scientific Excellence at the Semi-Periphery of Europe«, in: European Commission Community Research ( $\mathrm{Hg}$.$) , Gender and$ Excellence in the Making, Brüssel 2004, S. 135-145. 
»Misreadings $^{98}$ oder selektiver Wissenschaft fiele aus dieser wissenschaftshistorisch privilegierten Position leicht. In Anknüpfung an Sandra Hardings Verständnis des politischen und kulturellen Settings als "prisonhouse " und "toolbox " ${ }^{99}$ der Wissenschaft in Einem möchte ich deshalb abschließend den Begriff der bricolage diskutieren. Dieser erlaubt es zwar, gewisse Beobachtungen in Bezug auf die Situation der feministischen Kritik der polnischen 1990er Jahre zu illustrieren, birgt jedoch die Gefahr einer "Orientalisierung ${ }^{100}$ und einer verkürzten Analyse der untersuchten Phänomene.

Claude Lévi-Strauss entwickelte das Konzept der bricolage, der Bastelei, in $\mathrm{La}$ Pensée sauvage (1962). Die bricolage zeichne sich im Gegensatz zur Ingenieurskunst dadurch aus, dass sie »Mittel verwendet, die im Vergleich zu denen des Fachmanns abwegig sind «; doch sie »hat nichts anderes zur Hand. « ${ }^{101}$ Insofern lässt sich dieses Konzept hervorragend mit dem Narrativ der `Wiedergeburt des Feminismus und der feministischen Kritik in Polen verbinden. Im Kontext einer 'gekappten ‘radition und dem Bemühen um ein Erstellen eines feministischen Argumentariums aus dem `Nichts` erscheinen die theoretischen Ansätze der feministischen Kritik im Polen der 1990er Jahre tatsächlich »als eine Art intellektueller Bastelei « ${ }^{102}$, als eine »Verknotung" verschiedenster, eher zufällig zusammengefügter Ideen, Ansätze, Theorien, Methoden. ${ }^{103}$ Umso attraktiver erscheint diese Auslegung, wenn

98 I Siehe zu diesem Begriff Bloom, Harold: The Anxiety of Influence. A Theory of Poetry, New York 1973, S. 30; ders.: A Map of Misreading, New York 1975, S. 3. Bloom versteht jedoch den Begriff des "misreadings « oder auch der "misinterpretation « oder »misprision« primär als eine Art kreatives Weiterschreiben und misst inm keine (negative) Wertung bei: "reading is therefore a miswriting, just as writing is a misreading (ebd.). Vgl. auch Goffman: Frame Analysis, S. 308, der mit "misframing « ein ähnliches Phänomen sozialer Interaktion, jedoch als "systematically sustained, generative error " sowie als "a whole grammar of expectations, that will not work" (S. 309) beschreibt. Meine eigene Setzung des Begriffs des "Misreadings « im obigen Kontext tendiert eher in Goffmans Richtung, wenn ich auch generell das "Misreading « nicht negativ konnotieren möchte. 99 I Harding: Introduction, S. 5; siehe auch dies.: Is Science Multicultural? Postcolonialisms, Feminisms, and Epistemologies, Bloomington, Indianapolis 1998.

100 | Zum Begriff des Orientalismus als Fremdzuschreibung vgl. Said, Edward W.: Orientalism, New York 1979. Larry Wolff hat ähnliche Prozesse für »0steuropa« festgestellt, siehe Wolff, Larry: Inventing Eastern Europe. The Map of Civilization on the Mind of the Enlightenment, Stanford, California 1994. Die Diskussion um die Begriffe ‘West und >0st und deren spezifische Zuschreibungen in Bezug auf innereuropäische Beziehungen wird bereits seit längerem geführt, siehe etwa Janion, Maria: Niesamowita słowiańszczyzna. Fantazmaty literatury, Kraków 2006, S. 228-235; Wierzbicki, Andrzej: Wschód-Zachód w koncepcjach dziejów Polski. Z dziejów polskiej myśli historycznej w dobie porozbiorowej, Warszawa 1984.

101 I Lévi-Strauss, Claude: Das wilde Denken, Frankfurt a/M. 1968, S. 29.

102 | Ebd.

103 I Interessanterweise verwendet auch der US-amerikanische Soziologe David Stark in seiner Beschreibung der bisherigen Transformationsprozesse und deren potentieller Weiterentwicklung 
man bedenkt, wie populär das Verständnis in Polen ist, etwas zu »kombinieren« oder, treffender übersetzt, »sich etwas einfallen zu lassen « (kombinować), also eine unkonventionelle, aber praktikable Lösung für ein (zumindest mit konventionellen Mitteln) scheinbar unlösbares Problem zu finden. ${ }^{104}$

Was mich schließlich davon abhielt, das Konzept der bricolage tatsächlich als einen Schlüssel meiner Lektüre einzusetzen, war einerseits die Formulierung Lévi-Strauss', dass es sich hierbei um eine »Wissenschaft [...], die wir lieber eine >erste als eine primitive nennen wollen ${ }^{105}$, handle. Obwohl Lévi-Strauss vom Attribut "primitiv« letztlich absieht, bleibt doch der Nachgeschmack eines hierarchischen Denkens, das sich auch in der Bezeichnung »erste« verbirgt. Ob eine solch `koloniale`Ausgangsperspektive meinem Vorhaben nützlich wäre, egal wie ich den Begriff der bricolage schließlich ausfüllen würde, erschien mir zweifelhaft. Hinzu kam, dass ich zeigen wollte, dass die feministische Kritik der 1990er Jahre gerade nicht auf `Nichts` aufbauen konnte, wie sehr sie sich zum Teil auch selbst davon zu überzeugen versuchte. ${ }^{106}$ Diesem Vorhaben würde der bricolage-Begriff zumindest oberflächlich betrachtet zuwiderlaufen.

Endgültig verworfen habe ich die bricolage als leitendes Konzept aber mit Blick auf Paul Feyerabends "anarchistische Erkenntnistheorie«. Wie Feyerabend m. E. treffend festhält, kann Entwicklung auch im wissenschaftlichen Bereich nur durch Variation und Flexibilität stattfinden; ${ }^{107}$ ein >Anwenden` von dafür festgelegten Methoden jedoch reproduziert letztlich nur sich selbst. Feyerabend plädiert deshalb für »anything goes «, ${ }^{108}$ dessen Verwandtschaft zur Bastelei hier wohl nicht nachvollzogen werden muss. In gewisser Weise muss eine kritische Wissenschaft, zu der sich die feministische Kritik zählt, »kombinieren« und ungewohnte Wege eingehen, um nicht im Wiederholen der bestehenden Wissens- und damit Macht-

den Begriff bricolage, nämlich für die Negotiationen rund um die Einführung marktwirtschaftlicher Systeme in ehemalig sozialistischen Staaten, vgl. Stark, David: »Path Dependence and Privatization Strategies in East Central Europe«, in: East European Politics and Societies 6/1 (1991), S. 17-54, hier S. 52.

104 I Auf den Begriff kombinować beziehe ich mich, wenn auch an dem ganz anderen Beispiel des polnischen Bergsteigens in der Volksrepublik, in Seiler, Nina: »Gipfeltreffen. Polens bergiges Fenster zur Welt«, in: Frölicher, Gianna et al. (Hg.), »Dieser Mont Blanc verdeckt doch die ganze Aussicht! « Der literarische Blick auf Alpen, Tatra und Kaukasus, Zürich 2016, S. 207-220, hier S. 218.

105 | Lévi-Strauss: Das wilde Denken, S. 29.

106 | Vgl. hierzu bspw. Magnone: Die polnischen Gender Studies, S. 369f., deren Narrativ sich ebenfalls stark an die Vorstellung eines geschlechterdiskursiven Vakuums zwischen 1945 und 1989 anlehnt.

107 | Ähnlich argumentiert Haraway: Situiertes Wissen, S. 94, die schreibt: »Feministische Objektivität schafft Raum für Überraschungen und Ironien im Herzen jeglicher Produktion von Wissen." 108 | Feyerabend: Wider den Methodenzwang, S. 45. 
verhältnisse zu verharren. ${ }^{109}$ Damit wäre auch die »Verknotung« feministischer Ansätze in Polen nicht mehr ein »erstes«, behelfsmäßiges Verfahren, sondern ein lediglich deutlicheres Hervortreten der Mechanismen der Wissensproduktion und -rezeption. Es erschien mir somit sinnvoller, in der Analyse auf Verfahren der Distanznahme, Verfremdung und des »Misreadings « als bedeutungsproduzierende Mechanismen Bezug zu nehmen und die bricolage als intertextuellen Aspekt jeglicher Wissenschaft zu integrieren.

\subsection{Aufbau der Arbeit}

Die vorliegende Arbeit gliedert sich in fünf inhaltliche Teile. Zur Einführung in die Thematik geht den eigentlichen Analysekapiteln (3-6) eine Beschreibung des diskursiven Felds (Kapitel 2) voran. Dieses wird in den historischen Kontext eingebettet, womit die in den 1990er Jahren vorherrschenden Narrative und Gegennarrative überhaupt erst ihre wissenschaftliche wie gesellschaftliche Dimension gewinnen. Die Einbettung reicht bis ins 19. Jahrhundert, dessen Diskurse als zentral für die Geschlechterordnung gelten. Neben ersten Emanzipationsbestrebungen beschreibe ich besonders auch den Kontext vieler literarischer Werke, denen sich die von mir untersuchten Texte widmen. Dieser Teil der Kontextualisierung spielt deshalb für das Verständnis der Argumentation der feministischen Polonistinnen eine tragende Rolle. Mit der Aufarbeitung der Geschlechterdiskurse während der sozialistischen Zeit beabsichtige ich hingegen, eine Lücke im feministischen Argumentarium der 1990er Jahre zu schließen. Damit lassen sich die ,Wiedergeburts`narrative der 1990er Jahre, die das Wiederaufnehmen einer Geschlechterdebatte raus dem Nichts` postulieren, zumindest kontrastieren. In der Nachzeichnung der Dynamiken der 1990er Jahre gehe ich auf allgemeinere soziopolitische und ökonomische Faktoren genauso ein wie auf die Entstehung der sneuen` Frauenbewegung. Detailliert führe ich hier auch in die publizistische und akademische Entwicklung in Bezug auf feministische Ansätze ein.

Das Kapitel 3 widmet sich vollumfänglich der Polonistin Maria Janion und deren Werdegang in Bezug auf die Geschlechterforschung. Janion erscheint als eine Schwellenfigur, die die analytische Kategorie des Geschlechts ab den 1970er Jahren weitgehend unabhängig von westlichen feministischen Ansätzen an ihrem Forschungsmaterial entwickelte. Janions Forschung bildet das verbindende Element zwischen der Geschlechterforschung in der Volksrepublik und der feministischen Strömung der 1990er Jahre. In der posttransformationalen Zeit nimmt Janion die

109 | Vgl. dazu auch die Überlegungen Mieke Bals (Travelling concepts, S. 178f.) zum Konzept der "performativity «, die "becomes the instance of an endless process of repetition; a repetition involving similarity and difference, and therefore relativizing and enabling social change and subjects' interventions, in other words, agency."Bal selbst intendiert zudem "to mess up [...] concepts" (S. 177), um naive und »analytically unhelpful« Konzeptionen zu durchbrechen. 
Funktion einer Art `Mentorin` der feministischen Kritik ein, während sie selbst ihren Zugang noch pointierter feministisch ausrichtet. Den Veränderungen in der wissenschaftlichen Perspektive Janions und der Gewichtung bestimmter Aspekte schenke ich in diesem Kapitel besonderes Augenmerk. Diesen Verschiebungen soll mit der vergleichenden Analyse zweier Artikel Janions zur/zum Schriftsteller/in Maria Komornicka/Piotr Włast aus den Jahren 1979 und 1996 Rechnung getragen werden. Gleichzeitig wird an Janions Kobiety i duch inności ersichtlich, dass diese einen konzeptuell offeneren Zugang zur feministischen Kritik aufweist als andere Publikationen der 1990er Jahre.

Überleitend zu einem allgemeineren Blick auf die untersuchten feministischen Monographien frage ich in Kapitel 4 nach den in den Texten angelegten Rezeptionslinien westlicher Theorien. Dabei diskutiere ich sowohl die `Erzählung` über die feministische Kritik als wissenshistorisches Phänomen wie auch die spezifischen Strategien der Einbettung einzelner Ansätze oder Denktraditionen. Dabei achte ich auf Abgrenzungen und die Feststellung konzeptueller Divergenzen, aber auch auf Verfahren der Überlagerung. Mit der Psychoanalyse greife ich eine Analysetradition heraus, deren Einbettung in die polnische feministische Kritik gesondert untersucht wird. Dabei fallen besonders Strategien der Umgehung auf, in denen die feministischen Polonistinnen die Psychoanalyse oder Freud selbst durch andere Positionen implizit ersetzen. Der letzte Teil des Kapitels stellt die Frage nach Rezeptions- und Transferprozessen über die untersuchten Monographien hinaus. Hier diskutiere ich Texte und Akteure, die sich den Randgebieten der feministischen Kritik in der Polonistik zuordnen lassen und als >liminale Figuren`, als vermittelnde `Filtertexte` oder als `Katalysatoren` für die feministische Kritik bedeutsam werden.

In Kapitel 5 gehe ich detaillierter auf die Verfahren der feministischen Kritik der 1990er Jahre in Bezug auf ihre literarischen Vorlagen ein. Zunächst lässt sich feststellen, dass die Auseinandersetzung mit der Rezeption eines untersuchten Werks einen relevanten Teil der feministischen Kritik ausmacht und die bisherig dominierende Rezeption und kanonisierte Lektüre durch eine dezentralisierte, weibliche oder feministische Lesart kontrastiert wird. Dies wirft die Frage auf, was unter einer >weiblichen Literatur oder >weiblichem Schreiben stehen sei und inwiefern sich die feministischen Kritikerinnen darauf beziehen. In den Fokus rücken die Texte mehrheitlich die Verhandlung einer >Weiblichkeit ‘ als gemeinsamer Nenner von (schreibenden) Frauen. Im Anschluss daran lassen sich auch Versuche einer 'Traditionsbildung in Bezug auf weibliches Schreiben in den untersuchten polonistischen Texten feststellen.

Im letzten, sechsten Kapitel bespreche ich die feministische Kritik in Polen kritisch im Kontext der postsozialistischen 1990er Jahre, wobei ich nach Überschneidungen und Gegenströmungen zu den Diskursen dieser Zeit frage. Zunächst untersuche ich die Texte in Bezug auf bestimmte Motive und deren Verhandlung im feministischen Diskurs. Dabei handelt es sich um literarische Mutterfiguren, Themen wie Schwangerschaft, Geburt und Schwangerschaftsabbruch sowie letztlich 
die Frage nach der Reproduktionsarbeit und sozialen Klassen. In einem zweiten Schritt frage ich nach der Verortung der feministischen Kritik im postsozialistischen Diskursfeld, das starke Tendenzen der Politikmüdigkeit und der Individualisierung aufweist. Im Fokus stehen dabei auch die Verschiebungen von öffentlicher und privater Sphäre, die als vergeschlechtlichte Bereiche einerseits gelten und andererseits eine für den (post)sozialistischen Kontext spezifische Grundlage politischen Engagements bilden. Mit der feministischen Absage an die polnische Gesellschaft als ganze und der Verschiebung des Interesses auf ein übergeordnetes Patriarchat stellt sich letztlich die Frage, ob und welche Form von Gemeinschaft die feministischen Kritikerinnen anstreben. Deshalb fokussiere ich zum Schluss auf textuelle Mechanismen der Gruppenbildung und der affektiven Ein- und Ausgrenzung.

Im Schlusswort bringe ich die herausgearbeiteten Erkenntnisse unter den Begriffen der Intertextualität, der Intonation und des Ideologems erneut zusammen und öffne dabei den Blick auf weitere Entwicklungen nach 2000. Die Verortung feministischer Kritik im polnischen soziopolitischen Diskurs der 1990er Jahre wie auch im Kontext transnationaler feministischer Theorie muss dabei als Spannungsfeld verstanden werden. Die Divergenzen der Anknüpfungspunkte führen zu ambivalenten Argumentationen innerhalb der feministischen Kritik; gleichzeitig lässt sich mit der retraditionalisierenden Stärkung katholischer Positionen in der Politik und gewissen Teilen der Bevölkerung, die zunehmend säkularisierten, liberalen Gesellschaftskreisen entgegenstehen, von einer postsozialistischen Spaltung der Gesellschaft sprechen, die sich ab Mitte der 2010er Jahre immer deutlicher abzeichnet. Mit einigen wenigen letzten Textbeispielen möchte ich deshalb einen Ausblick auf diese Entwicklungen nach den 1990er Jahren skizzieren. 


\section{Geschlechtergeschichte Polens - Mythen, Fakten, Diskurse}

Um den Kontext verstehen zu können, in dem sich die feministische Kritik in den 1990er Jahren in Polen ansiedelt, ist eine Rückschau auf die historischen Geschlechtervorstellungen und Narrative zur Emanzipation unumgänglich. Der Diskurs über das Geschlecht ist jedoch besonders stark von einseitigen, emotional gefärbten Auslegungen und Kontroversen geprägt, weshalb sich das Problem >objektiver kultureller und wissenschaftlicher Tradierung historischer Diskurse hier verschärft stellt. ${ }^{1}$ Der Blick auf die historische Dimension geschieht deshalb im Folgenden aus der Sicht der 1990er Jahre. Vorgestellt werden einerseits die Geschlechterbilder, die die Forschung als die Dominanten der polnischen Geschlechterordnung beschreibt. Andererseits wird die Geschichte der Emanzipationsbewegung und feministischer Aktivitäten nachgezeichnet. Die weibliche soziale Handlungsfähigkeit war in Polen - wie der Diskurs ${ }^{2}$ feststellt - besonders groß. Dies wird jedoch aus unterschiedlicher Perspektive unterschiedlich bewertet - am Beispiel des 19. Jahrhunderts etwa als Nebenprodukt einer >Aufopferung für die Nation

$\mathrm{Zu}$ den Geschlechterdiskursen der näheren Vergangenheit schweigt die Forschung der 1990er Jahre hingegen mehrheitlich; die Nachkriegszeit bis 1989 wird rückblickend vom konservativen Narrativ einer `widernatürlichen Feminokratie` und vom feministischen Narrativ einer >Pseudoemanzipation von oben drängung in die Passivität als konkurrierende Erzählungen gleichzeitig doppelt negativ geprägt. Diese Negativschablone versuche ich durch eine kursorische Aufarbeitung von Publikationen zum Thema Geschlecht in der Volksrepublik zumin-

1 I Vgl. Marszałek, Magdalena: "Jeszcze raz o mózgu, płci, biologii i polityce«, in: Pełnym głosem 4 (1996), S. 41-47, hier S. 41. Zur Problematik allgemein siehe White, Hayden: Metahistory. The Historical Imagination in Nineteenth-Century Europe, Baltimore, London 1973.

2 I Vgl. Tacke, Charlotte: "Geschlecht und Nation«, in: Kemlein, Geschlecht und Nationalismus (2000), S. 15-32, hier S. 19, die den Diskurs als eine Form der »Kommunikation [...], die zugleich wirklichkeitsabbildend und wirklichkeitsbildend« ist, bezeichnet. 
dest ansatzweise zu destabilisieren und dabei auch eine Brücke zu den Diskursen der 1990er Jahre zu schlagen. Für die Zeit nach 1989 kontextualisiere ich den sozialen, politischen und ökonomischen Wandel entlang der Kategorie des Geschlechts. Die Entwicklung der Frauenbewegung und feministischen Kritik wird in diesem Feld und als Ausdruck davon beschrieben.

Diese Zusammenstellung von historischen `Fakten` und Mythen ${ }^{3}$ führt in die polnische Geschlechterdebatte ein und liefert den Kontext für die spätere Analyse feministischer Texte der 1990er Jahre. Die Fokusverengung auf das weibliche Geschlecht drängt sich aufgrund mangelnder Literatur zum männlichen Geschlecht auf, ist hier aber gleichsam pragmatisch gewählt als Ausgangspunkt der zu untersuchenden feministischen Kritik.

\subsection{Adliger Geschlechtervertrag und Matka Polka}

Als historischer Hintergrund der polnischen Geschlechterordnung werden meist zwei Aspekte oder Phasen angeführt, die sich aus dem 18. und 19. Jahrhundert in die Gegenwart auswirkten. Dies betrifft sowohl die konventionelle Geschichtsschreibung wie auch deren feministische Variante. Die erste Phase betrifft die polnische Adelsrepublik mit ihren relativ liberalen Rollenmustern; die zweite umreißt die stärkere Stilisierung der Geschlechterrollen unter der Teilungsherrschaft. Beide Aspekte, die im Folgenden in aller Kürze skizziert werden, heben sich von der bürgerlichen Geschlechterordnung entscheidend durch ihre weniger starke Zweiteilung in geschlechtlich markierte private und öffentliche Sphären ab.

Die polnisch-litauische Adelsrepublik (1569-1795) zeichnet sich - so der historiographische Konsens ${ }^{4}$ - durch ein verhältnismäßig partnerschaftliches Geschlechtermodell aus. Im Blickfeld steht die diskursbestimmende Adelsgesellschaft der Szlachta, während etwa der Stand von Bäuerinnen und Bauern relativ unerforscht ist. ${ }^{5}$ Die Adelsrepublik ermöglichte der Szlachta viele Freiheiten und Teilhabe an den Geschicken der Republik. Das ausgeprägte Standesbewusstsein

3 । Vgl. ebd., S. 25f. zur doppelten Strukturierung (historischer) sozialer Praktiken durch Diskurs und pragmatische Alltagsbewältigung und die daraus resultierenden Divergenzen von (tradiertem) Diskurs und tatsächlicher (historischer) sozialer Praxis.

4 । Als Gegenposition siehe aber etwa Dybel, Paweł: "Psychoanalyse in Polen - Herausforderung für Bräuche und Tradition?«, in: Krasnodębski, Zdzisław et al. (Hg.), Kulturelle Identität und sozialer Wandel in 0steuropa: das Beispiel Polen (= Beiträge zur 0steuropaforschung, Band 3), Hamburg 1999, S. 283-295, hier S. 289, der den Antifeminismus der Szlachtagesellschaft betont. 5 I Vgl. Pietrow-Ennker, Bianka: »Frau und Nation im geteilten Polen«, in: Kemlein, Geschlecht und Nationalismus (2000), S. 125-142, hier S. 125f. Allgemeiner siehe Tacke: Geschlecht und Nation, S. 19. Für eine Aufarbeitung der Geschlechtergeschichte der nicht-adligen Stände siehe Wawrzykowska-Wierciochowa, Dionizja: Od prządki do astronautki. Z dziejów kobiety polskiej, jej pracy i osiągnięć, Warszawa 1963. 
und die hochgehaltene Gleichheit unter den Szlachcicen erwirkten in Verbindung mit einem starken Marienkult ein positives Bild der adligen Dame als Mitglied der Szlachta. ${ }^{6}$ Besonders im Kontext der Geschlechterforschung wird dabei auf die symbolische Hochachtung Bezug genommen, die der adligen Frau durch den Geschlechtervertrag von Ritter und Dame im Rahmen eines "gemäßigten Patriarchalismus« zukam. Gleichzeitig verweisen feministische Arbeiten darauf, dass gerade dieses gesellschaftlich "hohe Ansehen" die faktische Beschneidung des weiblichen Selbstbestimmungsrechts ermöglichte. ${ }^{7}$

Ergänzt wird der Szlachtadiskurs im 19. Jahrhundert durch zwei mythische Dimensionen: Die Rekonstruktion des barocken polnischen Sarmatismus verweist darauf, dass die mythischen Sarmaten als Ahnen des polnischen Volkes Verbindungen zu einem Amazonenvolk aufwiesen, was das Bild starker und unabhängiger Frauenfiguren historisch legitimiert. ${ }^{8}$ Umgekehrt konstruiert der Ende des 19. Jahrhunderts aufkommende Pan- oder Neoslavismus das Bild eines friedliebenden, autochthonen polnischen Volkes ${ }^{9}$ - eine der gesamteuropäischen Norm kriegerischer Männlichkeit zuwiderlaufende Erzählung ${ }^{10}$ und Ausdruck des spezifischen martyriologischen Selbstbilds der Polinnen und Polen, das nach den Teilungen des polnischen Staatsgebiets entsteht.

Die Annektierung des polnisch-litauischen Staatsgebiets durch das Russische Reich, Österreich-Ungarn und Preußen (Teilungszeit 1772-1795 bis 1918) beraubte die polnische Adelsgesellschaft ihres politischen Mitbestimmungsrechts. Damit

6 I Vgl. Kuchowicz, Zbigniew: Żywoty niepospolitych kobiet polskiego baroku, Łódź 1989, S. 6; Partyka, Joanna: "Żona wyćwiczona«. Kobieta pisząca w literaturze XVI i XVII wieku (= Rozprawy Literackie, Band 82), Warszawa 2004, S. 30-60; Pietrow-Ennker: Frau und Nation, S. 127f. Die Klassenunterschiede fielen damit stärker ins Gewicht als die Differenzierung entlang des Geschlechts.

7। Titkow, Anna: »Kobiety pod presją? Proces kształtowania się tożsamości«, in: Titkow/ Domański, Co to znaczy (1995), S. 9-39, hier S. 11, 15. Vgl. auch Brach-Czaina, Jolanta: »Progi polskiego feminizmu«, in: Kwartalnik Pedagogiczny 155-156/1-2 (1995), S. 343-357, hier S. 352; Środa, Magda: "Kobieta: wychowanie, role, tożsamość«, in: Walczewska, Głos mają kobiety (1992), S. 9-17, hier S. 12; Walczewska, Sławomira: Damy, rycerze i feministki. Kobiecy dyskurs emancypacyjny w Polsce (= Kobieta, Kultura, Krytyka), Kraków 1999 (2000).

8 I Vgl. Lubamersky, Lynn: "The >Wild Woman in the Culture of the Polish-Lithuanian Commonwealth «, in: Shifrin, Susan (Hg.), Women as Sites of Culture. Women's Roles in Cultural Formation from the Renaissance to the Twentieth Century, Hampshire 2002, S. 183-193, hier bes. S. 186f.

9 I Siehe Taperek, Marta: "Sztuka sławiańska w wybranych pismach teoretycznych architekta Jana Sasa-Zubrzyckiego«, Unveröffentlichte Skizze, Warszawa 2016, S. 8-11.

10 | Vgl. Ostrowska, Elżbieta: »Matki Polki i ich synowie. Kilka uwag o genezie obrazów kobiecości i męskości w kulturze polskiej«, in: Radkiewicz, Gender (2004), S. 215-227, hier S. 225 zur Kritik an der »Verweiblichung « des "Volkscharakters" der Polen. Zu Männlichkeitsdiskursen wie dem »image of the warrior (S. 192) siehe Mosse, George L.: The Image of Man. The Creation of Modern Masculinity (= Studies in the History of Sexuality), New York, Oxford 1996. 
beschränkte sich der Aktionsradius der Szlachta fortan auf die zivilgesellschaftliche und familiale Sphäre. Mit der geläufigen Feststellung, dass »Polen [...] zur Familie wurde «" verwies Władysław Łoziński 1912 auf den Bedeutungsgewinn der Familie als Wirkungsbereich von Frauen wie Männern und zugleich auf die emotionale Bindung an die Kulturnation. "The family was [during partition] the only national institution, the fortress of the national spirit. Woman's position in the family constantly rose during the 19 th century ${ }^{12}$. Die Familie gerann zum Ort des verdrängten Politischen, und die polnischen (adligen) Frauen wurden zu symbolischen »Mitbürgerinnen « des imaginierten souveränen Staats. ${ }^{13}$

Das Bild der (adligen) Frau verdichtete sich im 19. Jahrhundert zur von der Romantik geprägten Figur der Matka Polka (Mutter Polin). Diese war zuständig für die patriotische Erziehung des Nachwuchses und den Erhalt des Polentums (polskość), der polnischen Kulturtradition und katholischer Werte. Das Bild der Matka Polka verband sich zunehmend mit demjenigen der Mutter Gottes und verkörperte Aufopferung, Hingabe und stilles Leid. ${ }^{14}$ Daran zeigt sich exemplarisch die in der polnischen Kulturgeschichte enge Verknüpfung der Geschlechterrollen mit der katholischen Werteordnung. Der Einfluss der katholischen Kirche als Stabilisatorin traditioneller Rollenmuster darf nicht unterschätzt werden. ${ }^{15}$

Daneben wurde die Matka Polka zur selbstständigen Hüterin von Haus und Herd und übernahm soziale Funktionen, »wenn der Mann kämpfte, im Gefängnis oder in der Verbannung oder gefallen war ${ }^{16}$. Dies ermöglichte eine Ausweitung weiblicher Tätigkeiten im zivilgesellschaftlichen Bereich, etwa in Hilfsorganisa-

11 | Łoziński, Władysław: Życie polskie w dawnych wiekach, Kraków 1958, S. 153. Siehe auch Siwicka, Dorota: »0jczyzna intymna«, in: Res Publica Nowa 58-59/7-8 (1993), S. 70-72, hier S. 70. 12 I Sokołowska, Magdalena: "The Woman Image in the Awareness of Contemporary Polish Society«, in: The Polish Sociological Bulletin 35/3 (1976), S. 41-50, hier S. 43. Vgl. auch Krzyżanowska, Natalia: Kobiety w (polskiej) sferze publicznej, Toruń 2012, S. 152; 0strowska: Matki Polki, S. 226. 13 I Krzyżanowska: Kobiety, S. 152. Vgl. Żarnowska, Anna: »Prywatna sfera życia rodzinnego i zewnętrzny świat życia publicznego - bariery i przenikanie (przełom XIX i XX wieku)«, in: Żarnowska/Szwarc, Kobieta i świat polityki (1994), S. 5-28, hier S. 16; sowie Pietrow-Ennker: Frau und Nation, S. 128 und 0strowska: Matki Polki, S. 219f. zur Verschiebung des Männlichen in die homosozialen aufständischen Vereinigungen.

14 | Vgl. Dybel: Psychoanalyse in Polen, S. 290f.; Janion, Maria: »Polonia powielona«, in: Gabryś, Monika et al. (Hg.), Polka. Medium. Cień. Wyobrażenie, Warszawa 2006, S. 19-31, hier S. 25; Kijowski, Andrzej: Arcydzieło nieznane, Kraków 1964, S. 18; Monczka-Ciechomska, Magda: »Mit kobiety w polskiej kulturze«, in: Walczewska, Głos mają kobiety (1992), S. 95-101, hier S. 95ff.; Walczewska: Damy, rycerze i feministki, S. 54ff.; Żarnowska: Prywatna sfera, S. 11-15. Zur Rolle der Frau in der Kulturtradition allgemein siehe auch Mosse: The Image of Man, S. 8.

15 I Vgl. Graff, Agnieszka: »Warum Frauen in Polen snicht stören««, in: Jahrbuch Polen 17 (2006), S. $34-44$, S. $40 f$.

16 I Jabłonowska, Zofia: »Rodzina w XIX i na początku XX wieku«, in: Komorowska, Przemiany rodziny polskiej (1975), S. 52-71, hier S. 68. 
tionen im Widerstand. ${ }^{17}$ Deshalb wird die polnische Geschlechterordnung des 19. Jahrhunderts mitunter gar als Matriarchat bezeichnet. ${ }^{18}$ Die weibliche Handlungsfähigkeit war aber gebunden an das Engagement für die nationale Unabhängigkeit. Weibliche `Emanzipation` wurde als Aufopferung für die Patria und als Selbstaufgabe toleriert, während Selbstbestimmungsbestrebungen besonders in der Romantik als Egoismus diskreditiert wurden. ${ }^{19}$ Dies betraf gar beide Geschlechter: »der Nationaldiskurs erfüllte über Jahre hinweg in der polnischen Gesellschaft die Funktion des `öffentlichen Schlüsselnarrativs`. Die Geschlechtsidentität ihrer männlichen wie weiblichen Mitglieder konstruierte sich in Abhängigkeit von diesem Narrativ. ${ }^{20}$

Bis heute fungiert die Matka Polka als das gängigste Referenzbild polnischer Frauen und wird oft - anknüpfend oder kontrastierend - als Schablone der Identitätskonstruktion verwendet. ${ }^{21}$ Dabei ist jedoch unklar, wie präsent diese Figur im Diskurs des 19. Jahrhunderts tatsächlich war. Fest steht hingegen, dass sie retrospektiv als Symbolfigur der polnischen Geschlechterordnung diskursiviert und ab den 1970er Jahren wieder in das öffentliche Narrativ aufgenommen wurde (s. u.). Auch die feministische Kritik der 1990er Jahre bezieht sich in ihren historischen Kontextualisierungen nicht selten auf die Matka Polka und den adligen Geschlechtervertrag, um auf eine traditionell hohe Stellung der Frau in der polnischen Kultur aufmerksam zu machen und gleichzeitig die normativen Rahmungen dieser Rollenbilder aufzuzeichnen (s. u.). Es formiert sich aber auch Kritik an der >mythisierten $`$ wie auch wenig produktiven Tradierung solcher Schablonen. ${ }^{22}$

\subsection{EmanZIPATIONSBESTREBUngeN}

Die polnische Emanzipationsbewegung widersetzte sich den oben beschriebenen Vereinnahmungen durch den nationalen Diskurs und versuchte gleichzei-

17 I Etwa Waffen- und Nahrungsmittelbeschaffung, Pflegedienste und Fluchthilfe, teilweise direkter bewaffneter Widerstand, vgl. Nietyksza, Maria: "Tradycyjne i nowe formy aktywności publicznej kobiet w warunkach zaborów«, in: Żarnowska/Szwarc, Kobieta i świat polityki (1994), S. 83-98; Pietrow-Ennker: Frau und Nation, S. 131; Żarnowska: Prywatna sfera.

18 I Etwa von Tadeusz Boy-Żeleński, vgl. Ostrowska: Matki Polki, S. 225, oder von Jabłonowska: Rodzina, S. 68.

19 | Vgl. Adam Mickiewicz am Collège de France, Paris 17.06.1842, nach Janion: Kobiety, S. 96f.

20 I Ostrowska: Matki Polki, S. 227. Siehe auch Siwicka: 0jczyzna intymna, S. 70 sowie Janion: Polonia powielona, S. 24, 27f. zum Männlichkeitsbild des 'Sohnes der Mutternation >Polonia<.

21 I Siehe beispielsweise Frąckowiak-Sochańska, Monika: »Aksjologiczny wymiar tożsamości polskich kobiet - obszary ciągłości i zmiany «, in: Frąckowiak-Sochańska/Królikowska, Kobiety w polskiej transformacji (2010), S. 347-377; Mrozik: Akuszerki transformacji, S. 141.

22 I Vgl. Limanowska, Barbara: »Pytania zadawane w cieniu pomnika«, in: Pełnym głosem 5 (1997), S. 42-46, hier S. 43; Walczewska: Damy, rycerze i feministki, S. 53-56. 
tig, die damit möglichen Freiheiten auszuweiten. Ab den 1830er Jahren war eine durchgängige Strömung emanzipatorischer Bestrebungen zu beobachten, deren Intensität und direkte politische Forderungen allerdings unterschiedlich ausfielen. An dieser Stelle möchte ich diese historischen Strömungen skizzieren, die implizit und explizit in der feministischen Kritik der 1990er Jahre nachwirken. Die Kenntnis der historischen Dimension hilft zudem, sich in den in dieser Studie untersuchten feministischen Monographien zu orientieren, die ihr literarisches Material zu einem Großteil aus der Zeit vor dem Zweiten Weltkrieg schöpften. Neben den emanzipatorischen Vorreiterinnen, den Entuzjastki der ersten Hälfte des 19. Jahrhunderts, bildete die Epoche des Positivismus mit ihren distinkten Stimmen zur Emanzipation der Frauen, die metaphysischen Geschlechtsverhandlungen der Moderne und die breiter abgestützten feministischen Forderungen der Zwischenkriegszeit die Basis der feministischen Kritik der 1990er Jahre. Viele der im Folgenden genannten Schriftstellerinnen respektive deren Texte figurieren somit implizit als Untersuchungsmaterial `zweiten Grades` der vorliegenden Arbeit.

In der Zeit zwischen dem Novemberaufstand von 1830/31 und dem Großpolnischen Aufstand 1848 entstand die Zeitschrift Pierwiosnek (Primel) mit rein weiblicher Redaktion ${ }^{23}$ sowie davon unabhängig die lose Frauengruppe der Entuzjastki (Enthusiastinnen), die sich um die Schriftstellerin Narcyza Żmichowska (1819-1876) formierte. Die Entuzjastki zeichneten sich durch ein liberales Verständnis der Geschlechterrollen wie auch durch eine kritische Haltung gegenüber der Institution der Ehe als sozialem Zwang aus. Sie nutzten die im Rahmen der patriotischen Aktivierung der Frauen gegebenen Freiheiten, ihr Tätigkeitsfeld zu erweitern. ${ }^{24}$ Es ist jedoch umstritten, wie stark die Aktivitäten der Entuzjastki tatsächlich im Rahmen patriotischen Engagements gesehen werden müssen. ${ }^{25}$ Dass die in Europa zu beobachtende Festigung bürgerlicher dichotomer Geschlechterrollen in der polnischen Gesellschaft aufgrund einer fehlenden bürgerlichen Schicht weitgehend ausblieb, kam den Entuzjastki auf jeden Fall zugute. ${ }^{26}$ Neben der familienkritischen Lebenshaltung war die Bildung von Frauen bzw. deren Systematisierung ein zunehmend diskutiertes Thema, zu dem etwa die patrio-

23 | Vgl. Walczewska, Sławomira: »Czy kobietom w Polsce potrzebny jest feminizm?«, in: Titkow/ Domański, Co to znaczy (1995), S. 245-256, hier S. 253. Siehe auch Borkowska: Cudzoziemki, S. 57. 24 | Vgl. Kurkowska, Mirella: »Narcyza Żmichowska w środowisku warszawskim lat czterdziestych XIX W.«, in: Żarnowska/Szwarc, Kobieta i świat polityki (1994), S. 235-244; Walczewska: Czy kobietom, S. 255.

25 I Vgl. dazu die Polemik von Borkowska: Cudzoziemki, S. 33-37, die ich in den Kapiteln 5.1.3 und 6.2 .4 bespreche.

26 | Vgl. Górnicka-Boratyńska, Aneta: »Idea emancypacji w literaturze polskiej XIX i XX wieku«, in: Ritz et al., Nowa świadomość płci (2000), S. 13-31, hier S. 15; Jabłonowska: Rodzina, S. 67; Walczewska: Damy, rycerze i feministki, S. 111f.; Żarnowska: Prywatna sfera, S. 19. 
tisch-konservativ ausgerichtete und von Żmichowska selbst kritisierte Schriftstellerin Klementyna z Tańskich Hoffmanowa (1789-1845) publizierte. ${ }^{27}$

In der Folge des Januaraufstands von 1863 verschärften sich die sozialen Spannungen aufgrund der Repressionen v. a. gegen männliche Aufständische. ${ }^{28}$ Immer mehr (adlige) Frauen blieben allein für die Versorgung der Familie zuständig, während die Arbeitswelt für dieses Bevölkerungssegment weitgehend verschlossen blieb; Anstellungen als Erzieherinnen und Lehrerinnen waren hart umkämpft. Der Mangel an Verdienstmöglichkeiten und der soziale Notstand wurden zunehmend als gesellschaftliches Problem thematisiert. ${ }^{29}$ So standen die »Bildung und [...] die Möglichkeit der Berufstätigkeit von Frauen « ${ }^{30} \mathrm{im} \mathrm{Ge}$ schlechterdiskurs bald ebenso im Vordergrund wie das patriotische Engagement. In allen Teilungsgebieten verstärkte sich die Ansicht, »dass die staatliche Einheit nur der letzte Schritt einer >organischen Arbeit`sein konnte, in der die Lage der Menschen durch ökonomischen Fortschritt und Bildung verbessert werden sollte. ${ }^{31}$ Industrialisierungsbestrebungen und wachsende Bevölkerungszahlen beschleunigten die faktischen Verschiebungen im Klassengefüge wie auch in der Geschlechterordnung. ${ }^{32}$

Auf der Ebene der kulturellen Produktion äußerten sich die sozialen Dynamiken in einer positivistischen Wende, die stärker auf innergesellschaftliche Gruppierungen und alltägliche Problemstellungen fokussierte. ${ }^{33}$ Im Rahmen des Positivismus (1863-ca. 1890) entstand mit Eliza Orzeszkowas (1842-1910) Marta (1873) der erste »feministische« Roman. Darin propagiert Orzeszkowa das weibliche

27 | Vgl. Borkowska: Cudzoziemki, S. 59f.; Krzyżanowska: Kobiety, S. $150 f$.

28 I Vgl. Górnicka-Boratyńska: Idea emancypacji, S. 13, die auf die gesellschaftliche Zäsur des Jahres 1863 aufmerksam macht.

29 । Vgl. ebd., S. 15. Siehe auch Żarnowska: Prywatna sfera, S. 8f., die darauf hinweist, dass dieses Phänomen insbesondere die Schichten der Gutsbesitzer und Intelligenz betraf, was wiederum von dessen Überhandnahme im Diskurs zeugt. Ähnlich Kałwa, Dobrochna: »Historia kobiet versus studia gender - o potrzebie interdyscyplinarnego dialogu«, in: Domańska, Ewa et al. (Hg.), Historia - dziś. Teoretyczne problemy wiedzy o przeszłości, Kraków 2014, S. 115-125, hier S. 123, die zudem die Frage nach der Emanzipation außerhalb des von der Repression nach 1863 betroffenen russischen Teilungsgebiet aufwirft.

30 I Krzyżanowska: Kobiety, S. 151. Vgl. auch Dajnowicz, Małgorzata: »Działalność publiczna kobiet polskich na pograniczu ziem północno-wschodniej Polski (od końca XIX wieku do 1939 roku)«, in: Pudłocki, Tomasz/Sierakowska, Katarzyna (Hg.), Aktywność publiczna kobiet na ziemiach polskich. Wybrane zagadnienia, Warszawa 2013, S. 69-83, hier S. 70.

31 | Alexander, Manfred: Kleine Geschichte Polens, Stuttgart 2003 (2008), S. 237.

32 I Vgl. Żarnowska: Prywatna sfera, S. 6 f.

33 | Vgl. Stegmann, Natali: »Wie die Soldaten im Feld Frauen für ,Vaterland und Frauenrechte im Ersten Weltkrieg«, in: Kemlein, Geschlecht und Nationalismus (2000), S. 197-216, hier S. 208. 
Recht auf Lohnarbeit, ohne das die polnische Familie in ihrer Notlage untergehe. ${ }^{34}$ Orzeszkowa notierte zudem in einer Zeitschrift, dass die symbolische Gleichstellung der Geschlechter nun in die Praxis überführt werden müsse. Sie forderte berufliche Bildung für Frauen und verwies - am Beispiel von Bäuerinnen - auf deren Fähigkeit zur physischen Arbeit. ${ }^{35}$ Das »traditionelle Erziehungsmodell und die Erfordernisse der Gegenwart $^{36}$ seien so diskrepant, dass Veränderungen unausweichlich würden.

Die Publizistin und Frauenrechtlerin Paulina Kuczalska-Reinschmit (18591921) kritisierte Orzeszkowa für ihre zu wenig explizit feministische Haltung, die stets noch die nationale Emanzipation über diejenige der Frauen stelle. Kuczalska-Reinschmit selbst, die die feministische Zeitschrift Ster (Steuer) gründete (Lwów 1895-1897, Warszawa 1907-1914), forderte die bedingungslose rechtliche wie auch soziale Gleichstellung der Frauen, die sie mit der »hohen Position der Frauen in der Gesellschaft als uralte polnische Tradition $\aleph^{37}$ begründete. Die Schriftstellerin Gabriela Zapolska (1857-1921) wiederum thematisierte in ihren oft als naturalistisch bezeichneten Romanen die gesellschaftliche Doppelmoral und die Repression weiblicher Figuren in verschiedenen Kontexten und aus der Perspektive unterschiedlicher sozialer Schichten. ${ }^{38}$

Die dem Positivismus entgegengesetzte, modernistische Strömung der Młoda Polska (Junges Polen, 1890-1918) war geprägt von der Vorstellung einer utopischen Geistigkeit und der Überwindung körperlicher Unvollkommenheit. Dieses Konzept wies misogyne Tendenzen auf, da das Weibliche diskursiv mit dem Körperlichen und Triebhaften verbunden wurde. Zentral in dieser Debatte waren auch in Polen das Denken Nietzsches und Schopenhauers sowie das frauenfeindliche biologistische Werk Otto Weiningers, Geschlecht und Charakter (1903). ${ }^{39}$ Mit dem Interesse an psychosomatischen Zusammenhängen rückte die Hysterie als

34 I Siehe zu Argumentationsstrategien zur weiblichen Lohnarbeit auch Pietrow-Ennker: Frau und Nation, S. 137, 140f., die auf die strategische Vorschiebung patriotischer Motive zur Emanzipierung und Verbesserung der sozialen Lage der Frauen verweist. Ebenso Żarnowska: Prywatna sfera, S. 9. 35 | Vgl. Orzeszkowa, Eliza: »Kilka słów o kobietach«, in: Tygodnik Mód i Powieści (1870), N.N. Siehe auch Górnicka-Boratyńska: Idea emancypacji, S. 15.

36 | Górnicka-Boratyńska: Idea emancypacji, S. 14.

37 I Stegmann, Natali: »Paradygmaty nauk przyrodniczych, ruch kobiecy i kategoria sexs: 0 ustaleniu ról płciowych w polskim ruchu na rzecz moralności w przededniu pierwszej wojny światowej«, in: Ritz et al., Nowa świadomość płci (2000), S. 33-49, hier S. 35. Siehe auch Górnicka-Boratyńska: Idea emancypacji, S. $18 f$.

38 । Siehe dazu Kłosińska: Ciało.

39 । Weininger, Otto: Geschlecht und Charakter. Eine prinzipielle Untersuchung, Wien 1919. Vgl. Baranowska, Agnieszka: Kraj modernistycznego cierpienia, Warszawa 1981, S. 5; Górnicka-Boratyńska: Idea emancypacji, S. 22; Janion: Kobiety, S. 229; Podraza-Kwiatkowska, Maria: "Salome i Androgyna. Mizoginizm a emancypacja«, in: dies., Symbolizm i symbolika w poezji Młodej Polski. Teoria i praktyka, Kraków 1975, S. 363-384; dies.: "Schopenhauer i chuć«, in: dies., Somnam- 
vergeschlechtlichtes Phänomen zunehmend in den Vordergrund. ${ }^{40}$ "Im Modernismus ist das Geheimnis der Menschlichkeit ein Geheimnis des Geschlechts « ${ }^{41}$, beschreibt Borkowska diese Epoche und verweist auf die zentrale Rolle, die dabei der Körper spielt.

Der auf die Erhabenheit des (männlichen) Geistes gegenüber der (weiblichen) somatischen Determinante fokussierte Zeitgeist manifestierte sich auch in den Werken einiger Schriftstellerinnen. Für die feministische Kritik der 1990er Jahre wurden diesbezüglich Leben und Werk von Maria Komornicka (1876-1949) zu einem leitenden Forschungsinteresse. ${ }^{42}$ Im Gegensatz dazu steht das Schaffen der jungen Zofia Nałkowska (1885-1954): »Leitthema des frühen Schaffens Nałkowskas ist das `Sein als Frau`, das nicht nur `Quell des Leidens`, sondern auch neuer Werte für die Kultur ist. « ${ }^{43}$ Damit hob sich Nałkowska vom frauenverachtenden Diskurs der Moderne ab, bzw. kehrte diesen in einer »triumphalen Akzeptanz des eigenen Geschlechts « ${ }^{44}$ geradezu um.

Ungeachtet des misogynen Zeitgeists wuchs die weibliche Teilhabe im öffentlichen Bereich und in der Arbeitswelt sowie in Form von oft emanzipatorisch ausgerichteter publizistischer Tätigkeit von Frauen. In Kongresspolen wurde 1907 der von Kuczalska-Reinschmit gegründete Verein zur Gleichstellung Polnischer Frauen (Związek Równouprawnienia Kobiet Polskich) legalisiert, der sich an »aus dem Westen fließenden Strömungen ${ }^{45}$ orientierte. Mit Cecylia Walewska (1859-1940) fand die Frauenbewegung, die auch sozialistisch oder religiös geprägte Ausformungen zeitigte, ${ }^{46}$ eine Chronistin. Walewska veröffentlichte das zweibändige Werk Ruch kobiecy w Polsce (Die Frauenbewegung in Polen, 1909) sowie den Band Z dziejów krzywdy kobiet (Geschichte des Frauenunrechts, 1908).

Die polnischen Emanzipationsbestrebungen forderten eine »legitimierte Anwesenheit der Frauen in der öffentlichen Sphäre, als vollwertige Bürgerinnen ${ }^{47}$,

bulicy - dekadenci - herosi. Studia i eseje o literaturze Młodej Polski, Kraków, Wrocław 1985, S. $162-172$.

40 I Siehe Schahadat, Schamma: "Szalone kobiety, nerwowi mężczyźni: histeria i gender na przełomie wieków«, in: Ritz et al., Nowa świadomość płci (2000), S. 245-268; Stegmann: Paradygmaty, S. 33f., 37.

41 I Borkowska, Grażyna: »Płeć jako skaza: Przybyszewski i Nałkowska«, in: Ritz et al., Nowa świadomość płci (2000), S. 77-87, hier S. 78.

42 I Siehe dazu die Ausführungen in Kapitel 3.3.

43 I Górnicka-Boratyńska: Idea emancypacji, S. 21.

44 I Podraza-Kwiatkowska, Maria: »Młodopolska femina. Garść uwag«, in: Teksty Drugie, Śmiech feministek (1993), S. 36-53, hier S. 39. Siehe auch Borkowska: Płeć jako skaza, S. 82.

45 I Sierakowska, Katarzyna: »Aspiracje polityczne Związku Równouprawnienia Kobiet Polskich «, in: Żarnowska/Szwarc, Kobieta i świat polityki (1994), S. 245-253, hier S. 245.

46 I Vgl. ebd., S. 247; Walczewska: Damy, rycerze i feministki, S. 180.

47 | Krzyżanowska: Kobiety, S. 153. Siehe dazu auch Walczewska: Damy, rycerze i feministki, S. $41-52$. 
wurden aber erst »sehr schwach wahrgenommen ${ }^{48}$. Dennoch konnte nach dem Ersten Weltkrieg eine "schmale Gruppe von Feministinnen ${ }^{49}$ erwirken, dass in der Zweiten Polnischen Republik (1918-1939/1944) mit der Erreichung der staatlichen Unabhängigkeit politische und zivile Rechte für Frauen festgeschrieben wurden. ${ }^{50}$ Diese relativ reibungsfreie Installierung der Bürgerinnenrechte sieht die Historikerin Natali Stegmann als Effekt der allgemeinen Neukonstitution des polnischen Staates und der Wiedereinführung des Stimmrechts auch für polnische Männer. Die politischen Rechte der Frauen wurden somit zu einem »Symbol der erstrebten Macht der polnischen Gesellschaft « ${ }^{51}$.

Der Wegfall der Teilungsmächte und die Unabhängigkeit der polnischen Republik verschoben die politischen Brennpunkte; Revolution und Krieg »lockerten die Gesellschaftsstruktur, die Sittenstrenge taute auf, und neue, innere Aufteilungen entstanden $~^{52}$ im Vielvölkerstaat Polen. Vor dem Hintergrund eines Wettstreits der Parteien und politisch-weltanschaulicher Massenbewegungen prägten Identitätskonstruktionen innerhalb der Staatsgrenzen und entlang gesellschaftlicher Gruppen (etwa als Antisemitismus) die polnische Zwischenkriegszeit. In diesem Kontext verortet Stegmann auch die Geschlechterfrage, da »die Staatsgründung zu einem Schulterschluss polnischer Männer und Frauen in Abgrenzung zu den neu geschaffenen $\gg$ Feinden « $^{53}$ führte. Gleichzeitig verknüpften sich in der aufblühenden weiblichen Publizistik (Reportagen, Feuilletons, Romane) Fragen nach der Geschlechtergerechtigkeit mit einem Interesse an ethnischen und sozial benachteiligten Gruppen. ${ }^{54}$

Der Brennpunkt der Frauenbewegung verschob sich von der Forderung nach politischen Rechten "auf das nicht weniger bedeutsame, aber noch völlig unveränderte Feld des Privatlebens ${ }^{55}$. Ins Blickfeld gerieten nun vermehrt der soziale Habitus und die sittliche Doppelmoral. ${ }^{56}$ Dies zeigt sich in zahlreichen Werken von Schriftstellerinnen der Zwischenkriegszeit, von denen viele an emanzipatorischen und feministischen Anliegen interessiert waren. Schriftstellerinnen wie Pola Gojawiczyńska (1896-1963) oder Wanda Melcer (1896-1972) rückten Phänomene in

48 | Żarnowska: Prywatna sfera, S. 18.

49 | Ebd.

50 I Vgl. Pietrow-Ennker: Frau und Nation, S. 141; Stegmann: Wie die Soldaten, S. 206f., $212 \mathrm{ff}$.

51 I Stegmann: Wie die Soldaten, S. 212.

52 I Zawiszewska, Agata: »Międzywojenna felietonistyka kobieca. Casus: Irena Krzywicka«, in: Iwasiów, Prywatne/publiczne (2008), S. 13-79, hier S. 47.

53 I Stegmann: Wie die Soldaten, S. 203. Vgl. auch Alexander: Kleine Geschichte Polens, S. 253, 293f.; Górnicka-Boratyńska: Idea emancypacji, S. 27; Zawiszewska: Międzywojenna felietonistyka, S. 15.

54 I Vgl. Kraskowska: Piórem niewieścim, S. 166f.

55 I Górnicka-Boratyńska: Idea emancypacji, S. 26.

56 I Beide sind aber bereits auch vor dem Ersten Weltkrieg Thema feministischer Kreise, vgl. Stegmann: Paradygmaty, S. 37-46. 
den Vordergrund, »die bislang als kulturelles Tabu galten, also die Erfahrung von Schwangerschaft, Geburt, Menstruation, Wechseljahren. Die mit linker Ideologie sympathisierenden Schriftstellerinnen betonten, dass der weibliche Körper unter

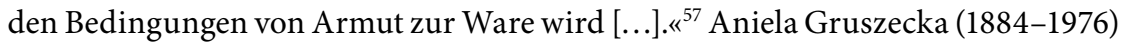
wiederum inszenierte im Roman Przygoda w nieznanym kraju (Abenteuer in einem unbekannten Land, 1933) eine Frauenfreundschaft mit homoerotischen Zügen. ${ }^{58}$ Als radikalste und wohl kontroverseste Figur gilt jedoch die Publizistin, Übersetzerin und Schriftstellerin Irena Krzywicka (1889-1994), die mit ihren »antibürgerlichen Ansichten ${ }^{59}$ sowohl in konservativen wie fortschrittlichen Kreisen aneckte:

"Sie erregte Anstoß mit ihren Artikeln zum Thema Ehe (als Befürworterin der Zivilgesetzgebung und freier Beziehungen), bewusster Mutterschaft (sie propagierte Empfängnisverhütung, schätzte Mutterschaft allein als bewusste Entscheidung, hielt den [...] Mutterinstinkt nicht für eine biologische Selbstverständlichkeit, sondern für ein kulturelles Vorurteil), erotischem Leben (sie schrieb u.a. über die weibliche Differenz im Erleben des Orgasmus und über sexuelle Minderheiten).« ${ }^{60}$

Auch der Schriftsteller Tadeusz Boy-Żeleński (1874-1941) nahm sich der Thematik der Geschlechterordnung an. Der »aufmerksame Kommentator und Befürworter der Emanzipationsbewegung “ ${ }^{61}$ publizierte etwa mit Piekło kobiet (Die Hölle der Frauen, 1930) Überlegungen zur Abtreibung im Kontext rechtlicher Regelungen, moralischer Vorstellungen und deren Verflechtung mit katholischen Narrativen. Boy-Żeleński gründete außerdem die "freidenkerische Gesellschaft ${ }^{62}$ Bund der Sittenreform (Liga Reformy Obyczajów).

Mit der Zäsur des Zweiten Weltkriegs und der Außerkraftsetzung einer übergeordneten polnischen Gesellschaftsstruktur erfuhren die Geschlechterrollen eine weitere Auflösung oder gar Revolutionierung und trugen so zu einer veränderten Ausgangssituation in der Nachkriegszeit bei, was jedoch in der Forschung noch wenig berücksichtigt wurde. ${ }^{63}$ Nach Kriegsende wurde das Geschlecht auch in der sozialistischen Volksrepublik (Polska Rzeczpospolita Ludowa PRL, 19441989) zum Thema sozialer Verhandlungen verschiedener Akteure. Die Geschlech-

57 | Borkowska, Grażyna: »Feminizacja kultury: głębia i powierzchnia. Literatura kobieca w latach 1900-1945«, in: Borkowska et al., Pisarki polskie (2000), S. 87-116, hier S. 87. Zur Ergänzung muss hier gesagt werden, dass sich dieser Themen bereits Gabriela Zapolska annahm.

58 I Vgl. ebd., S. 104; Kraskowska: Piórem niewieścim, S. 101-125.

59 । Borkowska: Feminizacja kultury, S. 97. Vgl. Zawiszewska: Międzywojenna felietonistyka, S. 14.

60 I Górnicka-Boratyńska: Idea emancypacji, S. 28.

61 I Borkowska: Cudzoziemki, S. 66.

62 । Borkowska: Feminizacja kultury, S. 97.

63 I Eine Ausnahme bildet hier etwa Weronika Grzebalskas Magisterarbeit Płeć powstania warszawskiego (Das Geschlecht des Warschauer Aufstands, 2013), die die weibliche Beteiligung am Warschauer Aufstand aus einer Genderperspektive untersucht. 
terordnung sollte aus sozialistischer Perspektive revolutioniert werden. Sie wurde zum Herzstück des Tauziehens zwischen Fortschritt und Konservatismus, Gesellschaftsreform und Tradition, war letztlich aber auch eine Plattform der Kompromissfindung:

"The short and ultimately unsuccessful anti-abortion campaign [of 1946], in which Catholic priests and lay activists openly supported stalinist anti-abortion law, demonstrated one important lesson for both communists and noncommunists: that gender politics could serve as a bridge between traditional segments of society and the new state seeking legitimacy in a hostile environment. « ${ }^{64}$

Viele Umstrukturierungen zugunsten der Geschlechtergleichstellung waren deshalb wohl theoretisch rigoros, blieben jedoch in der Praxis gegenüber etablierten Strukturen oft wirkungslos. ${ }^{65}$

\subsection{Gleichstellung in der VolksRepublik}

Die Geschlechterdiskussion in der Volksrepublik war geprägt von einer Abspaltung der $»$ nominellen Realität ${ }^{66}$ als propagiertem Idealbild von ihrer tatsächlichen (Nicht-)Umsetzung. Diese Doppelung der Realität verstrickt sich retrospektiv in weitere diskursive Überformungen und Umdeutungen, weshalb eine schlüssige und faktographische Übersicht nur schwierig zu rekonstruieren ist. Im Folgenden werden deshalb einzelne Punkte beleuchtet, die besonders für den Kontext nach 1989 von Interesse sind. Dazu gehören auch Verweise auf Publikationen in Bezug auf den Geschlechterdiskurs. Obwohl die »Bibliothek der Mutter « ${ }^{67}$ als mitprägender Hintergrund einzelner Feministinnen der 1990er Jahre gelten kann, werden diese Publikationen nach 1989 aber in der Regel nicht mehr aktiv diskutiert. Überhaupt lässt sich eine negierende Haltung feministischer Kreise gegenüber der sozialistischen Zeit feststellen, was im Verlauf der vorliegenden Studie noch eingehender thematisiert wird.

Die kommunistische Forderung nach Gleichstellung war in der Nachkriegszeit eine pragmatische und betraf die Einbindung weiblicher Arbeitskraft in den

64 I Fidelis, Malgorzata: Women, Communism and Industrialization in Postwar Poland, Cambridge 2010, S. 34.

65 I Vgl. Kałwa, Dobrochna: »Between Emancipation and Traditionalism - The Situation of Women and the Gender Order in Poland after 1945 «, in: Hering, Sabine (Hg.), Social Care under State Socialism (1945-1989). Ambitions, Ambiguities, and Mismanagement, Opladen, Farmington Hills, MI. 2009, S. 175-187, hier S. 175.

66 I Świda-Ziemba, Hanna: Człowiek wewnętrznie zniewolony. Mechanizmy i konsekwencje minionej formacji - analiza psychosocjologiczna, Warszawa 1997, S. 296.

67 I Iwasiów, Inga: Interview [unveröffentlicht], Szczecin 2013. 
Wiederaufbau und den Produktionsprozess. ${ }^{68}$ Die Position der Frau in Gesellschaft und Familie sollte zwar verändert werden, doch die `neue aler Grundstein des Staates bestehen bleiben. Von den sexuallibertären Ansätzen kommunistischer Denker/innen vor der Revolution war wenig übrig geblieben. ${ }^{69}$ Die Neuerungen betrafen somit vor allem die Sicherung gleicher Rechte (im Arbeits- wie etwa auch im Eherecht) und Bildungschancen, was sich in einem hohen Anteil gut ausgebildeter arbeitstätiger Frauen niederschlug. ${ }^{70}$ Dies zeigt sich in der bis heute starken Vertretung von Wissenschaftlerinnen an polnischen Institutionen.

1945 wurde die sozialistische Liga Kobiet (Frauenbund) ins Leben gerufen, die vor allem die Einbindung von Frauen ins sozialistische System sicherstellen sollte. Sie nahm sich der Bekämpfung von Diskriminierungen am Arbeitsplatz an und fungierte als eine Art Frauengewerkschaft, weshalb sie in den Betrieben und Arbeitskomitees keinen leichten Stand hatte. ${ }^{71}$ Frauen war zwar »das gleiche Recht zur Arbeit garantiert, was aber keine Gleichheit am Arbeitsplatz oder jenseits davon bedeutete und zu einer starken horizontalen und vertikalen Segregation führte ${ }^{72}$, also zu schlecht bezahlten feminisierten Berufen und fehlenden Aufstiegsmöglichkeiten für Frauen. Unangetastet blieben zudem »soziale Vorurteile oder allägliche Beschwerlichkeiten etwa im Zusammenhang mit der Mutterschaft ${ }^{73}$, die ihrer Entwicklung überlassen wurden. Mit den formal-rechtlichen Anpassungen galt die Frauenfrage von Seiten des Regimes als erledigt. ${ }^{74}$

68 | Vgl. Fuchs, Gesine: Die Zivilgesellschaft mitgestalten. Frauenorganisationen im polnischen Demokratisierungsprozess (= Politik der Geschlechterverhältnisse, Band 21), Frankfurt a/M., New York 2003, S. 60.

69 | Vgl. Ebert, Teresa L.: »Alexandra Kollontai und die Rote Liebe«, in: Sozialistische Zeitung 4 (2002), S. 24; Merfeld, Mechthild: Die Emanzipation der Frau in der sozialistischen Theorie und Praxis, Reinbek bei Hamburg 1972, S. 83-86; Sokołowska: The Woman Image, S. 45.

70 | Vgl. Czerwiński, Marcin: Przemiany obyczaju, Warszawa 1969, S. 92; Dybel: Psychoanalyse in Polen, S. 291; Fuchs: Zivilgesellschaft, S. 66; Kałwa: Emancipation and Traditionalism, S. 175f.; Sokołowska: The Woman Image, S. 46.

71 I Vgl. Fidelis, Małgorzata: "Szukając traktorzystki - kobiety i komunizm«, in: Znak 10 (2012), S. 42-49, hier S. 48f.; Fuchs: Zivilgesellschaft, S. 63f.; Gajewska, Agnieszka: »Feministyczne rozrachunki z PRL-em «, in: Frąckowiak-Sochańska/Królikowska, Kobiety w polskiej transformacji (2010), S. 463-478, hier S. 469; Kałwa: Emancipation and Traditionalism, S. 179; Walczewska: Czy kobietom, S. 249; Wrochno, Krystyna: Kobiety w Polsce, Warszawa 1969, S. $79 f ., ~ 84$.

72 I Szatlach, Maria Ewa: »Dylematy Polek na rynku pracy - aspekty teoretyczno-prawne a rzeczywistość społeczna«, in: Pierzchalski, Filip et al. (Hg.), Feminizm po polsku, Warszawa 2011, S. 129-181, hier S. 151.

73 | Czerwiński: Przemiany obyczaju, S. 95.

74 | Vgl. Sokołowska: The Woman Image, S. 49f.; Szatlach: Dylematy Polek, S. 152; Walczewska, Sławomira: „Dwie dekady feminizmu«, in: Walczewska, Feministki (2005), S. 5-20, hier S. 5. 
Die stalinistisch geprägte Arbeitsaktivierung der Frauen bedrohte aus gesellschaftlicher Sicht sowohl eine stereotype Weiblichkeit wie auch das nationale Selbstverständnis. Nach 1956 verloren deshalb Gleichstellung und weibliche Arbeit im Zuge der Entstalinisierung an Bedeutung. ${ }^{75}$ "Amid many doubts and dilemmas that communists faced at the threshold of reforming the stalinist system, the notion for natural gender roles was one issue that seemed certain and easy to fix " $^{76}$, fasst die Historikerin Małgorzata Fidelis diese Tendenzen zusammen.

In den prestigeträchtigen und gutbezahlten Berufen, etwa in der Schwerindustrie und im Bergbau, wurden Reglementierungen zum Schutz der >Mutterfunktion erlassen, was de facto die Diskriminierung in der Arbeitswahl wie auch in der Karriereentwicklung bedeutete. Zudem wurde die Institutionalisierung der Kinderbetreuung bedeutend verlangsamt und Frauen vermehrt zur Rückkehr an den Herd motiviert. ${ }^{77}$ Dies führte bei $»$ Arbeiter-Müttern $«,{ }^{78}$ die oft trotz allem zur Erwerbstätigkeit gezwungen waren, zu einer zunehmenden "Doppelbelastung" ("podwójne obciążenie«), deren gesellschaftliche Problematik aber in der Lohnarbeit und nicht in der mangelnden Arbeitsteilung im Haushalt gesehen wurde. ${ }^{79}$ 1957 wurde der Schwangerschaftsabbruch unter bestimmten Bedingungen, »für einen wirksamen Schutz der Gesundheit der Frau ${ }^{80}{ }$, legalisiert. Im Fokus der Geschlechterdiskussion standen ab Mitte der 1950er Jahre vor allem Arbeitshygiene und Medizin, worauf etwa Magdalena Sokołowskas breit rezipierte soziomedizinische Publikation Kobieta pracujaca (Die arbeitende Frau, 1963) und die Folgestudien in Kobieta współczesna (Die zeitgenössische Frau, 1966) verweisen. ${ }^{81}$

75 I Vgl. Fidelis: Women, Communism, S. 230; Kałwa: Emancipation and Traditionalism, S. 181.

76 | Fidelis: Women, Communism, S. 201.

77 | Vgl. Czerwiński: Przemiany obyczaju, S. 95f.; Fidelis: Szukając traktorzystki, S. 45; Fuchs: Zivilgesellschaft, S. 61; Kałwa: Emancipation and Traditionalism, S. 176; Sokołowska: The Woman Image, S. 46.

78 I Vgl. Dybel: Psychoanalyse in Polen, S. 291; Fidelis: Women, Communism; Fuchs: Zivilgesellschaft, S. 67; Kałwa: Emancipation and Traditionalism, S. 181f.; Kraft, Claudia: »Paradoxien der Emanzipation. Regime, Opposition und Geschlechterordnungen im Staatssozialismus seit den späten 1960er-Jahren«, in: Zeithistorische Forschungen/Studies in Contemporary History 3 (2006), S. 381-400, hier S. 389f.

79 | Vgl. Fidelis: Women, Communism, S. 212. Dieser vergeschlechtlichten Doppelbelastung begegnete in den 1960er Jahren die mäßig erfolgreiche Kampagne »Ludwiku, do rondla« (»Ludwik, an den Kochtopf«), die Männer für die Haushaltsarbeit motivieren und ein partnerschaftlicheres Familienmodell begründen sollte. Vgl. Walczewska: Damy, rycerze i feministki, S. 88.

80 | Wrochno: Kobiety w Polsce, S. 53.

81 I Vgl. Sokołowska, Magdalena: Kobieta pracująca. Socjomedyczna charakterystyka pracy kobiet (= Sygnały), Warszawa 1963; dies. (Hg.), Kobieta współczesna. Z badań socjologów, lekarzy, ekonomistów, pedagogów i psychologów. Materiały z seminarium pracy kobiet IFiS PAN (= Biblioteka Nauki o Pracy), Warszawa 1966. Sokołowska argumentierte für die Entlöhnung der als Pro- 


\subsubsection{Rückkehr des Geschlechts}

Trotz Gleichstellungsbestrebungen verschwand das Geschlecht nicht aus dem diskursiven Blickwinkel und trat ab Ende der 1950er Jahre wieder vermehrt in den Vordergrund..$^{82}$ Die stalinistische "Gleichmacherei« galt als gescheitert, und Fragen nach dem Grund des Scheiterns drängten sich auf: Sind Geschlechterrollen kulturell erlernt oder "aufgrund eines biopsychischen Unterschieds [odrębność] «83 eben doch metaphysisch verankert und deshalb institutionell nicht veränderbar? Trotz nomineller Gleichstellung hatten sich die patriarchalen Strukturen der Gesellschaft - besonders in der Privatsphäre - kaum verändert. Obwohl nur teilweise am Rande zur Kenntnis genommen, trugen die Theorien Freuds und der Psychoanalyse zusätzlich »to the perpetuation of traditional stereotypes ${ }^{84}$ bei. Die Frage nach der (Un)Veränderbarkeit der Geschlechterordnung beantwortete etwa der Soziologe Marcin Czerwiński mit der Schlussfolgerung, dass die Menschen, »um von der Gleichheit [równość] zu profitieren, sich nicht ihres verschiedenartigen Erlebens [odmienne sposoby przeżywania] und unterschiedlicher Werte [odrębne wartości] entledigen ${ }^{85}$ müssten. Mit dieser und ähnlichen Aussagen etablierte sich ein Diskurs unter dem Schlagwort der "Gleichheit in der Unterschiedlichkeit», der gemäß der Historikerin Claudia Kraft »enge Verwandtschaft mit demjenigen über den Egalitäts- und Differenzfeminismus in der neuen Frauenbewegung des Westens aufwies ${ }^{86}$. Auf eine Verwandtschaft der Diskurse lässt auch die Tatsache schließen, dass die Liga Kobiet als eine der Hauptakteurinnen der Geschlechterdebatte Kontakte zu Frauenorganisationen im westlichen Ausland, etwa in den USA, in England oder der BRD, aufrecht erhielt und somit mit den westlichen Schwerpunkten durchaus vertraut gewesen sein dürfte. ${ }^{87}$ Gleichzeitig setzte die

duktionsarbeit interpretierten und mit gesundheitlichen Risiken verbundenen Haushaltsarbeiten. Vgl. Walczewska: Damy, rycerze i feministki, S. 89.

82 । Zu Äußerungen der Geschlechtlichkeit in der Literatur vgl. Budrowska, Kamila: „Wykluczanie tradycji. Cenzurowanie międzywojennej literatury kobiecej w latach czterdziestych i pięćdziesiątych XX wieku (na przykładzie twórczości Zofii Nałkowskiej)«, in: Sztuka Edycji 7 (2015), S. 49-57; Iwasiów: Kresy, S. 32. Hervorzuheben ist etwa der Roman Anna Kowalskas (1903-1969) Safona (Sappho) von 1959, der »offen die Liebe zwischen Frauen darstellt. Kaliściak, Tomasz/Nęcka, Agnieszka: "Lesbijka w Safonie czy Safona w lesbijce? 0 jednej powieści Anny Kowalskiej«, in: Iwasiów/Galant, Pisarstwo kobiet (2011), S. 113-123, hier S. 114: »jawnie przedstawiający miłość między kobietami. "Siehe auch Kraskowska, Ewa: »Maria Dąbrowska i Anna Kowalska«, in: Iwasiów/Galant, Pisarstwo kobiet (2011), S. 81-97, hier S. 81.

83 । Czerwiński: Przemiany obyczaju, S. 106: "z racji odrębności biopsychicznej«.

84 I Sokołowska: The Woman Image, S. 49.

85 | Czerwiński: Przemiany obyczaju, S. 104.

86 | Kraft: Paradoxien der Emanzipation, S. 387.

87 | Vgl. Wrochno: Kobiety w Polsce, S. 92. 
Liga Kobiet ab den 1960er Jahren vermehrt auf traditionelle Rollenbilder, indem sie etwa Haushaltskurse und Ähnliches für Frauen anbot. ${ }^{88}$

Es entstand Raum für die erneute Betonung und Herausarbeitung geschlechtlicher Differenzen und unterschiedlicher Lebens- und Erfahrungsbereiche. Die sozialistische Realität der 1960er Jahre ließ die Auseinandersetzung mit "Privatheit und zwischenmenschlichen Beziehungen« zu, was zuvor als »bourgeoiser Individualismus und Ausdruck kleinbürgerlicher Neigungen nicht im öffentlichen Diskurs zugelassen war. ${ }^{89}$ Als verschobener Markstein dieser Entwicklung kann die Übersetzung von Simone de Beauvoirs Klassiker Le Deuxième sexe (1949) gelten, die 1972 unter dem Titel Druga płeć erschien. ${ }^{90}$ De Beauvoirs Texte wurden ab 1957 ins Polnische übersetzt, womit Texte und emanzipierter Lebensstil der Autorin in Polen bereits bekannt und Teil der "Bibliothek der Mutter " waren. ${ }^{91}$ Die Rezeption de Beauvoirs in den 1960er Jahren steht im Zusammenhang mit der Öffnung eines »Fensters nach Westen«, einem Interesse an existentialistischen Ansätzen und den Bestrebungen nach einem liberaleren Marxismus und der Reform der bestehenden Dogmen. ${ }^{92}$ Nach dem Niederschlagen der polnischen Studentenunruhen von 1968 bedeutete die Publikation von Druga płeć 1972 den Endpunkt der Rezeption de Beauvoirs in Polen. Die Jahre nach 1968 brachten neben der Abschottung vom Westen auch die Abwendung der Protestierenden von der Reformidee und einen wachsenden Widerwillen gegenüber den westlichen intellektuellen Linken.

In den 1960er Jahren zeichnete sich mit der >Geschlechterfrage $<$ auch die Frage der Männlichkeit in der Gesellschaft ab.

"Das Problem der Position der Frauen ist gleichzeitig ein wesentliches Problem der Position der Männer in der Gesellschaft. Wenn also die Frau Kinder gebären und erziehen, alle Hausarbeiten erledigen und finanziell für den Erhalt der Familie aufkommen kann, so kann sich der Mann in seiner bisherigen Position und Rolle bedroht fühlen « ${ }^{93}$,

88 । Vgl. Fidelis: Women, Communism, S. 56; Fuchs: Zivilgesellschaft, S. 64; Kałwa: Emancipation and Traditionalism, S. 177f.; Walczewska: Czy kobietom, S. 250.

89 I Szpakowska, Małgorzata: Chcieć i mieć. Samowiedza obyczajowa w Polsce czasu przemian (= Seria z Wagą), Warszawa 2003, S. 23.

90 I Vgl. Beauvoir, Simone de: Druga płeć. Tom I. Fakty i mity. Tom II. Kształtowanie się kobiety, sytuacja, usprawiedliwienia i ku wyzwoleniu, Kraków 1972.

91 I Beispielsweise Les Mandarins (1954, pl. 1957) und Mémoires d'une jeune fille rangée (1958, pl. 1960). Vgl. Nasiłowska, Anna: Jean Paul Sartre i Simone de Beauvoir (= Pary), Kraków 2006, S. 279.

92 I Siehe für das Beispiel ČSSR und die Rezeption de Beauvoirs Kraft: Paradoxien der Emanzipation, S. 386.

93 I Piotrowski, Jerzy: »Badania nad pozycją społeczną kobiet w Polsce Ludowej i wynikające stąd potrzeby społeczne«, in: Wrochno, Krystyna (Hg.), Kobieta, praca, dom. Problemy pracy za- 
schrieb der Soziologe Jerzy Piotrowski in einem Band der Liga Kobiet von 1967. Seine Fachkollegin Sokołowska notiert: »Die Beunruhigung der Männer nimmt unterschiedlichste Formen und Nuancen an: das Gefühl von Schwäche, Ratlosigkeit, Niederlage, Feindschaft gegenüber Frauen. « ${ }^{94}$ Infolgedessen wurden "Anschuldigungen an die Frauen bezüglich der Verfolgung [prześladowanie] der Männer « ${ }^{95}$ sowohl in der Literatur, in der Publizistik wie auch im Film laut. ${ }^{96}$ Trotz gegenteiliger Statistiken erschienen Veränderungen in der sozialen Struktur als „Große Invasion der Amazonen ${ }^{97}$ und ein misogyner >Feminokratie ${ }^{2}$ diskurs etablierte sich in den folgenden Jahren. ${ }^{98}$

Begünstigt wurde diese Entwicklung durch die versöhnlichere Position des Staates gegenüber aufbegehrenden »Arbeiter-Müttern«. Während die institutionellen Zugeständnisse den Frauen im Arbeitsalltag Erleichterungen einbrachten, zementierten sie auch die traditionelle familiäre Rollenverteilung. Dennoch wurden Erleichterungen zugunsten der Haushaltsführung und Kinderbetreuung oft als Privilegierung von Frauen betrachtet. ${ }^{99}$ "Frauen galten als >Verbündete des Staates, als diejenigen, die in dem zynischen Herrschaftssystem, das materielle Wohltaten an politisches Wohlverhalten knüpfte, am meisten profitierten. ${ }^{100}$ Das Überschätzen der Privilegien von Frauen hatte zur Folge, dass weiterhin bestehende Ungleichheiten und Diskriminierungen kaum adressiert wurden.

Nach dem Umbruch von 1968 folgte auf eine auch sittlich liberalere Phase im Geschlechterdiskurs in den 1970er Jahren eine stärkere Retraditionalisierung und Betonung der Familie als Grundstruktur der Geschlechterordnung wie auch der Gesellschaft insgesamt. Fragen des politischen Alltags drehten sich vermehrt um die konsumatorischen Grundbedürfnisse der Familie, womit Frauen ins Zentrum

wodowej kobiet i rodziny współczesnej. Materiały z konferencji naukowej zorganizowanej przez Zarząd Główny Ligi Kobiet w dniach 25-27 marca 1965 r., Warszawa 1967, S. 10-25, hier S. 25. 94 I Sokołowska, Magdalena: "Płeć a przemiany obyczaju«, in: Komorowska, Przemiany rodziny polskiej (1975), S. 164-172, hier S. 165. Die von Sokołowska zusammengetragenen medialen Effekte dieser Krise können mit Susan Faludi als backlash bezeichnet werden, siehe Faludi, Susan: Backlash. The Undeclared War against Women, London 1993.

95 I Graczyk, Ewa: »Być kobietą?«, in: Gosk, Hanna/Karwowska, Bożena (Hg.), (Nie)Przezroczystość normalności w literaturze polskiej XX i XXI wieku (= Seria Prac Zakładu Literatury Polskiej XX Wieku Instytutu Literatury Polskiej Uniwersytetu Warszawskiego), Warszawa 2014, S. 225243, hier S. 234.

96 I Siehe die Produktionen Sublokator (Janusz Majewski, 1966), Polowanie na muchy (Andrzej Wajda, 1969), oder für die 1980er Jahre Mężczyzna niepotrzebny! (Laco Adamik, 1981) und Seksmisja (Juliusz Machulski, 1984).

97 । Czerwiński: Przemiany obyczaju, S. 92.

98 । Vgl. Graczyk: Być kobietą, S. 233.

99 । Vgl. Kenney, Padraic: »Pojęcie >Matki-Polki< w języku opozycji i władzy«, in: Szarota, Tomasz (Hg.), Komunizm. Ideologia - system - ludzie, Warszawa 2001, S. 338-351.

100 I Kraft: Paradoxien der Emanzipation, S. 391f. 
der staatlichen Aufmerksamkeit rückten. ${ }^{101}$ Frauen wurden »verfamilisiert ${ }^{102}$, die emotionale Bindung zwischen Mutter und Kindern gewann an diskursivem Gewicht. ${ }^{103}$ Gleichzeitig wurde die Familie in den Dienst der Nation gestellt: Sowohl die sich formierende Opposition wie auch das Regime begannen an das patriotische Selbstverständnis der Matka Polka zu appellieren, die zu diesen Zwecken aus der Mottenkiste geholt wurde. ${ }^{104}$ Umgekehrt verwendeten beide Seiten $>$ weiblicher Prädikate (kobiecy, zniewieściały) zur Abwertung des politischen Gegenübers, und die Oppositionsbewegung war von einem stark maskulinen Charakter geprägt. ${ }^{105}$

Die Unterteilung in ein oppositionelles und ein regimetreues Lager dominierte den Diskurs der 1980er Jahre fast unumschränkt: Die Dichotomie von »wir« und »sie» (my i oni) ließ kaum Raum für andere Stoßrichtungen gesellschaftlicher Diskussion. ${ }^{106}$ Das stille Übereinkommen beider Seiten in Bezug auf die Relevanz

101 I Vgl. Dyczewski, Leon: Rodzina polska i kierunki jej przemian, Warszawa 1981, S. 5; Kałwa: Emancipation and Traditionalism, S. 185; Kenney: Pojęcie >Matki-Polki<, S. 339.

102 | »urodzinanie kobiet«, Formulierung aus dem Kolloquium des Zespół Literatura i gender am IBL PAN, 16.03.2016. Ausdruck davon ist auch der im feministischen Diskurs der 1990er Jahre häufig verwendete Begriff des "matriarchat domowy" (Hausmatriarchat), die scheinbare Machtstellung der Frau im Familiengefüge, vgl. Titkow: Kobiety pod presją, S. 31f. Siehe auch Kałwa: Emancipation and Traditionalism, S. 177, $183 f$.

103 | Vgl. Pietruczuk, Władysława: »Słowo wstępne«, in: Fiszerowa, Maria/Pietruczuk-Kurkiewiczowa, Władysława (Hg.), Mojego domu radości i troski. Kobiety o sobie, Warszawa 1978, S. 5-13, hier S. 10.

104 I Vgl. Kenney: Pojęcie >Matki-Polki`, S. 339. Siehe auch Biedrzycka, Jadwiga: [Vorwort], in: Konecka, Elżbieta (Hg.), Kobiety polskie, Warszawa 1986, S. 5; Jaruzelski, Wojciech: Przemówienia 1981-1982, Warszawa 1983, S. 373. Als beispielhaft kann die Tatsache betrachtet werden, dass die Liga Kobiet Anfang der 1980er Jahre in Liga Kobiet Polskich (Bund Polnischer Frauen) umbenannt wurde, was als ein Versuch der Aneignung patriotischer Inhalte durch das sozialistische System gelesen werden kann. Vgl. Malinowska, Ewa: Feminizm europejski demokracja parytetowa a polski ruch kobiet. Socjologiczna analiza walki o równouprawnienie płci, Łódź 2000, S. 121; siehe auch Kenney: Pojęcie >Matki-Polki<, S. 340.

105 | Vgl. Graff, Agnieszka: »Patriarchat po seksmisji«, in: Gazeta Wyborcza 141 (19.06.1999), S. 20; Kenney: Pojęcie 'Matki-Polki<, S. 340; Piotrowski, Piotr: Art and Democracy in Post-Communist Europe, London 2012, S. 247.

106 | Vgl. Dunin, Kinga: Tao gospodyni domowej, Warszawa 1996, S. 8; Kenney: Pojęcie >Matki-Polki<, S. 348; Nasiłowska, Anna: "Literatura lat osiemdziesiątych - czy warto o niej pamiętać?«, in: Gosk, Hanna/Karwowska, Bożena (Hg.), (Nie)Obecność. Pominięcia i przemilczenia w narracjach XX wieku (= Seria Prac Zakładu Literatury Polskiej XX Wieku Instytutu Literatury Polskiej Uniwersytetu Warszawskiego), Warszawa 2008, S. 424-434, hier S. 433. Interessant anzumerken ist an dieser Stelle die Entwicklung der Forschungsschwerpunkte der >Frauen<-Historikerin Dionizja Wawrzykowska-Wierciochowa, anhand deren sich die verändernden Diskurse über das Geschlecht resp. die politische Ordnung nachverfolgen lassen; vom marxistischen Blick auf die unteren Klassen hin zu einer von patriotischem Geist durchdrungenen Forschung nach wehr- 
der Familie und die patriotisch-ernährerische Mission der »Frauen-Mütter« unterband eine konstruktive Diskussion über die Geschlechternormen. Der Großteil der Frauen, »unterteilt in Klassen, Schichten und verschiedene soziale Milieus, identifizierte sich eher mit anderen Kategorien und Gruppen als mit einer abstrakten Menge von Personen desselben Geschlechts. ${ }^{107}$ Frauen nahmen beispielsweise eine bedeutende Rolle in der Organisation und Aufrechterhaltung der oppositionellen Gewerkschaft Niezależny Samorządny Związek Zawodowy (NSZZ) »Solidarność (Unabhängige Selbstverwaltete Gewerkschaft "Solidarität«) ein. Weibliche Emanzipation war aber für die NSZZ "Solidarność« weder Programmpunkt noch Thema, und im Zuge der Transformation wurde der hohe weibliche Anteil in der Gewerkschaft weitgehend aus dem kollektiven Gedächtnis verdrängt. ${ }^{108}$

Trotz alledem vertraten einige der weiblichen Mitglieder der NSZZ »Solidarność« feministische Ansätze. Dazu schreibt die Soziologin Ewa Malinowska:

"[D]as Streben der `Solidarność « nach der Einführung einer demokratischen Ordnung und Werten wie Freiheit, Gleichheit, Gerechtigkeit [hat] einigen Frauen [...] [die] Notwendigkeit bewusst gemacht, dass die Geschlechterstereotypen verändert werden müssen; ebenso die Notwendigkeit eines Wandels der protektionistischen Haltung gegenüber dem Feminismus, der als Bewegung betrachtet wurde, der die Polinnen mit ihrer konstitutionell garantierten Gleichberechtigung [równouprawnienie] überhaupt nicht tangiere - hin zu einer kritischen Haltung gegenüber der dekretierten Gleichheit [równość] im Kontrast zu ihrer tatsächlichen Umsetzung.«"109

Malinowska zufolge erwirkten die demokratischen Bestrebungen die Erkenntnis, dass bestehende Diskriminierungen nur mithilfe zivilgesellschaftlichen und eigenverantwortlichen Engagements angegangen werden können. Die Frage nach biologistischen Geschlechterdifferenzen trat gegenüber der faktischen Benachteiligung in den Hintergrund. ${ }^{110}$ Oftmals wurde die Lösung der Frauenfrage aber an die Befreiung vom sozialistischen System gebunden respektive als deren >logischer` sekundärer Schritt betrachtet. ${ }^{111}$

haften Frauen im Dienst der Allgemeinheit. Siehe bspw. Wawrzykowska-Wierciochowa, Dionizja: "Kobieta polska w zaraniu ruchu wyzwoleńczego«, in: Wiedza i Życie 3 (1954), S. 152-157; dies.: Z dziejów kobiety wiejskiej. Szkice historyczne 1861-1945, Warszawa 1961 sowie dies.: Rycerki i samarytanki, Warszawa 1988.

107 I Malinowska: Feminizm europejski, S. 121.

108 I Vgl. Fuchs: Zivilgesellschaft, S. 71ff.; Kenney: Pojęcie >Matki-Polki<, S. 348; Penn, Shana: Solidarity's Secret. The Women Who Defeated Communism in Poland, Ann Arbor 2006.

109 । Malinowska: Feminizm europejski, S. 124.

110 । Vgl. dazu auch den im drugi obieg (Untergrundliteratur) herausgegebenen Sammelband Bujwid, Andrzej (Hg.), Kobieta polska lat osiemdziesiątych, Warszawa 1988.

111 I Vgl. Dunin: Tao, S. 8; Janion: Kobiety, S. 326f.; Keff-Umińska, Bożena: »0dzyskać traktory«, in: Grzybek/Mrozik, Kobiety w czasach przełomu (2009), S. 14-26, hier S. 19f. Siehe auch Iwasiów, Inga: »Powieść w obiegach. Lata osiemdziesiąte i kontynuacje«, in: Iwasiów, Prywatne/ 
Obwohl die Geschlechterdebatte im sozialistischen Polen verschiedene Stadien durchlief, blieb im Zuge der Systemtransformation ab 1989 vor allem das Bild der von oben durchgesetzten Gleichmacherei der stalinistischen Periode bestehen. ${ }^{112}$ Die PRL wurde von feministischer wie auch antifeministischer Seite fortan als Epoche einer widernatürlichen Emanzipation betrachtet. Feministische Stimmen kritisierten besonders die Auferlegung der Emanzipation >von oben<, weshalb die Frauen in eine passive Rolle gedrängt worden seien. ${ }^{113}$ Außerdem sei diese Gleichstellung kaum mehr als eine propagandistische Floskel und die Vertuschung tatsächlicher Ungleichheiten gewesen. ${ }^{114}$ Während feministische Positionen die sozialistische Emanzipation als Hemmnis einer sechten ‘manzipation und Gleichstellung betrachten, sehen konservative Positionen diese primär als Versuch der Installierung einer widernatürlichen `Feminokratie`. Die sozialistische Verweiblichung der polnischen Gesellschaft besteht aus dieser Perspektive darin, dass die öffentlich-politische Sphäre - als männlich-aktiv konnotiertes Element - der Zivilgesellschaft weitgehend verschlossen gewesen sei. ${ }^{115}$

\subsection{Neuorientierung der 1990er Jahre}

Die wenigen Feministinnen der 1980er Jahre - so sie sich denn überhaupt so nannten - hegten die Hoffnung, dass mit dem Umsturz des Sozialismus und der Einführung eines demokratischen Systems auch die Frage der geschlechtlichen Diskriminierung aufgegriffen und gelöst würde. Zunächst aber trat das Gegenteil ein: Ungleichheiten verschärften sich. Der die Frau an Hausarbeit und Kinderbetreuung bindende Diskurs gewann an medialer Verbreitung und politischem Gewicht. Obwohl die polnische Gesetzgebung den Frauen relativ viele Rechte einräumte, herrschte eine "riesige Diskrepanz zwischen Recht und Sitte ${ }^{116}$, und Rechte würden weder umgesetzt noch konsequent eingefordert. Infolge solcher Diskrepanzen ließ sich ab den frühen 1990er Jahren ein stärkeres feministisches Engagement verzeichnen, das sich auch in der nunmehr möglichen Formalisierung frauenrechtlicher Organisationen niederschlug.

publiczne (2008), S. 131-192, hier bes. S. 158 zum politischen Charakter weiblicher Prosa im drugi obieg der 1980er Jahre.

112 | Vgl. Kałwa: Emancipation and Traditionalism, S. 185.

113 I Vgl. Fuszara, Małgorzata: »Feminizm i my - dyskusja nad tekstem Ann Snitow«, in: Spotkania feministyczne (1994/1995), S. 14-21, hier S. 18.

114 I Dieser Vorwurf betrifft auch die Liga Kobiet, die trotz kritischer Vertreterinnen verworfen wird. Vgl. Stańczak-Wiślicz, Katarzyna: »Traktorzystka - o potędze wizerunku«, in: Teksty Drugie 141/3 (2013), S. 150-163, hier S. 154; Keff-Umińska: Odzyskać traktory, S. $20 f$.

115 | Vgl. Graff: Warum Frauen, S. 36; Watson, Peggy: „Eastern Europe's Silent Revolution: Gender«, in: Sociology 27/3 (1993), S. 471-487, hier S. 484.

116 | Fuszara: Feminizm i my, S. 18. 
Die Gespräche am Runden Tisch zwischen Opposition und sozialistischer Regierung im Frühjahr 1989, denen teilweise freie Parlamentswahlen folgten, ermöglichten einen relativ fließenden Übergang der politischen Systeme. ${ }^{117}$ Auf wirtschaftlicher Ebene jedoch wurde mit dem Balcerowicz-Plan vom Oktober 1989 die Systemtransformation mithilfe der sogenannten Schocktherapie eingeleitet. Dabei wurde ohne begleitende Maßnahmen die freie Marktwirtschaft »als einzig mögliche ${ }^{118}$ Wirtschaftsform eingeführt, was massive Auswirkungen auf die Betriebslandschaft und den Arbeitsmarkt hatte. Frauen waren von den Massenentlassungen besonders stark betroffen; ${ }^{119}$ außerdem Angestellte mit niedriger und mittlerer Ausbildung, was auf die Inkongruenz bisheriger Ausbildungsmuster mit den neuen Herausforderungen des Arbeitsmarkts hinweist. Dies zog ein wachsendes Interesse am weniger tangierten höheren Bildungsweg und einen Prestigeverlust >einfacher Arbeiter/innen nach sich. ${ }^{120}$ Aufgrund des Wegfalls von Arbeitsplätzen in der Industrie drängten männliche Arbeitnehmer auch in >weibliche` Berufszweige wie den Dienstleistungssektor oder die Informatik. Dies resultierte in einer Feminisierung der wachsenden Arbeitslosenrate und der sich erst herausbildenden Armut (Sozialhilfebezüge etc.). ${ }^{121}$

117 | Vgl. dazu Alexander: Kleine Geschichte Polens, S. 361-364; Korbonski, Andrzej: »Poland ten years after: the church«, in: Communist and Post-Communist Studies 33 (2000), S. 123-146, hier S. $138 f$.

118 I Szatlach: Dylematy Polek, S. 161. Vgl. auch Ghodsee, Kristen: »Feminism-by-Design. Emerging Capitalisms, Cultural Feminism, and Women's Nongovernmental Organizations in Postsocialist Eastern Europe«, in: Signs 29/3 (2004), S. 727-753, hier S. 729; Stark: Path Dependence, S. 37-41; Wiarda, Howard J.: "Southern Europe, Eastern Europe, and Comparative Politics: 'Transitology and The Need for New Theory«, in: East European Politics and Societies 15 (2001), S. 485-501.

119 | Vgl. Grabowska, Genowefa: »Kobiety w prawie międzynarodowym«, in: Faliszek et al., Kobiety wobec przemian (1997), S. 98-108, hier S. 108.

120 । Vgl. Beskid, Lidia: »Bezrobocie kobiet«, in: Sikorska, Kobiety i ich mężowie (1996), S. 101116, hier S. 112; Duch-Krzystoszek, Danuta: "Relacje między pracą domową i zawodową", in: Sikorska, Kobiety i ich mężowie (1996), S. 85-99, hier S. 87; Ghodsee: Feminism-by-Design, S.729; Malinowska, Ewa: „Dwa oblicza uczestnictwa kobiet we współczesnych przemianach społeczeństwa polskiego«, in: Faliszek et al., Kobiety wobec przemian (1997), S. 159-175, hier S. 162; Ślęczka, Kazimierz: »Rola kobiet we współczesnych transformacjach społecznych (w zwierciadle feminizmu) «, in: Faliszek et al., Kobiety wobec przemian (1997), S. 129-141, hier S. 131; sowie Stark: Path Dependence, S. 21ff. zur Hoffnung, einen situierten, »pfadabhängigen« Kapitalismus einzuführen.

121 I Vgl. Ślęczka: Rola kobiet, S. 131-134. Knothe (Kobiety i praca, S. 11) verweist darauf, dass das Phänomen der >Arbeitslosigkeit‘ an sich überhaupt erst nach 1989 auftauchte. Im Mai 1993 waren von den prinzipiell arbeitstätigen Frauen 59\% auf der Suche nach Arbeit, sei es aus Arbeitslosigkeit oder zu einem geringeren Teil auch aus Furcht, die gegenwärtige (Teilzeit-)Stelle zu verlieren (Beskid: Bezrobocie kobiet, S. 109f.). Siehe auch Malinowska: Dwa oblicza, S. $161 \mathrm{ff}$. 
Angesichts dieser Entwicklungen wurde 1996 der Arbeitskodex erneuert, der die geschlechtliche Diskriminierung am Arbeitsplatz verbot und etwa beiden Elternteilen das gleiche Recht auf Elternurlaub garantierte. Die Auswirkungen auf die tatsächliche Handhabung waren aber gering. ${ }^{122}$ Bezeichnend ist überdies, dass der Gesetzesentwurf zur Herstellung eines "gleichen Status « ${ }^{123}$ der Geschlechter, der dem Sejm 1996, 1998 und 2002 vorgelegt wurde, bis heute nicht angenommen wurde. Mit der Transformation hielt ein neoliberaler Geist Einzug in den gesellschaftlichen Diskurs, der den Fokus auf Eigenverantwortlichkeit und -initiative legte und geschlechtliche Diskriminierungen am Arbeitsplatz den Frauen selbst als fehlendes Engagement zuschrieb. ${ }^{124}$

Der Rückzug des Staatsapparats manifestierte sich auch darin, dass über die Hälfte der bisherigen Kinderkrippen verschwand. Da zumeist Frauen in der Familie für die Kinderbetreuung sorgten, förderte dies das Ausscheiden verheirateter Frauen aus der Arbeitswelt - wenn dies aufgrund der materiellen Verhältnisse möglich war. ${ }^{125}{ }$ Wenn eine Traktorführerin oder Maurerin, die eine weitere Vollzeitstelle mit der Hausarbeit hat, der Ausdruck von Emanzipation sein soll, lohnt es sich wohl eher nicht, eine emanzipierte Frau zu sein oder die Gleichberechtigung der Frauen zu fordern $\aleph^{126}$, erklärt die Feministin Sławomira Walczewska den freiwilligen Verzicht vieler Frauen auf das Recht auf Arbeit. Diese Tendenzen hin zu einer traditionellen Aufteilung der Geschlechterrollen verstärkte der mediale, gesellschaftliche und politische Diskurs. ${ }^{127}$

Zur Armut siehe Grotowska-Leder, Jolanta/Warzywoda-Kruszyńska, Wielisława: „Feminizacja katowickiej biedy?«, in: Faliszek et al., Kobiety wobec przemian (1997), S. 203-224 für den Fall Katowice.

122 | Vgl. Desperak, Izabela: »Kobiety - wielkie przegrane polskiej transformacji«, in: Michalczyk, Tadeusz et al. (Hg.), Problemy społeczne w okresie transformacji ustrojowej (= Zeszyty Naukowe Instytutu Filozofii i Socjologii oraz Instytutu Agrobiznesu z Informatyką Stosowaną Filii Akademii Świętokrzyskiej im. Jana Kochanowskiego, Band 1), Piotrków Trybunalski 2004, S. 175-184, hier S. 179, sowie den Sammelband Siemieńska, Renata (Hg.), Wokół problemów zawodowego równouprawnienia kobiet i mężczyzn, Warszawa 1997.

123 I Walczewska: Damy, rycerze i feministki, S. 67. Vgl. Szatlach: Dylematy Polek, S. 161.

124 | Vgl. Chutnik, Sylwia: »Transformers, czyli przemiany w Polsce po 1989 roku w oczach trzydziestolatki«, in: Grzybek/Mrozik, Kobiety w czasach przełomu (2009), S. 37-50, hier S. 40.

125 I Vgl. Knothe: Kobiety i praca, S. 14; Szatlach: Dylematy Polek, S. 154. Der Anreiz zu außerhäuslicher Arbeitstätigkeit liegt Knothe (Kobiety i praca, S. 18) zufolge vor allem in materiellen Gründen; persönliche Entwicklung oder der soziale Kontext der Arbeit werden hingegen weniger häufig als Grund zur Lohnarbeit genannt.

126 I Walczewska: Czy kobietom, S. $250 f$.

127 | Vgl. dazu allg. die beiden Berichte von Bator, Joanna: Wizerunek kobiety w reklamie telewizyjnej, Warszawa 1998, und dies.: Wizerunek kobiety w polskiej debacie politycznej. Perspektywa feministyczna, Warszawa 1999. 


\subsubsection{Die Geschlechterfrage als Scheideweg}

In Bezug auf das Selbstbild der jungen Dritten Polnischen Republik und ihrer Verortung in einem sich neu formierenden Europa divergierten die Ansichten eines liberalen, westlich orientierten Lagers von denjenigen konservativer Kreise. ${ }^{128}$ Der Publizist Adam Michnik formulierte 1991 polemisierend: »It is a dispute between two ideas of nation and state: between the idea of a civil society and open nation on the one hand and, on the other, the idea of a >Catholic State of the Polish Nation and intolerance toward those who are different. $\ll^{129}$ Diese gegensätzlichen Bestrebungen zeichneten die polnische Politik und Zivilgesellschaft von Beginn der Transformation an aus.

Eine der Plattformen des ausgetragenen Ideologiestreits war (und ist) die Geschlechterpolitik. Einerseits galt die Geschlechterordnung als das Fundament der polnischen Gesellschaft, deren >Verdrehung`im Sozialismus nun rückgängig gemacht werden sollte. ${ }^{130}$ Traditionelle Geschlechterrollen gerannen in der sich rasant verändernden Gesellschaft ${ }^{131}$ zu einem stabilisierenden Faktor, einem Wert, an dem man sich orientieren konnte. »Die Polen sehnen sich nach der traditionellen Familie« ${ }^{132}$, schreibt die Soziologin Izabela Desperak. Dabei gingen die Verdrängung weiblicher Lohnarbeit und die diskursive Aufwertung weiblicher Haushalts- und Kinderbetreuungsarbeit als `Ideal der Weiblichkeit` Hand in Hand. Eine tragende Rolle in diesen Prozessen spielte das neue Phänomen der Reklame. Werbung und Massenmedien transportierten das Bild einer bürgerlichen Frau, die als `Einkaufende` für Familie und Haushalt im Fokus von Reklamekampagnen und der Schaffung neuer Bedürfnisse stand. ${ }^{133}$ Ergänzend dazu bildete sich das Modell der erfolgreichen Karrierefrau heraus, das sich stärker am neoliberalen Modernisierungsdiskurs orientierte. Dieses schloss aber die familienbetreuende

128 I Vgl. Chutnik: Transformers, S. 49; Desperak: Kobiety, S. 183; Keinz, Anika: Polens Andere. Verhandlungen von Geschlecht und Sexualität in Polen nach 1989, Bielefeld 2008, S. 57-65.

129 I Michnik, Adam: »Nationalism«, in: Social Research 58/4 (1991), S. 757-763, hier S. 763.

130 । Vgl. Graff, Agnieszka: Świat bez kobiet. Płeć w polskim życiu publicznym, Warszawa 2001, S. 22ff.; Keinz: Polens Andere, S. 107; Watson: Silent Revolution, S. 472, 483.

131 I Vgl. Keinz: Polens Andere, S. 75; Szacki, Jerzy: "Polish Democracy: Dreams and Reality«, in: Social Research 58/4 (1991), S. 711-722, hier S. 714: »[...] many people perceive this new reality not as a process of building a different social order which makes it necessary to learn the changing rules as quickly as possible, but as disintegration of all order. They do not know who or what could help stem this slide, especially since they are familiar only with the old system's methods of dealing with such phenomena."

132 I Desperak: Kobiety, S. 179. Siehe auch Frieske, Kazimierz W.: »Poza stereotypami: między Matką Polką a Kobietą Nierządną", in: Faliszek et al., Kobiety wobec przemian (1997), S. 198202, hier S. 198.

133 I Vgl. Bator: Wizerunek kobiety w reklamie, S. 21-29; Desperak: Kobiety, S. 179, 182; Nowakowska, Urszula: »Wprowadzenie«, in: Gadomska et al., Kobiety w Polsce (2000), S. 5-7, hier S. 6. 
Rolle oft mit ein und suggerierte so eine problemlose Vereinbarung dieser beiden Betätigungsfelder. ${ }^{134}$

Während die Geschlechterrollen einen Streitpunkt der progressiven und konservativen Kräfte darstellen, dienten sie gleichzeitig als deren Verhandlungsbasis: so scheiterte etwa das Gleichstellungsgesetz endgültig damit, dass die EU 2003/04 bei der Aufnahme Polens auf dessen Durchsetzung verzichtete, während im Gegenzug die katholische Kirche Polens ihr Einverständnis und ihre politische Unterstützung zum Europaanschluss gab. ${ }^{135}$

Die einflussreiche katholische Kirche nahm (und nimmt) in Polen eine zentrale Position in der Geschlechterdebatte ein, indem sie die Rolle der Frau als Mutter propagierte und sich aktiv in politische Entscheidungsfindungen einmischte. ${ }^{136}$ Die "Bedürfnisse und Interessen von Frauen ${ }^{137}$ sollten denjenigen von Familie und Nation untergeordnet werden, wobei das Modell der Matka Polka weitere Aufwertung erfuhr. So sollte der empirische Rückgang von Eheschließungen sowie die wachsende Zahl unehelicher Kinder und Scheidungen in den 1990er Jahren bekämpft werden. ${ }^{138}$ Die Kirche festigte damit ihren »Bedeutungsgewinn im politischen Machtgefüge«, während politische Parteien »christliche Werte als Grundlage ihrer Programme « ${ }^{139}$ übernahmen. Der Vergleich mit westlichen Gesellschaften diente teilweise auch zur Festigung 'nationalspezifischer`, traditioneller Muster, da der Westen »in eine Sackgasse in Bezug auf die Gleichheit der Geschlechter ${ }^{140}$ geraten sei. Die hier formulierten Tendenzen bilden zusammen mit

134 । Vgl. Łaciak, Beata: „Wzór osobowy współczesnej Polki«, in: Titkow/Domański, Co to znaczy (1995), S. 233-244; Walczewska: Damy, rycerze i feministki, S. 89. Bator (Wizerunek kobiety w reklamie, S. 29-38) kontrastiert das »traditionelle« Frauenbild mit einem »modernen «, mit sich selbst beschäftigten, in dessen Zentrum der gepflegte Körper der "narzisstischen Konsumentin « steht.

135 | Vgl. Chołuj, Bożena: Interview [unveröffentlicht], Zürich 2013; Chutnik: Transformers, S. 50; Keinz: Polens Andere, S. 193-199.

136 I Vgl. Ciechomska, Maria: Od matriarchatu do feminizmu, Poznań 1996, S. 318; Desperak: Kobiety, S. 175; Korbonski: Poland ten years after; Matuchniak-Krasuska, Anna: »Ruch feministyczny i kobiecy w Polsce. Interwencja socjologiczna 1994/95«, in: Acta Universitatis Lodziensis. Folia Sociologica 27 (1998), S. 123-150, hier S. 138; Węgierek, Monika: »Wybrane katolickie i protestanckie elementy płci kulturowej (gender) w stereotypie roli kobiety«, in: Kwartalnik Pedagogiczny 155-156/1-2 (1995), S. 179-197; Zielińska, Eleonora: »Between Ideology, Politics, and Common Sense: The Discourse of Reproductive Rights in Poland«, in: Gal/Kligman, Reproducing Gender (2000), S. 23-57, hier S. $36 f$.

137 | Szatlach: Dylematy Polek, S. 161.

138 | Vgl. Świątkiewicz, Wojciech: »Rodzina wobec kryzysu wartości«, in: Faliszek et al., Kobiety wobec przemian (1997), S. 178-186.

139 I Malinowska: Dwa oblicza, S. 163.

140 | Górski, P., „Do demokracji przez równość kobiet i mężczyzn«, in: Rzeczpospolita 154 (1992), S. 2, zit. nach Domański, Henryk: Zadowolony niewolnik? Studium o nierównościach między mężczyznami i kobietami w Polsce, Warszawa 1992, S. 142. 
einer wachsenden Einkommensschere seit der Transformation das der polnischen Gesellschaft inhärente Spannungsverhältnis, das sich spätestens mit den Wahlen 2015 in einen offenen politisch-ideologischen `Glaubens«konflikt auswuchs.

Im Hinblick darauf gilt die Abtreibungsdebatte als eine `Gretchenfrage der polnischen Gesellschaft. ${ }^{141}$ Bereits 1989 lancierte die katholische Kirche ein Projekt der umfassenden Illegalisierung von Schwangerschaftsabbrüchen, ohne Rücksicht auf Gesundheit, Psyche und soziale Umstände der betroffenen Frau. 1993 trat das Gesetz in abgemilderter Form in Kraft: Abtreibungen waren nur noch »bei Gefährdung von Leben oder Gesundheit der Mutter, im Falle einer schwerwiegenden Schädigung des Fötus oder bei Schwangerschaft infolge eines Delikts $\aleph^{142}$ erlaubt, nicht aber im Falle sozialer Vorbehalte. Die Geburt eines Kindes auch unter schwierigen gesundheitlichen oder sozialen Bedingungen verknüpfte das konservativ-katholische Narrativ als Form weiblichen Heldentums mit dem Opferdienst der Frauen an der Nation. ${ }^{143}$

Das Abtreibungsgesetz und die Diskussion darum bilden ein komplexes Diskursfeld mit unterschiedlichen Narrativen, das zulasten dringlicher staatskonstituierender Fragen als weltanschauliches `Stellvertreterproblem` auf das politische

141 | Vgl. Zielińska: Between Ideology, S. 24f., 52. Die Frage nach dem Schwangerschaftsabbruch bespreche ich in Kapitel 6.1.2 ansatzweise anhand der feministischen Kritik in der Polonistik.

142 । Nowakowska, Urszula/Korzeniewska, Maja: »Prawa kobiet w sferze prokreacji«, in: Gadomska et al., Kobiety w Polsce (2000), S. 225-256, hier S. 228.

143 I Zur Abtreibungsdebatte der 1990er Jahre siehe detailliert Zielińska: Between Ideology. Zur spezifischen Rhetorik innerhalb dieser Debatte vgl. Matuchniak-Krasuska, Anna: „Kategorie i reguły polskiego dyskursu 0 aborcji«, in: Czyżewski et al., Cudze problemy (1991), S. 129-156; dies.: "Czym była dyskusja o aborcji«, in: Titkow/Domański, Co to znaczy (1995), S. 189-212, S. 207; Pawlik, Wojciech: »Spór o aborcję, czyli sztuka parlamentarnej erystyki«, in: Czyżewski et al., Cudze problemy (1991), S. 157-189; Szczuka, Kazimiera: Milczenie owieczek. Rzecz o aborcji, Warszawa 2004.

Retrospektiv lässt sich festhalten, dass das Abtreibungsverbot respektive das »Gesetz zur Familienplanung, zum Schutz des menschlichen Fötus und zu den Bedingungen der Zulässigkeit des Schwangerschaftsabbruchs « (Ustawa o planowaniu rodziny, ochronie płodu ludzkiego $i$ warunkach dopuszczalności przerywania ciąży) kaum positive Folgen mit sich brachte: Abtreibungen verlagerten sich in den Untergrund und ins Ausland, wodurch ärmere Frauen zusätzlich benachteiligt wurden und die Gesundheitsrisiken anstiegen. Zudem wurden auch gesetzlich zugelassene Schwangerschaftsabbrüche nicht selten vom medizinischen Personal verweigert. Hinzu kamen eine fehlende Sexualaufklärung an den Schulen sowie der erschwerte Zugang zu Verhütungsmitteln. Alle genannten Aspekte erfahren ab Mitte der 2010er Jahre zusätzliche Verschärfung durch entsprechende Restriktionen. Vgl. Desperak: Kobiety, S. 180f.; Nowakowska: Wprowadzenie, S. 5. Siehe auch Nowakowska/Korzeniewska: Prawa kobiet, S. 241 sowie Zielińska: Between Ideology, S. $43-48$. 
Parkett gebracht wurde, wie liberale Kreise kritisieren. ${ }^{144}$ Viele (ex)kommunistische Politiker übernahmen den abtreibungskritischen katholischen Standpunkt, was ihnen den Vorwurf machiavellistischen Politisierens zur Sicherung ihrer eigenen Position einbrachte. ${ }^{145}$ Die Debatte um den Schwangerschaftsabbruch bewirkte zudem ein Auseinanderentwickeln und Verhärten der Argumentationen und Standpunkte. ${ }^{146}$ Hier kann von »divergent realities ${ }^{147}$ gesprochen werden, als sich Begrifflichkeiten, Semantiken und `Weltbild ‘ national-konservativer (pro-life) und europäisch-liberaler (pro-choice) Positionen im Abtreibungsdiskurs, aber im weiteren Sinne auch in der Geschlechterdebatte und im politischen Verständnis kaum mehr überschneiden. ${ }^{148}$ In Bezug auf politisch aktive Frauen schlägt sich dies in Form der beiden entgegengesetzten und angeblich unvereinbaren Stand-

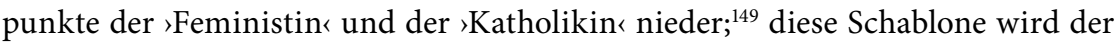
Vielfalt weiblicher Initiativen in den 1990er Jahren nicht gerecht, skizziert aber die grundsätzliche Problematik des polnischen Frauenaktivismus.

In den 1980er Jahren führten primär Studentinnen lose strukturierte Treffen und Veranstaltungen $\mathrm{zu}$ feministischen Themen durch. ${ }^{150}$ Einige dieser bereits bestehenden Gruppen formalisierten sich nach 1989, während weitere Frauenorganisationen zu verschiedenen Themen (Frauen in der Politik, natürliches Gebären u. v. m.) entstanden und Fonds mit auf Frauen zugeschnittenen Programmen eingerichtet wurden. Vereinzelte ’katholische` Organisationen begannen sich mit dem spezifischen Los von Frauen zu befassen. Feministische Theologie und christliche, aber pro-choice eingestellte Gruppierungen wagten den Brückenschlag zwischen sich ansonsten entgegenstehenden Narrativen. ${ }^{151}$ Auch die in der PRL veran-

144 | Vgl. Matuchniak-Krasuska: Czym była dyskusja, S. 197; Pawlik: Spór o aborcję, S. 161-168; Zielińska: Between Ideology, S. 24.

145 I Vgl. Brach-Czaina: Progi, S. 343; Chołuj: Interview; Graff: Warum Frauen, S. 40; Matuchniak-Krasuska: Czym była dyskusja, S. 191; Zielińska: Between Ideology, S. 24, $36 f$.

146 I Vgl. Matuchniak-Krasuska: Kategorie i reguły, S. 131; Michnik: Nationalism, S. 761. Siehe auch Szacki: Polish Democracy, S. 717f. zur Formung monolithischer kollektiver Subjekte als Identitätsangebot durch Abgrenzung sowie den Band Domański, Henryk et al.: Polska jedna czy wiele? (= Seria z rekomendacją), Warszawa 2005, zur Fragmentierung der polnischen Gesellschaft.

147 | Shweders, Richard A.: »Divergent Rationalities«, in: Fiske, Donald W./Shweder, Richard A. (Hg.), Metatheory in Social Science. Pluralisms and Subjectivities, Chicago, London 1986, S. 163-196.

148 I Vgl. Walczewska: Damy, rycerze i feministki, S. 39f.

149 | Vgl. Malinowska: Feminizm europejski, S. 168; Matuchniak-Krasuska: Ruch feministyczny, S. 127.

150 | Vgl. Chutnik: Transformers, S. 41, für den Polskie Stowarzyszenie Feministyczne; allg. Fuchs: Zivilgesellschaft, S. 75; Walczewska: Czy kobietom, S. 247.

151 I Vgl. Malinowska: Feminizm europejski, S. 181-184; Matuchniak-Krasuska: Ruch feministyczny, S. 133; Regulska, Joanna/Grabowska, Magdalena: "Post-1989 Women's Activism in Poland«, in: Regulska, Joanna/Smith, Bonnie G. (Hg.), Women and Gender in Postwar Europe. From Cold War to European Union, London, New York 2012, S. 212-230, hier S. 214; Sapkowska, Agata: 
kerte Liga Kobiet Polskich führte ihre Tätigkeiten weiter, wobei die Organisation jedoch deutlich schrumpfte. In der ersten Hälfte der 1990er Jahre bildeten sich so um die zehn neue Frauenorganisationen jährlich. ${ }^{152}$

Programm und politische Haltung der Organisationen richtete sich oft an persönlicher Erfahrung oder Beobachtung ihrer Initiantinnen aus: Ihr »Verständnis von Feminismus resultiert hauptsächlich aus Lebenserfahrungen, weniger jedoch aus theoretischer Lektüre ${ }^{153}$, stellt die Soziologin Anna Matuchniak-Krasuska fest. Viele der Initiativen gründeten auf den enttäuschten Hoffnungen in Bezug auf den Umbruch von 1989, der soziale Ungleichheiten und eine Neuinszenierung stereotyper Rollenmuster mit sich brachte. ${ }^{154}$ Das Abtreibungsgesetz und die damit verbundenen Proteste waren dabei in der Herausbildung des "frauenpolitischen Milieus [środowisko kobiece] « ${ }^{155}$ von besonderer Bedeutung.

Der feministische Diskurs der 1990er und 2000er Jahre sieht diese Debatte als Moment der Wiedergeburt des `Feminismus in Polen, wobei sozialistische Bestrebungen bewusst ausgeklammert wurden. ${ }^{156}$ Tatsächlich mobilisierten die Proteste gegen den Gesetzesentwurf ab 1989 größere Massen von Frauen, die Kundgebungen veranstalteten oder Protestbriefe schrieben und so letztlich die Abmilderung des Gesetzesentwurfs erwirkten. ${ }^{157}$ Ein weiteres wichtiges Ereignis der polnischen Frauenbewegung stellte der Weltfrauenkongress von 1995 in Beijing dar, für den verschiedene Organisationen einen unabhängigen Report als Gegengewicht zum offiziellen polnischen Bericht erstellten. ${ }^{158}$ Malinowska merkt an, dass

»Feminizm - wyzwanie czy zagrożenie dla Kościoła?«, in: Chańska/Ulicka, Polskie oblicza feminizmu (2000), S. 137-150, hier S. 142.

152 | Vgl. Malinowska: Feminizm europejski, S. 122, 128.

153 I Matuchniak-Krasuska: Ruch feministyczny, S. 142. Siehe auch Lipowska-Teutsch, Anna: "Śmiech i gniew«, in: Walczewska, Feministki (2005), S. 53-74, hier S. 56.

154 I Vgl. Chutnik: Transformers, S. 41, 49f.; Janion: Kobiety, S. 326f.; Matuchniak-Krasuska: Czym była dyskusja, S. 211; dies.: Ruch feministyczny, S. 126; Szacki: Polish Democracy, S. 713. 155 । Fuchs: Zivilgesellschaft, S. 113. Übersetzung im Original.

156 । Vgl. Gajewska: Feministyczne rozrachunki, S. 464 sowie Mrozik: Akuszerki transformacji, S. $391 f f$.

157 | Vgl. Walczewska: Czy kobietom, S. 247. Die Massen sverflüchtigten sich allerdings in der Folge größtenteils wieder und hinterließen eine nur schmale Basis an Frauenorganisationen, von denen wiederum nur einige sich dezidiert als feministisch bezeichneten. Zu nennen sind hier etwa der Polskie Stowarzyszenie Feministyczne (Polnischer Feministischer Verein) und das Centrum Praw Kobiet (Zentrum für Frauenrechte) in Warschau oder die Fundacja eFKa (Stiftung eFKa) in Krakau. Vgl. Chutnik: Transformers, S. 41; Filipowicz, Halina: »Przeciw >literaturze kobiecej «, in: Teksty Drugie, Śmiech feministek (1993), S. 245-258, hier S. 245; Fuszara: Feminizm i my, S. 20; Walczewska: Damy, rycerze i feministki, S. 40.

158 I Vgl. Malinowska: Feminizm europejski, S. 131f.; Matuchniak-Krasuska: Ruch feministyczny, S. 128; Regulska/Grabowska: Post-1989 Women's Activism, S. 213; Walczewska: Damy, rycerze i feministki, S. 43. 
"[sich b]ei dieser Gelegenheit allerdings auch die ideologischen Gräben in den NGOs der polnischen Frauenbewegung [vertieften]. Einige von ihnen, die ihre Programme auf >christliche Wertes stützten, sägten sich von den `Feministinnen ab, die ihrer Meinung nach die traditionelle soziale Rolle der Frau in der Familie geringschätzten. « ${ }^{159}$

Es zeigten sich außerdem Schwierigkeiten in der politischen Anbindung der Frauengruppierungen und feministischen Organisationen: Während das »wirtschaftliche Programm der Rechten «, nicht aber deren Geschlechterbild Unterstützung fand, stand die Linke »dem Feminismus in Frauenfragen näher, ist aber als politische Option nicht akzeptabel ${ }^{160}$ - so kurz nach dem Niedergang des sozialistischen Systems und gerade weil viele Frauenaktivistinnen in der antikommunistischen Opposition aktiv gewesen waren. Diese Position führte teilweise zu widersprüchlichen Argumentationen und einem rhetorischen Schlingerkurs.

Auch der Begriff `Feminismus` war mit Vorbehalten behaftet. In der Volksrepublik waren Bestrebungen zur Gleichstellung der Geschlechter mehrheitlich unter dem Begriff der `Emanzipation` geführt worden. `Feminismus hingegen galt als »bourgeoise Lappalie « ${ }^{161}$ und westliche Dekadenz. ${ }^{162}$ Ab 1989 häufte sich - in Anlehnung an westliche feministische Ansätze - die Verwendung des Begriffs `Feminismus` bzw. `feministisch ‘. Dazu gehört jedoch ein starkes politisches Selbstverständnis, und »die Aktivistinnen >neutraler Frauenorganisationen aus dem wirtschaftlichen Bereich und auf lokaler Ebene versuchen [den Begriff `Feminismus`] zu vermeiden ${ }^{163}$. Im gesellschaftlichen Diskurs funktionierte $>$ Feminismus «ach wie vor und immer stärker pejorativ.

Die konservative Seite brachte den Begriff einerseits mit der Volksrepublik in Verbindung und verstand darunter stalinistische `Gleichmacherei und Feminokratie`. Der Feminismus sei mit dem Kommunismus gleichzusetzen respektive diene als verschleiernder Euphemismus. ${ }^{164}$ Andererseits interpretierten konser-

159 | Malinowska: Feminizm europejski, S. 132f.

160 I Matuchniak-Krasuska: Ruch feministyczny, S. 141f. Siehe auch Szacki: Polish Democracy, S. 720 zur damit in Verbindung stehenden »very comforting practice of blaming communism for everything and anything ".

161 I Paczoska, Ewa: »Na strychu i po kątach. Pisarki czasu międzywojnia w cieniu i blasku PRLu (Rekonesans) «, in: Gosk, Hanna (Hg.), (Nie)Ciekawa epoka? Literatura i PRL (= Seria Prac Zakładu Literatury Polskiej XX Wieku Instytutu Literatury Polskiej Uniwersytetu Warszawskiego), Warszawa 2008, S. 198-220, hier S. 201.

162 I Vgl. Darska, Bernadetta: Głosy kobiet. Prasa feministyczna po roku 1989 wobec tożsamości i dyskursu, Olsztyn 2009, S. 31; Ghodsee: Feminism-by-Design, S. 733. In der Zwischenkriegszeit war der Begriff sfeministisch jedoch weit verbreitet und aus emanzipatorischer Sicht positiv konnotiert.

163 I Matuchniak-Krasuska: Ruch feministyczny, S. 127.

164 । Vgl. Fuchs: Zivilgesellschaft, S. 127; Keinz: Polens Andere, S. 119. 
vative Kreise den `Feminismus` als Ingerenz westlicher Hegemonialmächte, die die polnische nationale Identität zu unterwandern suchten. ${ }^{165}$ Angriffsfläche boten diesbezüglich etwa die westliche Finanzierung von NGOs und die Rezeption westlicher feministischer Ansätze. Mit solchen Ent-Fremdungsstrategien konstruierten seine Gegner den `Feminismus« als »detach[ed] from various groups of women ${ }^{166}$ und als »alien influence ${ }^{167}$. Einer der formalen Hauptkritikpunkte an feministischen Standpunkten war die Behauptung, dass Feministinnen »sich grundlos das Recht darauf anmaßen, die polnischen Frauen zu repräsentieren« und als »Geschlechtschauvinistinnen « ${ }^{168}$ eine verzerrte Wahrnehmung der Wirklichkeit hätten. Die hauptsächliche Verankerung des Feminismus in besser ausgebildeten, sozial privilegierten Schichten begünstigte Vorwürfe wie jener, dass Feministinnen »der wenig spektakulären, mühseligen und undankbaren Arbeit, die auf das praktische Unterbrechen der Kumulationsprozesse unterschiedlichster sozialer Marginalitäten der Frauen abzielt, kaum Aufmerksamkeit schenk[en] «169. Die Vermengung demonstrativ marxistischen Vokabulars mit einer auf die Affektivität der Frauenaktivistinnen (das "Temperament der Feministinnen ${ }^{170}$ ) abzielenden, suggestiven Argumentationsweise charakterisiert dabei die politisch diskreditierende Rhetorik der Feminismusgegner/innen.

Trotz der Vorbehalte gegen den Begriff `Feminismus` respektive dessen politischen Gehalt existierten in den 1990er Jahren offen feministische Organisationen: die Fundacja eFKa (Stiftung eFKa), die Fundacja »Ośrodek Informacji Środowisk Kobiecych» (Stiftung »Informationszentrum Frauenmilieus», OŚKa) in Warschau oder Konsola in Poznań. Der Unterschied zwischen sapolitischen Frauenorganisationen und Organisationen mit dezidiert feministischer Ausrichtung lag dabei darin, dass erstere vor allem Hilfe im Einzelfall boten, während feministische Organisationen das System und die Geschlechterordnung an sich hinterfragten und versuchten, mit einer politischen Vision tiefergreifende Veränderungen einzuleiten. ${ }^{171}$ Dabei waren neben liberalen Feministinnen, die wie Magdalena Środa oder Kazimiera Szczuka medial präsent waren, auch radikalere Kritiken am entstehenden System zu vernehmen. Es bildete sich etwa eine anarchofeministische Strömung heraus, die die Ausrichtung und Aktivitäten der Frauenbewegung mit-

165 I Vgl. Ghodsee: Feminism-by-Design, S. 230f.; Graff: Warum Frauen, S. 38f.; Nowakowska: Wprowadzenie, S. 6; Regulska/Grabowska: Post-1989 Women's Activism, S. 213.

166 | Regulska/Grabowska: Post-1989 Women's Activism, S. 213.

167 | Szacki: Polish Democracy, S. 720.

168 | Malinowska: Feminizm europejski, S. 184.

169 | Frieske: Poza stereotypami, S. 202. Siehe auch Brach-Czaina: Progi, S. 355; Fuchs: Zivilgesellschaft, S. 75ff.; Matuchniak-Krasuska: Czym była dyskusja, S. 211.

170 | Frieske: Poza stereotypami, S. 202.

171 | Vgl. Brach-Czaina: Progi, S. 346f.; Regulska/Grabowska: Post-1989 Women's Activism, S. 216. 
formte und mit der seit 2000 jährlich in Warschau stattfindenden Demonstration "Manifa« eines der Aushängeschilder feministischen Engagements begründete. ${ }^{172}$

Auf akademischer Ebene nahm der Umgang mit dem >belasteten >Feminismus` andere Züge an. Um den negativen und stark politisierten Konnotationen dieses Begriffs zu entgehen, bemühten sich einzelne Geschlechterforscherinnen um eine Depolitisierung der feministischen Kritik als methodisches Instrument, indem sie diese klar vom politischen Feminismus abgrenzten. ${ }^{173}$ Akademische Auseinandersetzungen wichen auch auf den zunächst noch als ıneutrak verstandenen Begriff der >Gender Studies`aus, obwohl zunächst vorwiegend feministische Kritik im Sinne einer Frauen- und Weiblichkeitsforschung betrieben wurde. ${ }^{174}$ Problematisch wurde hier außerdem die kryptische Bezeichnung gender (seltener: dżender) für das kulturelle Geschlecht, das parallel auch als rodzaj (Genus) oder eben als płeć kulturalna/socjalna (kulturelles/soziales Geschlecht) Eingang in die Diskussion fand. ${ }^{175}$ Die Etablierung des Begriffs gender zog letztlich neben Vorwürfen der wissenschaftlich-elitären Verschleierung auch die Unterstellung von konservativer Seite mit sich, unter dem Deckmantel von gender ein ganzes westlich geprägtes ideologisches System des Sittenzerfalls zu importieren. ${ }^{176}$

\subsubsection{Akademischer Feminismus}

Bereits in den 1980er Jahren fand eine kritische Diskussion der Geschlechterordnung ihren Weg an die polnische Akademie. Als Hauptbeitragende zur Geschlechterdiskussion in der PRL positionierte sich die Soziologie, in deren

172 | Vgl. Chutnik: Transformers, S. 44.

173 । Vgl. bspw. Kraskowska, Ewa: »Kilka uwag na temat powieści kobiecej«, in: Teksty Drugie, Śmiech feministek (1993), S. 259-273, hier S. 261.

174 । Vgl. Graff, Agnieszka: »Gender Studies in Poland. A View from Within«, in: aspasia. The International Yearbook of Central, Eastern and Southeastern European Women's and Gender History 4 (2010), S. 167-176, hier S. 169f.; Iwasiów: Interview. Als Beispiel dienen mag hier das Vorwort zum Kwartalnik Pedagogiczny 1-2 (1995), das sich von redaktioneller Seite der Problematik der Women's und Gender Studies widmet, während die Artikel selbst oft explizit auf den Feminismus verweisen.

175 । Siehe bspw. die Begriffsdiskussion bei Łebkowska, Anna: „Czy ’płeć‘ może uwieść poetykę?«, in: Bolecki, Włodzimierz/Tomasik, Wojciech (Hg.), Poetyka bez granic (= Z dziejów form artystycznych w literaturze polskiej), Warszawa 1995, S. 78-93, hier S. $78 \mathrm{f}$.

176 | Besonders deutlich wird diese Stoßrichtung seit den medial breit diskutierten Reden des damaligen Erzbischofs von Przemyśl, Józef Michalik, im Oktober 2013 über die »widernatürliche Gender-Ideologie« (Michalik, Józef: »Prawdziwa miłość dotyka nieskończoności«, Hirtenbrief vom 16.10.2013, Wrocław), die die Medien (ironisierend) zu einem >Gender-Monster ausbauten. Siehe auch 0ko, Dariusz: »Gender - ideologia totalitarna. Interview: Anna Cichobłazińska«, in: Niedziela. Tygodnik Katolicki 24 (2013), S. 40-43. 
Untersuchungen das Geschlecht eine häufige Analysekategorie bildete. Als feminologische - also im Geiste der Women's Studies geschriebene - Monographie galt etwa die arbeitssoziologische Studie von Irena Reszke, Prestiż społeczny a płeć (Gesellschaftliches Prestige und Geschlecht) von 1984. ${ }^{177}$ Die Soziologin Renata Siemieńska lenkte ebenfalls den Blick auf die Geschlechterrollen im öffentlichen Leben. ${ }^{178}$ Sie hielt an der Universität Warschau Seminare ab, in denen sie auch auf amerikanische Geschlechtertheorie zurückgriff und die Differenzierung von sex und gender einführte. Die von der Philosophin Teresa Hołówka herausgegebene Publikation Nikt nie rodzi się kobieta (Niemand wird als Frau geboren) von 1982 wiederum vereinte ausgewählte Texte amerikanischer Feministinnen, darunter Margaret Mead, Kate Millet oder Sherry B. Ortner. ${ }^{179}$

Siemieńska wie auch Hołówka und etwas später die Amerikanistin Agnieszka Graff sind jene Akademikerinnen, die während Aufenthalten in den USA mit der dortigen Frauenbewegung und feministischer Theorie in Kontakt kamen und diese nach der Rückkehr in Polen implementierten. ${ }^{180}$ Dabei war nicht nur die Rezeption der Theorie von Belang, sondern auch der direkte Vergleich von Gesellschaftsmodellen und sozialen Dynamiken, was Raum für Kritik am polnischen Modell öffnete. Mit dieser Einführung der Geschlechterforschung an polnischen Universitäten durch größtenteils polnische Akademikerinnen habe der polnische

177 | Vgl. Reszke, Irena: Prestiż społeczny a płeć. Kryteria prestiżu zawodów i osób, Wrocław 1984; Węgierek, Monika: »Przegląd ważniejszych polskich publikacji feminologicznych po roku 1980«, in: Kwartalnik Pedagogiczny 155-156/1-2 (1995), S. 417-449, hier S. 426. Reszke veröffentlicht zudem 1991 eine Monographie zu den verschiedenen Erklärungsversuchen der geschlechtlichen Ungleichheit in ökonomischen Theorien, siehe Reszke, Irena: Nierówności płci w teoriach: teoretyczne wyjaśnienia nierówności płci w sferze pracy zawodowej, Warszawa 1991.

178 । Vgl. Siemieńska, Renata: Płeć, zawód, polityka. Kobiety w życiu publicznym w Polsce, Warszawa 1990.

179 | Hołówka, Teresa (Hg.), Nikt nie rodzi się kobietą, Warszawa 1982. Hołówka bemerkt an anderer Stelle zu dieser Publikation: "Sie erweckte kein Interesse, [in Polen] hatten die Leute anderes im Kopf.«Hołówka, Teresa: Delicje ciotki Dee, Warszawa 1988, S. 133. Dieser Aussage widerspricht Węgierek: Przegląd, S. 420, die die Bedeutung dieser Übersetzungen für den polnischen Kontext betont.

180 । Vgl. Chołuj, Bożena: »Women's und Gender Studies in Polen«, in: Die Philosophin. Forum für feministische Theorie und Philosophie 17 (1998), S. 121-124, hier S. 123; Fuchs: Zivilgesellschaft, S. 75, 119; Graff, Agnieszka: »Feminizm ryzyka - i dlaczego w Polsce go nie ma«, in: Pełnym głosem 4 (1996), S. 19-23, hier S. 20; dies.: Świat bez kobiet, S. 6-9; Hołówka: Delicje ciotki Dee; Siemieńska, Renata: »To ona sprowadziła gender do Polski. Prof. Siemieńska u Kublik«, in: Gazeta Wyborcza Studio TV, 07.01.2014. Graff fungierte zunächst als Übersetzerin, etwa im Rahmen der Publikation Prawa człowieka prawem kobiet (Human Rights are Women’s Rights) von Amnesty International, die 1995 in Warschau herausgegeben wurde. Graff wurde später vor allem durch ihren essayistisch-polemischen Band Świat bez kobiet (Welt ohne Frauen, 2001) bekannt, in dem sie mit der polnischen patriarchal-sexistischen Gesellschaft abrechnet. 
Feminismus zudem eine stärkere lokale Kontextbindung als in anderen postsozialistischen Staaten, so Graff. ${ }^{181}$

Neben der Soziologie begannen sich in den 1990er Jahren auch geschichts- und literaturwissenschaftliche Disziplinen für geschlechtsorientierte Ansätze zu interessieren. Besonders produktiv und kreativ war außerdem die kritische Auseinandersetzung mit der Kategorie des Geschlechts in den bildenden Künsten, was jedoch in den 1990er Jahren wenig Niederschlag in wissenschaftlichen Publikationen fand und zudem unter dem diskursiven Druck der konservativen Politik stand. Anders als größtenteils die Geisteswissenschaften ließ sich das Milieu der kritischen Kunst nicht auf die Beschäftigung nur mit dem weiblichen Geschlecht reduzieren, sondern wandte sich auch dem männlichen Körper und männlichen Rollenmustern zu. Neben der Dekonstruktion und Dynamisierung des Geschlechterverhältnisses interessierten sich die Künste auch stärker für den Aspekt der Sexualität und die Interaktion mit dem Körper,; ${ }^{182}$ Paweł Leszkowicz spricht hier gar von einer "Explosion der Körperkunst ${ }^{183}$. Interessanterweise war jedoch die künstlerische Reflexion kaum Thema des akademischen Geschlechterdiskurses, und die institutionellen Überschneidungen und konzeptuellen Differenzen zwischen diesen Bereichen blieben bislang praktisch undokumentiert.

Die Institutionalisierung der Geschlechterforschung an den polnischen Hochschulen begann bereits 1989, als die Philosophin Elżbieta Pakszys an der Adam-Mickiewicz-Universität in Poznań den Interdisziplinären Kreis für Frauenforschung (Interdyscyplinarny Zespół Badawczy Problemów Kobiet) gründete. Neben Seminaren für die Studierenden wurden auch Konferenzen abgehalten, aus denen in den 1990er Jahren drei Sammelbände im Zyklus Humanistyka i pleć (Geisteswissenschaften und Geschlecht) sowie 2000 ein Sammelband zur Duchowość i religijność kobiet, dawniej i dziś (Geistlichkeit und Religiosität von Frauen, damals und heute) entstanden. ${ }^{184}$

181 । Vgl. Graff: Gender Studies, S. 169.

182 I Die Strömung der kritischen Kunst (sztuka krytyczna) der 1990er Jahre umfasst Künstler/ innen wie Paweł Althamer, Zofia Kulik, Artur Żmijewski, Zbigniew Libera und - im Kontext von Geschlechts- und (Homo-)Sexualitätsverhandlungen besonders oft genannt - Katarzyna Kozyra, vgl. Kowalczyk, Izabela: Ciało i władza. Polska sztuka krytyczna lat 90, Warszawa 2002, bes. S. 9; Leszkowicz, Paweł: Nagi mężczyzna. Akt męski w sztuce polskiej po 1945 roku, Poznań 2012, S. 241-252; Piotrowski: Art and Democracy, S. 249, 254-261.

183 | Leszkowicz: Nagi mężczyzna, S. 160: "eksplozją sztuki ciała«.

184 | Vgl. Miluska, Jolanta/Pakszys, Elżbieta (Hg.), Humanistyka i płeć. Tom I. Studia kobiece z psychologii, filozofii i historii, Poznań 1995; Pakszys, Elżbieta/Sobczyńska, Danuta (Hg.), Humanistyka i płeć. Tom II. Kobiety w poznaniu naukowym, wczoraj i dziś, Poznań 1997; Heller, Włodzimierz (Hg.), Humanistyka i płeć. Tom III. Publiczna przestrzeń kobiet. Obrazy dawne i nowe, Poznań 1999; Pakszys, Elżbieta/Sikorska, Liliana (Hg.), Humanistyka i płeć. Tom IV. Duchowość i religijność kobiet, dawniej i dziś, Poznań 2000. 
Aus der Perspektive historischer Forschung sind besonders die von Anna Żarnowska und Andrzej Szwarc ab 1990 organisierten Konferenzen zur Frauenforschung und die daraus hervorgehende Bandreihe Kobieta i ... (Die Frau und ...) zu erwähnen, die sich mit der Kondition der Frauen in verschiedenen sozialen Kontexten des 19. und 20. Jahrhunderts auseinandersetzten. ${ }^{185}$ Żarnowska wurde bereits 1966 Vorgesetzte der Kommission der Geschichte der Frauen im Polnischen Komitee der Geschichtswissenschaften (Komisja Historii Kobiet przy Polskim Komitecie Nauk Historycznych) und ab 1989 Leiterin eines Forschungsprojekts zur Geschichte der Frauen an der Universität Warschau. Die Bände Kobieta $i$... bildeten den breit gefächerten Output der geschlechtsorientierten Geschichtswissenschaft und versuchten, den historischen Diskurs um die `weibliche` Geschichte zu ergänzen.

Ebenfalls an der Universität Warschau, am Institut für Angewandte Sozialwissenschaften (Instytut Stosowanych Nauk Społecznych ISNS), entstand 1991 unter der Leitung der Soziologin Małgorzata Fuszara das Sozialrechtliche Forschungszentrum zur Situation der Frauen (Ośrodek Badań Społeczno-Prawnych nad Sytuacją Kobiet). Die Universität Łódź zog 1992 mit dem Wissenschaftlichen Forschungszentrum für Frauenproblematik (Ośrodek Naukowo-Badawczy Problematyki Kobiet) nach, das von der Amerikanistin Elżbieta Oleksy ins Leben gerufen wurde und für die Studierenden fakultative Veranstaltungen anbot. Siemieńska wiederum leitete ab 1992 am Institut für Sozialforschung (Institut Studiów Społecznych ISS) der Universität Warschau den Interdisziplinären Forschungskreis (Ośrodek Badań nad Społecznymi Problemami Płci), und am Institut für Philosophie und Soziologie (Instytut Filozofii i Socjologii IFiS) der Polnischen Akademie der Wissenschaften (Polska Akademia Nauk PAN) ebenfalls in Warschau gründete die Soziologin Anna Titkow 1994 den Arbeitskreis für Frauenforschung (Zespół Badań nad Kobietami i Rodziną). Als internationale Vertreterin der Geschlechterforschung lehrte überdies Ann Snitow, „the New York feminist and scholar much loved in Poland «, Mitte der 1990er Jahre an der Graduiertenschule der Sozialwissenschaften (Szkoła Nauk Społecznych) des IFiS PAN »some of the earliest gender studies courses $\aleph^{186}$ in Polen.

185 I Żarnowska, Anna/Szwarc, Andrzej (Hg.), Kobieta i społeczeństwo na ziemiach polskich w XIX wieku, Warszawa 1990; dies. (Hg.), Kobieta i edukacja na ziemiach polskich w XIX i XX wieku. Tom I i II, Warszawa 1992; dies. (Hg.), Kobieta i świat polityki. Polska na tle porównawczym w XIX i w początkach XX wieku, Warszawa 1994; dies. (Hg.), Kobieta i kultura. Kobiety wśród twórców kultury intelektualnej i artystycznej w dobie rozbiorów i w niepodległym państwie polskim, Warszawa 1996; dies. (Hg.), Kobieta i świat polityki w niepodległej Polsce 1918-1939, Warszawa 1996; dies. (Hg.), Kobieta i kultura życia codziennego. Wiek XIX i XX, Warszawa 1997; dies. (Hg.), Kobieta i praca. Wiek XIX i XX, Warszawa 2000; dies. (Hg.), Kobieta i kultura czasu wolnego, Warszawa 2001; dies. (Hg.), Kobieta i małżeństwo. Społeczno-kulturowe aspekty seksualności. Wiek XIX i XX, Warszawa 2004; dies. (Hg.), Kobieta i rewolucja obyczajowa. Społeczno-kulturowe aspekty seksualności. Wiek XIX i XX, Warszawa 2006.

186 I Vgl. Graff: Gender Studies, S. 169. 
Die Geschlechterforschung war somit an einigen Universitäten vertreten, musste aber meist aufgrund administrativer Hindernisse und institutsinterner "suspicion and ridicule ${ }^{187}$ auf eigene Studiengänge verzichten, weshalb sie sich mehrheitlich als fakultative Zusatzveranstaltungen einer bestehenden Disziplin oder als kostenpflichtige Studienprogramme für Postgraduierte ansiedelte. Als Beispiel hierfür dient der 1996 von Bożena Chołuj und Fuszara initiierte Nachdiplomstudiengang Gender Studies der Universität Warschau, der allen Abgänger/ innen der Geisteswissenschaften offensteht. Teilweise wurde die Thematik der Geschlechterforschung auch in bestehende Studienmodule integriert. Auf der Ebene der Forschung bildeten sich interdisziplinäre Zusammenschlüsse etwa in Form von Arbeitszirkeln heraus. ${ }^{188}$

Während solche Initiativen oft aus dritter Hand finanziert werden mussten, formulierte die polnische Regierung nach der Weltfrauenkonferenz in Beijing 1995 ein "Nationalprogramm für die Verbesserung der Situation der Frauen bis zum Jahre 2000 [...], in dem Gender Studies als Postulat formuliert wird « ${ }^{189}$. Generell bildeten sich an fast allen Universitäten in den 1990er Jahren Initiativen der Geschlechterforschung mit unterschiedlich starker institutioneller Anbindung und programmatischer Schärfe heraus. Gleichzeitig bestanden zwischen den akademischen Initiativen und dem politisch-aktivistischen Feld und den NGOs enge Verbindungen, und einige Professorinnen fungierten als Sprachrohre der Frauenbewegung auf der politischen und publizistischen Ebene, beispielsweise die Philosophin Środa. ${ }^{190}$

Ähnlich der institutionellen Ansiedlung der Geschlechterforschung entstanden auch die entsprechenden Publikationen nach 1989 zunächst vor allem im Rahmen der Soziologie und der Geschichtswissenschaft (hier vor allem als `Frauenforschung (), etwas später auch in den Philologien wie Polonistik oder Anglistik/Amerikanistik sowie als interdisziplinäre, oft auch essayistisch gehaltene Analysen der herrschenden Geschlechterordnung.

Das Jahr 1992 zeitigt Veröffentlichungen, die sehr unterschiedlich an die Geschlechterthematik herangehen. Darunter war eine programmatische Schrift für den polnischen Feminismus, die von der Feministin Walczewska herausgegebene Publikation Głos maja kobiety (Die Stimme haben die Frauen). Darin stellten verschiedene Feministinnen (zumeist Akademikerinnen) Diagnosen zur Situation der Frauen in Polen und subjektive Stoßrichtungen des feministischen Engagements vor. ${ }^{191}$ Das Themenheft 19B der literarisch-kulturellen Zeitschrift brulion (Kladde) unter dem Titel Feminizm. Magia Chaosu. Sadomasochizm (Feminis-

187 | Ebd., S. 167.

188 I Vgl. Chołuj: Women's und Gender Studies, S. 122f.; Graff: Gender Studies, S. 168-171.

189 | Chołuj: Women's und Gender Studies, S. 124.

190 । Vgl. Graff: Gender Studies, S. 169.

191 I Vgl. Walczewska, Sławomira (Hg.), Głos mają kobiety. Teksty feministyczne, Kraków 1992. 
mus. Magie des Chaos. Sadomasochismus) versammelte literarische und essayistische Texte von Autorinnen und Autoren aus Polen und internationaler Herkunft, etwa von Peter Sloterdijk oder Ursula K. LeGuin. Mit Texten von Walczewska, Izabela Filipiak und Maria Ciechomska waren auch zentrale Vertreterinnen der feministischen Strömung der 1990er Jahre präsent. ${ }^{192}$ Henryk Domański wiederum veröffentlichte den Band Zadowolony niewolnik? (Zufriedener Sklave?), in dem er der fehlenden Auflehnung der Frauen gegenüber offenkundigen sozialen Einschränkungen auf den Grund ging. Der Band kann aufgrund des in der feministischen Bewegung breit diskutierten Themas ${ }^{193}$ als ein Standardwerk der intensivierten Auseinandersetzung mit dem Geschlecht betrachtet werden, nahm aber letztlich eine ambivalente Haltung gegenüber der Emanzipation ein.

Als deutlich polemisch und für feministische Bestrebungen wenig förderlich kann die Übersetzung von Anne Moirs und David Jessels populärwissenschaftlichem Bestseller Brain Sex. The Real Difference between Men and Women (1989) von 1993 gelten. ${ }^{194}$ In Polen fiel diese »Theorie der genetischen Unterscheidung von Frauen- und Männerhirnen [...] auf besonders fruchtbaren Boden [und] füllte das Vakuum um die Frauenfrage aus. Sie wurde zum gesellschaftlich-kulturellen Ereignis ${ }^{195}$, bedauert Iwasiów den Erfolg dieser essentialisierenden und als `Beweis geschlechtlicher Differenz verwendete Publikation in Polen. ${ }^{196}$

Der Frage nach der Situation der Frauen in Polen und deren passiven $>$ Unterordnung « widmete sich auch die feministische Jahreszeitschrift Pełnym glosem (Mit voller Stimme), die von der Fundacja eFKa von 1993 bis 1997 herausgegeben wurde. Die populärwissenschaftlich ausgerichtete, programmatische Zeitschrift versammelte die Stimmen vieler namhafter Feministinnen aus unterschiedlichen Disziplinen und begründete eine blattinterne, aber auch externe Meinungen integrierende Diskussion über die Lage des polnischen Feminismus (s. u.). Als Grundstein dieser Diskussion gilt der in der ersten Nummer von Pelnym głosem 1993 veröffentlichte, aber bereits 1987 geschriebene Artikel der Kunsthistorikerin Barbara Limanowska unter dem Titel Dlaczego w Polsce nie ma feminizmu? (Warum gibt es in Polen keinen Feminismus?).

Neben Petnym głosem widmeten sich auch einzelne Nummern anderer Zeitschriften der Thematik des Feminismus. Zu erwähnen sind hier etwa Schwerpunkthefte der literaturwissenschaftlichen Zeitschrift Teksty Drugie (Zweite Texte) in den Jahren 1993 (4-6) und 1995 (3-4) (s. u.) oder die Themenhefte der

192 | Vgl. brulion: »Feminizm. Magia chaosu. Sadomasochizm«, 19B (1992).

193 I Vgl. Limanowska, Barbara: "Dlaczego w Polsce nie ma feminizmu«, in: Pełnym głosem 1 (1993), S. 3-24; Darska: Głosy kobiet, S. 26.

194 | Vgl. Moir, Anne/Jessel, David: Płeć mózgu. 0 prawdziwej różnicy między mężczyzną a kobietą, Warszawa 1993.

195 I Iwasiów, Inga: „Ślady porządków represywnych«, in: Pełnym głosem 2 (1994), S. 101-111, hier S. $102 f$.

196 | Vgl. auch Dunin: Tao, S. 54; Marszałek: Jeszcze raz o mózgu, S. $41 f$. 
katholisch-soziokulturellen Monatszeitschrift Więź (Bindung) 1993 (1) und 1998 (1), die Artikel zur Situation der Frauen in Gesellschaft und Kirche umfassten und sich aus feministischer Perspektive mit der päpstlichen Idee eines ıneuen Feminismus` auseinandersetzten. Die kulturpolitische Zeitschrift Res Publica Nowa (Neue Res Publica) wiederum widmete den Schwerpunkt ihrer Septembernummer 1997 dem Thema »Kobiety, feminizm i coś jeszcze» (»Frauen, Feminismus und noch etwas«). Darin fanden sich Artikel von bekannten Feministinnen wie Graff, Szczuka, der Soziologin Joanna Mizielińska, die sich mit nicht-heteronormativer Sexualität auseinandersetzt, oder der Polonistin Barbara Smoleń. Besonders erwähnenswert ist hier Szczukas kritische Auseinandersetzung mit feministischen Mythen. ${ }^{197}$ Die Organisation OŚKa nahm 1997 die Herausgabe ihres Bulletins OŚKa auf, das bis 2002 in 18 Nummern erschien und in vielen Bereichen an Argumentationen aus Pełnym głosem anknüpfte. Ebenfalls ab 1997 existierte mit Furia Pierwsza (Erste Furie) zudem eine Zeitschrift zur Thematik sexueller Minderheiten, deren achte und letzte Nummer 2000 erschien. 1999 schließlich wurde die erste Nummer der populärfeministischen Zadra (Stachel) veröffentlicht, die bis heute von der Fundacja eFKa herausgegeben wird und die wiederum die Diskussion über die Ausprägung des polnischen Feminismus aufleben ließ. Neben diesen Publikationen entstanden subkulturelle Zines in Einzelnummern oder als lose Reihen, die sich dem Feminismus und dessen serweiterten` Varianten wie Öko- oder Anarchafeminismus widmeten. ${ }^{198}$

In den 1990er Jahren waren zudem einige Sammelbände zur Geschlechterthematik und $\mathrm{zu}$ feministischen Ansätzen von besonderer Bedeutung. $\mathrm{Zu}$ nennen ist neben der bereits erwähnten Publikation Głos maja kobiety von 1992 oder den geschichtswissenschaftlichen Sammelbänden von Żarnowska/Szwarc etwa die Veröffentlichung der Spotkania feministyczne (Feministische Treffen) von 1994/1995, die Fragmente westlicher feministischer Ansätze (Ann Snitow, Susan Faludi, Naomi Wolf, Judith Butler) vorstellte und diskutierte. Besonders relevant wurde für den feministischen Diskurs der interdisziplinäre Sammelband Co to znaczy być kobieta w Polsce (Was es heißt, in Polen eine Frau zu sein) von 1995, der von Titkow und Domański herausgegeben wurde und populäre Problemstellungen, Narrative und Stereotypen aufgriff. Auch die von Jolanta Brach-Czaina herausgegebene Publikation Od kobiety do mężczyzny i z powrotem (Von der Frau zum Mann und zurück, 1997) deckte ein breites kulturwissenschaftliches Feld ab und beinhaltete dabei auch Studien zur Männlichkeit. Thematisch enger und methodologisch weniger an feministischer Kritik orientiert war hingegen etwa der Konferenzband Kobiety wobec przemian okresu transformacji (Frauen im Wandel

197 | Vgl. Szczuka, Kazimiera: „Czy feministki wybić się mogą na mit?«, in: Res Publica Nowa, Kobiety, feminizm (1997), S. 38-43.

198 I Vgl. Chutnik: Transformers, S. 43f. Zum Ökofeminismus siehe auch Sobczyńska, Danuta: »Macierzyństwo: wartości i dylematy«, in: Miluska/Pakszys, Humanistyka i płeć I (1995), S. 6984, hier S. 72. 
der Transformationszeit, 1997), der hauptsächlich (arbeits)soziologische Studien vereint, die teilweise auch implizit straditionalistisch ausgerichtet sind. ${ }^{199}$

Als ein Meilenstein des polnischen feministischen Textfundus erschien 1993 Maggie Humms Stownik teorii feminizmu (The Dictionary of Feminist Theory [1989]), übersetzt von der Polonistin Bożena Umińska und dem Übersetzer Jarosław Mikos. Diese Publikation war - Maria Ciechomskas Od matriarchatu do feminizmu (Vom Matriarchat zum Feminismus, 1996), das einen eher populärwissenschaftlichen globalhistorischen Überblick zur Position der Frau in verschiedenen Gesellschaftssystemen und Ideologien liefert, ausgenommen - bis zum Erscheinen von Kazimierz Ślęczkas umfangreichem Band Feminizm (Feminismus, 1999) die einzige enzyklopädische Bearbeitung des Themas in Polen. Stärker auf die gesellschaftspolitische Verankerung der Geschlechterrollen in der neuen polnischen Republik fokussiert waren die beiden Berichte von Joanna Bator, Wizerunek kobiety w reklamie telewizyjnej (Das Frauenbild in der TV-Werbung, 1998) und Wizerunek kobiety w polskiej debacie politycznej (Das Frauenbild in der polnischen politischen Debatte, 1999). Walczewskas Damy, rycerze i feministki (Damen, Ritter und Feministinnen, 1999) schließlich diskutierte polnische Weiblichkeitsbilder und den emanzipatorischen Diskurs aus der Perspektive feministischer Geschichtsschreibung anhand von Materialien von Schriftstellerinnen und Publizistinnen. Dieser essayistisch gehaltene Text kann als Subsumierung der bisherigen feministischen Narrative zur Geschlechterordung der Gegenwart und deren historisch-kulturellen Rahmungen gelten und wurde überaus kontrovers rezipiert. ${ }^{200}$ Viele der feministischen Publikationen an der Schnittstelle zwischen Akademie und Politik warfen die Frage auf, weshalb Frauen in Polen eine untergeordnete soziale Rolle gegenüber Männern einnehmen und weshalb dafür sowohl in der Gesellschaft allgemein wie auch unter Frauen kein Bewusstsein und kein Handlungsbedarf bestehe. Als Grund des in Polen schwachen weiblichen Engagements für gleiche Rechte und der fehlenden Solidarität zwischen Frauen galt der Mangel an einer kollektiven Identität, also an einem Bewusstsein eines gemeinsamen

199 । Vgl. Walczewska, Głos mają kobiety (1992); Żarnowska/Szwarc, Kobieta i społeczeństwo (1990); ... i edukacja (1992); ... i świat polityki (1994); ... i kultura (1996); ... i świat polityki w niepodległej Polsce (1996); ... i kultura życia codziennego (1997); .. i praca (2000); ... i kultura czasu wolnego (2001); ... i małżeństwo (2004); ... i rewolucja obyczajowa (2006); Spotkania feministyczne, Warszawa (1994/1995); Titkow, Anna/Domański, Henryk (Hg.), Co to znaczy być kobietą w Polsce, Warszawa 1995; Brach-Czaina, Jolanta (Hg.), Od kobiety do mężczyzny i z powrotem. Rozważania o płci w kulturze, Białystok 1997; Faliszek, Krystyna et al. (Hg.), Kobiety wobec przemian okresu transformacji, Katowice 1997; darin siehe bspw. Frieske: Poza stereotypami; Świątkiewicz: Rodzina.

200 । Vgl. Humm, Maggie: Słownik teorii feminizmu, Warszawa 1993; Ciechomska: Od matriarchatu; Ślęczka, Kazimierz: Feminizm. Ideologie i koncepcje społeczne współczesnego feminizmu, Katowice 1999; Bator: Wizerunek kobiety w reklamie; dies.: Wizerunek kobiety w debacie; Walczewska: Damy, rycerze i feministki. 
Frau-Seins. ${ }^{201}$ Laut Domański »stellten die Geschlechtsunterschiede aus der Sicht der Frauen keine bedeutsame Strukturierungsebene dar«, weshalb Frauen ihre "niedere Position« akzeptierten. Relevanter seien »Ungleichheiten zwischen sozialen Klassen, Berufsgruppen, Wirtschaftszweigen oder Betriebsbelegschaften. ${ }^{202}$ Als gewichtigen Faktor nannte Domański zudem die soziale Stabilität in Form von direkten zwischengeschlechtlichen Beziehungen, also das faktische Zusammenleben von Männern und Frauen etwa im Rahmen der Institution Familie, das ein Auflehnen der Frauen gegen die Ungleichbehandlung verhindere. ${ }^{203}$

Die Frage, ob ein polnischer Feminismus überhaupt existiere, beantwortete sich zunehmend selbst. ${ }^{204}$ Weshalb er aber in Polen verglichen mit anderen Ländern einen schweren Stand habe, lasse sich - so der Konsens vieler Feministinnen - nicht allein anhand der aktuell vorherrschenden Gesellschaftsstruktur beantworten. Polnische Feministinnen rücken drei historisch begründete Aspekte in den Vordergrund, die die Bildung eines weiblichen Kollektivbewusstseins auch nach 1989 verhinderten: ${ }^{205}$ die republikanische Adelsgesellschaft, die katholische Kirche sowie die Epoche kommunistischer Regierung.

Titkow verwies 1995 im wegleitenden Artikel Kobiety pod presją? Proces ksztattowania się tożsamości (Frauen unter Druck? Prozess der Identitätsbildung) auf die anhaltende Wirkmacht des Ethos der Adelsrepublik des 18. Jahrhunderts. ${ }^{206}$ Darin fuße die absolute Hochhaltung der kollektiven Freiheit in Form staatlicher Souveränität, der die individuelle Freiheit untergeordnet sei. Diese diskursive Gemeinschaftlichkeit, so Titkow, band die Frauen in der Teilungszeit, der Zwischenkriegszeit und während der Opposition gegen den kommunistischen Staatsapparat

201 । Vgl. Graff: Świat bez kobiet, S. 18. Dies ist nicht zwingend eine Spezifik des polnischen Kontexts, wird jedoch in den feministischen Ansätzen kaum je in einen internationalen Kontext gestellt oder etwa mit dem Phänomen des 'Postfeminismus` als 'Feminismusmüdigkeit‘ postfordistischer Gesellschaften in Verbindung gesetzt (vgl. zu verschiedenen Interpretationen des >Post ‘feministischen bspw. Genz, Stéphanie/Brabon, Benjamin A.: »Introduction. Postfeminist Contexts«, in: dies. (Hg.), Postfeminism. Cultural Texts and Theories, Edinburgh 2009, S. 1-50; Gill, Rosalind/ Scharff, Christina: »Introduction«, in: dies. (Hg.), New Femininities. Postfeminism, Neoliberalism and Subjectivity, Basingstoke 2011, S. 1-17.

202 I Domański: Zadowolony niewolnik, S. 140.

203 | Vgl. ebd., S. 141.

204 | Vgl. Rosner, Katarzyna: "Czy istnieje w Polsce ruch feministyczny?«, in: Pełnym głosem 5 (1997), S. 34-41, hier S. 34; Walczewska, Sławomira: »Feminizm? - jest!«, in: Pełnym głosem 4 (1996), S. 25-26, hier S. 25.

205 । Siehe die detaillierte Besprechung dieser Thematik anhand der Diskussion in Pełnym głosem bei Darska: Głosy kobiet, S. 23-46.

206 I Siehe auch Walczewska: Damy, rycerze i feministki, S. 11, die ebenfalls auf die Relevanz des "adligen Geschlechtervertrags « hinweist und diesen in ihrem Text eingehend behandelt, sowie Fuszara: Feminizm i my, S. 18, die einen "stillen, ungeschriebenen Vertrag, der die Verwendung scharfer Munition verbat«, für die Literatur des 19. Jahrhunderts feststellt. 
so stark ein, dass ein Bewusstsein für eine Identifizierung über die Kategorie des Geschlechts bis heute keinen Raum finde. ${ }^{207}$ Gleiches gelte für die Integration über den Katholizismus, wie andere Feministinnen konstatierten. Auch dieser stelle das Gemeinschaftswohl - besonders in Fragen zu den Geschlechterrollen - über das individuelle Wohl und lobe die Frau als sich aufopfernde, reine Mutter (Gottes) zwar hoch, sehe sie aber primär in ihrer gesellschaftsreproduzierenden Funktion. ${ }^{208}$

Die Einbindung in das gesamtgesellschaftliche Kollektiv förderte laut Brach-Czaina und Limanowska vor allem in den 1980er Jahren die Opposition der beiden diskursiven Mächte von sozialistischem Regime und katholischer Kirche. ${ }^{209}$ Zwischen diesen hierarchischen und autoritären Systemen habe kein Raum mehr existiert für die Beschäftigung mit anderen Unterteilungen oder überhaupt für individuelle Entscheidungen. Dies, obwohl gerade die antikommunistische Opposition den Mythos des Individualismus durch den Widerstand gegen das System aufrechterhalten habe. ${ }^{210}$

Etwas anders gelagert war die Erklärung, dass das Erbe des sozialistischen Systems ein feministisches Engagement verhindere. Unter Kritik steht hier die Implementierung einer >voreiligen`formellen Emanzipation. Diese habe die traditionell hohe Position der Frauen symbolisch aufrechterhalten. Tatsächliche Diskriminierungen gegenüber Frauen hätten deshalb »ihre Selbstbeurteilung und ihr Ehrgefühl nicht bedroht ${ }^{211}$. Gleichzeitig habe diese Emanzipation >von oben` dazu geführt, dass die Frauen in eine passive, erwartende Haltung gedrängt wurden. Dies räche sich nach 1989 in fehlendem Engagement. ${ }^{212}$

Diese Begründungen wurden teilweise ergänzt durch den Verweis auf die heimliche Machtstellung polnischer Frauen, wovon das »Management-« oder »Hausmatriarchat« (»matriarchat menedżerski« bzw. »domowy«) Ausdruck sei. Polnische Frauen hätten sich in der PRL als "gastronomische Mütter« (»Matka Gastronomiczna ${ }^{213}$ ) in der Dominanzposition der Verwalterin familiärer Mittel

207 | Vgl. Titkow: Kobiety pod presją. Ähnlich argumentiert Środa: Kobieta.

208 | Vgl. Ciechomska: Od matriarchatu, S. 316; Środa: Kobieta, S. 13.

209 । Vgl. Brach-Czaina: Progi, S. 351; Limanowska: Dlaczego w Polsce.

210 I Vgl. Brach-Czaina: Progi, S. 349f. Siehe auch Graff: Feminizm ryzyka, S. 20f. sowie Walczewska: Feminizm, S. 26, die das Bedürfnis nach einem `Massen`feminismus verneint; außerdem in der vorliegenden Arbeit Kapitel 6.2.

211 I Rosner: Czy istnieje, S. 38.

212 I Vgl. Fuszara: Feminizm i my, S. 17f.; Mrozik: Akuszerki transformacji, S. 391; Walczewska: Czy kobietom, S. 248. Siehe dazu auch den von Józef Tischner für das Polen der 1990er Jahre geprägten Begriff des homo sovieticus, der auf die allgemeine passive Prägung des (post) sozialistischen Menschen verweist, vgl. Tischner, Józef: Etyka solidarności oraz Homo sovieticus, Kraków 1992, S. 125. Laut Szacki (Polish Democracy, S. 720) genüge es aber nicht, solche "relics« "among us and within us" festzustellen, da diese vor allem als politische Ausrede und Strategie der Reinwaschung missbraucht werden können.

213 I Graff: Feminizm ryzyka, S. 21. 
und Relationen befunden. ${ }^{214}$ Parallel dazu wird argumentiert, dass polnische Frauen eigentlich stark und selbstständig seien, dies aber nicht öffentlich zur Schau tragen müssten. Diese positive Einschätzung der weiblichen "Stärke« vertraten auch einige Feministinnen. ${ }^{215}$ Anderen Feministinnen galten solche Aussagen von Frauen selbst als weiteres Hindernis feministischen Engagements. Limanowska etwa fragt: "Soll die Stärke der Frauen darin bestehen, die Zähne zusammenzubeißen und Hiebe zu empfangen? «216

Insgesamt lässt sich in der Debatte um den polnischen Feminismus respektive über die Lage der Frauen in Polen feststellen, dass besonders häufig Begründungen im historischen kulturellen Erbe gesucht wurden. Den polnischen Feministinnen der 1990er Jahre galt die fehlende Individualisierung und mangelnde Zuwendung $\mathrm{zu}$ eigenen Bedürfnissen als Hauptgrund des schwachen feministischen Interesses, das unter dem Narrativ des >polnischen Kollektivums` verkümmere. In diesen Versuchen, die Feminismusfeindlichkeit polnischer Frauen im soziohistorischen Rahmen erklär- und instrumentalisierbar zu machen, ging zuweilen der Blick auf den konkreten ökonomischen und politischen Wandel der 1990er Jahre verloren. Katarzyna Rosner kritisierte zudem, dass sich die Bewegung in kleinen Gruppen einschließe und die »demokratischen Strukturen zur Wirkungssteigerung « ${ }^{217}$ nicht auszunutzen wisse - oder nicht ausnutzen wolle. Rosner - selbst eine Feministin - warf der polnischen feministischen Bewegung unter anderem elitäres Selbstgefallen vor.

Auffällig in der Diskussion über den (fehlenden) polnischen Feminismus ist die starke Präsenz spezifischer lokaler Begründungen. Damit verweisen die polnischen Feministinnen darauf, dass das patriarchale System nicht global einheitliche Dimensionen aufweist, sondern sich je nach Gesellschaft und kulturellem `Erbe unterschiedlich ausprägen kann. ${ }^{218}$ Diese Feststellung der polnischen `Differenz in Bezug auf den patriarchalen Kontext und die sweibliche Bewusstheit ‘ mündete jedoch nicht in die Forderung oder Herausbildung seigener feministischer Ansätze, sondern neben der Justierung westlicher feministischer Argumente auf die polnische Situation ${ }^{219}$ primär in die Kritik am bestehenden soziokulturellen Kon-

214 | Vgl. Titkow: Kobiety pod presją, S. 31f.; Walczewska: Damy, rycerze i feministki, S. 164169. Interessanterweise überschneiden sich hier feministische und konservative Narrative, die ebenfalls auf die sunnatürlich dominante Stellung der Frau in der PRL hinweisen.

215 I Vgl. Węgierek, Monika: »Polski feminizm - jest czy go nie ma?«, in: Pełnym głosem 4 (1996), S. 3-6, hier S. 6. Siehe auch Borkowska: Interview; Rosner: Czy istnieje, S. 35.

216 I Limanowska: Pytania, S. 43. Siehe auch Graff: Feminizm ryzyka, S. 19.

217 | Rosner: Czy istnieje, S. 39.

218 | Vgl. Titkow: Kobiety pod presją, S. 35 sowie Ciechomska: Od matriarchatu.

219 | Vgl. Graff: Gender Studies, S. 169, 172. Siehe beispielsweise die Textfragmente und Diskussionen dazu in Spotkania Feministyczne 1994/1995, insbesondere Fuszara: Feminizm i my; Limanowska, Barbara: "Backlash, czyli kontratak«, in: Spotkania feministyczne (1994/1995), S. 34-39. 
text Polens. In gewisser Weise lässt sich hier von einer (versuchten) Anpassung der gesellschaftlichen Gegebenheiten an die sfortschrittliche` Theorie sprechen, anstatt eigene Wege zu entwickeln. ${ }^{220}$

\subsubsection{Feministische Polonistik}

Während feministische Debatten wie die oben skizzierte direkten Bezug auf die soziopolitische Situation und das Problem der >Verbreitung`des Feminismus nahmen, problematisierte die feministische Kritik in der polnischen Literaturwissenschaft, von der in der vorliegenden Arbeit die Rede sein wird, die gesellschaftliche und historische Einbettung weniger. Im Vordergrund stand hier die >Neuheit feministischer Methodik, also die wissenschaftliche Perspektivenverschiebung. Diese wurde aber nicht grundsätzlich vor einem politischen Hintergrund gesehen. Die neue gesellschaftspolitische Lage war selten Thema polonistischer Auseinandersetzung und wurde so implizit normalisiert. Zur direkten Vergangenheit der PRL hingegen nahm die Polonistik in der Regel Distanz; dies geschah beispielsweise über die Feststellung, die sozialistische `Durchpolitisierung` der Gesellschaft habe eine 'weibliche` Literatur verunmöglicht. ${ }^{221}$ Damit reihte sich die feministische Polonistik zusammen mit großen Teilen des feministischen oder Frauenmilieus in den ablehnenden Mainstreamdiskurs der 1990er Jahre gegenüber dem Sozialismus und linker Rhetorik ein. Gleichzeitig definierte der Mainstream den Feminismus als Erbe kommunistischer Ideologie. ${ }^{222}$ Diese paradoxe Situation im Dazwischen, ${ }^{223}$ an der Schnittstelle von diskursiver Ausgrenzung, (Wieder)Einschreibung und (anti)politischer Kritik, diskutiere ich für die feministische Kritik in der Polonistik ausführlicher in Kapitel 6.

Als Schwellenmoment der feministischen Publikationstätigkeit im polonistischen Bereich kann die Sondernummer 4-6 (1993) der literaturwissenschaftlichen

220 I Hier ist mit Matuchniak-Krasuska (Ruch feministyczny, S. 142) der Einwand berechtigt, dass sich gerade die Frauenbewegung und (feministische) Frauenorganisationen aufgrund konkreter sozialer Problemstellungen entwickelt haben und nicht aufgrund einer künstlichen Überstülpung importierter Problemfelder. Diese Tatsache wirkt sich allerdings kaum auf die theoretische Ebene aus. Gerade im akademischen Bereich ist der >Clash von lokalen Herausforderungen und globaler Theorie und die - als vorläufig angenommene - Inkongruenz dieser Bereiche besonders offensichtlich.

221 । Vgl. Borkowska: Emigrantki; Budrowska: Wykluczanie tradycji; Magnone: Die polnischen Gender Studies, S. 369; Paczoska: Na strychu, S. 200f. sowie Kapitel 6.2.1.

222 I Vgl. Graff: Warum Frauen, S. 35f.; Mrozik: Akuszerki transformacji, S. 388, 392; Seiler, Nina: "To Overcome the Hurdles: Locating Feminist Literary Research in 1990s' Poland «, in: Kadın/Woman 2000. Journal for Women's Studies 16/2 (2015), S. 23-43, hier S. $26 \mathrm{ff}$.

223 I Vgl. Seiler, Nina: »Geschlechterfragen an der Schnittstelle. Verortungen feministischer PoIonistik im postsozialistischen Gesellschaftsdiskurs«, in: Femina Politica 24/2 (2015), S. 54-67, hier S. 63f.; dies.: To Overcome, S. 39f. Siehe auch Schlusswort (Kapitel 7). 
Zeitschrift Teksty Drugie unter dem Titel Śmiech feministek (Das Lachen der Feministinnen) gelten. Die Nummer vereinte programmatische westliche Texte wie etwa denjenigen von Hélène Cixous unter dem Titel Śmiech Meduzy (Le Rire de la Méduse) oder ein Interview mit Toril Moi, Feminizm jest polityczny (Feminismus ist politisch), ${ }^{224}$ mit Studien zur polnischen Literatur unter dem Blickwinkel feministischer Kritik. Hier finden sich etwa Texte Maria Janions oder Maria Podraza-Kwiatkowskas, die sich bereits seit Jahren der Kategorie des Geschlechts in der Literatur widmeten. Ebenfalls erschien ein feminismusfreundlicher Beitrag Czesław Miłoszs, der bislang als eher >maskulin` eingestellter Schriftsteller gegolten hatte. ${ }^{225}$ Das Themenheft bildete eine Schnittstelle bisheriger polonistischer Forschung, die sich teilweise bereits der Kategorie des Geschlechts als Analyseachse bedient hatte, und westlicher feministischer Kritik. Anna Nasiłowska betonte im Vorwort, dass die feministische Kritik in Polen nur schwerlich als »westliche Neuheit «226 beschrieben werden könne, da die Debatte um das Geschlecht bereits vor 1989 mit anderen Vorzeichen im Gange gewesen sei.

In der Feminismusnummer der Teksty Drugie von 1993 ergaben sich die Bezüge zwischen lokalen und >globalen`Ansätzen eher durch die Zusammenstellung der Texte als explizit in den einzelnen Beiträgen. Ein deutlicher >dialogisches Konzept wies demgegenüber Spotkania feministyczne von 1994/1995 auf, wo die ‘westlichen Texte jeweils mit Kommentartexten versehen wurden, die sich direkt auf die Übersetzungen bezogen und deren Ansätze in einem neuen Kontext diskutierten. Stärker auf polnische Beiträge fokussierte schließlich das Schwerpunktheft der Teksty Drugie 3-4 (1995) zu Feminizm po polsku (Feminismus auf Polnisch). Auch hier zeigte sich ein unaufgeregter Umgang mit simportierten`Ansätzen, die als ergänzende oder ideengebende Inputs in die Interpretationen des zumeist polnischen Materials (teilweise im europäischen Vergleich) integriert wurden. ${ }^{227}$ Für die Literaturwissenschaft relevant war außerdem Graffs Übersetzung von Virginia Woolfs Własny pokój (A Room of One’s Own [1929]), die 1997 erschien und mit einem Vorwort der feministischen Schriftstellerin Filipiak versehen wurde. ${ }^{228}$

Für die feministische Kritik in der Polonistik wurde Brach-Czainas essayistisch-philosophischer Band Szczeliny istnienia (Spalten im Sein) von 1992 von

224 । Vgl. Cixous, Hélène: „Śmiech Meduzy«, in: Teksty Drugie, Śmiech feministek (1993), S. 147166; dies.: "Le Rire de la Méduse«, in: L’Arc 61 (1975), S. 39-54; Walicka-Hueckel, Małgorzata: »Feminizm jest polityczny. Rozmowa z Toril Moi«, in: Teksty Drugie, Śmiech feministek (1993), S. 97-114.

225 | Vgl. Borkowska, Grażyna: »Komandosi<, hippisi, feministki (I)«, in: Kresy 16 (1993), S. 239241, hier S. 239.

226 । Nasiłowska, Anna: »Drażliwe pytania?«, in: Teksty Drugie, Śmiech feministek (1993), S. 1-6, hier S. 1.

227 | Vgl. Teksty Drugie: »Feminizm po polsku«, 33-34/3-4 (1995).

228 | Vgl. Woolf, Virginia: Własny pokój, Warszawa 1997. 
richtungsweisender Bedeutung. ${ }^{229}$ Im Vordergrund stand hier die Auseinandersetzung mit der den Menschen umgebenden Dingwelt und die existentielle Qualität von Alltagshandlungen, die ein stetes Ringen von Sein und Nicht-Sein, von Ordnung und Chaos sei. Zentral wurde hier der Begriff des krzatactwo als das alltägliche Herumwirtschaften und -hantieren, dem als ephemere Handlung wenig Aufmerksamkeit zugemessen wird, jedoch die existentielle Bedingung des Alltags bildet. ${ }^{230}$ Der Fokus von Szczeliny istnienia auf das allgemein als wenig bedeutsam Betrachtete, auf den Alltag, aber auch auf die Prozesse von Schwangerschaft und Gebären und damit auf eine spezifische Form der Körperlichkeit ${ }^{231}$ widerspiegelte sich in der feministischen Kritik, die diesen Bereichen ebenfalls viel Aufmerksamkeit schenkte. Es war eine Abkehr von der 'großen ‘ Geschichte, eine Hinwendung zur als weiblich konnotierten Alltagswelt.

Ebenfalls als Schlüsseltext kann Nasiłowskas bündiges "Traktat« Domino betrachtet werden, das 1995 den Aspekt von Geburt und Mutter-Kind-Verhältnis aufnahm. Hier ging es auch um ein weibliches Schreiben, das sich selbst einen Weg bahne: »[D]er Text, der zu wuchern begann, erstaunte mich selbst. Nur schwerlich könnte man direkte Analogien in der Literatur finden.« Im Zentrum dieses Schreibens stand somit das, was »so oft von Schweigen und Scham umhüllt ist ${ }^{232}$, für das es keine literarische Form gibt und somit eine neue, intime Art des Schreibens selbst erforderte. Derartige Tendenzen wirkten sich teilweise auf die akademische Schreibtätigkeit aus. In den 1990er Jahren entstanden beispielsweise Dissertationsprojekte, die die wissenschaftliche Forschung mit einer subjektiven, intimen Sichtweise kombinierten und so einen neuen, von persönlichen Erfahrungen geprägten Narrationsstil akademischer Arbeiten herauszuarbeiten suchten. Die meisten dieser Projekte blieben jedoch laut Monika Rudaś-Grodzka in ihrer Entstehungsphase stecken und lägen nun "auf dem Estrich ${ }^{233}$. Allgemein kann aber in der feministischen Kritik von einer subjektiver motivierten Herangehensweise gesprochen werden, wo das eigene Interesse am Thema angesprochen oder die Forschungsperspektive als subjektiv-dezentrale herausgearbeitet wird. ${ }^{234}$

Im Bereich der Literatur sind ebenfalls einige Werke zu verzeichnen, die sich explizit an feministischen Standpunkten orientierten. Besonders kontrovers diskutiert wurde etwa Filipiaks Absolutna amnezja (Absolute Amnesie) von 1995. Der Roman kann als eine Abrechnung mit dem Aufopferungsmythos der polnischen

229 | Brach-Czaina, Jolanta: Szczeliny istnienia, Warszawa 1992. Siehe auch Szczuka: Czy feministki, S. 40, die diese Publikation ein »Kultbuch« nannte.

230 । Vgl. Brach-Czaina: Szczeliny, S. 103.

231 | Vgl. ebd., S. 26-71.

232 I Nasiłowska, Anna: Domino. Traktat o narodzinach, Warszawa 1995, o. S. [47].

233 I Rudaś-Grodzka im Kolloquium des Zespół Literatura i gender des IBL PAN, 14.01.2016. Siehe auch Iwasiów: Interview.

234 | Vgl. Iwasiów: Kresy, S. 21ff.; Kraskowska: Piórem niewieścim, S. 7. 
Gesellschaft gelesen werden, wobei gerade die Frau (im Roman u.a. das Mädchen Marianna) im Geflecht repressiver Sozialisierungsversuche unterzugehen droht. Ebenfalls 1995 erschien Olga Tokarczuks zweiter Roman E.E., in dem - wie bei Absolutna amnezja - das Einsetzen der Menstruation eine zentrale Rolle in der Entwicklung der Hauptfigur, ebenfalls ein heranwachsendes Mädchen, spielte. Tokarczuks dritter und damals erfolgreichster Roman Prawiek i inne czasy (Ur und andere Zeiten, 1996) verflocht die Generationen des Weilers Prawiek (Urzeit) in einer mythisch-zirkulären Zeitlichkeit, wobei wiederum Frauen das verbindende Element des Romans und seiner archetypischen Szenen darstellten. Auch die spätere Gründerin der Partia Kobiet (Frauenpartei, gegr. 2007) Manuela Gretkowska publizierte zu Beginn der 1990er Jahre Romane aus einer weiblichen, feministischen Sichtweise, gleiches gilt für Natasza Goerke oder Zyta Rudzka. ${ }^{235}$ Diese literarischen Werke bildeten einen Beitrag zur feministischen Diskussion in den 1990er Jahren und wurden sowohl in der Tagespresse wie auch im Bereich literaturwissenschaftlicher Auseinandersetzung diskutiert, was insbesondere auf Filipiaks Roman zutraf, der mit seiner "Menstruationspolizei ${ }^{236}$ ein strittiges Bild der zeitgenössischen polnischen Gesellschaft und ihrer Geschlechterordnung zeichnete.

Die feministische Literaturkritikerin und Schriftstellerin Kinga Dunin, die als eine der Schlüsselfiguren der feministischen Kritik zwischen Literaturwissenschaft und Gesellschaft gelten kann, veröffentlichte 1996 die Essaysammlung Tao gospodyni domowej (Hausfrauen-Tao). In deren Einleitung schreibt Dunin, das Buch sei ein »Logbuch, die Aufzeichnung meiner eigenen, fortwährenden Reise nach Ihrland [Jejlandia]. [...] Wenn das Feminismus ist, dann mein eigener, für den ich die volle Verantwortung übernehme. «"237 In ihren Texten geht Dunin kritisch auf die postsozialistische polnische Gesellschaft und deren neue Medien ein. Dabei verweist sie beispielsweise darauf, wie weibliche Homosexualität zwar in einer liberalen Medienlandschaft thematisiert werde, gleichzeitig aber stereotypen Normierungen unterliege. ${ }^{238}$ So kann Dunin aufzeigen, wie auch eine selbstdeklariert >offene`Gesellschaft Machtstrukturen reproduziert.

Neben diesen feministischen Neuerscheinungen ist die Beschäftigung mit historischer weiblicher (feministischer) Literatur im Rahmen der Literaturgeschichte zu erwähnen. Die feministische Kritik widmete sich - neben der Neulektüre von Werken bekannter Autorinnen und Autoren - >verschütteten`Schriftstellerinnen, deren literarisches Talent und gesellschaftlicher Scharfblick neu bewertet wurde. In diesen Prozessen der Aufarbeitung ist auch eine Form des Ideentransfers entlang einer diachronen Achse zu beobachten. Die Polonistinnen und Polonisten

235 I Vgl. Borkowska: Cudzoziemki, S. 255f.; Dunin: Tao, S. 63ff.; Magnone: Die polnischen Gender Studies, S. 371; Mrozik: Akuszerki transformacji, S. 41, 380ff.

236 | Vgl. Janion: Kobiety, S. 339-342; Magnone: Die polnischen Gender Studies, S. 370.

237 | Dunin: Tao, S. 10.

238 | Vgl. ebd., S. 23-34. 
diskutierten die sozialkritischen Ansätze historischer Schriftstellerinnen und prüften diese auf ihre Anwendbarkeit auf zeitgenössische Problemstellungen. Als Versuch einer (Re-)Integration emanzipatorischer Literatur in den polnischen Literaturkanon kann Aneta Górnicka-Boratyńskas Anthologie Chcemy całego życia (Wir wollen das ganze Leben) von 1999 gelten, die Schlüsseltexte bekannter wie auch vergessener polnischer Schriftstellerinnen der Vor- und Zwischenkriegszeit versammelte. ${ }^{239}$

Insgesamt war in der feministisch ausgerichteten Polonistik eine Hinwendung $\mathrm{zu}$ Werken von Schriftstellerinnen zu beobachten. Diese Stoßrichtung, die die Neubewertung weiblichen Schreibens und dessen Integration in einen erweiterten literarischen Kanon und in ein literaturhistorisches Bewusstsein im Allgemeinen umfasste, wurde in Polen als 'gynokritische bezeichnet und wies Verbindungen zur Ausrichtung der Women's Studies auf. Eine weitere, jedoch verhältnismäßig bescheidenere Strömung bildete die rrevindikative` Forschung, die Werke des literarischen Kanons (oder auch außerhalb davon) unabhängig vom Geschlecht ihres Autors neu las und dabei den Fokus auf die Geschlechterverhältnisse und deren sprachliche Abbildung im Text lenkte. Dieses Vorgehen wies eher in die methodische Richtung der Gender Studies. ${ }^{240}$ Die Auseinandersetzung mit dem literarischen Kanon, dessen Revision und Pluralisierung bildete dabei für beide Stoßrichtungen einen zentralen Ansatzpunkt. ${ }^{241}$

Das konzeptuelle Überwiegen einer 'gynokritischen` Ausrichtung der feministischen Kritik und die Auseinandersetzung primär mit der Weiblichkeit führten zu gewissen Ausschlussmechanismen. Halina Filipowicz machte bereits 1993 darauf aufmerksam, dass die Beschäftigung mit der Weiblichkeit kein prinzipiell feministisches Projekt sei: »Man muss keine Feministin sein, um im Einklang

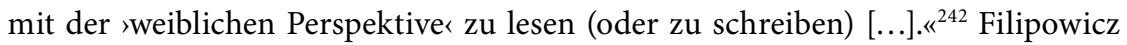
warnte vor den Fallen eines biologischen Essentialismus « $^{243}$ und der Tendenz, die Weiblichkeit als metaphysische Größe zu verstehen, während (lokale) soziokulturelle und historische Verwicklungen der Geschlechterrollen aus dem Blick gerieten. Sie stellte die für den polnischen Geschlechterdiskurs der 1990er Jahre kritischen Fragen:

"Überschreitet der polnische feministische Diskurs den Bannkreis der Weiblichkeit, in dem sich Frauen-Forscherinnen mit dem Schaffen von Frauen-Schriftstellerinnen befassen? Findet sich

239 | Vgl. Górnicka-Boratyńska, Aneta: Chcemy całego życia. Antologia polskich tekstów feministycznych z lat 1870-1939, Warszawa 1999.

240 I Siehe dazu Chołuj, Bożena: »Różnica między women's studies i gender studies«, in: Katedra 1 (2001), S. 26-33, hier S. 28, 30; Magnone: Die polnischen Gender Studies, S. 379; Majbroda: Feministyczna krytyka, S. 139-158.

241 I Vgl. Magnone: Die polnischen Gender Studies, S. 372; Ritz: Kanon i historia literatury, S. 30.

242 I Filipowicz: Przeciw literaturze kobiecej<, S. 246.

243 | Ebd., S. 248. 
Raum für Forschungen, die die gesamte polnische Literatur und ihre Rezeption aus einer feministischen Perspektive der kritischen Betrachtung unterziehen? ${ }^{244}$

Wie ich in der vorliegenden Arbeit feststelle, ist der Fokus auf die Weiblichkeit in den Monographien der feministischen Polonistik überdeutlich und dreht sich hier vor allem um die Frage nach `weiblichem Schreiben` und einer weiblichen (literarischen) Tradierung (siehe Kapitel 5). ${ }^{245}$

Zeugnis einer solchen Priorisierung der Weiblichkeit ist etwa die Marginalisierung der Ansätze Paweł Dybels im Kontext des literaturwissenschaftlichen Geschlechterdiskurses. Dybel hatte bereits 1988 in Ziemscy, słowni, cieleśni (Irdische, Wörtliche, Leibliche) das Forschungsinteresse auf die Körperlichkeit in der Literatur gelenkt und veröffentlichte 1995 mit Dialog i represja (Dialog und Repression) eine Arbeit zu Freud und der psychoanalytischen Hermeneutik, wo er auch auf Themen wie Eros oder den "Schatten des Vaters" einging. Überhaupt beschäftigte sich Dybel an der Schnittstelle von Kulturphilosophie und Literaturwissenschaft eingehend mit psychonanalytischen Ansätzen und deren Rezeption in Polen. Mit Zagadka »drugiej płci«. Spory wokół różnicy seksualnej w psychoanalizie i w feminizmie (Das Rätsel des »zweiten Geschlechts«. Streitigkeiten um die sexuelle Differenz in Psychoanalyse und Feminismus) positionierte er sich 2012 noch deutlicher im Kontext des Geschlechterdiskurses. ${ }^{246}$

Die stark auf die Weiblichkeit fokussierende Perspektive der polonistischen feministischen Kritik wurde ab Mitte/Ende der 1990er Jahre mit den Ansätzen German Ritz' aufgebrochen, der die Aufmerksamkeit der geschlechtsempfindlichen Lektüre auf das homosexuelle Begehren im Text lenkte und das männliche Geschlecht ebenso wie die Sexualität und deren kulturelle Rahmungen wieder stärker in die polonistische Geschlechterdebatte einbrachte (siehe Kapitel 4.3.3). Die 2000er Jahre wurden zum Ausgangspunkt einer zunehmend breiteren Auseinandersetzung mit den Geschlechtern im literarischen und sozialen Diskurs. Gleichzeitig bildeten die Jahre 2000 und 2001 Anlass zu einer Rekapitulation und zeichneten sich durch eine Häufung geschlechterthematisierter Publikationen aus; darunter fallen etwa die Konferenzbände Krytyka feministyczna. Siostra teorii $i$ historii literatury (Feministische Kritik. Schwester der Literaturtheorie und -geschichte, 2000) oder Polskie oblicza feminizmu (Polnische Antlitze des Feminismus, 2000) und die enzyklopädische Publikation Pisarki polskie od średniowiecza do współczesności (Polnische Schriftstellerinnen vom Mittelalter bis zur Gegenwart, 2000), die Anthologie zum 50. Geburtstag Ritz’ unter dem Titel Ciało,

244 | Ebd., S. 256.

245 I Vgl. auch Magnone: Die polnischen Gender Studies.

246 | Vgl. Dybel, Paweł: Ziemscy, słowni, cieleśni. Eseje i szkice, Warszawa 1988; ders.: Dialog i represja. Antynomie psychoanalizy Zygmunta Freuda, Warszawa 1995; ders.: Freuda sen o kulturze, Warszawa 1996; ders.: Urwane ścieżki. Przybyszewski - Freud - Lacan, Kraków 2000; ders.: Zagadka »drugiej płci«. Spory wokół różnicy seksualnej w psychoanalizie i w feminizmie, Kraków 2012. 
płeć, literatura (Körper, Geschlecht, Literatur, 2001) oder der Sammelband Nowa świadomość płci w modernizmie (Neues Geschlechterbewusstsein in der Moderne, 2000) sowie die essayistischen Veröffentlichungen Świat bez kobiet (Welt ohne Frauen, 2001) von Graff und Kopciuszek, Frankenstein i inne (Aschenbrödel, Frankenstein und andere, 2001) von Szczuka, oder letztlich Bators Auseinandersetzung mit globalen Theorieströmungen unter dem Titel Feminizm, postmodernizm, psychoanaliza. Filozoficzne dylematy feministek >drugiej fali (Feminismus, Postmoderne, Psychoanalyse. Philosophische Dilemmas der Feministinnen der ‘zweiten Welle`, 2001). ${ }^{247}$

247 | Vgl. Borkowska, Grażyna/Sikorska, Liliana (Hg.), Krytyka feministyczna. Siostra teorii i historii literatury, Warszawa 2000; Chańska, Weronika/Ulicka, Danuta (Hg.), Polskie oblicza feminizmu. Materiały z konferencji »Polskie oblicza feminizmu«, Uniwersytet Warszawski 8 marca 1999 roku, Warszawa 2000; Borkowska, Grażyna et al. (Hg.), Pisarki polskie od średniowiecza do współczesności. Przewodnik, Gdańsk 2000; Hornung, Magdalena et al. (Hg.), Ciało, płeć, literatura. Prace ofiarowane profesorowi Germanowi Ritzowi w pięćdziesiątą rocznicę urodzin, Warszawa 2001; Ritz, German et al. (Hg.), Nowa świadomość płci w modernizmie. Studia spod znaku gender w kulturze polskiej i rosyjskiej u schyłku stulecia, Kraków 2000; Graff: Świat bez kobiet; Szczuka, Kazimiera: Kopciuszek, Frankenstein i inne. Feminizm wobec mitu, Kraków 2001; Bator, Joanna: Feminizm, postmodernizm, psychoanaliza. Filozoficzne dylematy feministek >drugiej fali<, Gdańsk 2001. 



\section{Maria Janion - Wege zur feministischen Kritik}

Maria Janion $\left({ }^{\star} 1926\right)$ gilt mit ihrer literaturwissenschaftlichen Forschung als Wegbereiterin der feministischen Kritik in Polen. Bereits ab den 1970er Jahren machte sie die Kategorie des Geschlechts zu einem ihrer analytischen Ansätze. Sie stellte entlang dieser Achse normative Disziplinierungsmechanismen fest, die sich auch in kulturellen Texten äußerten. Das Interesse Janions am Geschlecht lässt sich anhand ihres Schaffens zurückverfolgen und an verschiedenen Faktoren festmachen. Das Forschungsgebiet der Romantik spielt dabei eine zentrale Rolle. Die polnische Romantik kann in Bezug auf die symbolische Geschlechterordnung und deren phantasmatischen Zuschreibungen als diskursformend gelten. Gleichzeitig hegten die romantischen Schriftsteller eine große Faszination für das Überschreiten dieser Rollenmuster. Aus diesem Motiv der Transgression entwickelte Janion ihre Forschungsperspektive auf Phänomene, die im sozionormativen Diskurs als (psycho)pathologisch disqualifiziert werden. In den Zuschreibungen von Wahnsinn in der und anhand von Literatur spielt das Geschlecht, wie Janion feststellt, eine tragende Rolle. Mit der Untersuchung des Phantasmas - eines begehrten Imaginären - in den Prozessen von Normüberschreitung und sozialer Disziplinierung nimmt die Forschung Janions auch psychoanalytische Perspektiven auf.

$\mathrm{Zu}$ vermerken ist außerdem, dass Janion in ihrer Forschung konsequent auch marxistische Perspektiven miteinbezog, ohne einer institutionellen Doktrin zu verfallen. Das sozialreformerische Moment zeigt sich darin, dass Janion Hierarchisierungsmechanismen im literarischen Diskurs in ihrer Wechselwirkung mit sozialen Realitäten und politischen Narrativen sah und ihre eigene Arbeit als politischen Beitrag verstand. Dies schlug sich in den Ermächtigungsprozessen ihrer Studierenden nieder, die Janion als gleichgestellte Diskussionspartner in ihre Überlegungen miteinbezog und so die Entwicklung kritischer Wissenschaft entscheidend förderte. 
Ein Aspekt, der ohne Zweifel ebenfalls zum Interesse der Forscherin für geschlechtliche Ungleichheiten beitrug, ist ihre Homosexualität. ${ }^{1}$ Obwohl diese sich im Schaffen Janions nicht offenbart, führte sie wohl doch zu einem offeneren $\mathrm{Zu}$ gang gegenüber gesellschaftlich tabuisierten Themen und prägte somit Janions Forschungsausrichtung mit. Dennoch lässt sich Janions Forschung nicht auf die Kategorie des Geschlechts oder der Sexualität reduzieren, da sie diese stets als einen Faktor unter anderen betrachtete. So sympathisiert Janion zwar mit der feministischen Kritik, lässt sich aber letztlich auch in ihrer Artikelsammlung Kobiety $i$ duch inności von 1996, die der vorliegenden Arbeit als Untersuchungsmaterial dient, nicht allein auf diese Perspektive reduzieren.

\subsection{Romantik, Phantasma, Transgression}

Janions Forschungsinteresse am Geschlechterdiskurs scheint in direktem Zusammenhang mit ihrem primären Forschungsfeld der Romantik zu stehen. Der romantische Diskurs verstärkte die Differenzierung der Geschlechterrollen und ordnete vielen seiner Schlüsselwörter eine vergeschlechtlichte Dimension zu, wie Janion herausarbeitet. Prominentestes Beispiel ist die geschlechtliche Konnotierung der Sphären von Natur und Kultur: das Weibliche wird mit der Natur und einer mythischen Urzeit in Verbindung gebracht, während das Männliche der Kultur und einer historischen, linearen Zeit zugeschrieben wird. ${ }^{2}$

Obwohl die Geschlechterbilder so eine Dichotomisierung erfuhren, wurde diese in der Romantik nicht nur festgeschrieben, sondern auch verwischt, wie Janion aufzeigt. Die Naturbegeisterung und eine Faszination für das Mythische, Vorzeitliche und Außernatürliche bildeten wichtige Formeln der von männlichen Dichtern geprägten Romantik. ${ }^{3}$ Dabei fanden phantasmatische Konstruktionen des >Anderen statt, das in einer der rationalen Zivilisation binär entgegengesetzten >weiblichen`Sphäre des Imaginären (Phantasmatischen), Unergründlichen angesiedelt wurde. ${ }^{4}$ Der Begriff des Phantasmas spielt in Janions Forschung eine zentrale Rolle. Das Phantasma als imaginative Erzeugung einer ‘zweiten` Realität

1 I Vgl. Janion, Maria/Szczuka, Kazimiera: Janion. Rozmawia Kazimiera Szczuka. Transe, traumy, transgresje. Tom 1. Niedobre dziecię (= Seria z Różą), Warszawa 2012, S. 130, wo Szczuka implizit auf diese Thematik hinweist.

2 I Vgl. Janion, Maria: Romantyzm, rewolucja, marksizm. Colloquia gdańskie, Gdańsk 1972, S. 245 sowie Barthes, Roland: »Ultra-płeć«, in: Janion/Rosiek, Maski I (1986), S. 139-141 zu Michelets Geschlechterdifferenzierungen.

3 I Vgl. Janion: Romantyzm, S. 250; Janion, Maria: Projekt krytyki fantazmatycznej. Szkice o egzystencjach ludzi i duchów, Warszawa 1991, S. 8; Wierzbicki: Wschód-Zachód, S. 93.

4 । Vgl. Janion: Projekt krytyki fantazmatycznej, S. 10. 
im Bereich der Vorstellung ist gleichsam an der Grenze von `Norm(alität)< und (geistiger) >Pathologie`sowie zwischen Sein und Nicht-Sein angesiedelt. ${ }^{5}$

»[D]ie Romantiker sind überzeugt von der Existenz einer anderen, transzendenten Realität, die durch die sichtbare, sinnliche Realität durchscheint. Die sichtbare Welt behandeln sie als Ausdruck der unsichtbaren Welt « ${ }^{6}$, hält Janion fest. Die Grenze der wahrnehmbaren Welt wurde damit zu einem Ort der Transgression, an dem sich der literarische Diskurs der Romantik entzündete. Janion spricht gar von einer "romantischen Revolution der Vorstellungskraft «" die Grenzen und Dichotomien konstruierte und gleichzeitig überwand. Phantasma und Transgression bilden damit die zwei Angelpunkte von Janions Forschung, die sie aus dem romantischen Material heraus entwickelte.

Das symbolische Weibliche als phantasmatische Konstruktion nahm in der polnischen Romantik die spezifische Funktion des begehrten Anderen ein. Dies mündete etwa bei Nationaldichter Adam Mickiewicz in einen spezifischen Kult des Weiblichen, wie Janion herausarbeitete. Die abstrakte Idee eines essentiellen Weiblichen war dabei aber nicht an konkrete weibliche Personen gebunden, sondern als ein Set bestimmter Eigenschaften wie Instinkthaftigkeit oder Gefühlsbetontheit konstruiert. ${ }^{8}$ Dies ermöglichte der männlich geprägten Romantik in ihrem Schaffen eine diskursive Teilhabe am Weiblichen.

Die Romantik - und mit ihr Janion selbst ${ }^{9}$ - hegte eine Faszination für das Un-Heimliche, das als Bedrohung der rationalen Zivilisation stets diskursiv ausgegrenzt werden musste, aber als verlockende Transgression just jenseits der normativen Rahmungen lauerte. ${ }^{10}$ Dabei gerieten das Individuum und die Introspektion mentaler Landschaften in den Blick der Romantik. ${ }^{11}$ Janion ließ sich von diesen in der Literatur angelegten Tendenzen epistemologisch leiten und gelangte Anfang der 1970er Jahre zum einzelnen Subjekt in seinem soziohistorischen Kontext und zur Untersuchung psychologischer Prozesse etwa des Begehrens. ${ }^{12}$ Wenn Janion schreibt, dass die gotische Schauerliteratur, die das romantische literarische Inventar entscheidend mitgeprägt habe, die emotionale Ambivalenz von Liebe und Hass gegenüber ein und demselben Objekt »noch vor Freud aufgespürt

5। Vgl. ebd., S. 5, 7.

6 I Janion: Romantyzm, S. 332: »romantycy są przekonani 0 istnieniu jakiejś innej, transcendentnej rzeczywistości, prześwitującej przez rzeczywistość widzialną, zmysłową, świat widzialny traktują jako przejaw świata niewidzialnego«.

7 । Janion: Projekt krytyki fantazmatycznej, S. 8: „wyobraźniowa rewolucja romantyczna«.

8 I Vgl. Janion, Maria: „Zbroje Grażyny«, in: Janion/Rosiek, Maski I (1986), S. 148-159, hier S. 153.

9 । Vgl. Szczuka: Czy feministki, S. 43.

10 | Vgl. hier Kristevas Beschreibung ähnlicher Phänomene durch den Begriff des abjects. Kristeva, Julia: Pouvoirs de l'horreur. Essai sur l'abjection, Paris 1980, bes. S. 9-14.

11 I Vgl. Janion: Romantyzm, S. 250. Hier ist die Rede von einem transeuropäischen Romantizismus.

12 । Vgl. ebd., S. 373-377. 
hatte $«^{13}$, verweist sie auf derartige Forschungsinspirationen durch die Literatur (siehe Kapitel 4.2).

Das in romantische Texte eingeflochtene Un-Heimliche verknüpfte sich mit einer Ablehnung der modernen Zivilisation und diente der diskursiven Sprengung gesellschaftlicher Normen. »Die Romantiker lehnten sich im Namen der Freiheit gegen jegliche Gefangenschaft auf. Die Gefangenschaft der bürgerlichen Familie und des Staates erschien einigen von ihnen (besonders den französischen) als etwas schon außerordentlich Abscheuliches. ${ }^{14}$ Die romantische Auflehnung gegen die Zwänge der Gesellschaft und gegen soziale Normierungs- und Disziplinierungsprozesse mündete in die Thematik von Revolution und Aufstand. Ein weiterer Knotenpunkt der Romantikforschung Janions bildete deshalb die Ergründung der Zusammenhänge zwischen Freiheitsrhetoriken, Normtransgression und Geschlecht. Besondere Aufmerksamkeit widmete Janion neben literarischen und historischen Revolutionärinnen auch den weiblichen Allegorien von Revolution und Aufstand, etwa La Liberté oder für den polnischen Kontext die Polonia als Figur des wiedererstehenden Polens. ${ }^{15}$ Nach Janion bedrohten die revolutionären Frauenfiguren nicht nur das herrschende Gesellschaftssystem, sondern mehr noch das moralische Wertesystem und die Geschlechterordnung. Die revolutionäre Frau übernahm in einem transgressiven Prozess Attribute der Männlichkeit und gefährdete so die Dichotomie der Geschlechter. ${ }^{16}$ Die Transgression der Geschlechterrollen vom Weiblichen zum Männlichen wurde in der Romantik deshalb stärker durch soziale Sanktionen verbüßt. ${ }^{17}$

Dieser Thematik nimmt sich Janion auch in der Bandreihe der Transgresje (Transgressionen) an, wo sie die Konzepte von Phantasma und Transgression an einer kulturhistorisch wie medial breiteren Materialbasis ausfeilt. Die TransgresjeReihe ist Zeugnis und Mitschnitt aus den gleichnamigen Seminaren, die Janion in den 1970er Jahren in Danzig mit großem Erfolg durchführte. Die Bände, die 1981-1988 erschienen, vereinen in den Seminaren vorgestelltes literarisches Material, Diskussionsmitschriften, Kommentare und einzelne Studien. ${ }^{18}$ Gleichzeitig

13 I Ebd., S. 387: »Gotycyzm przeczuł to przed Freudem«.

14 । Ebd., S. 248: »Romantycy w imię wolności podnieśli bunt przeciw wszelkiej niewoli - niewola burżuazyjnej rodziny i państwa wydawała się niektórym z nich (zwłaszcza francuskim) czymś wyjątkowo już odrażającym."

15 । Vgl. Janion: Kobiety, S. 5-77; Janion: Polonia powielona.

16 I Vgl. Janion: Kobiety, S. 21.

17 I Im Falle der Sanktionierung von Frauen handelte es sich hierbei oft um eine Pathologisierung des Verstandes, weshalb unbequeme Frauenfiguren meist des Wahnsinns beschuldigt und in entsprechenden Anstalten sneutralisiert‘ wurden. Vgl. ebd., S. 31ff., 198; auch Wisłobocki, Tomasz: Obywatelki. Kobiety w przestrzeni publicznej we Francji przełomu wieków XVIII i XIX, Kraków 2014, S. 266f.; sowie 3.1.2.

18 I Vgl. Janion, Maria/Rosiek, Stanisław (Hg.), Galernicy wrażliwości (= Transgresje, Band 1), Gdańsk 1981; Janion, Maria/Majchrowski, Zbigniew (Hg.), Odmieńcy (= Transgresje, Band 2), Gdańsk 1982; 
vermögen die Transgresje-Bände Atmosphäre und Themenvielfalt der Seminare Janions nur ansatzweise zu vermitteln. ${ }^{19}$ Die im Folgenden vorgestellten Aspekte müssen als herausgegriffene Beispiele verstanden werden, die nur einen kleinen Einblick in das breite Schaffen und Lehren Janions geben können.

Gemäß den Publikationen kreisten die Diskussionen in den Seminaren um Prozesse der gesellschaftlichen Normierung und der Überschreitung solcher Normen, was wiederum die diskursive Pathologisierung nicht-normativen Verhaltens und Denkens/Schreibens hervorrufe. Deutlich erkennbar ist in den TransgresjeBänden die Präsenz antipsychiatrischer Ansätze, die diese Mechanismen der Pathologisierung kritisch beleuchten und den repressiven Diskurs gesellschaftlicher Normen wie auch der medizinisch-psychiatrischen Versuche einer >Renormalisierung in ihren Analysen dekonstruieren. ${ }^{20}$ Zentral in Janions Ansätzen ist weniger die Frage nach tatsächlichen psychischen Verwirrungen als diejenige nach der diskursiven Macht, die solche Zuschreibungen wirkmächtig installieren kann. Der Fokus liegt dabei primär auf dem Individuum im Kontext des kulturell-gesellschaftlichen Diskurses. Mit einer solchen Ausrichtung ihrer Seminare und Forschungsinteressen, wie sie sich in der Transgresje-Reihe zeigt, positionierte sich Janion auch (wissenschafts)politisch (siehe 3.2).

Die Transgression des 'gesunden Menschenverstands` weist in den von Janion untersuchten kulturellen Texten oft eine vergeschlechtlichte Dimension auf. Die Polonistin vermerkt, dass nicht-konforme Verhaltensweisen weiblicher Akteurinnen besonders häufig pathologisiert werden. Damit werde nicht-normatives Verhalten `biologisiert und aus der >normalen Lebenswelt ausgegrenzt, letzteres oft mithilfe physischer Isolation der betroffenen Personen. Janion zeigte dies etwa an den Beispielen der französischen Revolutionärin Théroigne de Méricourt (17621817) ${ }^{21}$ und der/des polnischen Schriftstellerin/Schriftstellers Maria Komornicka/

Janion, Maria/Rosiek, Stanisław (Hg.), Osoby (= Transgresje, Band 3), Gdańsk 1984; dies. (Hg.), Maski. Tom I i II (= Transgresje, Band 4), Gdańsk 1986; Janion, Maria/Chwin, Stefan (Hg.), Dzieci (= Transgresje, Band 5), Gdańsk 1988.

19 I Das Projekt Archiwum Marii Janion (janion.pl) des IBL PAN und des Digitalen Laboratoriums der Geisteswissenschaften der Universität Warschau (Laboratorium Cyfrowe Humanistyki Uniwersytetu Warszawskiego, LaCH UW), das zu Janions 90. Geburtstag im Dezember 2016 online ging, verspricht hier interessante neue Akzente. Auf der Website finden sich etwa digitalisierte Tonaufnahmen von Janions Seminaren, wobei jedoch die Transgresje-Seminare leider (noch) nicht vertreten sind.

20 I Der antipsychiatrische Ansatz, der vor allem in englischsprachigen Gebieten entwickelt wurde, kann als diametral und kritisch eingestellt zur Medikalisierung und Chirurgisierung der bis in die 1960er Jahre nicht nur in westlichen Gesellschaften populären, sondern auch in Polen und den kommunistischen Staaten alleinig akzeptierten medizinischen Psychiatrie verstanden werden. Siehe dazu auch Kapitel 4.2.

21 I Théroigne de Méricourt agierte in der Französischen Revolution als eine der feministischen Wortführerinnen. Aufgrund einer öffentlichen Auspeitschung verlor sie - angeblich - den Ver- 
Piotr »Odmieniec« Włast (1876-1949) auf, wobei ich auf letzteren Fall noch eingehen werde (siehe 3.3). Neben historischen Figuren ließ Janion auch literarische Texte in Bezug auf das Verhältnis von Geschlecht und Wahnsinn diskutieren.

\subsubsection{Aufopferung und Emanzipation}

In der polnischen Romantik erkennt Janion eine bestimmte Spezifik, die mit der fehlenden staatlichen Souveränität zusammenhängt. Das Element des Aufständischen bezog sich im polnischen romantischen Diskurs nicht auf die Umstürzung sozialer Hierarchien, sondern auf das Abwerfen fremder Herrschaft. »Unsere Romantik hat Polen. [D]arauf gerade konzentriert sich die Utopie der polnischen Romantik. «22 Polen als utopisches Projekt und phantasmatische Vergangenheit zieht sich als roter Faden durch die Werke der polnischen Romantiker. Das Geschlecht bestimmte die Rollen im Projekt der nationalen Resurrektion.

Im Zusammenhang damit konzeptualisierte Janion 1974 eine antinomische Werteordnung, ein »System der polnischen Literatur « ${ }^{23}$, welches sich ihr zufolge insbesondere nach dem gescheiterten Aufstand von 1848 bemerkbar machte. Diese Antinomie

"[b]etrifft das Individuelle und Private sowie das Gesellschaftliche und Kollektive. Das höchste Recht wird ausschließlich dieser zweiten Seite zugestanden. [...] Die Einweihung in die Kollektivität zwingt dazu, mit dem bisherigen, als unwürdig angesehenen Privatleben zu brechen, besonders mit dem Liebesleben. Nun widmet sich der polnische Held restlos seiner patriotisch-gesellschaftlichen Mission. ${ }^{24}$

Dieses literarische System bewirkte also eine Verdrängung des privaten, intimen Lebens - und damit auch der intimen Beziehungen zwischen den Geschlechtern - zugunsten der Aufopferung des Lebens für die gemeinsame Sache: die polnische Souveränität. Es handelte sich um ein Zurückstoßen der »wahnsinnigen Liebe, die gemeinhin auch >echt romantische genannt wird « ${ }^{25}$, und des Familienglücks, um

stand und verbrachte die restlichen 23 Jahre ihres Lebens in einer Anstalt, vgl. Janion: Kobiety, S. 31-34.

22 I Janion: Romantyzm, S. 278: »Nasz romantyzm ma Polskę. [...] w niej właśnie skupia się utopia polskiego romantyzmu."

23 I Janion, Maria: »Tam gdzie rojsty«, in: Twórczość 4 (1983), S. 93-110, hier S. 106: "system literatury polskiej«.

24 । Ebd.: »Dotyczy ona tego, co indywidualne, prywatne, i tego, co społeczne, zbiorowe. Wszystkie najwyższe racje zostają przyznane wyłącznie owej drugiej stronie. [...] Wtajemniczenie w zbiorowość zmusza do zerwania z dawnym, uznanym za niegodne życiem prywatnym, najczęściej miłosnym. Teraz bohater polski poświęca się bez reszty swej misji patriotyczno-społecznej.« 25 I Janion, Maria: »Postscriptum: reprywatyzacja życia prywatnego«, in: dies., Tragizm, historia, prywatność. Prace wybrane. Tom 2 (= Klasycy Współczesnej Polskiej Myśli Humanistycznej), 
sich dem Ungemach des Widerstandskampfes zu unterziehen. Die Unterordnung unter das patriotische Kollektiv machte aus dem (männlichen) polnischen romantischen Helden somit per definitionem einen gemarterten Helden; »ein Verfemter, Gebrandmarkter; die Romantik ergötzte sich an solchen Figuren. $\aleph^{26}$

Mit dem deutlichen Konflikt zwischen Privatleben und patriotischer Hingabe war auch die Geschlechterfrage verknüpft. So war es das Weibliche, das den romantischen Helden zur Befriedigung persönlicher Bedürfnisse verlockte. Das Weibliche galt deshalb als Gefährdung der patriotischen Sendung; so zumindest legt Inga Iwasiów diese antithetische Werteordnung zu Beginn der 1990er Jahre aus. ${ }^{27}$ Doch die Hierarchisierung von persönlicher und kollektiv-patriotischer Ebene war auch für die Frauen bindend. So schrieb der romantische Diskurs den polnischen Frauen spezifische Eigenschaften zu, die der Erhaltung der Kulturnation $^{28}$ und der Wiedererlangung staatlicher Souveränität dienen sollen. In diesem Zusammenhang entstand auch die weibliche Idealfigur der Matka Polka. ${ }^{29}$

Während die Figur der Matka Polka eng an die Idee der nationalen Befreiung geknüpft war, offenbarte sich hier auch eine gewisse Liberalität gegenüber dichotomen Geschlechterrollen. »Die polnischen Frauen fühlten sich mehr als Staatsbürgerinnen ${ }^{30}$, schreibt Janion und impliziert damit ein im europäischen Vergleich größeres Engagement polnischer Frauen an gesamtgesellschaftlichen Dynamiken. Den Polinnen kam eine relativ aktive und auch in die öffentliche Sphäre übertretende Rolle zu. Diese öffentliche Sichtbarkeit und Selbstständigkeit polnischer Frauen wurde der nationalen Idee untergeordnet und führte zum Diskurs einer spezifisch polnischen Emanzipation. Janion zieht Nationaldichter Mickiewicz herbei: »Mickiewicz sieht den Platz der Frau vor allem im familiär-patriarchalen System. Aber doch findet auch bei ihm - dem Geist der Epoche folgend, der [...] von Frauenrechten spricht - die Emanzipation Erwähnung. ॥ $^{31}$ Mickiewicz verurteilte eine von Frauen aktiv formulierte Forderung nach gleichen Rechten, da ihm dies als zu unsittlich erschien und der idealen weiblichen Bescheidenheit zuwiderlaufe. »Der Weg durch das Opfer, durch den Dienst, durch die Hingabe ist für

Kraków 2000, S. 446-448, hier S. 448: „Szalonej miłości, zwanej i potocznie sprawdziwie romantyczną« «. Siehe auch Szczuka: Czy feministki, S. 43 zu Janions Interesse an der »romantischen Liebe«. 26 । Janion: Tam gdzie rojsty, S. 104: »kogoś wyklętego, napiętnowanego, romantyzm uwielbiał takie figury."

27 | Vgl. Iwasiów: Kresy, S. 77.

28 | Vgl. allg. zum Begriff der Kulturnation und der den Frauen zugeschriebenen Funktion in deren Erhaltung auch Yuval-Davis, Nira: Geschlecht und Nation, Emmendingen 2001, S. 45 sowie 68-113.

29 | Vgl. Janion: Niesamowita słowiańszczyzna, S. 273; 0strowska: Matki Polki.

30 I Janion: Kobiety, S. 79: „Kobiety polskie w większym stopniu czuły się obywatelkami.“

31 I Ebd., S. 96: »Mickiewicz miejsce kobiety polskiej widzi przede wszystkim w układzie rodzinno-patriarchalnym. Ale przecież pojawia się tutaj także - zgodnie z duchem epoki, mówiącej 0 prawach kobiet [...] - wzmianka o emancypacji.« 
Mickiewicz der einzige Weg der Emanzipation. ${ }^{32}$ Eine Gleichberechtigung könne nur stattfinden, indem Frauen sich für die Gemeinschaft aufopferten. So würden sie gemäß Mickiewicz den Männern ebenbürtig. ${ }^{33}$

Die Frage nach gleichen Rechten war somit im Material der Romantikforscherin Janion breit angelegt. Am Beispiel Polens zeigte sich in dieser Thematik eine besondere Rahmung: Obwohl die europäische Idee der Gleichberechtigung grundsätzlich gutgeheißen wurde, war eine aktive Forderung nach gleichen Rechten unerwünscht. Dieses restriktive Zugestehen von Rechten und Achtung ist es denn auch, was Janion als Grunddilemma der polnischen Emanzipation identifiziert, das sich bis in die Gegenwart hineinziehe. In verschiedenen Texten geht Janion auf dieses Paradox aus unterschiedlichen Perspektiven ein. So betont sie einerseits die tatsächlichen Erfolge dieser polnischen Emanzipation, die ihre Auswirkungen bis heute zeige: »Wenn Ausländer heute so oft die Originalität und Selbstständigkeit der polnischen Frauen bemerken, sollte man bedenken, dass ein wesentlicher Ursprung dieses Phänomens gerade jene spezifische Emanzipation in Polen ist. « ${ }^{34}$ Andererseits verweist Janion auch darauf, dass dieser Diskurs die Frauen in eine argumentative Passivität zwinge. Während ihnen eine symbolische Hochachtung zugeschrieben werde und ihre öffentliche Handlungsfähigkeit implizit bestehe, herrsche doch immer noch das Narrativ der Unterordnung und Demut vor. »In der Folge der romantischen Gebote gewöhnte sich die polnische Frau an, die Lasten des Familien- und öffentlichen Lebens im Schatten und Schweigen zu tragen, damit das Opfer bloß erhört werde. ${ }^{35}$

Janion nennt an dieser Stelle deutlich die Ausweglosigkeit einer solchen Situation. Sie prangert nicht nur den fortwährenden Diskurs des Zugestehens-durch-Aufopferung an, der zu keiner echten Gleichstellung der Geschlechter führe und die Frauen stets vom Wohlwollen der männlich geprägten diskursiven Macht abhängig mache. Die Forscherin stellt auch fest, dass ebenso die Frauen selbst für diese Pattsituation verantwortlich seien. Sie hätten sich dem Narrativ der weiblichen Zurückhaltung angepasst und verorteten sich selbst, ihre Handlungen und Ansprüche innerhalb dieses Diskurses. ${ }^{36}$ Diese Argumentation Janions steht dabei stellvertretend für viele feministische Stimmen der 1990er Jahre, die eine Loslösung der Weiblichkeit aus dem patriotischen Aufopferungsnarrativ fordern. ${ }^{37}$

32 | Ebd., S. 97: »Droga przez ofiarę, przez zasługę, przez poświęcenie jest dla Mickiewicza jedyną drogą emancypacji."

33 । Vgl. ebd.

34 । Ebd., S. 98: »Kiedy dziś cudzoziemcy tak często zwracają uwagę na oryginalność i samodzielność polskich kobiet, to trzeba pamiętać, że istotnym źródłem owego fenomenu jest właśnie osobliwa emancypacja w Polsce."

35 I Ebd., S. 99: „W efekcie romantycznych nakazów kobieta polska przyzwyczaiła się do dźwigania ciężarów życia rodzinnego i publicznego w cieniu i w milczeniu, byle spełniła się ofiara."

36 I Vgl. auch Domański: Zadowolony niewolnik, S. 137.

37 I Siehe etwa Borkowska: Cudzoziemki, S. 34-38; Walczewska: Damy, rycerze i feministki, passim. 


\subsubsection{Maskerade, Mentalismus, Wahnsinn}

Die weibliche Aufopferung für die Gesellschaft nahm in einigen romantischen Texten eine weitere Dimension an: diejenige der vollständigen Übernahme der männlichen, aktiveren Rolle in den Aufständen. Diese literarischen Frauenfiguren, die etwa mit der im Novemberaufstand von 1830/31 kämpfenden Regimentsführerin Emilia Plater (1806-1831) auch reale Vorlagen hatten, »nahmen die Männerrolle auf sich und erfüllten - oft in Verkleidung oder Maskierung - die Pflicht eines Ritters oder Söldners bis zuletzt $~^{38}$, wie Janion schreibt. Sie untersucht dieses Phänomen der »bewaffneten Frauen ${ }^{39}$ in der romantischen Literatur und stellt fest, dass diese Frauenfiguren die »sentimentale Pflicht, gefühlvoll zu sein « ${ }^{40}$ überschritten.

Am Poem Grażyna (1823) von Mickiewicz kann Janion aufzeigen, dass sich die Herrschersgattin Grażyna gegenüber der Gemeinschaft verpflichtet sieht, ihre Rolle als Frau, »die sie selbst akzeptiert«, aufzugeben und im Kriegsgeschehen die Rolle ihres zu passiven Gatten zu übernehmen. "Entweder verrät sie den Gatten oder sie verrät die Gesellschaft. «" ${ }^{41}$ Doch davor steht der »Verrat« des Herrschers an der Gemeinschaft, der seine Pflicht vernachlässigt und so die Gattin zwingt, seine Rolle einzunehmen - eine Verschiebung der antinomischen Werteordnung. Das Überschreiten der eigenen Rolle bezahlt die Heldin bei Mickiewicz unausweichlich mit dem Tod und dem »Offenbaren [ihrer] Weiblichkeit « ${ }^{42}$.

Die Transgression der Geschlechtergrenzen ist in Grażyna aufgrund zweier Bedingungen möglich: Die Transgression musste der übergeordneten Idee des gemeinschaftlichen Wohls gewidmet sein. ${ }^{43}$ Zudem stellt die weibliche Figur, die die Rolle des männlichen Anführers übernahm, einen zeitlich begrenzten Einzelfall dar. Mit ihrem Tod wird die nur vorübergehend außer Kraft gesetzte Geschlechterordnung wieder hergestellt. ${ }^{44}$ Janion stellt fest, dass Mickiewicz »keineswegs solche Neigungen hegte wie andere Romantiker « ${ }^{45}$, die sich im Rahmen der Faszination für das phantasmatische Andere auch für die Thematik geschlechtlich vieldeutiger und ungefestigter Identitäten begeisterten. Für viele romantischen Dichter galt: »besser ist `dort‘, schlechter ist `hier«", wie Janion schreibt. Diese Haltung führte zu einer »spezifischen Identitätskrise, die beim romantischen Träumer oft

38 | Janion: Zbroje Grażyny, S. 148: "przymowały na siebie rolę mężczyzn i-częstokroć w przebraniu, ale i w zamaskowaniu - spełniały aż do kresu powinność rycerzy, żołnierzy«.

39 I Janion: Kobiety, S. 81: »kobiet zbrojnych«.

40 । Ebd., S. 83: »sentymentalną powinność bycia czułą".

41 I Ebd., S. 87: "którą sama akceptuje«; »albo zdradzi męża, albo zdradzi społeczność."

42 I Ebd., S. 92: "ujawnienie kobiecości«.

43 I Vgl. ebd., S. $96 f$.

44 | Vgl. dazu auch die ähnlichen Überlegungen in Bronfen, Elisabeth: Over Her Dead Body. Death, Femininity and the Aesthetic, Manchester 1992.

45 I Janion: Zbroje Grażyny, S. 156: »bynajmniej nie żywił skłonności takich, jak inni romantycy«. 
vorkommt. Er jagt nach immer neuer Verkleidung, neuer Maske, neuem Kostüm. ${ }^{46}$ Während die Romantik die Geschlechterrollen zwar verstärkt normierte, erwirkte die Faszination für das Andere deren literarische Transgression und eine Art performativer Identitätskonstruktion, wie man die janionsche Terminologie gegebenenfalls weiterführen könnte.

Janions wissenschaftliches Forschungsparadigma bildet sich entlang der hier herausgearbeiteten Aspekte romantischer Literatur heraus. Gleichzeitig weitet es sich auf ein historisch, geographisch und medial breiter gefächertes Untersuchungsmaterial aus. Dies zeigt sich insbesondere in den Bänden der TransgresjeReihe, weshalb diese im Folgenden im Zentrum der weiteren Ausführungen über Janions Interessensgebiete und ihren Werdegang hin zur feministischen Kritik stehen. Janion stellte hier etwa anhand von Emma Santos' La Malcastrée (1975) die Frage nach der "allgemeinen Kondition des Menschen, oder wie Emma Santos es begreift, der Kondition des Mannes, welche der Frau und insbesondere der schreibenden Frau auferworfen wird ${ }^{47}$. Janion macht am Text Santos’ auf die Parallelität und gegenseitige Potenzierung verschiedener Diskriminierungen oder, wie es bei Janion im Anschluss an Santos genannt wird, Kolonisierungen sozialer Gruppen aufmerksam. Diese werden in der Diskussion in ihrem historisch-sozialen Kontext betrachtet und als dekonstruierbar verstanden. ${ }^{48}$

In den Transgresje-Bänden nimmt die Verbindung von »Wahnsinn« und literarischem Schaffen viel Raum ein. In den Diskussionen geht es um die Auslotung der Flexibilität literarischer Konventionen und um die normative Macht in der Ausgrenzung literarisch transgressiver Akte. In Bezug auf die Mechanismen von Wissen und Macht verweisen die Bände auch auf Michel Foucault und dessen These, dass Diskurse über die Sexualität als Instrument der Machtstrukturierung dienen. Im Rahmen dieser Strukturierung werde der weibliche Körper einem Hysteriediskurs unterworfen, der den "vollständig von Sexualität durchdrungenen« Körper disziplinieren soll. ${ }^{49}$ Somit bewegen sich Janion und ihre Studierenden am Rande der feministischen Dekonstruktion gesellschaftlicher und medizinischer

46 I Janion: Projekt krytyki fantazmatycznej, S. 11f.: »Lepsze jest stam‘, gorsze jest stutaj‘«; "osobliwym kryzysem tożsamości, występucjącym często u romantycznego marzyciela. Goni on za coraz to nowym przebraniem, nową maską, nowym kostiumem."

47 I Janion, Maria [et al.]: "Ciało skolonizowanych«, in: Janion/Rosiek, Galernicy wrażliwości (1981), S. 215-235, hier S. 218: »ogólną kondycją człowieka, to znaczy, jak rozumie to Emma Santos, kondycją mężczyzny narzuconą kobiecie, zwłaszcza kobiece piszącej«.

48 I In den Materialien der Transgresje-Bände sind aber auch essentialistischere Ansätze untergebracht, wie etwa ein unkommentiert abgedrucktes Gesprächsfragment von Marguerite Duras mit Xavière Gauthier von 1974. Darin stellt Duras fest, die Frau sei »dem Wahnsinn um vieles näher ... Da sie jeglichen Transgressionen viel näher ist. «Duras in Janion/Rosiek, Galernicy wrażliwości (1981), S. $212 f$.

49 | Vgl. Foucault, Michel: »Z ’Historii seksualności«, in: Janion/Majchrowski, Odmieńcy (1982), S. 392-396, hier S. $392 f$. 
Hysterisierung, ohne sich davon einengen zu lassen, und gehen gleichzeitig darüber hinaus. ${ }^{50}$ Im Folgenden stelle ich deshalb einige Akzente der Transgresje-Bände vor, die die Stoßrichtung der kritischen Auseinandersetzung mit der Geschlechterordnung demonstrieren.

Im Transgresje-Band von 1984 unter dem Titel Osoby (Personen) erschien eine Studie Janions zur polnischen Schriftstellerin Stanisława Przybyszewska (19011935) und deren idealisierendem Bild des französischen Revolutionärs Maximilien de Robespierre. Janion beschreibt, wie Przybyszewska sich selbst als die alleinige Interpretatorin stilisierte, die die Figur Robespierre als idealen Menschen in seiner Gesamtheit verstanden habe. Dabei betone Przybyszewska die Erhabenheit geistiger Bindungen zwischen den Menschen, die ungleich vollkommener seien als eine körperliche Vereinigung. Przybyszewska schreibt dazu: »Eine Freundschaft, kalt und hart wie Metall [...]. Die höchste und reinste Form einer Beziehung zweier [...] Menschen, die nur vollkommen erwachsenen, intensiv produktiven Naturen

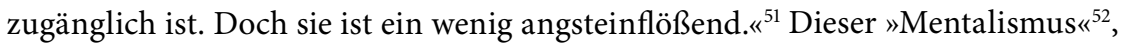
wie ihn Janion nennt, huldige einer enthumanisierten und völlig objektiven Geistigkeit, der reinen Rationalität, was Przybyszewska zufolge insbesondere Kennzeichen männlicher Freundschaften sei. Das weibliche Geschlecht, dem diskursiv das Gegenteil zugeschrieben werde, also Körperlichkeit, Naturverbundenheit, Subjektbezogenheit und Emotionalität, wäre hingegen per se von diesem Mentalismus ausgeschlossen.

Przybyszewska verweise aber darauf, dass eine solche Beziehung »auch beginn[e], zwischen zwei Menschen unterschiedlichen Geschlechts möglich zu sein ${ }^{53}$. Dafür müsse sich die Frau in das ideale männliche Paradigma einordnen, müsse - wie auch ihre männlichen Kollegen - der Körperlichkeit und den

50 | Am Beispiel des Films L'Histoire d'Adèle H. von François Truffaut (1975) etwa diskutierte Janion mit den Seminarteilnehmenden die Frage, ob die darin dargestellten Emanzipierungsbestrebungen Adèle Hugos (1830-1915), die von ihrem Umfeld als krankhaft interpretiert wurden, in den Kontext der Frauenbewegung - der amerikanischen Women's Liberation - gestellt werden können. Die Diskussion kreiste um Differenzierungen zwischen persönlichen Befreiungsversuchen und weiblicher Emanzipation, wobei bei Hugo das Geschlecht im Gegensatz zur familiären Rahmung eine untergeordnete Rolle gespielt habe. Janion betont in der Besprechung des Falls Hugo - wie auch an anderen Beispielen - die individuelle Ausprägung sowohl der identitären Problemstellungen wie auch der entsprechenden Auswege, Lösungen, Transgressionen. Vgl. Janion, Maria [et al.]: »Fałszywy paszport Adeli H.«, in: Janion/Majchrowski, Odmieńcy (1982), S. 113-126, bes. S. 121. 51 I Przybyszewska, Stanisława in einem Brief an Helena Barlińska, zit. nach Janion, Maria: »Przybyszewska pragnie stworzyć osobowość mentalną rewolucji«, in: Janion/Rosiek, Osoby (1984), S. 161-172, hier S. 170: »Przyjaźń zimna i twarda jak metal [...]. Najwyższa i najczystsza forma związku dwu (lub, jak to zaczyna być możliwym, dwojga) ludzi, dostępna tylko naturom całkowicie dorosłym, intensywnie produktywnym. Ale trochę straszna.«

$\mathbf{5 2}$ । Ebd.: »mentalizm«.

53 I Przybyszewska zit. nach ebd.: "związku dwu (lub, jak to zaczyna być możliwym, dwojga) ludzi«. 
Gefühlen entsagen. Dabei gehe es gemäß Przybyszewska um das Erreichen einer Objektivität und Neutralität, aus deren Position heraus historische Zusammenhänge erst in ihrer Gesamtheit erfasst werden können. ${ }^{54}$ Przybyszewska, so Janion, erkenne somit, dass Geschichtsschreibung vom jeweiligen Standpunkt abhänge. Ihre Energie verwende Przybyszewska - wie auch Komornicka, s. u. - darauf, sich in einen vermeintlich neutralen, synthetisierenden Standpunkt einzuschreiben.

Das Projekt der Menschwerdung der Frau durch das Einschreiben in einen männlich-rationalen Kanon betrachtet Janion mit Distanz. Eine solche Emanzipierung beinhalte die Gefahr, Hierarchien weiter zu festigen und »die bedrohliche Ideologie von `Herren` und `Sklaven « ${ }^{55}$ entstehen zu lassen. Die Übernahme der negativen Auslegung all der Charakteristiken, die dem weiblichen Geschlecht zugeschrieben werden, scheint Janion nicht die geeignete Lösung für die Problematik einer geschlechtlichen Ungleichheit zu sein, da hier Kolonisierungsstrategien (s. u.) des männlichen Paradigmas aufgenommen und übererfüllt werden, um sich als einzelne Frau in die `Herrenklasse « einschreiben zu können. Gleichzeitig kann sich auch Janion einer gewissen Faszination des Mentalismus nicht erwehren, wie sich in ihren Studien zu Komornicka/Włast zeigt (siehe 3.3).

Die Frage nach historischer Objektivität und einem neutralen menschlichen Standpunkt umfasst auch das Gebiet der Sprache und der Literatur. Auch hier gilt das männliche Paradigma als Leitgröße, an der sprachliche Äußerungen gemessen werden. Der einfachste und historisch oft einzige Weg zur schriftstellerischen Anerkennung ist die literarische Unterordnung unter dieses Paradigma - wie es etwa Komornicka, aber auch kanonisierte Schriftstellerinnen wie Orzeszkowa teilweise getan haben. ${ }^{56}$ Przybyszewska betrachtet das Drama erzähltechnisch als die literarische Gattung, mithilfe derer sie der objektiven Wahrheit am nächsten kommen könne. ${ }^{57}$

Dieses Urteil bestätigt Janion, indem sie in Przybyszewskas Roman Ostatnie noce ventôse'a (Die letzten Nächte des Ventôse, Erstausg. 1958) eine starke Intonation der narrativen Instanz feststellt. Der Roman offenbare »bestimmte Beweggründe, bestimmte Nuancen der Gedankengänge, die [im Drama] Sprawa Dantona [Der Fall Danton, 1929] nicht erkenntlich« seien und die Janion zufolge dasjenige verhüllten, was Przybyszewska »als das Wichtigste betrachtete: das unerbittliche Wirken der objektiv-mentalen Kraft. ${ }^{58}$ Es scheint, dass sich der Roman

$\mathbf{5 4}$ | Vgl. ebd., S. 161.

55 | Ebd., S. 170: »może się zrodzić groźna ideologia ’panów‘ i ’niewolników««.

56 I Vgl. Borkowska: Cudzoziemki, S. 160f.; Walczewska: Damy, rycerze i feministki, S. 75.

57 I Der dramatische Modus gilt in der Literaturwissenschaft als diejenige Gattung, in der am >direktesten erzählt wird (autonome direkte Figurenrede), in der das Wirken einer vermittelnden Instanz auf ein Minimum reduziert ist. Vgl. Martinez/Scheffel: Einführung, S. 51.

58 I Janion: Przybyszewska, S. 162: »ujawnia ona pewne motywacje, pewne niuanse rozumowania, których w Sprawie Dantona nie widać, gdyż zostały ukryte - jako zaciemniające i zasłaniające to co Przybyszewska uznała za najważniejsze: nieubłagane działanie siły obiektywno-mentalnej.« 
als Gattung gerade »unter [Przybyszewskas] Feder weniger zu diesen Zwecken eignete ${ }^{59}$ und stärker auf die historische und soziale Position verweise, aus der heraus er geschrieben wurde. Diese Feststellung Janions zielt bereits in die Richtung der feministischen Kritik in der Polonistik der 1990er Jahre, die besonders in Prosatexten der Vergeschlechtlichung des Schreibstils und einer spezifisch weiblichen personalen Intonation nachgeht (siehe Kapitel 5.2).

Während Przybyszewska eine Unterordnung unter das Paradigma der Objektivität intendiere, lasse sich bei anderen Schriftstellerinnen Widerstand gegen diese Norm entdecken. So notiert Janion, dass das `neutrale` Paradigma in Santos' La Malcastrée zu einem Gefühl der Entfremdung führe:

"Die ganze Malcastrée durchdringt das andauernde Gefühl, dass das Schreiben in der gegebenen Sprache ein Schreiben in einer fremden, uneigenen Sprache ist, dass die überworfene Sprache eigentlich die Sprache der Kolonisatoren für die Kolonisierten ist, annektiert von feindlichen Mächten dieser Welt. Angesichts dessen muss das Problem aufkommen, inwieweit eine eigene Sprache wiedererlangt, in der eigenen Sprache geschrieben werden kann, von der man enteignet wurde. ${ }^{60}$

Das Problem eines solchen >Wiedererlangens` einer eigenen Sprache stelle sich insbesondere für die Frau, die als verrückt erklärt wurde. Janion schreibt, dass die Geisteskrankheit Santos' die willentliche Unterordnung unter das herrschende Paradigma verunmögliche und sie von Versuchen der Selbstnormierung disqualifiziere; trotz alledem bleibe sie aber in den sprachlichen Konventionen gefangen.

"[W]enn sie in eine umgangssprachliche, banale Literarizität verfällt, beginnt sie gleich zu beißen, treten und schreien. Nun ja, aber aus einem Gefühl der Machtlosigkeit - deshalb, weil sie nicht vollständig über die eigene Sprache herrscht und weiß, dass sie sich etwas einreden, aufdrängen lässt. « 61

Was einerseits als psychotischer Zustand gelesen werden kann - und dem widerspricht Janion nicht -, in dem das Subjekt die Realität als feindlich eingestellt wahrnimmt, gilt andererseits entlang feministischer Argumentationen für die Geschlechterordnung als alltägliche Realität. Die feministischen Ansätze der 1970er Jahre, in deren Geist auch La Malcastrée geschrieben wurde, sehen das Weibliche

59 । Ebd.: "pod jej piórem mniej się do tych celów nadawała«.

60 I Janion: Ciało skolonizowanych, S. 218, Hervorh. i. 0: »Całą Źle wykastrowaną przenika jedno ciągłe odczucie, że pisanie w tym języku, który jest dany, jest pisaniem w cudzym, nieswoim języku, że język narzucony to właśnie język kolonizatorów dla skolonizowanych, zawłaszczony przez jakieś wrogie potęgi tego świata. I musi powstać wobec tego problem, w jakim stopniu można odzyskać swój język, pisać oczywiście własnym językiem, z którego się zostało wywłaszczoną." 61 I Ebd., S. 220: "gdy popada w taką potoczną, banalną literackość, to zaczyna zaraz gryźć, kopać i krzyczeć. No tak, ale to z poczucia bezsilności - dlatego, że nie włada w pełni własnym językiem i wie, że daje sobie coś wmówić, coś narzucić.“ 
als vom »Phallogozentrismus « dominiert und marginalisiert, innerhalb dessen es verstumme. ${ }^{62}$ Janion verzichtet hier auf die Berücksichtigung feministischer Theorien und gewichtet bei Santos stärker die Thematik der Psychopathologisierung als diejenige des Geschlechts. Die Kategorie des Geschlechts spielt aber auch bei Janion eine Rolle: »Ja, es ist die Suche eines Wortes, aber - deutlich gesagt - die Suche eines Wortes für den Wahnsinn, für die Frau, für die wahnsinnige Frau. « ${ }^{63}$ Santos' Suche nach sanderen Zeichen, nach einer Kommunikativität außerhalb der symbolischen Ordnung, stoße gerade deshalb auf eine vom Leiden geprägte "Sprache des Körpers « ${ }^{64}$, was in der feministischen Kritik wiederum als Merkmal weiblichen Schreibens gelten kann (siehe Kapitel 5.2.2).

Die Nähe zwischen dem Forschungsfokus Janions und der fast zeitgleich entwickelten französischen feministischen Kritik zeigt sich an der Thematik der verrückten Frau besonders deutlich. Janion war sich dieser konzeptuellen Verwandtschaft bewusst und würdigte die Ansätze des französischen Feminismus, wie die folgende Aussage über den feministischen Pariser Verlag Éditions des Femmes zeigt, bei dem u. a. die zweite Ausgabe von Santos' La Malcastrée erschien. Dessen Publikationen

"gestatten es, die Stimme einer unterdrückten Welt zu hören, die bislang stumm war. Besonders große Bedeutung schreibt man hier dem weiblichen Sprechen, Schreiben, Lesen, Herausgeben, Filmen zu, das unbehindert vom 'männlichen Bild der Frau und ihres Körpers` möglich sein soll. Überall sind Frauen unterdrückt, überall kämpfen sie um ihre Rechte, überall suchen sie eine neue Sprache: Mit diesen Schlagworten werden Frauen zum Schaffen und zur Freiheit motiviert, die innen in 'phallokratischen Gesellschaften v versagt sind. « ${ }^{65}$

Während somit bei Janion das Bewusstsein und die wissenschaftliche Praxis ıfeministischer Kritik vorhanden sind, erscheint ihr die Frauenfrage im Kontext der 1970er und 1980er Jahre in Polen nicht als die drängendste sozialpolitische Frage;

62 I Vgl. Lindhoff, Lena: Einführung in die feministische Literaturtheorie, Stuttgart 1995, bspw. S. 40 zu Showalters Konzept der Frauen als muted group, das diese im Essay Feminist Criticism in the Wilderness entwickelt, sowie S. 115 zu Cixous und deren écriture féminine als »Hörbarwerden der sStimme im Text«. Siehe dazu Cixous: Le Rire; Showalter, Elaine: »Feminist Criticism in the Wilderness«, in: Critical Inquiry 8/2 (1981), S. 179-205.

63 I Janion: Ciało skolonizowanych, S. 218: „Tak, to jest poszukiwanie słowa, ale - powiedzmy jasno - jest to poszukiwanie słowa dla szaleństwa, dla kobiety, dla kobiety szalonej."

64 । Ebd., S. 220: „Cierpienie jako integralną część języka ciała«.

65 I Ebd., S. 215f.: »pozwalających usłyszeć głos świata stłumionego, jakby dotychczas niemego. Szczególnie istotne znaczenie przypisuje się tu kobiecej możliwości mówienia, pisania, czytania, wydawania, filmowania, możliwości nieskrępowanej smęskim obrazem kobiety i jej ciała‘. Wszędzie kobiety są uciskane, wszędzie walczą o swoje prawa, wszędzie poszukują nowego języka: tymi hasłami właśnie zachęca się kobiety do twórczości i wolności, które są im odmawiane w sspołeczeństwach fallokratycznych‘.» 
zunächst, wie sie später selbstkritisch schreibt, müsse das sozialistische System als solches reformiert werden. ${ }^{66}$

\subsubsection{Jenseits geschlechtlicher Binarität}

Weibliches Schreiben hat, wie bislang festgestellt, zwei Möglichkeiten seiner Realisierung. Es kann durch normative Disziplinierungsprozesse ins Wahnhafte abgedrängt werden, wobei es seine >Weiblichkeit` als Divergenz von der Norm überbetont; oder es kann sich dem >objektiven >männliche` literarische Normen übernehmen. Beide Strategien speisen sich jedoch aus einer geschlechtlichen Binarität und sind entsprechend markiert - wenn auch die >männliche` Tradition dies zu verhüllen sucht. Nun interessiert sich die janionsche Forschung aber auch für Transgressionen, die solche Binaritäten überschreiten. So finden sich in der Transgresje-Reihe auch vielfältige Beispiele, in denen Geschlechtstransgressionen im Fokus stehen, die ein dichotomes Geschlechtsverständnis auflösen. So werden etwa unter dem Titel Pierwsza, druga, trzecia, czwarta płeć (Erstes, zweites, drittes, viertes Geschlecht) ${ }^{67}$ von 1986 Auslotungen eines dritten oder vierten Geschlechts in literarischen Auszügen vorgestellt. In Stanisław Lems (1921-2006) Erzählung Maska (Die Maske, 1976) etwa ist es zunächst ein geschlechtlich/grammatikalisch neutrales Subjekt, das spricht: »[...] ich vergrößerte und erkannte mich [powiększałom się i rozpoznawałom siebie], erfuhr die eigenen Grenzen und kann nicht offenbaren, wann ich [kiedym mogło] schon genau die eigene Gestalt erfassen, jeden Ort erkennen konnte, an dem ich endete [ $\mathrm{gdziem}$ ustawało]. ${ }^{68}$ Auffallend ist die grammatikalische Markierung des Subjekts als neutrales oder nicht-geschlechtliches, als Subversion des binären Geschlechtssystems. In Kombination mit Lems phantastisch-futuristischer Gedankenwelt zeigen sich hier bereits Merkmale einer posthumanen Hybridität, wie sie Donna Haraway in ihrem Cyborgmanifest ${ }^{69}$ herausarbeitet.

In diesem wie auch in weiteren im Transgresje-Band Maski (Masken, 1986) publizierten Fragmenten ist das Geschlecht nicht vorgegeben, sondern konstituiert sich durch >Verschiebungen` und `Mutationen`, die die Zweigeschlechtlichkeit destabilisieren. Das unkommentiert abgedruckte Material suggeriert, dass sich die Seminarteilnehmenden mit der Frage beschäftigten, inwiefern Geschlecht wie auch Identität als ein Zustand betrachtet werden können, oder ob hier nicht eher

66 I Vgl. Janion: Kobiety, S. 326.

67 | Vgl. Janion/Rosiek: Maski I, S. 202-214.

68 I Lem, Stanisław: Maska, Kraków 1976, S. 5: »[...] powiększałom się i rozpoznawałom siebie, doświadczając własnych granic i nie potrafię wyjawić, kiedym mogło już dokładnie ogarnąć własny kształt, rozpoznać każde miejsce, gdziem ustawało."

69 । Vgl. Haraway, Donna: »A Cyborg Manifesto: Science, Technology, and Socialist-Feminism in the Late Twentieth Century«, in: dies., Simians, Cyborgs, and Women. The Reinvention of Nature, New York 1991, S. 149-181. 
von einem performativen Prozess gesprochen werden sollte. In Maski und anderen Transgresje-Bänden finden sich Analysen von Janions Studierenden, die sich mit solchen Themen auseinandersetzen. So schreibt etwa Małgorzata Baranowska über Roland Topors (1938-1997) Roman Le Locataire chimérique (1964):

"Als Heldin erweist sich die Identität, die Unmöglichkeit eines Erkennens der Identität. Uns zeigen sich >vorübergehende Formen ‘ der Realität. [...] Die literarische Anamorphose Topors [...] belässt uns im Unklaren nicht nur über die Identität der sogenannten Protagonisten, sondern auch über die Identität unserer Kenntnisse in der von inm geschaffenen Realität. « ${ }^{70}$

Die Destabilisierung von Identität und Wahrnehmung wird somit als zentrales Motiv des Textes diskutiert. Besonders relevant wird in diesem Zusammenhang die Sprache, die diese Uneindeutigkeiten herstellen könne: "[A]llein die Literatur ist imstande, bestimmte uneindeutige Zustände und verzerrte Logiken wiederzugeben, die ausschließlich durch das Wort herausgebildet werden können, Zustände, in denen es diesen `bestimmten`, > unantastbaren` Perspektivenpunkt nicht gibt. «1 $^{71}$ Es ist also, so Baranowska, gerade die Literatur bzw. die Auseinandersetzung mit ihr, die die Erkenntnis instabiler und performativer Identitäten fördere.

Auch Stanisław Rosiek sieht in seinem Beitrag zu Jean Genets (1910-1986) Pompes funèbres (1948) die Sprache als Identitätsausdruck, der jedoch nicht als abschließend zu verstehen sei. »[D]ie Grenze zwischen diesen Sprachen und zwischen den damit im Zusammenhang stehenden Rollen wird von Genet überschritten. Das Opfer identifiziert sich mit dem Henker, wird zum Henker [...] Die Zeitweiligkeit des `Henker-Seins` und `Opfer-Seins` wird demaskiert, was die Täuschung offenlegt, überhaupt jemand Einzelnes zu sein. ${ }^{72}$ Die Vorgänge des durch die Sprache vollzogenen temporären Rollentausches, so Rosiek, wiederholen sich bei Genet, werden zu einer iterativen Verschiebung und Überlagerung von scheinbar gegensätzlichen Identitäten. Rosiek erkennt darin die männliche, homosexuelle »verdoppelte« Identität. Er spricht von der Unmöglichkeit einer »einfachen«,

70 I Baranowska, Małgorzata: „Anamorfoza i tożsamość«, in: Janion/Rosiek, Maski II (1986), S. 333-340, hier S. 339f., Hervorh. i. 0: »Bohaterką okazuje się tożsamość, niemożność poznania tożsamości. Zjawiają się nam ’przechodnie formy rzeczywistości. [...] Anamorfoza literacka Topora [...] pozostawia nas w niepewności nie tylko co do tożsamości tak zwanych bohaterów, ale co do tożsamości naszego rozeznania w stworzonej przez niego rzeczywistości.«

71 I Ebd., S. 338, Hervorh. i. 0: »literatura jedyna jest w mocy oddać pewne stany niejednoznaczne i pewne zmącenia logiki, możliwe do wytworzenia wyłącznie przez słowo, stany, w których owego spewnego<, snietykalnego < punktu perspektywy nie ma."

72 I Rosiek, Stanisław in Janion, Maria [et al.]: „Przekroczenie stało się faktem«, in: Janion/ Majchrowski, Odmieńcy (1982), S. 285-328, hier S. 294f., Hervorh. i. 0: »granica między tymi językami i między rolami, z jakimi są związane, jest przez Geneta przekraczane. Ofiara utożsamia się z katem, staje się katem [...] Demaskuje się chwilowość ’bycia katem` i ’bycia ofiarą‘, ujawnia złudność bycia w ogóle kimkolwiek pojedynczym.« 
einzelnen Identität. Entlang der Erzählung Genets legt Rosiek die nur temporäre, indefinitive Identitätswerdung frei, die nicht nur für die dargestellten Figuren, sondern sim Allgemeinen gelte.

Solche in den Transgresje-Seminaren diskutierten Texte und Besprechungen weisen über eine strukturalistische Herangehensweise hinaus, wie sie in den 1970er und 1980er Jahren in Polen verbreitet war. Janions Seminare schöpften Inspiration aus einer westeuropäisch-amerikanischen Tradition und deren poststrukturalistischen Ansätzen der 1970er Jahre. Mit Thesen zur Performativität von Identität und Geschlecht unterwanderten die janionschen Seminare in gewisser Weise auch den Trend zur Identitätspolitik im westlichen Diskurs. Interessant ist hierbei, dass diese Akzente in der publizierten Reihe gerade von den Seminarteilnehmenden stammten, was vor allem auf eine liberale und unabhängiges Denken fördernde Atmosphäre der Veranstaltungen schließen lässt. Ihre Beiträge stehen im Kontrast zum eher konservativen, essentialistisch-identitären Geschlechterdiskurs, der sich in den 1990er Jahren in der feministischen Polonistik als Leitmotiv bemerkbar machte und erst ab den 2000er Jahren in relevanterem Maße durch Ansätze eines performativen Geschlechtsverständnisses aufgelockert wurde.

\section{2 "Hermeneutik der Verdachte«: Kritische Wissenschaft}

Nach einer eher thematischen Aufrollung des wissenschaftlichen Interesses Janions soll an dieser Stelle nun der Fokus verstärkt auf die methodische, epistemologische Ebene dieser Entwicklung gelenkt werden. Die Forschung Janions lässt sich im Kontext der Volksrepublik und im Besonderen der strukturalistischen Phase der Literaturwissenschaft ab den 1970er Jahren ${ }^{73}$ als eher unkonventionell, engagiert und engagierend sowie methodisch offen beschreiben. Der methodische Eklektizismus, der sich aus Janions marxistisch-kritischem Grundgerüst entwickelte, kann als Umsetzung einer materialgeleiteten, undogmatischen Lektüre gesehen werden. Teil dieses Eklektizismus oder der spezifischen Polyphonie ${ }^{74}$ von Janions Forschungsarbeiten ist zudem die Integration studentischer Stimmen, denen im Gegenzug eine eigene wissenschaftliche Handlungsfähigkeit zugesprochen wird.

Der Anfang von Janions wissenschaftlicher Tätigkeit fällt in die marxistisch-revolutionären Strömungen nach dem Zweiten Weltkrieg. »Rückständigkeit

73 I Vgl. Borkowska: Interview; Janion, Maria/Szczuka, Kazimiera: Janion. Rozmawia Kazimiera Szczuka. Transe, traumy, transgresje. Tom 2. Profesor Misia (= Seria z Różą), Warszawa 2014, S. 85.

74 | Vgl. zu Bachtins Konzept des Polyphonen Bachtin, Michail: Probleme der Poetik Dostoevskijs (= Literatur als Kunst), München 1971, etwa S. 10, wo er die Polyphonie als »Vielfalt selbständiger und unvermischter Stimmen und Bewusstseine « umreißt. Siehe dazu auch Kristeva: Sèméiotikè, S. 152, 169; Sasse, Sylvia: Michail Bachtin zur Einführung, Hamburg 2010, S. 85, 88. 
und Fortschritt waren die Schlüsselbegriffe dieser Zeit $\aleph^{75}$, rekapituliert Janion. Dies führte zu einer Revision des polnischen Verständnisses von Kultur und Tradition und dem Versuch der Enttarnung verfälschender, bourgeoiser Ideologie. ${ }^{76}$ Das wissenschaftliche Interesse lenkte sich auf den »Einfluss der Literatur auf das Gesellschaftsbewusstsein ${ }^{77}$, und die akademischen Praktiken ordneten sich der Maxime des sozialen Fortschritts unter. Die Gesellschaft und deren Mechanismen galten als übergeordnetes Interesse, während Faktoren wie Individualität, Psyche oder auch intersubjektive Beziehungen außer Acht gerieten. ${ }^{78}$

Die hier skizzierten marxistischen Ansätze formen den Forschungszugang Janions entscheidend mit. Selbst bezeichnet sie ihr damaliges akademisches Umfeld als "marxistisch geneigt" (marksizujące), betont aber, dass dessen Ausrichtung nicht einem strikten Dogma unterworfen gewesen sei. ${ }^{79}$ Die auch politisch geprägte Problematik des 'marxistischen` Vermächtnisses Janions, das ihr retrospektiv immer wieder als diskreditierendes Element angelastet wurde, kann im hier vorliegenden Rahmen nicht abschließend behandelt werden. ${ }^{80}$ Festzuhalten ist jedoch, dass marxistische Ansätze in Janions Forschungszugang durchgehend einen Referenzpunkt darstellten. So hielt Janion auch nach 1968 weiter an der Relevanz Marx'scher Theorien und der Notwendigkeit einer Revision marxistischer Forschung fest, während sich die polnische Wissenschaft und Gesellschaft endgültig vom Marxismus abwandte. ${ }^{81}$ Janion beschäftigte sich auch mit der westlichen Marxrezeption und der dortigen Relevanz der Marx'schen Ansätze für die Forschung des 20. Jahrhunderts. Sie führte etwa das antipsychiatrische Konzept

75 | Janion/Szczuka: Niedobre dziecię, S. 63: „Wsteczność i postęp to były pojęcia kluczowe tamtych czasów«. Siehe auch ebd., S. 100. Auffällig sind hier auch die begrifflichen Parallelen zur Transformationszeit nach 1989.

76 | Vgl. ebd., S. 75, 101.

77 । Ebd., S. 71: »jej [literatury] wpływem na świadomość społeczną«; vgl. auch Janion/Szczuka: Profesor Misia, S. 63.

78 I Vgl. Borkowska: 'Komandosi<, S. $239 f$.

79 | Vgl. Janion/Szczuka: Niedobre dziecię, S. 73, 78.

$\mathbf{8 0}$ I Vonnöten wäre hierfür eine detaillierte Analyse ihres Gesamtwerks, besonders auch der frühen Schriften, sowie eine historisch-biographische Aufarbeitung jenseits der Textanalyse. Die biographischen Interviews Szczukas mit Janion dienen in der vorliegenden Untersuchung zwar als ergänzendes Material, müssen jedoch auch als subjektiv gewichtete Informationsquelle betrachtet werden. Vgl. ansatzweise Helbig-Mischewski, Brigitta: »Guru przełomu tysiąclecia. Dyskurs Nowej Ery w pracach Marii Janion«, in: Teksty Drugie 43-44/1-2 (1997), S. 165-192, hier S. 179; Janion/Szczuka: Profesor Misia, passim, etwa S. 34, 151.

81 I Vgl. Janion, Maria: »Morze zjawisk i okruchy egzystencji. Rozmowa Zbigniewa Majchrowskiego z Marią Janion«, in: Owczarski, Colloquia gdańskie (2008), S. 103-136, hier S. 128; Janion/ Szczuka: Profesor Misia, S. $33 f$. 
der Entfremdung auf dessen marxistisches Element zurück ${ }^{82}$ oder machte auf die gemeinsamen Komponenten von marxistischen und psychoanalytischen Ansätze aufmerksam.

»In der westeuropäischen Kritik werden nicht selten Psychoanalyse und Marxismus kombiniert. Nicht nur wegen des demaskatorischen Einschlags beider Richtungen (die eine erörtert schamhaft geheimgehaltene Komplexe, die andere enthüllt die Klassenstruktur des Handelns), sondern auch, weil sie eine säußere`, Rahmenbedingungen miteinbeziehende Haltung bspw. der Literatur gegenüber einnehmen.«83

Ähnlich postfreudianischen feministischen Ansätzen, die sich im westlichen Diskurs herausbildeten, integrierte Janion die Psychoanalyse als methodologischen Versuch der $» H e r v o r k e h r u n g$ dessen, was verborgen liegt ${ }^{84}{ }^{4}$ in ihr Analyseinstrumentarium, etwa um die romantische Faszination am Unerklärlichen und Unterbewussten greifen zu können. Die Ergänzung marxistischer Hermeneutik durch psychoanalytische Ansätze in den 1970er Jahren wich von den in der polnischen Literaturwissenschaft dieser Zeit vorherrschenden strukturalistischen Tendenzen ab. ${ }^{85}$ Mit ihrem stärker subjekt- und diskursorientierten Ansatz stieß Janion in einem auf das Systemische und die textinhärente Struktur konzentrierten akademischen Kontext wie auch mit ihrem Festhalten am Marxismus auf Unverständnis und Ablehnung. ${ }^{86}$

Janion bezeichnete ihren Ansatz als »Hermeneutik der Verdachte ${ }^{87}$. Er vereinte hermeneutische Methoden, die die Suche nach Bedeutung, Ursprung und Identität bedeuteten, mit einer dekonstruktivistischen Herangehensweise. Letztere stellte die hermeneutische Suche wieder in Frage und spürte in der Einheit die Differenz, den Bruch und das Ungereimte auf. In diesem Zusammenhang spielten gemäß Janion auch die von Barthes bzw. Bachtin geprägten Begriffe der Relektüre

82 I Vgl. Janion, Maria [et al.]: »Komentarze 1«, in: Janion/Rosiek, Osoby (1984), S. 345-353, hier S. 349. Zum Phänomen solcher >Rezeptionslinien` siehe auch Kapitel 4.

83 I Janion, Maria: Humanistyka: poznanie i terapia, Warszawa 1982, S. 54f.: »W krytyce zachodnioeuropejskiej niejednokrotnie zestawia się ze sobą psychoanalizę i marksizm. Idzie tu nie tylko o demaskatorskie zacięcie obydwu kierunków (jeden nicuje wstydliwie konspirowane kompleksy, drugi odsłania klasową podszewkę postępowania); idzie również o ich 'zewnętrzną<, wyjaśniającą za pomocą warunkujących okoliczności postawę, np. wobec literatury."

84 I Janion: Romantyzm, S. 36: »uczynić jawnym to, co ukryte«.

85 | Vgl. Janion, Maria: »Droga«, in: Borkowska/Sikorska, Krytyka feministyczna (2000), S. 1119, hier S. 16.

86 | Vgl. Janion, Maria [et al.]: »Komentarze 3«, in: Janion/Rosiek, Osoby (1984), S. 391-449, hier S. 393.

87 I Janion: Droga, S. 15: »hermeneutyka podejrzeń«. 
- als neues Lesen, das die Differenz sichtbar macht - und der textuellen Dialogizität eine richtungsweisende Rolle..$^{88}$

Während die Kombination von bedeutungsabschließenden und -öffnenden Methoden als Eklektizismus erscheinen mag - was Janion nie abstritt -, sah die Polonistin gerade darin die Voraussetzung für ein sozial kritisches Denken und Forschen.

»Aber gerade hier, in dieser Spannung oder dem Aufeinanderprallen von >Universalismus und >Idiom ‘ als 'Unterschied , des salleinigen< Sinns und der unendlichen Vielfalt von Bedeutungen, des Absoluts und der Anerkennung des Andersseins, entstand bei mir das Interesse am Feminismus. [...] Inspiriert vom marxistischen Denken, setzte die >Hermeneutik der Verdachte radikale Kritik an zur Zerschlagung von Bedeutungsdogmen oder -stereotypen. Wiederum erschien der Feminismus am Horizont, als Kritik des bestehenden Darstellungssystems, als Kritik am bürgerlich-patriarchalen Machtdiskurs. ${ }^{89}$

Janions wissenschaftliche Arbeitsmethode beruht auf der Synthese unterschiedlicher, sich nur auf den ersten Blick widersprechender Ansätze. Die Suche nach Bedeutung kontrastierte sie mit der Hinterfragung fester Bedeutungen an sich; marxistische Ansätze ergänzte sie der kritischen Wissenschaft willen mit psychoanalytischen und dekonstruktivistischen Herangehensweisen. In diesem pragmatischen »Eklektizismus« sieht sie selbst letztlich auch die feministische Kritik verortet, der sie sich jedoch erst in den 1990er Jahren deutlicher zuwandte - einer Zeit, in der sie mehr denn je das sozial- und marktkritische Element vermisste. ${ }^{90}$

\subsubsection{Transnationale Perspektiven}

In den Arbeiten Janions sind Referenzen auf westeuropäische und amerikanische Theorien deutlich ersichtlich; diese verarbeitete Janion aber oft mit einer spezifisch polnischen Perspektive, um einen umfassenden und verstehenden Blick auf die polnische Kulturtradition und Gesellschaft zu erlangen - Janion »schafft große Landschaften um bestimmte Problematiken «"1 ${ }^{91}$ wie es Anna Nasiłowska formulierte. Trotz ihrer transnationalen Ausrichtung ist die Faszination für das >Polnische und dessen spezifische kulturelle Narrative durchgehend in den Texten

88 । Vgl. ebd., S. 11ff. sowie dies.: Odnawianie znaczeń, Kraków 1980.

89 | Janion: Droga, S. 15: „Ale właśnie tu, w tym napięciu czy zderzeniu między suniwersalizmem a ১idiomem<, ‘różnicą‘, między ’jedynym‘ sensem a nieskończoną różnorodnością sensów, między absolutem a uznaniem inności, rodziło się we mnie zainteresowanie feminizmem. [...] Inspirowana przez myśl marksistowską ’hermeneutyka podejrzeń‘ używała radykalnej nieraz krytyki do rozbijania znaczeń-dogmatów, znaczeń-stereotypów. Tu również pojawił się na horyzoncie feminizm jako krytyka zastanego systemu przedstawień, krytyka dyskursu władzy: mieszczańskiej, patriarchalnej.«

90 | Vgl. Janion/Szczuka: Profesor Misia, S. 152.

91 I Nasiłowska in Janion: Kuferek Harpagona, S. 201. 
Janions zu spüren; so etwa für das Narrativ des Tragischen, das der antithetischen Werteordnung entspringt. ${ }^{92}$

Es ging Janion weder darum, ihre Forschung ganz in einen westlichen Theoriezusammenhang einzuschreiben, noch sie von diesem loszulösen, sondern für die lokal relevante Forschung die fruchtbarsten Ansätze transnational zusammenzubringen. Damit sollte eine Isolation lokaler Wissenschaft verhindert werden. Dieses Vorgehen schien für Janion besonders in Krisenzeiten unumgänglich, um intellektuelle Freiheiten verteidigen zu können. ${ }^{93}$

Dieser Ansatz zeigt sich etwa auch bei den Transgresje-Seminaren, in denen neben polnischem auch westeuropäisches und amerikanisches Material als Diskussionsgrundlage eingesetzt wurde. Janion ließ für die Seminare eigens Übersetzungen des ausgewählten Materials anfertigen, die dann durch simples Abschreiben unter den Studierenden kursierten. In dieser Hinsicht nahmen die letztlich in der Transgresje-Reihe veröffentlichten Materialien eine besondere Rolle in der polnischen Publikationslandschaft ein. Wie Janion retrospektiv schildert, strebte sie eine akademische Auseinandersetzung auf einem »europäischen Niveau ${ }^{94}$ an: "[...] hier, wo wir sind, ist Europa. Das hiesige intellektuelle Niveau darf demjenigen der europäischen Hochschulen in nichts nachstehen. Ich tat alles, um dies zu gewährleisten. ${ }^{95}$ Dies betraf auch die intellektuelle Herausforderung. Die Studierenden, die in den Seminaren und auch im wissenschaftlichen Austausch Janions allgemein eine wichtige Funktion einnahmen, profitierten von dieser offeneren Form der Wissensvermittlung und der Förderung des kritischen Denkens. Besonders wichtig war Janion auch 1972 schon die "zeitgenössische, wissenschaftliche und literarische, ambitionierte Publizistik Europas und Amerikas. Eine Publizistik, die versucht, sich mit der Situation des Menschen heute und in Zukunft auseinanderzusetzen ${ }^{96}$, also sich nicht nur auf eine beschreibende und analysierende Funktion beschränkt.

92 | Auch über sich selbst sagt Janion: »Ich bin ein Mensch des 0stens. Sogar mein Patriotismus ist östlich, dunkel, tragisch. « Janion in Dziurdzikowska, Renata: »Maria Janion. Samotność humanisty«, in: Twój Styl 30/1 (1993), S. 14-19, hier S. 17: »Jestem człowiekiem Wschodu. Nawet mój patriotyzm jest wschodni, ciemny, tragiczny.«

93 I Wiederum in den Worten Janions: »Unter dem Beilrücken der Märzgreuel warf ich mich mit verdoppelter Kraft auf französische und deutsche Bücher und Zeitschriften«, beschreibt sie ihre Reaktion auf die Verschärfung der staatlichen Kontrolle und die Absage an das revisionistische Lager rund um die Studentenproteste im März 1968. Janion/Szczuka: Profesor Misia, S. 33: »Pod obuchem zgrozy marcowej rzuciłam się na francuskie i niemieckie książki i czasopisma ze zdwojoną mocą." 94 | Dziurdzikowska: Maria Janion, S. 19.

95 I Janion/Szczuka: Profesor Misia, S. 33: »tu, gdzie jesteśmy, jest Europa, tu poziom intelektualny w niczym nie może ustępować uczelniom europejskim. Robiłam wszystko, żeby tak było.« 96 I Janion: Romantyzm, S. 246: »współczesnej, naukowej i literackiej, ambitnej publicystyki europejskiej i amerykańskiej. Takiej publicystyki, która próbuje się zajmować sytuacją człowieka dziś i w przyszłości«. 
Janions Anliegen war es, sich gerade nicht dem offiziellen Wissenschaftsdiskurs in Polen zu unterwerfen, der die Forschungsperspektive auf bestimmte Themen und Methoden reduzierte. Janion verweist darauf, dass die Politik »nicht speziell« Thema ihrer Seminare war,

»aber unser grundsätzliches Problem war Polen. Ohne Unterbruch sprachen wir über das geknebelte und leidende Polen, was wir aber mit einem enormen Misstrauen gegenüber dem patriotischen Kanon kombinierten. Allein die von uns behandelte Problematik der Transgression war schon ein gewichtiger Widerspruch angesichts nationaler Pflichten. « ${ }^{97}$

Darin äußerte sich auch die von Janion proklamierte »kulturelle Linksorientiertheit ${ }^{98}$ : als Forschung, die frei sein sollte von Denkangst, sich dennoch aber dem politischen Projekt einer Gesellschaftsreform widmete.

$\mathrm{Zu}$ diesem Projekt gehörte auch der Versuch einer Bildung, die die Schüler/innen und Studierenden zum Denken anregt. "Man muss die Leute nur öffnen, und schon zeigen sich die Talente. ${ }^{99}$ Im Gesellschaftsprojekt Janions ging es um die Anregung (besonders der Jugend) zu einem kritischen Denken, das sich über hegemoniale Diskurse hinwegsetzen könne. ${ }^{100}$ In diesen Kontext stellte Janion auch ihre Unterrichtsform des aktiven Miteinbezugs der Studierenden. Diese Form des integrativen und partizipativen >Lernens` respektive der Hervorbringung kritischer Gedanken sah Janion als ein Legat spezifisch mittelosteuropäischer Kommunikations- und Edukationsansätze: »Als Tragen der Fackel der Bildung, als Unumgänglichkeit der Aufklärung des Volkes, der unteren oder unaufgeklärten Schichten. ${ }^{101}$ Dieser Unterricht, der jegliche sozialen Schichten umfasse, berge das Potential einer egalitären Gesellschaft.

Im Vordergrund dieser Bildungsform standen gemeinsame Überlegungen und das Voranbringen von Analysen und Interpretationen in der Diskussion. Dieses vom Dialog geprägte Vorgehen bildete auch die Basis der janionschen Forschungsarbeit. »Die Methode ist folgende: zuerst muss der Gedanke der Probe unterzogen werden, er muss viele Male formuliert werden - und zwar gegenüber Leuten, de-

97 | Janion/Szczuka: Niedobre dziecię, S. 147: »natomiast zasadniczym naszym problemem była Polska. Bez przerwy rozmawialiśmy o Polsce zniewolonej i cierpiącej, zestawiając to jednocześnie z wielkim buntem i sprzeciwem wobec kanonu patriotycznego. Sam dobór problematyki transgresyjnej był już poważnym sprzeciwem wobec narodowych obowiązków.«

98 । Janion/Szczuka: Profesor Misia, S. 22: »kulturowa lewicowość«.

99 | Janion in Dziurdzikowska: Maria Janion, S. 18: »Trzeba tylko ludzi otworzyć, a natychmiast ujawniają się te talenty."

100 | Vgl. Janion/Szczuka: Profesor Misia, S. 71.

101 I Janion/Szczuka: Niedobre dziecię, S. 153: „W sensie niesienia tego kagańca oświaty, konieczności oświecania ludu, warstw niższych czy nieoświeceniowych.» 
ren Reaktion ich beobachten kann. «102 $^{10}$ gs geht hier somit um eine Art kollektiver Denk- und Forschungsarbeit, die erst durch das Einbringen und Diskutieren verschiedener (subjektiver) Standpunkte die benötigte Schärfe und analytische Tiefe gewinnt. Bereits 1972 beschrieb Janion, wie sie ihre Forschungsperspektiven entwickelte, nämlich »auch aus dem Verlauf der Seminarstunden, aus den Dialogen mit den Hörern, die ihren Dozenten oft - und dies glücklicherweise! - mit ihren Gedanken und Interessen leiten. $\aleph^{103}$

In den obigen Ausführungen zu performativen Geschlechtsübertretungen kamen vor allem die Studierenden Janions zu Wort. Gerade bei diesen lassen sich die am weitesten in Konzepte des Performativen vorrückenden Beispiele finden zumindest, was die Transgresje-Publikationen betrifft. Dieses Phänomen lässt darauf schließen, dass es sich bei den Transgressionsseminaren tatsächlich um eine dialogische und mehrperspektivisch inspirierte Diskussionsrunde gehandelt hat. Gleichzeitig entwickelten die Studierenden und Doktorierenden die von Janion angestoßenen Themen weiter; Janion selbst streifte manche Bereiche nur. Ähnlich verhielt es sich mit der feministischen Kritik, die in Janions Arbeiten bis in die 1990er Jahre nie konkret (als `feministische`) thematisiert wurde.

\subsubsection{Feministische Kritik als Notwendigkeit}

Wie im Verlauf des Kapitels mehrfach angedeutet, bezog Janion ab den 1970er Jahren die Frage nach vergeschlechtlichten Machtdiskursen in ihre Forschung mit ein und verlieh ihr Relevanz. Dieses Interesse an der Kategorie des Geschlechts sieht Janion retrospektiv als eine Konsequenz ihres Versuchs, Hermeneutik und Dekonstruktion - als Methoden der Identitätsfindung resp. Differenzbildung zusammenzudenken. Doch während Janion unzweifelhaft Sympathien für die soziopolitischen Bestrebungen etwa der Women's Liberation in den USA hegte, stellte sie deren Anliegen für sich selbst und den polnischen Kontext nicht in den Vordergrund.

Janion verhandelte $>$ feministische` Fragestellungen am Beispiel literarischer Texte, bezog allerdings theoretisierende Arbeiten zum Feminismus kaum in ihr Schaffen ein. Zusammen mit den Texten Santos' gelangten die feministischen Publikationen des Pariser Verlags Éditions des femmes nach Polen und in Janions Seminare. Janion resümiert rückblickend: »[D]ahinter erschienen bereits die unserem Geist auflauernden Figuren Hélène Cixous’ oder Luce Irigarays. ${ }^{104}$ Diese Aussage suggeriert, dass Janion die Texte Cixous' und Irigarays als eine Art >Be-

102 | Janion: Kuferek Harpagona, S. 199: »Metoda jest taka: najpierw myśl trzeba poddać próbie, trzeba ją sformułować wiele razy i to wobec ludzi, których reakcje mogę śledzić."

103 I Janion: Romantyzm, S. 7: "jak i z toku zajęć seminaryjnych, dialogów ze słuchaczami, częstokroć - i jakże szczęśliwie! - kierującymi myślami i zainteresowaniami swego wykładowcy.« 104 । Janion: Droga, S. 16: „w jej głębi pojawiły się już czyhające na nasze umysły postacie Hélène Cixous czy Luce Irigaray.« 
drohung ‘ wissentlich ausklammerte. Man kann allerdings nur vermuten, dass sich dieser Ausschluss darauf zurückführen lässt, dass Janion diese Texte mit ihrer zentralen Betonung des Geschlechts und der weiblichen Erfahrung als zu eindimensional einschätzte.

Janion sieht die Frage nach dem Geschlecht immer im Kontext weiterer Hierarchisierungen und diskursiver Mechanismen, wie etwa der Norm bzw. Abnormität im Bereich des Geistes oder der Kreativität. Die Geschlechterordnung ist bei Janion relational und eng verknüpft mit weiteren Faktoren gesellschaftlicher Strukturierung. Darin liegt auch der Grund, weshalb Janion bis in die 1990er Jahre eine feministische Positionsergreifung nicht als dringlich sah:

»ch erinnere mich, wie ich während einer feministischen Diskussion in internationalem Kreis in Westberlin Ende der 80er Jahre daran festgehalten habe, dass die sSolidarność zuerst Unabhängigkeit und Demokratie für die ganze Gesellschaft erkämpfen müsse. Erst danach könne sie sich in aller Ruhe der Frauenfrage und der Verbesserung der Lage von Frauen widmen. « ${ }^{105}$

Diese die Gesamtgesellschaft als historische Priorität in den Vordergrund stellende Perspektive revidierte Janion allerdings im Zuge des Transformationsprozesses, der geschlechtliche Ungleichheiten deutlicher zum Vorschein brachte und verstärkte. Janions Erkenntnis im Zuge der 1989 einsetzenden Transformation, dass die Aufhebung vergeschlechtlichter Hierarchien nicht im Interesse der sallgemeinen Gesellschaft liege und gar auf Widerstände stoße, brachte die Polonistin zu deutlicherem Vokabular.

Janion spricht in den 1990er Jahren dezidierter aus einer feministischen Position und über die patriarchale Gesellschaftsordnung. Diese Wende wurde unterstützt durch das Engagement etwa der Janion-Schülerin Kazimiera Szczuka, die sich bereits intensiver mit feministischer Kritik auseinandergesetzt hatte und diese Perspektive an Janion weitervermittelte. Darauf verweist eine Anmerkung Janions in ihrem zweiten Aufsatz zu Komornicka/Włast, den sie im Zeichen dieser 'neuen<, zugespitzten Forschungsperspektive verfasste. ${ }^{106}$ Diesen Perspektivenwandel untersuche ich im Folgenden anhand von Janions beiden Studien zu Komornicka/Włast von 1979 und 1996 genauer.

An dieser Stelle soll aber schon angemerkt werden, dass es sich bei diesem ,feminist turn Janions um keine endgültige und abschließende Wende handelte, sondern um eine Intensivierung der Thematik und eine stärkere Anbindung an westliche feministische Ansätze in den 1990er Jahren. Die feministische Kritik

105 I Janion: Kobiety, S. 326: »Pamiętam, jak podczas dyskusji feministycznej w gronie międzynarodowym w Berlinie Zachodnim pod koniec lat 80-tych utrzymywałam, że 'Solidarność musi najpierw wywalczyć niepodległość i demokrację dla całego społeczeństwa, a potem dopiero będzie mogła spokojnie zająć się kwestią kobiecą i polepszeniem kondycji kobiet."Siehe auch Janion/Szczuka: Profesor Misia, S. 149.

106 I Vgl. Janion: Kobiety, S. 241. Allgemeiner siehe dies.: Droga, S. 17. 
erfuhr in Polen aufgrund der gesellschaftlichen wie auch wissenschaftlichen Entwicklungen der 1990er Jahre einen Aufschwung, obwohl sie wie auch der feministische Aktivismus ein marginales Phänomen blieb. Dieses allgemeinere Interesse an feministischen Ansätzen schien auch bei Janion eine begriffliche Angleichung und Perspektivenschärfung hervorzurufen. Dies bedeutet jedoch nicht, dass Janion ihre >eigene` Sprache verließ oder ihren Forschungshorizont längerfristig auf das Geschlecht verengte.

\subsection{IIKONeN` der feministischen POLONISTIK}

Der folgenden Analyse der beiden Studien Janions über Maria Komornicka bzw. Piotr Włast möchte ich die Rezeptionsgeschichte der Texte Komornickas/Własts voranstellen, um die beiden hier untersuchten Studien verorten zu können. Anschließend vergleiche ich die Studien von 1979 und 1996 mit dem Fokus darauf, wie sich Janions Beurteilung der `Frauenfrage und ihre Herangehensweise an das Geschlecht als Analysekategorie veränderten und welche Rolle feministische Ansätze dabei einnahmen. Danach setze ich Janions Studien in den Kontext des breiteren Interesses, das Komornicka/Włast mit den 1990er Jahren zuteil wurde, und beleuchte dabei Janions Positionierung innerhalb der sich entwickelnden feministischen Kritik in Polen.

Die ikonische Stellung der/des Schriftsteller/in Komornicka/Włast in der feministischen Literaturwissenschaft Polens ist eng verknüpft mit ihrer/seiner außergewöhnlichen Biographie. Maria Komornicka (1876-1949) debütierte kurz vor der Jahrhundertwende erfolgreich als junge Schriftstellerin der Młoda Polska. Mit der Ablegung des weiblichen Geschlechts und der Neudefinition als Mann unter dem Namen Piotr "Odmieniec (»Sonderling») Włast brach ihre/seine Karriere 1907 jedoch radikal ab. Neben der männlichen Selbstbenennung schrieb Włast fortan im männlichen Genus und kleidete sich nach männlicher Art, womit er sich »an den wichtigsten kulturellen Orten, an denen sexuelle Dichotomie sich äußert«, "neu markiert ${ }^{107}$. Diese Geschlechtstransgression wurde von ärztlicher Seite als Nervenkrise diagnostiziert. Das literarische Interesse an Własts Texten versiegte vollständig. ${ }^{108}$ Von 1907 bis 1914 wurde Włast in verschiedenen Anstalten hospitalisiert; mit dem Ausbruch des Ersten Weltkriegs kehrte er zu seiner Familie zurück und verstarb 1949 von der Gesellschaft isoliert auf dem elterlichen Hof.

Dieser biographische sSonderfall führte ab den 1970er Jahren zu einem Interesse nicht nur an den literarischen Texten, sondern auch an der Biographie Komornickas/Własts. Diese stand stets ebenso im Mittelpunkt der literaturwis-

107 | Ritz, German: »Maria Komornicka: Die gefährdete Autorschaft in den Wirren des Geschlechts. Die widerständige Identität der Transvestitin«, in: Frank, Susi et al. (Hg.), Mystifikation - Autorschaft - Original, Tübingen 2001, S. 135-161, hier S. 137.

108 I Vgl. Janion: Kobiety, S. 186; Ritz: Maria Komornicka, S. 137. 
senschaftlichen Auseinandersetzung und verdrängte das literarische Werk teilweise gar aus dem Interessenshorizont. ${ }^{109}$ Die feministische Kritik warf der bisherigen Rezeption (oder besser: Nicht-Rezeption) vor, dass diese aus dem Leben des Schriftstellers unhaltbare Rückschlüsse auf das literarische Schaffen gezogen habe, setzte sich aber selbst auch intensiv mit der Biographie auseinander.

Janion positioniert ihre eigene Auseinandersetzung mit dem Werk und der Person Komornickas/Własts im Kontext der beginnenden Rehabilitierung, die Janion auch als Ausdruck sich wandelnder sozialer Vorstellungen sieht. 1969 lenkte Podraza-Kwiatkowska mit ihrem Artikel Tragiczna wolność (Tragische Freiheit) das polonistische Interesse auf die »völlig vergessene Poetin und Essayistin « ${ }^{110}$ Komornicka; 1977 folgte eine Publikation bisher unveröffentlichter später Gedichte Własts durch Maria Dernałowicz. ${ }^{111}$ Die Gedichte, so Janion, "fanden großes Gefallen, besonders bei jungen Leuten, die an verschiedenste unkonventionelle Formen der Poesie gewöhnt sind; die in der inneren Erfahrung Wahrheit suchen, wo einst nur Signal und `Beweis` der Abart [...] und des Wahnsinns gesehen wurde. $\aleph^{112}$ Janion sieht darin eine Bereitschaft zur Auseinandersetzung mit Themen, die bis in die 1960er Jahre tabuisiert und pathologisiert wurden.

Im Spezifischen kritisiert Janion damit die Publikation in der Reihe Archiwum Literackie (Literarisches Archiv) von Stanisław Pigoń aus dem Jahre 1964, die das Spätwerk Własts ausblendete. ${ }^{113}$ Diese bibliographische Zensur steht Janion zufolge in engem Zusammenhang mit dem Urteil über die psychische Verwirrung Własts, welche sich laut Pigoń als Unverständlichkeit in den Texten niederschlage. Diese Auslassung begründete Pigoń mit einem gemäß Janion "pseudomedizinischen ${ }^{114}$ Gutachten des Arzts Aleksander Oszacki, ${ }^{115}$ der seine Diagnose psychischer Krankheit Komornickas aus einem ihrer Werke ableitete. Dieses Gutachten nimmt in der archivalischen Publikation die prominentere Rolle ein als die (späten) Werke Własts selbst. Janion schreibt in ihren Studien gegen dieses Verdikt

109 | Vgl. Filipiak, Izabela: »W.+M. = M.W.«, in: Ritz et al., Nowa świadomość płci (2000), S. 111140, hier S. 113.

110 | Podraza-Kwiatkowska, Maria: »Tragiczna wolność. 0 Marii Komornickiej«, in: dies., Młodopolskie harmonie i dysonanse, Warszawa 1969, S. 137-168, hier S. 137.

111 I Vgl. Dernałowicz, Maria: »Piotr Odmieniec Włast«, in: Twórczość 3 (1977), S. 75-78.

112 I Janion: Kobiety, S. 187: „Bardzo się one ogólnie podobały, zwłaszcza ludziom młodym, przyzwyczajonym do rozmaitych niekonwencjonalnych sposobów uprawiania poezji i poszukującym prawdy w doświadczeniu wewnętrznym, które kiedyś wydawało się tylko sygnałem i ‘dowodem dewiacji, [...], szaleństwa."

113 | Vgl. Pigoń, Stanisław (Hg.), Miscellanea z pogranicza XIX i XX wieku (= Archiwum Literackie, Band 8), Wrocław u.a. 1964.

114 I Janion: Kobiety, S. 222: "pseudomedyczne«.

115 | Vgl. Oszacki, Aleksander: "Spowiedź niedorodzonej. Kilka uwag lekarza o psychice Marii Komornickiej«, in: Pigoń, Miscellanea (1964), S. 342-349. 
an, indem sie die Texte Własts nicht zu werten versucht, sondern darin nach den existentiellen Bedrängnissen Komornickas/Własts forscht.

Janions erster Text zu Komornicka, "Gdzie jest Lemańska?!" (»Wo ist Lemańska?!«, 1979), erschien $1982 \mathrm{im}$ Rahmen der Transgresje-Reihe, ist aber auch im Band Kobiety i duch inności von 1996 enthalten. ${ }^{116}$ Dort wird er kontrastiert mit dem eigens für diese Publikation geschriebenen zweiten Text Maria Komornicka, in memoriam. ${ }^{117}$ Die beiden Studien trennt eine Zeitspanne von über 15 Jahren sowie der Umbruch des Systems von 1989 und damit auch ein Setting in unterschiedlichen gesellschaftlichen und wissenschaftlichen Kontexten.

Grundsätzlich lässt sich die erste Studie auf Janions Interesse an der diskursiven Grenze zum `Wahnsinn`zurückführen. Sie verweist auf die gesellschaftliche Sanktionierung nicht-normativen Verhaltens - bei Komornicka betrifft dies vor allem die transformative Selbstdefinition als Mann -, die in die Pathologisierung von "Sonderlingen « münde. Dies belegt sie mit dem Gutachten Oszackis, das dem normativen Rahmen dieser Zeit Rechnung trage und das Material einem Normierungsprozess unterziehe. Dieser Prozess sei, wie Janion an Oszackis Urteil aufzeigt, von verschiedenen Achsen wie Gemeinschaftsdenken oder Katholizismus geprägt, die einen "gebändigten Egozentrismus « ${ }^{118}$ anstrebten.

Janion bezieht sich in ihrer ersten Analyse primär auf antipsychiatrische Ansätze, die ihre kritische Haltung der diskursiven Macht der Ausgrenzung jeglicher Normverstöße gegenüber ergänzen. Im Kontrast zu den strukturalistischen Schwerpunkten der Polonistik der 1970er und 1980er Jahre fokussiert Janion auf psychologische Aspekte und individuelle Reibungen mit dem gesellschaftlichen Diskurs. Das Geschlecht erscheint hier aufgrund des Geschlechtswandels Komornickas/Własts als eine relevante Größe, steht aber eher im Hintergrund der »existenzphilosophischen «"19 Diskussion der »inneren Erfahrung « ${ }^{120}$ und mentalen Entwicklung.

Die zweite Studie entstand nicht nur aus eigenem Bedürfnis Janions heraus, neue Aspekte in der Untersuchung zu berücksichtigen. Auslöser für die Revision ihres Standpunktes war laut Janion eine Replik des Literaturhistorikers Roman Zimand auf ihre erste Studie. ${ }^{121}$ Zugleich bezieht Janion auch Inputs ihrer Studentinnen mit in den Ansatz ein: von Szczuka, was die feministische Kritik betrifft, und von Alina Gałązka, die mit Transfiguracja Marii Komornickiej (Die Transfiguration Maria Komornickas, 1992/93) eine Magisterarbeit zum Thema verfasste.

116 | Janion, Maria: »Gdzie jest Lemańska?!«, in: Janion/Majchrowski, Odmieńcy (1982), S. 152-199 sowie in: Janion: Kobiety, S. 186-239.

117 | Janion: Kobiety, S. 241-318.

118 | Oszacki: Spowiedź niedorodzonej, S. 349: "poskromionego egocentryzmu«.

119 I Zimand, Roman: "Klucze do Marii P.O.W.«, in: ders., Wojna i spokój. Szkice trzecie, London 1984, S. 123-143, zit. nach Janion: Kobiety, S. 242.

120 I Janion: Kobiety, S. 187: »doświadczenie wewnętrzne«.

121 | Vgl. Zimand: Klucze. 
Janions zweite Studie zu Komornicka/Włast fokussiert stärker auf Komornickas Verhältnis zum Geschlecht, was laut Zimand in der ersten Studie zu wenig berücksichtigt wurde. Janion betont die Unvollständigkeit ihrer früheren Thesen und die neuen Perspektiven, die sich ihr dank der kritischen Rezeption ihres ersten Artikels eröffnet hätten: »In meinem intellektuellen Leben spielte Zimands Standpunkt eine wichtige Rolle; er hat mich zum erneuten Nachdenken über viele Fragestellungen angeregt, die mit Komornicka - und nicht nur - in Verbindung stehen. ${ }^{122}$ Ebenfalls verweist sie auf die Relevanz feministischer Kritik in der neuen Studie. ${ }^{123}$ Der Hauptfokus dieser Studie liegt somit auf der systemischen Misogynie des Patriarchats, deren Inkorporierung durch Komornicka und der Geschlechtstransformation als Kapitulation. Die Verschiebung hin zu einer stärkeren Berücksichtigung nicht nur der Kategorie des Geschlechts, sondern auch feministischer Kritik zeigt sich etwa in der neuen Perspektive auf die Archiwum Literackie-Publikation Pigońs. ${ }^{124}$ Trotz dieser Fokussierung auf das Geschlecht finden sich auch in der zweiten Studie Janions viele Nebenstränge, die diese Thematik überschreiten.

Die Auseinandersetzung mit Komornicka/Włast fügt sich in vielen Bereichen in die Hauptinteressen der polnischen feministischen Kritik der 1990er Jahre ein; dies betrifft etwa die spezifische Zensur und Bevormundung, die Leben und Werk der/des Schriftsteller/in erfasste. Die Studien über Komornicka/Włast weichen jedoch in einem zentralen Punkt von der in den 1990er Jahren unter dem Schlagwort feministischer Kritik vermehrt praktizierten Aufwertung >weiblicher Literatur ab; Komornicka/Włast selbst lehnte `weibliches`Schreiben nämlich kategorisch ab. Die nachfolgend detaillierter untersuchten Studien Janions ordnen sich der feministischen Strömung somit zu, wie sie sich auch davon absetzen. Damit illustriert der Casus Komornicka/Włast gleichsam die oszillierende Rolle und Selbstverortung Janions in der polonistischen Auseinandersetzung mit der Kategorie des Geschlechts.

\subsubsection{Die Kondition der Frauen}

Die Frage nach Geschlechterkonventionen stellt Janion nicht nur in Bezug auf das Schreiben, sondern besonders auch in Bezug auf die historische Figur Komornicka/Włast. In der Studie von 1979 betont Janion diesbezüglich die Auflehnung Komornickas gegen die sie als Frau treffende soziale Repression. Der herrschende Diskurs, der Frauen jegliche Kreativität absprach, habe bei Komornicka eine

122 | Janion: Kobiety, S. 241: „W moim życiu intelektualnym odegrało ono [stanowisko Zimanda] ważną rolę - zmusiło mnie do ponownego przemyślenia wielu zagadnień związanych z Komornicką i - w końcu - nie tylko z Komornicką."

123 | Vgl. ebd.

124 | Vgl. ebd., S. 303f. Auf diese Verschiebungen in der Rezeptionsrevision gehe ich in Kapitel 5.1.1 detailliert ein. 
Verneinung der eigenen weiblichen Geschlechtlichkeit erwirkt. Trotz ihres weiblichen Körpers »empfand Komornicka nie eine Zugehörigkeit zu den Frauen [...]. Sie wollte stets Künstler, Poet, Kritiker, Philosoph, Guru, Priester sein; was aber das Verwerfen der Kondition der Frau verlangte, die dies alles nicht sein konnte oder besser - nicht sein sollte. ${ }^{125}$ Komornicka habe sich stets der männlich-universalen Geistessphäre zugehörig gefühlt, was schließlich in die Überschreitung der sozialen Geschlechtergrenzen mündete - Komornicka »wurde zum Symbolischen Mann ${ }^{126}$.

Janion sieht 1979 die Transfiguration zum männlichen Geschlecht als ein Ausdruck des Aufbegehrens, den man »auf keinen Fall Kapitulation nennen kann. « ${ }^{127}$ Mithilfe der männlichen Selbstdefinition im kulturellen Geschlecht wie auch im literarischen Ausdruck habe Włast den Rahmen der ausschließlichen Weiblichkeit sprengen und in das "allgemeine Menschsein « ${ }^{128}$ übertreten können, die die Befreiung des Geistes von der von Komornicka/Włast verachteten Körperlichkeit ermöglicht habe.

Der Forschungsfokus liegt 1979 auf der Ergründung gesellschaftlicher Integrations- und Ausgrenzungsmechanismen. Janion interpretiert die Transformation zum symbolischen Mann als Form der Transgression gesellschaftlicher Normen, als ein Bruch mit dem Diskurs und als selbstgewählte Distanzierung, die auch die soziale Ausgrenzung in Kauf nehme. Mit dem Fokus von 1996 auf die symbolische Geschlechterordnung des Patriarchats und deren Wertehierarchie stellt Janion hingegen fest, dass Komornicka die misogynen Stereotype ihrer Zeit inkorporiert habe. »Sie verschloss nicht einmal die Augen vor den misogynen Motiven ihrer Lektüre; ihr Radikalismus bestand gerade darin, dass sie sich an diesen orientierte. Sie übernahm die schlimmsten Dinge, welche die Philosophen über Frauen schrieben, `nahm sie auf sich «. « ${ }^{129}$ Da der gesellschaftliche Diskurs den Frauen kreatives Talent und Verstand absprach, musste Komornicka in ihrem Eigenverständnis »im Grunde« ein Mann im falschen Körper sein. Die Verachtung des Weiblichen und des eigenen Körpers, die zum symbolischen Abstreifen des Weiblichen und zur Überhöhung des männlichen Ideals führten, sieht Janion nun als eine diskursive Assimilation.

125 । Ebd., S. 229: »Komornicka nigdy nie miała żadnego poczucia łączności z nimi [kobietami-samicami] [...]. Zawsze chciała być Artystą, Poetą, Krytykiem, Filozofem, Guru, Kapłanem wymagało to jednak porzucenia kondycji kobiety, która nie mogła - czy raczej nie powinna - być tym wszystkim."

126 | Ebd.: "Stała się Symbolicznym Mężczyzną. “

127 | Ebd., S. 228: »nie można nazwać w żadnym wypadku kapitulacją."

128 | Ebd., S. 230: "0gólną człowieczość«.

129 । Ebd., S. 247: »Nie tylko nie przymykała oczu na mizoginiczne wątki swoich lektur, lecz jej radykalizm polegał na tym, że nastawiała się właśnie na nie. Przymowała, niejako ১brała na siebie‘, najgorsze rzeczy, które filozofowie pisali o kobietach.« 
Als Schlüsselsituation beschreibt Janion die Konfrontation mit dem diskriminierenden Gesellschaftssystem in England, als Komornicka 1894 in Cambridge studierte. Hier beobachtete Komornicka die

»umfassende Eliminierung der Frauen aus dem öffentlichen Leben, das Wegdrängen aus Positionen der Machtausübung. Anhand der Erinnerungen aus Cambridge könnte man Komornicka für eine Befürworterin der Emanzipation halten, deren Stimme Virginia Woolfs A Room of One's Own vorwegzunehmen scheint. Dem ist jedoch nicht so.« ${ }^{130}$

Die fehlende Auflehnung respektive freiwillige Unterordnung der englischen Frauen unter das repressive System habe für Komornicka den Beweis erbracht, dass Frauen den Männern gegenüber tatsächlich niedereren Ranges seien. ${ }^{131}$ Dieses hierarchische, metaphysische Geschlechterverständnis habe Komornicka zu einer der weiblichen Emanzipation und dem Feminismus entgegengestellten Position geführt. ${ }^{132}$

Janion zufolge liegt die grundlegende Differenz zur protofeministischen Position Woolfs »darin, dass Komornicka unter den Frauen keine Verbündeten wahrnimmt. Sie sieht zwischen ihnen wenig Potential auf $>$ geistige Kollegialität..${ }^{133}$ Das Projekt Komornickas, sich der Fesseln des Geschlechts zu entledigen, habe also mit Solidarität und einer Mobilisierung von Mit-Frauen zur Veränderung der Geschlechterordnung nichts gemeinsam. Komornicka vollziehe mit ihrer Transformation zum Mann eine symbolische und endgültige Trennung vom Weiblichen als individualistisches Projekt.

Janion nimmt in ihrer Studie keine explizite Wertung der kontrastierten Ansätze von Woolf und Komornicka vor. Sie hegt offensichtlich Sympathien für die solidarisch-emanzipatorische Herangehensweise Woolfs, respektiert aber auch die >Antwort` Własts auf die Geschlechterordnung. Die misogyne Einstellung des Schriftstellers und seine Flucht in die Männlichkeit sieht Janion zwar als kritikwürdig an, fasst diesen Schritt jedoch als für Włast möglicherweise einzigen und einsamen Ausweg aus dem repressiven Gesellschaftssystem auf. Janion sieht 1996

130 | Ebd., S. 256: "wszechstronnego wyeliminiowania kobiet z życia publicznego, odsunięcia od możliwości sprawowania władzy. Na podstawie wspomnień z Cambridge Komornicka mogłaby uchodzić za emancypantkę, której głos zdaje się poprzedzać Własny pokój Wirginii Woolf. Ale jednak tak nie jest."

131 I Vgl. ebd., S. 248.

132 I Vgl. ebd., S. 243. Siehe auch Kralkowska-Gątkowska, Krystyna: "Dziwne miasto EropoliS. Obrazy i funkcje erotyki w tekstach Marii Komornickiej«, in: Piętkowa, Eros, psyche, seks (1993), S. 27-34, hier S. 27, die in den frühen Texten Komornickas die "kämpferisch-feministische, emanzipatorische Ideologie der Epoche« widergespiegelt sieht.

133 I Janion: Kobiety, S. 259: „to, że Komornicka nie dostrzega sojuszniczek wśród kobiet. Nie widzi między nimi szerszej możliwości ’koleżeństwa umysłowego‘." 
Włast somit nicht mehr als ১Überwinder` des normativen Geschlechterdiskurses, sondern implizit als dessen Opfer.

\subsubsection{Geschlecht und Identität}

Daran anknüpfend scheint es mir notwendig zu diskutieren, in welchen Zusammenhang Janion Geschlechtlichkeit und Identität am Beispiel Komornickas/ Własts bringt. Interessant ist dabei, dass Janion auf den Aspekt der Körperlichkeit kaum eingeht und das Geschlecht vor allem als Effekt sozialer und psychologischer Prozesse begreift. Dabei wirft das untersuchte Material Komornickas/ Własts die Frage auf, ob und auf welche Weise Geschlechtlichkeit überwunden werden kann.

Die Auseinandersetzung mit dem Geschlecht betrifft in der Studie von 1979 vor allem die Evolution zum von Komornicka imaginierten neuen, neutralen Menschen, von dem Frauen grundsätzlich weiter entfernt seien als Männer. »Weil sie sich nicht als `neue Frau realisieren konnte, wurde Komornicka zum wiedergeborenen Menschen«, schreibt Janion, und die Figur Włast sei »im Grunde ein asexuelles Wesen. Der männliche grammatische Genus signalisierte das allgemeine Menschsein [...]. « ${ }^{134}$ Komornicka schreibe die Geschlechtlichkeit der »Trivialität der im Sumpf festgefahrenen Spießbürger « ${ }^{135} \mathrm{zu}$, während der »vom heißen Atem des Dämons der Erkenntnis umwehte ${ }^{136}$ neue geistige Mensch geschlechtsneutral sei. Das Geschlecht wird in Janions Auslegung somit von einer Skala des Geistes (duch) wie auch von den Achsen von Realität und Utopie sowie Norm und Transgression durchdrungen.

Eine analytische Dimension des Geschlechterkonzepts brachte Janion 1979 mit der vom US-amerikanischen Psychiater Robert Stoller skizzierten Unterscheidung verschiedener Ebenen der Geschlechtsidentität ein.

»Robert Stollers Sex and Gender führte dazu, dass man sich drastisch der Schwierigkeiten in der Definierung des Geschlechts bewusst wurde, und legte überzeugend dar, dass in einem Individuum bedeutende Konflikte zwischen dem spsychologischen Geschlecht und dem ssozialen oder sanerzogenen Geschlecht existieren können, also zwischen einem dem Geschlecht zugeschriebenen Äußeren und der inneren Geschlechtsidentität. « ${ }^{137}$

134 | Ebd., S. 230: »Nie mogąc się spełnić jako ’kobieta nowa<, Komornicka stała się odrodzonym człowiekiem. [...] w gruncie rzeczy istotą aseksualną. Męskie odmiany gramatyczne sygnalizowały ową ogólną człowieczość [...]."

135 | Ebd., S. 213: »trywialności grzęznących w błocie filistrów«.

136 | Ebd., S. 206: »owianej gorącym tchem demona, demona poznania«.

137 | Ebd., S. 227f.: »Badania nad tożsamością seksualną Roberta Stollera doprowadziły do drastycznego uświadomienia trudności w zdefiniowaniu płci oraz do przeświadczenia, że mogą istnieć w jednostce poważne konflikty między ’płcią psychologiczną، a ’płcią społeczną czy ’płcią wykształconą<, między przypisywanym płci wyglądem zewnętrznym a wewnętrzną tożsamością płciową." 
Janion beschreibt hier die Unterscheidung eines psychologischen und eines sozialen Geschlechts. Dabei handelt es sich allerdings nur um zwei Ebenen der von Stoller vorgeschlagenen Trichotomie von sex, gender identity und gender role. Stoller nämlich untersucht und konzeptualisiert primär die Differenzierung von sex (als biologischem Geschlecht) und gender (als sozialem Geschlecht). Gender wiederum unterscheidet er in gender identity (als psychologisches Geschlechts empfinden`) und gender role (als soziale Geschlechterrolle). ${ }^{138}$ Es ist diese Unterscheidung von externer, kulturell vorgeschriebener Geschlechterrolle und individuellem internen Empfinden, die Janion in ihrer Untersuchung des Falls Komornicka/Włast interessiert.

Mit der Unterscheidung in psychologisches und soziales Geschlecht, die die sex/gender-Dichotomie weiter differenziert, führte Janion eine Dimension ein, die in den polnischen 1990er Jahren mehrheitlich übersehen wird. Die feministische Kritik der 1990er Jahre differenziert selten zwischen biologischem und kulturellem Geschlecht und spricht auch die potentielle Problematik von Divergenzen zwischen zugeschriebenem und 'gefühltem` Geschlecht kaum an. Das Geschlecht resp. die ,Weiblichkeit` erscheint hier als abgeschlossene Größe, der lediglich eine neue Position in der sozialen Ordnung zugeschrieben werden müsse (siehe Kapitel 5). Janion hingegen suggerierte 1979 mit dem Verweis auf "Spezialisten", dass es gerade die Selbstwahrnehmung sei, die als leitende Größe der Geschlechtsidentität anerkannt werden sollte: »Viele zeitgenössische Spezialisten sind der Meinung, dass vor allem das 'psychologische Geschlecht‘ als Leitgröße zu betrachten ist. Man kann vermuten, dass gerade so auch Komornicka vorging. ${ }^{139}$ Janions Ansatz gab hier deshalb eine weniger essentialistische Richtung vor, als sie sich später in den 1990er Jahren herausbildete.

Die biologische Komponente hingegen schien für Janion gänzlich irrelevant, weshalb sie wohl auch den Gegensatz von sex und gender in ihrer Studie nicht einführte und Körperlichkeit oder das biologische Geschlecht kaum berücksichtigte. Die Dimension des Körpers erscheint im Text nur im Zusammenhang mit frühen Gedichten Komornickas, wobei der »Körper als Instrument der metaphysischen Entrückung verstanden wird. $\aleph^{140}$ Im Vordergrund der körperlichen Ekstase steht jedoch das geistige Begehren. Własts Verachtung der Körperlichkeit verdrängte diese auch aus dem Sichtfeld Janions. ${ }^{141}$

138 | Vgl. Stoller, Robert J.: Sex and Gender. Volume I. The Development of Masculinity and Femininity, London 1968 (1984), S. 9 f.

139 I Janion: Kobiety, S. 228: »Wielu współczesnych specjalistów podziela przekonanie, że należy dopuszczać do kierowania się przede wszystkim odczuciem ’płci psychologicznej. Można domniemywać, że Komornicka tak właśnie postąpiła."

140 । Ebd., S. 216: "ciało rozumiane jest jako narzędzie metafizycznego uniesienia."

141 I Siehe dazu auch Kralkowska-Gątkowska: Dziwne miasto Eropolis, S. 28f., die auf die Fragmentarizität der in den frühen Texten dargestellten Körperlichkeit sowie auf die Vorrangstellung eines intellektuellen Bündnisses zweier Figuren eingeht, während die Erotik bloß »instrumentell« 
In der zweiten Studie von 1996 setzt sich Janion von Komornickas misogynem Geschlechterkonzept und der Vorstellung, dass die Männlichkeit einer idealen, geschlechtlosen Menschlichkeit näherstünde, deutlich ab. »Was für Komornicka metaphysisch war [...], ist im Grunde ein soziales Phänomen. Es betrifft die Aufteilung der Geschlechterrollen in der Gesellschaft. « ${ }^{142}$ Janion hält fest, dass die (Selbst)Diskriminierungen, die Komornicka in der Gesellschaft beobachte, durch den sozialen Diskurs geformt und aufrechterhalten würden und sich nicht auf eine bestimmte geschlechtliche Essenz zurückführen ließen.

Interessanterweise erscheinen im Artikel von 1996 die Differenzierungen von psychologischem und sozialem Geschlecht nicht mehr explizit. Nun verweist Janion stärker auf die Körperlichkeit als Basis des zugeschriebenen sozialen Geschlechts. Komornicka/Włast jedoch streife diese in einer mentalen Negierung ab: »Komornicka war völlig überzeugt von der Transformation, die sie in ihrem Geist beschlossen hatte, und hegte keine Zweifel daran, dass sie ein Mann war [...]. «143 Dabei betont Janion, dass die Überwindung des weiblichen Geschlechts als Körperlichkeit ausschließlich auf einer sozialen Ebene stattfand, während der Körper als Träger des biologischen Geschlechts an Bedeutung verlor. »Es war ein geistiger Akt des Wechsels der Geschlechtsidentität, frei von jeglichen physischen Korrekturbestrebungen. Die >Operation`vollzog sich bei [Komornicka] vor allem auf der sprachlichen Ebene, auch im Sinne der `Zeichen der Kleidung`. « ${ }^{144}$

Die Abneigung gegen das Weibliche sieht Janion nun zudem in einem männlich-homosexuellen Kontext: »Ihr biologischer und ästhetischer Widerwille gegenüber der Weiblichkeit und die >Umgestaltung`zum Mann mögen davon zeugen, dass sie nicht nur zum Mann wurde, sondern zum homosexuellen, misogynen Mann. ${ }^{145}$ Hier muss Janion aber entgegengehalten werden, dass sich das Begehren des Männlichen bei Komornicka/Włast nicht auf einer körperlich-sexuellen, sondern auf einer »mentalistischen « Ebene abspielte. Meines Erachtens ließe sich deshalb eher von einem homosozialen Begehren sprechen, das von der körperlichen Dimension losgelöst ist.

(S. 29) eingesetzt werde. Dagegen spricht Ritz: Maria Komornicka, S. 151 diesbezüglich von einer fehlgehenden feministischen Auslegung, die »die Körperlichkeit nur von ihrer oberflächlichen Erscheinung her«begreife. Auch Filipiak: W.+M. bestreitet eine Abkehr Komornickas vom Körper. 142 । Janion: Kobiety, S. 243: „Co dla Komornickiej było metafizyczne [...], jest w istocie społeczne. Dotyczy podziału rół płciowych w społeczeństwie.«

143 | Ebd., S. 290: »Komornicka była całkowicie pewna transformacji, którą po prostu postanowiła w swym umyśle, i nie miała żadnych wątpliwości, że jest mężczyzną [...].«

144 । Ebd., S. 228: »Był to duchowy akt zmiany tożsamości płciowej - bez dążenia do jakichkolwiek męskich korekcji fizycznych. >Operacja‘ zmiany płci przebiegała u niej w sferze języka przede wszystkim, języka również w sensie sznaków ubranias."

145 । Ebd., S. 287: »Jej biologiczny i estetyczny wstręt do kobiecości i jej ’przekształcenie się، w mężczyznę mogą świadczyć o tym, że stała się nie tyle mężczyzną, ile mężczyzną homoseksualnym, mizoginicznym.« 
In beiden Studien vermeidet Janion die Festschreibung einer Geschlechtsidentität Komornickas/Własts. Den Wunsch Komornickas, die weibliche Geschlechtlichkeit abzustreifen, führt Janion nicht endgültig auf einen Grund zurück. Ob sozial bedingte Inkorporierung ${ }^{146}$ des patriarchal-misogynen Diskurses oder eine a priori >männliche` Psyche Komornickas - die 1996 resp. 1979 diskutierten Möglichkeiten schließen sich weder gegenseitig aus noch wägt Janion sie explizit gegeneinander ab. Die Frage nach der >Geschlechtsidentität Komornickas/Własts bleibt somit in den Studien letztlich nur andiskutiert und offen.

Janion interessiert vor allem die Herausforderung des Subjekts gegenüber der symbolischen Geschlechterordnung. Sie untersucht die Wechselwirkungen diskursiver Geschlechterrollen mit deren individueller Ausformung, sucht aber nicht nach einer essentiellen Geschlechtsidentität. Damit lässt sich der Ansatz Janions eher in der Nähe der Gender Studies verorten, die das Geschlecht als stetige Aushandlung mit dem normativen Diskurs interpretieren. Mit der Nicht-Festlegung einer geschlechtlichen Identität und dem Ausblenden des diskursiv eng mit dem Weiblichen verbundenen Körpers widersetzen sich die beiden Komornicka/ Włast-Studien Janions der >Weiblichkeitsforschung`, die als normierende Strömung große Teile der feministischen Kritik der 1990er Jahre bestimmt.

\subsubsection{Komornicka/Włast, Janion und die feministische Kritik}

Die Studie »Gdzie jest Lemańska?!« von 1979 reflektierte die intensive Auseinandersetzung mit antipsychiatrischen Ansätzen in Janions Seminaren. Der Fokus dieser Studie liegt auf der Transgression der gesellschaftlichen Grenze von Verstand und Wahnsinn, wobei in diesen Überlegungen die Kategorie des Geschlechts eine der zentralen Rollen spielt. Damit spiegelt sich der Zeitgeist der 1970er Jahre, in denen geistige Gesund- oder Krankheit und soziale Pathologisierungen international diskutiert wurden, sowohl in der Transgresje-Reihe allgemein wie auch in Janions erster Studie zu Komornicka/Włast.

Als Beispiel der Aufweichung diskursiver Pathologisierungen kann etwa die Transsexualitätsforschung dienen. Janion weist auf einen Trendwandel hin: »[I]m ersten Jahrzehnt unseres Jahrhunderts dachte man, dass sich hinter dem [Geschlechtswandel] etwas Schreckliches verberge. Heute hat sich die Situation selbstverständlich geändert. Einige sprechen gar von einer `Ära des Transsexualismus`, die irgendwann in den 1950er Jahren begonnen habe. ${ }^{147}$ Janion schreibt von einer beginnenden Normalisierung von Transsexualität, die mit der Etablierung eines

146 | Vgl. zu meiner Verwendung dieses Begriffs Bourdieu, Pierre: Die männliche Herrschaft, Frankfurt a/M. 2005, S. 43-62, der auf die soziale wie somatische Komponente diskursiver Normen aufmerksam macht.

147 | Janion: Kobiety, S. 227: „w pierwszym dziesięcioleciu naszego wieku, uważano, że kryje się w tym [w zmianie płci] raczej coś przerażającego. Dziś oczywiście sytuacja się zmieniła. Niektórzy mówią wręcz o >erze transseksualizmu<, poczynającej się gdzieś od lat pięćdziesiątych.“ 
differenzierteren Geschlechterverständnisses einhergehe, und plädiert für den Respekt gegenüber nicht-normativen Geschlechtsentwürfen.

Die Thematik von Verstand/Wahnsinn und deren Überschneidungen mit dem Geschlechterdiskurs, auf die Janion 1979 aufmerksam macht, erinnern an eine andere Publikation aus dem gleichen Jahr: Für die internationale feministische Kritik wegleitend wird in diesem Bereich vor allem Sandra Gilberts und Susan Gubars The Madwoman in the Attic. ${ }^{148}$ Auf diese Publikation, die weibliche viktorianische Prosa untersucht, geht Janion in ihrer zweiten Studie zu Komornicka/ Włast ein. Dabei zieht sie vor allem das von Gilbert und Gubar besprochene Beispiel Emily Dickinsons (1830-1886) als Vergleichsfall hinzu. ${ }^{149}$

In Maria Komornicka, in memoriam von 1996 verwendet Janion häufiger Begriffe, die im feministischen Vokabular gängig sind; so verweist sie etwa expliziter auf das Patriarchat, das Komornicka/Włast inkorporierte und dem sie sich unterordnete. Das im früheren Aufsatz eingehender diskutierte »Familiengeschlecht» (ród), das im Verständnis Komornicka/Własts dem Subjekt historische Dimensionen und geistige Konturen gebe, erscheint in Janions Studie von 1996 als »unabdingbarer Bestandteil des Patriarchats ${ }^{150}$. Auch in Janions Formulierung, der Editor Pigoń habe in der archivalischen Publikation »die Stimme Komornickas als Dichterin durch die Stimme des Arztes « ${ }^{151}$ ersetzt, finden feministische Argumentationen ihren Widerhall, die auf die Marginalisierung der Stimme der Frauen im patriarchalen System verweisen. ${ }^{152}$ Insgesamt lässt sich aber sagen, dass Janion zugunsten ihres eigenen Ausführungsstils sparsam mit spezifisch feministischer Terminologie umgeht und diese auch nicht weiter erläutert.

In Janions beiden Studien ist die Interaktion von biographischem Kontext und Werkinterpretation deutlich erkennbar. Gerade in ihrem späteren Artikel scheint die Auseinandersetzung vor allem auf die soziohistorische Ebene zu fokussieren, während das literarische Schaffen als deren Ergänzung und in seiner Funktion als missverstandenes Kommunikationsmittel mit der Umwelt miteinbezogen wird. Damit überträgt Janion die »Gesprächsstruktur « ${ }^{153}$ der Hermeneutik auf die Dekonstruktion der Interferenzen von Literatur und außerliterarischen Mechanis-

148 | Vgl. Gilbert/Gubar: Madwoman in the Attic. Siehe auch Kraskowska: Piórem niewieścim, S. 206, die ebenfalls auf die motivischen Parallelen von Janions Komornicka/Włast-Studien und der Monographie Gilberts und Gubars hinweist.

149 | Beiden Figuren sei eine "Abgeschottung [odosobnienie] - trotz des Wohnens im elterlichen Haus -, eine spezifische Selbstverbannung [samowygnanie], die Selbstverurteilung zum Schweigen und Verstecken [skazanie się na milczenie i ukrycie] " eigen gewesen, wobei gerade das soziale Geschlecht erwirkte, dass auf die "Selbstverbannung " weitere folgten - »von Zuhause, aus der Gesellschaft, aus der Literaturgeschichte«. Janion: Kobiety, S. 317.

150 | Ebd., S. 264: »nieodzowny składnik patriarchatu«.

151 | Ebd., S. 303: „głos Komornickiej jako poetki zastąpił głosem lekarza«.

152 | Vgl. Lindhoff: Einführung.

153 I Janion: Humanistyka, S. 128: "struktura rozmowy«. 
men, Machtstrukturen und historischen Bedingungen. ${ }^{154}$ So verstärkt Janion auf dem von ihr eingeschlagenen methodischen Weg den Fokus auf das Geschlecht und inszeniert die geschlechtliche Diskriminierung als Grunderfahrung der Weiblichkeit. Janion macht sich deshalb auch nicht von einzelnen Werken der feministischen Kritik abhängig, nach denen sie ihre Forschung ausrichtet; vielmehr sieht sie diese, wie etwa The Madwoman in the Attic, als Ergänzung und Vergleich oder als einzelne Stimme in der Textstruktur.

In Bezug auf feministische Inputs erwähnt Janion in der Studie von 1996 ihre Studentin Szczuka, die ihr einen feministischen Standpunkt nähergebracht habe: »Mit ihr habe ich einzelne Fragen diskutiert, vor allem bezüglich der Perspektive der feministischen Kritik. ${ }^{155}$ Darin zeigt sich eine bereits angesprochene Spezifik der Forschung Janions: die Integration studentischer Inputs und die Berücksichtigung kritischer Stimmen. Der Forschungsprozess, von dem Janion sagt, dass er »unter der Kontrolle der Schüler und unter Berücksichtigung ihrer Erkenntnisanforderungen ${ }^{156}$ stattfinde, verbindet sich auf textueller Ebene mit theoretischen Ansätzen und Sekundärliteratur zu einer polyphonen Struktur. Diese resultiert aus der Kombination und Kontrastierung multipler Standpunkte und Ansichten. Die Intertextualität wissenschaftlichen Schaffens ist hier offen dargelegt. Janions Schreibduktus hebt den Text als ein transponierendes Lesen/Schreiben unzähliger Texte hervor.

Das Subjekt `Janion` verschwindet mehrheitlich ’hinter dieser polyphonen Textstruktur. Hier könnte man von einer dialogischen Struktur sprechen, in der sich die formgebende Intonation Janions nur selten enthüllt und primär als (verhüllte) Doppelung des Wortes verstanden werden muss. ${ }^{157}$ Dies erschwert die Metaanalyse der Texte Janions, da sich zunächst scheinbar offenliegende Bedeutungen bei einem »overreading " entziehen. ${ }^{158}$ Nur in vereinzelten emotionalen Einschüben tritt das schreibende Subjekt deutlich zutage (siehe Kapitel 6.3.3). Diese Stellen offenbaren den Widerstand der Schreibenden gegen gesellschaftliche Marginalisierung und Pathologisierung sowie gegen eine als falsch empfundene akademische Tradierung. Dabei inszeniert sich Janion jedoch primär als Instanz

154 | Vgl. Janion/Szczuka: Profesor Misia, S. 83.

155 I Janion: Kobiety, S. 241: "z którą omawiałam poszczególne kwestie, zwłaszcza z punktu widzenia krytyki feministycznej."

156 | Janion: Romantyzm, S. 7: "pod kontrolą uczniów i z uwzględnieniem ich zamówien poznawczych«.

157 | Zur Dialogizität siehe Bachtin: Probleme, bspw. S. 49: "schließlich dringt der Dialog nach innen, in jedes Wort des Romans und macht es zweistimmig«; siehe auch Kristeva: Sèméiotikè, S. 147-158; Sasse: Michail Bachtin, S. 89-95.

158 | Darauf verweist auch Janion selbst in Bezug auf die Beurteilung ihrer Arbeiten in der Volksrepublik: "Sich hinzusetzen und meine Arbeit als ideologisch fehlgeleitet [ideologicznie niesłuszną] zu bewerten wäre schwierig, das war den Dogmatikern zu kompliziert. Also galt sie als Kuriosität [dziwactwo].« Janion/Szczuka: Profesor Misia, S. 34. 
der Metaebene, die diese Mechanismen aus kritischer und zum Teil auch ironisierender Distanz betrachtet. ${ }^{159}$

Janions Bezug auf Szczuka verweist aber auch auf einen weiteren Aspekt ihrer feministischen Auseinandersetzung. Janion scheint das Feld der explizit feministischen Kritik weitgehend einer jüngeren Generation zu überlassen, die sich zum Teil bereits intensiver damit auseinandergesetzt hat ${ }^{160}$ Die Publikation Kobiety $i$ duch inności kann deshalb als eine 'Kontraktion ‘ des bislang in Janions Studien angelegten Interesses an Geschlechterfragen betrachtet werden. Janion verdichtet für die Artikelsammlung den Fokus auf das Geschlecht und schafft damit dank ihres wissenschaftlichen Gewichts gleichsam einen `Türöffner für weitere feministische Publikationen. In ihren nachfolgenden Veröffentlichungen verlässt Janion jedoch die Konzentration auf allein feministische/geschlechtsbezogene Fragestellungen wieder und integriert das Geschlecht erneut als einen Parameter unter anderen.

Dies zeigt sich besonders deutlich an der Forschungstradition zu Komornicka/ Włast. Janion wurde bereits früh auf diesen sehr spezifischen Fall aufmerksam. Ihr Interesse gründete auf der Neupublikation einzelner Gedichte durch Dernałowicz 1977 und schrieb sich in den antipsychiatrischen Zeitgeist der 1970er Jahre ein. Der Topos Komornicka/Włast blieb im Folgenden im wissenschaftlichen Umfeld Janions haften und erweckte offenbar auch unter ihren Studentinnen Interesse, wie die Magisterarbeit Gałązkas von 1993 zeigt. Mit einem gesteigerten Interesse an Fragen der Geschlechtlichkeit auch im literaturwissenschaftlichen Diskurs Polens nahm Janion die Thematik erneut auf und positionierte sich so als Pionierin einer kritisch-sozialrevisionistischen Strömung. Diese Hervorhebung Komornickas/Własts, die/der auch in Kobiety i duch inności eine prominente Stellung einnimmt, führte letztlich zur intensiven Untersuchung dieser Figur in der feministischen Kritik.

Die 1990er Jahre erlebten laut der Polonistin Krystyna Kralkowska-Gątkowska zum Thema Komornicka/Włast eine "wahre Lawine unterschiedlicher Aussagen, die deutlich von neuen methodologischen Trends geleitet sind: von der Psychiatrie, der humanistischen Psychologie und dem Feminismus - bestimmt am meisten. ${ }^{161}$ Die erste Monographie zu Komornicka/Włast, Modernistyczny dramat ciała (Das modernistische Drama des Körpers, 1998) von Edward Boniecki steht allerdings nicht unter dem Zeichen einer Auseinandersetzung mit dem Geschlecht und stellt das Schicksal Komornickas/Własts vor allem in den

159 | Vgl. auch Szczuka: Czy feministki, S. 43: "Janion pflegt eine wohlgesinnte, aber auf jeden Fall eher erkenntnis- als bekenntnisgeleitete Einstellung [raczej poznawczą niż wyznawczą postawę] gegenüber den Mythen der kanonischen Kulturtradition."

160 | Vgl. Janion: Droga, S. 17.

161 I Kralkowska-Gątkowska, Krystyna: Cień twarzy. Szkice o twórczości Marii Komornickiej, Katowice 2002, S. 8. Vgl. auch Helbig-Mischewski, Brigitta: Strącona bogini. Rzecz o Marii Komornickiej (= Polonica Leguntur. Literatura polska w krajach języka niemieckiego, Band 11), Kraków 2010, S. 22. 
Kontext des modernistischen Zeitgeists, der sich durch eine starke Dichotomie von Geist und Körper auszeichnete. ${ }^{162}$ Das Geschlecht resp. dessen Transgression rückt Ritz 2000-2002 mit drei Artikeln ins Zentrum, in denen er sich dieser Thematik aus der Perspektive der Genderforschung nähert, dabei aber neben Komornicka/Włast auch andere Beispiele behandelt. ${ }^{163}$ Ritz stellt dabei treffend fest, dass »[d]ie ungesicherte Identität von Person, Autorschaft und letztlich Text die Vereinnahmungen von mehreren Seiten [provoziert]. Die Rezeption gibt davon beredtes Zeugnis. ${ }^{164}$ Spätere Auseinandersetzungen interpretieren die Geschlechtstransgression als pathologische Folge biographischer Traumata und als Entsagung von einer Weiblichkeit, wie sie etwa Kralkowska-Gątkowska in ihrer Habilitationsschrift Cień twarzy (Der Schatten des Gesichts, 2002) hochhält, oder verweisen wie Brigitta Helbig-Mischewski in ihrer Dissertation Ein Mantel aus Sternenstaub (2005) auf die spezifische Verflechtung von Familiengeschichte, einem tief verankerten Schuldempfinden und einer unerwiderten Liebe, die Helbig-Mischewski zufolge als Auslöser der psychischen Krankheit fungierten. ${ }^{165}$ Filipiak verweist noch vor der Publikation ihrer Dissertation zu Komornicka/Włast unter dem Titel Obszary odmienności (Gebiete der Verschiedenheit, 2006), die sie unter Janion verfasste, implizit auf ein von der Forschung bisher verschwiegenes homosexuelles (lesbisches) Begehren Komornickas, das sich in Własts Spätwerk W Grabowie podczas wojny. Xięga poezji idyllicznej (In Grabów während des Kriegs. Buch der idyllischen Poesie, 1917-1927) zeige und mit dem die Dichterin in den Augen der Gesellschaft zusätzlich »zum >Problem` wurde. $" 166$ Karolina Krasuska schließlich verbindet 2012 die Geschlechtsproblematik mit derjenigen einer nationalen Rahmung, wobei beide Elemente eine performative Inszenierung erforderten. ${ }^{167}$

Bezeichnend für die Komornicka/Włast-Rezeption ist primär der Streit um die Auslegung der Geschlechtstransgression und das Bestätigen oder Bestreiten der psychischen Krankheit. Im weiteren Kreis dieser Problemstellungen werfen die Untersuchungen die Frage nach der geschlechtlichen Identität und der sexuellen Ausrichtung Komornickas/Własts auf, die die literaturwissenschaftlichen Arbei-

162 I Vgl. Boniecki, Edward: Modernistyczny dramat ciała. Maria Komornicka, Warszawa 1998.

163 । Vgl. Ritz, German: »Transgresja płciowa jako forma krytyki spod znaku gender i transformacja dyskursu«, in: Ritz et al., Nowa świadomość płci (2000), S. 89-110; ders.: Maria Komornicka; ders.: »Młoda Polska a transgresja płciowa«, in: ders., Nić w labiryncie pożądania. Gender i płeć w literaturze polskiej od romantyzmu do postmodernizmu, Warszawa 2002, S. 111-136.

164 । Ritz: Maria Komornicka, S. 136.

165 | Vgl. Helbig-Mischewski, Brigitta: Ein Mantel aus Sternenstaub. Geschlechtstransgress und Wahnsinn bei Maria Komornicka, Norderstedt 2005, bes. S. 413-420.

166 I Filipiak: W.+M., S. 134.

167 | Vgl. Krasuska, Karolina: Płeć i naród: Trans/lokacje. Maria Komornicka/Piotr Odmieniec Włast, Else Lasker-Schüler, Mina Loy (= Lupa obscura), Warszawa 2012, S. 34-70 sowie Magnone: Die polnischen Gender Studies, S. 392f. 
ten abwechselnd und wechselseitig durch eine biographistische oder textbasierte Analyse zu klären versuchen.

Erschwerend kommt hinzu, dass zwar ab den 1960er Jahren und ab den 1990er Jahren zunehmend Analysen zu Komornicka/Włast verfasst wurden, ihr/sein literarisches Schaffen aber bis heute nur in Fragmenten vorliegt; dies, obwohl 1996 ausgewählte Werke unter dem Titel Utwory poetyckie prozq $i$ wierszem (Poetische Werke in Prosa und Gedichten) und 2011 die zweisprachige Edition der französischen Gedichte aus der bereits erwähnten Xięga poezji idyllicznej veröffentlicht wurden. „Obwohl kaum jemand ihre Gedichte gelesen hatte, muss ich selten ab ovo erklären, wer sie war«, bemerkt Filipiak und fügt an: »Komornicka ist in der Geschichte unserer Literatur das, was >unheimlich ‘ [ niesamowite`] ist [...]. « ${ }^{168}$ Tatsächlich wurde Komornicka/Włast gerade deshalb auch zu einer Ikone der feministischen Kritik, weil sich bislang weder ihre biographische Selbstkonstruktion noch ihr literarisches Schaffen definitiv in Begriffe fassen ließen und von Widersprüchlichkeiten durchsetzt sind.

Somit hat auch Janion nicht einfach eine Interpretationsrichtung vorgeschlagen, die anschließend verfeinert wurde. Ihre Studien bieten neben Anknüpfungspunkten genauso viele Stellen, an denen nachfolgende Untersuchungen kritisch ansetzen. Kritikbehaftet ist etwa der emotionale Gehalt ihrer Studien, den Helbig-Mischewski als »uneingeschränkte persönliche Anteilnahme « ${ }^{169}$ und als Versuch der Sakralisierung Komornickas/Własts durch Janion auslegt. Dies stellt meines Erachtens eine Überdehnung dar, da Janion zwar ohne Zweifel die gesellschaftliche Repression gegenüber Komornicka/Włast anprangert, dabei jedoch nicht die historische Figur selbst als schuldlos zu präsentieren sucht. Was ich jedoch als unbestreitbar erachte, ist eine gewisse `Näheく Janions zu Komornicka/ Włast, die in Janions Faszination am »romantischen Mythos $\aleph^{170}$ der Transgression und den $»$ Paradoxien des Innenlebens ${ }^{171}$ Komornickas/Własts gründet.

Im Vergleich der beiden Studien von 1979 und 1996 zeigt sich Janions Perspektivenverschiebung hin zu einer expliziteren Auseinandersetzung mit feministischer Kritik. Die Studie von 1979 nimmt dabei bereits die Kategorie des Geschlechts respektive dessen Überschreitung in ihre Forschungsperspektive auf - was auch bei einem `Fall wie Komornicka/Włast nicht zwingend geschehen muss, wie Podraza-Kwiatkowskas Aufsatz von 1969 zeigt. ${ }^{172}$ Janions Studie von 1996 letztlich orientiert sich stärker an einem feministischen Paradigma, das aber zurückhaltend eingebracht wird.

168 | Filipiak: W.+M., S. 113.

169 | Helbig-Mischewski: Mantel aus Sternenstaub, S. 66.

170 । Szczuka: Czy feministki, S. 43.

171 I Janion: Kobiety, S. 189: "paradoksy życia wewnętrznego«.

172 | Vgl. Podraza-Kwiatkowska: Tragiczna wolność. 
Es wird ersichtlich, dass sich Janion wenig für die (Re)Konstruktion einer essentiellen Weiblichkeit interessiert. Weiblichkeitsbilder ruft Janion in ihren Texten vor allem auf, wenn es um normative Gesellschaftsmechanismen geht, die solche Essentialisierungen vornehmen. Mit Komornicka/Włast beschäftigte sich Janion mit einer Thematik, die solche Normierungen überschreitet und sich einer eindeutigen Verortung auf der einen oder anderen Seite von multiplen Dichotomien wie männlich-weiblich, körperlich-geistig, emanzipatorisch-misogyn oder gesund-krank entzieht. In Janions Ansatz steht damit anders als in den Arbeiten einiger anderer feministischer Kritikerinnen der polnischen 1990er Jahre ein $>$ typisch «eibliches Schreiben nicht im Zentrum (siehe Kapitel 5.2). In gewisser Hinsicht kann deshalb bei Janion von einer gleichsam proto- wie postfeministischen Ausrichtung gesprochen werden.

Allgemein lässt sich über die Forschung Janions sagen, dass sich die Geschlechterfrage bereits ab den 1970er Jahren in ihren Arbeiten zeigte. Mit den 1990er Jahren geschah zwar eine Zuspitzung, aber keine ausschließliche Fokussierung auf dieses Themengebiet. Die Integration der Kategorie des Geschlechts in die Forschung lässt sich auf das untersuchte Material zurückführen, das nicht nur Fragen $\mathrm{zu}$ den Geschlechterrollen aufwirft, sondern mit dem Fokus auf psychologische Problemstellungen in das Gebiet von Psychoanalyse und phantasmatischem Begehren hineinführt. Dieses Gebiet diente Janion als Ausgangspunkt der Untersuchung gesellschaftlicher Machtdiskurse. So kehrte sie in ihrer Forschung die sozial- und kulturpolitische Komponente hervor und betonte ihr Ziel einer Aushebelung sozialer Ungleichheiten und einer offeneren, toleranteren Gesellschaft. $\mathrm{Zu}$ diesem Zweck versuchte sie die auch im (historischen) literarischen Diskurs wirksamen Machtstrukturen aufzudecken, um mit einem reflektierteren Zugang zu Tradition und Kultur festgefahrene Denkmuster zu durchbrechen.

Das feministische Engagement Janions kann deshalb in den Kontext einer allgemein politisch ausgerichteten Forschung gestellt werden. Dabei ging es Janion jedoch sowohl vor 1989 wie auch danach nicht ausschließlich um geschlechtliche Ungleichheiten, sondern um vielerart Diskriminierungs- und Disziplinierungsachsen. Dass Janion aber gerade Mitte der 1990er Jahre ihre Aufsatzsammlung Kobiety i duch inności veröffentlichte, lässt sich einerseits damit erklären, dass sie selbst erkannte, dass auch nach der Systemtransformation geschlechtliche Ungleichheiten aufrechterhalten oder gar gefestigt wurden. Andererseits fügte sich diese Publikation in die aufkeimende wissenschaftliche Nische der feministischen Kritik, mit deren Bedienung Janion nicht nur der Nische selbst zu größerer Popularität und Tragweite verhalf, sondern sich auch selbst - einmal mehr - als Pionierin auf einem bestimmten Gebiet profilieren konnte. 


\section{Rezeptionslinien}

Am Beispiel Janions habe ich nun bereits aufgezeigt, wie diese ihre geschlechtsorientierte Forschung entwickelte und welche Verschiebungen dabei in den 1990er Jahren auftraten, in denen Janion den Fokus auf das (weibliche) Geschlecht nochmals zuspitzte. Ihre Forschungsperspektive ergab sich einerseits in der Auseinandersetzung mit dem literaturhistorischen Material, andererseits aus der Rezeption theoretisch-methodischer Strömungen wie der Antipsychiatrie. Die Zuspitzung auf das Geschlecht in den 1990er Jahren hing letztlich auch mit der soziopolitischen Lage der polnischen Gesellschaft zusammen; Janion sieht ihr expliziteres Hinweisen auf die Differenz sozialer Geschlechterrollen als politischen Beitrag zur Transformationsgesellschaft.

Diese bei Janion beobachteten drei intertextuellen Bezugsebenen - theoretisch-methodische, literarische und sozialhistorische Einschreibungen - können als Ausgangspunkt der Analyse der feministischen Texte in den polnischen 1990er Jahren gesetzt werden. Die folgenden drei Kapitel fächern sich deshalb nach diesen Ebenen der Bezugnahme oder Einschreibung in bestehende Diskurse auf. Im vorliegenden Kapitel konzentriere ich mich auf transnationale Theoriebezüge und die Verknüpfung westlicher und polnischer Wissenschaftstraditionen. In Kapitel 5 fokussiere ich auf den Miteinbezug und das Neulesen des literarischen Forschungsmaterials, während sich Kapitel 6 den Einschreibungen der untersuchten Texte in die gesellschaftlichen und politischen Diskurse der polnischen 1990er Jahre widmet.

Das vorliegende Kapitel zu theoretischen Rezeptionslinien gliedert sich wiederum in drei Teile. Zunächst betrachte ich die untersuchten Monographien im Hinblick auf ihre Bezüge zu einer westlichen feministischen Kritik. Dabei frage ich nach den Erzählungen über den westlichen Feminismus, die die Polonistinnen in ihren Texten konstruieren, und ob sie ihre Argumentation direkt an bestimmte feministische Denktraditionen anbinden. In einem zweiten Schritt greife ich das polonistische Verhältnis zur Psychoanalyse gesondert heraus, die in den untersuchten Texten eine zentrale Rolle spielt, zugleich aber oft an den Rand gedrängt wird. Im letzten Teil des Kapitels frage ich nach Texten und Figuren, die nicht mehr strikte Teil meines Untersuchungsfelds sind, sondern dessen 
Grenzen auf verschiedene Weise überschreiten und so ebenfalls die feministische Kritik in Polen mitprägen.

\subsection{Geschichte(N) des Feminismus}

Die polnischen feministischen Kritikerinnen der 1990er Jahre sehen ihre Forschung als Pionierarbeit in Polen, wo eine feministische Perspektive in der Wissenschaft wie im politischen Alltag eingeführt werden müsse. Dabei skizzieren die polnischen Kritikerinnen ein Bild von westlichen feministischen Strömungen, um sich so eine Basis und einen Bezugsrahmen zu schaffen. Interessant ist, dass dabei unterschiedliche Erzählungen über die Entwicklung und den aktuellen Stand feministischer Reflexion zusammenkommen. Die spezifischen Gewichtungen und die sich zum Teil überlagernden, zum Teil sehr unterschiedlich ausgerichteten Einschreibungen, die die fünf untersuchten polonistischen Monographien innerhalb des feministischen Diskursfelds vornehmen, zeichne ich im Folgenden an einzelnen Beispielen nach.

Besonderes Augenmerk lege ich auf historische Verortungen und die verschiedenen Zugänge eines Nach-Lesens feministischer Theorien. Diese reichen von einem pastichierenden Herausarbeiten feministischer Perspektiven im postmodernen Duktus über artikulierte Grenzziehungen zwischen dem Lokalen und dem Globalen bis hin zu einem nivellierenden Einschreiben in die transnationale feministische Kritik. So untersuche ich vom konkreten polonistischen Text ausgehend Prozesse der intertextuellen Traditionskonstruktion und -einbettung, das heißt, ich frage nach den Verfahren, mit denen die feministischen Kritikerinnen eine Genealogie feministischer Theorien entwerfen und sich zu dieser positionieren. ${ }^{1}$ An einzelnen Stellen ziehe ich weitere Texte der besprochenen Polonistinnen hin$\mathrm{zu}$, in denen solche Positionierungen deutlicher werden. Zudem sollte nicht vergessen werden, dass die polonistischen Anbindungen an westliche feministische Kritik in Korrespondenz mit dem jeweiligen inhaltlichen Fokus des Textes stehen und auch soziale Kontexte eine gewisse Rolle spielen können.

Zunächst untersuche ich diejenigen Passagen der polonistischen Texte, in denen sich diese zur Entwicklung und zum Theoriestand feministischer Kritik im Westen äußern. Die Präferenzen und Interessen der Polonistinnen führen zu einer jeweils sehr spezifischen `Erzählung` über die westliche feministische Kritik, die wiederum ihre jeweiligen ideellen und methodischen Bezugsrahmen absteckt.

1 I Es geht mir dabei insbesondere um den spezifischen Konstruktcharakter dieser Genealogie und darum, wie der jeweilige Text seinen feministischen Bezugshintergrund gestaltet. Zum Begriff der Genealogie siehe auch die Überlegungen von Foucault, wobei sich meine Verwendung hier nicht völlig mit dessen Konzept deckt. Vgl. "Nietzsche, la généalogie, l'histoire« in Foucault, Michel: CEeuvres. Volume II (= Bibliothèque de la Pléiade, Band 608), Paris 2015, S. 1281-1304, bes. S. 1292. 
Diese theoretischen Einführungen fallen sehr unterschiedlich in inhaltlicher Gewichtung und Länge aus.

Iwasiów etwa resümiert in ihrer Dissertation von 1994 bündig: »Die Wurzeln eines so verstandenen Feminismus reichen bis zu den Emanzipationsbewegungen des 19. Jahrhunderts, deren Ziel das Aufzeigen der patriarchalen Unterdrückung und somit der Kampf um menschliche Rechte der Frau war. «² Iwasiów schreibt der feministischen Bewegung einen "stricte ideologischen Charakter « ${ }^{3} \mathrm{zu}$, was auch für den wissenschaftlichen Zweig der feministischen Kritik gelte. Den internationalen Feminismus unterscheidet Iwasiów in drei Hauptströmungen, nämlich den »amerikanischen Soziohistorismus, die französische psychoanalytisch-dekonstruktivistische Variante sowie die britische marxistisch-sozialistische Bewegung « ${ }^{4}$. Diese Kategorisierung entnimmt Iwasiów zwei literaturtheoretischen Einführungen aus den USA respektive Australien, ${ }^{5}$ weist aber auch auf Vermischungen und intertextuelle Bezüge zwischen den Strömungen hin. ${ }^{6}$ Unklar ist jedoch die Funktion dieser Aufzählung in Iwasióws Text, da sie in der Skizzierung ihrer eigenen feministischen Strategie auf keine dieser Strömungen Bezug nimmt. Es geschieht weder eine Einschreibung in eine bestimmte Tradition noch eine Abgrenzung, und so bleibt die feministische Haltung Iwasióws vor diesem Hintergrund weitestgehend konturlos.

Bei Janion fällt in Bezug auf die Auseinandersetzung mit westlichen Feminismen vor allem der kurze Aufsatz über das 1993 auf Polnisch übersetzte Werk XY, de l'identité masculine von Élisabeth Badinter auf.7 Janions Diskussion der Thesen

2 I Iwasiów: Kresy, S. 21: »Korzenie tak pojętego feminizmu sięgają dziewiętnastowiecznych ruchów emancypacyjnych, których celem było wykazanie opresji patriarchalnej, a przez to - walka o ludzkie prawa kobiety."

3 । Ebd.: "charakter stricte ideologiczny«.

4 । Ebd., S. 21f.: "amerykański socjohistoryzm, francuską opcję psychoanalityczno-dekonstruktywistyczną oraz brytyjski ruch marksistowsko-socjalistyczny«.

5 I Siehe Buchbinder, David/Milech, Barbara H.: Contemporary Literary Theory and the Reading of Poetry, Melbourne 1991; Leitch, Vincent B.: American Literary Criticism from the Thirties to the Eighties, New York 1988.

6 I Vgl. Iwasiów: Kresy, S. 22. In ihrem späteren Band Gender dla średnio zaawansowanych (Gender für fortgeschrittene Anfänger, 2004) unternimmt Iwasiów diese Unterscheidungen nicht mehr und präsentiert die feministische Strömung mehrheitlich als eine monolithische, lineare Entwicklung mit einem Fokus auf die US-amerikanische feministische Kritik. Vgl. Iwasiów: Gender; Seiler, Nina: "Brüche im Kontinuum. Feministische Kritik im Spannungsfeld polnischer Identitätssuche«, in: Traverse. Zeitschrift für Geschichte 23/2 (2016), S. 97-107, hier S. 101f. Iwasiów verweist auch darauf, dass die französische Strömung in die amerikanische Forschung »übertragen « wurde, siehe Iwasiów: Kresy, S. 22.

7 I Vgl. Badinter: XY. Der Text Janions zu dieser Publikation stellt gleichzeitig das Vorwort für die polnische Übersetzung dar, vgl. Janion, Maria: »Niańka i kowboy«, in: Badinter, XY (1993), S. 9-15; ebenso in Janion: Kobiety, S. 174-185. 
Badinters ist allerdings ambivalent, und so kann auch hier nicht von einem einfachen Einschreiben oder Anknüpfen gesprochen werden. Die Grenze zwischen befürwortendem Nacherzählen und ironischer Brechung ist fließend (siehe Kapitel 6.3.3), und eine ideologematische Orientierung fällt schwer. Dies hat mit der Vielzahl von im Text präsenten Stimmen zu tun - Badinter, deren Kritiker/innen und Janion selbst - wie auch damit, dass Janion einen Kritikpunkt an Badinter selbst wiederholt. Badinter, so Janion, differenziere argumentativ zwischen französischen und US-amerikanischen feministischen Ansätzen, deren Entwicklung von lokalen Geschlechterverhältnissen geprägt sei. Die Differenz gründe darin, dass die Geschlechtergegensätze in den USA sehr viel tiefer und gewaltvoller seien als im relativ liberalen Frankreich des familiären Laisser-faire. ${ }^{8}$ Diese inhaltliche Unterscheidung verwische Badinter aber durch eine methodische Anbindung an beide Traditionen und somit deren Annäherung. Die feministische Herangehensweise Badinters als explizit französische wird laut Janion

"als saufgeklärt‘ angesehen, als sreformatorisch und stolerant‘. Und all dies im Gegensatz zum amerikanischen Feminismus. Diesem aber verdankt Badinter das Konzept des Patriarchats, das sie jedoch deutlich mäßigt, wie es ihr üblich ist. Bei ihr gibt es also keine heftigen Beschuldigungen und Verfluchungen, wie sie die amerikanischen und auch deutschen Feministinnen auf das gesellschaftliche und ideelle System herausschleudern, das unüberschaubare Massen an Frauen fesselt, zerquetscht und in lebenslanges Unglück stürzt. «9

Diese Passage zeigt, dass Janion wie auch Badinter selbst durch Parallelführungen »französischer« und »amerikanischer« Verfahren diese zugleich unterscheidet wie auch zusammenbringt und rhetorisch vermengt. Janions Kommentar zu XY bringt somit zwar Einblick in eine theoretische Debatte und offenbart den Wunsch nach kritischeren Geschlechterdebatten auch in Polen, bietet aber letztlich ebenfalls keinen in sich geschlossenen Anknüpfungspunkt. Deutlicher als bei Iwasiów treten hier interne Divergenzen des `Feminismus` und die ambivalente Haltung Janions zu feministischen Überspitzungen hervor. ${ }^{10}$

Die Einführung in westliche feministische Ansätze, die Borkowska in $\mathrm{Cu}$ dzoziemki unternimmt, ist in ihrer erklärenden Kategorisierung weniger direkt in die Ambivalenzen der Geschlechterforschung verstrickt als das obige Beispiel

8 I Vgl. Janion: Kobiety, S. 176f.

9 । Ebd., S. 178f.: »bywał uznawany za >oświecony<, >reformistyczny<, stolerancyjny‘. Wszystko to w przeciwieństwie do feminizmu amerykańskiego. Jemu to jednak zawdzięcza Badinter koncepcję patriarchatu, którą przecież, zgodnie ze swą postawą ogólną, wyraźnie moderuje. Nie ma więc u niej gwałtownych oskarżeń i przekleństw miotanych przez amerykańskie, ale i niemieckie feministki na ten system społeczny i myślowy, który zniewolił, zmiażdżył i wtrącił w całożyciowe nieszczęście niezliczone rzesze kobiet."

10 । Vgl. ebd., S. $179 f$. 
Janions. ${ }^{11}$ Borkowska bezieht sich auf die feministische Kritik als "Denkweisen über die Kultur (das Kunstwerk) «12 - thematisiert also den Feminismus als politisch-aktivistische Strömung nicht - und stellt hier vier Typen vor.

Als erste Strömung nennt sie diejenige, die das Kunstwerk als Spiel ( $g r a)$ verstehe. Im Zentrum dieser psychoanalytischen, 'postfreudianischen Denkweise stünden die erotische Komponente des Kunstwerks und der Genuss der Rezeption sowie das schöpferische Begehren. Diese Strömung, der sie einzelne Arbeiten Shoshana Felmans, Nancy J. Vickers und Barbara Johnsons zuordnet, sei »klarer und heiterer als die Mutterversion ${ }^{13}{ }^{13}$ der freudschen Psychoanalyse.

Die zweite feministische Denkweise, die das Kunstwerk als Subjektakt begreife, rücke das Verhältnis von (schaffendem) Subjekt und Text in den Fokus. Hier finden sich Ansätze wie die Arachnologie Millers, die Barthes Hyphologie weiterentwickelt als weibliches Sich-Schreiben, oder eine an Jane Gallop angelehnte Biologisierung des Autorinnen-Werk-Verhältnisses, wobei der »Schaffensprozess [...] an den Akt der Geburt erinnert $^{14}$.

Diejenige (dritte) Denkweise, die das Kunstwerk als Reinterpretation der bestehenden Realität betrachte, ist laut Borkowska besonders an kulturellen Mechanismen und Normierungen interessiert, die in den Text chiffriert und aus diesem entsprechend dechiffriert werden können. Borkowska verweist in diesem Teil auf die Arbeiten Elaine Showalters sowie Gilberts und Gubars. Ein Hauptanliegen dieser Strömung sei auch die Revision und Umformung des Kanons, darunter etwa das »Eliminieren von Werken, die Frauen abgeneigt sind $\aleph^{15}$, sowie die Dekonstruktion von Annahmen einer allgemeinen Wahrheit.

Die letzte von Borkowska vorgestellte Denkweise schließlich begreife das Kunstwerk als Kontaktraum (przestrzeń kontaktu). Hier verweist Borkowska erstmals auf eine historische Verortung, als diese "neue Konzeption, von der zweiten Generation der zeitgenössischen Feministinnen ausgearbeitet und damit von Wissenschaftlerinnen, die noch keine vierzig Jahre alt sind und in den letzten zehn Jahren oder in den $90 \mathrm{er}$ Jahren unseres Jahrhunderts debütierten « ${ }^{16}$, getragen

11 I Borkowska unternahm 1990 eine Einführung in die feministische Kritik im Westen, in der sie viele Dilemmata der feministischen Kritik darstellt und die verschiedenen Entwicklungen durchspielt. Publiziert wurde diese unter »Córki Miltona (o podmiocie krytyki feministycznej)« (Miltons Töchter (über das Subjekt feministischer Kritik)) in den Teksty Drugie 2. Ich verwende im Folgenden die erweiterte Fassung dieses Texts, vgl. Borkowska, Grażyna: „Córki Miltona. (0 krytyce feministycznej ostatnich piętnastu lat)«, in: Nycz, Po strukturalizmie (1992), S. 71-92.

12 I Borkowska: Cudzoziemki, S. 7: "sposoby myślenia o kulturze (dziele sztuki)«.

13 । Ebd., S. 9: »jaśniejszy i pogodniejszy niż wersja macierzysta«.

14 । Ebd., S. 13: "proces twórczy [...] przypomina akt narodzin«.

15 । Ebd., S. 15: »usunięcie z niego dzieł wyjątkowo niechętnych kobietom «.

16 I Ebd., S. 16f.: »koncepcja nowa, wypracowana przez drugie pokolenie współczesnych feministek, a zatem przez badaczki, które nie mają czterdziestu lat i debiutowały w ostatnim dziesięcioleciu lub w latach dziewięćdziesiątych naszego wieku.« 
wurde. Gleichzeitig knüpft Borkowska an Woolfs »Postulat der weiblichen Solidarität « ${ }^{17}$ als Richtungsweiser an. Kennzeichen dieser Strömung sei ein Verständnis des Texts als Plattform des Austauschs, wo ein intimer Kontakt zwischen Autorin und Leserin stattfinde, der insbesondere durch das Einbinden des subjektiven Standpunkts in den Text zustande komme.

Borkowska scheint die von ihr berücksichtigten feministischen Ansätze weitgehend assoziativ und nach eigenen Schwerpunkten zu gruppieren, ohne dabei auf bestimmte Traditionslinien zu verweisen. Gemäß Borkowska gebe es einen Unterschied zwischen feministischen und postfeministischen Ansätzen: Während feministische Ansätze versuchen würden, das weibliche Schaffen zu konzeptualisieren und zu beschreiben, würden postfeministische Ansätze »annehmen, dass es im Kunstwerk keine spezifischen Indikatoren seiner Weiblichkeit gibt « ${ }^{18}$. Diese beiden Strömungen werden von Borkowska nicht in einen historischen Zusammenhang gebracht. Die spostfeministischen Ansätze erscheinen nicht als Überwindung oder Weiterentwicklung feministischer Thesen, sondern als sich parallel dazu bildende Strömung.

Diese drei unterschiedlichen `Erzählungen` über den westlichen Feminismus mit ihren jeweils anders gelagerten Schwerpunkten und Kategorisierungen belegen, dass sich im polnischen Kontext noch kein festgeschriebenes Narrativ zur Entwicklung feministischer Theorie herausgebildet hat. ${ }^{19}$ Dies hat einerseits damit zu tun, dass die drei oben besprochenen Arbeiten von 1994 bis 1996 in einem in Polen sehr jungen Feld entstanden; andererseits bilden die 1990er Jahre auch im Westen mit der Entwicklung performativer, >post $\_$feministischer Positionen noch Teil des Masternarrativs, wie es Hemmings für die USA rekonstruiert hat. ${ }^{20}$ Aus der polnischen wie auch globalen Perspektive ist es deshalb zu Beginn der 1990er Jahre schwieriger, eine `schlüssige` Erzählung über die Entwicklung feministischer Theorien zu entwerfen, als dies aus heutiger Perspektive erscheinen mag.

Bei diesen früheren Arbeiten fällt zudem auf, dass die Wissenschaftlerinnen zwar bestimmte Anhaltspunkte zu feministischen Strömungen im Westen geben, sich aber innerhalb dieses Angebots nicht positionieren. Die westliche feministische Kritik scheint bei allen drei Polonistinnen ein eher lose geknüpftes Bezugs-

17 | Ebd., S. 17: »postulatu kobiecej solidarności«.

18 । Ebd., S. 6: „zakładające, że nie ma w dziele sztuki specyficznych wykładników jego kobiecości«. 19 । Dies zeigt sich etwa auch in den Unterschieden zwischen Borkowskas sErzählung von 1990/92 und ihrer anders gewichteten Komprimierung von Strömungen in Cudzoziemki, vgl. Borkowska: Córki Miltona.

20 । ,Westliche، Erzählungen über den Feminismus sprechen von einer Abfolge von Zweite-WelleFeminismus (Differenzfeminismus), der darauffolgenden Kritik, Dezentrierung und Öffnung von Seiten ethnischer und sexueller Minderheiten (black feminism, lesbischer Feminismus) und der letztlichen Phase der Dritten Welle mit performativen und 'post‘-feministischen Thesen (gender und queer studies). Vgl. Hemmings: Why Stories Matter. 
netz zu sein. Janion sieht den westlichen Feminismus als Ergänzung ihrer eigenen, bereits etablierten Analyse der Kategorie des Geschlechts. Durch die Figur und Thesen Badinters bringt Janion eine Position von saußen sie mit der Stimme einer >Anderen ` pointierte Kritik üben, die sie zwar selbst nicht zweifelsfrei befürwortet, aber als Antidotum für die polnische Gesellschaft anerkennt. ${ }^{21}$ Iwasiów bezieht ihren weiblich-dezentralen Standpunkt direkt aus der dekonstruktivistischen Lektüre und pastichiert so gewissermaßen die westliche feministische Reflexion, ohne sich jedoch konkret auf diese zu beziehen. Borkowska wiederum summiert die vorgestellten feministischen Ansätze zu einem theoretischen Hintergrund, an dem sie sich pauschal orientiert. Sie verweigert die Konzentration auf eine bestimmte Strömung, da eine "solche Auswahl eine Einschränkung wäre «22. Die westlichen Theorien erscheinen ihr zudem zu radikal, weshalb sie diese in gemäßigter Form als Denkanstoß einsetzt, wie dieses Beispiel zeigt: »Ich denke auch, dass die Kategorie der Lust, von der Felman schreibt, auftauchen wird, obwohl mir die Perversion dieser Autorin fern liegt. Ich mag >meine` Schriftstellerinnen einfach, ich mag ihre Bücher. ${ }^{23}$

Wie Borkowska bezieht sich auch Kraskowska in ihrer 1999 erschienenen Monographie auf die feministische Kritik als ausschließlich kulturwissenschaftlichen Ansatz. Sie unterscheidet, wie für die polnische feministische Kritik nun bereits üblich, zwischen einer revisionistischen und einer gynokritischen Herangehensweise. ${ }^{24}$ Zur revisionistischen Strömung zählt Kraskowska de Beauvoir mit Le Deuxième sexe (1949) und Kate Millett mit Sexual Politics (1970). ${ }^{25}$ Als Hauptmerkmal revisionistischer feministischer Kritik skizziert Kraskowska die »Reinterpretation der Literaturgeschichte als Demaskierung der darin eingeschriebenen sexistischen Stereotypen ${ }^{26}$, wobei die Revisionen auf die Literatur allgemein

21 I Vgl. Janion: Kobiety, S. $179 f$.

22 I Borkowska: Cudzoziemki, S. 20: „wybór taki byłby ograniczeniem«. Magnone (Die polnischen Gender Studies, S. 382) weist darauf hin, dass für Borkowska besonders der Ansatz Gilberts/ Gubars in The Madwoman in the Attic zentral war. Im Text Borkowskas selbst ist aber eine solche klare Bevorzugung nicht ersichtlich, siehe Borkowska: Córki Miltona, bes. S. 81-86.

23 | Borkowska: Cudzoziemki, S. 20: »Myślę też, że kategoria przyjemności, o której pisze Felman, będzie się pojawiać, choć daleko mi do perwersyjności tamtej autorki. Ja po prostu lubię sswoje pisarki, lubię ich książki. B Borkowska bezieht sich hier auf Felman, Shoshana: Le Scandale du corps parlant. Don Juan avec Austin ou la séduction en deux langues, Paris 1980.

24 I Vgl. dazu Majbroda: Feministyczna krytyka, S. 139-158, die diese Unterschiedung ebenfalls als Hauptströmungen hervorhebt. Die revisionistische strömung nennt sie allerdings anders als Kraskowska »revindikative".

25 I Vgl. Beauvoir, Simone de: Le Deuxième sexe. Volume 1. Les Faits et les mythes. Volume 2. L'expérience vécue, Paris 1949; Millett, Kate: Sexual Politics, New York 1970.

26 I Kraskowska: Piórem niewieścim, S. 8f.: »wątek rewizjonistyczny«; »w ramach którego dokonuje się reinterpretacji historii literatury pod kątem demaskowania wpisanych w nią stereotypów seksistowskich«. 
zielten. Ganz auf die weibliche schöpferische Tätigkeit fokussiere hingegen die gynokritische Strömung, deren Essenz Kraskowska in Showalters Aufsatz Toward a Feminist Poetics von 1979 findet. ${ }^{27}$ Anders als die bisher besprochenen Wissenschaftlerinnen bezieht Kraskowska in dieser Unterteilung eindeutig Stellung für die gynokritische Strömung, "also das Beschreiben und Definieren der >femininen Ästhetikı, verbunden mit dem Aufdecken der verlorenen Tradition der weiblichen Literatur. Mit einer solchen Haltung identifiziere ich mich zu einem großen Teil, [...] die mir die Chance gibt, Werke sals Frau zu lesen und zu untersuchen. $\aleph^{28}$

Anders gestaltet sich wiederum die Herangehensweise Kłosińskas. Sie sieht sich in ihrer Publikation ebenfalls von 1999 nicht verpflichtet, einen Überblick über feministische Positionen zu liefern. Ihr Anknüpfen an die westliche feministische Kritik, die »alternative, wenn nicht gar unvereinbare Konzeptionen herausarbeite«, »resultiert aus der Textlektüre [Zapolskas] auf eine - wie ich sagen würde - >natürliche` und für mich selbst erstaunliche Art. « ${ }^{29}$ Obwohl auch Kłosińska äußert, dass sie »[k]eine der vielen Strömungen der feministischen Kritik bevorzuge ${ }^{30}$, verknüpft sie ihre Beobachtungen vor allem mit den Ansätzen Millers, Kristevas und Irigarays und nimmt eine stark psychoanalytisch informierte Perspektive ein. Mit diesem Verfahren demonstriert Kłosińska den `naturalisiertesten`Umgang mit westlichen Theorien, der auf eine Skizzierung der Genealogie überhaupt verzichtet.

\subsubsection{Erbfolgen. Zur Genealogie feministischer Kritik}

Am Beispiel der >revisionistischen`Strömung möchte ich nun einige Überlegungen zur Entwicklung feministischer Kritik im Allgemeinen und in Polen im Spezifischen anstellen. Kraskowskas Verweis auf de Beauvoir und Millett zeigt, dass die westliche >revisionistische`Strömung, die vergeschlechtlichte Machtstrukturen in den Werken bekannter Autor/innen aufdeckt, der Zweiten Welle des Feminismus vorausging. Kraskowska skizziert diese Entwicklung als Ablösung: Während der revisionistische Zugang »tatsächlich sehr nahe beim Feminismus« liege, hält sie auch fest, dass »die Mode solcher Revisionen ausläuft. «11 "Zwar war der Feminismus der Entstehensimpuls sowohl der feministischen Kritik wie auch anderer Zweige der Women's Studies; doch diese Disziplinen haben es mehrheitlich ge-

27 | Vgl. Showalter: Toward a Feminist Poetics, S. 25.

28 I Kraskowska: Piórem niewieścim, S. 9: „czyli opisywanie i definiowanie sestetyki żeńskiej<, połączone z odkrywaniem zagubionej tradycji literatury kobiecej. Z taką postawą w dużej mierze się identyfikuję, [...] dającą mi szansę czytania i badania utworów jjako kobietas."

29 | Kłosińska: Ciało, S. 290: „tworzących alternatywne, jeśli nie wykluczające się koncepcje«; "jako wynik lektury tekstów w sposób - powiedziałabym - ’naturalny، i zaskakujący dla mnie samej." 30 | Ebd.: »Nie preferuję któregoś spośród wielu nurtów krytyki feministycznej.«

31 I Kraskowska: Piórem niewieścim, S. 9: »istotnie bardzo blisko do feminizmu«; »moda na takie rewizje wygasa." 
schafft, sich vom Feminismus loszureißen und funktionieren heute vollends un-

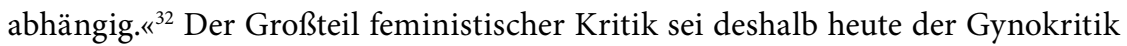
zuzuordnen, deren methodische Beschäftigung mit dem weiblichen Geschlecht nichts mehr mit einer politischen Haltung zu tun habe. Zur Problematik der Depolitisierung feministischer Kritik komme ich in Kapitel 6.2 zurück.

Kraskowska löst die feministische Kritik von ihren politischen `Wurzeln` und sieht sie als davon unabhängige akademische Disziplin. Gleichzeitig konstruiert sie die gynokritische Auseinandersetzung mit der Weiblichkeit als Endpunkt einer fortschreitenden Entwicklung (s. u.). Eine solche Darstellung der Dynamiken feministischer Kritik ist aber stark vereinfacht. Sie ignoriert die Tendenz feministischer Diskurse, die Fokussierung auf das weibliche Geschlecht wieder aufzulösen und als essentialisierend zu dekonstruieren. Anders als etwa Borkowska berücksichtigt Kraskowska die Pluralisierung der Ansätze nicht. Die Position, aus der heraus sie spricht, lässt sich mit feministischen Positionen der 1970er Jahre vergleichen. Während Kraskowska die historischen Beziehungen feministischer Kritik `kappt‘, immobilisiert sie auch deren `Stand in einer weiblichkeitsbejahenden, identitätskonstruierenden Strömung der Frauenforschung. Dieser Ansatz ist symptomatisch für einen Großteil der polnischen feministischen Kritik, die sich bis heute mit Vorliebe auf 'weibliches Schaffen $<$ konzentriert und dabei revisionistische und gender-Lektüren eher am Rande betreibt. ${ }^{33}$

Eine etwas andere Konstruktion der Genealogie feministischer Kritik lässt sich bei Borkowska aufzeigen. Borkowska engt ihren Begriff der feministischen Kritik auf die Behandlung der »weiblichen Kunst « ${ }^{34}$ ein und lässt damit den ganzen Zweig revisionistischer Forschung, die auch ımännlicheく Werke berücksichtigt, unerwähnt beiseite. Allerdings ist ihr zufolge auch die Kategorie sweiblichen Schaffens« als geschlechtlich markierte problematisch, denn »nie wurde klar umrissen, welche Parameter man der weiblichen Kunst zuschreiben kann $\aleph^{35}$. Borkowska schreibt auch: »Es ist zweifelhaft, ob man angesichts der vielen Versuche, die sogenannte écriture féminine zu beschreiben, in dieser Sache mit einem Fortschritt rechnen kann. ${ }^{36}$ Auffällig ist an dieser Stelle die Verflachung des Begriffs

32 I Ebd., S. 8: »Wprawdzie to feminizm był impulsem do powstania zarówno krytyki feministycznej, jak i innych gałęzi Women's Studies, lecz dyscypliny owe w więkżości zdołały się od feminizmu oderwać i dzisiaj funkcjonują w pełni autonomicznie."

33 I Vgl. die Kritik von Filipowicz: Przeciw sliteraturze kobiecej<, die sich besonders auf Mois Sexual/Textual Politics stützt; vgl. Moi, Toril: Sexual/Textual Politics. Feminist Literary Theory (= New Accents), London 1985 sowie Magnone: Die polnischen Gender Studies, S. 379-386.

34 I Borkowska: Cudzoziemki, S. 5: "sztuka kobieca«.

35 । Ebd., S. 6: »nigdy jasno nie określono, jakie parametry można przypisać sztuce kobiecej«. Mit der Berücksichtigung des Werks Orzeszkowas integriert Borkowska auch ein nach ihrem Maßstab snicht-weibliches، Schaffen in ihre Untersuchung.

36 | Ebd.: »Należy wątpić, czy wobec wielu prób opisania tzw. écriture féminine, można liczyć na postęp w tej materii.« 
der écriture féminine, die bei Borkowska nurmehr wörtlich als »weibliches Schreiben « zu verstehen ist und als solches problematisiert wird. Borkowska geht jedoch nicht darauf ein, dass dieser Begriff, der 1975 von Cixous konzeptualisiert wurde, ${ }^{37}$ gleichzeitig analytischer Ansatz wie auch programmatische Forderung nach einer Sprache/Literatur außerhalb des männlichen Logos darstellt.

Während Borkowska wie oben beschrieben vier Denkweisen als Parallelphänomene auffächert, setzt sie diese historisch nicht in Bezug zueinander. Den wissenshistorischen Bezugsrahmen feministischer Kritik verortet sie folgendermaßen:

»Der Großteil der von uns besprochenen Arbeiten wäre nie entstanden ohne die kritischen Errungenschaften des französischen und amerikanischen Dekonstruktivismus - also ohne die Bücher von Jacques Derrida und der Yale-Schule (P[aul] de Man, H[arald] Bloom, G[eoffrey] Hartman). Die Verdankensschuld gegenüber Freud und Lacan haben wir schon erwähnt. In die lange Reihe der Gläubiger gilt es noch Nietzsche und die zeitgenössischen Interpreten des Marxismus zu stellen.«38

In dieser Aufstellung finden sich nur `männliche` Texte unter den Bezugstexten. In Verbindung mit der Unterschlagung historischer Entwicklungen innerhalb der feministischen Kritik scheint es, als bilde die feministische Kritik eine nur dünne Schicht, unter der der >männliche` Unterbau hervorscheine.${ }^{39}$ Der Beachtung wert sind im obigen Zitat auch die Formulierungen der `Schuldigkeit`, die die feministische Kritik gegenüber ihren Vorgängertexten, den Gläubigern (wierzyciele) habe. Borkowska formuliert dies hier so, als handle es sich bei den feministischen Ansätzen um Nutznießer vorheriger Gedankenarbeit und als müsse dieser Umstand des theoriegestützten Weiterdenkens besonders hervorgehoben werden.

In gewisser Weise lässt sich Ähnliches bei Iwasiów feststellen. Iwasióws feministische Kritik zielt zwar schon allein dadurch, dass sie sich einer revisionistischen Lektüre widmet, in eine andere Richtung als diejenige Borkowskas. Doch auch sie verortet ihre Bezugspunkte - gar noch direkter - in der vorwiegend männlich geprägten (post)strukturalistisch-dekonstruktivistischen Denktradition. Nebst einigen Randverweisen auf feministische Ansätze (Millett) stützt sich Iwasiów vorwiegend auf die derridasche Philosophie, etwa in Form der polnischen

37 I Siehe Cixous: Le Rire. Cixous findet im Werk Borkowskas keinerlei Erwähnung.

38 । Borkowska: Cudzoziemki, S. 18f.: »Większość z omawianych przez nas prac nie powstałaby, gdyby nie dorobek krytyczny francuskiego i amerykańskiego dekonstrukcjonizmu - a więc gdyby nie książki Jacquesa Derridy i szkoły Yale (P. de Man, H. Bloom, G. Hartman). 0 długu wdzięczności wobec Freuda i Lacana już wspominaliśmy. W długim szeregu wierzycieli postawić trzeba jeszcze Nietzschego i współczesnych interpretatorów marksizmu."

39 । Auch Borkowska selbst stellt sich quasi in die smännliche` Tradition, als sie in ihren Ausführungen die männlich-personale grammatische Kategorie des Plurals verwendet (»wspominaliśmy«, »wir erwähnten«). 
Derrida-Einführung Maszyna do pisania (Schreibmaschine, 1992) von Tadeusz Rachwał und Tadeusz Sławek. Diese verbinden die Überlegungen Derridas, Kristevas und Lacans zu einem Ansatz der >Resignation` aus der dominanten, phallogozentrischen Position, einer Resignation, die die Frau kennzeichne, die somit zum »Wahrheitsraum, den Kristeva vréel nennt ${ }^{40}$, werde. So gelangt auch Iwasiów zu einer theoretischen Konzeption von Geschlecht, in der allerdings die Ansätze Kristevas eine untergeordnete Rolle spielen.

Iwasióws Vermeiden feministischer Konzepte und Begrifflichkeiten kann als Versuch gelesen werden, eine epistemologische »Unmarkiertheit« (nieoznaczność) zu bewahren, während die »Begriffsbildung den Verlust der Bande mit der Wirklichkeit ${ }^{41}$ bedeute und die von ihr angestrebte »Fluktuation und Subjektivismus ${ }^{42}$ verhindere. Die postmodernistisch dezentrale Axiologie ist für Iwasiów gleichbedeutend mit einer feministischen: »[N]ur die Frau ist zur Differenz befähigt. « ${ }^{43}$ Die >männliche Provenienz ihrer Bezugspunkte und Verortungen, die sich das Weibliche in ihren Konzepten aneignen, ${ }^{44}$ stellt für Iwasiów offenbar kein Thema dar, das es zu problematisieren gäbe.

Die Vermeidung (feministischer) Terminologie gelingt Iwasiów jedoch insbesondere in Bezug auf ihre Archetypen-Forschung kaum. Hier setzt Iwasiów Schlagworte wie Patriarchat, phallischer Vaterkult oder Frauentausch in eine Argumentationsstrategie ein, die sich neben Freud, feministischen Anleihen (Millett) und den theoretischen Schriften Georges Batailles zur Erotik vor allem auch des ethnologischen Strukturalismus (Lévi-Strauss, Marcel Mauss) bedient. ${ }^{45}$

Intertextuell interessant ist zudem der von Iwasiów untersuchte Raum der ukrainischen Kresy, den sie als »Enklave der Vorgeschichte, Lagerraum von Archetypen, Vaterland der Phantasmen ${ }^{46}$ fasst. Diese Formulierungen verweisen auf eine Art Vorsprachlichkeit dieses Raums; gleichzeitig machen sie auf die diskursive Überformung des Kresy-Raums aufmerksam und markieren das Textfeld, in dem sich Iwasiów bewegt. An anderer Stelle ${ }^{47}$ verweist Iwasiów auf die Phantas-

40 I Rachwał, Tadeusz/Sławek, Tadeusz: Maszyna do pisania. 0 dekonstruktywistycznej teorii literatury Jaquesa Derridy, Warszawa 1992, S. 133. Vgl. Kristeva, Julia: »Le Vréel«, in: Kristeva, Julia/Ribettes, Jean-Michel (Hg.), Folle vérité. Vérité et vraisemblance du texte psychotique (= Tel Quel), Paris 1979, S. 11-35; dies.: Pouvoirs de l'horreur.

41 I Iwasiów: Kresy, S. 22: "tworzenie pojęć to zatracanie więzi z rzeczywistością«. Iwasiów bezieht sich hier auf José Ortega y Gasset.

42 I Ebd.: "fluktuacj[a] [i] subjektywizm«.

43 I Ebd.: »tylko kobieta jest zdolna do różni."

44 I Etwa Jonathan D. Culler, der für die Formulierung "a woman reading as a woman reading as a woman« verantwortlich zeichnet; Culler, Jonathan D.: On Deconstruction. Theory and Criticism after Structuralism, Ithaca, New York 1982, S. 64, zit. nach Iwasiów: Kresy, S. 22.

45 । Vgl. Iwasiów: Kresy, S. 100-106.

46 | Ebd., S. 11: »enklawą pre-historii, magazynem archetypów, ojczyzną fantazmatów«.

47 | Vgl. ebd., S. 18. 
ma-Konzeption Janions, die in Tam gdzie rojsty (Wo die Moore sind) von 1983 den Raum der Kresy als »Daimonion « beschreibt. ${ }^{48}$ Die Kresy nehmen in der polnischen Imagination eine zentrale Rolle in der Kulturkonstituierung wie auch die Bedeutung eines Grenzgebiets in vielerlei Hinsicht an.

Der Kresy-Topos bietet sich deshalb für eine dekonstruktivistische, poststrukturalistische Lektüre geradezu an. Inwiefern Iwasiów in ihren Beschreibungen der Kresy als "nicht glatten Raum « ${ }^{49}$ des Imaginären oder andernorts als "glatten Raum der vom Schneegestöber bedeckten Steppe « ${ }^{50}$ von den Konzepten Gilles Deleuzes und Félix Guattaris geprägt wurde, lässt sich durch keine Verweise auf diese Ansätze bestimmen; deren Philosophie ist jedoch mit den Begriffen des "Rhizoms « (kłącze) und der »Falte» $\left(\right.$ fałda) implizit in Iwasióws Text präsent. ${ }^{51}$ In gewisser Weise könnte man hier von einer Art »metaphorischer Intertextualität« nach Renate Lachmann sprechen, da bestimmte konzeptuelle Ähnlichkeiten parallel herausgebildet werden, mutmaßlich ohne in direktem Bezug zu stehen. ${ }^{52}$ In diesem Fall wäre der Text Iwasióws ein erstaunliches Beispiel einer `Pfadabhängigkeit , in der die poststrukturalistische `Anlage die Richtung derart vorbestimmt, dass ähnliche oder gar identische Begrifflichkeiten herausgearbeitet werden. Eine solche Auffassung zielt in eine ähnliche Richtung wie das bereits festgestellte Pastichieren feministischer Ansätze, das Iwasiów als eigener Nachvollzug von Gedankengängen in ihrer Dissertation praktiziert.

Die Texte Janions weisen ebenfalls auf die `männlichen $`$ Verflechtungen feministischer Ansätze hin. Im nachfolgend vorgestellten Fall sind besonders die Verschiebungen in der Begriffsdefinition bemerkenswert. Janions Definition des Begriffs `Feminismus und ihr Umgang damit veränderte sich in den 1990er Jahren durch den Input von Studentinnen wie Szczuka und Filipiak von einem rallgemeinen (männlichen) zu einem `weiblichen`Feminismus. Aufzeigen lässt sich dies an ei-

48 । Vgl. Janion: Tam gdzie rojsty, S. 100f. Janion umschreibt hier zwar den »Urwald« (puszcza) und die "Moore ( rojsty) der litauischen Kresy, was in gewissem Gegensatz zu den Steppengebieten und »offenen Räumen « (otwarte przestrzenie) (Iwasiów: Kresy, S. 112) der ukrainischen Kresy steht; die Verortung des Phantasmas trifft jedoch auf beide Räume zu.

49 । Iwasiów: Kresy, S. 78: "nie jest co prawda gładką przestrzenią".

50 । Ebd., S. 124: "gładkiej przestrzeni zasypywanego śnieżną zawieją stepu«.

51 I Vgl. ebd., S. 9, 131. Rachwał/Sławek (Maszyna do pisania, S. 120) verweisen in der von Iwasiów verwendeten Einführung zu Derrida darauf, dass das Rhizom kein von Derrida selbst explizit eingesetzter Begriff ist (anders als die »Falte«), sondern erst von Deleuze/Guattari (Rhizome, S. 18) eingeführt wurde. Iwasiów nimmt bei ihrer Begriffsetzung keinen Bezug auf Letztere. Siehe auch Deleuze, Gilles/Guattari, Félix: $\$ 1440$ - le lisse et le strié«, in: dies., Mille plateaux. Capitalisme et schizophrénie tome 2, Paris 1980, S. 592-625; Deleuze, Gilles: Le Pli. Leibniz et le baroque, Paris 1988.

52 | Vgl. Lachmann, Renate: Gedächtnis und Literatur. Intertextualität in der russischen Moderne, Frankfurt a/M. 1990, S. 39f. 
nem Text Janions über das Poem Grażyna und das Verhältnis Mickiewiczs zum weiblichen Geschlecht. In der Erstveröffentlichung ihrer Analyse schrieb Janion 1986: »Der Feminismus, der Mickiewicz das ganze Leben begleitete, betrieb einen Kult der Frau als Kult des Instinkts, des Herzens, der Gefühlsanwandlung. ${ }^{53}$ In der späteren Überarbeitung des Textes für die Publikation in Kobiety i duch inności eliminierte Janion das Wort `Feminismus` aus der Formulierung: »Mickiewicz betrieb während seines ganzen Lebens einen Kult der Frau als [Kult] des Instinktes, des Herzens, der Gefühlsanwandlung. ${ }^{54}$

Mit Blick auf diesen Vergleich scheint es offensichtlich, dass sich Janions Verständnis von Feminismus innerhalb der zehn Jahre gewandelt hat. Janion verwendete den Begriff `Feminismus`, der für sie ein eher loses semantisches Feld absteckte, in den 1980er Jahren selten. Er überlagerte sich mit dem »Kult der Frau«, also einer Zuschreibung bestimmter Eigenschaften, die zu Hochachtung und Verehrung der (symbolischen) Frau führen. Janion selbst sah sich nicht als `Feministin mit einer verflachten `Meinung ‘ zum weiblichen Geschlecht, sondern im Gegenteil als kritische Beobachterin von Stereotypen im kulturellen Kontext. Die `westliche Definition des Feminismus war für Janion zweitrangig und für den polnischen Kontext vorläufig irrelevant. ${ }^{55}$

1996 jedoch taugte die Definition von Feminismus als »Kult der Frau« nicht mehr. Im veränderten sozialen und wissenschaftlichen Kontext konnte Janion Mickiewiczs Haltung nicht mehr feministisch nennen, da solche Haltungen zur Festigung und Aufrechterhaltung des symbolischen Geschlechterungleichgewichts beitrugen. ${ }^{56}$ Janion legte ihr neues Verständnis von Feminismus in einem Gespräch in den Teksty Drugie von 1997 dar: "Ich habe auch oftmals davon gesprochen, dass Frauen wie Männer im Leben stets einer Unterdrückung unterworfen sind, die Frauen aber auf eine spezielle, zusätzliche Weise.« Die ideelle Haltung Janions hatte sich nicht verändert, neu war jedoch die stehende Bezeichnung dafür: »Der feministische Standpunkt besteht darin, diese zusätzliche Unterdrückung zu beschreiben. $\aleph^{57}$ Janion hebt hervor, dass sie diesen kritischen Blick bereits seit langem pflege (»ich habe oftmals davon gesprochen«) und »[d]er Feminismus nur eine neue Bezeichnung für diese Idee $\aleph^{58}$ sei. Ihre eigene feministische Haltung bezeich-

53 I Janion: Zbroje Grażyny, S. 153: »Towarzyszący Mickiewiczowi przez całe życie feminizm uprawiał kult kobiety jako kult instynktu, serca, porywu uczuciowego."

54 I Janion: Kobiety, S. 87: »Mickiewicz przez całe życie uprawiał kult kobiety jako instynktu, serca, porywu emocjonalnego."

55 I Vgl. ebd., S. 326.

56 I Vgl. Brach-Czaina: Progi, S. 352; Titkow: Kobiety pod presją, S. 11; Walczewska: Damy, rycerze i feministki, S. $54 \mathrm{ff}$.

57 | Janion: Kuferek Harpagona, S. 206: »Mówiłam też wielokrotnie o tym, że żyjąc i kobiety, i mężczyźni podlegają zawsze opresji, ale kobiety w sposób szczególny, dodatkowy.«; »Feministyczny punkt widzenia polega na tym, żeby opisać tę dodatkową opresję."

$\mathbf{5 8}$ । Ebd.: »Feminizm to tylko nowy wyraz dla tej idei.« 
net Janion im gleichen Zug als relativ gemäßigt. Sie knüpft an Germaine Greers Position in The Female Eunuch (1970) an und schreibt:

"[E]s geht um die Notwendigkeit, dass Frauen ihr eigenes Erleben definieren. Man kann sagen, das sei eine frühe und ziemlich milde Form des Feminismus, die mir jedoch am meisten entspricht. Ich halte dieses Erleben für unzureichend erkundet und dessen Beschreibung für etwas außergewöhnlich Wichtiges. ${ }^{59}$

Greer selbst sieht ihren Ansatz als weniger radikal und umfassend als die revolutionären Utopien der Neuen Linken. „Die schärfste Kritik wird von meinen Schwestern aus der Linken kommen ${ }^{60}$, prophezeit Greer über die Rezeption ihres Texts. Sie fordert, die Frau »könnte damit anfangen, nicht die Welt zu ändern, sondern selber zu einem neuen Selbstverständnis zu gelangen. ${ }^{61}$ Erst in zweiter Linie formuliert Greer Hoffnung auf eine post-bürgerliche und -kapitalistische Gesellschaft. Für Greer ist die `Frauenfrage` dringlicher als die Kritik an Klassenverhältnissen oder ethnischen und sexuellen Diskriminierungen. Janion übernimmt diese Priorisierung, da sie in der Transformation der polnischen Gesellschaft nach 1989 ihre Hoffnung auf eine kritische Auseinandersetzung mit vergeschlechtlichten Ungleichheiten enttäuscht sieht. ${ }^{62}$ Umso stärker betont sie etwa in der Besprechung von Filipiaks feministischem Roman Absolutna amnezja von 1995, dass die inhaltliche und stilistische Herausarbeitung einer spezifisch weiblichen Erfahrungswelt überaus legitim sei und auf die partikulare Position polnischer Frauen hinweise. ${ }^{63}$ Janions Ansatz, der anders als die oben besprochenen theoriefokussierten Genealogieerzählungen vor allem den soziopolitischen und persönlichen Kontext einbezieht, zielt somit auf eine Aneignung des Feminismus durch die Frauen und auf eine Emanzipierung vom patriarchalen `Frauenkult‘.

Das feministische Aneignen weiblichen (differenten) Erlebens kann durch transnationale Lektüreprozesse initiiert werden, wie Kraskowska beschreibt. Erst durch die Lektüre englischer weiblicher Prosa sei Kraskowska Mitte der 1980er

59 | Ebd.: »chodzi o konieczność zdefiniowania własnych doznań przez kobiety. Ktoś może powiedzieć, że to wczesna i dość łagodna postać feminizmu. Ale to mi najbardziej odpowiada. Uważam, że doznania owe są niedostatecznie poznane, a ich opisywanie jest czymś niebywale istotnym." 60 । Greer, Germaine: Der weibliche Eunuch. Aufruf zur Befreiung der Frau, Frankfurt a/M. 1971, S. 22.

61 I Ebd., S. 14.

62 I Vgl. Janion: Kobiety, S. $326 f$.

63 । Vgl. ebd., S. 328. Über den in den 1990er Jahren in den postsozialistischen Staaten aufkommenden "kulturellen Feminismus" formuliert Ghodsee (Feminism-by-Design, S. 328), dass dieser "privilege[s] a gender-based analysis of oppression over an analysis more sensitive to class issues" und »often aims at meeting women's special needs within the status qu0". Siehe dazu auch Kapitel 6.1.3. 
Jahre aufgefallen, dass "Weiblichkeit in der Literatur ${ }^{64}$ als Erkenntniskategorie möglich sei. ${ }^{65}$ Selbsterfahrung und Lektüreerlebnis kongruierten, und die Texte »beschrieben die Welt als solche, wie ich sie täglich sehe und erlebe. ${ }^{66}$ Dieses Entdecken eines Überlappens von persönlichen Erfahrungen als `weibliche` prägte Kraskowskas feministischen Ansatz. Dessen Kernstück bildet die Ergründung weiblicher Identitätskonstruktion und die Frage nach einer geschlechtsspezifischen Erfahrungswelt innerhalb der und in Abgrenzung zur Gesellschaft.

Eine solche Personalisierung des feministischen Ansatzes als »Sprache meiner eigenen Erfahrung oder der Erfahrungen mir bekannter Frauen ${ }^{67}$, wie Kraskowska es formuliert, verschiebt die Erkenntnis von einer theoretischen Ebene weg und schreibt sie der weiblichen Alltagserfahrung zu. "Entgegen der bis vor Kurzem leitenden Losung Simone de Beauvoirs - sniemand wird als Frau geboren - wird heute betont, dass die Frau als Frau geboren wird und dass niemand außer ihr besser die Aufgaben ausführt, die ihr das Leben anvertraut hat. ${ }^{68}$

Kraskowska beschreibt mit der hier formulierten sglobalen« Tendenz zur Affirmation der Weiblichkeit und der "Aufgaben, die ihr das Leben anvertraut hat", nicht nur eine metaphysische Universalität /weiblicher`Merkmalszüge, in der dekonstruktivistische oder performative Ansätze feministischer Kritik keinen Raum finden. Sie betreibt auch eine Art Gegenwissenschaft, in deren Rahmen sie feministischen Klassikern das snatürlicher weibliche Empfinden entgegenstellt. Ein in diesem Sinne feministisch ermächtigtes weibliches Subjekt kann ganz aus sich selbst schöpfen und ist nicht auf feministische Theorien und Denkgenealogien angewiesen. Mit dieser Intimisierung oder kollektiven Individualisierung der Weiblichkeit ist bereits ein Thema angesprochen, das ich im Kapitel 6 im Kontext der Einbettung in den soziopolitischen Diskurs erneut aufnehme.

\subsection{2 (In)Kongruenzen}

Die feministischen Kritikerinnen Polens notieren die Differenz der weiblichen von der männlichen Erfahrungsweise. Eine ähnliche Differenz stellen sie jedoch teilweise auch im interkulturellen Vergleich fest - als Divergenz polnischer soziokultureller Erfahrung vom westlichen (feministischen) Narrativ. Die Erkenntnisse westlicher feministischer Kritik werden mit eigenen Beobachtungen von Phäno-

64 I Kraskowska: Piórem niewieścim, S. 8: »kobiecością w literaturze«.

65 I Diese Inspirierung durch eine internationale weibliche Literatur beobachtet Kraskowska übrigens auch an ihrem Forschungsmaterial der polnischen Zwischenkriegsschriftstellerinnen, vgl. ebd., S. 32.

66 | Ebd., S. 7: »opisały świat takim, jakim go co dzień oglądam i przeżywam.«

67 | Ebd.: "językiem mego własnego doświadczenia lub doświadczenia znanych mi kobiet«.

68 I Kraskowska: Piórem niewieścim, S. 157: »Wbrew sztandarowemu jeszcze nie tak dawno hasłu Simone de Beauvoir - snikt nie rodzi się kobietą - dziś kładzie się nacisk na fakt, że kobieta rodzi się kobietą i nikt lepiej od niej nie wykona zadań, które powierzyło jej życie.« 
menen im polnischen Kulturbetrieb kontrastiert. Ich greife hier Beispiele solcher Kontrastierungen heraus, um aufzuzeigen, dass die feministischen Kritikerinnen trotz weitgehender Übernahme westlicher Ansätze nicht immer von einer völligen Kongruenz der beschriebenen Erfahrungen ausgehen.

Als ein Beispiel nennt Borkowska die Pseudonymwahl der polnischen Schriftstellerin Żmichowska Mitte des 19. Jahrhunderts. Żmichowska verwendete für ihre Schriften das weibliche Pseudonym Gabryella, womit sie keinen Anspruch auf die Machtposition eines männlichen Schreibers erhebe. Diese Strategie läuft gemäß Borkowska den feministischen Theorien zur Pseudonymsetzung zuwider. ${ }^{69}$ Borkowska notiert: "Mit dieser winzigen Geste stellt [Żmichowska] die ganze Ordnung der zeitgenössischen feministischen Kritik auf den Kopf, welche scheinbar über ein feines Instrumentarium der Beschreibung und Analyse weiblichen Schaffens verfügt. $"{ }^{70}$ Borkowska suggeriert, dass die feministische Kritik ihre Argumente ganz auf der Annahme aufbaue, dass weibliche Autorinnen männliche Pseudonyme wählten. Von dieser Annahme ausgehend habe die feministische Kritik eine Fülle von detailreichen Analysen und Hypothesen aufgestellt, deren Ordnung jedoch bei Veränderung der Grundannahme in sich zusammenbreche.

In ihrem theoriekritischen Misreading scheint Borkowska den im Polen der 1990er Jahre oft geäußerten Kritikpunkt zu bestätigen, dass die feministische Kritik auf einer ideologischen Basis fuße. In dieses ideologische Gefüge feministischer Theorien lasse sich das polnische Beispiel Żmichowskas jedoch nicht einordnen. Borkowska suggeriert, dass die Dekonstruktion feministischer Thesen durch eine »winzige Geste« gewissermaßen unbeabsichtigt stattfinden könne, womit sie die Annahmen der feministischen Kritik grundsätzlich hinterfragt. Dieses Aufbrechen der >globalen ‘ feministischen Theorie mit dem lokalen, beinahe unschuldigen - da unbeabsichtigten - Gegenbeispiel greift aber hier argumentativ nur, weil Borkowska die `Theorie` rhetorisch nicht nur vereinheitlicht, sondern auch als ideologisch vorbestimmte und deshalb unflexible konstruiert.

Auch an einer weiteren Stelle vermerkt Borkowska die Unzulänglichkeiten der feministischen Kritik, nämlich als sie die literarische Figur der Künstlerin in der polnischen Literatur zu konzeptualisieren versucht. »Jegliche Versuche, dieses Phänomen durch geläufige Tropen der feministischen Kritik zu erklären, erweisen sich als unzutreffend. « ${ }^{71}$ Auch hier scheint es mehr, als negiere Borkowska die Gültigkeit feministischer Ansätze im Allgemeinen - da sie sich auf keinen konkreten

69 । Vgl. dazu auch Borkowska: Córki Miltona, S. 76. Borkowska bezieht sich hier vor allem auf Gilbert/Gubar: Madwoman in the Attic sowie Showalter: Toward a Feminist Poetics.

70 । Borkowska: Cudzoziemki, S. 101: "Tym drobnym gestem wywraca do góry nogami cały porządek wpisany we współczesną krytykę feministyczną, dysponującą, zdawałoby się, subtelnymi narzędziami opisu i analizy twórczości kobiecej."

71 | Ebd., S. 171: "Wszelkie próby objaśniania tego fenomenu poprzez obiegowe tropy krytyki feministycznej nie wydają się trafne. Ta polska artystka jest bowiem wyjątkowo niepewna siebie, 
Ansatz bezieht -, als dass sie mit ihrer Feststellung eine Erweiterung und Pluralisierung feministischer Thesen anstrebe. ${ }^{72}$ In beiden angeführten Textstellen konstatiert Borkowska, dass die feministische Kritik weder das Phänomen weiblichen Schreibens erschöpfend beschrieben habe noch zwingend einen universalen Anspruch haben könne. Die Beispiele polnischer Schriftstellerinnen dienen ihr als Gegenbeweis. Der polnischen Kultur wird eine Sonderstellung zugeschrieben, da sich diese den >westlichen $>$ Gesetzesmäßigkeiten nicht unterwirft und gar die westlichen feministischen Ansätze destabilisiert. Borkowska baut so eine gewisse Binarität zwischen dem globalen Westen und der lokalen polnischen Kultur auf. Ähnlich argumentiert übrigens Iwasiów in Gender dla średnio zaawansowanych (Gender für fortgeschrittene Anfänger) von 2004. Im Gegensatz zu Borkowska sieht sie die Inkongruenz jedoch als Defizit des polnischen, vor allem auch gesellschaftlichen, Kontexts, während sie westliche feministische Ansätze als zu erreichendes Ideal darstellt. ${ }^{73}$

Kłosińskas transnationale Vergleiche zielen im Gegensatz zu denjenigen von Borkowska nicht auf die Konstruktion von Differenz. ${ }^{74}$ Wie bereits festgestellt, integriert Kłosińska feministische Ansätze am synthetischsten in ihre Forschung, was ihrer Meinung nach mit der psychoanalytisch-feministischen Anlage der untersuchten Texte zu erklären sei. »[D]ie Autorin selbst kreist ununterbrochen um diejenigen Fragen, die auch den Gründer der Psychoanalyse im nahen Wien faszinierten [...].« ${ }^{75}$ Kłosińska parallelisiert das Interesse Zapolskas an psychologischen Problemstellungen mit demjenigen Freuds, was zu einer Art Gleichzeitigkeit führt. Zudem verweist Kłosińska auf die räumliche Nähe. Sie konstruiert ein Diskurskontinuum, in das sie Zapolska und den polnischsprachigen Raum (hier Lemberg als Teil der Österreichisch-Ungarischen Monarchie) einschreibt. Kłosińska scheint keinen Grund zu sehen, das polnische Material oder ihr eigenes wissenschaftliches Setting von einem gesamteuropäisch-amerikanischen Theorie- und Kulturkontext abzusetzen. Dies ist wohl nicht zuletzt in der psychoanalytischen Ausrichtung begründet, die von allgemeingültigen >Regeln` der menschlichen

przerażona i samotna. Nie ma więc mowy o jakichś prometejskich zamiarach, które kobiety-artystki chciałyby wprowadzić w życie."

72 I Zudem widerspricht sich Borkowska in gewisser Weise selbst, wie ein Vergleich mit ihrer Zusammenfassung westlicher feministischer Kritik von 1992 zeigt, vgl. Borkowska: Córki Miltona, S. 72.

73 | Vgl. Seiler: Geschlechterfragen, S. 58-61; dies.: Brüche im Kontinuum, S. $103 f$.

74 I Kłosińska ist von den untersuchten Wissenschaftlerinnen auch diejenige, die sich - neben Iwasiów - am wenigsten für die Figur der Schriftstellerin interessiert. Dies zeigt sich darin, dass sie den Text nicht genetisch als persönlichen Ausdruck der Autorin liest; die Gegenposition bezieht Borkowska, deren Interesse eigentlich primär der Autorinnenfigur gilt. Siehe dazu auch Kapitel 6.3 sowie Magnone: Die polnischen Gender Studies, S. 375f., 384.

75 I Kłosińska: Ciało, S. 291: "sama pisarka krąży bezustannie wobec tych zagadnień, które w nieodległym Wiedniu fascynowały założyciela psychoanalizy [...].« 
Psyche ausgeht und dabei lokale wie auch kulturelle Differenzierungen übergeht oder gar konzeptionell ausschließt. ${ }^{76}$

Eines der großen Themenfelder, die Kłosińska beschäftigen, ist die Hysterie. Im feministischen Hysteriediskurs »werden Antworten auf die Fragen wichtig: wer erzählt, schildert, interpretiert die Geschichte der Hysterie, wer beleuchtet oder verdunkelt sie? «77 Kłosińska liest in Zapolskas Przedpiekle ein kritisches Aufgreifen der Hysterie, in dem der psychomedizinische Diskurs kontextualisiert und hinterfragt werde. In der bildlichen Beschreibung der Hysterie im Roman erkennt Kłosińska eine Art Blaupause der zu dieser Zeit leitenden Forschungserkenntnisse, die in Frankreich von Jean-Martin Charcot vorgestellt worden waren. Kłosińska betont die beinahe kopistische Überschneidung der beschriebenen Phänomene:

»die hysterischen Attacken [...] sind dieses Mal ausgewachsene Darstellungen der vier Phasen der grande hystérie, gleichsam die Aufzeichnungen Charcots abbildend. Da ist die sopisthotonischer Position, das Stadium des arc-en-cercle [...] Der in das Pensionat gerufene Arzt gibt den Pensionatsschülerinnen Beruhigungsmittel und wendet eine routinemäßige, auch in der Salpêtrière praktizierte Maßnahme an [...]. « ${ }^{78}$

Indem Kłosińska Parallelen zwischen der französischen protomedizinischen Beschreibung der Hysterie und den im polnischen Roman abgerufenen Symptomen eines hysterischen Anfalls zieht, schreibt sie diese beiden Darstellungen in dasselbe Diskurskontinuum ein. Den intertextuellen Bezug sieht sie in Zapolskas mimetischer Nach-Schreibung (»odwzorowujące«, abbildend) der Prozesse an der Salpêtrière und der dort etablierten Klassifizierung bestimmter `Phasen ‘. Die Salpêtrière als Ereignisraum wird somit in Zapolskas Roman transponiert. Diese analoge Transposition setzt zudem eine Übereinstimmung der Rahmenbedingungen der Hysterie voraus.

Während in beiden Kontexten die gleichen Schablonen der Symptome und ihrer Behandlung zur Anwendung kommen, unterscheiden sich laut Kłosińska die jeweiligen Verfahren der Darstellung.

76 | Vgl. Dybel, Paweł: Psychoanaliza - ziemia obiecana? Z dziejów psychoanalizy w Polsce 1900-1989. Część I. Okres burzy i naporu. Początki psychoanalizy na ziemiach polskich okresu rozbiorów 1900-1918 (= Dzieje psychoanalizy w Polsce), Kraków 2016, S. 12, der auch auf die starke Verankerung (polnischer) psychoanalytischer Ansätze in einer gesamteuropäischen »Wissenschafts- und Kulturtradition « hinweist.

77 | Kłosińska: Ciało, S. 212: „ważne stają się odpowiedzi na pytania: kto historię histerii opowiada, przedstawia, interpretuje, kto ją rozświetla bądź zaciemnia?«

78 | Ebd., S. 227: »histeryczne ataki [...] [t]ym razem są rozwiniętymi przedstawieniami czterech faz grande hystérie, jakby odwzorowującymi zapis Charcota. 0to pozycja >opisthotoniczna<, stadium arc-en-cercle [...] Zawezwany na pensję lekarz podaje pensjonarkom środki uspokajające i stosuje rutynowy, praktykowany także w Salpêtrière, zabieg [...].« 
»Die Hysterie ist bei Zapolska kein Gegenstand der Kontemplation, kaum wird sie gezeigt, verschwindet sie schon wieder, wie hinter dem Vorhang in einem Theater. Die Schriftstellerin greift das in der Salpêtrière herausgebildete 'Repräsentationsregime` des hysterisierten Körpers nicht auf. Sie ästhetisiert diesen nicht. Sie verwirft gleichsam dessen Dechiffrierung in den Kategorien des männlichen Blicks und der männlichen Sprache`, als ob sie sich von der Produktion `phantasmatischer Ereignisse in der Schule Charcots distanzierte. ${ }^{79}$

Der Unterschied zwischen Charcots und Zapolskas Zugang zur Hysterie zeige sich nicht im Inhalt, sondern in der Form des `Darstellensı. Zapolska, so Kłosińska, verweigere sich der Zurschaustellung und Entblößung des hysterisierten Körpers und vermeide so die Entsubjektivierung der betroffenen weiblichen Figur. Die Inkongruenz in der Darstellung liegt hier jedoch nicht in einer kulturell-geographischen Distanz begründet, sondern in einer geschlechtsbedingten Perspektivenverschiebung.

Bislang habe ich im vorliegenden Kapitel auf einige Verfahren der Anbindung an und Abgrenzung von westlichen feministischen Ansätzen in der feministischen Polonistik aufmerksam gemacht. Entlang der Beispiele von Borkowska und Kłosińska habe ich aufgezeigt, dass die feministischen Polonistinnen ihr Material mit Erkenntnissen aus der westlichen Forschung vergleichen. Die Feststellung von Unterschieden wird dabei aber nicht zwangsläufig als kulturelle Differenz identifiziert. Am Beispiel der Psychoanalyse und deren Transposition in die feministische Polonistik möchte ich die Überlegungen zur Theorieaufarbeitung und zu Formen der Einbettung nun vertiefen.

\subsection{Die grosse Abwesende: Psychoanalyse}

Feministische Exponentinnen der polnischen 1990er Jahre weisen darauf hin, dass die sspäte Entwicklung feministischer Positionen in Polen mit dem spezifischen Vakuum ‘ an psychoanalytischen Ansätzen in der Volksrepublik zusammenhänge. Die kommunistische Führung und Ideologie stellte die Umformung der materiellen Bedingungen in den Vordergrund, weshalb die Auseinandersetzung mit psychologischen Prozessen und die Notwendigkeit "geistige[r] Wandlungen « ${ }^{80}$

79 | Ebd., S. 230: »Histeria nie jest u Zapolskiej przedmiotem kontemplacji, ledwie ukazana, znika zaraz, niby za kurtyną w teatrze. Pisarka nie podejmuje ukształtowanego w Salpêtrière reżimu reprezentacji zhisteryzowanego ciała. Nie estetyzuje go. Odrzuca tym samym jego deszyfrację ,w kategoriach męskiego spojrzenia i męskiej mowy«, jakby dystansowała się wobec produkcji ,fantazmatycznych zdarzeń w szkole Charcota. "Die Binnenzitate stammen aus Pollock, Griselda: Vision and Difference. Femininity, Feminism, and the Histories of Art, London 1988, S. 190 sowie Decottignies, Jean: Physiologie et mythologie du feminin, Lille 1989, S. 22.

80 I Rattner, Josef/Danzer, Gerhard: Sozialismus und Psychoanalyse. Studienausgabe (= Enzyklopädie der Psychoanalyse, Band 4), Würzburg 2009, S. 163. Vgl. auch ebd., S. 83f.; Merfeld: 
vernachlässigt worden sei. Dies habe den Blick auf soziale Prozesse auch in Bezug auf das Geschlecht verstellt. ${ }^{81}$ Zudem habe sich dadurch keine `weiblicheく Literatur herausgebildet, wie Iwasiów anmerkt: »Die Psychoanalyse und der weibliche Roman überwinterten auf dem gleichen Regal. ${ }^{82}$

Die polnischen psychoanalytischen Ansätze der Zwischenkriegszeit fokussierten auf das Gespräch und die Anregung zur Selbstreflexion, weshalb sie ein potentiell subversives Element bargen. Sie wurden nach dem Zweiten Weltkrieg weitgehend von einer Psychiatrie verdrängt, die auf der »entsprechenden Auswahl der Tablette oder chirurgischen Eingriffen ${ }^{83}$ beruhte. Die Psychoanalyse wurde als »eine der `bürgerlichen ‘ intellektuellen Strömungen von Universitäten und anderen staatlichen Einrichtungen verbannt $~^{84}$, $»$ ihr privates Praktizieren verboten $~^{85}$, schreibt Dybel, der sich mit der Ideengeschichte der Psychoanalyse beschäftigt. Die polnischen Geisteswissenschaften wie auch die Psychologie wurden so von den westlichen Entwicklungen in diesem Bereich abgeschnitten. Die Psychoanalyse wurde als anachronistisch abgetan, und ab den 1960er Jahren dominierten positivistisch-empirische Herangehensweisen. ${ }^{86}$ In den Literaturwissenschaften »neutralisierten Strukturalismus und Semiotik, die den Autor für tot erklärten, gleichzeitig sein Geschlecht, womit sie dem Problem der >geschlechtlichen`Charakteristiken der Literatur jegliche Berechtigung entzogen ${ }^{87}$, schreibt Kraskowska und spricht damit eine Herausforderung an, die sich der feministischen Kritik auch in der poststrukturalistischen Tradition stellt.

Emanzipation, S. 92. Es gab jedoch auch Bemühungen der Vermittlung zwischen Marxismus und Psychoanalyse (Merfeld: Emanzipation, S. 92-101); zudem weist Dybel auf die »ungewöhnliche Ehe « zwischen den (linken) Strömungen freudscher Psychoanalyse und Marxismus hin, deren Vertreter "sich einander durch die kritische Diagnose der traditionellen Selbsterkenntnis und der patriarchalen bürgerlichen Gesellschaft annäherten, sowie durch die Überzeugung, dass diese radikal verändert werden sollte."Dybel: Psychoanaliza, S. 24.

81 । Vgl. Borkowska: Cudzoziemki, S. 239f. sowie Heim, Edgar: Die Welt der Psychotherapie. Entwicklungen und Persönlichkeiten, Stuttgart 2009, S. 63ff., 68f., der aber darauf aufmerksam macht, dass Polen im Vergleich zu anderen sozialistischen Staaten relativ liberal zur Psychoanalyse eingestellt war.

82 I Iwasiów: Gender, S. 154: „Psychoanaliza i powieść kobieca zimowały na tej samej półce.»

83 | Dybel: Psychoanaliza, S. 20.

84 | Dybel: Psychoanalyse in Polen, S. 283.

85 | Dybel: Psychoanaliza, S. 15.

86 | Vgl. ebd., S. $19 f$.

87 | Kraskowska: Piórem niewieścim, S. 13: „Strukturalizm i semiotyka, uśmiercając autora, neutralizowały zarazem jego płeć, a tym samym pozbawiały zagadnienie ’płciowychく wyróżników literatury wszelkiej zasadności. «Zur Vorherrschaft des Strukturalismus in der PRL ab den 1970er Jahren siehe auch Borkowska: Interview; Janion: Droga, S. 13; Janion/Szczuka: Profesor Misia, S. 85; Nycz, Ryszard: »0d redaktora«, in: ders., Po strukturalizmie (1992), S. 7-8. 
Angesichts des deutlichen Bezugs vieler westlicher feministischer Ansätze auf die freudsche und postfreudianische Psychoanalyse erstaunt es deshalb nicht, dass in der literaturwissenschaftlich strukturalistisch geprägten PRL keine feministischen Theorien entstanden wie etwa in Frankreich oder den USA in den 1970er Jahren. Darüber hinaus erschwerte das Fehlen von psychoanalytischem Basiswissen in Polen nach 1989 die Einbettung der auf psychoanalytischen Ansätzen basierenden feministischen Kritik. Interessant ist etwa auch, dass Janion, die sich für psychologische Prozesse und die antipsychiatrische Strömung interessierte, in ihren Arbeiten nur am Rande auf Freud einging, worauf ich noch zurückkomme. Die Polonistinnen der 1990er Jahre beziehen sich aufgrund fehlender Theorien häufig auf die in den untersuchten literarischen Texten angelegten psychologischen Ansätze. Freud selbst erfährt so eine gewisse Umgehung, da seine Schriften zwischen der weiblichen psychologischen Literatur des 19. Jahrhunderts und vor allem auch der analytischen Klammer postfreudianischer feministischer Kritik durch ihre antifeministische Haltung rabfallen`.

\subsubsection{Literatur als epistemologisches Medium}

Die feministischen Kritikerinnen der 1990er Jahre stellen fest, dass die Gattung des psychologischen Romans in der weiblichen Literatur des 19. und des frühen 20. Jahrhunderts in Polen gut vertreten war. Die Literatur erscheint als Pionierin in der diskursiven Verhandlung der menschlichen Psyche wie auch der Fragen zu sozialen Rollen. Darauf verweist Kraskowska mit ihrer Aussage, dass »die Belletristik Versuche der Bestimmung [der >weiblichen Identität] lange vor der Psychologie unternahm, welche die Frage nach der Geschlechterdifferenz erst vor relativ Kurzem in ihre Forschung zur Identität einführte. ${ }^{88}$ Insgesamt sei die Auseinandersetzung mit der Kategorie des Geschlechts in der Literatur traditionsreicher als in der explizit als solche gekennzeichneten Wissenschaft. ${ }^{89}$

So entwickelt beispielsweise Janion 1972 ihre Analyseperspektive auf The Monk (1796) von Matthew Gregory Lewis (1775-1818) direkt aus dessen inhärenter Dynamik sexuellen Begehrens, die bereits viele der später in der Psychoanalyse aufgegriffenen Aspekte aufweise. Im Fokus des literarischen Texts stehe die Macht des Unbewussten, des Es, das den Mönch Ambrosius zu seinen Taten verleite. Später »erwacht in Ambrosius das Gewissen, das Superego meldet sich « ${ }^{90}$ : Janion bleibt nur noch, die im Text beschriebenen psychologischen Prozesse mit psycho-

88 I Kraskowska: Piórem niewieścim, S. 88: »literatura piękna podjęła próby jej [’tożsamość kobieca‘] określenia na długo przed psychologią, która do swoich badań nad tożsamością dopiero stosunkowo niedawno wprowadziła kwestię zróżnicowania płciowego.« Siehe auch ebd., S. 19.

89 I Die Philosophin Danuta Sobczyńska erwähnt etwa, die Literatur habe sich der Problematik der Mutterschaft gewidmet, während die Philosophie dieses Themenfeld ignoriert habe. Vgl. Sobczyńska: Macierzyństwo, S. 70.

90 I Janion: Romantyzm, S. 376f.: »w Ambrozju budzi się sumienie, odzywa się superego«. 
analytischen Fachtermini zu verschlagworten. Diese Tatsache spricht ihr zufolge für die psychologische Durchdachtheit des literarischen Texts.

Der Soziologe Szacki argumentiert, dass die Literatur auch in der PRL gewisse Denktraditionen aufrechterhalten oder begründet habe, die in publizistischen und wissenschaftlichen Arbeiten keinen Raum gefunden hätten. So sei etwa

»in der dissidenten Literatur implicite eine bestimmte Philosophie des Menschen enthalten - eine in hohem Maße individualistische Philosophie. Mehr noch, gerade der Dissidentismus scheint die erste ernsthaftere Manifestation des Individualismus im politischen (oder parapolitischen, wie es einem beliebt) Denken 0steuropas gewesen zu sein, wo die individualistische Tradition arm und fast ausschließlich auf literarische Texte beschränkt war. «" ${ }^{91}$

Es war Szacki zufolge das Medium der Literatur, das philosophisch-politische Inhalte transportierte, ${ }^{92}$ welche sich später als dissidente (Anti-)Politik weiterentwickelten. Die literarische Tradierung individualistischer und auf die Privatsphäre gerichteter Lebenshaltungen wird auch für die feministische Kritik der 1990er Jahre relevant, wie ich noch argumentieren werde.

Die Literarisierung von Denkansätzen bietet insbesondere die Möglichkeit, diese auf verschiedenen narrativen Ebenen zu thematisieren oder sie bestimmten Figuren zuzuschreiben. Durch die Figurensteuerung können diese Themen positiv oder negativ betont werden, hoffnungsvoll oder pessimistisch stimmen. Dies beobachtet Borkowska in Żmichowskas Książka pamiątek (Buch der Andenken, 1847-48/1885) am Beispiel der wissbegierigen Helusia: »[D]ie deutlich vergegenwärtigte Eigenheit eines weiblichen Charakters und Intellekts wurde in Żmichowskas Roman nicht verwirklicht. Helusia bringt keine Frucht hervor. Ihr Verstummen und [...] verfrühter Tod erinnern an die Ohnmacht einer jungen Pflanze, die in ungünstigen Bedingungen vertrocknet. ${ }^{93}$ Borkowska suggeriert,

91 I Szacki, Jerzy: Liberalizm po komunizmie (= Demokracja. Filozofia i praktyka), Kraków 1994, S. 102, Hervorh. i. 0. Siehe auch Czerniawski, Adam: »A Poetical Political History«, in: Eile/Phillips, New Perspectives (1992), S. 6-27, hier S. 23.

92 I Die Literatur als Teil der Ideen- und Wissensgeschichte verfügt über spezifische Verfahren, die diese in Epochen stärkerer Reglementierung der Kommunikationsformen und -inhalte zu einem unabdingbaren Instrument der Wissensvermittlung machen. Prägnantes Beispiel ist hier etwa die "äsopische Sprache«, die in der Literatur unter dem Sozialismus Anwendung fand. Vgl. Loseff, Lev: On the Beneficience of Censorship. Aesopian Language in Modern Russian Literature (= Arbeiten und Texte zur Slavistik, Band 31), München 1984; Pawlicki, Aleksander: "Sonderwege der Zensurpolitik in der Volksrepublik Polen«, in: Bock, Ivo (Hg.), Scharf überwachte Kommunikation. Zensursysteme in 0st(mittel)europa (1960er - 1980er Jahre) (= Das andere 0steuropa. Dissens in Politik und Gesellschaft, Alternativen in der Kultur (1960er - 1980er Jahre). Beiträge zu einer vergleichenden Zeitgeschichte, Band 1), Berlin 2011, S. 209-361, hier S. 349-352.

93 I Borkowska: Cudzoziemki, S. 115: »jasno uświadamiana odrębność kobiecego charakteru i intelektu nie została w powieści Żmichowskiej zrealizowana. Helusia nie wydaje z siebie żadnego 
dass Żmichowskas `Sterben-lassen` der sich emanzipierenden Figur nicht als Kritik an deren Lebenshaltung, sondern an den rahmenden Bedingungen zu lesen sei. Żmichowskas Haltung gegenüber der Emanzipation sei von einem Pessimismus geprägt, der sich aus der Erkenntnis der sozialen Realien schöpfe.

In Książka pamiątek sieht Borkowska in der Äußerung einer der Protagonistinnen, Maria-Regina, eine Art feministischer Kritik. Maria-Regina ziehe einsichtsreiche Schlüsse über die Wissbegierde der Figur Helusia, die im Kontext einer männlich geprägten Lehre als ıfremd erscheinen müsse. »[D]ie geistreichen Ausführungen Maria-Reginas lassen sich leicht auf zeitgenössische feministische Theorien übertragen. Die Überzeugung vom antispekulativen und antiuniversalistischen Charakter weiblichen Denkens ist das Kernstück der philosophischen Basis des Feminismus. ${ }^{94}$ Gemäß Borkowska führt Żmichowska in diesem Text die Grundgedanken feministischer Theorie ein. Sie liefere in ihrer literarischen Verarbeitung bereits eine klare Analyse des geschlechtlich organisierten Diskurses von Wissen und Macht. ${ }^{95}$ Die feministischen Kritikerinnen positionieren somit die Literatur als der Wissenschaft in der kritischen Auseinandersetzung mit der Kategorie des Geschlechts ebenbürtig. Damit dekonstruieren sie die positivistischen Bestrebungen, erkenntnistheoretische Verfahren und Wissensproduktion als Bereich allein der Wissenschaft einzugrenzen und Letztere zu nobilitieren.

Die diskursiven Überschneidungen von Wissenschaft und Literatur scheint auch Freud in seinen Arbeiten zum Thema gemacht zu haben. Dybel zufolge war Freud nicht abgeneigt, »in den Mythen und in der Literatur die beredten Zeugen seiner psychoanalytischen Einsichten zu finden ${ }^{96}$. Seine eigenen Texte versuchte er aber gegen die Literatur abzugrenzen, die als Gattung bereits die von ihm untersuchten psychologischen Themen verhandelte. Obwohl es auch bei Freud primär um ein Erzählen (der Patientin/des Patienten wie auch um das übergeordnete, >ordnende` Erzählen des Arztes) gehe, versuche er diesem, so Kłosińska, den >Unterhaltungseffekt $\mathrm{zu}$ entziehen.

»Freud kreist unaufhörlich um die Frage, wie zu schreiben und mit der jugendlichen Patientin zu sprechen sei, um aus dem Schreiben und der Kommunikation zum Thema Sex das Element der Stimulation zu verbannen. Jane Gallop macht deutlich, dass der Psychoanalytiker seine Erzählung von der Geschichte Doras nicht zufällig mit einer `Anleitung, wie man sie lesen sollte`, beginnt.

owocu. Jej zamilknięcie i, jak można sądzić, przedwczesna śmierć przypominają martwotę młodej rośliny, usychającej w niesprzyjających warunkach."

94 । Ebd.: »błyskotliwy wywód Marii-Reginy łatwo daje się przełożyć na współczesne teorie feministyczne. Przeświadczenie 0 antyspekulatywnym i antyuniwersalistycznym charakterze kobiecego myślenia jest sednem filozoficznej bazy feminizmu."

95 I Vgl. auch Magnone: Die polnischen Gender Studies, S. 374.

96 I Dybel, Paweł: »Die Idee des Ödipuskomplexes«, in: Kowalewicz, Michel Henri (Hg.), Formen der Ideengeschichte (= Vestigia Idearum Historica. Beiträge zur Ideengeschichte Europas, Band 2), Münster 2014, S. 217-237, hier S. 230. 
[...] Trotz solcher Absicherungen bleibt Freud hilflos denjenigen - zahlreichen - gegenüber, die in solcher Lektüre den Genuss suchen und die Geschichte Doras als Roman lesen. « ${ }^{97}$

Freud versuche, sich aus der literarischen Gattung sauszuschreiben`, was er in seinen Texten deutlich mache. Laut Dybel betonte Freud »auf jedem Schritt, dass die Psychoanalyse eine Wissenschaft mit starken empirischen Grundlagen ist ${ }^{98}$. Doch trotz versuchter Trennung der Disziplinen und der 〉Objektivierung`des medizinischen Diskurses als wissenschaftlicher Forschungsbericht enthält dieser dennoch deutlich narrative Elemente, die sich einer `nicht-wissenschaftlichen` Lektüre anbieten. ${ }^{99}$ "Man kann also sagen [...], dass die Psychoanalyse vor allem eine spezifische Art der Hermeneutik ist, da sie sich der Prozeduren des Verstehens und der Interpretation bedient [...]. « ${ }^{100}$ Die Nähe der freudschen `wissenschaftlichen Texte $\mathrm{zu}$ literarischen Texten vereinfacht den feministischen Kritikerinnen in Polen letztlich die Substituierung des psychoanalytischen durch den literarischen Text. Damit wird eine auf Erkenntnis ausgerichtete Lektüre der literarischen Texte, die diese als Medium bestimmter Ideen und Konzepte versteht und nutzt, begünstigt (siehe Kapitel 5).

Die polnischen Literaturwissenschaftlerinnen stellen fest, dass sich die von ihnen untersuchten Texte zum Teil einer psychoanalytischen Lesart nicht nur fügen, sondern dass sie diese selbst hervorbringen. Besonders erwähnenswert erscheint den Polonistinnen, dass ihr literarisches Material den Texten Freuds zeitlich oft vorgelagert ist. In ihrer Lektüre verweisen die feministischen Kritikerinnen deshalb häufig darauf, dass die literarischen Texte unvermutet >modern` und reflektiert erscheinen. Besonders Borkowska und Kłosińska stellen dies bei den Texten von Żmichowska respektive Zapolska fest.

Borkowska beschreibt ihre Lektüreerfahrung so: »Man muss zugeben, dass uns Żmichowskas Bewusstsein und Wissen verblüfft. [...] Einige geäußerte Meinungen tönen so modern, dass es geradezu schwerfällt zu glauben, dass sie eine

97 I Kłosińska: Ciało, S. 136f.: »Freud nieustannie kręci się wokół kwestii, jak pisać i jak rozmawiać z młodocianą pacjentką, aby z pisania na temat seksu i z komunikacji na temat seksu wyrugować element pobudzenia. Jane Gallop zaznacza, że nieprzypadkowo psychoanalityk swoją opowieść o historii Dory zaczyna od instrukcji, jak powinno się ją czytać.` [...] Pomimo takich ubezpieczeń Freud pozostaje bezradny wobec tych - wcale licznych - co szukają w podobnej lekturze przyjemności, co czytają historię Dory jak powieść. "Siehe Gallop, Jane: »Keys to Dora«, in: Bernheimer, Charles/Kahane, Claire (Hg.), In Dora's Case. Freud, Hysteria, Feminism (= Gender and culture), New York 1985, S. 200-220, hier S. 206.

98 | Dybel: Psychoanaliza, S. 13.

99 । Vgl. ebd., S. 21f., 38. Diese Tatsache bringe der Psychoanalyse vonseiten der sharten « naturwissenschaftlichen Disziplinen das Verdikt der Unwissenschaftlichkeit ein.

100 | Ebd., S. 23. 
Autorin formuliert hat, die vor 150 Jahren lebte. ${ }^{101}$ Borkowska verweist auf die historische Entlegenheit der Lebenswelt Żmichowskas. Doch sie macht auch deutlich, dass Żmichowskas ideelle Ansätze diese historische Distanz mühelos überwinden und sich fugenlos in die Gegenwart einschreiben; die Forscherin wird hierbei zu einer Art passivem Medium (»man muss zugeben«, es »verblüfft uns«) der stets noch wirkmächtigen Ansätze Żmichowskas.

Ebenso »beeindruckt« ist Kłosińska, die wie Borkowska die anhaltende Gültigkeit der in der Literatur angetroffenen Ansätze beschreibt. Dabei scheint gerade das Medium der Literatur die Aktualität der Ansätze zu konservieren und in einer heute noch verständlichen Sprache zu vermitteln. "Auf verblüffende Art « ${ }^{102}$ bringe Zapolska die Instanzen der Psyche in den Text ein und beschreibe »mit sicherer Hand mehrere Jahre vor Freud ${ }^{103}$ Prozesse, die es in der analytischen Lektüre bloß noch zu benennen gelte (etwa als $I d$ ).

Die Schriftstellerinnen des 19. und des frühen 20. Jahrhunderts lassen sich jedoch nicht nur als Vorläuferinnen oder Paralleldenkerinnen einer Psychoanalyse begreifen, wie sie Freud entwickelt hat. ${ }^{104}$ Obwohl die untersuchten Texte viele Mechanismen auf eine dem Freudismus ähnliche Weise beschreiben, sehen die feministischen Polonistinnen bedeutsame Differenzen in der Interpretation dieser Mechanismen. So schreibt Kłosińska zum Phänomen der Hysterie in Przedpiekle, dass Zapolska wie Freud eine sexuelle Perversion als Ausgangspunkt der Hysterisierung setze, aber: »Die Schriftstellerin öffnet mutig die Büchse der Pandora und zeigt, anders als einige Jahre später Freud, dass nicht die perverse Sexualität des Kindes, sondern die Perversion des erwachsenen Mannes den Körper des Kindes hysterisiert. ${ }^{105}$ Hier findet im Vergleich zur späteren Auslegung Freuds - wie auch bei der Transposition der Erkenntnisse Charcots, siehe 4.1.2 - eine Verschiebung in der Auslegung der Hysterie statt.

Borkowska verweist in einer ähnlichen Wortwahl darauf, dass bei Żmichowska Abweichungen zum späteren Freudismus auftreten. Gleichzeitig deutet sie auf

101 I Borkowska: Cudzoziemki, S. 82f.: »Trzeba przyznać, że świadomość i wiedzę Żmichowskiej przyjmujemy z zaskoczeniem. [...] Niektóre opinie brzmią tak nowocześnie, że aż trudno uwierzyć, iż sformułowała je autorka żyjąca sto pięćdziesiąt lat temu."

102 I Kłosińska: Ciało, S. 103: „W sposób zaskakujący«. Weitere Beispiele bei Kłosińska siehe S. 70f., 186, 223, 252.

103 | Ebd., S. 240: "pewną ręką na kilka lat przed Freudem«.

104 I Diesem Ansatz widerspricht die Aussage Ewa Truszkiewicz-Budziłos, die davon ausgeht, dass erst die freudsche Psychoanalyse einen "Blick auf das Subjekt aus einer völlig anderen Perspektive ermöglicht habe. Truszkiewicz-Budziło, Ewa: "Dyskusja feminizmu z freudyzmem«, in: Pełnym głosem 4 (1996), S. 48-56, hier S. 49.

105 I Kłosińska: Ciało, S. 223: „Pisarka z odwagą otwiera puszkę Pandory wskazując, inaczej niż kilka lat później Freud, że nie perwersyjna seksualność dziecięca lecz perwersja dorosłego mężczyzny histeryzuje ciało dziecka.« 
die Parallele von Żmichowskas Texten zur postfreudianischen Weiterentwicklung und Kritik der Psychoanalyse hin.

"[...] Żmichowska wird sich - wie die Postfreudisten - für positive Anreize interessieren und nicht für die Mechanismen der Repression. Anders als später Freud wird sie die Weiblichkeit und nicht die Männlichkeit als universalen Modus der geschlechtlichen Identifikation setzen, als Anfang des langen Weges zur Reife.«106

Mit der Parallelziehung von Żmichowska und der postfreudianischen Psychoanalyse drängt Borkowska den Freudismus diskursiv in den Hintergrund. Dieser habe zwar einen prägnanten Beitrag zur Wissensgeschichte von Geschlechterordnung und psychischen Prozessen geliefert, disqualifiziere sich aber wegen seiner konzeptuellen Bevorteilung der Männlichkeit quasi selbst.

Borkowskas Beschreibung weckt den Eindruck einer zyklischen Entwicklung psychoanalytischer Ansätze, da diese letztlich wieder zu bereits hundert Jahre zuvor angedachten Konzepten gelangten. »Wohlgemerkt sind auch heute psychoanalytische Untersuchungen des weiblichen Schaffens im Allgemeinen sehr kritisch gegenüber Freudismus und Lacanismus. [...] Der Fall Żmichowskas ist deshalb eine ungewöhnlich spannende Vorwegnahme von Fakten, die erst in unserem Jahrhundert ihre Entwicklung erleben. $\aleph^{107}$ An dieser Stelle könnte man die Frage nach der damaligen Rezeption der Ansätze Żmichowskas stellen, was Borkowska in diesem Fall nicht explizit tut. ${ }^{108}$ Ihre Arbeit jedoch kann als Versuch einer (Wieder)Integration Żmichowskas in den wissenshistorischen Diskurs gelten.

Ich erachte die Frage nach dem Modus der Rezeption dieser Texte als wesentlich für das Verständnis der feministischen Kritik als kritisches Verfahren. Darauf möchte ich am Beispiel Kłosińskas eingehen. Umgekehrt als bei Freuds Dilemma der literarischen Lesart wissenschaftlicher Texte können die von Kłosińska und auch Borkowska besprochenen literarischen Texte als konzeptuelle gelesen, als Analyse und Kritik psychologischer und sozialer Prozesse. Doch inwiefern war die Subversion, die die feministischen Kritikerinnen aus den Texten herauslesen, Teil der Lektüreerfahrung des 19. Jahrhunderts?

106 | Borkowska: Cudzoziemki, S. 140f.: "[...] Żmichowska będzie się interesować - tak jak postfreudyści - bodźcami pozytywnymi a nie mechanizmami represji. Inaczej niż później Freud uzna kobiecość, a nie męskość za uniwersalny modus identyfikacji płciowej, za początek długiej drogi do dojrzałości."

107 | Ebd., S. 254: "Zauważmy, że także dzisiaj psychoanalityczne badania twórczości kobiecej są na ogół bardzo krytyczne wobec freudyzmu i lacanizmu. [...] Przypadek Żmichowskiej jest więc niezwykle intrygującym uprzedzeniem faktów, które dopiero w naszym stuleciu doczekają się rozwinięcia."

108 | Die Frage stellt sie dafür am Beispiel der versteckten Kritik Żmichowskas an Hoffmanowa, vgl. ebd., S. 70 sowie Kapitel 6.3.1. 
Interessant erscheint mir in diesem Zusammenhang die folgende Aussage Kłosińskas über Zapolskas Przedpiekle und dessen Darstellung der Hysterie: »Und obwohl die medizinische Autorität, personifiziert in der Stimme des Arztes, über die Polyphonie der Aussagen zu herrschen scheint, warnt schon allein die Vielstimmigkeit den Leser vor einer naiven Lektüre, gemäß der die Hysterie ein unumstößliches Sein $[b y t]$ wäre. ${ }^{109}$ Unklar ist hier, ob Kłosińska mit ihrer Formulierung des »Lesers« (czytelnik) eine/n zeitgenössische/n Leser/in oder eine/n in kritischen Methoden konditionierte/n Leser/in der Postmoderne im Blick hat. ${ }^{110}$ Sie suggeriert, dass die Dekonstruktion der vorgebrachten medizinischen >Wahrheiten selbst angelegt sei: Die »Vielstimmigkeit warnt den Leser», womit der literarische Modus zum Prüfstein der Lektüre wird. Damit setzt Kłosińska im Prinzip voraus, dass die Lektüre als Transposition in den sozialen und historischen Diskurs einheitlich und historisch gleichbleibend ist. Ob diese Vielstimmigkeit aber stets (implizit) als Subversion der Definitionsmacht des Arztes gelesen wurde, lässt sich kaum rückverfolgen. Kłosińskas Lesart und Auslegung der Polyphonie ist durch ihre psychoanalytisch informierte Lektüre gestimmt. Diese ermöglicht es ihr, im Text Zapolskas literarische Verfahren wie die Polyphonie als solche zu identifizieren und deren Bedeutung in der Wissensvermittlung rückwirkend zu formulieren. Während Kłosińska aber subversive Lektüreansätze als textinhärent und Möglichkeit einer Lesart des 19. Jahrhunderts zu sehen scheint, empfindet sie diese Verfahren etwa in der reflektierten Darstellung der Hysterie im Text Zapolskas dennoch als historisch "verblüffend « (zaskakujący). Mit diesem Prädikat offenbart Kłosińska gleichzeitig eine Distanzkonstruktion und deren Überwindung, da der Text entgegen den Erwartungen affektiv `nah und modern ist.

\subsubsection{Umgänge mit Freud - Freud umgehen?}

Mit der Feststellung, dass >psychoanalytische`Ansätze auch schon in der Literatur des 19. Jahrhunderts aufzufinden seien, legitimieren die feministischen Polonistinnen der 1990er Jahre einerseits den Miteinbezug freudscher Theorien in ihre Analysen. ${ }^{111}$ Andererseits können sie psychologisierende Ansätze direkt aus ihrem Untersuchungsmaterial beziehen, womit die Rolle der freudschen Psychoanalyse eingeschränkt wird. Die Erkenntnis, dass die Auseinandersetzung mit der Psyche

109 | Kłosińska: Ciało, S. 212: »| chociaż autorytet medycyny, uosobiony w głosie lekarza, wydaje się panować nad tą polifonią wypowiedzi, to już sama wielogłosowość ostrzega czytelnika przed naiwną lekturą, z której wynikałoby, że histeria jest jakimś niepodważalnym bytem."

110 | An anderer Stelle verweist Kłosińska explizit auf die "Leser des 19. Jahrhunderts«, für die bereits »der Partikularismus ihres [Zapolskas] Standpunktes offensichtlich war«. Ebd., S. 290: "Już dla XIX-wiecznych czytelników oczywisty był partykularyzm jej punktu widzenia«. Wie auch Borkowska verwendet Kłosińska die männliche Form des Lesers, besonders wenn es nicht um konkrete Lektüresituationen oder eine geschlechtlich strukturierte Appellfunktion geht.

111 I Vgl. Kłosińska: Ciało, S. $289 f$. 
bereits vor Freud auf reflektierte Weise stattgefunden habe, erlaubt den Wissenschaftlerinnen eine Pluralisierung der psychoanalytischen Bezugsrahmen. Einige solcher >Umgehungen choanalyse möchte ich im Folgenden diskutieren.

Janion setzte die freudschen Ansätze in ihren Analysen der 1970er und 1980er Jahre pragmatisch neben anderen Theorien ein, wodurch sich ein auf das jeweilige Material zugeschnittener Synkretismus ergab. In Bezug auf die Untersuchung des Phantasmatischen befand Janion die Psychoanalyse Freuds als treffender als den antipsychiatrischen Ansatz Ronald D. Laings, den sie sonst in ihrer Forschung stark miteinbezog: "So oder so will ich Ihnen nun aber die Diagnose Freuds vorstellen, da mir diese zutreffender erscheint und für uns vielleicht auch einfach bequemer. ${ }^{112}$ An diesem Beispiel lässt sich Janions begründende Rhetorik illustrieren. Sie will die Thesen Freuds erklärend einführen, sichert sich aber gleichzeitig legitimierend ab. Diese Argumentationsweise lässt sich als Einbettungsstrategie in einen wissenschaftlichen Kontext lesen, der der kaum vorhandenen psychoanalytischen Tradition skeptisch gegenübersteht. Janion könnte sich deshalb verpflichtet gefühlt haben, die Wahl ihres theoretischen Bezugs stärker argumentativ auszuführen.

Auch bei Iwasiów finden sich Gegenüberstellungen, die hier jedoch zu Ungunsten der freudschen Theorien ausfallen. Iwasiów bezieht sich in ihrem »Lesen der Bilder des Anfangs, der ursprünglichen Realität « ${ }^{113}$ auf die anthropologischen Ansätze René Girards. Obwohl Iwasiów auf Girards Nähe zum »frühen, kanonischen Entwurf des Freudismus« in der Verhandlung der archetypischen Grundmuster menschlichen Verhaltens verweist, zieht sie dessen Thesen vor, da sich diese nicht allein auf das »erotische Begehren «114 beschränkten und somit von größerer Universalität seien. Interessant ist, dass Iwasiów ihre konzeptuelle Bevorzugung Girards explizit als solche markiert, indem sie dessen Thesen mit denjenigen von Freud kontrastiert. Im Gegensatz zu Janion geht Iwasiów also argumentativ umgekehrt vor: Während Janion Freud punktuell miteinbezieht, obwohl sie die Kritik an seinen Thesen durchaus mitdenkt, ${ }^{115}$ drängt Iwasiów Freud aus ihren Ansätzen hinaus, obwohl sie ihn als zentralen Referenzpunkt in der besprochenen Thematik anerkennt. Diese divergierenden Argumentationsstrategien widerspiegeln in gewisser Weise die wissenschaftliche und ideengeschichtliche Neuorientierung nach 1989, die die freudsche Psychoanalyse als wissenshistorisches Desiderat identifizierte. ${ }^{116}$

112 I Janion: Komentarze 1, S. 351: „Tak czy owak, chcę państwu jednak przedstawić teraz rozpoznanie Freuda, gdyż wydaje mi się ono trafniejsze, a może i dla nas po prostu wygodniejsze.«

113 I Iwasiów: Kresy, S. 13: „czytaniu obrazów początku (rzeczywistości pierwotnej)«.

114 | Ebd., S. 15: »wczesny, kanoniczny schemat freudyzmu«; »pożądaniem erotycznym«.

115 | Vgl. Janion, Maria [et al.]: »Rozmowa druga: o współczesnej mediokracji«, in: Janion/Rosiek, Galernicy wrażliwości (1981), S. 371-401, hier S. 395-399.

116 | Vgl. Dybel: Dialog i represja, S. 8; Urwane ścieżki, S. 20f; Janion: Projekt krytyki fantazmatycznej, S. 5f.; Nasiłowska, Anna: »Feminizm i psychoanaliza - ucieczka od opozycji«, in: Teksty Drugie, Feminizm po polsku (1995), S. 132-141, hier S. 132. 
Die Theorien Freuds werden häufig durch eine vermittelnde Lektüre in die feministische Polonistik eingebracht, wie etwa bei Iwasiów, die ihre Überlegungen »mit einer neuen - von B[runo] Bettelheim, D[anuta] Danek und M[aria] Janion projektierten - Lektüre Freuds verflicht. «117 Iwasiów greift hier nicht direkt auf die Texte Freuds zu, sondern orientiert sich an einem vorhandenen Lektürevorschlag. Die Ansätze Freuds setzt sie so in eine Art rezeptive Klammer, die bereits eine kritische Aufarbeitung beinhaltet. Eine selektive Lektüre beobachtet Janion auch bei Badinter, die sich ebenfalls an Freud orientiere und "von ihm den Mut des Entdeckers neuer Kontinente und die Methode der Erkenntnis erbt, aber die doktrinären Extreme der Psychoanalyse vermeidet. ${ }^{118}$ Gegenüber den Thesen Freuds, so impliziert die Aussage Janions, sei Vorsicht geboten. Während sie in gewisser Hinsicht inspirierend sein könnten, drohe auch ein Abrutschen in dogmatische Engführungen, besonders in Bezug auf die Charakterisierung der Geschlechter. ${ }^{119}$ Eine bereits durch `Filtertexte`(siehe 4.3.2) vermittelte Lektüre kann auf solche Gefahren aufmerksam machen.

Die feministische Kritik der 1990er Jahre in Polen stützt sich im Miteinbezug der Ansätze Freuds primär auf die feministische Lektüre und Kritik dieser Ansätze. Die feministische Strömung postfreudianischer Kritik berücksichtigt zwar die psychoanalytischen Ansätze Freuds als Ausgangspunkt, dekonstruiert aber - oft mit Verweis auf Lacan und Derrida - deren metaphysisches Geschlechterverständnis. Eine gynophilere Perspektive kontrastiert Freuds androzentrischen Blick auf die psychischen Prozesse des Menschen. ${ }^{120}$

Ein Integrieren freudscher Ansätze qua feministischer Filterkonzepte lässt sich auch bei Kłosińska beobachten. Auslöser für den psychoanalytischen `Reflex Kłosińskas bildet das Schlagwort des "Mangels « ${ }^{121}$, auf das die Wissenschaftlerin in den von ihr untersuchten Rezensionen zu weiblicher Literatur stößt:

"Das Beschreiben und Bewerten [...] literarischen Schaffens, das sich des Wortes >Mangel bedient, weckt sofort Assoziationen mit Freud und seiner Projektion des 'weiblichen Seins‘. Die Frau (und ihr Geschlecht) definiert sich bei ihm durch den >Mangek dessen, was der Mann hat (volles, vollkommenes Sein in Bezug auf die intellektuelle wie physiologische Ausstattung). ,Über die

117 I Iwasiów: Kresy, S. 18: »przeplatam nową - zaprojektowaną przez B. Bettelheima, D. Danek i M. Janion - lekturą Freuda."

118 | Janion: Kobiety, S. 175: »dziedzicząc po nim odwagę odkrywcy nowych kontynentów i metodę poznawczą, ale unikając doktrynalnych skrajności psychoanalizy.«

119 । Siehe dazu auch Truszkiewicz-Budziło: Dyskusja, bes. S. 50.

120 | Vgl. ebd., die die Kritik von Betty Friedan und Gloria Steinem an Freud diskutiert.

121 In Freud, Sigmund: »Einige psychologische Folgen des anatomischen Geschlechtsunterschieds«, in: Internationale Zeitschrift für Psychoanalyse 11/4 (1925), S. 401-410, spricht Freud etwa vom »Penismangel« (S. 405). 
weibliche Sexualität - schreibt L[uce] Irigaray - >dachte man immer ausgehend von männlichen Parametern nach.« «22

In der Argumentation Kłosińskas geschieht die Verknüpfung der angesprochenen Thematik des »Mangels« mit Freud reflexartig. Die Rezensionen, auf die das Zitat anspricht, überlagern sich mit den Theorien Freuds am Angelpunkt eines Wortes - eben jenes "Mangels" in Bezug auf und als Abwertung des weiblichen Geschlechts. Die Assoziation mit Freud sei unumgänglich; Kłosińska ersetzt ihn im Text letztlich aber mit der »Stimme der Frau«. Der knapp skizzierten These Freuds folgt ein Metakommentar der Feministin Irigaray als direktes Zitat und somit als unvermittelte Aussage. Dieses Zitat übernimmt zwei Funktionen: es `rahmt die männlichen Aussagen über den Mangel und usurpiert deren Stelle aus einer kritischen Metaposition. Gleichzeitig ersetzt die Aussage Irigarays auch die vermittelnde Position Kłosińskas selbst, die ihre eigene Kritik an Freud durch eine weitere, feministische Instanz einbringt.

Auf der formalen Ebene fällt auf, dass Kłosińska zu Freud keinen Literaturverweis setzt. Dies verweist einerseits darauf, dass Kłosińska die Thesen Freuds als >Basiswissen $<$ eines (literatur)wissenschaftlichen Diskurses setzt, das keiner weiteren Erklärung bedarf. Andererseits lässt diese Ausklammerung darauf schließen, dass die Rezeption Freuds über die postfreudianische feministische Theorie stattfand und weniger über die Schriften Freuds selbst. ${ }^{123}$

Kłosińska lässt den Schritt einer direkten Konfrontation mit Freud weitgehend aus. Die Rezeption westlicher, psychoanalytischer Literatur wird beschleunigt, denn These und Kritik werden in einem Zug miteinander verflochten und in die Argumentation der polnischen Forscherin - hier Kłosińska - eingebaut. Die Thesen Freuds erscheinen als in gewissen Bereichen überholt, weshalb diese sübersprungen werden können. Als Referenzpunkt der darauf aufbauenden feministischen Ansätze lässt sich Freud jedoch nicht aus der Narration tilgen. `Freud` und seine Werke und Thesen treten deshalb in der feministischen Kritik der polnischen 1990er Jahre als eine Art Phantasma auf. Sie sind begehrtes Imaginäres, das im wissenschaftlichen

122 I Kłosińska: Ciało, S. 16: »0pis i wartościowanie [...] literackiej twórczości posługujące się słowem sbrak budzi od razu skojarzenia z Freudem i jego projekcją sbytu kobiecego،. Kobietę (jak jej płeć) definiuje u niego sbraks: tego, co ma mężczyzna (byt pełny, doskonały, zarówno pod względem uposażenia intelektualnego, jak i fizjologii). >0 seksualności kobiecej - pisze L. Irigaray - zawsze myślało się, wychodząc od parametrów męskich‘" Siehe Irigaray, Luce: Ce Sexe qui n'en est pas un, Paris 1977, S. 23.

123 I Sollte dies der Fall sein, hinge ein solches Vorgehen wohl weniger mit einer Nicht-Verfügbarkeit der Schriften Freuds zusammen als mit der oben angedeuteten Praktikabilität einer bereits kritisch beleuchtenden Rezeption und Dekonstruktion. Freuds Werke wurden - trotz allem - bereits in der Volksrepublik teilweise übersetzt; ab Mitte der 1990er Jahre folgen Neuübersetzungen ins Polnische. Darüber hinaus stand Kłosińska einer Rezeption französischer oder englischer Ausgaben nichts im Wege, wie man aus anderen Literaturverweisen schließen kann. 
Diskurs bisher keinen Platz fand, und gleichzeitig entsagtes abject, ${ }^{124}$ dessen Position aus der feministischen Kritik sausgeschrieben` werden muss. Die Projektion Freuds ist jedoch notwendig, um vor diesem Hintergrund die eigene, feministische Herangehensweise aufzubauen. `Freud wird im Prozess des Schreibens feministischer Polonistik mithilfe kritischer Ansätze an den Rand derjenigen gedrängt, denen im Text die Stimme gegeben wird; von diesem Rand bricht er aber immer wieder in die Narration ein. Dieses performative Ausschließen Freuds bedient sich darüber hinaus manchmal der Strategie der >Überführung`, die Freud ein Unwissen nachweist $^{125}$ oder seine Theorien auf sein eigenes sublimiertes Begehren zurückführt. ${ }^{126}$ Als eine Strategie der Befreiung von der abjektierten Dominanz Freuds kann zudem der Einsatz von Humor gelten, was Kłosińska als Verfahren der Dekonstruktion der freudschen Thesen durch »scherzhaftes Auffassen ${ }^{127}$ legitimiert.

Ich möchte nun noch einmal auf die Rolle der freudschen Psychoanalyse bei Janion zurückkommen und aufzeigen, dass auch Janion die Verfahren von Anrufung und Ausschluss Freuds einsetzt. Dabei gehe ich zunächst auf Janions Gegenüberstellung von Freud und dem US-amerikanischen Psychiater Stoller ein. Die Positionen der beiden Analytiker unterscheiden sich grundsätzlich darin, dass Stoller eine These der primären Weiblichkeit des menschlichen Kindes präsentiert, während Freud die Männlichkeit als primären Identifikationsmodus setzt. Janion nimmt in diesem Prämissenstreit keine der beiden Seiten ein und handelt sie in ihrer Besprechung als reine Hypothesen ab. ${ }^{128}$

Besonders hinweisen möchte ich auf die Funktion Stollers in Janions Studie von 1979 über Komornicka/Włast. Stoller nimmt hier die Rolle des >Überschreibers` Freuds und der Vorantreibung der Geschlechterforschung ein. Diese Rolle wird in den späteren Texten der feministischen Polonistik der 1990er Jahre feministisch besetzt. Janion bezieht sich auf Stollers Unterscheidung der Ebenen der Geschlechtsidentität, wobei sie die zwei Ebenen von gender identity (psychologisches Geschlechts`empfinden`) und gender role (sozial zugeschriebene Geschlechterrolle) berücksichtigt, während Stoller diese beiden dem sex (als biologischem Geschlecht) gegenüberstellt (siehe auch Kapitel 3.3.2). ${ }^{129}$

Stoller selbst bezieht sich in Sex and Gender auf Freud und erwähnt dessen Verdienste in der `Entbiologisierung` der Sexualität und damit auch des Geschlechts.

"[...] Freud forced the world to recognize that much of what was called sexuality was determined by one's life experiences from infancy on and was not simply a matter of inheritance, biochemis-

124 | Vgl. Kristeva: Pouvoirs de l'horreur, S. 9-14.

125 । Vgl. Iwasiów: Kresy, S. 106.

126 I Vgl. Kłosińska: Ciało, S. 33.

127 | Ebd.: "żartobliwym ujęciu«.

128 I Vgl. Janion: Kobiety, S. 179.

129 | Vgl. ebd., S. 227f.; Stoller: Sex and Gender, S. $9 f$. 
try, and other organic factors. While his work was amplified and refined by subsequent analysts, no such profound or simple statement has supplemented or supplanted Freud's original work. «130

Bei Freud sei die Differenzierung biologischer und psychologischer Prozesse/Ebenen angelegt respektive gar mit Wirkmacht (»forced to recognize«) dargelegt. ${ }^{131}$ Weitere Ausarbeitung sowie die Einführung des Begriffs gender erfuhr diese Differenzierung in den 1950er Jahren mit den Studien zum Hermaphroditismus des Sexuologen John Money, ${ }^{132}$ auf die sich auch Stoller bezieht.

Janion schreibt Stollers Ansätzen die zentrale Rolle in der Konzeptualisierung des Geschlechts zu. Dies ist insofern interessant, als Stoller (wie im übrigen auch Money) im feministischen Geschlechterdiskurs höchstens marginal verankert ist. ${ }^{133}$ Die Unterscheidung von sex und gender gilt in der Regel als Errungenschaft der 1970er Jahre, in denen dieses Konzept breiteren Eingang in die feministische Theorie fand. Indem Janion in ihrer feministischen Ausrichtung (die sie allerdings nicht so nennt) bewusst auf feministische Ansätze aus dem Westen verzichtete ${ }^{134}$ und dafür den Psychiater Stoller als Referenzfigur einsetzte, begründete sie für Polen eine divergierende Form des kritischen Geschlechterdiskurses. Gleichzeitig scheint diese smännliche` Tradierung auch ein Symptom der Forschung Janions zu sein, die sich bis über die 1990er Jahre hinaus der Festschreibung auf ein Geschlecht entzog und die Geschlechterordnung mit wenigen Ausnahmen aus einer Art Metaperspektive analysierte. Janions Anliegen ist es nicht, eine sweibliche Form der Literaturwissenschaft zu betreiben, sondern die Machtstrukturen zu durchbrechen und so Raum für salle`Stimmen zu schaffen. ${ }^{135}$

Im Folgenden möchte ich auf eine Tendenz hinweisen, die im Zusammenhang mit der Selbstpositionierung Janions im wissenschaftlichen Diskurs steht. Es geht darum, dass Janion in ihren Texten gewisse Parallelen ihrer eigenen Forschung zur Entwicklung der Interessen und Ansätze von Freud konstruiert. Bereits habe ich gezeigt, dass Janions Interesse an der Kategorie des Geschlechts unter anderem

130 I Stoller: Sex and Gender, S. vii.

131 I Im Artikel Über die Psychogenese eines Falles von weiblicher Homosexualität (1920) nennt Freud diese beiden Bereiche somatische resp. psychische Geschlechtscharaktere. Vgl. Freud, Sigmund: „Über die Psychogenese eines Falles von weiblicher Homosexualität«, in: ders., Werke aus den Jahren 1917-1920. Gesammelte Werke. Zwölfter Band, Frankfurt a/M. 1947, S. 269-302, hier S. 300.

132 I Beispielsweise in Money, John: »Hermaphroditism, Gender and Precocity in Hyperadrenocorticism. Psychologic Findings", in: Bulletin of the Johns Hopkins Hospital 96 (1955), S. 253-264. 133 I Dies hängt auf jeden Fall auch mit der starken theoretischen Ausrichtung Janions auf psychiatrische Forschung zusammen, die im Allgemeinen in feministischen Ansätzen sonst keine so zentrale Rolle spielt.

134 | Vgl. Janion: Kobiety, S. 326; dies.: Droga, S. 16.

135 | Auf die sgeschlechtslose Perspektive Janions in Bezug auf das Geschlecht komme ich in Kapitel 6.3.3 noch zu sprechen; zur Polyphonie der janionschen Arbeiten siehe Kapitel 3.3.3. 
mit ihrer Romantikforschung und deren Topoi der Phantasmata und Transgressionen zusammenhängt (siehe Kapitel 3.1). Janion argumentiert, dass die romantische Faszination für das Imaginäre und Irrationale sowie die darauf folgende positivistische Bekämpfung dieses Phänomens Freud zu seiner Forschung bewegt hätten. Freud war, so Janion,

»ein hervorragender Kenner der deutschen Romantik. Aber nicht nur das, Freud war nämlich auch Zeuge der heftigen Kritik an den Romantikern [...]. Sofort offenbart sich die Zwiespältigkeit der widersprüchlichen Inspirationen Freuds: der aufklärerisch-positivistischen wie der romantischen. Es gelang inm jedoch schließlich, diese in Einklang zu bringen. « ${ }^{136}$

Die Faszination für das Unerklärliche und Unterbewusste ergänze sich bei Freud mit der positivistischen Perspektive des Ergründens und Beschreibens. Es ist der Verweis auf die Tatsache, dass Freud ein »hervorragender Kenner der deutschen Romantik« war, der die Parallele zu Janion in den Vordergrund rückt. Die literaturwissenschaftliche Beschäftigung mit den »dunkeln Winkeln der Seele» ist es denn wohl auch, der bei beiden den Fokus auf die Möglichkeiten der sprachlichen Erzeugung des Unterbewussten, Phantasmatischen lenkt.

Janion macht darauf aufmerksam, dass die Erkenntnisse Freuds nicht aus einem Vakuum heraus entstanden seien. Vielmehr nahm Freud eine Verwissenschaftlichung bereits bestehender Annahmen vor, eine theoretische Zusammenfassung literarisch tradierter Erkenntnisse (vgl. 4.2.1). Janion betont die Einbettung Freuds in eine kulturelle Tradition und seinen Wissensbezug daraus und verweist somit auf ein graduelles Entstehen kulturellen Wissens: »[...] Goya und der gotische Roman bereiteten den Weg für die Romantik. Und für Freud. « ${ }^{137}$

Obwohl die Auseinandersetzung mit dieser kulturellen Tradition bei Freud und Janion ähnliche Interessen weckt, sind die Schlüsse, die sie aus ihren Analysen ziehen, sehr unterschiedlich, wie Janion selbst betont. Freud entwerfe dichotomische Modelle, in denen er etwa die Kultur als der Liebe entgegengesetzt betrachte und die Geschlechter jeweils einer der beiden Sphären zuordne. Die Sphären begreife er als sich in einem Wettstreit befindend, wobei das Weiblich-Triebhafte die männliche Sublimierung hin zur Kultur zu verhindern suche. Diese Naturalisierung der kulturellen Geschlechterdifferenz kritisiert Janion an den Ansätzen Freuds. "Freud kommt gar nicht erst auf den Gedanken an die gesellschaftlichen Bedingungen von `Kultur und `Liebe`. Seine Ansicht trägt die Züge extremen Na-

136 | Janion: Projekt krytyki fantazmatycznej, S. 12: "[...] świetny znawca romantyzmu niemieckiego. Ale nie tylko to. Freud był przecież także świadkiem gwałtownej krytyki romantyków [...]. Od razu ujawnia się dwoistość sprzecznych inspiracji Freuda: oświeceniowo-pozytywistycznych oraz romantycznych. Udało mu się jednak je w końcu pogodzić."

137 | Janion: Romantyzm, S. 388: »[...] Goya - jak i powieść gotycka - torował drogę romantyzmowi. I Freudowi.« 
turalismus. $^{138}$ Die Differenzen, die Freud im kulturellen Geschlechterverhalten beobachte, führe er auf eine biologische Grundlage zurück, die das Geschlecht unverrückbar festschreibe. Janion hingegen sieht in diesen Ansichten eine Blindheit gegenüber der Macht kultureller Bedingungen, die durch ihre Omnipotenz und Tradierung die Geschlechterunterschiede als ahistorisch erscheinen lassen.

Freuds Akzeptanz kulturell hergestellter Merkmale als ınatürlich‘, sprich biologisch, und die gleichzeitige Hierarchisierung der somit angenommenen Dichotomie von männlich - weiblich kritisiert Janion stark. Während Freud zwar »das Verborgene aufdecken ${ }^{139}$ wolle, gehe er dabei aber den Weg einer biologistischen Determinierung psychologischer Prozesse. Im Rahmen ihrer Kritik an Freud verweist Janion implizit auf die Rezeption seiner Theorien, die im Allgemeinen und besonders auch im polnischen, sozialistischen Kontext ${ }^{140}$ starken Vereinfachungen unterliegen. Gegen die Verkürzungen einer einseitigen Lektüre der Ansätze Freuds führt Janion eine ’komplexe und ambivalente Lesart an, die Freuds `Enthüllen` der Phantasmen gleichzeitig als Aufrechterhaltung und `Wiederverhüllen` versteht. »Freud gilt, natürlich, als Meister der Verdachte und als großer Demystifikator. Aber die Phantasmen rührte er nicht an; er zeigte sie, entdeckte ihre Existenz - und bewahrte sie. ${ }^{141}$ In diesem Fall weist Janions Vermittlung darauf hin, dass den Thesen Freuds in gewissen Aspekten zugestimmt werden sollte. Dieses Verfahren Janions wirkt wie eine Art Belehrung, in der sich Janion bemüht, ein differenziertes Verständnis der Lehre Freuds an ihre Leser/innen weiterzugeben. Sie selbst positioniert sich als Verfechterin der Relevanz kultureller Phantasmen und hält Freud zugute, dass dieser diese ebenfalls nicht $\mathrm{zu} »$ demystifizieren « suche. An anderer Stelle aber ist die Kritik Janions wieder deutlich: »Daran denkt man vielleicht nicht mehr, aber doch sollte stets daran erinnert werden, dass Freud - wie ihm übrigens schon oft vorgeworfen wurde - ein Rassist des Sexuellen war, ein `Sexist $`$ und >Phallokrat $` .{ }^{142}$ Auch hier weist Janion auf bestimmte Muster der Rezeption hin und betont die Notwendigkeit einer gesamthaften Beurteilung der Thesen Freuds, deren Hintergründe sich unweigerlich in der Interpretation der von ihm untersuchten Fälle und deren Konzeptualisierungen niederschlügen.

Janions Selbstpositionierung in Bezug auf Freud kann sowohl als jene einer vermittelnden Instanz wie auch jene der Kritik verstanden werden. Durch ih-

138 I Janion: Rozmowa druga, S. 398: »Freudowi nawet nie przychodzi do głowy myśl o społecznych uwarunkowaniach zarówno ’kultury‘, jak ’miłości<. Jego rozumowanie nosi cechy skrajnego naturalizmu."

139 | Janion: Romantyzm, S. 36: »uczynić jawnym to, co ukryte«.

140 | Vgl. Dybel: Psychoanaliza, S. 14.

141 I Janion: Komentarze 1, S. 352: »Uchodzi Freud, owszem, za mistrza podejrzeń i wielkiego demistyfikatora. Ale fantazmatów nie naruszył; objawił, odkrył ich istnienie - i zachował je."

142 I Janion: Rozmowa druga, S. 398: „Tego się może nie pamięta, ale trzeba to jednak stale przypominać, że Freud - jak go o to zresztą już nieraz oskarżano - był rasistą seksu, sseksistą<, 'fallokratąs،" 
ren ähnlichen wissenschaftlichen Werdegang vollzieht Janion die Überlegungen Freuds selbstständig nach und modifiziert diese an bestimmten Stellen. Janions Argumente erscheinen wie eine Art Pastiche, eine sekundäre Entwicklung ähnlicher Gedanken, die jedoch offen abweichende Akzente tragen. Janions Herangehensweise an die Thesen Freuds ist geprägt von einer größeren Selbstermächtigung und -inszenierung der eigenen Forschungsposition als diejenige der polnischen feministischen Kritikerinnen der jüngeren Generation, für die die Psychoanalyse Freuds auch historisch ein distanzierteres Phänomen darstellt. Für die jüngeren Polonistinnen bildet die Psychoanalyse wie auch die feministische Kritik daran Strömungen, zu denen sie sich zunächst aus einer externen Sicht positionieren; Janion aber bezieht durch ihre historische Parallelentwicklung an den Rändern der im Westen dominanten Ansätze eine Position des eigenständigen, selbstermächtigten Wissens, was in ihren Texten teilweise auch rhetorisch zutage tritt.

Die freudsche Psychoanalyse nimmt in der feministischen Kritik der 1990er Jahre die Position eines gleichzeitig angesprochenen wie verdrängten Bezugsrahmens ein. Freuds Theorien wurden in den polnischen feministischen Texten als Schlagworte zwar eingeflochten, doch dieses Einbinden war zumeist mit Abgrenzungsrhetoriken verbunden. Das nur schlagwortartige Einbringen der Ansätze Freuds läßt darauf schließen, dass diese bereits als kollektives Wissen gesetzt werden, das metonymisch durch die Rezitation des Namens Freuds aufgerufen wird. `Freud steht hier somit nicht für eine historische Person, sondern für ein Netz von Hypothesen und Untersuchungsergebnissen, das eine bestimmte, androzentrische ideelle Ausrichtung aufweist. Dieses Konglomerat von Ansätzen wird in seiner Gesamtheit impliziert und gleichzeitig ausgegrenzt, was im wissenschaftlichen Kontext des postsozialistischen Polens bestimmte Komplikationen mit sich bringt.

Im Hinblick auf die nur marginale Rezeption der Psychoanalyse in Polen vor der Transformation der 1990er Jahre kann in Bezug auf `Freud ‘ von einem Graubereich des wissenschaftlichen Diskurses gesprochen werden; obwohl (zumindest imaginär) existent, weist das freudsche Theorienkonglomerat doch ızerfransteく, instabile Konturen auf. Diese relative Undefiniertheit und das Oszillieren zwischen hier und dort weist auf den liminalen Charakter `Freuds` im polnischen wissenschaftlichen Kontext hin. Das Liminale bewegt sich »on the margins between the known and the unknown ${ }^{143}$, wie Anne McClintock schreibt. `Freud « wird zu einem diskursiven Grenzgänger oder einer liminalen Figur, die sich einer Festschreibung entzieht.

143 I McClintock, Anne: Imperial Leather. Race, Gender and Sexuality in the Colonial Contest, New York, London 1995, S. 24f. McClintock orientiert sich am turnerschen Liminalitätsbegriff: "For Turner, a liminal condition is ambiguous, eluding the network of classifications that normally locate states and positions in cultural space.« Siehe Turner, Victor: The Ritual Process. Structure and Anti-Structure, Ithaca, New York 1969, S. 95. 
Performative Teilhabe an der Liminalität `Freuds ‘ oder der Psychoanalyse nehmen auch die untersuchten feministischen Texte, die `Freud ‘ an der Grenze des Unausgesprochenen verorten und primär durch die postfreudianischen feministischen Ansätze überhaupt in die Argumentation dringen lassen. Letztere nehmen dabei die Funktion von Filtertexten ein, die Wissen aufbereiten und in einer bereits vermittelten, dezentrierten Form weitergeben. Mit dieser >Filtrierung`geschieht auch eine Überlagerung und Synchronisierung einer Rezeptionstradition, die in diachroner Abfolge entstanden ist. Freud wird dabei quasi in seine feministische Rezeption shineingefaltet ${ }^{144}$ und dringt durch diese gleichsam hindurch. Diese Synthetisierung freudscher und postfreudianischer Ansätze kann als Fallbeispiel einer epistemologischen »Verknotung « angesehen werden, von der Kulpa und Mizielińska sprechen. ${ }^{145}$

Dieses ideenhistorisch »verknotende« Vorgehen möchte ich hier als snormalen` Prozess wissenschaftlicher Entwicklung verstehen, da ein Nachverfolgen von Ideen oder Theorien bis zu deren >Ursprung` weder machbar noch sinnvoll ist. Spezifisch an der polnischen Situation, in der die feministischen Kritikerinnen ihr Interesse zumeist gleich auf das erkenntnistheoretische Zusammentreffen feministischer und psychoanalytischer Ansätze richten, ist allerdings ihr Selbstverständnis als >verspäteter Rezeption. Im Zuge des Aufholungsnarrativs, das etwa Iwasiów 2004 als Versuch eines »Überwindens mehrerer Hindernisse gleichzeitig « ${ }^{146}$ umreißt, scheinen die feministischen Kritikerinnen der 1990er Jahre eine vertiefte Auseinandersetzung mit der - bereits dekonstruierten - Psychoanalyse Freuds als unnötigen `Zeitverlust $`$ zu betrachten. Diese Auslassung der frühen postsozialistischen Zeit wird seit Mitte der 1990er Jahre von Dybel und mit den 2010er Jahren von Magnone systematisch aufgefüllt. ${ }^{147}$

\subsection{Grenzgehen. Liminale Figuren, liminale Texte}

Das Konzept der Liminalität möchte ich nun anhand anderer >Grenzgänger/innen und am Beispiel der disziplinären Grenzüberschreitung aufgreifen. Die liminalen Figuren siedeln an den Rändern der polonistischen feministischen Kritik und werden aus dieser Position für die Prozesse sinnerhalb dieser von Bedeutung. Ich gehe vor allem auf polnische liminale Figuren, auf Filtertexte, die die Grenzen

\section{4 | Siehe Deleuze: Le Pli.}

145 | Vgl. Kulpa/Mizielińska: >Contemporary Peripheries‘, S. 15.

146 I Iwasiów: Gender, S. 82: "przeskoczyć przez kilka przeszkód naraz«.

147 | Vgl. Dybel: Dialog i represja; Freuda sen; Psychoanalyse in Polen; Urwane ścieżki; Zagadka; Magnone, Lena: Emisariusze Freuda. Transfer kulturowy psychoanalizy do polskich sfer inteligenckich przed drugą wojną światową. Tom 1 i 2 (= Horyzonty Nowoczesności, Band 120), Kraków 2016; dies. (Hg.), Psychoanaliza w Polsce 1909-1946. Tom 1 i 2 (= Klasycy Polskiej Nowoczesności), Warszawa 2016. 
von Disziplinen und kultureller Lokalität überwinden, und auf den ’katalysierenden Blick von Außen auf Polen ein. In der Diskussion einzelner Beispiele soll dabei immer auch die Frage nach einer partikularen Perspektive auf die Disziplin und den soziohistorischen Kontext mitgedacht werden.

Bereits diskutiert habe ich den liminalen Charakter der freudschen Psychoanalyse in der feministischen Kritik der 1990er Jahre. Als eine liminale Figur der polnischen feministischen Kritik kann auch Janion verstanden werden, die eine Art Mentorinnenrolle der feministischen Kritik Polens einnimmt, sich aber in ihrer Forschung nicht auf die feministische Strömung allein beschränken lässt. Ihre Funktion in der feministischen Polonistik ist aber nur schon deshalb eine aktivere als jene Freuds, als ihre Forschung lokal und disziplinär eingebettet ist und sie sich selbst `zeitgleich in den Diskurs einschreibt.

\subsubsection{Die Funktion liminaler Figuren}

Mit dem Schriftsteller und Literaturwissenschaftler Czesław Miłosz komme ich nun auf das Beispiel einer liminalen Figur zu sprechen, die in gewissen Bereichen eine ähnliche Funktion einnimmt wie Janion, sich aber jenseits der Grenze feministischer Kritik ansiedelt. Als Untersuchungsmaterial dient mir neben einem Text Miłoszs zum Feminismus vor allem die Argumentation Borkowskas in $\mathrm{Cu}$ dzoziemki, die Miłosz stärker noch über die Disziplinengrenze der feministischen Kritik >hineinzieht.

Miłosz selbst schreibt im Sonderband Śmiech feministek der Teksty Drugie von 1993 von seinem Verhältnis zum Feminismus, das grundsätzlich von einer kritischen Einstellung dominiert sei: »Die Ehrlichkeit gebietet mir zu gestehen, dass ich selbst dazu geneigt bin, Feministinnen als Spinnerinnen zu betrachten, weil sie, revolutionären Passionarien ähnlich, kein Maß kennen und außerdem mit der Wahl von Führerinnen Mühe haben. $\aleph^{148}$ Etwa zeitgleich verweist Borkowska in einer anderen Zeitschrift (Kresy 16) darauf, dass Miłoszs Werke - zumindest jene der Nachkriegszeit - von einer misogynen Haltung geprägt seien. Die literarischen »Ansichten der Autoritäten«, darunter Miłosz, seien »diskret misogyn«, wenn diese »über die expansive Weibhaftigkeit der weiblichen Prosa nörgeln $\aleph^{149}$.

In Miłoszs Artikel von 1993 ist trotz aller bis zum Schluss bestehenden Vorbehalte eine Entwicklung festzustellen, was Miłosz auch thematisiert. Zu Beginn lehnt er die Forderung, bestimmte Werke aufgrund ihrer misogynen Intonation

148 | Miłosz, Czesław: „W stronę kobiet“, in: Teksty Drugie, Śmiech feministek (1993), S. 7-14, hier S. 13: "Uczciwość nakazuje mi przyznać się, że sam jestem skłonny uważać feministki za wariatki, dlatego że, podobnie jak rewolucyjne passionarie, miary nie mają, a poza tym źle sobie radzą z wyborem przywódczyń."

149 । Borkowska: ’Komandosi<, S. 239: »opinie autorytetów«; »podszyte dyskretnym mizogynizmem«; »wybrzydzają na rozlewną babskość prozy kobiecej«. 
aus dem Literaturkanon auszuschließen, noch ab - „Kanonrevisionen überzeugen mich nicht übermäßig « ${ }^{150}$. Doch später im Text formuliert er: »[N]ach einiger Überlegung denke ich, dass der Ausschluss mancher literarischer Werke, darunter auch Stücke Shakespeares, aus dem Kanon nicht unvernünftig wäre. $«^{151}$ Diesen Prozess des Verstehens einzelner feministischer Forderungen ermöglichte ihm, wie Miłosz schreibt, die Auseinandersetzung mit den Werken Anna Świrszczyńskas (1909-1984). Die empathische Haltung Świrszczyńskas, deren Texte sich in einer chauvinistischen Gesellschaft demonstrativ auf die Seite der »Frauen, auch alter « ${ }^{152}$ Frauen, stellten, raffektiert letztlich auch Miłosz. Diese Entwicklung widerspiegelt der Titel des Artikels, $W$ stronę kobiet (Auf die Seite der Frauen).

Miłoszs Text zeigt eine Lernbereitschaft, und aus einer negativen Haltung wird eine verhalten positive. Miłosz kann deshalb hier als eine liminale Figur betrachtet werden: Er stellt sich nicht explizit auf die Seite feministischer Kritik, macht aber gewisse Zugeständnisse. Mit dieser an der Grenze zu feministischen Ansätzen oszillierenden Position vertritt er eine Haltung, die im Bezug auf den Feminismus in Polen selten ist. Die Frage nach dem Feminismus polarisiert vor allem und ruft primär klare Haltungen der Unterstützung oder der Ablehnung hervor. ${ }^{153}$ Miłosz hingegen holt die Skeptiker in ihrer kritischen Einstellung ab und führt sie leicht auf die Seite feministischer Positionen, indem er ihnen via Świrszczyńska eine weibliche Perspektive auf eine hostile Gesellschaft zu ermöglichen versucht. Gleichzeitig geht dieses Zugeständnis dem Feminismus gegenüber auch nicht sehr weit, da Miłosz nur einen der von ihm angesprochenen Aspekte der feministischen Strömung in milderem Licht betrachtet, nämlich die Revision des Kanons. ${ }^{154}$

Miłoszs Demonstration der ideellen Annäherung ist im Kontext der feministischen Texte im Band Śmiech feministek von großer Bedeutung. Der Artikel von Miłosz nimmt im Themenheft die privilegierte Stellung des ersten Beitrags ein und wird so zu einer Art Türöffner. Trotz der im Großen und Ganzen antifeministischen Haltung des Texts übernimmt dieser im Gesamtkonzept des Bandes die Funktion, die potentielle Zugänglichkeit feministischer Konzepte aufzuzeigen. Grundvoraussetzung ist dabei das Auflösen verhärteter und vorurteilsbehafteter Positionen. Miłosz demonstriert hier eine Art learning by doing, bei der eine empathische Textlektüre im Zentrum des transformativen Prozesses steht. Diese

150 । Miłosz: W stronę kobiet, S. 10: »rewizje kanonu literatury niezbyt mnie przekonują".

151 । Ebd., S. 14: "po namyśle sądzę, że wyłączenie z kanonu niektórych dzieł literackich, także sztuk Szekspira, nie byłoby nierozsądne."

152 । Ebd.: "kobiet, również starych«.

153 | Vgl. bspw. Fuchs: Zivilgesellschaft, S. 127; Matuchniak-Krasuska: Ruch feministyczny, S. 127; Walczewska: Damy, rycerze i feministki, S. $39 f$.

154 I Miłosz ändert mitnichten seine Meinung über alle Phänomene feministischen Engagements; seine Ablehnung gegenüber einer genderkorrekten Schreibweise etwa wird im Text nicht revidiert. 
empathische Haltung, so scheint die Positionierung des Artikels zu suggerieren, sollte eine Öffnung hin zum `Anderen` der feministischen Lektüre ermöglichen. ${ }^{155}$

Die Rolle Miłoszs im Binnenkontext des Feminismus-Sonderbandes ist ähnlich derjenigen Janions im allgemeineren Rahmen der feministischen Polonistik. ${ }^{156}$ Beide Figuren wissen von feministischen Positionen, bevor sie sich diesen aktiv zuwenden. Beide betonen die Vermittlung dieser Positionen durch eine bestimmte Figur; bei Miłosz ist es die Lektüre der Texte Świrszczyńskas, während Janion von ihrer Studentin Szczuka auf eine explizit feministische Sichtweise gelenkt wird. ${ }^{157}$ Bei beiden ist die erkenntnistheoretische Fokussierung auf die feministische Kritik jedoch beschränkt und temporär, wenn sie auch bei Janion um vieles umfangreicher ist als bei Miłosz. Und nicht zuletzt nehmen beide aufgrund einer langjährigen akademischen (und bei Miłosz literarischen) Karriere eine Autoritätsfunktion ein, wodurch sie der feministischen Perspektive zusätzliche Legitimation zukommen lassen.

Nun möchte ich auf die Stelle in Borkowskas Cudzoziemki eingehen, in der diese auf Miłoszs Text verweist. Borkowska notiert:

»Czesław Miłosz hingegen, nicht nur Dichter und Nobelpreisträger, sondern auch (hier wichtig!) Professor einer amerikanischen Universität, schrieb, dass man einige Werke William Shakespeares, u.a. The Taming of the Shrew, gut und gerne aus dem Theaterrepertoire zurückziehen kann, da diese mindestens die Hälfte der Menschheit beleidigen. «158

Auffällig ist daran, dass Borkowska die Aussagen Miłoszs zuspitzt: Aus Miłoszs "nicht unvernünftigem « Ausschluss wird in den Worten Borkowskas »kann man gut und gerne zurückziehen«; die »Hälfte der im Zuschauerraum anwesenden Personen« weitet Borkowska zu »mindestens der Hälfte der Menschheit« aus; die Werke »kränken« nicht mehr nur »die Gefühle« bestimmter Personen, sondern die Personen selbst. ${ }^{159}$ Zudem zeichnet sie nicht den in Miłoszs Artikel aufscheinenden empathischen Prozess nach, sondern präsentiert nur dessen Ergebnis. Ebenfalls außen vor bleiben vonseiten Borkowskas nun Hinweise auf Miłoszs frühere misogyne Werke.

155 I Zum Begriff der Empathie vgl. Łebkowska, Anna: Empatia. 0 literackich narracjach przełomu XX i XXI wieku (= Modernizm w Polsce, Band 22), Kraków 2008, bes. S. $171 \mathrm{f}$.

156 | Es ist denn auch Janion, der in Śmiech feministek nach Miłosz der zweite Platz im Inhaltsverzeichnis zugestanden wird.

157 | Vgl. Janion: Kobiety, S. 241.

158 | Borkowska: Cudzoziemki, S. 16: »Natomiast Czesław Miłosz, nie tylko poeta i noblista, ale także (tu ważne!) profesor amerykańskiego uniwersytetu, napisał, że niektóre dzieła Williama Szekspira, m.in. Poskromienie złośnicy, śmiało można wycofać z repertuaru teatralnego, gdyż obrażają co najmniej połowę ludzkości."

159 । Vgl. Miłosz: W stronę kobiet, S. 14: »sie kränken die Gefühle der Hälfte der im Zuschauerraum anwesenden Personen«; »obrażają one uczucia połowy osób obecnych na widowni«. 
Borkowska unterzieht somit den Artikel Miłoszs einer Art selektivem Misreading, bei dem sie einzelne Stellen herausgreift und deren Aussage hin zu einer entschiedener feministischen Perspektive überschreibt. Mit der Umdeutung des "Zuschauerraums" in die "Menschheit" nimmt sie zudem einen im Kontext der feministischen Kritik der 1990er Jahre nicht irrelevanten Schritt zur Universalisierung vergeschlechtlichter Erfahrungen vor (siehe Kapitel 5 und 6.2.4). Borkowska zieht in ihrer Auslegung Miłosz weiter auf die Seite der `Frauen` und macht aus der oszillierenden Grenzfigur einen eindeutigeren Verfechter feministischer Standpunkte.

Was außerdem auffällt, ist die Auszeichnung Miłoszs mit nobilitierenden Prädikaten: Er wird nicht nur als Dichter, sondern auch als Nobelpreisträger vorgestellt. Dies unterstreicht seine soziokulturell gesetzte Stellung, was die Relevanz seiner Aussage für die feministische Kritik noch steigert. Interessant ist aber vor allem die Betonung Borkowskas, dass Miłosz Professor an einer amerikanischen Universität und dies im von ihr angesprochenen Kontext besonders wichtig sei. Die Relevanz dieses Faktums kann auf verschiedene Arten gemeint sein, die ich hier kurz andeuten möchte.

Der Zusammenhang von Miłoszs Aussage und seiner Position an einer US-amerikanischen Universität könnte deshalb besonders wichtig sein, da diese Position im englischsprachigen Raum auch die Deutungshoheit über das ebenfalls englischsprachige Schaffen Shakespeares verleiht. Über das Sprachverständnis wäre somit die Kompetenz gegeben, den »kränkenden« Charakter dieser Texte beurteilen zu können. Naheliegender scheint es jedoch, diese angenommene Deutungshoheit über den Faktor transnationaler Vektoren des kulturellen Wissens zu konstruieren: Dem Schaffen Shakespeares wird in der westlichen Kultur eine wesentliche Bedeutung zugemessen, die über dessen Entstehenskontext hinausstrahlt. Dieser Bedeutung erscheint hier nur die im transnationalen Wissens- und Wissenschaftsgefüge ebenso zentrale Institution einer »amerikanischen Universität« ebenbürtig und somit als kritikberechtigt. Diese Lesart legt nahe, dass Kritik nur zentrifugal wirksam werden kann, aus dem Kern einer so verstandenen Deutungshoheit heraus. Ein solcher Ansatz trägt antidemokratische Züge und reiht sich kaum in postkoloniale Herangehensweisen ein.

In eine ähnliche Richtung zielt auch eine weitere Lesart der Textstelle. Borkowskas Betonung der "amerikanischen « Position Miłoszs könnte damit in Zusammenhang stehen, dass dem US-Kontext größere Erfahrungen mit und auch größere Affinitäten zu feministischen Ansätzen zugeschrieben werden. In diesem Fall, so die Implikation, hätte der ausgewanderte Professor seine misogyne Prägung aus Polen im Laufe seines Aufenthalts in den USA abgelegt und zu einer egalitäreren Haltung gefunden. Dies legt nahe, dass der US-amerikanische Kontext als Vorbild feministischer Bestrebungen in Polen angesehen werden sollte. Die Stimme Miłoszs als Stimme des polnischen Eigenen wie des globalen Anderen nimmt damit die Stellung einer saufgeklärten` Instanz ein, der kraft ihrer transnationalen Suggestivwirkung ein Teil der Argumentationsmacht übertragen wird. Miłosz 
fungiert damit für die polnische feministische Kritik als zweifache Schwellenfigur im Hier und Dort: Er ist dem polnischen wie auch dem US-amerikanischen Kontext eingeschrieben und residiert mit seinem empathischen Text $W$ stronę kobiet an den Rändern der feministischen Kritik. Vielleicht ist es gerade diese Doppelung seiner liminalen Position, die ihm auch in Bezug auf die feministische Kritik eine ambivalente Haltung ermöglicht. Als außenstehender Dazugehörender durchbricht er die Binariät von feministischen und antifeministischen Positionen, wie sie sich im Polen der 1990er Jahre herausbilden.

\subsubsection{Filtertexte}

Im oben besprochenen Themenheft der Teksty Drugie nehmen die polnischen literaturhistorischen Autoritäten Miłosz und Janion die oberen Positionen im Inhaltsverzeichnis ein, während westliche Theoretikerinnen - hier Showalter und Cixous - erst im Mittelteil des Heftes vertreten sind. Die Publikation Spotkania feministyczne von 1994/1995 kehrt diesen Aufbau in ihrer Konzeption der Beiträge um. Hier folgen auf einzelne swestlicher Texte polnische Kommentare, die deren Anwendbarkeit auf den polnischen Kontext abwägen. Die Kommentare stammen von den Teilnehmerinnen feministischer Treffen in Warschau, bei denen die westlichen Texte als Inputs für Diskussionsrunden genutzt wurden. ${ }^{160}$ An diesem Materialbeispiel möchte ich den Begriff und die Funktion von Filtertexten eingehender diskutieren.

Filtertexte können als Texte verstanden werden, die eine vermittelnde und aufbereitende Rolle in Bezug auf Ursprungsmaterial einnehmen und dieses so für den rezipierenden Kontext zugänglicher machen, aber auch bestimmte Auslegungen und Rezeptionspfade verschließen. Oben habe ich in Bezug auf die westlichen feministischen Texte von Filtertexten zwischen freudscher Psychoanalyse und feministischer Polonistik gesprochen. Beim im Folgenden untersuchten Beispiel handelt es sich um ausschließlich feministische Texte, weshalb die Differenz primär an soziokulturellen und wissenshistorischen Grenzen festgemacht wird.

Zunächst möchte ich kurz den Artikel Snitows ins Zentrum der Aufmerksamkeit rücken, die ihrerseits als `Katalysatorfigur` des polnischen Feminismus und der polnischen feministischen Kritik gelten kann (s. u.). Snitow entwirft in ihrem Text Przyszłość feminizmu w krajach postkomunistycznych (Die Zukunft des Feminismus in den postkommunistischen Staaten), der 1993 in der Zeitschrift Peace \& Democracy News erstveröffentlicht wurde, eine erste Topographie postkommunistischer Diskurse und verknüpft diese mit Ansätzen und Problemstellungen ei-

160 | Dieser Aufbau widerspiegelt die Treffen des feministischen Zirkels, innerhalb dessen westliche feministische Texte diskutiert wurden, aus denen letztlich die Publikation resultierte. Vgl. B.L./T.O.: »Wstęp«, in: Spotkania feministyczne (1994/1995), S. 4-5, die im Übrigen auf die finanzielle Unterstützung des Zirkels durch die niederländische Botschaft hinweisen - eine weitere Form der Förderung eines transnationalen Ideentransfers. 
ner feministischen Perspektive. ${ }^{161}$ "Ihr Text erwies sich als idealer Ausgangspunkt für die Diskussion über uns, über unsere Situation und über die Zukunft des Feminismus in Polen « ${ }^{162}$, schreibt Fuszara in der Einleitung zur in Spotkania feministyczne publizierten Zusammenfassung der Diskussion über Snitows Text.

Fuszaras Einleitungstext stellt nun in Bezug sowohl auf Snitows Artikel wie auch auf die »erste Diskussion zu diesem Thema ${ }^{163}$ im Zirkel einen Filtertext dar: Er greift einzelne »Probleme, die in der Diskussion am häufigsten auftauchten «, und besonders diejenigen Teile, in denen »wir nicht mit Anns Beschreibungen und Urteilen einverstanden waren ${ }^{164}{ }^{16}$, heraus und stellt diese vor. Hinzu kommt, dass es sich im Grunde um einen polyphonen Text handelt, in dem die Aussagen vieler Diskutandinnen zu einzelnen thematisch gruppierten Aspekten verschmelzen.

In der Diskussion wird herausgestellt, dass gerade die in Polen »[s]päte Entwicklung des Feminismus hoffen lässt, diejenigen Irrtümer zu vermeiden, die wir dem Feminismus im Westen zuschreiben können. «165 Als solcher Irrtum erscheint in der Diskussion der ideologische Charakter feministischer Strömungen im Westen, während ein polnischer Feminismus aufgrund seines »Widerwillens zur Ideologisierung " sich ohnehin »selbst vor Ideologisierung in Acht nehmen wird und nicht als ideologische Bewegung betrachtet werden muss. $"{ }^{166}$ Dass diese Hoffnung der Diskutandinnen jedoch auch in Polen nicht unbedingt >erfüllt` wird, zeigen etwa die Angriffe feministischer Kritikerinnen, die sich als unpolitisch verstehen, auf den politischen Feminismus als `Ideologie` (siehe Kapitel 6.2.2).

Des weiteren kritisieren die Diskutandinnen bestimmte Feststellungen Snitows über den postkommunistischen Feminismus. »Erstaunen und Widerspruch weckte vor allem die Aussage, dass die `Bourgeoisität` des Feminismus ein Grund sei, weshalb dieser in postkommunistischen Ländern auf Ablehnung treffe. $«{ }^{167} \mathrm{Ob}$ wohl dieser Punkt nicht weiter ausgeführt wird, zeigt sich in dieser Aussage doch stark der Wille einer Loslösung vom kommunistischen Erbe und die Bereitschaft, westliche und bürgerlich geprägte Modelle zu übernehmen. Die polnische Diskussion richtet sich hier gegen Snitows Blick von Außen, der in der postsozialis-

161 । Vgl. Snitow, Ann: »Przyszłość feminizmu w krajach postkomunistycznych«, in: Spotkania feministyczne (1994/1995), S. 6-13.

162 । Fuszara: Feminizm i my, S. 14: »Jej tekst okazał się doskonałym punkten wyjścia do dyskusji o nas, o naszej sytuacji i o przyszłości feminizmu w Polsce."

163 । Ebd.: "pierwsza na taki temat dyskusja«.

164 | Ebd.: "problemy, które w dyskusji pojawiały się najwięcej«; »nie zgadzałyśmy się z Ann w dokonanych przez nią opisach i ocenach."

165 । Ebd., S. 19: „Późny rozwój feminizmu stwarza bowiem nadzieję na uniknięcie tych pomyłek, które przypisać możemy feminizmowi na Zachodzie."

166 | Ebd., S. 20: »niechęć do ideologizacji«; »sam będzie się wystrzegał ideologizacji i nie musi być traktowany jako ruch ideologiczny."

167 | Ebd., S. 21: „Zdziwienie i sprzeciw wzbudził zwłaszcza punkt odwołujący się do `burżuazyjności< feminizmu, jako przyczyny jego odrzucenia w krajach postkomunistycznych.» 
tischen Gesellschaft eine stärkere Bindung an kommunistische Denkstrukturen und Rhetoriken vermutete. Diese Fremdzuschreibung weisen die Diskutandinnen "erstaunt" von sich und zeigen in dieser affektiven Geste auch die Tendenz, die postsozialistische Kondition als solche voreilig zu negieren. Die von Snitows Auslegungen abweichenden Diskussionsresultate werden dabei teilweise auf den zeitlichen Aspekt zurückgeführt. Einige Punkte erscheinen als »nicht mehr aktuell«, wobei hervorgehoben wird, »wie schnell in unserem Teil der Welt die Zeit vergeht und Änderungen vonstatten gehen ${ }^{168}$, wie Fuszara im Namen der Diskussionsteilnehmerinnen resümiert. Die sozialistische Vergangenheit wird so rhetorisch aus dem Blickfeld gedrängt.

Neben der im Prinzip soziologisch-politisch ausgerichteten Diskussion des Snitow-Texts möchte ich nun auf einen weiteren Rezeptionsfall eingehen, der sich in der Spotkania feministyczne-Publikation findet. Im Band wurden Auszüge aus Butlers Gender Trouble (1990) in polnischer Übersetzung untergebracht, gefolgt von einem Beitrag von Bożena Chołuj. Letztere geht in ihrem Beitrag thematisch über die abgedruckten Auszüge hinaus und bespricht allgemeiner Thesen von Butler, die diese in Gender Trouble und Bodies That Matter (1993) entwickelte. ${ }^{169}$ Konkret untersuchen möchte ich jedoch ein weiteres Glied in der Rezeptionskette, nämlich Iwasióws Verweis auf diese Texte in ihrem Gender->Handbuch ‘ von 2004.

Das Vorgehen von Iwasiów in Gender dla średnio zaawansowanych illustriert die Schwierigkeiten, die sich aus Übersetzungs- und Rezeptionswegen ergeben, und zeigt zudem die dichte intertextuelle Verstrickung der Ideengeschichte auf. Iwasiów bespricht die Rezeptionsgeschichte von Woolfs A Room of One's Own (1929)..$^{170}$ Dabei zeichnet sie die Lektüre Woolfs von Toril Moi (1985) nach und kontrastiert deren Verständnis von Geschlechtsidentität mit den performativen Ansätzen Butlers. Mit dieser Triade klassischer Ansätze feministischer Theorie konstruiert Iwasiów eine palimpsestartige Kette von Lesarten der Kategorie Geschlecht, wobei jeweils das letzte Glied die vorherigen Glieder überlagert, ohne deren lineare Weiterentwicklung darzustellen.

Diese Kette ergänzt Iwasiów um die Position Chołujs, und es sind gerade die Beziehungen zwischen >Butler und `Chołuj‘ im Text Iwasióws, die ich hier nun genauer betrachten möchte. Iwasiów spricht von den

"Ansichten Judith Butlers [...], welche ihre Übersetzerin und Kommentatorin Bożena Chołuj in eine Theorie der Verhandlung weiterentwickelt. Sie [Chołuj] schlägt vor, eine Person als dynamisches

168 | Ebd.: "nieaktualne «; "jak szybko płynie czas i następują przemiany w naszej części świata." 169 I Siehe Butler, Judith: Gender Trouble. Feminism and the subversion of identity, New York, London 1990; dies.: Bodies That Matter. On the Discursive Limits of 'Sex<, New York 1993; dies.: »Podmioty płci / płciowość / pragnienia«, in: Spotkania feministyczne (1994/1995), S. 58-67; Chołuj, Bożena: »Tożsamość płci - natura czy kultura? /kulturowe aspekty kobiecości, różnica płci nie istnieje; postfeminizm/«, in: Spotkania feministyczne (1994/1995), S. 68-73.

170 | Vgl. Woolf, Virginia: A Room of One's Own, London 1929. 
Individuum zu verstehen, das sich in Kommunikationsakten realisiert; als stetiges Verhandeln eines der subversiven 'Person entspringenden Selbsts, was die Flucht aus dem Gefangensein in der Bedeutungsordnung ermöglicht. « ${ }^{171}$

Obwohl Iwasiów die Ansätze Mois nominell mit denjenigen Butlers kontrastiert, bezieht sie sich inhaltlich vollständig auf den Kommentar Chołujs. Die Position Chołujs verdrängt in Iwasióws Text `Butler`vollkommen aus der Argumentation und übernimmt deren Stelle als Kontrastpunkt zu Moi. Dies ist insofern besonders interessant, als die Triade der >großen Namen` westlicher Feminismen gebrochen wird und an deren Endpunkt die im von Iwasiów angesprochenen englischsprachigen Raum wohl kaum bekannte Chołuj tritt. Die »Ansichten Judith Butlers» hingegen werden zu einem leeren Terminus im Text, der ohne zusätzlich beigezogenes Wissen vollkommen enigmatisch bleibt.

Mit diesem Verfahren nivelliert Iwasiów die anderswo angesprochenen Diskrepanzen zwischen westlicher und polnischer Theoriebildung. Es handelt sich jedoch nur um eine temporäre Einsetzung der Thesen Chołujs, die hier die >Leere des butlerschen Ideenkonglomerats ersetzen müssen; bereits nach der zitierten Passage wendet sich Iwasiów wieder der englischsprachigen Feminismustradition zu. Im Prinzip übernimmt der Text Chołujs in Bezug auf Butler die gleiche Funktion als Filtertext, wie ich sie unter 4.2.2 am Beispiel des Überschreibens der Psychoanalyse Freuds durch feministisch-psychoanalytische Kritiker/innen festgestellt habe. Die Motivation des Einsatzes von Filtertexten ist jedoch leicht unterschiedlich: Zwar handelt es sich sowohl bei den Ansätzen Freuds wie auch Butlers um bislang im polnischen Kontext kaum verfügbare Texte; die Übersetzung von Butlers Gender Trouble erscheint, von den in Spotkania feministyczne publizierten und von Chołuj kommentierten Fragmenten von 1994/95 abgesehen, erst 2008. ${ }^{172}$ Während aber Freud als `überholte` Theorie gilt und die feministische Psychoanalyse somit einen ‘fortgeschritteneren` Entwicklungsschritt darstellt, ist die Sache bei Butler komplexer und »verknoteter«. Denn obwohl Iwasiów hier aus einer nachgestellten Perspektive die >Rezeptionslagen Chołuj) verfolgt und somit eine historische Entwicklung beschreibt, konstruiert sie in einer anderen Textpassage die performativen postfeministischen Strömungen der 1990er Jahre der USA als einen anderswo gegenwärtigen, für Polen jedoch zukünftigen Theoriestand und Denkhaltung. ${ }^{173}$ Dies bringt Chołuj in die Position eines Kommentars, der `zu progressive Theorie aufbricht und in eine intelligible

171 I Iwasiów: Gender, S. 64f.: "poglądami Judith Butler, które ich tłumaczka i komentatorka Bożena Chołuj rozwija w teorię negocjacji, proponując rozumienie osoby jako dynamicznego indywiduum, realizującego się w aktach komunikacji; każdorazowe negocjowanie siebie, którego źródłem jest subwersywna >osoba<, pozwalające uciec z niewoli porządku znaczenia."

172 | Vgl. Butler, Judith: Uwikłani w płeć. Feminizm i polityka tożsamości, Warszawa 2008.

173 I Vgl. Iwasiów: Gender, S. 82; Seiler: Geschlechterfragen, S. 58-61; dies.: Brüche im Kontinuum, S. 103f. sowie die Ausführungen dazu im Schlussteil der vorliegenden Arbeit. 
Sprache verschiebt - was bei Texten Butlers ohnehin hilfreich ist. Chołujs Kommentar ist - in der Auslegung Iwasióws, aber auch allgemeiner in Polen - dem butlerschen Text somit gleichzeitig vor- wie nachgelagert, da sich hier polnische und globale Perspektiven verknoten.

\subsubsection{Katalysatoren}

Oben habe ich unter dem Begriff `Filtertexte $<$ Beispiele von polnischen Texten besprochen, die westliche geschlechtertheoretische oder feministische Ansätze für den polnischen Kontext aufbereiten. Unter dem Schlagwort der `Katalysatoren betrachte ich im Folgenden ein ähnliches Phänomen liminaler Texte oder Figuren. Den Unterschied sehe ich darin, dass die polnischen Filtertexte aus einer Innenperspektive agieren und der Bezug auf den polnischen Kontext deshalb nicht zwingend expliziert werden muss. Die `Katalysatoren nicht im polnischen Kontext selbst angesiedelt, beziehen sich aber auf diesen und bringen ihre Texte auch in polnischer Sprache in diesen ein. ${ }^{174}$ Die Perspektive der Katalysatoren ist somit eine sinformierte`Außenperspektive, deren Nutzen und Nachteile ich bereits in der Einleitung besprochen habe.

Den Begriff des `Katalysators« setze ich jedoch nicht allgemein für Texte, die einen externen Blick auf Polen entwickeln, sondern eingrenzender für Texte oder Figuren, deren Tätigkeit im polnischen Kontext selbst aktiv wird und die mit ihrer Forschung gewisse Entwicklungen in Gang setzen oder beeinflussen. Der oben bereits angesprochene Text Snitows kann als solcher Katalysatortext gelten. Gleichzeitig wird aufgrund der unterschiedlichen Reaktionen der polnischen Feministinnen auf die darin vorgeschlagenen Sichtweisen ersichtlich, dass das Phänomen des `Katalysierens` nicht als mechanische Einflussnahme verstanden werden soll. Den folgenden letzten Abschnitt dieses Kapitels widme ich den Texten Snitows und Ritz', die als Katalysatorfiguren betrachtet werden können.

Snitow bemühte sich, den polnischen Kontext mitzuformen und ein feministisches Bewusstsein zu fördern. Dies tat sie nicht nur als externe Beobachterin und Diagnostikerin, als die sie im oben eingeführten Text Przyszłość feminizmu w krajach postkomunistycznych auftritt. Snitow war neben ihrer publizistischen Tätigkeit in den 1990er Jahren als Gastdozentin an der Polnischen Akademie der Wissenschaften in Warschau aktiv und erfreute sich in polnischen feministischen Kreisen großer Popularität. ${ }^{175}$ Mit Przyszłość feminizmu w krajach postkomunistycznych schrieb sie bestimmte Ideen aus einer Außenperspektive, aus einem wissenshistorisch anders gelagerten lokalen Diskursfeld, in den postsozialistischen Kontext ein.

Hier könnte man von einem Ideentransfer sprechen, der von saußen stattfindet. Damit stellt sich die Frage nach der Innen-/Außenperspektive entlang der

174 । Bei den beiden im Folgenden besprochenen Beispielen handelt es sich dabei um Übersetzungen, die aber teilweise (im Falle Ritz') als Erst- oder Parallelveröffentlichungen erschienen.

175 । Vgl. Graff: Gender Studies, S. 169. 
geographisch-kulturellen (nicht aber inhaltlichen, sprich feministischen) Verortung des Texts. Eine solche Verortung ist in sich problematisch, als hier quasi der geographische Standpunkt der schreibenden Instanz zum auszeichnenden Charakteristikum eines Texts essentialisiert wird. Damit rückt auch die schreibende Instanz an sich stärker in den Vordergrund - der Text kann nur als sexterner identifiziert werden, wenn er dies entweder thematisiert oder wenn er als Derivat einer geographisch-kulturell definierten Autor/inneninstanz verstanden wird. In der Charakterisierung eines Textes als intern/extern spielt somit immer auch ein gewisses expliziertes Kontextwissen mit, das sich auf den/die >Autor/in` und dessen/deren `Zugehörigkeit‘ zum lokalen Diskurs bezieht.

Im hier besprochenen Fall bezieht sich dieses Wissen darauf, dass Snitow als US-amerikanische Professorin der Anglistik in New York lehrt, wie der Band Spotkanie feministyczne angibt. ${ }^{176}$ Das Einsetzen einer graduellen Zugehörigkeit zum polnischen `Innen steht in Zusammenhang mit Snitows Mitbegründung des Network of East-West Women (NEWW) in den 1990er Jahren, das feministische Organisationen in Mittelosteuropa unterstützt und den transnationalen Austausch und die Wissensvermittlung fördern soll. Auf diese Kontaktaufnahme mit dem `Osten`nimmt Snitows Artikel Bezug, setzt gleichzeitig aber Abgrenzungsrhetoriken: "Nach dem Überschreiten der Grenze zwischen Westen und Osten verschwimmen die erwarteten Ähnlichkeiten oft « ${ }^{177}$, stellt Snitow fest und verweist damit auf die Notwendigkeit, überhaupt in Kontakt zu treten, um Unterschiede feststellen zu können. Diese Kontaktnahme erscheint in Snitows Aussage als einmaliges, definiertes Ereignis des »Überschreitens« einer offenbar klar feststellbaren »Grenze«, obwohl Snitow zunächst von größerer Ähnlichkeit der beiden Gebiete ausgeht.

Aus dieser durch den Kontakt informierten Position schreibt Snitow: "Und dennoch bin ich erstaunt darüber, dass liberale, demokratische Ideen im Osten auf eine eigene Art diskutiert werden, die für uns schwierig zu verstehen ist. ${ }^{178}$ Die Grenze wird hier konstruiert durch die Bezeichnung »im Osten «, die im Gegensatz zu »uns« steht, und intensiviert durch die Attribute »eigene« (odrębny), »schwierig zu verstehen" und besonders auch »erstaunt«: Das Erstaunen erscheint als Reflex der unerwarteten Differenz, als Effekt der sich vor dem Blick von Außen verschließenden Undurchdringlichkeit des postkommunistischen Kontexts. Die Differenz affektiert die swestlicher Wissenschaftlerin und wirft deren Wissen auf sich selbst zurück, während das Erstaunen die anfängliche, in gewisser Weise naive Haltung Snitows enthüllt. Es ist neben dem Erstaunen die »Schwierigkeit zu verstehen«, die das Eindringen in den `östlichen` (für unseren

176 | Vgl. Snitow: Przyszłość feminizmu, S. 7.

177 । Ebd.: "Po przekroczeniu granicy między Zachodem i Wschodem, spodziewane podobieństwa często się rozpływają."

178 । Ebd., S. 6: »A jednak jestem zaskoczona tym, że liberalne, demokratyczne idee są na Wschodzie dyskutowane w sposób odrębny, dla nas trudny do zrozumienia." 
Fall polnischen) Kontext erschwert und die Außenperspektive immer wieder als solche rekonstruiert; eine sIndigenisierung، des Blicks Snitows kann nicht ohne erheblichen kognitiven Aufwand geschehen. ${ }^{179}$

Trotz der assimilierenden Bemühungen Snitows werden in der Diskussion der polnischen Feministinnen über ihren Text die Grenzen zwischen außen und innen erneut nachvollzogen. Dies zeigt sich etwa darin, dass eine physische Distanz zwischen Snitow und dem polnischen Diskussionszirkel existiert. „Wir gingen davon aus, dass die Autorin am Seminar teilnehmen würde. Es kam jedoch anders - Ann konnte damals nicht nach Polen reisen. ${ }^{180}$ Hier erscheint Snitow zudem als ideengebende Einzelperson mit (vor)namentlicher Nennung, während die polnischen Feministinnen als anonymisiertes "wir« in Polen auftreten. Diese Hierarchisierung wird wiederholt mit der folgenden, bereits zitierten Formulierung, wo wiederum eine vektorielle Richtung von außen nach innen auftritt; von einem >externen« Blickpunkt verschiebt sich die Diskussion »über uns « zu einer internen Perspektive: »Ihr Text erwies sich als idealer Ausgangspunkt für die Diskussion über uns, über unsere Situation und über die Zukunft des Feminismus in Polen. ${ }^{181}$ Die agency der polnischen Feministinnen manifestiert sich darin, dass diese den Text Snitows kritisch lesen und gewisse Aussagen als Ansatzpunkt weiterer Diskussionen einsetzen, andere jedoch ablehnen.

Zentral ist zudem, dass es sich bei der polnischen Diskussion um eine Polyphonie verschiedener Ansichten und Meinungen handelt, die sich zu keiner einstimmigen Haltung kondensieren lässt. ${ }^{182}$ Solche divergierenden Ansichten zeigen, dass es im Polen der 1990er Jahre nicht nur unterschiedliche persönliche Ansichten über bestimmte Aspekte der Geschlechterdebatte gab; sie illustrieren auch die Vielzahl von unterschiedlich gewichteten und sich zum Teil widersprechenden Narrativen und damit letztlich die Uneinheitlichkeit eines Diskursfelds, das über sich selbst (noch) keine 'Meistererzählung` entwickelt hatte. Dies widerspiegelt sich insbesondere in den polemischen Diskussionen der 1990er Jahre beispielsweise in der feministischen Zeitschrift Pelnym głosem über die Existenz und die Lage eines polnischen Feminismus (siehe Kapitel 2.4.2). Die Abwesenheit einer Meistererzählung kann denn auch für die US-amerikanische Akademikerin einer der Hauptgründe für die Undurchdringlichkeit des polnischen Geschlechterkontextes gewesen sein.

179 | Snitow ist dabei bemüht, ihren Blick nicht als »colonial appropriation (Bhabha: Location of Culture, S. 86) einzusetzen, sondern umgekehrt den lokalen Kontext intellektuell zu »inkorporieren« (Vgl. Bourdieu: Die männliche Herrschaft, S. 43-62); mit Bhabha könnte man hier von einer Strategie der invertierten Mimikry sprechen (Bhabha: Location of Culture, S. 90).

180 | Fuszara: Feminizm i my, S. 14: „Spodziewałyśmy się, że w seminarium weźmie udział autorka. Stało się jednak inaczej - Ann nie mogła wówczas do Polski przyjechać."

181 I Ebd.: "Jej tekst okazał się jednak doskonałym punktem wyjścia do dyskusji o nas, o naszej sytuacji i o przyszłości feminizmu w Polsce."

182 | Vgl. etwa ebd., S. 20. 
Im besprochenen Beispiel zeigen sich die Grenzziehungen sowohl im Text selbst wie auch in einem breiter gefassten Kontextwissen, das sich auf die schreibende Instanz und die jeweiligen Diskursfelder bezieht. Das Konstruieren einer Grenzziehung zwischen innen und außen respektive einer >Außenperspektive im Fall Snitows gerät jedoch mit der Tatsache unter Druck, dass Snitow regelmäßig und über längere Zeit in Polen anwesend war und die Distanz durch den Kontakt mit den Studierenden ihrer Gender Studies-Kurse in Warschau in gewisser Hinsicht reduziert wurde. Inwiefern somit in ihrem Fall noch von einer Außenperspektive gesprochen werden kann oder wie stark Snitow letztlich zwischen dem US-amerikanischen und dem polnischen Diskursfeld oszilliert, soll hier nicht festgelegt werden. Klar scheint jedoch, dass sich diese beiden Diskursfelder durch Akteure und Akteurinnen wie Snitow annäherten, was besonders auf einem >Verschieben des polnischen Diskursfelds beruhte. Als Katalysatorin war Snitow zwar selbst gewissen Prozessen der Transformation und ideellen Assimilation unterworfen, gab aber dem polnischen Kontext durch ihre Sichtweise auch entscheidende Impulse und erschloss bestimmte Themen für den polnischen feministischen Diskurs.

Dasselbe gilt auch für den Schweizer Polonisten Ritz, der für die literaturwissenschaftliche Geschlechterforschung in Polen von richtungsweisender Bedeutung war. Die feministische Polonistik der 1990er Jahre zeichnete sich vor allem durch einen starken Fokus auf die `Frau<bzw. auf die Weiblichkeit aus, während der Blick auf das männliche Geschlecht und allgemein die Dynamiken einer vergeschlechtlichten Gesellschaft mitunter verloren ging. ${ }^{183}$ Die Transposition der Überlegungen der Gender Studies und die Einführung der Kategorie gender als Analyseinstrument literarischer Texte in die Polonistik wird als Verdienst der literaturwissenschaftlichen Texte Ritz' ab Mitte der 1990er Jahre angesehen.

Obwohl bereits in der Feminismus-Sondernummer der Teksty Drugie von 1993 mehrfach die Rede von gender oder den Gender Studies war, kann hier noch von keinem produktiven Einbringen dieser Perspektive gesprochen werden. Czesław Karkowski etwa bezeichnet die Gender Studies als eine Art ‘fremdes` Instrument, »hinter dessen ziemlich euphemistischer Bezeichnung sich die Problematik jeglicher anderen sexuellen Orientierungen versteckt, vor allem der Homosexuellen und Lesben [sic!]. ${ }^{184}$ Karkowski anerkennt zwar die Ansätze der »Homosexuellen und Lesben «, von »oni i one ${ }^{185}$, als eine marginalisierte Gruppe, geht aber gleichzeitig auf Distanz zu diesen >Anderen` der Geschlechterdebatte, die sich hinter dem »Euphemismus« der Gender Studies verstecken.

183 I Vgl. auch Magnone: Die polnischen Gender Studies, S. 388.

184 । Karkowski, Czesław: "Świat według Paglii«, in: Teksty Drugie, Śmiech feministek (1993), S. 206-212, hier S. 208: »za którym to dość eufemistycznym określeniem kryje się problematyka wszelkich innych orientacji seksualnych, przede wszystkim homoseksualistów i lesbijek.«

185 । Ebd.; »oni«: "sie« in der männlich-belebten Form der 3. Person Plural; »one«: »sie« in der nicht-männlich(-unbelebten) Form der 3. Person Plural. 
Im genannten Teksty Drugie-Band bezieht sich auch Halina Filipowicz auf den Begriff gender. Sie expliziert die Unterscheidung von sex und gender, aber auch die Kategorie gender als wissenschaftliches Utensil. Filipowicz wiederum grenzt die Gender Studies implizit als apolitisch aus: »Aber der kritische Diskurs, der gender ins Zentrum stellt, ist nicht unbedingt ein feministischer Diskurs. ${ }^{186}{ }^{\text {Sie stellt die }}$ Gender Studies in den Kontext "apolitischer weiblicher oder feminozentrischer Kritik « ${ }^{187}$. Beide Positionen - Filipowiczs wie Karkowskis - greifen einzelne Aspekte der Gender Studies heraus und beschreiben diese, während sie gleichzeitig die Nutzbarmachung für ihre eigene Forschung negieren. Demgegenüber präsentiert Anna Łebkowska in einem Artikel von 1995 nicht nur eine umfängliche und vielseitige Einführung und Begriffsdiskussion der Kategorie gender (wobei sie den Begriff rodzaj vorschlägt, also »Genus«) für die (polnische) Literaturwissenschaft, sondern exerziert deren Funktionalität in einer Analyse von Tadeusz Konwickis Czytadło (Schmöker, 1992) auch gleich vor. ${ }^{188}$

Der Ansatz von Ritz geht weniger auf das einführende und erklärende Element ein und integriert die Kategorie gender, die Kategorie des kulturellen Geschlechts, als bereits bewährte, mit der er in seinen Analysen eine weitere Dimension der untersuchten Texte aufschlüsseln kann. Diese Ausrichtung Ritz' entwickelte sich aus der Untersuchung des homosexuellen Begehrens in den Texten des polnischen Modernisten Jarosław Iwaszkiewiczs (1894-1980). Während Ritz in einer Studie zu Iwaszkiewicz von 1994 die Kategorie gender noch nicht explizit benannte, setzte er sie 1997 in einem vergleichenden Artikel zu literarischen Prozessen der Sublimation homosexuellen Begehrens als poetologische Kategorie ein. ${ }^{189}$ Ritz sieht das `Geschlecht in seinem Forschungsmaterial nicht als ontologische Größe, sondern als im modernen Roman neues literarisches Verfahren der Subjektwerdung und Objektivierung gleichermaßen. Deshalb »verlangt auch gender als poetologische Kategorie unausweichlich nach einem historischen Verständnis von Geschlechtsbewusstsein und Gattungspoetik. ${ }^{190}$ Geschlecht soll also in seiner literarischen

186 | Filipowicz: Przeciw >literaturze kobiecej‘, S. 255: »Ale dyskurs krytyczny, który w centrum stawia gender, niekoniecznie jest dyskursem feministycznym."

187 । Ebd.: "apolitycznej krytyki kobiecej czy feminocentrycznej«. Vgl. dazu auch Vatter: Rezeption der Gender Studies, S. $27 f$.

188 | Łebkowska: Czy spłeć‘ może uwieść poetykę. Maggie Humms Eintrag zu Gender im 1993 auf Polnisch übersetzten The Dictionary of Feminist Theory (1989) bezieht sich stärker auf soziologische Aspekte, weshalb diese Position für die Literaturwissenschaft weniger zentral wurde. Vgl. Humm: Słownik teorii feminizmu.

189 | Vgl. Ritz, German: »Eros i sublimacja u Jarosława Iwaszkiewicza«, in: Teksty Drugie 25/1 (1994), S. 29-48; ders.: »Niewypowiadalne pożądanie a poetyka narracji«, in: Teksty Drugie 45/3 (1997), S. 43-60.

190 | Ritz: Niewypowiadalne pożądanie, S. 44: »gender, jako kategoria poetologiczna, bezwzględnie wymaga historycznego ujmowania świadomości płci i poetyki gatunków literackich.« 
Ausformung als dynamisches Verhältnis verstanden werden, das sich in steter Aushandlung befindet.

Die Ansätze Ritz' unterscheiden sich insofern von denjenigen vieler polnischer feministischer Kritikerinnen, als sie die Sexualität zum Ausgangspunkt ihrer Überlegungen machen. Neben das homoerotische Begehren tritt dabei in dessen Sublimierung auch das heterosexuelle Verhältnis. Ritz führt jedoch auch vor Augen, dass erst der heteronormative Diskurs des 19. Jahrhunderts überhaupt die Konzeption einer `homosexuellen Identität erwirkte; diese Überführung von der prozessualen `Handlung zur >Identität liest er als heteronome Festschreibung. ${ }^{191}$ In der diskursiven Konstruktion eines `Anderen` zur Selbstdefinierung der (heterosexuellen, männlichen) Norm sieht Ritz denn auch die Überschneidungen des ohnehin eng verknüpften Geschlechter- und Sexualitätsdiskurses:

"Der männliche Diskurs gibt sich als neutraler Diskurs der Kultur, d. h. er wird mit der Kultur identifiziert. Wenn sich der weibliche oder der homosexuelle Diskurs im Bewusstsein als das Andere der Kultur einprägen, muss der männliche (heterosexuelle) Diskurs eingestehen - in Anbetracht jener -, dass er ein Konstrukt ist. So verliert er die sorgfältig bewachte Rolle dessen, was sseit jeher existiert. ${ }^{192}$

Diese Offenlegung der normativen Prozesse von Fremd- und Selbstbestimmung ist eine der Grundleistungen der Genderanalyse. ${ }^{193}$

Für den polnischen Geschlechterdiskurs zeigt Ritz damit einerseits, dass die Differenzierungs- und Ausgrenzungsmechanismen des >männlichen Diskurses` nicht nur als binäre Hierarchisierung von `männlich` und `weiblich` zu verstehen sind. Der patriarchale Diskurs erweist sich auch als heteronormativer, womit die in der Grundidee des Feminismus priorisierte Binarität des Geschlechts als gesellschaftsordnende Struktur dezentralisiert wird. Gleichzeitig lenkt Ritz den Fokus auf die Konstruktion solcher Differenzierungen als literarische Verfahren, wobei das >Andere als kulturelles Konstrukt hervortritt: »[D]ie Imagination des Anderen [ist] gleichzeitig ein Grundakt literarischer Imagination. ${ }^{194}$ Die Kategorie des Geschlechts oder der Sexualität überlagert sich mit textuellen Mechanismen, und mithilfe literarischer Verfahren schreibt sie sich in den Text ein. Aufgrund dieser

191 । Vgl. ebd., S. 47.

192 | Ebd., S. 43: »Męski dyskurs podaje się za neutralny dyskurs kultury, tzn. utożsamia się go z kulturą. Jeśli dyskursy kobiecy lub homoseksualny utrwalają się w świadomości jako Inność kultury to dyskurs męski (heteroseksualny) musi uznać - przeglądając się w tamtych - że jest konstruktem. Tym samym traci pilnie strzeżoną rolę tego, co istnieje >od zawsze‘."

193 I Vgl. auch Scott, Joan W.: "Gender: A Useful Category of Historical Analysis«, in: The American Historical Review 91/5 (1986), S. 1053-1075.

194 I Ritz, German: »Neue Welt und altes Frauenbild. Ein Gender-Blick auf die polnische Avantgarde nach 1918«, in: Die Welt der Slaven 42 (1997), S. 272-290, hier S. 288. 
Überlagerung schlägt Ritz deshalb eine »doppelte Lektüre dessen, was aussprechbar ist, als poetologische Aussage und als Aussage bezüglich gender « ${ }^{195}$, vor.

Dieses analytische Vorgehen erinnert an jenes von Kłosińska, die »weibliche Signaturen« im Text verfolgt und dabei doppelt codierte »Wort-Ächzer« untersucht (siehe Kapitel 5.2). ${ }^{196}$ Auch bei ihr ist ein enges Zusammendenken von Geschlecht und Text zu erkennen. Kłosińska orientiert sich jedoch stärker an einer `Weiblichkeit und deren metaphysischer Charakterisierung und schreibt 1993 in einem Artikel etwa, dass der weibliche Körper »die Grundfigur, die Allegorie der Lektüre darstellt «197. Die von Ritz vorgeschlagene Genderlektüre bietet deshalb im Kontext feministischer Kritik der 1990er Jahre den Ansatz einer De-Essentialisierung der Kategorie des Geschlechts (und auch der noch kaum besprochenen Sexualität) ${ }^{198}$ und bricht den starken Fokus auf die 'Weiblichkeit als Orientierungsgröße auf.

Die Forschung Ritz', die sich als Genderlektüre »gezielt gegen den Text richtet ${ }^{199}$, widersetzt sich auch den Versuchen einer geschlechtlichen Identitätskonstruktion und Gemeinschaftsfindung qua Text, wie sie in der feministischen Kritik im Polen der 1990er Jahre vor allem für die Kategorie der Weiblichkeit gefordert wurde. Solche Widerstände brachten den Ansätzen der Gender Studies wohl letztlich auch Filipowiczs Vorwurf der Apolitizität ein. ${ }^{200}$ Gleichzeitig öffnet die Forschung Ritz' den normativen Horizont der polonistischen Geschlechterforschung der späteren 1990er Jahre für Ansätze, die sich einer essentialisierenden Lesart

195 | Ritz: Niewypowiadalne pożądanie, S. 48: »podwójnej lektury tego, co wypowiadalne, jako wypowiedzi poetologicznej i wypowiedzi dotyczącej gender.«

196 | Vgl. Kłosińska: Ciało, S. 58f., $276 f$.

197 I Kłosińska, Krystyna: »Jestem wszędzie i nigdzie mnie nie ma. Miejsce kobiety w dyskursie współczesnym«, in: Piętkowa, Eros, psyche, seks (1993), S. 17-22, hier S. 17: »stanowi figurę podstawową, alegorię lektury«.

198 I Der Sammelband Eros, Psyche, Seks zur Konferenz in Katowice unter dem Titel »Język a erotyka (Sprache und Erotik) deutet darauf hin, dass bereits vor der Zuwendung Ritz' zu diesem Thema Sexualität und Eros in der Polonistik diskutiert wurden. Dies gilt im Besonderen auch für die Forschung Maria Podraza-Kwiatkowskas, die die Frage nach Geschlecht und Sexualität seit ihrer Monographie Młodopolskie harmonie i dysonanse (Harmonien und Dissonanzen der Młoda Polska) von 1969 an die Literatur der Młoda Polska stellte. Es bleibt im Rahmen der vorliegenden Arbeit jedoch zu vermuten, dass viele der früheren Arbeiten zum Geschlecht und/oder der Sexualität oberflächlichere, motivischere Lektürevorschläge anboten. Vgl. Piętkowa, Romualda (Hg.), Eros, psyche, seks. Materiały z konferencji »Język a erotyka« zorganizowanej przez koło naukowe językoznawców Uniwersytetu Śląskiego, Katowice 1993; Podraza-Kwiatkowska: Tragiczna wolność.

199 | Ritz: Neue Welt, S. 272.

200 | Filipowiczs Text ist diesbezüglich ein ambivalenter: Während er die Gender Studies als apolitisch disqualifiziert und damit letztlich einem Misreading aussetzt, engagiert er sich gleichzeitig dafür, auch die Weiblichkeit nicht als apolitische Größe zu verstehen und sich nicht auf deren Rekonstruktion auszuruhen. Vgl. Filipowicz: Przeciw literaturze kobiecej<, S. 255 und passim. 
literarischer Geschlechterverhandlungen entgegenstellen. Diese erweiterte dekonstruktivistische Lektüre liest kulturelle Machtstrukturen nicht mehr nur als patriarchale Unterdrückung der Frauen und verschiebt so die Thematik auf eine neue Ebene des Politischen. ${ }^{201}$ Die Probleme, die die Einführung des Begriffs gender in Polen hervorruft, habe ich in Kapitel 2.4.1 bereits kurz erwähnt; darauf komme ich am Beispiel der »doppelten Lektüre« im Schlussteil der vorliegenden Arbeit zurück.

Mit der Öffnung des Untersuchungshorizonts über die fünf feministischen polonistischen Monographien der 1990er Jahre hinaus konnte ich in diesem letzten Teil des vorliegenden Kapitels einige Phänomene besprechen, die sich an den >Rändern` der feministischen Polonistik abspielten. Es erschien mir wichtig, diese Dynamiken zumindest exemplarisch zu erfassen, um die feministische Kritik in der Polonistik nicht als isoliertes Diskursfeld zu verstehen. Im vorliegenden Kapitel ging es jedoch auch bei den `grenzgehenden`Untersuchungen vor allem um die Anbindung an westliche Theorietraditionen, während ich die allgemeinere Kontextualisierung der untersuchten Monographien im kulturellen und soziopolitischen Feld erst in Kapitel 6 unternehme. Insgesamt habe ich hier versucht, die Mechanismen der Anbindung und Abgrenzung als poetologische Verfahren zu lesen und dabei die Selbstpositionierungen der feministischen Kritikerinnen in - oft unterschiedlich konstruierten - feministischen Genealogien zu bestimmen. Als prägnantestes Beispiel habe ich die Ein- und Ausgrenzung der freudschen Psychoanalyse untersucht, welche in den feministischen Texten der Polonistik der 1990er Jahre als eine Art abject umrissen werden kann. Dabei habe ich festgestellt, dass das literarische Untersuchungsmaterial der feministischen Kritik teilweise die Funktion von ideengebenden und analytischen Texten einnimmt. Im nächsten Kapitel möchte ich deshalb diese Thematik aufnehmen und die in der feministischen Polonistik analysierte Literatur als intertextuelles Bezugsfeld untersuchen. Im Vordergrund stehen dabei die drei Aspekte des Lesens, Schreibens und Tradierens, oder anders gesagt: wie die feministische Kritik als spezifische Form der Lektüre den analysierten Text als Ausdruck eines marginalisierten Schreibens versteht, und welche Zusammenhänge des Tradierens sie außerhalb konventioneller Kanonisierung konstruiert.

201 I An dieser Stelle möchte ich mich bei Dorota Sajewska und Monika Rudaś-Grodzka bedanken, die mich auf diese Spur geführt und deren Relevanz für die feministische Entwicklung in Polen betont haben. Vgl. für das besprochene Phänomen auch Łebkowska: Czy ’płeć‘ może uwieść poetykę, S. 82, 92. 


\section{Literatur und Geschlecht}

Im vorliegenden Kapitel möchte ich die Texte der feministischen Kritik der 1990er Jahre in Polen im Hinblick auf ihren Miteinbezug des literarischen Materials diskutieren. Wie im vorhergehenden Kapitel festgestellt, inszenieren einige Kritikerinnen ihr Material als Träger bestimmter Ideen, etwa als der Psychoanalyse Freuds historisch vorgelagerte psychologische Studien. Im Folgenden möchte ich den Fokus stärker auf die literarisch-intertextuelle Tradierung von Ideen, Theorien oder Verfahren im polnischen Kontext feministischer Kritik lenken. Dabei zeichnen sich grundsätzlich drei Aspekte ab: Erstens bezieht die feministische Polonistik die bisherige Rezeption der von ihr untersuchten Texte mit ein, wobei diese oft als Kontrastpunkt zur feministischen Perspektive gesetzt wird. Im Zentrum steht dabei die Frage nach Beurteilungskriterien und deren diskursiver Einbettung. Die feministischen Monographien versuchen, einen anderen, dezentralen, weiblichen Blick auf die literarischen Texte zu werfen. Diesen Aspekt, in dem die >Deutungshoheit über literarische Texte verhandelt wird, fasse ich unter dem Begriff der Rezeptionskritik zusammen.

Eng damit verknüpft ist der zweite Aspekt, der sich um die Frage nach der Spezifik `weiblichen Schreibens` dreht. Im Zuge der `Neubewertung ` der untersuchten literarischen Texte diskutiert die feministische Kritik die Problematik eines vergeschlechtlichten Schreibens. Dabei unternehmen einige Polonistinnen den Versuch, ‘weibliche Literatur jedoch insbesondere aufgrund des (fragwürdigen) Zusammenhangs von der Geschlechtlichkeit der >Autorin`/des >Autors` und des Texts nicht schlüssig entschieden werden kann. Dennoch verhandelt die feministische Polonistik bestimmte inhaltliche und formale Aspekte weiblichen Schreibens und stellt daraus eine Art Instrumentarium der Weiblichkeit zusammen.

Unter dem dritten Aspekt untersuche ich, wie die feministischen Kritikerinnen im Hinblick auf die Erkenntnis der Marginalisierung weiblichen Schreibens mit der Frage nach einer Tradierbarkeit umgehen. Dabei geht es insbesondere um die Kontaktaufnahme zwischen Gegenwart und Vergangenheit, da die sweiblicher literarische Tradition als fragmentarisch oder gänzlich unterbrochen angesehen wird. Diese Thematik gewinnt gerade im Hinblick auf feministische Anknüpfun- 
gen in den polnischen 1990er Jahren eine Dringlichkeit, als die Zeit vom Zweiten Weltkrieg bis zum Beginn der demokratischen Transformation von 1989 als Vakuum in Bezug auf Äußerungen des Weiblichen interpretiert wird. ${ }^{1}$

Alle drei Aspekte intertextueller Bezugnahme weisen implizit und explizit Herangehensweisen an den literarischen Kanon einerseits und die literarische Konvention bestimmter Epochen andererseits auf. Die feministische Kritik der polnischen 1990er Jahre stellt sich somit auch die Frage, inwiefern feministische Perspektiven eine Revision und Pluralisierung der literarischen Konvention und Rezeption anstreben, und inwiefern eine selbstbestimmte marginale Position und Tradition erstrebenswert sei.

\subsection{ReZEPTIONSKRITIK}

Die Rezeptionsgeschichte ist für das Verständnis weiblicher Literatur und generell für die Tradierung literarischer Diskurse richtungsweisend. Sie steht in Form publizistischer Literaturkritik und literaturgeschichtlicher Untersuchungen als Teil des kulturellen Diskurses neben dem eigentlichen Text und bestimmt dessen aktuelle Lesart historisch mit. Gleichzeitig organisiert sie durch Kanonisierungsprozesse literarischer Werke das kulturelle und historische Selbstverständnis einer Kulturnation mit. Dieses Thema habe ich am Beispiel marxistischer Neulektüre und der Ermächtigungsprozesse des literaturhistorischen Editors Pigoń in Kapitel 3 bereits angeschnitten. Im Verlauf der Zeit und mit dem Wandel wissenschaftlicher und kultureller Paradigmen kann sich die Auslegung eines Werkes oder der Ein-/Ausschluss aus dem literarischen Kanon verändern.

An diesem Punkt setzt die feministische Literaturwissenschaft an. Sie weist auf den Interpretationskontext jeglicher Lektüre hin und zeigt auf, wie Deutungen literarischer Werke vom jeweils vorherrschenden Diskurs geprägt sind. Die literaturwissenschaftliche Arbeit der feministischen Kritik ist somit oft auch eine Auseinandersetzung mit einer männlich-hegemonial geprägten Rezeption. Sie stellt eine diskursive Marginalisierung des Weiblichen in der Literatur und weiblicher literarischer Tätigkeit in patriarchalen Gesellschaften fest, deren Grundstrukturen sie als ideologisch dekonstruiert. Als Spezialfall dieser Rezeptionskritik kann das »reading among women $\aleph^{2}$ gelten, das weibliche Texte der männlichen Rezeption zu entreißen versucht und im Sinne einer weiblich-solidarischen Position eine rangemessenere Sichtweise auf das Material entwickelt.

Im Folgenden untersuche ich die feministischen Texte der polnischen 1990er Jahre unter dem Aspekt der Rezeptionskritik. Die feministische >Rezeptionskritikı ist dabei nur unter Hilfskonstruktionen von der Arbeit am Primärmaterial

1 I Vgl. Borkowska: ’Komandosi‘; dies.: »Emigrantki (2)«, in: Kresy 17 (1994), S. 182-184, hier S. 184; Magnone: Die polnischen Gender Studies, S. 369f.

2 I Majbroda: Feministyczna krytyka, S. 147. 
unterscheidbar, da die literaturwissenschaftliche Arbeit stark intertextuell ausgerichtet ist und zu einem großen Teil aus dem Abwägen, Kombinieren und Dekonstruieren bereits bestehender kultureller Deutungen besteht. Dennoch möchte ich hier zunächst auf die Bezugnahme der feministischen Kritik auf die Rezeption fokussieren und das zugrundeliegende literarische Werk solange außer Acht lassen - soweit dies überhaupt möglich ist. Es geht mir darum, zu beobachten, wie die feministische Arbeit mit den Rahmungen umgeht, die der kulturelle Diskurs um einen bestimmten Text oder um literarische Konventionen herum legt; und wie sie diese Rahmungen aufzuheben, zu durchbrechen oder zu ergänzen versucht. In diesem Kontext wird es auch um Fragen der Subjektivität und Objektivität gehen - inwiefern wird versucht, einer 'Wahrheit auf den Grund zu gehen oder `Gerechtigkeit ‘ herzustellen? Werden bestehende Rezeptionsmuster als `falsch` abgelehnt oder durch feministische Perspektiven eher ergänzt?

Zunächst stelle ich die Rezeptionskritik Iwasióws und Janions in den Vordergrund, anhand deren stärker revisionistischen Vorgehens ich ihre feministische Dezentrierung des $>$ Rezeptionskanons« nachzeichnen möchte. Den primär auf das weibliche Schreiben ausgerichteten Zugang Kraskowskas, Borkowskas und Kłosińskas untersuche ich schließlich stärker unter dem Gesichtspunkt des »reading among women«. Gemeinsam ist allen Ansätzen die Kontrastsetzung oder gar Abgrenzung zu bisherigen Rezeptionsweisen, womit anstelle einer positiven Anbindung eine Genealogie ex negativo, als Abweichung, geschaffen wird. In dieser Loslösung manifestiert sich oft auch die jeweilige Stossrichtung der eingesetzten feministischen Verfahren.

\subsubsection{Den Zeitgeist dekonstruieren}

Die feministischen Positionen in der Literaturwissenschaft setzen sich nicht nur in Bezug auf die Rezeption weiblichen Schreibens kritisch mit literaturhistorischer Tradierung auseinander. Es gilt allgemein, normative Rezeptionstraditionen aufzubrechen und einer marginalen Lesart Raum zu geben. Dabei weisen feministische Arbeiten auf Verstrickungen im Machtdiskurs hin, vor denen auch literaturwissenschaftliche oder -kritische Texte nicht gefeit sind. Das Aufzeigen der Zusammenhänge von kulturpolitischen Diskursen und der darin gefangenen Rezeption eines literarischen Texts steht somit als Anfangspunkt einer feministischen Rezeptionskritik.

Diese Strategie wendet Iwasiów in ihrer Revision der bisherigen Rezeption Odojewskis an. Sie zeigt auf, wie die Kritiken in der Volksrepublik vom Zeitgeist geprägt waren und vorgefertigte, auf den existentialistischen Charakter der Texte Odojewskis verweisende Auslegungsmuster als `Asyl dienten, um einerseits eine »intellektuelle Haltung « zu beweisen und andererseits »ideologische Auseinan- 
dersetzungen zu umgehen «³ ${ }^{3}$ Den Grund für diese vereinfachte `Erklärung` der Texte sieht Iwasiów im wissenschaftspolitischen Klima der damaligen Jahre. Dies gelte umso mehr, als die Texte Odojewskis sich weder formell noch inhaltlich dem »allgemein anerkannten Wertesystem « ${ }^{4}$ fügten und für die Rezeption somit ein potentielles Gefahrenquell darstellten. Das `Rahmen ‘ der Romangeschehnisse als Existentialismus und deren Enthistorisierung und -politisierung bedeutete somit laut Iwasiów ein Hinarbeiten auf die eigene politische Sicherstellung der Rezensierenden.

Iwasiów verweist auf das Phänomen zeitgeistlicher Einbettung der Kritiken vor dem Hintergrund sozialistischer $»$ Kulturideologie ${ }^{5}$, die zu einem stärkeren und für das rezensierende Individuum dringlicheren Normierungsdruck führte. Die Tatsache, dass der/die Rezensent/in mit der Kritik literarischer Werke auch die eigene Position im kulturellen Diskurs verhandle, gelte jedoch generell, wie Iwasiów entlang dekonstruktivistischer Ansätze argumentiert. Diese machten darauf aufmerksam, dass sich ein Text nie völlig aus seinem Kontext lösen könne und immer ideologisch motiviert sei: »Die damalige, ideologische Lektüre entschuldigt übrigens der Dekonstruktivismus, der den historischen und lokalen Aspekt jeder Interpretation betont « $^{6}$, schreibt Iwasiów.

Gleichzeitig hält dies die feministischen Kritikerinnen - Iwasiów ebenso wie Janion, Borkowska, Kłosińska und Kraskowska - nicht davon ab, diesen »historischen und lokalen Aspekt jeder Interpretation « in den Vordergrund zu kehren und damit die postulierten Urteile zu historisieren und anfechtbar zu machen. Diese Dekonstruktion der Rezeptionstradition geht bei Iwasiów einher mit der Gegenüberstellung ihrer eigenen, ebenso »ideologischen« Lektüre als Frau. ${ }^{7}$ Dabei spielt für Iwasiów der Begriff des Randes oder der Grenze eine wichtige Rolle: Sie verbindet ihre Lektüre thematisch mit dem untersuchten Material, dessen Handlung sich in den zivilisatorischen Randgebieten der Kresy abspielt. Ihre eigene Lektüre soll ebenso eine Randposition einnehmen und die Dezentralität ihrer Perspektive betonen: »Die Interpretation des Schaffens Odojewskis, die ich vorschlage, hat einen supplementären und appendixhaften Charakter. Sie ist marginal, lokal und auf vieldeutige Art zum Grenzland gehörig [kresowa]. Sie verortet sich am Rande dessen, was als grundlegende, umfassende, zentrale Lesart gilt. ${ }^{8}$

3 I Iwasiów: Kresy, S. 43: »intelektualną postawę«; »uniknąć roztrząsań nieuchronnie ideologicznych."

4 | Ebd.: "powszechnie przyjętego systemu wartości«.

$\mathbf{5}$ । Ebd.: »ideologii kulturalnej«.

6 | Ebd., S. 32: "Ówczesną lekturę, lekturę ideologiczną, rozgrzesza zresztą dekonstruktionizm, akcentując historyczny i lokalny aspekt każdej interpretacji."

7 । Vgl. ebd., S. 21.

8 | Ebd., S. 7: »Interpretacja twórczości Włodzimierza Odojewskiego, jaką proponuję, ma charakter suplementarny i apendyksowy. Jest marginalna, lokalna i w wieloznaczny sposób kresowa. Ulokowana na obrzeżach tego, co uchodzi za odczytanie zasadnicze, całościowe, centralne.« 
Diese Worte deuten darauf hin, dass Iwasiów die vorhergehende Forschung aus einer differenten Perspektive vor allem ergänzt. Es zeigt sich aber, dass Iwasiów durchaus auf eine Dekonstruktion der von ihr als einseitig, verkürzt und ungenau empfundenen »existentialistischen « Auslegung abzielt. Einzelne Rezeptionstexte beurteilt Iwasiów besonders kritisch: »Ich übergehe die von Ignoranz und Kompetenzmangel zeugende, fehlerhafte Rekonstruktion der Handlung « ${ }^{9}$, äußert sie etwa über eine Rezension. Fehler in der Handlungsdarstellung verweisen für Iwasiów auf Oberflächlichkeit und einen Unwillen zur genauen Lektüre und disqualifizieren die betreffende Rezeption als bloße Reproduktion vorbestimmter Urteile.

Die Offenheit der Texte Odojewskis und deren Durchlässigkeit untereinander in Form von mehrperspektivischem, fragmentarischem Erzählen, dessen Handlung in mehreren Romanen repetitiv beleuchtet wird, bereite der auf "sozrealistischen Axiomen« beruhenden Kritik laut Iwasiów unüberwindbare Probleme. »Der Fehler liegt [...] in der generellen Annahme, dass irgendetwas eine endgültig abgeschlossene Einheit bilden könne. Es ist somit nicht so sehr ein axiologischer als ein epistemologischer Fehler. ${ }^{10}$ Iwasiów sieht das Scheitern der bisherigen Kritik darin, dass diese die Texte als abgeschlossenes, kohärentes Ganzes lese.

Diesem epistemologischen Vorgehen der Suche nach der »abgeschlossenen Einheit« stellt sie ihre eigene Überzeugung entgegen, dass ein Text niemals abgeschlossen sein kann. Damit demonstriert Iwasiów ihr eigenes Einschreiben in eine poststrukturalistische Denktradition. Die »Unabgeschlossenheit « setzt Iwasiów allerdings nicht mehr explizit in die Klammern einer »ideologischen « Annahme, womit diese in ihrem Text die Stelle der epistemologischen >Wahrheit übernimmt. Hier liegt denn auch das Grundproblem von Iwasióws Odojewski-Text. Dieser ist von gegenläufigen Bewegungen geprägt, wie sich etwa in der folgenden Formulierung offenbart: »Ich vertraue aber darauf, dass die weibliche Lektüre den Text dem Ideal annähert. «" Das Bestreben einer feministisch motivierten De- und Rekonstruktion beschreibt Łebkowska in ihrer Rezension zu Iwasióws Monographie als Grund für die innere Widersprüchlichkeit des Texts. Sie sieht den Hauptwiderspruch in der »unverhüllten, ja gar manifestierten Ideologie, die die Lektüre begleitet. «12 Tatsächlich scheint die Arbeit Iwasióws durch ein inneres Spannungsverhältnis selbst fragmentarisiert. Dabei geht es aber meines Erachtens weniger um den Widerspruch einer dekonstruktivistischen Herangehensweise in Verbindung mit einer feministischen Ausrichtung, als um die gegenläufige Bewegung einer marginalen Lektüre sam Rand , die zum `Ideal und somit zum Zentrum

9 | Ebd., S. 39: „Pomijam świadczącą o ignorancji i braku kompetencji błędną rekonstrukcję fabuły«. 10 | Ebd., S. 32: "socrealistycznych pewników«; »Błąd nie tkwi więc w unikaniu ideologii, a w generalnym założeniu, iż cokolwiek może stanowić ostatecznie domkniętą całość. Jest to więc błąd nie tyle aksjologiczny, co epistemologiczny."

11 I Ebd., S. 21: »Ufam jednak, że kobieca lektura zbliża tekst do ideału.«

12 | Łebkowska: Kobieta czytająca, S. 187: »nieskrywaną, czy wręcz manifestowaną ideologią towarzyszącą odczytaniu tekstu." 
strebt. ${ }^{13}$ Die marginale feministische Lektüre, so könnte man Iwasióws Aussage verstehen, soll die Erkenntnis auf eine hermeneutische Weise weiterbringen und das intertextuelle Geflecht der Kresy gleichsam vervollständigen. Während Iwasiów mit ihrer Lektüre zwar eine >Randbemerkung intendiert, stellt sie diesen Rand gleichsam ins Zentrum. Damit verdrängt sie auch die bisherige Rezeption an die Ränder resp. grenzt diese teilweise als `fehlerhaft‘ aus. Iwasióws Umgang mit bisherigen Rezeptionsansätzen ist von einem vollständigen Überschreiben der randeren< Positionen geprägt.

Iwasiów schreibt ihre Arbeit noch auf einer weiteren Ebene in ein Verhältnis von Rand und Zentrum ein, ohne dies konkret zu thematisieren. Neben der bisherigen Rezeption kann auch der Diskurs des postsozialistischen Polens als Kontext ihres eigenen Texts betrachtet werden. Dieser befindet sich in einer Phase der (nationalen) Identitäts(re)konstruktion und bildet neue Narrative heraus, die sich spezifisch gegen die Zeit des sozialistischen Systems abgrenzen. Iwasióws Dekonstruktion der Rezeption Odojewskis in der Volksrepublik kann als Methode des ¿Zentrums` gelten, da sich Iwasiów so in die allgemeine Abkehr von allem, was mit der `Kommune in Verbindung gebracht wird, einreiht. Gleichzeitig bildet die feministische Lektüre in diesem Kontext eine umstrittene und marginaliserte Lektüre, beginnt sich aber in den 1990er Jahren als literaturwissenschaftliches Instrument herauszubilden.

Iwasiów operiert hier also nicht nur mit der feministischen Strategie der Rezeptionskritik und bezieht infolgedessen eine `Randstellung ‘. Ihr Verfahren kann gleichwohl als Strategie der Einschreibung in den postsozialistischen Diskurs gesehen werden. Dies zeigt sich beispielsweise in der Bedienung eines Narrativs der Revalorisierung historischer Ereignisse, das nach dem Ende der Volksrepublik an Bedeutung gewinnt. Iwasiów hält den Kritikern aus den 1950er und 1960er Jahren vor, mit ihrer existentialistischen Auslegungsart den Kresy-Zyklus Odojewskis enthistorisiert und die darin verhandelten Konflikte nicht mehr als relevante Größe behandelt zu haben. "Ein entfremdeter Protagonist ohne Biographie - wie sie ihn im Schaffen des Schriftstellers sahen - musste an keine konkreten Dramen, keine von der Nation erlebte Tragödie erinnern. ${ }^{14}$ Diese Aussage könnte auch als Versuch gelesen werden, die Texte Odojewskis für eine identitäre Lektüre zu

13 I Wie Krzysztof Pstrong in seiner Rezension von Kresy w twórczości Włodzimierza Odojewskiego feststellt, ist diese gegenläufige Bewegung von Rand und Zentrum auch der Unmöglichkeit geschuldet, an einen Anfang oder zu einem svorinterpretatorischen Stadium zu gelangen: »Deshalb wird dieser 'Versuch<, der zur Nichtentdeckung der Vor-Wahrheit verdammt ist und der nur als Interpretation der Interpretation doch das Stigma der Nichterfüllung auf sich tragen wird, am Rand ausgetragen.«Pstrong, Krzysztof: »Próba niezupełnie feministyczna«, in: Teksty Drugie, Feminizm po polsku (1995), S. 187-195, hier S. 189.

14 I Iwasiów: Kresy, S. 43: »Bohater wyobcowany, bez biografii - jakiego widzieli w twórczości pisarza - nie musiał się kojarzyć z żadnymi, konkretnymi dramatami, z żadną doświadczoną przez naród tragedią." 
erschließen, die sich für die in der Volksrepublik diskursiv >verdrängteく Vergangenheit der polnischen Nation interessiert, was gleichsam als Bewegung von einer Randposition hin zum Zentrum der Gesellschaft erscheint.

Die Lektüre und Rezeptionskritik Iwasióws kann also als Versuch der doppelten Aneignung - einer ffeministisch--persönlichen und einer postsozialistischen - verstanden werden. Dabei legt Iwasiów ihre Lektüre der dezentralen und marginalisierten Texte Odojewskis als ebenso dezentral und marginal motiviert aus, was jedoch, wie hier gezeigt werden konnte, immer wieder von zentripetalen Bewegungen durchbrochen wird. Iwasióws feministische Rezeptionskritik ist jedoch insofern spannend, als sie auf die multivektoriellen Strukturierungsmechanismen von Diskursen hinweist und dabei nicht etwa 'Weiblichkeit allein als Merkmal einer Marginalisierung akzeptiert.

Die Ansätze Janions sind in dieser Hinsicht denjenigen Iwasióws nicht unähnlich, als beide ihre Rezeptionskritik nicht allein auf die Kategorie des Geschlechts reduzieren. Janions Zugang ist auch über ihre sfeministischen` Texte hinaus eng verknüpft mit den Aspekten von Rezeption, Auslegung und Tradierung, mithilfe derer sie ihre spolyphonen< Arbeiten modelliert. Hier liegt auch der in Bezug auf die Rezeptionskritik deutlichste Unterschied zur Strategie Iwasióws: Während diese in ihrer Dissertation die bisherige Rezeption Odojewskis gleich zu Beginn durch ihre eigene Randposition sverdrängtı, verflicht Janion in der Regel die Rezeptionsansätze derart miteinander, dass ihre eigene Position nur in der Struktur des Geflechts durchscheint.

Etwas anders liegt der Fall jedoch in Janions Rezeptionskritik am bereits thematisierten Beispiel von Komornicka/Włast (siehe Kapitel 3.3). Hier greift Janion aktiver in die Argumentation ein, als eine Gegenposition zu der kritisierten $>$ Rezeptionsverweigerung Pigońs überhaupt erst herausgearbeitet werden muss. Ähnlich wie Iwasiów zeigt Janion in der Studie von 1979 auf, wie stark die bisherigen Urteile in ihrer eigenen Zeit verstrickt sind. Janion nimmt gegenüber diesen als sveraltet inszenierten Positionen eine historisch fortgeschrittenere Haltung ein, in die sie auch ihre Leser/innen integriert. Ihre Rezeptionskritik besteht primär darin, die sozionormativen Urteile Pigońs und Oszackis sich selbst dekonstruieren zu lassen.

Dies erreicht Janion, indem sie insbesondere Oszacki direkt zitiert und in der Folge dessen Aussagen mit einer raufgeklärteren` und liberaleren Sichtweise ihrer selbst und der performativ miteinbezogenen Leser/innen konfrontiert. Schlüsselelement dieses Verfahrens ist der ironische Einschub Janions, der die vorgetragenen Urteile Oszackis ins Lächerliche zieht. So entwerfe Oszacki einerseits ein essentialisierendes Konzept einer "Frauenseele«, dem Komornicka/Włast nicht entspreche; Letzteres konstatiert Oszacki mit einem mitfühlenden Verständnis, das gleichzeitig seine zur Bewertung und Bevormundung berechtigende Position unterstreicht. ${ }^{15}$ Andererseits transponiere er sein Urteil anhand einer verkürzten

15 | Vgl. Oszacki: Spowiedź niedorodzonej, S. 349. 
Lektüre eines von inneren Spannungen geprägten Texts auf die historische Figur der Autorin/des Autors. Die ironische Reaktion Janions auf Oszackis Urteil zeigt, wie entschieden sie sich von einer solchen Moralisierung distanziert und überhaupt den Erkenntniswert von Oszackis Text infrage stellt: „Wahrhaftig, man weiß nicht, was bestaunenswerter ist: die normative Vorstellung der `Frauenseele oder aber die Unkenntnis Komornickas und ihres Werks. « ${ }^{16}$

Das `Gespräch`mit Oszacki, das Janion hier vordergründig führt, ist letztlich ein verweigertes Gespräch; der Dialog findet auf einer synchronen Ebene zwischen Janion und ihrem Leser/ihrer Leserin statt, die durch eine gemeinsame >Rationalität k konstituiert wird. Der besprochene Text selbst jedoch erscheint als rational nicht argumentationsfähig. Somit re-inszeniert Janion die Sprechweise Pigońs und Oszackis >über Komornicka, indem sie Oszacki in einem ähnlichen textuellen Verfahren der selbstbestimmten Stimme beraubt. Mit diesem Ausschluss Oszackis aus dem Dialog öffnet sich hingegen Raum für die Integration Komornickas/Własts.

In ihrer zweiten Studie zu Komornicka/Włast von 1996 verweist Janion neben den mangelhaften Argumenten der Rezeption stärker auf die Definitionsmacht des Editors. «Dass Pigoń kein einziges Gedicht aus der Xięga poezji idyllicznej veröffentlichte [...], bezeugt, dass er [...] eigenmächtig die Obhut des literaturhistorischen Kanons übernahm. ${ }^{17}$ Janion kehrt die Macht des wissenschaftlichen Diskurses hervor, dessen Urteil über das Bestehen oder Nichtbestehen literarischen Schaffens entscheidet. 1996 verweist Janion nun auch eindeutiger auf das Verfahren der Stimmgebung und -verweigerung:

»Wie bereits erwähnt, ersetzte Stanisław Pigoń in der archivalischen Publikation die Stimme der Dichterin durch die Stimme des Arztes. Im Grunde äußert sich der Arzt an ihrer Stelle, an der Stelle der Frau. Denn in seinem Urteil ist es gerade relevant, dass Komornicka eine Frau ist - eine Verirrte $[\ldots] . \ll^{18}$

Im Vordergrund steht nun die diskursive Fremdbestimmung der Frau und Wahnsinnigen. Die beiden Männer der Wissenschaft, Pigoń und Oszacki, sprechen anstelle der betroffenen Frau - Komornicka -, die nicht zu Wort kommt und dadurch gerade als solche bestätigt wird. Die Zensur des włastschen Werks diente damit auch der Aufrechterhaltung der symbolischen Geschlechterordnung. Diese fehlende Respektierung der Selbstdefinition und das Überwerfen eines moralischen

16 I Janion: Kobiety, S. 223: „Doprawdy, nie wiadomo, co bardziej podziwiać: normatywną ideę ’duszy kobiecej‘ czy też nieznajomość Komornickiej i jej utworów.«.

17 | Ebd., S. 304: »Nieopublikowanie żadnego z wierszy z Xięgi poezji idyllicznej [...] świadczy, że Pigoń [...] sam sprawował pieczę nad kanonem historii literatury.«

18 । Ebd., S. 303f.: "Jak już o tym była mowa, Stanisław Pigoń w publikcaji archiwalnej z roku 1964 głos Komornickiej jako poetki zastąpił głosem lekarza. Właściwie to lekarz wypowiada się za nią, za kobietę. Bo w jego ocenie ważne jest to, że Komornicka to właśnie kobieta - zbłąkana [...].« 
Korsetts sieht Janion besonders 1979 als Verfahren eines überholten Zeitgeists; 1996 betont sie die anhaltende patriarchale Komponente stärker.

\subsubsection{Reading among women}

Obwohl sich Włast selbst als Mann definierte, wurden er und sein Spätwerk einer Verdrängung unterworfen, die besonders oft die literarische Tätigkeit von Frauen betrifft. $\mathrm{Zu}$ dieser Feststellung der systematischen Marginalisierung weiblichen literarischen Schaffens kommt die feministische Strömung der Gynokritik. Diese interessiert sich ihrer »Projektgeberin « Showalter folgend für die »Ästhetik der Weiblichkeit in der Literatur und [die] Tradition der weiblichen Literatur ${ }^{19}$ im Rahmen eines männlich-hegemonialen Literaturparadigmas. Gynokritische Rezeptionskritik fokussiert somit auf die geschlechtliche Differenz der >Weiblichkeit und deren sandere Parameter als Ausgangspunkt der Revision von Rezeptionsverfahren. Eine solche Rezeptionsrevision bedeutet in Anlehnung an die Strategie des »reading among women«, wie es Majbroda vorstellt, die »Interpretation von Rezensionen [und] literaturkritischen Skizzen (meist männlicher Autorschaft), die dem sog. weiblichen Schaffen gewidmet sind $\aleph^{20}$, und erlaube es, deren $»$ im androzentrischen Prisma unsichtbare Charakteristiken und Inhalte $\ll^{21} \mathrm{zu}$ erfassen.

Die männliche Rezeptionstradition erscheint somit in der gynokritischen Revision als Kontrastmaterial, auf dessen Dekonstruktion und Widerlegung die feministische Argumentation aufbaut. Relevant ist hier, dass die geschlechtlichen Markierungen als binäre Pole der Wertung inszeniert werden: Für die männliche Kritik ist weibliche Literatur besonders dann `weiblich` (resp. als solche markiert) ist, wenn sie den (männlichen) Literaturkonventionen nicht entspricht. Umgekehrt ist für die feministische Revision gerade dann die männliche Kritik ımännlich oder `patriarchak , wenn sie sich abwertend über die `weibliche` Literatur äuBert und deren Diskrepanz zur Konvention als negativ in den Vordergrund stellt.

Die Formel des "reading among women« kann somit als Versuch gesehen werden, die negative männliche Rezeption zu dekonstruieren und die weiblichen Texte aus einer weiblichen Perspektive zu analysieren. Diese Haltung suggeriert gleichzeitig, dass eine Lektüre aus der Zentrumsposition auf die dezentralen, fragmentarischen Texte 'weiblicher $<$ Literatur nicht anwendbar sei und diesen deshalb nicht gerecht werden könne. ${ }^{22}$ Die gynokritisch arbeitenden Lektüren der feministischen Kritik der 1990er Jahre greifen oft zur Strategie, zunächst die >männliche`

19 I Kraskowska: Piórem niewieścim, S. 203: "projektodawczyni«; »estetyką kobiecości w literaturze i nad tradycją pisarstwa kobiecego".

20 I Majbroda: Feministyczna krytyka, S. 147.

21 । Ebd., S. 144.

22 I In gewisser Weise ordnet sich hier deshalb auch die Rezeptionskritik Iwasióws ein, die ein dezentrales Textkonglomerat mit einer dezentralen Lektüre verknüpft, in Abgrenzung zu den >Vereinheitlichungsbestrebungen der bisherigen Rezeption. 
Lektüre der zu untersuchenden Texte vorzustellen und diese als solche zu enthüllen - als männliche Lektüre, die ihre eigene Machtposition durch einen steten Prozess des Ausgrenzens des `Anderen` performativ herstellen und behaupten muss. Obwohl auch Iwasiów und Janion solche Verfahren anwenden, kann bei ihnen jedoch nicht von einem "reading among women" gesprochen werden: Iwasióws Referenzpunkt ist ein männlicher Autor, der zudem in ihrer Lektüre keine Rolle spielt, während Janion ihre eigene Geschlechtlichkeit kaum in den Vordergrund rückt und deshalb nur ansatzweise als >weibliche` Leserin verstanden werden kann.

Borkowska, Kraskowska und Kłosińska hingegen beziehen eine explizit >weibliche`Lektüreposition. Sie gehen mit der männlichen, spatriarchalen`Rezeption auch einig, dass weibliches Schreiben grundsätzlich eine Abweichung von der literarischen Norm darstelle und als asynthetisches, kleinräumiges, personalisiertes oder somatisches Schreiben (siehe 5.2) gefasst werden könne. Diametral unterscheiden sich jedoch die Wertungen der feministischen Forscherinnen und der >männlichen` zeitgenössischen Literaturkritik in Bezug auf die beobachtete Differenz.

Weshalb diese Differenz aus der männlich-zentralen Sicht negativ bewertet werde, erläutert Kraskowska: Der Literaturkritiker erwarte, dass sich eine Frau im bislang männlich geprägten Bereich der Literatur an die geltenden Regeln halte. "[D]ie Beteiligung der Frau an Wissenschaft und Kunst erscheint ihm als Teilnahme am männlichen Leben, was natürlich erfordert, sich an die männliche Weltsicht, die männliche Erkenntnisweise und Wirklichkeitsbeschreibung anzupassen. ${ }^{23}$ Mit der distinkten Herausbildung einer weiblichen Literaturströmung, die sich vom Modell des »Nacheiferns« (naśladować) ${ }^{24}$ emanzipiert und auf Differenz und Perspektivenwechsel setzt, sehe sich die etablierte Literaturkonvention hinterfragt. Problematisch werde dies insbesondere mit der Popularität weiblicher Literatur. "Die lärmigen, geschwätzigen und alles vereinfachenden Schriftstellerinnen erfreuen sich also einer Beliebtheit, die den männlichen Genies zukommen sollte. ${ }^{25}$ In Kraskowskas leicht spottenden Worten ist bereits der Konflikt ausgelegt, der sich auf einer auch emotionalen Ebene abspielt. Sie hält der männlich geprägten Literaturkritik deren eigene Trotzreaktion vor, die auf verletzten Gefühlen des Stolzes und der Einzigartigkeit basiere.

Kłosińska hingegen versucht die männlichen Reaktionen auf den weiblichen Text ernst zu nehmen und als Grundlage einer integrativeren Haltung gegenüber dem anderen Geschlecht zu behandeln.

23 । Kraskowska: Piórem niewieścim, S. 16: »udział kobiety w nauce i sztuce jawi mu się jako jej uczestnictwo w życiu męskim, wymagające, rzecz jasna, przystosowania się do męskiej postawy wobec świata, męskich sposobów rozpoznawania i opisywania rzeczywistości.«

24 । Vgl. ebd., S. 204.

25 | Ebd., S. 18: »Hałaśliwe, gadatliwe i upraszczające wszystko pisarki cieszą się więc poczytnością, która powinna przypaść męskim geniuszom." 
»Über das weibliche Schreiben zu schreiben heißt nicht, alles zu ignorieren, was Männer bisher zu diesem Thema gesagt haben, die diese >Weiblichkeit‘ mit Geringschätzung, Mitleid oder gar Verachtung fassten. Vielleicht lohnt es sich dennoch, aufmerksam zu lesen, was sie geschrieben haben? Alle von Metaphern hinterlassenen Spuren sammelnd: die Spuren von Traumata und Ängsten. « ${ }^{26}$

Kłosińska begreift die tendenziöse Ausrichtung vieler Rezensionen als Ausdruck sich verschiebender, instabiler Geschlechternormen. Die Ausgrenzung des >Weiblichen aus der Literatursphäre zeige jedoch eine konträre Wirkung, nämlich, dass sich dieses noch stärker als un-heimliche `Fremdheit bemerkbar mache: »Die Kritik streicht aus ihrem Interessensfeld das, was als Weibliches anders, fremd ist. Und das, was fremd ist, weckt Unruhe, gebiert Furcht, wird also ausgeschlossen, exorziert [...]. « ${ }^{27}$ In Anlehnung an Showalter beschreibt Kłosińska hier implizit einen Effekt der Abjektivierung.

Kłosińska erkennt in den zeitgenössischen Kritiken Argumente, die ähnlich wie die freudsche Psychoanalyse das Weibliche vor allem über die Negativität definieren: »Definiert über den `Mangel«, wird der weibliche Text mit dem Defekt, dem Gebrechen, der Unvollständigkeit (Kastration?) identifiziert. ${ }^{28}$ Dabei stellt Kłosińska auch die Frage nach einer essentiellen oder `zugeschriebenen`Charakteristik des weiblichen Texts: »Das Problem des Standpunkts lässt sich nicht umgehen: Ist der weibliche Text fragmentarisch? Oder ist seine Fragmentarizität Effekt der Beurteilung durch den Kritiker? « ${ }^{29}$ Diese Frage lässt Kłosińska insofern offen, als sie den weiblichen Text als Ausdruck einer fragmentarisierenden männlich-normativen Ausgrenzung der Weiblichkeit begreift; die Fragmentarizität sei also gegeben, gründe aber im patriarchalen Kontext. Gleichzeitig suggeriert Kłosińska mit Irigaray und Lemoine-Luccioni die Möglichkeit eines anderen, ‘angemesseneren Blicks auf die weibliche Literatur. ${ }^{30} »$ Für wen präsentiert sich denn die Realität in weiblichen Romanen als banal? Für die Weberin? Oder für den Kritiker? « ${ }^{31}$ Kło-

26 । Kłosińska: Ciało, S. 275: »Pisać o kobiecym pisaniu, to nie znaczy zignorować wszystko, co dotąd na ten temat powiedzieli mężczyźni, ujmując ową 'kobiecość z lekceważeniem, politowaniem lub pogardą. Może jednak warto przeczytać uważnie, co napisali? Zbierając wszelkie ślady, jakie zostawiły metafory: ślady urazów, lęków."

27 । Ebd., S. 19: »Krytyka wykreśla z pola swego zainteresowania to, co jako kobiece jest inne, obce. I co, jako obce, wzbudza niepokój, rodzi lęk, więc zostaje wykluczone, wyegzorcyzmowane [...].«

28 । Ebd., S. 16: „Definiowany przez ’brak‘, tekst kobiecy zostaje utożsamiony z defektem, ułomnością, niekompletnością (kastracją?)."

29 । Ebd., S. 17: „Nie da się uniknąć problemu punktu widzenia: czy tekst kobiecy jest fragmentaryczny? czy jego fragmentaryczność jest efektem oceny krytyka?«

30 I Vgl. ebd., S. 17f.; siehe auch Irigaray: Ce Sexe, S. 29; Lemoine-Luccioni, Eugénie: Partage des femmes (= Le Champ freudien), Paris 1976.

31 I Kłosińska: Ciało, S. 19: „Dla kogo bowiem rzeczywistość w powieściach kobiecych przedstawia się jako banalna? Czy dla prządki? Czy dla krytyka? "Da die Übersetzung von prządka, die »Spinnerin« als Fachberuf, im Deutschen irreführend sein kann, habe ich diese hier im Fließtext 
sińska verweist auf die Möglichkeit divergierender weiblicher Rezeptionsmuster, die aus der patriarchalen Ausgrenzung des Weiblichen resultieren, den weiblichen Text aber für eine weibliche Rezeption öffnen.

Kraskowska und Kłosińska machen die negativen Kritiken weiblicher Literatur zumindest teilweise daran fest, dass sich das >Weibliche patriarchalen Literaturparadigma anpasse, sondern daraus ausbreche. Dieser $>$ Ungehorsam` wird von den beiden Polonistinnen grundsätzlich positiv gesehen, was nicht heißt, dass sie das konkrete Werk 'weiblicher gelungen betrachten. Unabhängig von einer ästhetischen Wertung betonen sie jedoch die Notwendigkeit einer divergenten Perspektive, die das weibliche Erleben nicht nur beschreiben, sondern mit literarischen Verfahren auch erfahrbar machen soll.

Die ablehnenden männlichen Rezensionen interpretieren beide Forscherinnen als Verteidigungsversuch der Machtposition. Sie stünden im Kontext der Missgunst über den publizistischen Erfolg der Frauen als Schriftstellerinnen und einer latenten Furcht vor sozialen Umbrüchen und weiterer Destabilisierung eingespielter Geschlechterrollen. Kłosińska und Kraskowska verweisen ebenfalls darauf, dass negativ gewichtete Rezensionen oft nicht Resultat einer genauen Lektüre des untersuchten Texts seien, sondern diesen im Kontext historisch-diskursiver Normen und Paradigmen vorschnell und aufgrund moralisch-ideologischer Unvereinbarkeiten verwerfen. Die feministische Kritik Kraskowskas und Kłosińskas hingegen versucht, die >weibliche` Literatur aus einer Position der Nähe neu zu betrachten und als - besonders bei Kraskowska eher essentialistisch verstandenes - weibliches Identitätsangebot fruchtbar zu machen.

\subsubsection{Affektive Lektüren, vorgefertigte Urteile}

Im Folgenden komme ich detaillierter auf den affektiven Gehalt literarischer Rezeption und die feministische Verschiebung hin zu einer textnahen Lektüre 'weiblicher Literatur zu sprechen. Wie Kraskowska und Kłosińska feststellen, bedienen sich oberflächliche Lesarten ’weiblicher`Texte gerne rhetorischer Mittel wie der Parodie oder Karikierung. Generell stellt Kraskowska fest, dass die männliche Kritik die weibliche Literatur mit wenig Ernsthaftigkeit behandle und der literaturkritische Text eher als Plattform individueller Chauvinismen diene. Sie weist in den Kritiken »merkwürdige« Argumente nach, die mit Mitteln wie einem »kümmerlichen Scherz« oder dem »äußerst pfiffigen« rhetorischen Kniff der suggestiven Auslassung dem zeitgenössischen Misogynismus zudienten, ohne dabei die »Redlichkeit des Kritikers « ${ }^{32}$ aufs Spiel zu setzen.

mit der »Weberin « (tkaczka) ersetzt und so eine Abflachung der mythologischen Dimension in Kauf genommen.

32 I Kraskowska: Piórem niewieścim, S. 16: »0sobliwe«; S. 18: »marny żarcik«; S. 21: »nad wyraz przemyślny«; »rzetelność krytyka«. 
Der diskursive Ausschluss der Weiblichkeit aus einer vergeistigten, rationalen Kreativität führt laut Kłosińska und Kraskowska dazu, dass das Gros der Literaturkritiker die weibliche Literatur im Kontrast zum (männlichen) Genius nur als »Handwerk« interpretiere, dazu noch nicht selten als »erbärmlich geschriebenes $\aleph^{33}$. Die inhaltliche Zuwendung weiblicher Literatur zu Alltagshandlungen finde ihren Niederschlag auch in der Wortwahl der zeitgenössischen Rezeption, wie Kłosińska schreibt: »herausexorzierte« Metaphern »verbauen` den Bereich weiblichen Schreibens. Die Frauen-Autorinnen [kobiety-autorki] sind demnach $>$ Spinnerinnen einer banalen Realität, , literarische Klageweiber` [...], und ihre Erzeugnisse sind `Früchte der Schreibmanie « ${ }^{34}$ Mithilfe dieser Metaphern werde weibliches Schreiben auf stereotypisch weibliche Handlungen und Zuständigkeitsbereiche im gesellschaftlichen Leben zurückgeführt und diesen gleichgeschaltet. ${ }^{35}$

"Das weibliche Schreiben wird in einer aus dem Kochbuch entlehnten Sprache besprochen. [...] Das Urteil der Kritiker ist klar. Die Kompetenzen einer Köchin, die die Zusammensetzung von Gerichten und deren Zubereitungsarten kennt, verwandeln sich in literarische Mängel, wenn frau die eine Kunst durch die andere ersetzen will. « ${ }^{36}$

Diese Beschlagwortungsstrategie suggeriere eine Inkongruenz von `natürlich weiblichen Betätigungsfeldern wie Kochen oder Spinnen mit der Tätigkeit des literarischen Schreibens. Neben Hausarbeitsmetaphoriken bedienten sich die Kritiker der Vorkriegszeit auch der Metaphorik von Schmutz und Reinheit. Hier sei das Bild der Ansteckung und Verschmutzung zentral, womit die potentielle Affektierung der Literaturkonvention durch die subversive weibliche Literatur angesprochen ist. Diese Befürchtung der Literaturkritik um die Wende und zu Beginn des 20. Jahrhunderts stellen sowohl Kraskowska wie auch Kłosińska fest. Kraskowska beschreibt die Reaktion eines Kritikers, der »mit Beunruhigung notiert, dass das weibliche Schaffensmodell in vielen Fällen einen ebenso großen Einfluss auf die Autoren männlichen Geschlechts ausübe, wie die smännliche` Literatur auf die Schriftstellerinnen des $>$ männlichen Typus $\triangleleft .{ }^{37}$

33 । Ebd., S. 16: »rzemiosło«; S. 163: »marnie napisanej«.

34 । Kłosińska: Ciało, S. 19: »wyegzorcyzmowane«; »zabudowujących obszar kobiecego pisania. Kobiety-autorki to zatem >prządki banalnej rzeczywistości<, słłaczki literackie‘ [...], a ich wytwory są ’płodami grafomanii<."

35 । Zum rhetorischen Einsatz von Metaphern siehe auch White: Tropics of Discourse.

36 I Kłosińska: Ciało, S. 20: „Kobiece pisanie omawia się, pożyczając język z książki kucharskiej. [...] 0sąd krytyków brzmi jasno. Kompetencje kucharki, która zna receptury potraw i sposoby ich przyrządzania, przekształcają się w wady literatury, jeśli kobieta zechce zastąpić jedną sztukę przez drugą."

37 | Kraskowska: Piórem niewieścim, S. 17: "z niepokojem odnotowuje, iż kobiecy model twórczości w wielu wypadkach wywiera równie duży wpływ na autorów płci męskiej, jak literatura ‘męska< na pisarki stypu męskiego< [...].« 
Kraskowska stellt mit der Reaktion des Kritikers fest, dass die intertextuellen Bezüge zwischen ‘weiblichem` und `männlichem`Schreiben nicht als einseitige Beeinflussung des Weiblichen durch das Männliche beschrieben werden können. Kłosińska formuliert diese Metaphorik so: »Frauen verunreinigen durch ihr Schreiben die Literatur, wandeln sie in einen Behälter für Abfälle (Müll) oder gar Exkremente (>Misthaufen $\triangleleft$ ) um. « $^{38}$ Deutlich wird in dieser Umschreibung des ,Verschmutzungs`bildes, dass die Literatur als gesamthafte Institution betroffen scheint. Dies erklärt die umso heftigeren und stärker mit affektiven Rhetoriken spielenden Reaktionen der Literaturkritik. Besonders betrifft dies die von Kłosińska untersuchte Schriftstellerin Zapolska, da ihr die zeitgenössische Literaturkritik einen übertriebenen Hang zum Naturalistischen, zu körperlichen Gebrechen und zur Verdorbenheit der Welt unterstellte. Kłosińska hingegen fasst dies als scharfsinniges Beobachten eines ansonsten nicht zu Wort kommenden Milieus weiblicher und sozial niedriggestellter Figuren.

Eine sensationslüsterne Fokussierung auf erotisch konnotierte Passagen sieht Kłosińska im Gegenteil bei den Kritikern: »Das Paradox der Lektüre Zapolskas liegt darin, dass sie dessen beschuldigt wird, was der Kritiker verübt, der auswählt und aus dem Text das Schauspiel der Entblößung des Körpers ausschneidet. « ${ }^{39}$ Gerade in der Hervorhebung und Verwerfung der ssexualisierten Romane Zapolskas versuchen, so Kłosińska, die Kritiker ihre eigene Erfahrung am Text zu vertuschen. So sei es nämlich das von Zapolska präsentierte ınackte` Wort, das - von Tabus behaftet - im Leser eine Beschämung und im Folgenden einen Prozess des Begehrens auslöse. ${ }^{40}$ Diese phantasmatische Wirkmächtigkeit des Textes auf den Körper des Rezipienten löse eine Abwehrhaltung aus, die sich in vernichtenden, auf einer affektiven Ebene vorgetragenen Kritiken niederschlage.

Die feministischen Kritikerinnen identifizieren die oberflächliche Lektüre entlang eines bereits vorgefertigten Leseschlüssels und die affektive Abwehrhaltung als eines der Probleme der Rezeption weiblicher oder marginalisierter Literatur. Während Iwasiów eine vorschnelle und verkürzte Abhandlung der Texte über das Raster des Existentialismus kritisiert, nimmt Kłosińska dasselbe Problem mit dem angeblich übermäßigen Naturalismus Zapolskas in Angriff. Auch diesen stellten die zeitgenössischen Kritiker als Mode dar, welche Zapolska aufgrund fehlender eigener literarischer Kreativität als Vorlage verwende. ${ }^{41}$ Mit der Feststellung bestimmter Motive und deren Interpretation entlang fixierter Deutungsvorlagen kartographiere die Literaturkritik Zapolskas Werk nur oberflächlich, ohne auf potentielle Textspezifika einzugehen. Dieses Reaktivieren vorgefertigter Lesemuster

38 । Kłosińska: Ciało, S. 22: »Kobiety pisząc zanieczyszczają literaturę, przekształcają ją w zbiornik odpadków (śmieci), a nawet odchodów (’gnojowisko‘).«

39 । Ebd., S. 276: »Paradoks lektury Zapolskiej polega na oskarżaniu jej o to, czego dokonuje krytyk, który wybiera, wycina z tekstu widowisko obnażania ciała."

40 I Vgl. ebd., S. 33.

41 I Vgl. ebd., S. $28 f$. 
nennt Kłosińska nach Barthes déjà-lu. ${ }^{42}$ Sie intendiert deshalb in Anlehnung an Miller, die Perspektive des déjà-lu zugunsten einer tiefgründigen, »dichten Lesart» oder overreading (nadczytanie) ${ }^{43}$ zu verwerfen.

Ähnlich argumentiert Borkowska, deren Rezeptionskritik hier als letzte vorgestellt werden soll. Im Fokus von Borkowskas Rezeptionskritik steht eine motivische Lesart, die Leben und Werk von Schriftstellerinnen des 19. Jahrhunderts einer patriotischen Schablone unterwirft (siehe Kapitel 6.2.4). Borkowska kritisiert nicht wie Kłosińska und Kraskowska die zeitgenössische Rezeption der von ihr untersuchten Texte, sondern primär die geisteswissenschaftliche Rezeption der 1980er und 1990er Jahre. Sie stellt eine svorgegebene patriotische Auslegung weiblicher Texte und Lebensentwürfe in Frage und plädiert dafür, die untersuchten Phänomene und Texte erst einmal `wörtlich zu nehmen.

Besonders verdächtig erscheint ihr die Einstimmigkeit der bisherigen Interpretationsansätze: »In dieser Sache herrscht eine seltsame Übereinstimmung der Meinungen. Sogar Kurkowska kapituliert [...]. $\aleph^{44}$ Borkowska greift zu geradezu martialischem Vokabular (»herrschen", »kapitulieren«), womit sie die diskursive Macht des etablierten Interpretationsparadigmas illustriert. Es sei gerade diese unhinterfragte Einstimmigkeit, die nach einer kritischen Lektüre rufe. Gewisse Aussagen entlang der patriotischen Interpretation erscheinen Borkowska denn bei näherer Betrachtung als völlig verdreht: »Da kann man getrost sagen, dass es in diesem Satz nicht ein Wort der Wahrheit gibt. ${ }^{45}$ Borkowska stellt der patriotischen Lesart ihre eigene, auf das Weiblich-Private fokussierende Lektüre entgegen, die jedoch - das hier angemerkt - selbst auch nicht frei ist von vorgeformten Urteilen: etwa wenn Borkowska die untersuchten Phänomene bereits zu Beginn als »Handlungen unpolitischer Natur ${ }^{46}$ bezeichnet.

Im Sinne einer `Entpatriotisierung kritisiert Borkowska aus einer internen Perspektive (»wir») die wissenschaftliche Forschungspraxis. Diese beuge sich einem patriotischen Paradigma, dessen Ursprung Borkowska in der politischen Auslegung der romantischen Kultur festmacht, wie sie Janion und Maria Żmigrodzka 1978 entworfen haben. ${ }^{47}$ Dieses Paradigma gelte auch für Studien zur Rolle der polnischen Frau im 19. Jahrhundert, die Borkowska als »feministische< Reflexion [mit] patriotisch-martyriologischem Charakter ${ }^{48}$ bezeichnet. Von einem sol-

42 I Vgl. Barthes, Roland: S/Z. Essai (= Tel Quel), Paris 1970, S. 28; Kłosińska: Ciało, S. 62.

43 I Vgl. Kłosińska: Ciało, S. 62; Miller: Subject to Change, S. 83.

44 I Borkowska: Cudzoziemki, S. 41: »W tej sprawie panuje dziwna zgodność poglądów. Kapituluje nawet Kurkowska [...].«

45 | Ebd.: 》0tóż można śmiało powiedzieć, że w zdaniu tym nie ma słowa prawdy.«

46 । Ebd., S. 36: »działań z natury niepolitycznych «.

47 | Vgl. Borkowska: Cudzoziemki, S. 38; Janion, Maria/Żmigrodzka, Maria: Romantyzm i historia, Warszawa 1978, S. 523.

48 | Ebd., S. 34: »Nie można jednak nie zauważyć, że refleksja sfeministyczna ma w odniesieniu do wieku XIX charakter patriotyczno-martyrologiczny." 
chen »Feminismus« ohne emanzipatorischen Fokus setzt sich Borkowska jedoch ab. Ihre eigene feministische Haltung zielt auf eine Neulektüre des literarischen Wortlauts, die das Element der Eigenständigkeit und einer individuell-persönlichen Entfaltung sowie den Ausbruch aus dem kollektiven Wertsystem verfolgt. So zeigt Borkowska etwa anhand der privaten Korrespondenz Żmichowskas ein völliges Fehlen von Hinweisen auf eine konspirative Tätigkeit der Schriftstellerin auf. Vielmehr entdeckt Borkowska darin gar negative Äußerungen über das patriotisch-widerständige Engagement, dessen Auswirkungen auf die polnische Gesellschaft Żmichowska als überflüssiges, trostloses und vermeidbares Leid bezeichnet habe. ${ }^{49}$

Es ist gerade Borkowskas Analyse der Epistolographie, die den Unterschied zwischen ihrer eigenen »feministischen « und der "patriotischen « Lektüre verdeutlicht. Borkowska vertritt eine unbedingte Texttreue: Jedes der Worte Żmichowskas nimmt sie genau für das, was es ist. Sie >glaubt $<$ Żmichowskas Argumentation und lässt die Frage gar nicht erst aufkommen, ob die zitierten Passagen auf eine zweideutige, "äsopische « ${ }^{50}$ Lesart ausgelegt sein könnten. Eine nicht-wörtliche Deutung ist für Borkowska ausgeschlossen. Dieses Vorgehen legitimiert sie durch das eingangs dargelegte Bestreben, jegliches `Hineinlesen`verhindern zu wollen, was sie bei Żmichowskas Texten mit ihrer `naiven` Lektüre konsequent durchzieht. ${ }^{51}$ Indem Borkowska es vermeidet, Themen wie textuelle Ironie oder Selbstzensur anzusprechen, verweigert sie auch den Dialog mit den von ihr eingangs kritisierten Ansätzen.

Zusammenfassend lässt sich feststellen, dass die feministische Rezeptionskritik als Versuch gelesen werden kann, das Urteilen über literarische Texte einer nur scheinbar objektiven Rezeptionstradition zu entreißen. Als relevant erweist sich der eigene, von wissenschaftlichen oder sonstigen kulturellen Paradigmen unverstellte Blick auf den Text, wobei eine gemeinsame weibliche Erfahrungswelt als direkterer Zugang zum Text verstanden wird. Vor allem bei den Ansätzen Kłosińskas und Kraskowskas handelt es sich im Prinzip um metanationale Kritiken einer als übergreifend verstandenen vergeschlechtlichen Hierarchisierung, in der weibliches kulturelles Schaffen marginalisiert wird. Deutlicher Bezug auf die polnische Situation nehmen Iwasiów und Borkowska, die die Strategien von

49 | Ebd., S. 45, $132 f$.

50 । Vgl. Loseff: On the Beneficience; Pawlicki: Sonderwege der Zensurpolitik, S. 349-352.

51 I Etwas anders sieht es mit inrer Lektüre der Texte Orzeszkowas aus, denen sie eine gewisse Unehrlichkeit vorwirft. Vgl. Borkowska: Cudzoziemki, S. 164, wo sie über Orzeszkowa schreibt: »keiner der Sätze ist wirklich echt« und »hinter dieser beneidungswürdigen kulturellen Staffage versteckt sich auch ein Unwille zu exhibitionistischen Bekenntnissen« (»żadne ze zdań nie jest do końca prawdziwe«; "za tym godnym pozazdroszczenia sztafażem kulturowym kryje się też niechęc do ekshibicjonistycznych wynurzeń«), womit Borkowska also gerade hinter dem eigentlichen Wortsinn nach Bedeutung sucht. Siehe zur unterschiedlichen Lektüre Żmichowskas und Orzeszkowas bei Borkowska Kapitel 6.3. 
Literaturkritik und Geisteswissenschaften als spezifisch historisch und lokal eingebettete Diskurse verstehen. Während Iwasióws Revision der Rezeption im sozialistischen Polen aus der Perspektive einer auch ideengeschichtlich >liberalisierten « und pluralisierten Gesellschaft stattfindet, macht Borkowska auf das Fortwähren epistemologischer Normierungen in der lokalen Forschung aufmerksam und durchbricht diese gleichsam.

Janion nimmt in Bezug auf die lokale Verortung eine Mittelposition ein: Sie fokussiert zwar stärker als Kraskowska und Kłosińska auf die axiologischen Verschiebungen in Wissenschaft und Gesellschaftsdiskurs, versteht jedoch diese am Beispiel Komornicka/Włast auch eher als globale Dynamiken denn als spezifisch polnisches Phänomen. In ihrer Rezeptionskritik bezüglich Filipiaks Roman $A b$ solutna amnezja spielt die polnische Situation beispielsweise eine größere Rolle, gerade da diese diskursiv zu normativeren Geschlechterzuschreibungen zurückkehrt. ${ }^{52}$

Grundsätzlich kann auch festgehalten werden, dass die feministischen Kritikerinnen den Dialog mit der angesprochenen smännlichen aufnehmen. Es wiegen Strategien des Überschreibens vor, die die normativen Werturteile ausradieren und an deren Stelle die `feministische` Lektüre stellen, die allerdings bei den einzelnen Wissenschaftlerinnen sehr unterschiedlich ausfallen kann. Es stellt sich das Problem, dass die feministischen Kritikerinnen mit der Dezentrierung bisheriger Rezeptionsparadigmen Gefahr laufen, ihre eigenen, `weiblichen`Lesarten für die `Weiblichkeit` zu universalisieren. Im Folgenden will ich deshalb den Fokus darauf richten, wie `Weiblichkeit in den Verhandlungen über das `weibliche Schreiben` als marginalisierte konstruiert wird.

\subsection{Weibliches Schreiben}

Die Neubetrachtung >weiblicher Literatur aus einer >weiblichen`, feministischen Perspektive versucht, den untersuchten Texten jenseits des >männlichen onsparadigmas gerecht zu werden. Der relevante Aspekt weiblicher Literatur setzt sich für Kraskowska wie auch für Borkowska und Kłosińska verallgemeinernd aus einer sanderen` Themensetzung und einer Gewichtung unkonventioneller, nicht-hegemonialer Perspektiven und literarischer Verfahren zusammen. Dies heißt jedoch nicht, dass die feministischen Kritikerinnen das ‘weibliche Schreiben nun als Maßstab literarischer Fertigkeiten setzten; etwa Kraskowska weist bei verschiedenen Autorinnen auf eine schreibwerkstattliche Durchschnittlichkeit oder Manieriertheit hin. ${ }^{53}$ Als positiv wertet sie allerdings die thematischen Grenzüberschreitungen der von ihr untersuchten weiblichen Texte, die literarische wie auch soziale Tabus durchbrechen.

52 I Vgl. Janion: Kobiety, S. 324-330.

53 I Vgl. Kraskowska: Piórem niewieścim, bes. S. 37, auch S. 159, 163. 
Das ıweibliche Schreiben wurde in den 1990er Jahren in Polen zu einem stehenden Begriff konzeptualisiert. Die Betonung des »Schreibens (pisanie) verweist auf den Versuch, die exklusive Kategorie der »Literatur" (literatura) aufzubrechen und vielfältigere, weniger elitäre und auch prozessuale Formen der Schriftlichkeit in den Fokus zu rücken. Im Zentrum stehen dabei Prosatexte, die als »weibliche Prosa " (proza kobieca), »Frauenroman« oder gar »feministischer Roman « (powieść kobieca/feministyczna) bezeichnet werden. ${ }^{54}$ Gleichzeitig zieht das Postulat eines distinkten, oft auch als subversiv verstandenen `weiblichen Schreibens $<$ in die Wissenschaft selbst ein - hier lässt sich ein experimentellerer und auch subjektiverer Zugang im Zeichen der feministischen Kritik beobachten. ${ }^{55}$

Im Folgenden befrage ich die feministische Kritik der 1990er Jahre, was diese unter weiblichem Schreiben versteht und wie dieses thematisch und stilistisch verortet werden kann. Da sich insbesondere Borkowska, Kłosińska und Kraskowska mit `weiblicher Literatur beschäftigen, sollen ihre Texte hier im Vordergrund stehen. Während Iwasióws Monographie von 1994 sich dieser Thematik nicht annimmt - mit der Fokussierung auf einen männlichen Autor nicht verwunderlich -, sollen Janions Untersuchungen ebenfalls teilweise mit berücksichtigt werden. Im Zentrum ihrer Aufmerksamkeit steht jedoch selten das weibliche Schreiben als abgrenzbare Kategorie. ${ }^{56}$

Die Konzepte der Polonistinnen zum weiblichen Schreiben sollen zunächst darlegen, mit welchem Material sich die >gynokritische` Form der feministischen Kritik beschäftigt und wie sie dieses in Anlehnung und Abgrenzung zur smännlichen Norm zu greifen versucht. Dabei handelt es sich in gewisser Weise um den Versuch der Konstituierung eines Forschungsbereichs, dessen Ränder jedoch wie vor allem Borkowska feststellt - diffus bleiben. ${ }^{57}$

54 । Die Übersetzung ins Deutsche muss hier mit einer gewissen Differenzierung zwischen `Frauen-` und 'weiblich arbeiten, während das polnische kobieca sowohl die eher stereotype Bezeichnung `Frauenliteratur` wie auch die revisionistischere Bezeichnung >weibliche` (Literatur/Roman/ Schreiben) umfasst resp. zwischen diesen begrifflich nicht unterschieden wird.

55 I Vgl. Iwasiów: Interview; Rudaś-Grodzka im Kolloquium des Zespół Literatura i gender des IBL PAN, 14.01.2016.

56 I In einer der wenigen Referenzen auf einen konventionell als 'weiblich bezeichneten Schreibstil lassen sich bei Janion keine Anzeichen einer Aufwertung dieser Inhalte erkennen, wenn sie diese als »im Grunde kitschigen und provokativen `weiblichen Ästhetismus und Erotismus « bezeichnet. Vielmehr verliere die Autorin - es geht hier um die allgemein smännlich، schreibende Komornicka - vorübergehend »ihre bisherige Kompromisslosigkeit zugunsten einfacher Schönheiten, die als Attribut einer raffinierten, ’üsternen<, sinnlichen Weiblichkeit gelten. « Janion: Kobiety, S. 194: »W istocie tandetny i ostentacyjny, ’kobiecy estetyzm i erotyzm«; »Autorka zatraciła tu jakby swą dotychczasową bezkompromisowość na rzecz łatwych piękności, uchodządzych za atrybut wyrafinowanej - >lubieżnej‘, zmysłowej kobiecości.«

57 I Die Definitionsversuche weiblicher Literatur, so Borkowska, »befriedigen paradoxerweise nicht das in jede Aussage eingeschriebene Bedürfnis der Klarheit«. Borkowska, Grażyna: »Meta- 


\subsubsection{Definitions- und Kategorisierungsversuche}

Es ist schwierig, eine Definition weiblichen Schreibens zu finden, die sich nicht in der einen oder anderen Form auf die (männliche) Norm bezieht. Das weibliche Schreiben wird - in seiner typischsten, prägnantesten Form - in der feministischen Kritik gerade als das Andere der männlich-hegemonialen Literatur umschrieben. Dabei erstaunt es nicht, dass insbesondere weibliche homosexueller Literatur als radikalste Abweichung von diesem Paradigma betrachtet wird, ${ }^{58} \mathrm{da}$ hier neben der Kategorie der Geschlechtlichkeit auch diejenige der Sexualität mit hineinspielt und die männliche Figur als Bezugsgröße entfällt. Abweichungen von der `männlichen` Norm interpretieren die feministischen Kritikerinnen grundsätzlich als positive Subversion.

Borkowska und Kraskowska, die sich am intensivsten mit der Kategorisierung des weiblichen Schreibens auseinandergesetzt haben, gehen darin einig, dass das Geschlecht der schreibenden Instanz keine ausreichende Bedingung rweiblichen Schreibens sei und die 'Weiblichkeit eines Texts in dessen Stil und Thematik selbst liege. ${ }^{59}$ Inwiefern das Geschlecht der Autorin/des Autors aber eine notwendige Bedingung darstellt, erscheint bereits weniger eindeutig. Borkowska schlägt in einem Artikel von 1995 vor, dass weibliches Schreiben »unabhängig vom biologischen Geschlecht des faktischen Autors« auftreten könne, »überall dort, wo die Geschlechtlichkeit des sprechenden Subjekts akzentuiert ist, überall dort, wo sich die Beziehung zwischen Körper und Text offenbart « ${ }^{60}$.

Borkowska und auch Kraskowska widmen sich in ihren Monographien jedoch ausschließlich `weiblicher Literatur, die auch von Frauen geschrieben wurde. Das Geschlecht der schreibenden Instanz scheint damit dennoch ein ausschlaggebender Faktor zu sein, und gerade Borkowska knüpft mit ihrer extensiven Berücksichtigung und Fokussierung auf die Autorinnenbiographie den Text eng an die biographisch-geschlechtliche Erfahrung der Schreibenden. ${ }^{61}$ Kraskowska berücksichtigt zwar die konkrete Biographie der Schriftstellerinnen weniger, sieht aber

fora drożdży. Co to jest literatura/poezja kobieca«, in: Teksty Drugie, Feminizm po polsku (1995), S. 31-44, hier S. 38: "paradoksalnie nie zaspakajają wpisanej w każdą wypowiedź potrzeby jasności«.

58 I Vgl. Iwasiów: Gender, S. 74; Janion: Kobiety, S. $138 f$.

59 | Ähnlich argumentiert Ritz: Literatura w labiryncie pożądania, S. 94.

60 । Borkowska: Metafora drożdży, S. 44: »Bez względu na biologiczną pleć faktycznego autora. «; »wszędzie tam, gdzie akcentuje się plciowość podmiotu mówiącego, wszędzie tam, gdzie ujawnia się związek między ciałem a tekstem «. Siehe dazu auch Mrozik: Akuszerki transformacji, S. 46.

61 I Diese paradoxe Haltung Borkowskas stellen auch Dunin: Tao, S. 61 und Mrozik: Akuszerki transformacji, S. 45f. fest. Diese steht in gewissem Zusammenhang mit den unterschiedlichen westlichen feministischen Ansätzen, die Borkowska rezipiert. Mit Gilbert und Gubars The Madwoman in the Attic gewinnt die Komponente weiblicher Erfahrung, die sich in den Text ergießt, an Gewicht (Borkowska: Córki Miltona, S. 72; dies.: Cudzoziemki, S. 20); mit Kristeva und Irigaray 
ebenfalls einen direkten Zusammenhang zwischen 'weiblicher sozialer Erfahrung und 'weiblichem $<$ Schreiben. ${ }^{62}$

Die Frage nach der Definition 'weiblichen $<$ Schreibens wird in den 1990er Jahren kontrovers diskutiert, findet jedoch keine endgültige Antwort. ${ }^{63}$ Ein Streitpunkt scheint auch die eigentliche Bezeichnung der besprochenen Literatur zu sein. Borkowska verwendet die Begriffe von »feministischer « und »weiblicher" Literatur synonym, die beide ihre Geschlechtlichkeit enthüllende Texte umfassen. ${ }^{64}$ Mit dieser Begriffsverwendung polemisiert Kraskowska, die die "feministische" Literatur »höchstens als Teilmenge oder Variante ${ }^{65}$ der weiblichen Literatur versteht. Es zeigen sich allerdings - nicht nur bei Borkowska - in den 1990er Jahren viele Begriffsverschiebungen und konzeptuelle Neuausrichtungen, was als Symptom der ideengeschichtlichen Verknotung und ‘Beschleunigung betrachtet werden kann. Eine detaillierte Analyse der unterschiedlichen Ansätze, Definitionen, Abgrenzungen und Begriffsverwendungen der einzelnen Polonistinnen führte an dieser Stelle jedoch zu weit und muss deshalb ausgeklammert werden. ${ }^{66}$

In den untersuchten Monographien wird jedoch weniger das Problem einer 'weiblichen Literatur überhaupt diskutiert, sondern eher deren innere Kategorisierung. Am deutlichsten unternimmt dies Kraskowska in Piórem niewieścim, wobei sie Showalter folgend drei historische Kategorien weiblicher Literatur darstellt. ${ }^{67}$ Showalter skizziert die drei Kategorien als sequentielle Phasen, die die englischsprachige weibliche Literatur durchlaufen habe: die feminine, feminist und female Literatur. ${ }^{68}$ Kraskowska appliziert diese Kategorien Showalters auf die polnische Literatur und benennt sie neu. Dabei verschiebt sie sie von der diachronen auf eine synchrone Ebene, stellt diese also als parallel auftretende Strömungen der weiblichen Literatur der Zwischenkriegszeit dar.

Als erstes Modell nennt Kraskowska die transgressive (feminine/transgresyjna) Literatur, die sich an der männlichen (literarischen) Norm messe und diese

hingegen die Auflösung des Geschlechts der schreibenden Instanz (Borkowska: Metafora drożdży, S. 37f.). Siehe auch Magnone: Die polnischen Gender Studies, S. 382.

62 । Vgl. Mrozik: Akuszerki transformacji, S. 46ff.

63 I Dunin schreibt dazu: »Auf jeden Fall besteht das Problem und einfache Kriterien - von Frauen geschrieben, über Frauen, für Frauen - helfen uns nicht weiter.« Dunin: Tao, S. $61 f$.

64 । Vgl. Borkowska, Grażyna: »Wstań, siostro! Wstań! - polska proza kobieca (1840-1918)«, in: Rocznik Towarzystwa Literackiego imienia Adama Mickiewicza 26-27 (1991/1992), S. 51-61, hier S. $56 \mathrm{f} ., 60$.

65 I Kraskowska: Piórem niewieścim, S. 91: „co najwyżej podzbiór lub odmianę«. Siehe außerdem Filipowicz: Przeciw literaturze kobiecej<, S. 251 zur Kritik der Verwischung der Attribute »feministyczny« und »kobiecy«.

66 I Vgl. dazu allg. ansatzweise Majbroda: Feministyczna krytyka, S. 97f., 175ff.

67 । Auf Showalters drei Phasen verweist Kraskowska bereits 1993 in Kilka uwag, S. 261.

68 । Vgl. ebd.; dies.: Piórem niewieścim, S. 204; sowie Showalter: Toward a Feminist Poetics, S. $35 f$. 
zu imitieren suche. Das zweite Modell, jenes der feministischen (feminist/feministyczna) Literatur, wende sich gegen die männliche Norm und fordere explizit sowie »oft [...] sehr tendenziös « ${ }^{69}$ Rechte für Frauen ein. Als letztes Modell nennt Kraskowska die integrale (female/integralna) Literatur, die sich weder an der männlichen Norm orientiere noch explizit gegen sie wende. Wie auch Showalter favorisiert Kraskowska die weibliche Literatur in ihrem integralen Modell, das somit als Inbegriff weiblichen Schreibens auftritt.

"Es umfasst solche von Frauen geschriebenen Werke, für die tatsächlich der Ausgangspunkt, wenn es sowohl um die Thematik wie um die Schreibtechnik geht, die spezifisch weibliche Lebenserfahrung und Wahrnehmungsweise der Welt und anderer Menschen ist, die weibliche Biologie und Physiologie sowie eine weibliche Werthierarchie. Sie entstehen wie außerhalb des patriarchalen Systems als solches, wie es die Literatur widerspiegelt, und beziehen sich weder ideologisch noch emotional auf Fragen wie den Geschlechterkampf oder die Ungleichheit, sondern begnügen sich mit der Feststellung und Betonung ihrer Unterschiede und der sich daraus ergebenden Konsequenzen. ${ }^{70}$

Dieses Modell, als dessen Prototyp Kraskowska Helena Boguszewskas Roman Całe zycie Sabiny (Das ganze Leben Sabinas) von 1934 nennt, sei »ebenso Überwindung wie Synthese der beiden vorherigen ${ }{ }^{71}$ Modelle. Das von Kraskowska integral genannte Modell kann als Orientierungspunkt der feministischen Kritik der 1990er Jahre in Polen dienen, wenn es um die Definition weiblicher Literatur geht.

Eine ähnliche Kategorisierung transportiert Janions Studie zu Nicole Müllers Denn das ist das Schreckliche an der Liebe. Müller, so Janion einem Artikel von 1993 aus der Neuen Zürcher Zeitung folgend, gehöre zu einer

"erstaunlichen Generation von Autorinnen. In den 1960er Jahren in der deutschsprachigen Schweiz geboren, repräsentieren sie eine neue Haltung - sie sind weder ergebene Ehrenämtlerinnen noch fanatische Feministinnen. Sie streben nicht ostentativ zur Selbstverwirklichung. Ihr Schreiben zeichnet sich durch einen Nonkonformismus aus, der aber voller Leichtigkeit, Ironie, Sinn für das Groteske und Gespür für absurde Situationen ist. « ${ }^{72}$

69 | Kraskowska: Piórem niewieścim, S. 205: »często [...] w stopniu bardzo tendencyjnym«.

70 । Ebd.: »0bejmuje on takie utwory pisane przez kobiety, dla których istotnie punktem wyjścia, zarówno jeśli idzie o tematykę, jak i technikę pisarską, jest specyficznie kobiece doświadczenie życiowe, sposób postrzegania świata i innych ludzi, kobieca biologia i fizjologia, kobieca hierarchia wartości. Powstają one niejako poza systemem patriarchatu takim, jakim go odzwierciedla literatura, nie odnoszą się ideologicznie i emocjonalnie do takich kwestii, jak walka czy nierówność płci, poprzestając na stwierdzeniu i podkreślaniu ich różnicy oraz wynikających z niej konsekwencji.«

71 । Ebd.: »tyleż przezwyciężeniem, co syntezą dwóch poprzednich«.

72 I Janion: Kobiety, S. 136: "zadziwiającej generacji autorek. Urodzone w latach sześćdziesiątych pisarki niemieckojęzycznej Szwajcarii reprezentują nową postawę - nie są ani oddanymi spo- 
Janion grenzt diese Generation vom Modell der »ergebenen Ehrenämtlerinnen «das Parallelen zum transgressiven Modell aufweist - wie auch vom feministischen Modell ab. Die Frage, inwiefern der neue »Nonkonformismus« an die Geschlechtlichkeit geknüpft ist und sich wie bei Kraskowskas integralem Modell aus der differenten weiblichen Erfahrungswelt speist, wird in Janions Studie nicht beantwortet. Janion interessieren an Müllers Text vor allem die literarischen Verfahren einer nicht-heteronormativen Sexualität, wobei die Differenz der 'Weiblichkeits von derjenigen der ১Homosexualität kaum zu lösen ist und so eine Doppelung erfährt. ${ }^{73}$

Borkowska kontrastiert in Cudzoziemki die literarischen Stile von Żmichowska und Orzeszkowa und konstruiert daraus zwei unterschiedliche "Strategien". Bei Żmichowska stellt Borkowska ein Einbringen der biographischen, ১weiblichen Erfahrung fest, die sie als Differenz sieht. Die Verbindung von Persönlichem und Literarischem benennt Borkowska als "Strategie der Biene, d.h. schmerzhafter Stiche ${ }^{74}$, wobei verhüllte, subversive Techniken gegen soziale und literarische Normen Anwendung fänden. Das Offenbaren der Differenz und einer eigenen Position ist gemäß Borkowska mit persönlichem `Einsatz« verbunden: »Der andauernde Kraftakt der ersten Entuzjastki, die ihr Anderssein einsam trugen, war eine schwere, bisweilen erdrückende Lebenserfahrung. Deshalb ist die entomologische Metapher der Biene, die schmerzhaft sticht, aber ab diesen Stichen stirbt, [...] vollkommen angebracht. . $^{75}$

Bei Orzeszkowa hingegen stellt Borkowska ein völliges Fehlen eines so verstandenen persönlichen Einsatzes fest. Orzeszkowa sei bemüht, ihr eigenes Leben - und ihr weibliches Geschlecht - im literarischen Ausdruck vollkommen auszulöschen. Diese Unterdrückung des Persönlichen, die Borkowska als ১unehrlich kritisiert (siehe Kapitel 6.3.2), erweise Orzeszkowas literarisches Verfahren als Assimilation an die >männliche< Literaturnorm. Diese literarische Form bezeichnet Borkowska deshalb als »Strategie der Mimikry «76, als ein Vertuschen der Geschlechtlichkeit zugunsten der literarischen und sozialen Norm.

łeczniczkami, ani żarliwymi feministkami. Nie dążą ostentacyjnie do samorealizacji. Ich pisarstwo cechuje nonkonformizm, ale pełen luzu, ironii, zmysłu groteski i wyczucia sytuacji absurdalnych." 73 I Zu beachten ist auch, dass diese von Janion beschriebene sneue Generation zu Beginn der 1990er Jahre in der Deutschschweiz verortet ist, während gemäß Kraskowska und Showalter die polnische und englische Literatur ein ähnliches `Modelk weiblichen Schreiben bereits zu Beginn des 20. Jahrhunderts entwarfen. Damit wird auch klar, dass eine lineare Entwicklung und Beschreibung >der weiblichen Literatur nur mit großen Abstrichen erreicht werden kann, denn hier zeigen sich Wellen- oder Zirkelbewegungen wie auch lokale Differenzen.

74 । Borkowska: Cudzoziemki, S. 71: "strategię pszczoły, tzn. bolesne ukąszenia«.

75 । Ebd., S. 71f.: »Bieżący wysiłek pierwszych entuzjastek, samotnie dzwigających swą inność, był ciężkim, nieraz miażdżącym doświadczeniem życiowym. Dlatego entomologiczna metafora pszczoły - kłującej boleśnie, ale i ginącej od tych ukłuć - jest [...] zupełnie na miejscu."

76 | Ebd., S. 160: "strategię mimikry«. 
Die Parallelen dieser »Strategie« zu Kraskowskas Modell der transgressiven weiblichen Literatur sind unübersehbar, ungeachtet dessen, dass Kraskowska Orzeszkowas Roman Marta als Typenvertreter feministischer Literatur setzt. Während sich Borkowskas Beschreibung von Żmichowskas Schaffen grundsätzlich in Kraskowskas Umschreibung der integralen Literatur fügt, scheint dennoch ein entscheidender Unterschied zu bestehen: Die "Strategie der Biene» transportiert ein stärker soziopolitisches Element (auch wenn Borkowska dieser Bezeichnung nicht zustimmen würde), während Kraskowskas Konzept integraler Literatur gerade die völlige Abkehr von der Gesamtgesellschaft und politischen Bestrebungen $\mathrm{zu}$ beinhalten scheint. ${ }^{77}$

Ich möchte deshalb nun diskutieren, inwiefern die feministischen Kritikerinnen das `weibliche` Schreiben als abgeschlossene - wenn auch nicht endgültig definierbare - Kategorie betrachten. Hierbei geht es mir konkret darum zu fragen, ob ein weibliches Schreiben als »für Frauen ${ }^{78} \mathrm{zu}^{\mathrm{z}}$ betrachten sei, oder ob dieses eine für die `Gesamtliteratur` und damit auch für die Gesamtgesellschaft gültige Funktion übernehme. Diese stärker auf den/die Leser/in fokussierende Frage steht damit auch im Zusammenhang mit den Diskussionen um den Kanon und inwiefern ein unabhängiger, >weiblicher Literaturkanon installiert werden soll. ${ }^{79}$

Borkowska verweist 1995 auf die Gefahr, mit einer strikten Definition weiblicher Literatur diese »im ungewollten Ghetto des Geschlechts ${ }^{80}$ einzuschließen. Dabei geht es ihr jedoch mehr darum, Texte weiblicher Autorschaft, die ihre Geschlechtlichkeit nicht explizit thematisieren, nicht als `weibliche Literatur $\triangleleft$ fremdzubestimmen. Dennoch kritisiert sie in Cudzoziemki Orzeszkowa gerade für deren zu `männliche`, sich dem `weiblichen Schreiben` widersetzende Literatur, womit Borkowska selbst eine normative Vorstellung weiblichen Schreibens offenbart. Die Frage nach der Relevanz weiblichen Schreibens für die Allgemeinheit greift sie dabei nicht auf; die Problematik der Leser/innenschaft stellt sich in Cudzoziemki damit im Prinzip nicht, und Borkowska schreibt dem wissenschaftlichen Habitus gemäß vom »Leser « (czytelnik). ${ }^{81}$

Kraskowska beantwortet diese Frage in Piórem niewieścim eindeutiger und mit Blick auf ein weibliches Publikum, ${ }^{82}$ wenn sie schreibt, dass ‘weibliche Thematiken für Männer »schlicht uninteressant ${ }^{83}$ seien. Sie konstruiert eine verge-

77 I Meine Auffassung von Kraskowskas Misreading in Bezug auf Boguszewskas Całe życie Sabiny erläutere ich ansatzweise in Kapitel 6.1.3.

78 । Dunin: Tao, S. 61: »dla kobiet«.

79 I Siehe zum Kanon Majbroda: Feministyczna krytyka, S. 158-163.

80 । Borkowska: Metafora drożdży, S. 39: »w niechcianym getcie płci«.

81 I Die Ausnahme bilden einige Passagen, in denen Borkowska auf die Apellfunktion an - ihres Erachtens - konkret weibliche Leserinnen hinweist, etwa bei der Verhandlung >lesbischer Textstellen, vgl. Borkowska: Cudzoziemki, S. 236.

82 । Vgl. dazu Mrozik: Akuszerki transformacji, S. $47 f$.

83 । Kraskowska: Piórem niewieścim, S. 98: »po prostu nieciekaw[e]«. 
schlechtlichte Divergenz der Interessensgebiete, die sie in Zuschreibung zum biologischen Geschlecht naturalisiert und legitimiert. Kraskowska setzt deshalb die sweiblichen ‘ Bereiche von Alltag und Literatur von der Gesellschaft als gesamter $\mathrm{ab}$ und spricht ihnen einen geschlossenen Wirkungsbereich zu - unter Frauen. Kraskowska vertritt damit unter den von mir untersuchten feministischen Kritikerinnen der polnischen 1990er Jahre am deutlichsten eine Perspektive der Differenz, in der sie die `weibliche Sphäre` undurchlässig von der `männlichen` isoliert.

Auch Kłosińska verweist auf die Divergenz der Erfahrungswelten, wenn sie bei einem Kritiker »einen Mangel an Akzeptanz gegenüber ihm fremden Erfahrungen und einer fremden Welt, wo so prosaische Tätigkeiten wie `Kaffeetrinken, Bäder und Spaziergänge ‘ auf die Ebene der Handlung erhoben werden ${ }^{84}$, feststellt. Sie hält fest, dass das Empfinden der thematischen Relevanz geschlechtlich geprägt sein kann. ${ }^{85}$ Kłosińska legitimiert hier einerseits die weibliche Literatur und ihre Inhalte als selbstrelevant, also als von Bedeutung für eine wie auch immer verstandene weibliche Interessensgruppe. Andererseits entbindet sie aber - anders als Kraskowska - die männliche Interessensgruppe nicht aus ihrer Verpflichtung gegenüber `weiblichen` Themen, die als Bestandteil der gesellschaftlichen Gesamtheit auch die männliche/neutrale Erfahrungswelt betreffen und mit ihr interagieren.

»Einer der Kritiker gab Kaśka Kariatyda den Spitznamen 'Entbindungsliteratur‘, womit diese an einen engen Kreis von >Interessierten` gerichtet sei und eine Bresche in oder gar eine Herausforderung an den Universalismus der Literatur darstelle. Ein vom Geschlecht von Autorin und Leserin geprägter Diskurs wurde sofort, wie man sieht, nicht nur registriert, sondern auch bagatellisiert und ausgeschlossen. Als ob die Geburt jemandes Sache sei und nicht jeden betreffe. ${ }^{86}$

Die Identifizierung der von Zapolska behandelten Thematiken - etwa die Stigmatisierung unehelicher Schwangerschaft oder die Geburt eines Kindes - als spezifisch weiblich und die daran anschließende Ausgrenzung aus der für die Allgemeinheit relevanten Erfahrungswelt ist für Kłosińska nicht gerechtfertigt. In ihren Augen betreffen diese Themen die gesamte Gesellschaft, die sich mit ihren Problemen und Ungleichgewichten unabhängig von geschlechtlichen Differenzierungen auseinandersetzen muss. In Anlehnung an Irigaray fordert Kłosińska eine

84 । Kłosińska: Ciało, S. 18: »brak akceptacji dla obcego mu doświadczenia i obcego mu świata, w którym tak prozaiczne czynności, jak: ’picie kawy, kąpiel i spacery urastają do rangi historii.“ 85 । Vgl. ebd., S. 19.

86 | Ebd., S. 89: »Jeden z krytyków nadał Kaśce Kariatydzie przezwisko >literatury położniczej‘, czyli skierowanej do niewielkiego kręgu zzainteresowanych‘, stanowiącej wyłom, a nawet wyzwanie wobec uniwersalizmu literatury. Dyskurs naznaczony płcią autorki i czytelniczki od razu, jak widać, stał się obiektem nie tylko rejestracji, ale zarazem lekceważenia i wykluczenia. Tak jakby położnictwo było czyjąś sprawą, nie dotykającą każdego." 
Katharsis des männlichen Lesers durch die Bekanntmachung und das literarische Durchleben der Unpässlichkeiten weiblicher Lebensläufe. ${ }^{87}$

Kłosińska deutet hier den Wunsch einer Universalisierung an - es geht aber nicht um eine Universalisierung der weiblichen Literatur im Sinne einer >Maskulinisierung`, sondern vielmehr um eine tatsächliche Universalisierung der Literatur durch den Miteinbezug auch `weiblicher`, sanderer` literarischer Beiträge. Anders als Kraskowska fordert Kłosińska somit keine (protektionistische) Trennung geschlechtlicher Sphären, sondern eine zur Kenntnis nehmende, anerkennende Gleichberechtigung >männlicher` und sweiblicher` Erfahrungswelten und deren literarischer Ausformung.

Wieder anders legt Janion die Durchlässigkeit der weiblichen Erfahrungswelt aus. Auf den Versuch einer Aneignung der Thematik von Filipiaks Absolutna amnezja durch einen männlichen Kritiker (Każdy był mała dziewczynka (Jeder war ein kleines Mädchen), so der Titel der Kritik Jerzy Sosnowskis) reagiert Janion in Anlehnung an Dunin wie folgt: ${ }^{88}$

»Gegenüber der Weiblichkeit werden speziell repressive Verfahren angewandt - und nur gegenüber der Weiblichkeit. Elementarer Rechte der Selbstbestimmung beraubt, in ihre restlos der sozialen Kontrolle unterworfene Körperlichkeit verwickelt, müssen Frauen ihre eigene Subjektivität als stigmatisierte Zugehörigkeit zum >niederen Geschlecht empfinden. « ${ }^{89}$

Gerade deshalb können gemäß Janion die im Roman angeführten repressiven Mechanismen, die der Weiblichkeit gegenüber in Gang gesetzt sind, von einem männlichen Rezipienten nie erfahren und nachvollzogen werden.

Filipiaks "Menstruationsliteratur" (»literatura menstruacyjna») ist deshalb laut Janion - anders als bei Kłosińska die "Entbindungsliteratur» (»literatura położnicza«) - Ausdruck einer von der männlich-allgemeinen Norm divergierenden Erfahrungswelt und für diese weder erfassbar noch nachvollziehbar. Damit tendiert Janion hier zu einer (strategisch-pragmatischen) Abgrenzung der weiblichen Erfahrungswelt, um überhaupt ein weibliches Bewusstsein für die gesellschaftlichen Disziplinierungsverfahren der `weiblichen Sphäre zu generieren. Im Lichte von Janions sonstigen Ansätzen muss diese Strategie aber als eine temporäre Hilfskonstruktion gesehen werden, die vor allem auf eine politische Bewusst-

87 I Vgl. ebd. Siehe auch Irigaray, Luce: Je, tu, nous. Pour une culture de la différence, Paris 1990, S. 132.

88 । Vgl. Sosnowski, Jerzy: »Każdy był małą dziewczynką", in: Ex Libris 80 (1995), S. 4-5; Dunin, Kinga: »Polska policja menstrualna«, in: Ex Libris 80 (1995), S. 6-7.

89 | Janion: Kobiety, S. 328: „Wobiec kobiecości stosuje się szczególnie represyjne zabiegi - i tylko wobec kobiecości. Pozbawiane elementarnych praw do stanowienia 0 sobie, uwikłane w swoją cielesność jako poddaną bez reszty społecznej kontroli, kobiety muszą odczuwać własną podmiotowość jako napiętnowaną przynależnością do sniższej‘ płci.« 
werdung und letztlich mehr auf eine Dynamisierung denn auf eine statische Trennung vergeschlechtlichter Sphären zielt.

\subsubsection{Eine eigene Sprache}

Während nun vor allem thematische Spezifika besprochen wurden, die ‘weibliche Literatur für ein vergeschlechtlichtes Publikum qualifizieren, bindet die feministische Kritik die Kategorie weiblichen Schreibens eng auch an deren literarische Verfahren. Das Aufscheinen der weiblichen Erfahrungswelt gilt vielen feministischen Kritikerinnen als Bedingung für weibliches Schreiben. Themenfelder, die der patriarchale Diskurs als relevant betrachtet - politische Ereignisse oder >große` geschichtliche Zusammenhänge -, finden sich im `weiblichen Schreiben oft nur am Rande. Als typisches Zeichen weiblicher Literatur wird hingegen eine Abkehr von den >großen، Geschichten zugunsten des Details und des Alltags gedeutet, welche in der konventionellen Literatur nur als "Zierde» (ozdoba) eingesetzt werden. ${ }^{90}$

Der Bruch mit der >großen`Geschichte finde sich in der weiblichen Literatur nicht nur in der thematischen Ausrichtung, sondern auch in der Form. Das weibliche Schreiben, so Kraskowska in Anlehnung an eine Charakterisierung Woolfs, sei in der Tendenz von einer größeren Vielstimmigkeit und Fragmentarizität geprägt, von einem lockereren syntaktischen Stil und Gattungsexperimenten, von einer Auflösung des klassischen Spannungsbogens und der Synthese zugunsten kleiner Studien sowie von einer Offenheit gegenüber Neuem und Ungewohntem. ${ }^{91}$ Mit der »avantgardistischen psychologischen Prosa ${ }{ }^{92}$ finde zudem eine Verschiebung von einem stärker handlungsbetonten Spannungsbogen zum Fokus auf das Innenleben der Figuren statt, womit das weibliche Schreiben die historische Entwicklung literarischer Konventionen vorwegnehme. ${ }^{93}$

Eine solche Vorreiterrolle sieht Borkowska etwa im Schaffen Żmichowskas. Diese habe ihre Vorstellungen über das "neue Bild der Frauen« nicht in publizistischen Texten festhalten wollen,

»deshalb hat Żmichowska sie auf das Gebiet des Romans übertragen, gerade des ssylvischen Romans, der sich an Verschiedenartigkeit und Reichtum orientiert und vielstimmig, polemisch, >offen ist. Hinzuzufügen ist, dass sie ein solches Romanschema nirgendwoher entlehnen und den eigenen Bedürfnissen gemäß adaptieren konnte; sie musste es erfinden und ihm Inhalt einhauchen. ${ }{ }^{94}$

90 I Vgl. Kraskowska: Piórem niewieścim, S. 23; Kłosińska: Ciało, S. $18 f$.

91 I Vgl. Kraskowska: Piórem niewieścim, S. 15, 17f. sowie 21, 165.

92 । Ebd., S. 17: "awangardowej prozy psychologicznej«.

93 । Vgl. ebd., S. 15.

94 । Borkowska: Metafora drożdży, S. 33f.: »nowym wizerunkiem kobiet«; »Dlatego też Żmichowska przeniosła je na teren powieści, w dodatku powieści ssylwicznej‘, nastawionej na różnorod- 
Borkowska hält fest, dass für Żmichowska »jedes menschliche Thema [...] gleich wichtig war. Und jedes wurde vom schwierigen Moment der Auswahl der entsprechenden Erzählregeln begleitet.«" ${ }^{95}$ Sie geht gar so weit, Żmichowskas Werk als postmodernistisch zu bezeichnen. Ihr Werk sei stilistisch in gewisser Hinsicht der Aufklärung und der Romantik verhaftet und damit bereits anachronistisch, nehme aber gleichzeitig spätere (postmoderne) Stilformen vorweg. Darin spiegle sich ihr komplexes Verhältnis zum eigentlichen Schreiben. „Die Schriftstellerin hinterließ bloß eine unvollendete, verstümmelte literarische Produktion (unfertige und in sich zu verzettelte, uneinheitliche, hybride Werke), denn sie konnte die Zweifel und Vorbehalte, die den Prozess des Erzählens (und Schreibens) blockierten, nie ganz loswerden. ${ }^{96}$ Aufgrund dieser inneren Brüche nehme Żmichowskas Schaffen in der polnischen Literatur eine "totale Ausnahmeposition « ein und qualifiziere mit seinem »Konstruieren, das gleichzeitig Bestimmung der Konstruktionsregeln ist«, im Zusammenbringen von Vergangenem und dem, was »erst die Zukunft erfüllen kann, ein unvollkommenes Projekt, eine zu lösende Aufgabe « ${ }^{97}$, als modellhaft postmodern im lyotardschen Sinne.

Ähnlich argumentiert Kraskowska in Bezug auf das Schreiben Elżbieta Szemplińskas, deren

»Element die kleine Form ist, das Fragment, die Montage, Stilvariationen, das Fehlen einer einheitlichen Formel und plötzliche Wechsel des Tons. Diese Chimerität kann heute gefallen; in der Zwischenkriegszeit, die dem formalistischen Experiment den Vorzug gab und mit Vorliebe in allem ein pattern sah, war sie Quell einer gewissen Konsternation [...]. « ${ }^{98}$

Wie auch Borkowska stellt Kraskowska fest, dass das weibliche Schreiben nicht in die vorgefertigten Muster der jeweiligen Zeit passe; mehr noch, beide Forscherin-

ność i bogactwo, wielogłosowej, polemicznej, >otwartej‘. Warto dodać, że takiego wzorca powieściowego nie mogła znikąd wypożyczyć i zaadaptować do własnych potrzeb, musiała go wymyślić i natchnąć treścią."

95 । Borkowska: Cudzoziemki, S. 135: »Każdy temat ludzki był dla Narcyzy równie ważny. I każdemu towarzyszył trudny moment wyboru odpowiednich reguł opowiadania."

96 । Ebd., S. 96: »Pisarka dawała jedynie ułomną, kaleką produkcję literacką (utwory nie dokończone i zbyt rozchwiane wewnętrznie, niejednorodne, hybrydyczne), ponieważ nigdy do końca nie mogła wyzbyć się wszystkich wątpliwości i zastrzeżeń, blokujących proces opowiadania (i pisania).» 97 । Ebd., S. 96f.: »Pozycja [...] jest zupełnie wyjątkowa«; »konstruowanie jest jednoczesnym ustalaniem reguł konstrukcji«; »dopiero przyszłość może zapełnić, ułomny projekt, zadanie do wykonania«. Siehe auch Lyotard, Jean-François: La Condition postmoderne. Rapport sur le savoir, Paris 1979 .

98 I Kraskowska: Piórem niewieścim, S. 140: „żywiołem jest mała forma, fragment, montaż, różnostylowość, brak jednolitej formuły i nagłe zmiany tonacji. Ta chimeryczność dziś może się podobać; w Dwudziestoleciu, które preferowało eksperyment w duchu formalistycznym i lubiło wszędzie widziec pattern, była źródłem pewnej konsternacji [...].« 
nen beschreiben ihre Beispiele als stilistisch `zu fortschrittlich` für ihre Zeit. Erst mit der historischen Verschiebung bzw. Auflösung literarischer Konventionen sei eine Wertschätzung dieser Formen überhaupt möglich geworden.

Neben diesen avantgardistischen Tendenzen, die für die Literatur allgemein fruchtbar wurden, interessiert die polnischen feministischen Kritikerinnen in Anlehnung an Konzepte wie dasjenige der écriture féminine am weiblichen Schreiben auch die Frage, inwiefern sich dieses überhaupt von Konventionen absetzen könne. Dazu muss zunächst untersucht werden, mit welchen Mitteln >weiblich geschrieben` werden kann, wenn das Weibliche im patriarchalen System aus der logozentrischen Sprache gedrängt wird, wovon die polnischen feministischen Kritikerinnen im Anschluss an französische feministisch-psychoanalytische Arbeiten ausgehen. Letztere sehen das kommunikative System des Menschen und damit auch die Geschlechterordnung nach einer symbolischen Ordnung strukturiert. Mit der Sozialisierung werde die patriarchale Ordnung stets wieder hergestellt und verdränge dabei das prä-ödipale, vorsprachliche Semiotische, das in diesem Zusammenhang als das >Weibliche` angesehen wird. ${ }^{99}$ Kristeva konzeptualisiert für diesen Bereich des Semiotischen den Begriff der (mütterlichen) chora, ${ }^{100}$ in der Subjekt und Objekt noch nicht voneinander getrennt seien und ein kontinuierliches Zeit-Raum-Gefüge herrsche, eine »nicht-expressive Totalität « ${ }^{101}$.

Das System hingegen, nach dem Erfahrungen, Wissen und Kommunikate geordnet sind, sei ein männliches (und heteronormatives), das auf der Dominierung des Weiblichen und genereller gesagt jeglichen >Anderen weibliche Erfahrungswelt »etwas vom verdrängten `Semiotischen « ${ }^{102}$ bewahre, lasse sich das Andere trotz der Suche nach unkonventionellen Ausdrucksformen etwa im `weiblichen Schreiben` kaum außerhalb einer >männlich`strukturierten Sprache und Kommunikationsform artikulieren. Die Frage stellt sich somit, inwiefern sich ein randeres Schreiben, das kommunikativ auf die symbolische Ordnung mit ihrer >männlich` geprägten Literatur, Sprache und einem ebenso "phallogozentrischen « ${ }^{103}$ Denken angewiesen ist, aus dieser Ordnung befreien könne, ohne selbst wieder in die Binarität von System und Opposition als (hierarchisches) Strukturmerkmal der männlich-symbolischen Ordnung zu verfallen.

Diese Überlegungen, die ab den 1970er Jahren in Frankreich angestellt wurden, finden ihren Weg auch nach Polen. Der Problematik eines Ausbruchs aus der symbolischen Ordnung widmet sich etwa Janion 1981 am Beispiel von Santos' Text La Malcastrée (siehe auch Kapitel 3.1.2). Während die >normale`Sprache bei Santos zu einem Gefühl der Entfremdung führe, stelle sich die Frage, »inwieweit eine eigene Sprache wiedererlangt, in der eigenen Sprache geschrieben werden

99 | Vgl. Lindhoff: Einführung, S. $111 f$.

100 । Vgl. Kristeva: Révolution du langage poétique, S. 22-30.

101 । Ebd., S. 23.

102 I Lindhoff: Einführung, S. 117.

103 | Ebd., S. 90. 
kann, von der man enteignet wurde. ${ }^{104}$ Janion sieht Santos' psychische Krankheit als Verunmöglichung, sich der "gegebenen", phallogozentrischen Sprache ohne Widerspruch unterzuordnen; gleichzeitig interpretiert sie den »Wahnsinn « als Ort der Transgression des normativen Sprachsystems. Das literarische Projekt Santos' sei somit nicht ein Wieder-Einschreiben in die symbolische Ordnung, sondern das Ringen um eine Kommunikativität außerhalb derselben. Die Ambivalenz bleibe jedoch bestehen, und Santos »lebt $<$ bewusst von dieser Antinomie, [...] >lebt vom Wahnsinn, von den Versuchen seines Aussprechens in einer Sprache, die schließlich ex definitione die Verneinung des Wahnsinns ist. $\ll^{105}$

In den 1990er Jahren werden solche Überlegungen zur Transgression der symbolischen Ordnung zu einem Diskussionspunkt feministischer Ansätze in Polen. So schreibt Ciechomska 1992 über die Unmöglichkeit eines Ausbruchs aus dem System: "Im patriarchalen System lebend, bleiben wir dessen Kinder sogar dann, wenn wir es bekämpfen [...]. «106 Wie als Replik darauf merkt Filipowicz 1993 in einer kritischen Studie an, dass Feministinnen »[s]ich nicht vormachen, dass eine reine, vom Patriarchat unverseuchte [nie skażona] intellektuelle und künstlerische Sphäre existiere ${ }^{107}$. 1996 greift auch Janion diese Problematik wiederum auf, wenn sie schreibt,

"[d]er Mythos des Westens reduziert sich auf den Mythos des Logos, der nach der Konzeptualisierung einer Realität als System hierarchisierter Gegensätze gebaut ist; auch irreduzible Gegensätze zwischen den Geschlechtern, die immer zum Nutzen des Männlichen ausfallen. Binarität und Hierarchie sollen die grundlegenden Merkmale des Logos sein. Schreibende Frauen kritisieren dieses System, können aber nicht aus inm ausbrechen. «108

Der Problematik einer Außenperspektive widmet sich auch Kłosińska. Kłosińska stellt jedoch fest, dass gerade die weibliche literarische Perspektive Zapolskas aus einer `männlichen〈 Sicht nicht greifbar sei: »[W]enn der Kritiker diese Sichtweise zu umschreiben versucht, stößt er auf unüberwindbare Schwierigkeiten, alles

104 I Janion: Ciało skolonizowanych, S. 218, Hervorh. i. 0.: »w jakim stopniu można odzyskać swój język, pisać oczywiście własnym językiem, z którego się zostało wywłaszczoną."

105 । Ebd., S. 225, Hervorh. i. 0.: »świadomie ‘żyjeく z tej antynomii, [...] ‘żyjeく z szaleństwa, z próby jego wypowiedzenia w języku, będącym przecież ex definitione zaprzeczeniem szaleństwa.« 106 | Ciechomska, Maria: »Feminizm a macierzyństwo«, in: brulion, Feminizm (1992), S. 249254, hier S. 250.

107 | Filipowicz: Przeciw literaturze kobiecej‘, S. 255.

108 I Janion: Kobiety, S. 137: "Mit Zachodu sprowadza się do mitu Logosu, zbudowanego na konceptualizacji rzeczywistości jako systemu zhierarchizowanych przeciwieństw; również nieredukowalnych przeciwieństw między płciami, układających się zawsze na korzyść tego, co męskie. Binarność i hierarchia mają być podstawowymi cechami Logosu. Kobiety piszące krytykują ów system, lecz nie mogą poza niego wyjść." 
verschwimmt zu allgemeinen Formulierungen [...].«109 Kłosińska betont damit die eigentliche Unbeschreibbarkeit dieser Perspektive, da diese (auch) jenseits des semantisch Strukturierten spreche. Kłosińska identifiziert nämlich in den Texten Zapolskas doppelbödige Wörter, die sie »Worte-Ächzer» (»słowa-jęki«) nennt. Das Wort werde durch das körperliche Zeichen gedoppelt, womit es nicht mehr als symbolisch geordnete Äußerung verstanden werden könne, sondern Bedeutung gerade durch seine Unstrukturiertheit und artikulative Leerstelle gewinne: »Die Worte kann man nicht von den nichtartikulierten Geräuschen trennen, Zapolska spricht mithilfe von `Worte-Ächzern`, `Worte-Schluchzern`. [...] Die Schreie entweichen unerwartet von unter der Textoberfläche, die Expression unterliegt keiner Disziplin [...]. «110

Während der »Wort-Ächzer« als Ansatzpunkt einer »archäologischen« Lektüre dienen kann (s. u.), möchte ich hier auf die von Kłosińska hervorgehobene somatische Dimension eingehen. Diese spielt im feministischen Verständnis eine zentrale Rolle in der Konzeptualisierung weiblichen Schreibens. Der »Somatismus" gilt Kraskowska in Anlehnung an Woolf als "allgegenwärtig« in der weiblichen Prosa und nimmt etwa in Brach-Czainas wegweisenden Szczeliny istnienia von 1992 eine zentrale Rolle ein. ${ }^{111}$ Weiblichkeit und Körperlichkeit bilden dabei in der patriarchalen Gesellschaft diskursiv verknüpfte Bereiche, die beide aus der logozentrischen Rationalität abjektiert werden. Symptom solcher Ausgrenzungen ist etwa der Hysteriediskurs, der weibliche Körperlichkeit pathologisiert und diese Pathologisierung auf das weibliche literarische Schaffen überträgt. ${ }^{112}$

Das Themenfeld psychosomatischer Abweichungen von der Norm wird auch in der weiblichen Literatur selbst angesprochen. So versuche etwa Santos das Paradoxon gleichzeitigen Ausschlusses und unumgänglicher Rahmung durch das logozentrische System mitzuteilen, indem sie ihren >Wahnsinn »Sprache des Körpers«, deren »integraler Teil« das »Leiden ${ }^{113}$ sei, beschreibbar mache, wie Janion feststellt. Kłosińska wiederum schreibt, dass Zapolskas Przedpiekle »die Pension als einen Ort vorstellt, an dem die junge Frau hysterisiert und

109 । Kłosińska: Ciało, S. 276f.: »kłamstwa współczesnego Polaka«; »kiedy krytyk próbuje ten punkt widzenia dookreślić, natrafia na trudność nie do pokonania, wszystko rozpływa się w ogólnych formułach«. Kłosińska bezieht sich auf Brzozowski, Stanisław: Współczesna powieść i krytyka, Kraków 1984, S. 118.

110 । Kłosińska: Ciało, S. 276f.: "Słów nie można tam oderwać od dźwięków nieartykulowanych, Zapolska mówi przez ssłowa-jęki<, ssłowa-szlochy‘. [...] Krzyki wydobywają się spod powierzchni tekstu niespodziewanie, ekspresja nie podlega dyscyplinie [...].«

111 I Kraskowska: Piórem niewieścim, S. 18: »wszechobecny [...] somatyzm«; vgl. Brach-Czaina: Szczeliny, S. 186 und ebd. die Kapitel »Otwarcie« und »Metafizyka mięsa«.

112 I Vgl. Kłosińska: Ciało, S. 14f., 22.

113 | Janion: Ciało skolonizowanych, S. 220: „Cierpienie jako integralną część języka ciała«. 
getötet wird « ${ }^{114}$. Beim weiblichen Schreiben handle es sich jedoch nicht primär um ein (voyeuristisches) Schreiben über das Körperliche (siehe Kapitel 4.1.2), sondern um ein Schreiben mit dem Körper. Dabei geht es einerseits um die Sprache des Körpers, die sich in körperlichen Symptomen und Handlungen äußert und die als eine Art 'Text gelesen werden kann; andererseits wird das Körperliche auch als Beweggrund und Ursprung des literarischen Schreibens betrachtet. ${ }^{115}$

Paradigmatisch für den feministischen Diskurs der 1990er Jahre in Polen in Bezug auf die Verbindung von Körperlichkeit und Schreiben kann neben Brach-Czainas Szczeliny istnienia auch Nasiłowskas Domino von 1995 gelten. Nasiłowska beschreibt ihr Traktat o narodzinach (Traktat über die Geburt, so der Untertitel) als einen für sie selbst unvorhersehbaren, erstaunlichen "Text, der zu wuchern begann ${ }^{116}$. Dieses selbstständig wachsende und wuchernde (rozrastać się) bringt Nasiłowska in Verbindung damit, dass der Prozess von Schwangerschaft und Geburt gemeinhin von einem Tabu belegt sei, weshalb es keine Erzählkonvention gäbe. Der Körper und seine Dynamiken verschafften sich deshalb selbst Überhand über das Erzählen und bestimmten auch die intimen Gespräche, die in der jungen Familie stattfinden und ebenfalls in das Traktat einfließen. Es sei letztlich das körperliche und emotionale Erleben, das etwas in Bewegung setze und so selbst zu einer `Stimme ‘ werde. So wird das tatsächliche, körperliche Gebären durch einen textuelles Gebären parallelisiert.

Auf die Verbindung der beiden 'Schöpfungsprozesse k kommt auch Borkowska zu sprechen, die sich dieser Gleichschaltung aber entgegenstellt. Sie resümiert, dass einige Feministinnen behaupteten,

»dass die Beziehung von Subjekt und Text biologischen Charakter habe, der dem Akt der Geburt eines Kindes eng entspricht. Die entschiedene Mehrheit wählt eine mildere Version der erwähnten Verwandtschaft: Der Text stellt eine Figur des Körpers dar, und der Schaffensprozess erinnert nur an den Geburtsakt. « ${ }^{117}$

Während Borkowska also hier lediglich eine metaphorische Parallele sieht, verknüpft Kłosińska Körperlichkeit und Schreibprozess direkter miteinander. Sie skizziert das Paradox der gesellschaftlich verankerten metaphysischen Annahme, dass Frauen nicht zur Kreation befähigt seien. Diese Annahme bestätige zudem die freudsche Psychoanalyse - doch

114 | Kłosińska: Ciało, S. 236: "przedstwia pensję jako miejsce, w którym młodą kobietę histeryzuje się i zabija«.

115 | Vgl. ebd., S. 21-25; Lindhoff: Einführung, S. 150-155.

116 | Nasiłowska: Domino, 0. S. [47].

117 | Borkowska: Cudzoziemki, S. 13: "że związek podmiotu i tekstu ma charakter biologistyczny, ściśle odpowiadający aktowi narodzin dziecka. Zdecydowana większość wybiera łagodniejszą wersję wspomnianego pokrewieństwa: tekst jest figurą ciała, a proces twórczy tylko przypomina akt narodzin.« 
"trotzdem schreibt [die Frau]. Man kann sich an dieser Stelle nur schwer der unfreiwilligen Assoziation widersetzen, die diese nicht-schaffende und doch mit dem Innern ihres Körpers schreibende Frau mit der Spinne in Verbindung bringt. Wie die Spinne, die aus ihrem Inneren Fäden spinnt, spinnt sie ohne sdarzustellen`, dazu verurteilt, lediglich ihre eigenen Tätigkeiten zu reproduzieren. ${ }^{118}$

Das weibliche literarische Schaffen werde im Patriarchat gerade nicht als kreative Tätigkeit definiert, sondern als bloße Reproduktion der eigenen Körperlichkeit. Der Text »ergieße« sich wie eine leibliche Geburt »besinnungslos» aus dem Leib der Frau, und »[i]hr Schreiben sieht man eher als eine automatische Tätigkeit an [...] denn als ein intellektuelles und volitionales Handeln. ${ }^{119}$ Obwohl Kłosińska diese Überlegungen als Resultat normativer Geschlechtervorstellungen und deren psychoanalytischer Auslegung darstellt, widersetzt sie sich der Umschreibung weiblichen Schreibens als somatischen Prozess nicht per se. Der "antifeministischen Haltung « ${ }^{120}$ hält sie allerdings entgegen, dass Selbstbestimmung und Kreativität auch im weiblichen Schreibprozess vorhanden seien und mit einem stärkeren Miteinbezug des Körperlichen nicht in Konflikt stünden.

An dieser Stelle lässt sich wieder an die Argumentation Borkowskas anschließen, die eine Korrespondenz zwischen der leiblichen Mutterschaft und dem literarischen Schaffen sieht, auch wenn sie diese nicht in eins setzen will. Von Żmichowska schreibt sie, dass diese

"das Band einer Gemeinschaft zwischen Schaffen und Mutterschaft baue. In der zurückhaltenden, verständigen Schaffenshaltung, die sie schätzte und achtete, und in der mütterlichen Haltung erblickte sie denselben Zug verantwortungsbewusster Liebe und Aufopferung, der überbordende Phantasien und Ambitionen selbstbeherrschte; dieselbe zärtliche Besorgnis, die die eigenen Pläne und Absichten überragte. « ${ }^{121}$

Es zeigt sich, dass Borkowska im Anschluss an Żmichowska eine grundsätzlich andere Parallele zwischen der leiblichen und der textuellen Mutterschaft zieht,

118 | Kłosińska: Ciało, S. 23f.: »jednak pisze. Trudno oprzeć się w tym miejscu mimowolnemu skojarzeniu owej, nietwórczej, a jednak piszącej wnętrzem swego ciała, kobiety z pająkiem. Jak pająk, wysnuwając ze swych wnętrzności nici, przędzie ona nie sprzedstawiając‘, skazana na to, by reprodukować jedynie własne czynności.«

119 | Ebd., S. 15: „Pisanie jej postrzega się bardziej jako czynność automatyczną [...], niż działanie intelektualne i wolicjonalne."

120 | Ebd., S. 23: "antyfeministyczną postawą".

121 I Borkowska: Cudzoziemki, S. 116: "zbudowała nić wspólnoty między twórczością a macierzyństwem. W powściągliwej, rozumnej postawie twórczej, tej, którą ceniła i szanowała, i w postawie macierzyńskiej dostrzegała ten sam rys odpowiedzialnej miłości i oddania, samoposkramiający wybujałe fantazje i ambicje, tę samą czułą troskę, górującą nad własnymi planami i zamierzeniami.« 
als dies bei den von Kłosińska vorgestellten gesellschaftlichen und psychoanalytischen Stereotypen der Fall ist. Borkowska findet nämlich bei Żmichowska einen Prozess der Sublimation, der sich auf leibliche Mutterschaft wie auch auf das literarische Schaffen bezieht. Dieses sei somit nicht Zeugnis von nicht-lesbaren "überbordenden Phantasien", sondern von einer Selbstüberwindung und -disziplinierung zugunsten des Anderen - des Textes. Dieser Prozess beruhe allerdings - und das ist für Borkowskas Weiblichkeitsbild von vorrangiger Bedeutung - auf einer emotionalen Bindung, die eine solche Selbsteingrenzung erlaube.

Während somit Żmichowska Borkowska zufolge die Körperlichkeit und das Schreiben der sozialen Ordnung unterwerfe, betont Kłosińska das Ungeordnete, Abjektierte, das im weiblichen Schreiben seinen Ausdruck finde und als solches die semantische Ordnung unterwandere. Der weibliche Text ist also in der Auffassung Kłosińskas nicht ein rein auf einer logozentrischen Intertextualität gründendes Neu-Schreiben, sondern von den somatischen Einbrüchen des Semiotisch-Vorsprachlichen durchlöchert. ${ }^{122}$ Auf diese Brüche des weiblichen Texts, an denen die Ambivalenz in der Lektüre erkennbar wird, möchte ich nun als Letztes eingehen.

\subsubsection{Oberfläche und Spalten}

Stellt man den Schreibprozess als solchen in den Hintergrund und betrachtet den weiblichen Text als Lektüregegenstand, ermöglicht dies ein erneutes Zurückkommen auf Kłosińskas Umschreibung der »Worte-Ächzer«. Diese bestehen, wie oben festgestellt, gleichsam aus Wörtern und einem Stöhnen, das nicht entlang des Symbolischen ausgerichtet, sondern "nichtartikuliert« ist. Beide Dimensionen würden sich weder definitiv auseinanderhalten lassen noch völlig miteinander verschmelzen. Die »Worte-Ächzer« können somit als eine Art dialogisches Verhältnis von Symbolischem und Semiotischem verstanden werden, wobei das Semiotische den Gegenspieler und die Subversion des männlichen Logos bildet; gleichzeitig werden diese hybriden `Worte zum Ansatzpunkt der feministischen Suche nach dem `Anderen $<$ des weiblichen Schreibens.

Hier werden Parallelen zu Brach-Czainas Konzeption sichtbar, die sich in Szczeliny istnienia mit den Bruchstellen der Oberfläche der `Realität beschäftigt. Ihr zufolge ist diese Oberfläche von unvermittelten Spalten (szczeliny) durchsetzt. "Das, was unsichtbar ist, versteckt sich in Ritzen, Spalten, Rissen, die ins Innere führen, unter die Oberfläche, auf die andere Seite derselben Wirklichkeit. ${ }^{123}$ In diese Spalten werde man gleichsam hineingesaugt, ohne sich völlig darin wiederfinden zu können. Als Ausgangspunkt der Oszillation von Oberfläche und Spalte gilt Brach-Czaina der Körper, und »die Welt platzt an der Stelle, die wir sind.»124

122 I Vgl. den Verweis auf die Signatursetzung der Romanfigur Kaśkas, die das Blatt des patriarchalen Vertrags aufreißt, Kłosińska: Ciało, S. 64-68.

123 I Brach-Czaina: Szczeliny, S. 172.

124 । Ebd., S. 185. 
Solche Verfahren des Eindringens unter die Textoberfläche hin zu einem von mir hier verallgemeinernd als \Semiotisches`Benannten lassen sich in vielen der feministischen Texte der 1990er Jahre finden. Interessant ist etwa die Umkehrung der Stoßrichtung, die Janion am Beispiel von Müllers Denn das ist das Schreckliche an der Liebe postuliert. An die Stelle einer Bewegung nach außen, dem Bestreben eines >Herausgelangens` aus dem System, tritt diejenige nach innen, unter die Oberfläche.

"Die Aufgabe, die sich Nicole Müller stellt, ist das Hineingelangen ins Innere der Realität, das Öffnen von Fakten. Diese nimmt auch körperliche Bedeutung an. Die Metapher des Körpers offenbart seine Beziehungen mit der Schreibprozedur. Michel Tournier zitiert Paul Valéry: >Die Wahrheit ist nackt; aber unter dem Nackten ist das Abgehäutete.« ${ }^{125}$

Wie bei Valéry geht es Janion zufolge auch bei Müller um ein Abtauchen unter die Oberflächenschicht, die sie metaphorisch als Haut bezeichnet. Janion sieht hier somit eine textuelle Offenlegung des Darunterliegenden, des Abgehäuteten (écorché) der Wirklichkeit, eine Entblößung der verhüllten Tiefenmechanismen des patriarchalen, heterosexuellen Diskurses.

Während Müller in der Auslegung Janions die Grenze von Oberfläche und Tiefenstruktur durchbricht und so das Innere an die Oberfläche holt, betonen andere feministische Kritikerinnen bei den von ihnen untersuchten Werken, dass diese eine textuelle Doppelbödigkeit aufrechterhalten. Sehr ähnliche Interpretationen bekunden Borkowska und Kłosińska, die beide von einer Art »subalternen« - wenn man hier die Terminologie Spivaks anwenden will ${ }^{126}$ - Textschicht ausgehen, die sich der einfachen Lektüre nicht (sofort) offenbart.

Borkowska spricht in diesem Zusammenhang von Żmichowskas »Strategie der Biene«, die sie am Beispiel von Żmichowskas »Vor-Einleitung« zu Hoffmanowas Dzieła (Werke, 1876) konzeptualisiert. ${ }^{127}$ Sie entdeckt im Text eine Häufung ironischer, zum Teil gar bissiger Kommentare, ${ }^{128}$ die jedoch gut verhüllt und durch das

125 I Janion: Kobiety, S. 142: „Zadanie, jakie stawia przed sobą Nicole Müller, to dostanie się do wnętrza realności, otworzenie faktów. Nabiera ono również znaczenia cielesnego. Metafora ciała ujawnia swe związki z procederem pisarstwa. Michel Tournier cytuje Paula Valéry: 'La vérité est nu, mais, sous le nu, il y a l'écorché.` [sic!]« Vgl. Valéry, Paul: Schlimme Gedanken und andere, Frankfurt a/M. 1963, S. 131.

126 | Vgl. Spivak, Gayatri Chakravorty: "Subaltern Studies: Deconstructing Historiography", in: Guha, Ranajit/Spivak, Gayatri Chakravorty (Hg.), In Other Worlds. Essays in Cultural Politics, 0xford 1988, S. 197-221.

127 | Vgl. Żmichowska, Narcyza: "Słowo przedwstępne do dzieł dydaktycznych pani Hoffmanowej«, in: dies. (Hg.), Dzieła Klementyny z Tańskich Hoffmanowa. Tom 8, Warszawa 1876, S. 207-297.

128 | Vgl. Borkowska: Cudzoziemki, S. 71. Siehe auch Walczewska: Damy, rycerze i feministki, S. 118f., die diese Auslegung Borkowskas als Fehllektüre kritisiert. 
»blinde Ansehen« der Rezipierenden für Hoffmanowa abgesichert seien: "Nicht viele Leser werden sich des Stachels gewahr, der im Essay über die didaktischen Schriften der anerkannten Autorin steckt. ${ }^{129}$ Die Polemisierung Żmichowskas gegen Hoffmanowas eher konservatives Frauenbild ziele, so stellt Borkowska fest, auf einen »scharfsinnigen, intelligenten Leser«, auf dessen »Reaktion [Żmichowska] zählt«. ${ }^{130}$ Diese Strategie könne man deshalb als eine Strategie der Kritik und des gleichzeitigen Selbstschutzes verstehen. Indem Borkowska aber hier von einem doppelbödigen Spiel mit der Literaturkritik und dem gesellschaftlichen Diskurs ihrer Zeit spricht, vollführt sie gleichsam eine Volte in ihrer eigenen Argumentation, in der sie zuvor eine wortlautgetreue Lektüre gefordert hatte (siehe 5.1.3).

Kłosińska entdeckt bei Zapolska ebenfalls eine Taktik der Herstellung einer skonformen Oberfläche, um darunter subversive Inhalte zu verstecken. Dies kann, so Kłosińska in folgendem Zitat, als eine Maskierungsstrategie gelten, die dem Weiblichen im patriarchalen Paradigma aufgedrängt werde und deshalb auch im Schreiben Anwendung finde. »In dieser Auffassung hat die `Zeichnung auf der Oberfläche` den Charakter einer gleichzeitig unwillkürlichen wie beabsichtigten Camouflage. Die schreibende Frau überträgt einfach ihre Maskierungsstrategie vom Leben auf die Literatur.« ${ }^{131}$ Diese Ambivalenz des Textes lässt sich laut Kłosińska an Textstellen ausmachen, in denen scheinbar Unbedeutendes Bedeutung gewinnt. Was in ’herkömmlichen` Texten als bloßer effet de réel nach Barthes ${ }^{132}$ diene, also als Einflechtung materieller Details zur Erzeugung eines Wirklichkeitseffekts, verweise im weiblichen Text Zapolskas auf die zweite, subalterne Ebene: an dieser Stelle dringe die weibliche Signatur durch. ${ }^{133}$

In gewisser Weise interpretiert somit die feministische Kritik das weibliche Schreiben als einen steten Verhandlungsprozess zwischen der Verdrängung an den Rand und dem Versuch einer bewussten Transgression zu einem Außen. Im Text äußere sich dies als Brüche oder Spalten, die bei »zweifacher« Lektüre ein Eindringen in die Tiefenstrukturen des herrschenden Systems ermöglichten. Das weibliche Schreiben hat somit keinen fixen Ort im literarischen Paradigma, sondern bedient sich verschiedener Strategien der Transgression oder des Oszillierens an den Grenzen des Symbolischen. Im Zusammenhang mit dieser Ortlosigkeit

129 | Borkowska: Cudzoziemki, S. 70: »ślepe uznanie«; »Niewielu czytelników dostrzeże żądło tkwiące w eseju na temat pism dydaktycznych uznanej autorki.«

130 | Ebd.: »licząc na reakcję ze strony domyślnego, inteligentnego czytelnika.«

131 I Kłosińska: Ciało, S. 28: »W tym ujęciu ’rysunek na powierzchniく ma charakter kamuflażu, zarazem mimowolnego i zamierzonego. Po prostu pisząca kobieta przenosi swoją strategię maskowania z życia do literatury.«

132 | Vgl. Barthes, Roland: "L'Effet de réel«, in: Communications 11/1 (1968), S. 84-89.

133 I Kłosińska: Ciało, S. 65f. Den Begriff der Signatur entlehnt Kłosińska von Miller: Subject to Change, S. 84. Miller operiert außerdem mit dem bei Kłosińska (Ciało, S. 75) ebenfalls eingesetzten Begriff der Hieroglyphe, die »as an open invitation to a feminist reading (Miller: Subject to Change, S. 78) gelten könne. 
steht auch die »Fragmentarizität und Episodiziät« des weiblichen Texts, die aus einer patriarchalen Sicht die »Kohärenz des Romans « ${ }^{134}$ zerstöre, wie Kłosińska schreibt. Auch Janion merkt an, dass die "Montage von Fragmenten « und die »Diskontinuität« Grundlage seien einer neuen »Erkenntniskraft. Die Fragmente werden zu einem Teil des neuen Diskurses « ${ }^{135}$.

Mit den obigen Ausführungen zeigt sich, dass die feministische Kritik den Begriff des >weiblichen Schreibens umreißen und thematisch wie stilistisch verorten kann, wenn auch eine abschließende Definition unmöglich erscheint. Zentral an der feministischen Herangehensweise, auch der polnischen 1990er Jahre, ist, dass die gesellschaftlichen und literarischen Stereotype über Weiblichkeit dekonstruiert werden und ihre negative Markierung verlieren. Das weibliche Anderssein wird als Erkenntnisgewinn verstanden und dessen literarischer Ausdruck nicht nur auf der Ebene literarischer Fiktion, sondern auch als Symptom und Verfahren der weiblichen Marginalisierung im patriarchalen System gesehen.

Die feministischen Polonistinnen binden dabei die soziale Geschlechtserfahrung der schreibenden/lesenden Instanz unterschiedlich stark an die Kategorie der weiblichen Literatur. Kraskowska vertritt hier die deutlichste Position des Isolationismus, der die Durchlässigkeit `weiblichen` und `männlichen`Schreibens/Lesens aufgrund geschlechtlicher `Eigenschaften`stellenweise vollkommen verneint. Janion nimmt die am wenigsten auf ein >weibliches Schreiben/Lesen fokussierte Haltung ein, weist aber in Kobiety $i$ duch inności teilweise genauso explizit auf eine `weibliche` Erfahrung hin, die von Männern nicht geteilt werden könne. Grundsätzlich lässt sich jedoch festhalten, dass die Ideologeme der untersuchten Monographien selten in sich völlig kohärent sind, sondern immer wieder Brüche und Verschiebungen der Argumentation stattfinden. Dies kann zwar einerseits wohl als Ausdruck der ideengeschichtlichen Verknotung und `Beschleunigung der 1990er Jahre gelesen werden, scheint mir jedoch ebenso der Thematik der literarischen Vergeschlechtlichung selbst geschuldet. Diese entzieht sich nicht nur einer ontologischen Festsetzung, sondern bleibt auch epistemologisch uneindeutig.

Alle Kritikerinnen sehen das ‘weibliche Schreiben als eine spezifische Form der Literatur, in der sich inkorporierte Zuschreibungen der >Weiblichkeit im Patriarchat - wie Somatismus, fehlende Synthesefähigkeit, Fokus auf den Alltag bemerkbar machen und in einer aufmerksamen »Überlektüre« des »Untergelesenen « ${ }^{136}$ fruchtbar gemacht werden können. Das Fruchtbarmachen bedeutet in den 1990er Jahren vor allem, einem weiblichen Lektürepublikum das vergeschlechtlichte Los der Frauen im Patriarchat vor Augen zu führen und gleichzeitig darauf

134 । Kłosińska: Ciało, S. 17: »Fragmentaryczność i epizodyczność niszczy spójność powieści«. 135 I Janion: Kobiety, S. 137: »Montaż fragmentów«; »nieciągłość«; »siłą poznawczą. Fragmenty stają się częścią nowego dyskursu«.

136 | Vgl. Miller: Subject to Change, S. 83. 
zu verweisen, dass trotz der Abjektivierung des Weiblichen im Patriarchat eine Art weiblicher Tradition bestehe. Auf diese möchte ich nun als letzten Punkt im vorliegenden Kapitel zu sprechen kommen.

\subsection{Tradierungen}

Mit der Erkenntnis, dass das Weibliche und sein literarischer Ausdruck marginalisiert werden, stellt sich die Frage, ob dieses in seinem Ausschluss und seiner Fragmentarizität überhaupt die Möglichkeit einer Traditionsbildung habe. Wie oben festgestellt, sehen die feministischen Kritikerinnen die Doppelbödigkeit weiblichen Schreibens als Einbruch des Somatischen und Semiotischen in das sprachlich geordnete Symbolische. Die feministische Kritik verweist darauf, dass trotz der patriarchalen Marginalisierung »die Erzählung der Frauen« »unter« der symbolischen Ordnung »ist, lebt ${ }^{137}$ : dass also eine Tradition in gewisser Hinsicht bestehe. Wie aber kann weibliche Schriftlichkeit und literarische (Gegen-)Konvention weitergegeben werden, wenn sie aus dem Diskurs weitgehend ausgeschlossen ist, oder anders gefragt: Wie kann das Semiotische gefasst und tradiert werden, wenn es mit der Sozialisierung verschüttet wird?

Einen Schlüssel sehen die feministischen Kritikerinnen im Somatischen: Die Intertextualität verschiebt sich auf die Körperlichkeit, einerseits auf die biologische Sequenz von Körpern sowie andererseits auf deren Affektivität. So schreibt Kraskowska, dass die größere Empathiefähigkeit von Frauen eine starke emotionale Bindung von Leserin, Schriftstellerin und Protagonistin über den Text herstelle. ${ }^{138}$ Die Leserin nehme so die Tradition auf, die der Text mitbringe. Hier geht es somit um eine Tradierung, die textimmanent stattfindet, im Prozess der Lektüre. Dies setzt allerdings einen konkret vorhandenen weiblichen Text voraus. Kłosińska hingegen suggeriert, dass sich weibliches Schreiben neben einer schriftlichen Tradierung auch aus sich selbst, aus der lebensweltlichen Erfahrung der Frauen im Patriarchat, reproduzieren könne. So sei etwa das literarische Verfahren der Mimikry ${ }^{139}$ - nicht zu verwechseln mit Borkowskas »Strategie der Mimikry« - als ambigues Schreiben, in dem das Wort das somatisch-semiotische Ächzen gleichsam verhüllt wie auch offenbart, eine Strategie, die die Weiblichkeit im sozialen Leben präge und sich somit aus diesem selbst speise. >Weibliches< Schreiben erscheint deshalb als Produkt einer sozialen Ordnung, deren Kontinuität auch die Kontinuität weiblichen Schaffens mit sich bringe.

Das weibliche Schreiben wird in der feministischen Kritik einerseits als Verdrängtes und Verschüttetes wahrgenommen, andererseits eröffne es durch seine Position am Rand des logozentrischen und hegemonialen Systems die Möglichkeit

137 I Iwasiów: Gender, S. 154: "pod spodem jest, żyje - opowieść kobiet«.

138 | Vgl. Kraskowska: Piórem niewieścim, S. 90.

139 । Vgl. Kłosińska: Ciało, S. 28. 
von Differenz und Wandel. Es beziehe sich aber nicht nur auf das zentrale männliche literarische Paradigma, sondern auch auf sich selbst. Damit steht es in einem doppelten intertextuellen Kontext, indem es sowohl das normative Paradigma wie auch die Differenzsetzung dazu als Rahmen der Transposition miteinbezieht. Somit führt ein prototypisches weibliches Schreiben seine subversive Tradierung gleichsam weiter. An dieser Stelle wird die feministische Spurensuche am Text relevant. Wie Kłosińska feststellt, kann sich das weibliche Schreiben trotz der Marginalisierung im patriarchalen System auf eine matrilineare Tradierung stützen, die sich über das intime Schreiben und den Alltagsgegenstand weitergeben lässt. Gleichzeitig lassen sich, wie Janion, Borkowska und Kłosińska beschreiben, im Text Spuren einer darunterliegenden Bedeutung finden. Diese Spuren lassen sich an Brüchen oder »Spalten« im Text festmachen, an denen die textuelle Oberfläche "aufplatzt«.

Die Lektüre, die in die Tiefen des Texts vorzudringen sucht, fragt nach der Sphäre weiblicher Tradierung, die außerhalb literarischer Fixierung, als eine Art Kristeva'scher chora, bestehen soll. Dieses Eindringen in den Text und die Suche nach Spuren des Weiblichen untersuche ich im vorliegenden Unterkapitel. Dabei wird ersichtlich, dass die feministischen Kritikerinnen im Zug archäologischer Lektüren Verweise auf kanonisierte Frauenfiguren etwa aus der griechischen Antike freilegen, an deren Schicksal sie die Beständigkeit patriarchaler Ausgrenzung aufzeigen. Zentraler noch wird für die feministische Kritik aber das Konzept der matrilinearen Genealogie. Diese erstreckt sich einerseits bis auf die Vorstellung eines vorzeitlichen Matriarchats, andererseits bezieht sie sich auf die Aufrechterhaltung der matrilinearen Tradition in jeder Generation mit der Weitergabe von Mutter zu Tochter. Hier kommt erneut Kristevas Konzept des Semiotischen ins Blickfeld, das als Sphäre des Mütterlichen diese Tradierung garantieren soll.

\subsubsection{Archäologien am Text}

Die feministische Neulektüre kann textintern die Form archäologischen ${ }^{140}$ oder auch detektivischen Vorgehens annehmen. Dabei kann die Popularität von Brach-Czainas philosophischem Essay Szczeliny istnienia von 1992 wohl als Mitauslöser der archäologischen Tiefenforschung der feministischen Kritikerinnen am literarischen Text gelten. Brach-Czainas Ergründung der »Spalten des Daseins" fügt sich konzeptuell reibungslos in die archäologischen Lektüren, wie sie Iwasiów oder Kłosińska vorschlagen. Im Text unwillentlich angelegte Spuren, die in der Lektüre kultursoziologisch ausgewertet werden können, rechtfertigen ein Lesen des Textes auch "gegen den Strich«. Kraskowska beschreibt das Lektüreverfahren in einem Artikel von 2002 so: »Die Leser-Frau sieht sich selbst oft in der Rolle eines Detektivs, der die vom Verursacher der Tat (des Textes) ungewollt

140 I Iwasiów setzt diese Terminologie in Anlehnung an Foucaults Archäologie des Wissens ein, vgl. Iwasiów: Kresy, S. 18. Siehe auch »L'Archéologie du savoir« in Foucault: CEeuvres, S. 3-224. 
hinterlassenen Spuren verfolgt. ${ }^{141}$ Relevant wird insbesondere der Verweis auf den unbeabsichtigten Charakter der Spuren, denen die feministische Kritik folgt. Es gehe also nicht um das Aufschlüsseln eines im Text intentional angelegten Rätsels, sondern um das Aufspüren nur reliktartig vorhandener Zeugnisse systemischer Macht und deren Subversion. Ein weibliches Schreiben, wie es Iwasiów für sich selbst projektiert, muss deshalb »[d]ie Spur wiederfinden, das Ende des Fadens erhaschen, ein spinnenes Netz bauen [...]. Den Rauch, den Abdruck im Sand, den verhallenden Atemzug beschreiben. ${ }^{142}$

Das Ausgraben von »Tieferliegendem« funktioniert in der Arbeit mit Texten sowohl weiblicher wie männlicher Autorschaft, wie Iwasiów mit ihrer Absicht demonstriert, in Odojewskis Werk die »Figur, die am tiefsten im textuellen Gebirge liegt ${ }^{143}$, aufzuspüren. Dabei enthüllt sie archetypische Muster, deren Traditionen die Figuren unbewusst folgen: »Das weiß weder [die Figur Paweł] selbst noch sonst irgendwer, keine Textinstanz, noch der Zyklus als autonome Sinneinheit. Erst die archäologische Lektüre enthüllt diesen Zustand [...]. 144 $^{14}$

Kłosińska beschreibt ihr Vorgehen ebenfalls in archäologischen Termini:

"[W]ir müssen die von der Schriftstellerin hinterlassenen Spuren verfolgen und so eine archäologische Arbeit ausführen, bei der wir versuchen, in die Tiefenschichten des Texts vorzudringen, auf denen dann die vom Roman aufgezeichnete Gesellschaftsordnung siedelt. Unter dem, was der Roman darstellt, ist etwas, das verhüllt wurde und das die Lebensquelle für Romanheldin und Autorin bildet. ${ }^{145}$

Iwasiów und Kłosińska gehen von der Annahme aus, dass die archäologische Textlektüre eine hinter der Fassade des Textes stehende Struktur zu enthüllen vermag. Diese Struktur nennt Iwasiów Archetypus, Kłosińska aber »das ewig verdrängte

141 I Kraskowska, Ewa: „Czytelnik jako kobieta«, in: Zacharska, Jadwiga/Kochanowski, Marek (Hg.), Wiek kobiet w literaturze, Białystok 2002, S. 15-31, hier S. 21: "Czytelnik-kobieta często widzi siebie w roli detektywa tropiącego pozostawione niechcący przez sprawcę czynu (tekstu) ślady."

142 I Iwasiów: Ślady, S. 101: "0dnaleźć ślad, chwycić koniec nitki, zbudować pajęczą sieć [...]. Opisać dym, odcisk na piasku, zamierające tchnienie."

143 I Iwasiów: Kresy, S. 12: »figury, która - leżąc najgłębiej w tekstowym górotworze«.

144 । Ebd., S. 95: »0 tym nie wie ani on [Pawel] sam, ani ktokolwiek, jakakolwiek instancja tekstu, ani cykl jako autonomiczna jednostka sensu. Dopiero lektura archeologiczna odsłania ten stan nierównowagi."

145 I Kłosińska: Ciało, S. 193f.: "musimy tropiąc ślady pozostawione przez pisarkę wykonać pracę archeologiczną, próbując dotrzeć do głębinowych warstw tekstu, na których potem osiada zapisany przez powieść porządek społeczny. Pod tym, co powieść przedstawia, jest coś, co zostało zasłonięte, a co stanowi żywicielskie źródło dla bohaterki powieści i autorki.« 
mütterliche signifié ${ }^{146}$. Beide Umschreibungen bezeichnen etwas Unerreichbares und dadurch Begehrliches, das als solches den sozialen und literarischen Diskurs (unbemerkt) mitforme. Der kulturelle Text baue auf dieser Grundstruktur auf und aktualisiere diese so. Es handelt sich um eine Intertextualität, bei der der "Archetext« nicht als versprachlichter Text verstanden werden muss, sondern als eine Art primärer kultureller Ordnung. ${ }^{147}$ Von dieser »Lebensquelle« ( $\dot{z} y$ wicielskie źródło) ist gemäß Kłosińska nicht nur der Roman, sondern auch die Schriftstellerin geprägt.

Kłosińska verweist auf den Ansatzpunkt in der Textfassade, an dem die archäologische Arbeit ansetzen kann. »Die Texte Zapolskas [...] sind innerlich geborsten: Neben dem, was sie als vorhanden festhalten, artikulieren sie immer einen gewissen Mangel, irgend ein Bedürfnis. ${ }^{148}$ Auf diese Brüche und Lücken deute im Text die weibliche Signatur hin, der Kłosińska auf die Spur geht. ${ }^{149}$ In Zapolskas Kaśka Kariatyda setzt die des Schreibens unkundige Bedienstete Kaśka anstelle einer Unterschrift ein bloßes Kreuzchen $(k r z y z \dot{z} k)$. Dieses werde laut Kłosińska zur weiblichen Signatur im patriarchalen System: »Ihre Identität bescheinigt Kaśka mit dem Setzen des Kreuzchens - dem Zeichen des Leidens und des Todes. « ${ }^{150}$ Indem Kaśka beim Setzen des Kreuzchens gar das weiße Papier des Haushaltsinventars etwas aufreißt, werde diese Textstelle umso mehr zum Ansatzpunkt der zweifachen Lektüre, die durch diesen Riss auf das Dahinterliegende stoße. Das »Kreuzchen« als »Zeichen-Narbe gebietet [każe] an eine gewisse matriarchale Ursprünglichkeit zu denken ${ }^{151}$ und kann damit wohl als typischer Vertreter eines »Wort-Ächzers« gelten.

In der archäologischen Lektüre legen die feministischen Kritikerinnen die Verbindungen der literarischen Protagonistinnen zu mythologischen Frauenfiguren frei. Manchmal sind diese Verbindungen offen im Text angelegt, wie bei Zapolskas Kaśka Kariatyda, die schon im Titel auf die mythologische Karyatide

146 । Ebd., S. 193, Hervorh. i. 0.: »wiecznie odsuwane macierzyńskie signifié«.

147 | Auf diese quasi vor- oder urkulturelle Dimension verweist bei Iwasiów die Häufung geologischer und organistischer Metaphern: das "Gebirge " (górotwór), die »tektonischen Schichten« (warstwy tektoniczne) mit Erosionen und inneren Erschütterungen (erozje i wewnętrzne wstrząsy) oder die »Quelle « (źródło); auch »Wurzeln« (korzenie), »Baumgewirr« (plątaninę drzew), »Dickicht« (gąszcz) und schließlich »Rhizom « (kłącze), um die hinter dem Text siedelnde Struktur zu beschreiben (Iwasiów: Kresy, S. 9 [132], 12, 26). Damit unterstreicht Iwasiów die archaische und nur schwerlich zu überblickende Struktur, die dem Text zugrunde liegt, und die sich durch überlagernde sSchichten` oder verwirrendes Geäst der einfachen Lektüre entzieht.

148 I Kłosińska: Ciało, S. 288: „Teksty Zapolskiej [...] są wewnętrznie pęknięte: prócz tego, co zapisują jako obecne, zawsze artykułują pewien brak, jakieś pragnienie."

149 | Vgl. ebd., S. 59.

150 । Ebd., S. 67: "Swoją tożsamość zaświadcza Kaśka stawiając krzyżyk - znak cierpienia i śmierci."

151 I Ebd., S. 68: »znak-blizna [...] każe myśleć o pewnej matriarchalnej pierwotności«. 
hinweist, oder in Filipiaks Roman Absolutna amnezja, der wiederholt auf die Figur der Iphigenie referiert. Zentral bei solchen Parallelführungen ist in der Regel, mithilfe der antiken Figur und ihres Schicksals einen spezifischen Aspekt der neuzeitlichen literarischen Figur oder deren Geschicke im Handlungsgeschehen hervorzuheben. Die Figuren erscheinen als schwesterliche Leidensgenossinnen unter einem fortwährenden patriarchalen System. Die griechischen Mythen werden deshalb in der feministischen Kritik in Polen als ein Fundus archetypischer Konstellationen von Charakteren im sozialen Kontext verstanden und als solche Urmuster in den literarischen Texten gelesen. Die antiken Motive dienen als zusätzliche Auslegungsinformation: Wenn bei Filipiak die Rede von Iphigenie ist, dann weist der Roman der Iphigenie-Sage folgend verstärkt auf den Aspekt des weiblichen Opfers für die Gemeinschaft hin.

Parallelen zwischen literarischen Figuren und mythischen oder biblischen Figuren lassen sich auch ohne direkten namentlichen Verweis im Material finden: Iwasiów erkennt in der Mutter/Schwiegermutter Woynowiczowa aus Odojewskis Kresy-Zyklus die biblische Figur der ortsverbundenen Frau Lots. ${ }^{152}$ Damit schließt sich Iwasiów der Auslegung dieser Figur an, wie sie in der Odojewski-Rezeption bereits hervorgehoben wurde und die mit dem Tod der Woynowiczowa, die ihren Hof nicht aufgeben wollte und als gelynchte Hausherrin letztlich in der Jauchegrube zu einer Säule gefriert, auch im Text selbst deutlich angelegt ist. ${ }^{153}$

Die feministische Kritik vermerkt, dass die mythischen `Schwestern weiblichen Literatur mehr als eine reine Abbildfunktion einnehmen können. Die mythologische Figur kann neue Dimensionen gewinnen und ihr Schicksal intertextuell umgeschrieben werden. Dies ist insofern relevant, als die aufgerufenen Figuren in aller Regel tragische Figuren sind, die zumeist unverschuldet für die Verfehlungen ihrer jeweiligen Gesellschaft büßen. Eine solche Transformation zeigt sich etwa bei Filipiak, wo der Iphigenie-Mythos gemäß Janion "zum Phönixmythos wird. [...] Sie soll als Opfer auf dem Scheiterhaufen verbrennen; dieser aber kann zum Feuer werden, aus dem der Wundervogel Phönix aufersteht. $\wedge^{154}$ Der Ausbruch aus dem antiken Muster liegt bei Filipiak in der Einstellung der Hauptfigur Marianna, wie Janion feststellt: Sie erklärt sich nicht mehr zur Aufopferung bereit und entzieht sich der Pflichten, die ihr die Gesellschaft auferlegt. Janion zufolge macht diese Umdeutung und Neuschreibung des tradierten Rollenmuster den feministischen Charakter von Filipiaks Text aus. ${ }^{155}$

152 I Vgl. Iwasiów: Kresy, S. 114 sowie Hadaczek, Bolesław: Kresy w literaturze polskiej XX wieku. Szkice, Szczecin 1993, S. 144.

153 | Vgl. Odojewski: Zasypie wszystko, S. 452f.

154 I Janion: Kobiety, S. 342f.: »staje się mitem Feniksa. [...] Ma spłonąć na stosie ofiarnym, ale może on stać się stosem, na którym odradza się cudowny ptak Feniks. "Diese >Wiedergeburt fügt sich allerdings noch in den antiken Iphigenie-Mythos ein, wo Iphigenie nach einigen Tradierungen im Moment ihrer Opferung von Artemis gerettet wird. Vgl. ebd., S. 332.

155 | Vgl. ebd., S. 327. 
Auf den produktiven Charakter der Parallelenziehung von mythischer Figur zu Romanfigur verweist auch Kłosińska anhand von Kaśka Kariatyda. Es gehe aber weder um ein Umschreiben des Musters noch »um ein antikes Kostüm, [...] ein Spiel mit antikem Zubehör «156, wie Kłosińska zu Zapolskas Verweis auf den Karyatiden-Mythos schreibt. Es handle sich um eine Form der Tradierung, der Matrilinearität, die an eine mythische weibliche Gemeinschaft anschließe:

"Daher ist die Identität mit den Karyatiden 'Schwesternschaft‘, Blutsbande, die eine für das Matriarchat grundlegende Verwandtschaft bilden. In der titelgebenden Verbindung 'Kaśka Kariatyda tritt das Wort 'Karyatide ‘ an die Stelle, an der dem patriarchalen Brauch gemäß das Patronym erwartet wird, das den rechtlichen Besitzer des Familiennamens ausweist, den Vater. Das Patronym ist also der die (patriarchale) Kultur ordnende 'Name des Vaters . Zapolska, die das Patronym mit einem, sagen wir, ’Matronym < ersetzt, verweist auf die matrilineare Genealogie Kaśkas. In dieser Berufung auf die schwesterlichen und mütterlichen Bindungen steckt eine aufwieglerische Geste. ${ }^{157}$

Die Matrilinearität verdrängt Kłosińska zufolge den - in Kaśka Kariatyda tatsächlich vollkommen abwesenden - Vater aus seiner definierenden Position. Anstelle der patrilinearen Genealogie werde eine weibliche Tradition hergestellt, die mit dem Verweis auf die mythische Säulenfigur der Karyatide als gleichzeitig unterdrückte wie auch tragende Parallelwelt der patriarchalen Gesellschaft konstruiert wird. Die Funktion der Karyatide als `Trägerin`, als Stütze der Gesellschaft, impliziert gleichzeitig deren potentielle Macht der Verweigerung und des Zusammenbruchs der Ordnung. Kłosińskas Auslegung des Karyatidenmythos und ihre überzeugende Argumentation in Bezug auf die Ersetzung des Patronyms durch ein Matronym kontextualisieren die Figur der Kaśka in einem matrilinearen Kontinuum, das als potentielle Gegenkraft zur patriarchalen Gesellschaft aktiviert werden könnte. Die mythische Karyatide bildet als einzige uneigennützige Verbündete der Hauptfigur ein weibliches Gemeinschaftsangebot, das im Roman Kaśka Kariatyda allerdings nicht eingelöst wird.

Die Anbindungen an die mythischen Schwestern haben somit nicht nur illustrativen Charakter. Für die feministische Kritik dienen sie außer als Analyseschlüssel der Texte auch als Ansatzpunkte der Subversion der etablierten symbolischen Ordnung. Mit der intertextuellen Anbindung eröffnet sich so eine Form

156 । Kłosińska: Ciało, S. 52: »0 kostium antyczny, [...] grę antycznymi akcesoriami.«

157 | Ebd.: "A zatem tożsamość z Kariatydami to ssiostrzaność<, więzy krwi, które budują pokrewieństwo, zasadnicze dla matriarchatu. W tytułowej zbitce ’Kaśka Kariatyda‘, słowo ’Kariatyda występuje w miejscu oczekiwanego zgodnie ze zwyczajem patriarchatu patronimu, gdzie wskazywał on prawnego właściciela nazwiska rodowego, 0jca. Patronim zatem jest porządkującym kulturę (patriarchalną) simieniem 0jca<. Zapolska zastępując patronim, powiedzmy, ’matronimem‘, wskazuje na matrylinearną genealogię Kaśki. W tym odwołaniu się do więzi siostrzanych i macierzyńskich zawiera się gest burzycielski.« 
der Tradierung weiblicher Schicksale, in deren Fort- oder Umschreibung gesellschaftliche Verschiebungen genauso angesprochen werden wie die Beständigkeit der patriarchalen Ordnung.

Diese Parallelführung zu »zivilisatorischen Archetypen« zumindest der westlichen Kultur erlaubt es den feministischen Kritikerinnen, gewisse Verallgemeinerungen und Essentialisierungen über die weibliche Erfahrung im patriarchalen System zu treffen. Der historisch-mythische Kontext legt sich über die neuzeitlichen Diskurse und Lebenswelten: »Es läuft darauf hinaus, dass wir die Sage leben. Oder wir bemühen uns, sie zu überwinden « ${ }^{158}$, resümiert Iwasiów 2004. Eine solche Ineinssetzung von Mythos und Gegenwart liefert bequeme Verallgemeinerungen sozialer Handlungsmuster, womit die gesellschaftlichen Dynamiken Ende des 20. Jahrhunderts gleichsam lesbarer und intersektionelle Verstrickungen heruntergebrochen werden. Mit der mythischen Dimension hebt die feministische Kritik die Determiniertheit des weiblichen Loses im Patriarchat stärker hervor und kann so entlang der archetypischen Konstellationen mögliche subversive Handlungsmuster prägnanter entwickeln; gleichzeitig geht dabei jedoch der Blick auf interferierende Dynamiken etwas verloren (siehe Kapitel 6.1.3).

\subsubsection{Matrilineare Genealogien}

Im Zuge der archäologischen Verfahren der feministischen Kritik tauchen neben den mythischen `Schwestern auch Verweise auf eine matriarchale Gemeinschaft auf. Diese wird im vorsprachlichen Bereich angesiedelt und sei durch die historische oder individuelle Sozialisierung verdrängt worden: Sie kann prähistorische Dimensionen annehmen und als Urgottheit der Muttergöttin (Wielka Bogini) aufgefasst werden, wie etwa Iwasiów vorschlägt. Kłosińska hingegen sieht die matriarchale Gemeinschaft im Sinne feministischer Psychoanalyse als die vorsprachliche, prä-ödipale Phase des Kindes, in der dieses in Einheit mit der mütterlichen Sphäre weilt. Beiden Wissenschaftlerinnen geht es um die Wiederaufnahme eines Kontaktes mit diesen jeweiligen matriarchalen Sphären, um die Suche nach dem "verhallenden Atemzug « ${ }^{159}$ der matriarchalen Vorzeitlichkeit oder dem »Phantasma der mütterlichen Stimme $«^{160}$. Im Folgenden will ich deshalb abschließend untersuchen, wie diese Kontaktnahmen über den Text zur Konstruktion einer matrilinearen Genealogie ausgebaut werden und welche Fährten der Tradierung die feministischen Kritikerinnen dabei vorschlagen.

Iwasiów stellt fest, dass die patriarchale Ordnung im Kresy-Zyklus Odojewskis bereits eine unter der eigentlichen Handlung liegende »Schicht» des Textgebirges darstelle. »Der patriarchale Mythos ist von einer Haut kultureller Gesten

158 I Iwasiów: Gender, S. 138: "Tak się składa, że żyjemy sagą. Lub staramy się ją przezwyciężyć."

159 I Iwasiów: Ślady, S. 101: "zamierające tchnienie«.

160 । Kłosińska: Ciało, S. 194: »fantazmat głosu macierzyńskiego«. 
bedeckt, die voll funktionsfähig sind «161 und die die operative Oberfläche des patriarchalen Systems bilden. Obwohl der wirklichkeitsformende patriarchale Mythos somit "unter « den »kulturellen Gesten« liege, geht Iwasiów in ihrer Suche nach dem »Anfang " (początek), der "Dämmerung " (zmierzch), ${ }^{162}$ noch weiter. Dabei entdeckt Iwasiów, dass die Geschlechterordnung nur deshalb so strikt dual organisiert sei, weil sie stets von ihrer Überwerfung durch das ,Verschüttete bedroht sei: »Die besondere Unerbittlichkeit, mit der das Patriarchat versucht, sich die Rolle der Frau unterzuordnen, stammt von der aktiven Funktion des Archetypus der Mutter, der immer noch das kulturelle Unterbewusstsein der Menschheit in Aufruhr bringt. ${ }^{163}$ Hinter - respektive historisch vor - der patriarchalen Ordnung stehe der Archetypus der Mutter, versinnbildlicht in der vorzeitlichen Muttergöttin.

Interessant an diesen Ausführungen Iwasióws zum Topos der Muttergöttin ist, dass ihre Überlegungen weniger in der Tiefenlektüre des Odojewski-Texts gründen, sondern als Chiffren eines kulturwissenschaftlich-ethnographischen Metatexts auf das literarische Beispiel übertragen werden. Iwasiów bezieht sich hier nämlich auf ein Konglomerat von Texten, das von Freud, Jung und Bruno Bettelheim über den Religionsethnologen James George Frazer bis hin zu Bataille und Lévi-Strauss gewichtige Namen der entsprechenden Forschungsrichtungen aufweist. Iwasiów macht die grundsätzlichen Mängel der Theorien Freuds daran fest, dass dieser kein Interesse für das Ur-Weibliche aufbringe, wie er in Totem und Tabu (1913) einräume: »Wo sich in dieser Entwicklung die Stelle für die großen Muttergottheiten findet, die vielleicht allgemein den Vatergöttern vorhergegangen sind, weiß ich nicht anzugeben. ${ }^{164}$

Die Argumentationen Jungs und vor allem Bettelheims affirmieren die Archetypus-Suche Iwasióws. Sie verstünden die patriarchale Ordnung als Inversion der primären Ordnung: als Negierung und Verdrängung des Weiblichen und gleichzeitiges Begehren dieses `Urzustands «. »Der Mann sehnt sich nach der Weiblichkeit«, fasst Iwasiów die Thesen Bettelheims in Symbolic Wounds (1954) zusammen, und: »Das psychische Gefängnis des Mannes ist das Gefühl, als Nicht-Frau ein nicht vollwertiger Mensch zu sein. ${ }^{165}$ Mit der patriarchalen Umkehrung habe

161 I Iwasiów: Kresy, S. 100: »Mit patriarchalny przykryty jest naskórkiem kulturowych gestów, w pełni funkcjonalnych«.

162 | Vgl. ebd., S. 7.

163 | Ebd., S. 102. „Szczególna zajadłość, z jaką patriarchat stara się upodrzędnić rolę kobiety, bierze się z aktywnej funkcji archetypu matki, wciąż podsycającego kulturową podświadomość ludzkości."

164 I Freud, Sigmund: Totem und Tabu. Einige Übereinstimmungen im Seelenleben der Wilden und der Neurotiker. Gesammelte Werke. Neunter Band, Frankfurt a/M. 1973, S. 180. Vgl. Iwasiów: Kresy, S. 106.

165 I Iwasiów: Kresy, S. 152: »mężczyzna tęskni do kobiecości«; »Więzieniem psychicznym mężczyzny jest poczucie bycia niepełnowartościowym człowiekiem jako nie-bycie-kobietą.« 
auch ein »Wandel des Beschreibungscodes des 'männlichen Elements und des 'weiblichen Elements [ [stattgefunden]. Frau bedeutet seither ein passives Wesen, dem Gott-Vater ergeben [...]. ${ }^{166}$ Diese umgekehrten »Elemente« des Patriarchats sind es denn auch, die Iwasiów in der Struktur des Kresy-Zyklus Odojewskis wiederfindet, und die sie als Verweis auf das verdrängte Matriarchat auslegt.

Iwasiów widmet sich dem Ursprungsmythos des Matriarchats in seiner historischen Dimension, als Ursprung der menschlichen Geschichte. Auf die 'Neuinszenierung des Ursprungs mit der Geburt jedes Menschen weist hingegen Brach-Czaina in Szczeliny istnienia hin, die sich wie Iwasiów der Begriffe des »Anfänglichen« (poczatkowe) und »Ursprünglichen« (pierwotne) bedient. Hier, beim Phänomen der Geburt, wiederhole sich die Frage nach der Geschlechtwerdung. Diese Frage bespricht auch Janion 1993 am Beispiel der polnischen Übersetzung von Badinters $X Y$, de l'identité masculine ${ }^{167}$ Badinter reihe sich dabei in eine Tradition, die sich der freudschen Auslegung der primären männlichen Geschlechtsorientierung widersetze und das Weibliche als das Ursprüngliche betrachte.

»Die Protoweiblichkeit des menschlichen Kindes übernimmt Badinter [von Stoller] als Grundvorannahme. Erstrangige Bedeutung hatte für sie auch die Inspiration durch den Physiologen Alfred Jost, der vierzig Jahre zuvor aufzeigte, dass bei allen Säugetieren das weibliche das ursprüngliche Geschlecht ist. Diese Beweise aus wissenschaftlichen Untersuchungen können auch ideologischen Überzeugungen dienen: Die Hinterfragung der biologischen Ursprünglichkeit der Männlichkeit eignet sich zum Untergraben des im Patriarchat gängigen Primats des Mannes, dem die Frau auf `natürliche` Art untergeordnet sei.

Am Anfang war also die Frau und aus inr wurde alles geboren. « ${ }^{168}$

In diesen Ausführungen finden Verwischungen zwischen dem "geschlechtlichen Identifikationsmodus" und der »biologischen Ursprünglichkeit» eines Geschlechts statt. Die Grenzen zwischen biologischer und sozialer Ausprägung von Geschlechtlichkeit zieht Janion hier nicht klar; sie scheinen sich gegenseitig zu

Siehe auch Bettelheim, Bruno: Symbolic Wounds. Puberty Rites and the Envious Male, Glencoe, III. 1954.

166 I Iwasiów: Kresy, S. 102: "zmianę kodu opisującego spierwiastek męski i spierwiastek żeński<. Kobieta oznacza odtąd istotę bierną, poddaną Boga-0jca«.

167 | Janion: Niańka i kowboy, hier zit. nach Janion: Kobiety.

168 I Janion: Kobiety, S. 179f.: »Protokobiecość ludzkiego dziecka zostaje przyjęta przez Badinter jako podstawowe założenie. Pierwszorzędne znaczenie miała dla niej również inspiracja fizjologa, Alfreda Josta, dowodzącego przed czterdziestu laty, że u wszystkch ssaków płcią pierwotną jest płeć żeńska. Te zaczerpnięte z badań naukowych dowody mogą służyć również przeświadczeniom ideologicznym [1996: innego typu]: zakwestionowanie biologicznej pierwotności męskości przydaje się do podważenia przyjętego w patriarchacie prymatu mężczyzny, któremu w sposób 'naturalny ma być podporządkowana kobieta. Na samym początku więc była kobieta i z niej się wszystko zrodziło.« 
durchdringen. ${ }^{169}$ Ungeachtet dessen stellt Janion fest, dass Badinter die Männlichkeit als "sekundär« (wtórny) ${ }^{170}$ definiere, womit diese ihre natürliche Vormachtstellung verliere. Diese Feststellung »zielt auf die Bibel, auf Freud, auf das Patriarchat ${ }^{171}$ und damit auf die Grundfeste westlicher Gesellschaften. Janion sieht trotz Vorbehalten den Thesen Badinters gegenüber ${ }^{172}$ einen großen Bedarf an kritischer Hinterfragung patriarchaler angeblicher `Offensichtlichkeiten`:

"Es scheint, dass jedes auch nur gedankliche Experiment in dieser Materie in Polen eine kolossale Bedeutung annehmen kann - in einem Land, in dem das patriarchale Bauerndenken im Verbund mit einem ebenso patriarchalen Lehrstil der katholischen Kirche dominiert. Wenn das Buch Badinters bei uns auch nur im geringsten Grad dazu beitrüge, diese alle erniedrigende Redeweise von den `Kosten der Frauenemanzipation` zu ändern... «"173

Janion verstärkt damit die Position sich emanzipierender Frauen, die keine Usurpatorinnen der reigentlich` patriarchalen Ordnung seien. Sie konstruiert deren Forderungen als legitim, das patriarchale System hingegen als überfällig. Diese argumentative Umkehrung gewinnt besonders im Zusammenhang mit dem Aufopferungsnarrativ an Gewicht, dem die polnischen Frauen diskursiv untergeordnet werden (siehe Kapitel 6.2.4).

Eine ähnliche Argumentation wie jene Badinters erkennt Borkowska bei Żmichowska. ${ }^{174}$ Sie verweist darauf, dass Żmichowska sich »- wie die Postfreudisten für positive Anreize und nicht für die Mechanismen der Repression [interessiert]. Anders als später Freud hält sie die Weiblichkeit, nicht die Männlichkeit für den universalen Identifikationsmodus des Geschlechts, für den Beginn des langen Weges zur Reife. « ${ }^{175}$ Żmichowska, so Borkowska, inszeniere die Weiblichkeit oder das Mütterliche als weniger repressive Kraft, die die »natürlichen Veranlagungen« und

169 | Später spricht Janion von Badinters "Suggestion, dass jeder Embryo zuerst weiblichen Geschlechts sei« (ebd., S. 180: "sugestię, jakoby każdy embrion był pierwotnie wyposażony w płeć żeńską«) - es geht hier also durchaus auch um einen biologischen Aspekt.

170 । Ebd., S. 179.

171 I Ebd., S. 180: "godzi w Biblię, we Freuda, w patriarchat«.

172 I Siehe dazu Kapitel 6.3.3.

173 | Janion: Kobiety, S. 179: „Wydaje się, że każdy, choćby myślowy eksperyment w tej materii, może mieć kolosalne znaczenie w Polsce - kraju, w którym dominuje patriarchalne myślenie chłopskie sprzężone z równie patriarchalnym stylem nauk Kościoła katolickiego. Gdybyż książka Badinter przyczyniła się u nas - choćby w najmniejszym stopniu - do zmiany tego poniżającego wszystkich sposobu mówienia 0 ’kosztach emancypacji kobiet...."

174 I Borkowska bezieht sich konkret auf Janions Vorwort zu Badinters $X Y$, vgl. Borkowska: Cudzoziemki, S. 140.

175 । Ebd., S. 140f.: »będzie się interesować - tak jak postfreudyści - bodźcami pozytywnymi a nie mechanizmami represji. Inaczej niż później Freud uzna kobiecość, a nie męskość za uniwersalny modus identyfikacji płciowej, za początek długiej drogi do dojrzałości.» 
damit die »innere Harmonie des Geisteslebens « ${ }^{176}$ des Nachwuchses zu fördern verstehe. Der literarische Ansatz Żmichowskas, der die Weiblichkeit höher einstufe als die von Freud favorisierte Männlichkeit, gewinnt bei Borkowska einen mit postfreudianischen Theorien gleichgestellten Rang (siehe auch Kapitel 4.2).

Stärker auf die negativen Folgen der Verdrängung des Mütterlichen in der Sozialisation des Kindes geht Kłosińska am Beispiel von Zapolskas Przedpiekle ein. Der Muttermangel der Mädchenfigur Stasia bewirke, dass sie in der Pension und insbesondere durch das Erlernen des Klavierspiels bei einem restriktiven Lehrer in hysterische Anfälle verfalle. Die Tonleiter des Klaviers als symbolisch-strukturierte werde jedoch durch das Rauschen des Schilfrohrs kontrastiert, in dem sich das weiblich geprägte Semiotische und die »Unveräußerlichkeit der mütterlichen Stimme ${ }^{177}$ äußere. Das monotone, "aquatische « Rauschen des Schilfs führe zu einem "positiven Regress des Mädchens zur mütterlichen Quelle « ${ }^{178}$. Die mütterliche, semiotische chora sei also trotz ihrer »Übertönung« und Unterdrückung in der symbolischen Ordnung in gewissen Bereichen zugreifbar, wie Kłosińska anhand des Werkes Zapolskas feststellt. ${ }^{179}$ Kłosińska verweist bei Przedpiekle auf die Funktion von Musik und Geräuschen als »Spalten« in der symbolischen Ordnung; gleiches gilt für die »Wort-Ächzer« in Kaśka Kariatyda, die hinter die Kulissen des Romans führen und mithilfe derer eine Anknüpfung an die mütterliche chora und somit eine Subversion des patriarchalen Systems möglich wird. So sei es einerseits das Mütterliche, das die weibliche Tradierung garantiere; andererseits die zweifache Lektüre, die sich im Text auf dieses einlasse. »Unter dem, was der Roman vorstellt«, entdeckt Kłosińska das »ewig abwesende Objekt des Begehrens [...], das ewig verdrängte mütterliche signifié..180

Kłosińskas Monographie mit ihrer psychoanalytisch-postfreudianischen Ausrichtung arbeitet stark mit den Aspekten der Sozialisierung und des Unterbewussten, weshalb sie im vorliegenden Unterkapitel gehäuft zu Wort kam. In Kłosińskas Konzeption zeigt sich jedoch teilweise eine mythisierte Vorstellung von Weiblichkeit, wovon der folgende Textausschnitt Zeugnis ist. Geht man wie Kłosińska davon aus, dass weibliche Schriftlichkeit aus dem literarischen Kanon verdrängt wird, müssen sinoffizielle` Wege der Tradierung und Erinnerungsarbeit gesucht werden. ${ }^{181}$ Solche Tradierungswege konstruiert die Polonistin, wenn sie

176 | Ebd., S. 141: "naturalne predyspozycje«; »wewnętrzną harmonię życia duchowego«.

177 | Kłosińska: Ciało, S. 193: »niezbywalność głosu macierzyńskiego«.

178 । Ebd., S. 191: "pozytywny regres dziewczynki do macierzyńskiego źródła«.

179 | Vgl. ebd., S. $192 f$.

180 । Ebd., S. 194: »Pod tym, co powieść przedstawia«; »fantazmat głosu macierzyńskiego«; »wiecznie nieobecnego obiektu pożądania [...], wiecznie odsuwane macierzyńskie signifié."

181 I Kłosińska blendet hier aus, dass gerade weibliche Autorinnen zu Ende des 19. Jahrhunderts und in der Zwischenkriegszeit höchst populär waren und ihre Werke oft breiter gelesen wurden als diejenige ihrer männlichen Kollegen. Tatsache ist jedoch, dass weibliche Texte - besonders solche, die wie oben beschrieben als 'weibliches Schreiben` definiert werden können - verhält- 
die Weitergabe von weiblichen Texten als eine Form des intimen Vermächtnisses betrachtet, das matrilinear und somit im »Untergrund« über die Generationen weitergegeben wird.

"[Die Frau] übermittelt [das Geheimnis] im Testament [...] als einzigen >eigenen Nachlass ihren Nachfolgerinnen (der Tochter, Nichte, Enkelin). [...] Auf diese Weise kursiert das Schreiben der Frauen im weiblichen Untergrund. [...] Die verheimlichte Kommunikation regulieren die Blutsbande zwischen Mutter und Tochter. Diese Bande wurden vom Recht des Patriarchats zerrissen, aber die Frau, die sich in die List des Sklaven flüchtet, stellt sie erneut her und hält sie aufrecht - indem sie schreibt. Die matrilinearen Verbindungen baut gerade das Schreiben der Frauen. Die männliche Kultur akzeptierte diese Tätigkeit der Frauen sim Untergrund ohne vorherzusehen, dass daraus eine umstürzlerische, veröffentlichte weibliche Literatur wird. « 182

Matrilineare Tradierung und weibliches Schreiben bedingen sich in Kłosińskas Verständnis gegenseitig - das Schreiben und die Weitergabe schaffe im Geheimen, am Rande des patriarchalen Systems eine zwar marginalisierte, aber doch kontinuierliche Tradition. Zentral ist für Kłosińska auch die Kleinräumigkeit dieser Tradierung, innerhalb des Haushalts und entlang biologischer Bande. Es scheint geradezu, dass die Verwandtschaft überhaupt erst die Weitergabe und das verstehende Lesen der Schriftstücke ermögliche.

Ähnlich gestaltet auch Iwasiów 2004 in Gender dla średnio zaawansowanych eine Aussage zur Tradierung und zum Wissen über die Vorgängerinnen heutiger Feministinnen. Unter die historischen Phänomene reiht sie die »Figuren unserer Urgroßmütter « ${ }^{183}$, womit sie die Emanzipationsbewegung quasi >einfamilisiert», während das textuelle »wir« als direkte Erbfolger/innen dieser Linie installiert wird. Und während Iwasiów einigermaßen unkonkret auf historische Figuren verweist, verwendet Kłosińska im obigen Beispiel nachgerade ein mythisches Präsens, das ihre Beschreibung aus der zeitlichen Ordnung hebt und zu einer allgemeingültigen Tatsache macht. Erst mit dem letzten Satz in Kłosińskas Zitat bricht die Geschichtlichkeit mit einem potentiellen Wandel in ihre Ausführung hinein.

nismäßig selten ihre eigene Aktualität überdauerten und in den Kanon shoher Literatur integriert wurden.

182 I Ebd., S. 26f.: "[Kobieta] [p]rzekazuje [tajemnice] w testamencie [...] jako jedyne ’własne dziedzictwo swoim następczyniom (córce, siostrzenicy, wnuczce). [...] W ten sposób pisanie kobiet krąży w kobiecym podziemiu. [...] Ową utajnioną komunikację regulują więzy krwi pomiędzy matką i córką. Te więzy zostały zerwane przez prawo patriarchatu, ale kobieta, uciekając się do podstępu niewolnika, ustanawia je na nowo i podtrzymuje - pisząc. Matrylinearne związki buduje właśnie pisanie kobiet. Kultura męska akceptowała tę działalność kobiet ’w podziemiu<, nie przewidując, że jej owocem stanie się wywrotowe, upublicznione pisarstwo kobiece.«

183 I Iwasiów: Gender, S. 60: "postaci naszych prababek«. 
Mit einer solchen Verschiebung in das Mythische gewinnt die matrilineare Tradierung ein unhinterfragbares Dasein. ${ }^{184}$ In der Konstruktion einer existenten, aber fragmentarischen und verhüllten weiblichen Sphäre macht Kłosińska deutlich, dass mit einer weiblichen/feministischen Lektüre Bereiche enthüllt werden können, die bisher als inexistent oder unzugänglich erschienen. Ob diese weibliche Sphäre als essentiell zu verstehende Größe einer metaphysischen Weiblichkeit gedeutet werden soll oder als Produkt der patriarchalen Marginalisierung allein, lässt Kłosińska offen. Fest steht für sie und die anderen in der vorliegenden Arbeit untersuchten feministischen Kritikerinnen jedoch, dass das weibliche Schreiben Bereiche der patriarchalen Gesellschaft dokumentiert, die in einer ‘konventionellen Literatur keinen Raum finden. Eine weibliche, zweifache Lektüre sei zudem vonnöten, um die Ambivalenz weiblicher Texte in ihrem sozialen und historischen Kontext zu verstehen.

Solche Überlegungen einer distinkten weiblichen Kommunikationsform, die in einer >männlichen`Lektüre nicht ihr volles Potential entfalte, schaffen zwar Raum für divergente Lektüre- und auch Schreibpraktiken. Mit dem Ausschluss des >Männlichen`ziehen sie jedoch auch die Grenze zwischen den Geschlechtern erneut nach. Die feministischen Kritikerinnen heben die Zusammenhänge zwischen dem (sozialen) Geschlecht der lesenden/schreibenden Person und dem Prozess der lesenden/schreibenden Transposition weiblicher Texte hervor. Die Geschlechtlichkeit siedelt in dieser Auslegung nicht nur im literarischen Text selbst, sondern manifestiert sich im Besonderen in der Transposition zwischen literarischem Text und sozialem, historischem Kontext. Während die Markierung der Geschlechtlichkeit jedoch bei einem `männlichen` Leser/Schreiber entfalle, erscheine sie im gesellschaftlichen Verständnis im Fall einer >weiblichen` Leserin/ Schreiberin umso deutlicher. Diese Deutlichkeit re-inszenieren die feministischen Kritikerinnen in ihren Arbeiten noch zusätzlich.

Da in der feministischen Kritik der polnischen 1990er Jahre der Zusammenhang zwischen im Text codierten `Geschlechtsmarkern` und der sozialen und historischen Erfahrung der schreibenden/lesenden Person als vergeschlechtlichte Person in den Vordergrund gerückt wird, scheint es umso legitimer zu fragen, wie sich die feministische Kritik selbst in den sozialen und historischen Kontext einbettet. Die Erkenntnisse im vorliegenden Kapitel suggerieren, dass eine weibliche Identität und deren kulturelle Parameter im Zentrum der feministischen Aufmerksamkeit stehen. Der Literatur kommt dabei die Rolle der Trägerin dieser identitären Parameter zu, die durch die feministisch-literaturwissenschaftliche Lektüre hervorgekehrt und gesellschaftlich rehabilitert werden sollen. Einige dieser Parameter möchte ich deshalb im folgenden letzten Kapitel aufgreifen und im Kontext der polnischen 1990er Jahre und deren gesellschaftlicher Neuorientierung diskutieren.

184 I Magnone (Die polnischen Gender Studies, S. 376) verweist darauf, dass gerade zweitrangige Schriftstellerinnen die Schaltstellen der Tradierung bildeten und diese so aufrechterhalten hätten. 



\section{Postsozialistische Abgrenzungen}

Im letzten Kapitel soll nun die dritte Dimension intertextueller Bezüge thematisiert werden, die als sozialer und historischer Kontext neben die Referenzdimensionen von transnationaler feministischer Kritik und untersuchtem literarischem Material tritt und sich mit diesen vermengt. Im Folgenden frage ich, wie sich die Argumentationen der feministischen Kritikerinnen im Diskurs der polnischen 1990er Jahre verorten, wobei auch hier die intertextuelle Anbindung an Theorie und Literatur eine tragende Rolle spielt. Stärker als in den vorhergehenden Kapiteln möchte ich aber auf die Konzeptualisierungen der einzelnen untersuchten Texte als Ideologeme eingehen, da diese Frage für die Einbettung in den postsozialistischen Gesellschaftsdiskurs entscheidend ist.

Zunächst bespreche ich im vorliegenden Kapitel, wie die feministische Kritik in Polen die Diagnose eines Defizits an Privatsphäre in der (post)sozialistischen Gesellschaft stellt und gleichzeitig das Private und Intime als elementar für die weibliche Erfahrungswelt und somit auch für ein weibliches Schreiben definiert. Davon ausgehend möchte ich fragen, welche Argumentationen der `Intimisierung und Aneignung einer ‘weiblichen Privatsphäre die feministischen Texte einbringen. Dies untersuche ich entlang einiger wiederkehrender Motive: der Mutterfigur, der Schwangerschaft, der Geburt und der Frage nach dem Schwangerschaftsabbruch; außerdem kontrastiere ich das feministische Erschreiben des Topos vom Haushaltsalltag mit einer auffallenden Dethematisierung sozialer Klassenunterschiede. Diese Aspekte sind eng an das literarische Material der feministischen Kritik gebunden, werden hier aber nun in den Kontext der gesellschaftlichen Diskurse der 1990er Jahre gestellt.

Anschließend widme ich mich der Frage nach dem politischen Charakter feministischer Kritik. Diese Frage bezieht die spezifischen Narrative zum >Politischen in Polen mit ein, die sich aus den 1980er Jahren in die postsozialistische Zeit ziehen. Im Besonderen interessiert mich das Paradox der feministischen Kritik als Hervorkehren vergeschlechtlicher Unterschiede und des dazu parallel verlaufenden Narrativs der `Privatisierung`von Weiblichkeit, was als spezifisch postsozialistische Problematik verstanden werden kann. Thematisch verwandt damit ist meine Untersuchung der feministischen Loslösung vom polnischen 
Aufopferungsnarrativ, das Frauen (und Männer) stets in einen national-gemeinschaftlichen Zustand einzubinden suchte; dieses Narrativ wird in der feministischen Kritik durch die Feststellung einer patriarchalen Ordnung und damit einer neuen inner- und metagesellschaftlichen Grenzziehung destabilisiert. Hier stellt sich wiederum die Frage nach dem Zusammenhang mit den postsozialistischen Individualisierungstendenzen.

Die Thematik abrundend frage ich danach, inwiefern die feministische Kritik eine neue Gemeinschaftsbildung anstrebt, wie diese aussehen soll und mit welchen textuellen Verfahren eine solche Gemeinschaft hergestellt wird. Besonders interessiert mich dabei der affektive Gehalt der feministischen Texte und wie dieser als Mittel der Gemeinschaftsbildung eingesetzt wird. Einerseits geht es hier um die affektive Anbindung der Polonistinnen an die von ihnen behandelten Texte und Figuren. Dabei geschehen auch negative Anbindungen in Form eines Aufeinanderprallens der Ideologeme der untersuchten Texte mit jenen der untersuchenden Kritikerinnen, was oft in ein feministisches Überschreiben der literarischen Texte mündet. Andererseits versuche ich auch die feministischen Texte selbst als Anlage einer affektiven Transposition zu verstehen, die im Prozess der Lektüre aktiviert wird. Ich möchte also herausfinden, wie die Texte selbst Gemeinschaft herstellen und wie diese in der Lektüre ein- oder ausschließend wirken kann.

\subsection{Die weibliche Sphäre}

Wie im vorhergehenden Kapitel festgestellt, versucht die feministische Kritik die Grundlagen für eine >Weiblichkeit $z u$ bestimmen, die sich etwa über die Matrilinearität zu gewissen Teilen vom patriarchalen System und dessen für Frauen beschränkten Möglichkeiten der Gemeinschaftsfindung emanzipieren soll. Während das patriarchale System als Normgesellschaft erscheint, die die Frauen über institutionelle wie habituelle Festschreibungen vereinzelt und ihre 'Funktion` in der Gesellschaft degradiert, gilt das sozialistische System als Versuch der gesamthaften Politisierung und Kollektivierung jeglicher Bereiche. Beide Systeme überlagerten sich zu einer umfassenden Abwertung und Dethematisierung der privaten Sphäre, die die feministischen Kritikerinnen als `weiblichen`Bereich verstehen. Es gelte somit, sich der privaten Sphäre zuzuwenden und sich diese im Hinblick auf weibliche Identitätspolitik anzueignen.

Feministische Retrospektiven auf die sozialistische Zeit und deren kulturelles Schaffen zeigen die Forderung einer $>$ Reprivatisierung` der Weiblichkeit besonders deutlich. Borkowska sieht in der polnischen Nachkriegszeit eine Epoche, die ein weibliches Schreiben verunmöglicht habe, wie die Polonistin in einem Essay von 1993 schreibt. Als grundsätzliches Hindernis der Entwicklung einer weiblichen Literatur definiert sie die »übermäßige Politisierung jeglichen Verhaltens ${ }^{1}$, die das

1 I Borkowska: ’Komandosi<, S. 241: »nadmiernego upolitycznienia wszelkich zachowań«. 
Individuelle und Intime verdrängt hätte: »Die sozrealistische Kunst kannte nur einen Typ von Konflikt und nur ein wirklich wichtiges Ziel des Schreibens. [...] die intimen Probleme des Individuums fanden selten ihren literarischen Ausdruck. ${ }^{2}$ Von der sozialistischen Nachkriegszeit bis in die 1970er Jahre sieht Borkowska deshalb eine weibliche Literatur nicht als möglich an, da letztere die »intimen Probleme des Individuums « in den Vordergrund stelle und eine psychologische Ausrichtung aufweise. ${ }^{3}$ Die Bereiche des Intimen, Individuellen und Psychologischen sieht sie in der sozialistischen Epoche marginalisiert zugunsten eines bis in die privatesten Winkel eindringenden Kollektiven und Politischen: »Niemand [...] konnte seine Privatheit bewahren in einem Land, in dem das kollektive Denken praktiziert wird. « ${ }^{4}$ Die sozialistische Epoche gehe mit einer Unterdrückung des Weiblichen einher. Borkowska widersetzt sich einer möglichen Transponierung des ,Weiblichen in den Bereich des Öffentlich-Politischen und bindet das Weibliche essentiell an das Private.

Durch die Verortung des Kollektiv-Politischen im Sozialismus konstruiert Borkowska einen auch historischen Gegensatz: Die anbrechende demokratischkapitalistische Epoche nach 1989 erscheint noch deutlicher von Privatheit und Individualismus geprägt. Damit bietet sie auch das weibliche Schreiben begünstigende Bedingungen, welches sich in einem dekollektivierten Kontext ganz auf seine Kernbereiche konzentrieren könne, wie Borkowska zu suggerieren scheint. In diesem Sinne kann Borkowskas Essay als Kritik am Sozialismus und als Lob des neuen Gesellschaftssystems gelesen werden. Dies ist insofern hervorzuheben, als konservative Kreise die feministische Kritik oft in die Nähe sozialistischer Konzepte stellen und als eine Neuauflage des Klassenkampfs inszenieren, der sich auf das Geschlecht verlagert habe. Mit ihrem Essay negiert Borkowska jegliche Sympathien mit kommunistischem Gedankengut und gleichzeitig auch das Interesse an einer expliziten Politisierung der Geschlechterfrage: Das Geschlecht interessiert sie allein im Rahmen einer sunpolitischen<, individuellen, privaten Weiblichkeit.

Im Rahmen ihres Konzepts matrilinearer Tradierung (siehe Kapitel 5.3.2) verweist auch Kłosińska auf die dafür tragende Rolle von Privatheit und Intimität. Das Private erscheint in der matrilinearen Tradierung des 19. Jahrhunderts als Ort, wo unverstellt gesprochen/geschrieben werden könne. Das intime Schreiben ermögliche der Frau eine Ehrlichkeit gegenüber sich selbst und ihren potentiellen Leserinnen, während sie in der Gesellschaft stets gezwungen sei, eine Art Mimikry oder Camouflage zu inszenieren. ${ }^{5}$ Der Offenheit des Privaten stellt Kłosińska das normative Öffentliche der Gesellschaft entgegen. Den Übertritt weiblicher

2 I Ebd., S. 239: "Sztuka socrealistyczna znała tylko jeden typ konfliktu i jeden naprawdę istotny cel pisania. [...] intymne problemy jednostki rzadko znajdowały literacki wyraz."

3 । Vgl. ebd., S. $239 \mathrm{ff}$.

4 । Ebd., S. 241: »nikt [...] nie umiał uchronić swej prywatności w kraju, gdzie praktykuje się myślenie wspólnotowe."

5 I Vgl. Kłosińska: Ciało, S. 28. 
Schriftlichkeit in die Sphäre des Öffentlichen signalisiert sie nur ansatzweise und - im Gesamtkonzept ihrer Argumentation betrachtet - als im Weiblich-Privaten wurzelnde "veröffentlichte weibliche Literatur", deren »umstürzlerische ${ }^{6}$ Charakteristika sich vor allem auf eine radikale Selbstzuwendung des weiblichen Geschlechts beziehen. Kłosińskas feministisches Interesse scheint sich damit primär um die Freiheit des Weiblich-Privaten zu drehen.

Kraskowska betont den Aspekt der Privatisierung des Weiblichen in ihrer Besprechung von Boguszewskas Całe życie Sabiny. Das Leben der Hauptfigur Sabina spiele sich im Horizont des privaten Lebens und primär im Haushalt ab. Sabinas jugendliche Faszination für das »Putzen, Kochen, Waschen und ähnliche Rituale» weiche dabei zunehmend einem »Gefühl der Hoffnungslosigkeit der Bemühungen ${ }^{7}$. Das negative Empfinden, das durch die gesellschaftliche Geringschätzung dieser "Bemühungen" hervorgerufen werde, überwinde Sabina aber kurz vor ihrem Tod. Spezifisch ist hier die Formulierung Kraskowskas, die diese Versöhnung mit dem eigenen Schicksal in eine Art Heilsterminologie übersetzt: "Aber Sabina ist in ihren letzten Tagen etwas mehr gegeben; es gelingt ihr, in diesem scheinbar unwichtigen Lebensbereich den wahren Sinn des Daseins zu erkennen. ${ }^{8}$ Diese Versöhnung erscheint in Kraskowskas Worten beinahe als eine Erleuchtung, zu der die Hausfrau hingeführt wird ( jest jej dane). In Anbetracht dessen, dass Kraskowska den hier besprochenen Roman Całe życie Sabiny als Prototyp des von ihr favorisierten integralen Modells weiblicher Literatur setzt, ${ }^{9}$ muss dieser $>$ spirituellen Wende einige Bedeutung auch im Wertesystem Kraskowskas zugemessen werden. Man kann also davon ausgehen, dass Kraskowska nicht an der Überwindung der geschlechtlichen Sphärentrennung gelegen ist. Ihr scheint es um den Bedeutungsgewinn der weiblich-privaten Sphäre zu gehen, um eine Aufwertung der Hausarbeit.

Das Private nahm in der polnischen Kulturproduktion seit Ende des 18. Jahrhunderts eine dem Politischen untergeordnete Rolle ein. Spätestens mit den 1980er Jahren tritt jedoch eine Umkehrung ein, wobei das Private und Individuelle der polnischen Zivilgesellschaft nominell zum Desiderat wird (siehe 6.2). Dies scheint auch für die feministische Kritik der 1990er Jahre zuzutreffen. Das Private wird als Ort des Weiblichen und somit als existentielle Grundlage weiblichen Schreibens konzeptualisiert, das sich erst mit dem Wegfall eines übergeordneten diskursiven Zwangs zum Politischen entfalten kann. Auch Janion weist darauf hin, dass das Private in der polnischen Kultur bislang zu wenig wertgeschätzt wurde. Ihre Argumentation unterscheidet sich aber von denjenigen ihrer jüngeren Kol-

6 | Ebd., S. 27: „wywrotowe, upublicznione pisarstwo kobiece."

7 I Kraskowska: Piórem niewieścim, S. 98: "sprzątanie, gotowanie, pranie i tym podobne obrzędy«; "poczucie beznadziejności wysiłków«.

8 । Ebd.: "Ale Sabinie w jej ostatnich dniach dane jest coś więcej; potrafi ona dostrzec w tej na pozór nieważnej dziedzinie życia prawdziwy sens istnienia."

9 | Vgl. ebd., S. 205. 
leginnen, als sie das Private nicht als Sphäre des spezifisch 'Weiblichen`, sondern insgesamt als eine in der polnischen Gesellschaft unterschlagene Größe versteht. Obwohl auch Janion die Vereinnahmung des Privaten durch den Zwang zur $>\mathrm{Ge}-$ meinschaft kritisiert, ist für sie der Inbegriff des Privaten der potentiell gemischtgeschlechtliche »Absolutismus der wahnsinnigen Liebe«, der »unserer Literatur so nötig wie Luft « ${ }^{10}$ sei. Janion fordert somit das Private nicht nur für eine $>$ Weiblichkeit oder als Voraussetzung für ein weibliches Schreiben, sondern grundsätzlich als aufzuarbeitendes Defizit der polnischen Gesellschaft und Kultur. In gewisser Weise handelt es sich hier um den Ruf nach der Auflösung einer starken Gemeinschaftlichkeit, die für den Diskurs um das `Polentum diese Verdrängung sieht sie - wie auch Borkowska - die jeweiligen »historischen Umstände ${ }^{12}$ verantwortlich, die von der romantischen Aufstandspflicht über den sozialistischen Kollektivismus bis hin zur »antipolitischen « Opposition der 1980er Jahre reichen. ${ }^{13}$

Die feministische Kritik in Polen richtet mit dem Wegfall des systembegründeten kulturellen Zwangs zum Politischen den Blick auf (literarische) Topoi, die von Privatheit und Intimität gezeichnet sind. An vorderster Stelle steht der Topos der Mutterschaft und die literarische Figur der Mutter. Die Mutterfigur, so die feministische Kritik, stelle die Schlüsselfigur der weiblichen Tradierung dar, könne aber im patriarchalen System ihre Funktion nur unzulänglich erfüllen. Ich untersuche deshalb die Motive der 'pathologischen«, von der patriarchalen Ordnung zermürbten Mutter sowie der sphantasmatischen Mutter als feministisches Idealbild einer matrilinearen Identitätsstifterin, die in der feministischen Kritik anhand literarischer Beispiele diskutiert werden. Wie auch bei den folgenden Topoi stelle ich die Frage danach, wie sich diese Diskussionen implizit im Diskurs der 1990er Jahre positionieren.

Der Topos von Schwangerschaft und Geburt steht in engem Zusammenhang mit demjenigen der Mutterfigur. Bei beiden Aspekten ist in der feministischen Kritik der Versuch zu beobachten, diese aus dem gesamtgesellschaftlichen, patriarchalen Diskurs zu lösen. Das Zurückstoßen der Gesellschaft und die Bindung der weiblichen Erfahrungswelt an den Mutterschaftstopos bestätigt jedoch teilweise auch konservative Narrative, was ich am Beispiel des Schwangerschaftsabbruchs bespreche. Ebenfalls im Rahmen postsozialistischer Narrative kann das Ausblenden der Thematik sozialer Hierarchisierungen in der feministischen Kritik der 1990er Jahre gelesen werden, die trotz der in der untersuchten Literatur zum Teil angelegten Klassenkritik allein auf die Kategorie des Geschlechts und deren kulturelle Dimension fokussiert.

10 I Janion: Postscriptum, S. 448: »absolutyzm szalonej miłości [...] potrzebny jest naszej literaturze jak powietrze«.

11 I Vgl. Graff: Feminizm ryzyka; Środa: Kobieta.

12 I Janion: Postscriptum, S. 448: »okoliczności dziejowych«.

13 I Vgl. Janion: Tam gdzie rojsty; Kobiety, S. $98 \mathrm{f}$. 
Die große Abwesende unter den vorgestellten Topoi ist die Frage nach der Verortung von Religion und Kirche. Die katholische Kirche stellt im Zusammenhang mit den sozialutilitaristischen Reproduktionsforderungen an die polnischen Frauen auch in den 1990er Jahren eine der treibenden Kräfte der gesellschaftlichen Einbindung der Weiblichkeit dar. Diese Thematik wird jedoch in den von mir untersuchten Texten so vollständig übergangen, dass ich hier ebenfalls nur auf diese Lücke hinweisen kann.

\subsubsection{Pathologische und phantasmatische Mütter}

Im Folgenden untersuche ich, wie die feministischen Kritikerinnen auf die literarische Darstellung matrilinearer Verbindungen respektive deren patriarchale Verhinderung reagieren und welche Schlüsse sie daraus für ihre eigenen feministischen Argumentationen ziehen. Die Korrumpierung matrilinearer Verbindungen zwischen Mutter und Tochter äußere sich in der (weiblichen) Literatur als vakante Stelle der positiven Mutterfigur, die entweder ganz fehle oder durch snegativer Mutterfiguren besetzt sei. Negativ dargestellt werden etwa literarische Mutterfiguren, die sich ganz sich selbst widmen, statt ihre Energie auf die Erziehung der Kinder zu verwenden. Sie unterliegen oft sowohl der Kritik der intradiegetischen Gesellschaft wie auch der der Erzählstimme. Weibliche Autorinnen konstruieren in der Regel solches Verhalten ebenfalls als negatives Element, wie dies etwa die Texte Orzeszkowas oder Zapolskas belegen, von denen nun die Rede sein wird.

Borkowska stellt in den Werken Orzeszkowas eine »deutliche santimütterlicheく Aussage ${ }^{14}$ fest, während Vaterfiguren in aller Regel neutral oder positiv bewertet würden. Damit verbinde sich nicht eine misogyne Haltung per se, sondern neben einem Generationenkonflikt eine Ablehnung der dekorativen Rolle der Frau zugunsten einer praktischeren (männlichen) Lebenshaltung: „Die Titelheldin teilt die Auffassungen ihrer Gebärerin in keiner Weise, sie träumt vom Leben, das ihr Vater als Gelehrter führt « ${ }^{15}$, schreibt Borkowska über Orzeszkowas Pamiętnik Wacławy (Wacławas Tagebuch, 1871). Der Generationen- oder Epochenkonflikt kann als Zäsur Orzeszkowas hin zu einem positivistischen Weltbild gelesen werden. Die Darstellungen der Muttergeneration würden auf ein von der Romantik geprägtes gesellschaftliches System verweisen, das den Frauenfiguren ein exaltiertes Selbstverständnis als Objekt romantischer Empfindungen im wahrsten Sinne des Wortes inkorporierte, an dem sie nun physisch leiden und damit ihre Umwelt als »toxische Mütter ${ }^{16}$ belasten würden.

14 I Borkowska: Cudzoziemki, S. 172: »wyraźny wydźwięk >antymacierzyński««.

15 । Ebd., S. 173: »Tytułowa bohaterka w niczym nie podziela zapatrywań swej rodzicielki, marzy o życiu, które prowadzi jej ojciec, uczony."

16 | Gajewska, Agnieszka: »Macierzyństwo - prezentacja pojęcia w dyskursie feministycznym w Polsce«, in: Radkiewicz, Gender (2004), S. 253-272, hier S. 266. 
Über die wohl bekannteste spathologische` Mutterfigur Orzeszkowas, Emilia Korczyńska aus Nad Niemnem (An der Memel, 1888), schreibt Borkowska: »Krank und überempfindlich, bietet sie ihren Kindern keinen Halt. Eher sind sie es, die sich bemühen, das schwankende Gleichgewicht der Mutter zu sichern. ${ }^{17}$ Borkowska interpretiert aber weder die am Romantizismus leidenden Mütter noch die positivistische, gefühlsnivellierende Tochtergeneration in den Werken Orzeszkowas positiv. Im Rahmen ihres Misstrauens oder Unglaubens Orzeszkowa gegenüber der sie gefühlsentleerte Figuren und eine emotionale Falschheit vorwirf ${ }^{18}$ - identifiziert Borkowska die >toxische Mutter als Effekt der "psychologischen Blockade «" ${ }^{19}$ Orzeszkowas. Deren »Ethik der Zurückhaltung und Entsagungen ${ }^{20}$ filtere auch positive Emotionen als Bedrohung aus ihren Erzählungen heraus: „Das Schaffen Orzeszkowas ist gezeichnet von der wahnwitzigen Auffassung, dass das Glück ein gefährlicher Zustand sei, der die Gruppen- und Familieninteressen bedrohe. ${ }^{21}$ In den Erzählungen würden damit lediglich negative und manierierte Emotionen übrigbleiben: die »bissigen Bemerkungen, Zänke, schmerzhaften Sticheleien und Anspielungen « und der »hysterische Widerstand « des "pathologischen Falls einer Mutter ${ }^{22}$

Die Verlagerung der Problematik von der Diegese auf die extradiegetische Ebene der schreibenden Instanz erlaubt es Borkowska, Orzeszkowas Diagnose des gesellschaftlichne Phänomens der `hysterischen Mutter zu umgehen. Mit der Bezeichnung des "pathologischen Falls« meint Borkowska nicht so sehr die beschriebene Mutterfigur selbst, als die Art der Beschreibung und Figurenkonzeption. Diese resultiere laut Borkowska aus einem übertriebenen positivistischen Bestreben Orzeszkowas - womit Borkowska Orzeszkowa selbst als einen "pathologischen Fall« einer hysterischen `Mutter ihrer Werke zu skizzieren scheint. Die Sublimierung von Leidenschaft und Begehren ${ }^{23}$ und das »Unvermögen zuzugeben, dass das Gefühl des persönlichen Glücks und Unglücks zu einem riesigen Teil von der emotional-erotischen Sphäre abhängt « ${ }^{24}$, erwirkten laut Borkowska die Unehrlichkeit der Texte Orzeszkowas, womit auch ihre Figuren nicht als mimetisch zu behandeln seien.

17 | Borkowska: Cudzoziemki, S. 173: "Chora i przewrażliwiona nie stanowi oparcie dla swych dzieci. To raczej one starają się o zapewnienie matce chwiejnej równowagi.«

18 | Vgl. ebd., S. 164-169.

19 | Ebd., S. 164: »blokada psychologiczna«.

20 । Ebd., S. 166: "etyka powściągliwości i wyrzeczeń«.

21 I Ebd., S. 169: »Twórczość Orzeszkowej cechuje to szaleńcze pojmowanie szczęścia jako stanu niebezpiecznego, zagrażającego interesom grupowym, rodzinnym."

22 । Ebd., S. 173: »zgryźliwych uwag, awantur, bolesnych przycinków i aluzji«; »histeryczny opór«; "Patologiczny przypadek matki«.

23 । Vgl. ebd., S. 176.

24 | Ebd., S. 164: »nieumiejętność przyznania, że poczucie osobistego szczęścia i nieszczęścia zależy w ogromnym stopniu od sfery uczuciowo-erotycznej«. 
Die Auslegung der negativen Mutterfigur bringt Kraskowska bereits 1993 deutlicher auf den Punkt. Sie stellt fest, dass negative Mutterfiguren als Regelelemente weiblicher Prosa zu finden seien, wobei eher ein Zusammenhang mit der Psychologie der Schreibenden zu suchen sei als ein mimetisches Verfahren: Die »Mutterphobie« sei »nur eine Metapher des Hasses auf sich selbst. ${ }^{25}$ Erst ein positiveres weibliches Selbstbewusstsein könne diese »Obsession« überwinden und das Mutter- und somit Selbstbild in positivere Rahmungen fassen. ${ }^{26}$ Auch Kraskowska, die hier Überlegungen Showalters zusammenfasst, versteht die negative literarische Mutterfigur also als psychologisches Problem und eher als Selbstkritik der Schreibenden denn als deren Kritik am patriarchalen System - was hier allerdings argumentativ zusammenfällt, da mit der Selbstkritik das inkorporierte Minderwertigkeitsgefühl von Frauen in der symbolischen Geschlechterordnung manifest werde.

Besonders aufschlussreich in Bezug auf eine >defekte` Matrilinearität ist die Auseinandersetzung Kłosińskas mit dem literarischen Phänomen der >pathologischen Mutterfiguren. Zapolskas negative Mutterdarstellung in Przedpiekle fokussiere auf die Mütter, die im Wartezimmer eines Gynäkologen versammelt seien. Diese seien gegenüber »den elementarsten Prinzipien der Hygiene, dem Wissen über das Leben und die Entwicklung des Körpers « ${ }^{27}$ ignorant, wie Kłosińska schreibt: „Die realen Mütter sind [...] Geschöpfe der Kultur der Vergangenheit, Zöglinge der Kunst der Exaltation und des übermäßigen Sentimentalismus, Figuren ‘aus der Operette`, von außerhalb der Realität, es sind Mütter-〉Gräber`.«" ${ }^{28}$ Zapolskas literarische Inszenierung der Mütter weist wie jene Orzeszkowas ein aufklärerisches Element und einen Generationenkonflikt auf. Zapolska verweise dabei auf den >Defekt $`$ in der matrilinearen Tradierung und Wissensvermittlung: Der »von Generation zu Generation wiederholte Clan der Mütter, dessen Wesen Zapolska in der suggestiven Metapher der noch nicht reifen, aber schon sfaulenden Frucht $\triangleleft$ wiedergibt $\ll^{29}$, vermittle bildhaft die Korrumpierung der weiblichen Psyche und des weiblichen Körper. Diese sei einer "pathologischen Induktion des Erotismus $\aleph^{30}$ durch das patriarchale System zuzuschreiben. Das Patriarchat reduziere also die matrilineare Tradierung auf die $»$ Verführungskunst $\star^{31}$ und die

25 । Kraskowska: Kilka uwag, S. 270: "matkofobia [...] to tylko metafora nienawiści do samej siebie.«

26 | Kraskowska bezieht sich auf Showalter: Toward a Feminist Poetics.

27 । Kłosińska: Ciało, S. 207: »najbardziej elementarnych zasad higieny, wiedzy dotyczącej życia i rozwoju ciała."

28 | Ebd.: »Matki realne są [...] wytworami kultury przeszłości, wychowankami sztuki egzaltacji i nadmiernego sentymentalizmu, postaciami 'z operetki<, spoza rzeczywistości, to matki->groby<." 29 | Ebd.: "powtarzany z pokolenia na pokolenie, klan matek, którego istotę Zapolska oddaje w sugestywnej metaforze jeszcze nie dojrzałego, a już sgnijącego owocu<."

30 । Ebd., S. 255: "patologicznej indukcji erotyzmu«.

31 । Ebd., S. 207: »Sztuce uwodzenia«. 


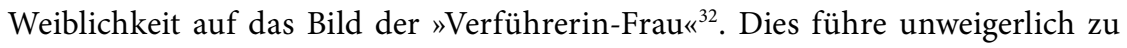
pathologischen Frauenfiguren, was aber der Aufrechterhaltung der patriarchalen Geschlechterordnung entgegenkomme: "Stellt sich damit nicht eine bis heute aktuelle Frage? Ist denn in der Kultur des 20. Jahrhunderts die Nachfrage nach einer entfremdeten und kranken Frau verschwunden? «33

Kłosińska liest wie Kraskowska und Borkowska die negative Mutterfigur als Ausdruck des patriarchalen Systems, wobei sie jedoch den Fokus von einer psychologisierenden auf eine kulturkritische Lektüre verlegt, in der die Persönlichkeit der Schriftstellerin keinen Analyseschlüssel darstellt. Die negative Mutterfigur ist stets Teil einer Sozialisierung, die die Tochter in eine untergeordnete, instabile und identitätsfeindliche Position einweise. Bei den Untersuchungen Borkowskas und Kłosińskas zeigt sich, dass die negative Mutter die Anforderungen der Gesellschaft gerade durch ihre Dysfunktionalität erfüllt, weshalb sich kein Raum für eine subversive, affirmierende Lektüre der weiblichen `Negativität` eröffnet. Iwasiów stellt hingegen bei Odojewskis Texten fest, dass die gemäßigt negativen Mutterfiguren ihre systemtragenden Rollen übererfüllen. Stichwort ist hier die Sippenzugehörigkeit, aufgrund derer die leibliche Mutter Katarzynas, die als quasi-uneheliche Witwe unter sozialem und familiärem Druck steht, ihr Kind weggibt und so erneut in den Heiratsmarkt integriert werden kann. Auch die Schwiegermutter Katarzynas agiert primär entlang des patriarchalen Sippenbewusstseins, wenn sie als Ersatzmutterfigur »die Witwe des einen Sohns beinahe dem zweiten Sohn zuhielt « ${ }^{34}$. Iwasiów sieht in diesen ambivalent ausgelegten Figuren nicht nur `Opfer`, sondern aktiver noch Ausführende der patrilinearen gesellschaftlichen Ordnung. Iwasiów beschreibt zudem, wie das unscharfe Mutterbild die Figur Katarzyna daran hindere, ihre eigene Identität und Position in der Gesellschaft festlegen zu können. ${ }^{35}$ Janion zeitigt eine ähnliche Argumentation für Filipiaks Absolutna amnezja: Der gesellschaftliche Konformismus der Mutter in Form der Aufopferung für den oppositionellen Kampf erwirke eine Isolierung und Vernachlässigung der Tochter und deren Bedürfnisse als heranreifende Frau. Die Gesellschaft verdränge das Weibliche, wie Janion diesen Konflikt zusammenfasst: Als die »erschrockene Marianna« wegen der ersten Menstruation »ihre Matka Polka zu sich ruft, macht ihr diese Vorwürfe, dass auf den Straßen der richtige Kampf herrsche, echte Schüsse fallen, dass jeder Verband gebraucht werde. Die Frauen sollten ihren letzten Tampon denen abtreten, die ihr Blut für das Vaterland vergießen. « $^{36}$

32 । Ebd., S. 210: "kobietę-kusicielkę".

33 I Ebd., S. 235: "Czyż nie stawia się tutaj kwestii aktualnej do dzisiaj? Czyżby w kulturze XX wieku zniknęło zapotrzebowanie na kobietę wyalienowaną i chorą?»

34 I Iwasiów: Kresy, S. 114: "prawie stręczyć wdowę po jednym synu synowi drugiemu«.

35 । Vgl. Iwasiów: Kresy, S. $112 f$.

36 I Janion: Kobiety, S. 341: "przerażona Marianna wzywa do siebie swą Matkę-Polkę, ta czyni jej wyrzuty, że na ulicach toczy się prawdziwa walka, padają prawdziwe strzały, potrzebny jest każdy opatrunek. Kobiety winny oddać ostatni tampon tym, którzy przelewają krew za ojczyznę." 
Bei Janion und Iwasiów handelt es sich somit um die Kritik an einer Mutterfigur, die die Tochter zugunsten gesellschaftlicher Verpflichtungen und Normvorstellungen vernachlässige. Beide Forscherinnen sehen in diesem literarischen Muster tatsächliche Mechanismen der patriarchalen Gesellschaft abgebildet, die die weibliche Figur sich selbst entfremde und von einer stützenden matrilinearen Tradierung isoliere. Stärker noch betonen dieses Element Borkowska und Kłosińska. Borkowska macht die Familienverhältnisse von Żmichowska selbst zum Thema und legt Żmichowskas (real-biographischen) Verlust der Mutter als unheilbare Wunde aus: "So eine frühe Waise kann nicht einmal lieben, sie gibt oder verlangt immer zu viel Liebe; dieses nicht im Verstand, sondern im Instinkt notwendigste Gefühlsmaß ist für sie völlig verloren. $\aleph^{37}$ Es ist in der Auslegung Borkowskas das 'gesunde Maß an Emotionen und der Schutz vor emotionalen Beeinflussungen, die die Mutterfigur der Tochter vermitteln sollte/würde. Eine ähnliche Erkenntnis formuliert Kłosińska anhand von Zapolskas Przedpiekle, wo das Fehlen der Mutter zu einem Defizit bei der Tochter führe, die den Einflüssen der patriarchalen Umwelt umso schutzloser ausgesetzt sei. ${ }^{38}$ Letztlich stellen alle von mir untersuchten feministischen Kritikerinnen fest, dass eine `defekte`matrilineare Beziehung zwischen Mutter und Tochter sich negativ auf die Entwicklung Letzterer auswirke und zu einer instabilen Identitätsbildung führe.

Bereits wird deutlich, dass die feministischen Kritikerinnen die Mutter-Tochter-Beziehung potentiell nicht nur als einen Teil und Stütze des patriarchalen Systems wahrnehmen. In einer >unbeschädigten` matrilinearen Tradierung sehen sie die Sicherstellung weiblicher emotionaler und identitärer Psychohygiene der Tochter. In gewisser Weise müsse die Mutter-Tocher-Beziehung deshalb als der patriarchalen Ordnung zuwiderlaufend interpretiert werden, als hier subversives Wissen tradiert werde und eine stabile weibliche Identität auch zu einer gefestigteren oder selbstbewussteren Position in der gesellschaftlichen Ordnung führen könne. Obwohl Kłosińska in Zapolskas Przedpiekle die Abwesenheit der Mutter als physische Figur feststellt, sei diese jedoch "als signifié rekonstruierbar « ${ }^{39}$ und könne als phantasmatische Erzeugung der Tochter diese dennoch positiv beeinflussen. Als "phantasmatische Mutter« (matka fantazmatyczna) wird sie zur positiven imaginären Gegenspielerin nicht nur der negativ ausgelegten Figuren von Vater und Stiefmutter, sondern der gesamten patriarchal geprägten Umwelt der Tochter.

Mit der Demonstration der deutlich negativen Folgen der Durchtrennung der Mutter-Tochter-Bindung richte sich Zapolska gegen die spätere »freudsche Theorie, die das Zerreißen des Bandes der `Liebe` zwischen Mutter und Tochter als

37 । Borkowska: Cudzoziemki, S. 121: "Taka wczesna sierota nawet kochać nie potrafi, do zbytku zawsze wyda lub zapragnie miłości; owa najpotrzebniejsza, nie w rozsądku, lecz w instynkcie, miara uczucia, dla niej stracona zupełnie.« Vgl. auch ebd., S. 128.

38 । Vgl. Kłosińska: Ciało, S. 223ff.

39 | Ebd., S. 208: »Matka fantazmatyczna, możliwa do zrekonstruowania jako signifié«. 
Muss ansah, und auch gegen die Überzeugung Lacans, dass die Subjektwerdung zum Preis des Verstummens des Mütterlichen möglich sei « ${ }^{40}$. Dem stelle Zapolska ein Idealbild der Mutter-Tochter-Beziehung entgegen, die in einem »Heranwachsen unter dem Auge der Mutter ${ }^{41}$ bestehe, welche »ihren Töchtern die Erfahrung glücklicher Mutterschaft übermittelt $\aleph^{42}$. Kłosińska argumentiert, dass die Mutter in Przedpiekle nicht nur »Objekt des Begehrens der Tochter«, sondern auch »Phantasma der Autorin $\aleph^{43}$ sei.

Borkowska zufolge schreibt auch Żmichowska in Książka pamiątek "vom Identifikationsprozess der Tochter mit der Mutter als Bedingung ihrer späteren emotionalen Reife ${ }^{44}$, wobei Borkowska hier Parallelen zu psychoanalytisch-feministischen Theorien wie denjenigen Nancy Chodorows oder Irigarays erkennt. ${ }^{45}$ Żmichowskas Verständnis der Mutter als Vermittlerin zwischen Welt und Tochter ziele aber nicht auf ein Einfinden in die patriarchale Ordnung, sondern auf eine davon losgelöste weibliche Tradition: Żmichowska verstehe die Mutter-Tochter-Beziehung »als eine Art Band, das neben dem (offiziellen) patriarchalen System gebaut wird oder sogar in Opposition zu diesem « ${ }^{46}$, wie Borkowska schreibt.

Die matrilineare Tradierung als Garant weiblicher Psychohygiene ließe sich jedoch auch in der Rahmung des patriarchalen Systems verorten. Darauf verweisen die Fälle spathologischer Mütter, deren Dysfunktionalität vom patriarchalen System ebenso in Kritik gestellt wird. Wenn die weibliche Psychohygiene als Verhinderung emotionaler Schwankungen oder des Abgleitens in sozial definierte Pathologien wie die Hysterie verstanden wird, so hat diese Psychohygiene auch einen direkt gesellschaftsstützenden, utilitaristischen Charakter. Dennoch - und hier zeigt sich die Ambivalenz emanzipatorischer Narrative - gilt der feministischen Kritik die Matrilinearität in ihrer Funktion als Garant weiblicher Psychohygiene primär als subversives oder zumindest autarkes, nur der >Weiblichkeit dienendes Element. Dies thematisiert etwa Kłosińska, wenn sie auf die Problematik der sexuellen Erziehung der Töchter referiert. In Przedpiekle bemüht sich der männliche Gynäkologe als Vertreter eines soziomedizinischen Gesundheitsdiskurses um die erotische Psychohygiene der heranwachsenden Mädchen. Kłosińska stellt

40 । Ebd., S. 193: „Wbrew freudowskiej teorii, która uznawała konieczność zerwania ’miłosnej‘ więzi między matką i córką, a także wbrew lacanowskiemu przekonaniu, że stawianie się podmiotem jest możliwe za cenę zamilknięcia tego, co macierzyńskie«.

41 I Ebd., S. 255: »dojrzewanie pod okiem matki«.

42 । Ebd., S. 207: "przekazać swym córkom doświadczenia szczęśliwego macierzyństwa«.

43 । Ebd., S. 226: »obiektem pożądania córki«; »fantazmatem autorki«.

44 । Borkowska: Cudzoziemki, S. 120: »0 procesie identyfikacji córki z matką jako warunku jej późniejszej dojrzałości emocjonalnej«.

45 I Borkowska verweist auf Chodorow, Nancy: The Reproduction of Mothering, Berkeley 1978; Irigaray: Ce Sexe u. a.

46 I Borkowska: Cudzoziemki, S. 172: »jako rodzaj więzi zbudowanej obok układu patriarchalnego (oficjalnego) lub nawet w opozycji do niego.« 
aber zu Zapolskas Narrativ fest, dass »[d]ie Wonne hier von der Schriftstellerin als Geheimnis behandelt wird, das nur den Frauen zugänglich ist, das nur unter ihnen erzählt werden kann. Es wäre ein geheimes Wissen der Frauen-Mütter. Dem gynäkologischen Arzt wäre dieses Wissen nicht eigen. « ${ }^{47}$ Obwohl der Gynäkologe das »Verfaulen ${ }^{48}$ der Mädchen verhindern wolle, bewerte Zapolska dessen Bemühungen als unzulänglich. Kłosińska beschreibt diesen Ausschluss des Männlichen als das subversive Element der Matrilinearität, da eine rein weibliche Beziehung per se eine Abweichung von der patriarchalen Norm und somit deren Gefährdung darstelle. ${ }^{49}$ In anderen Worten könnte deshalb von einer literarischen Inszenierung der weiblichen Selbstermächtigung zur Handlungsfähigkeit gesprochen werden.

Die obigen Beispiele nennen in der Regel die Mutter als `Einweiserin` der Tochter, wie hier bei Kłosińska: »die Mutter kann und soll der eigenen Tochter [...] die Wahrheit [...] vermitteln $\aleph^{50}$, wobei gerade das besitzanzeigende Attribut »eigene» (własna) hervortritt. Während in Zapolskas Przedpiekle die Bande zur Mutter als letztlich untrennbare Blutsbande erscheine, beruhe die Beziehung zum Vater auf einer gesellschaftlichen Konvention. Der Vater als personifiziertes »Recht des Vaters « kann diese Konvention brechen, wovon er in Przedpiekle Gebrauch macht, da seine Tochter die `neue Mutter, die Stiefmutter, nicht anerkennt. »Im Namen der Treue gegenüber der Mutter verletzt die Tochter die Macht des Patriarchen und erschüttert deren soziale Regulation. ${ }^{51}$ Tatsächlich scheint in Zapolskas Roman eine >echte Matrilinearität nur möglich, wenn es sich um »Blutsbande mit der Mutter ${ }^{52}$ handelt. In der Verweigerung einer der institutionellen `Ersatzmütter - die Stiefmutter oder das Mädcheninternat als Erziehungsinstitution - sieht Kłosińska in Anlehnung an die Argumentation Irigarays die potentielle »umstürzlerische Kraft« (element wywrotowy) ${ }^{53}$ der Matrilinearität: als Emanzipation vom väterlichen Recht und als Ablehnung >ruhigstellender Ersatzangebote. Den Ausbruch qua Blutsbande nimmt auch Iwasiów 2004 auf, die diese Möglichkeit als insofern »tröstend « befindet, da »schließlich jede von uns eine Großmutter hat « ${ }^{54}$. Iwasiów verweist darauf, dass die Matrilinearität nicht zwingend (nur) ein allgemeines weibliches Wissen mit sich tragen muss, sondern dass es sich um ein »Einweihen

47 । Kłosińska: Ciało, S. 139: »Rozkosz traktowana jest tu przez pisarkę jako tajemnica dostępna tylko kobietom, która może być opowiadana tylko pomiędzy nimi. Byłaby jakąś wiedzą tajemną kobiet-matek. Lekarz ginekolog byłby jej pozbawiony.«

48 | Ebd., S. 202: "gnicie".

49 । Vgl. ebd., S. $201 f$.

50 । Ebd., S. 139: »matka, może i [powinna] przekazywać własnej córce [...] prawdę«.

51 । Ebd., S. 201: »W imię wierności matce córka narusza władzę patriarchy i chwieje społeczną jej regulacją." Vgl. auch S. $198 f$.

52 । Ebd., S. 201: "więzi krwi z matką«.

53 I Ebd. Siehe auch Irigaray, Luce: Le Corps-à-corps avec la mère, Montréal 1981, S. 86.

54 I Iwasiów: Gender, S. 141: »pocieszająco«; »przecież każda z nas ma babkę«. 
in die [...] weibliche Familientradition $\aleph^{55}$ und die »lokale, mikroskopische Narration« »mit der nächsten Familie mütterlicherseits $\aleph^{56}$ handle.

Fasst man die Untersuchungen der feministischen Kritikerinnen zur Mutterfigur zusammen, drehen sich diese vor allem um die Möglichkeit der Abgrenzung von der patriarchalen Ordnung durch die intime Beziehung und Wissensvermittlung von Mutter zu Tochter. Die matrilineare Verbindung sehen sie als Element, das aus dem gesellschaftlichen Narrativ herausgelöst und für die 'Weiblichkeit« fruchtbar gemacht werden müsse. Neben die Tradierung weiblicher Literatur als Etablierung einer vom `männlichen Literaturparadigma emanzipierten Tradition (siehe Kapitel 5.3.2) tritt somit in der feministischen Analyse der matrilinearen Beziehung am Beispiel literarischer Figuren der soziale Aspekt als politisch-emanzipierende Funktion. Die feministische Kritik versucht gegen die Marginalisierung rrealer Frauen wie auch des weiblichen Schreibens anzugehen. Generell zielt sie dabei in Richtung einer Haltung der Differenz und der Loslösung von gesellschaftlichen Anforderungen, wobei eine matrilineare Tradierung zunächst helfen soll, eine positive und stabile weibliche Identität herzustellen. Diese wiederum soll als Basis einer weiblichen Gemeinschaftlichkeit dienen, was ich unter 6.3 eingehender diskutiere. Hier möchte ich noch anmerken, dass eine solche Ablösung der Matrilinearität von ihrem sozialen Kontext als gesellschaftliche Isolierung verstanden werden kann und somit auch dazu beiträgt, die Geschlechterdifferenzen zu reinszenieren und das 'Weibliche` verstärkt in den Kontext des `Privaten`, aber auch des `Natürlichen` einzuschreiben.

\subsubsection{Schwangerschaft, Geburt, Abort}

Der Fokus einiger feministischer Texte auf die biologische Matrilinearität steht in Zusammenhang mit der Revalorisierung des Somatischen, das bereits als Element des weiblichen Schreibens identifiziert wurde (siehe Kapitel 5.2.2). Dieses findet insbesondere im Prozess der Geburt seinen Ausdruck, der in den 1990er Jahren in die weibliche literarische und philosophische Aufmerksamkeit rückt. Brach-Czaina etwa inszeniert den Prozess des Gebärens als auch mystisch verstandenen »Ausnahmezustand», in dem »wir das eigene Gesicht [erkennen].» Der Körper als Antagonist der »Verstandesidentität" (rozumna tożsamość) spielt eine zentrale Rolle in dieser Selbsterkenntnis und in der Vereinigung "mit dem Körper der Welt«. ${ }^{57}$ Eine ähnliche Stoßrichtung zeitigt Nasiłowskas Traktat o narodzinach von 1995. Mit der Aufmerksamkeit auf Schwangerschaft und Geburt gerät in den 1990er Jahren die erste polnische Erzählung zu diesem Thema aus der Perspektive einer Frau ${ }^{58}$ ins feministische Blickfeld: Kuncewiczowas Przymierze $z$ dzieckiem

55 I Ebd., S. 156: »wtajemniczenia w [...] kobiecą tradycję rodziny«.

56 । Ebd., S. 141: »narracji lokalnej, mikroskopijnej«; »z najbliższą rodziną po kądzieli«.

57 | Brach-Czaina: Szczeliny, S. 30f.

58 | Vgl. Kraskowska: Piórem niewieścim, S. 153. 
(Allianz mit dem Kind) von 1927. Aufgrund der ambivalenten, wenn nicht gar negativen Gefühle der weiblichen Hauptfigur Teresa in Bezug auf ihre Schwangerschaft und später das Kind scheiden sich an dieser Erzählung die feministischen Geister. Während einige Arbeiten Verständnis für die in der Erzählung dargelegte Figur und ihre schwierige Eingewöhnungsphase als Mutter zeigen, ${ }^{59}$ reagiert Kraskowska darauf polemischer.

Im Hauptfokus der Kritik Kraskowskas steht der Lebensstil Teresas, der sich mit der Schwanger- und Mutterschaft nur schwer vereinbaren lasse. Kraskowska verweist auf den Körperkult »à la garçonne« (chłopczyca), der Frauen die schwangerschaftsbedingten Verformungen des weiblichen Körpers verleide. Der »modischen Ehefrau « ${ }^{60}$ Teresa sei der Körper Quell ihres »narzisstischen Interesses «, und Kraskowska kritisiert implizit die »Abscheu und Furcht, die die reizende Heldin beim Anblick des ihre eigene Katastrophe vorhersagenden schwangeren armen Weibes verspürt ${ }^{61}$. Kraskowska scheint in ihrer Besprechung von Przymierze $z$ dzieckiem beinahe mit Genugtuung die »übermächtige Natur, den Instinkt, der trotz heftig verspürtem Unwillen zur sofortigen Reaktion auf jedwelchen Reiz vonseiten des >schreienden Korbes`zwingt«, festzustellen und die »demütige Rückkehr ans Kinderbettchen ${ }^{62}$ zu begrüßen.

Kraskowska betont wie Nasiłowska die Furcht Teresas vor der (unkontrollierten) Körperlichkeit, die als etwas gesellschaftlich Intolerables, als der hochgehaltenen geistigen Kultur Entgegengesetztes verstanden werde. ${ }^{63}$ Beide Forscherinnen sehen bei Kuncewiczowa die Tendenz zur offengelegten Verachtung gegenüber der snatürlichen К Körperlichkeit als Resultat normativer gesellschaftlicher Diskurse. Das Thematisieren der Geburt als ‘grauenerregender` Akt hingegen verbietet sich Kraskowska: »In der polnischen Literatur hatte wohl einzig [Stefan] Żeromski den Mut, in Dzieje grzechu [Geschichte einer Sünde, 1908] die Brutalität der Geburt

59 I Nasiłowska macht darauf aufmerksam, dass Kuncewiczowa anhand der Hauptfigur Teresa darlege, "dass sogar für eine snormale Ehefrau die Schwangerschaft eine schwierig zu akzeptierende Tatsache sein [kann] - und das nicht aufgrund von materiellen Schwierigkeiten der Familie oder Unsicherheiten in der emotionalen Beziehung mit dem Gatten. "Nasiłowska, Anna: "Natura jako źródło cierpień«, in: Teksty Drugie, Śmiech feministek (1993), S. 189-194, hier S. 190. Ähnlich argumentiert Danuta Sobczyńska, die Kuncewiczowa zugute hält, dass diese »es schaffte, mit der Mythologie der mütterlichen Liebe, die ab dem Zurweltbringen des Kindes eintrete, abzurechnen und deren Herausbilden als langsamen, schwierigen und für die junge Frau manchmal schmerzhaften Prozess zu zeigen. Sobczyńska: Macierzyństwo, S. 71.

60 I Kraskowska: Piórem niewieścim, S. 153: "żona modna«.

61 । Ebd., S. 154: »jej narcystycznego zainteresowania«; »wstręt i trwogę, jakich doznaje śliczna bohaterka na zapowiadający jej własną katastrofę widok ciężarnej kobieciny“.

62 I Ebd., S. 156: "przepotężna natura, instynkt, który wbrew żywiołowo odczuwanej niechęci zmusza do natychmiastowej reakcji na każdy bodziec ze strony ’krzyczącego kosza««; »pokornym powrotem do łóżeczka dziecka."

63 । Vgl. Nasiłowska: Natura, S. 193. 
naturalistisch darzustellen, was er aber auf eine Art tat, die diesen Akt verekelte. Ihn zu zitieren wäre sowohl ein Grauen wie eine Geschmacklosigkeit. « ${ }^{64}$

Anstelle einer Tabuisierung oder monströsen Verzerrung sollte, wenn man dieser Stoßrichtung Kraskowskas folgt, eine akzeptierende und bejahende Haltung gegenüber Schwangerschaft, Geburt und Mutterschaft bevorzugt werden, was sich in den weiblichen literarischen Topoi der 1990er Jahre auch abzeichnet. ${ }^{65}$ Kraskowska lobt an Nasiłowskas Traktat o narodzinach einen Erzählstil des Geburtsgeschehens "ähnlich der Genesis « ${ }^{66}$, während bei Kuncewiczowas Erzählung aus der Zwischenkriegszeit wenn nicht apokalyptische, so doch ambivalente Töne vorherrschten. Im Zuge der weiblichen Identitätssuchen der feministischen Bewegung der 1990er Jahre findet die Mutterschaft als >rein weibliche` Erfahrung Eingang in den feministischen Diskurs und eine feministische Aneignung.

Kłosińska versteht die Geburt analog zum Orgasmus und dem hysterischen Anfall als »Spasmus der Hyperweiblichkeit ${ }^{67}$ und somit als Scheitelpunkt weiblicher »Wonne« (rozkosz). In Kłosińskas Analyse von Kaśka Kariatyda nimmt das Thema von Schwangerschaft und Geburt jedoch eine andere Dimension an. Hier geht es vor allem um den Umgang mit unerwünschten Schwangerschaften und der Geburt unehelicher Kinder. Der gesellschaftliche Un-Ort dieses Geschehens ist das Haus der Hebamme und Engelmacherin Sznaglowa. Obwohl außerhalb des repressiven patriarchalen Systems angesiedelt und nur von Frauen bewohnt, dient er als unabdingbares Ventil der gesellschaftlichen Doppelmoral. »Bei Sznaglowa sind die Frauen komplett von den Männern isoliert, aber statt einer Utopie haben wir eine schockierende Antiutopie ${ }^{68}$, urteilt Kłosińska. Schwangerschaft, Geburt und Mutterschaft erscheinen hier nicht als »Wonnen«, sondern als hartes Geschäft mit Körpern und Emotionen. Damit bilde dieser Ort ein verdrehtes und ebenso repressives Abbild der Lemberger Gesellschaft. Kłosińska merkt an, dass Zapolska mit der Hauptfigur Kaśka »die Mutterschaft außerhalb des Rechts des Patriarchats, außerhalb des Namens des Vaters resakralisiere ${ }^{69}$ und somit nicht die Tatsache einer außerehelichen Schwangerschaft an sich an den Pranger stelle,

64 I Kraskowska: Piórem niewieścim, S. 152: „W literaturze polskiej bodaj jeden [Stefan] Żeromski miał odwagę w Dziejach grzechu [1908] naturalistycznie przedstawić brutalność porodu, ale uczynił to w sposób, który ów akt zohydził. Cytować go - i zgroza, i niesmak."

65 | Vgl. die Hinwendung zur Biologizität des Körpers und den natürlichen somatischen Prozessen wie Reifung und Alterung, wie sie in der Literatur etwa mit der Prosa Tokarczuks deutlich wird.

66 | Kraskowska: Piórem niewieścim, S. 157: »genezyjski raczej«.

67 I Kłosińska: Ciało, S. 283: „spazmu hiperkobiecości«. Siehe auch Showalter, Elaine: »Hysteria, Feminism, and Gender «, in: Gilman, Sander L./Showalter, Elaine (Hg.), Hysteria Beyond Freud, Berkeley 1993, S. 286-335, hier S. 286.

68 I Kłosińska: Ciało, S. 77: »U Sznaglowej kobiety są całkowicie odcięte od mężczyzn, ale zamiast utopii mamy szokującą anty-utopię."

69 । Ebd., S. 76: »Można by więc uznać, że Zapolska resakralizuje macierzyństwo poza prawem patriarchatu, poza imieniem 0jca«. 
sondern deren gesellschaftliche Ächtung und das daraus resultierende Geschäft mit ihr. Trotz dieser subversiven Haltung zur Mutterschaft sei jedoch der letzte Ort, der zum Ausbruch aus der repressiven Gesellschaft vonnöten wäre, von der Antiutopie der skrupellosen Engelmacherin besetzt.

Die in drastischen Bildern beschriebene Dystopie der Abtreibungsmanufaktur der Sznaglowa gerät von Kłosińska wie auch von Zapolska unter die gleiche Kritik wie die normativ-repressive Gesellschaft, die diese überhaupt erst hervorbringe. So rückt auch die Abtreibung an sich, die hier als aufgezwungene Lösung einer repressiven Gesellschaft dargestellt wird, in die implizite Kritik. Diese versteckte Kritik am Schwangerschaftsabbruch, die auch Kraskowska mit ihrer Beschreibung der »Abtreibungsmode" der Zwischenkriegszeit als Ausdruck gesellschaftlicher Moden und ästhetischer Normen betreibt, ${ }^{70}$ positioniert sich wie die im Folgenden untersuchte Aussage Kraskowskas im Kontext der polnischen 1990er Jahre in einer Spannung zu feministischen Argumentationen, die das weibliche Recht auf Abtreibung politisch zu erhalten versuch(t)en.

Kraskowska schreibt, dass frühere emanzipatorische und feministische Positionen der prokreativen Funktion der Weiblichkeit kritisch gegenüberstanden und diese »als Bürde, derer man sich entledigen muss, oder als Schwäche, die es zu besiegen gelte«, behandelt hätten. Im Gegensatz dazu sieht sie nun eine Hinwendung zu und »Aufwertung dessen, was Fundament der Weiblichkeit ist«, nämlich dass wheute die Tatsache betont wird, dass die Frau als Frau geboren wird und niemand außer ihr die Aufgaben besser erledigt, die ihr das Leben anvertraut hat. ${ }^{71}{ }^{\mathrm{Da}} \mathrm{D}$ mit hat Kraskowska - im Hinblick auf ihre eigene Haltung und diejenige weiterer Befürworterinnen des weiblichen Reproduktionsprivilegs - nicht unrecht; tatsächlich erscheint in den 1990er Jahren gerade in Polen die Mutterschaft in einem günstigeren Licht als in den Jahren davor. Dies betrifft jedoch nicht nur feministische Positionen und deren »Akzeptanz der eigenen Biologizität $\aleph^{72}$, sondern auch dezidiert antifeministische, die die Weiblichkeit schon lange auf die Mutterschaft reduzierten. Gleichzeitig ist eine derartige Aussage angesichts pluraler feministischer Ansätze zu pauschalisierend und erscheint im Kontext nicht nur der bereits verlorenen Abtreibungsdebatte, sondern auch feministischer Selbstbestimmungsforderungen politisch ungünstig.

Die Mystifizierung des Zusammenhangs von Weiblichkeit und Mutterschaft wird von anderen feministischen Kritikerinnen als Doppelmoral des patriarchalen Systems entlarvt, das hier nämlich noch eine weitere Achse einfüge: „Die angeblich `heilige Mutterschaft ist heilig, wenn sie durch legalen Beischlaf herbei-

70 | Vgl. Kraskowska: Piórem niewieścim, S. 153.

71 । Ebd., S. 157: »jako brzemię, którego należy się pozbyć, albo słabość, którą należy przezwyciężyć«; »dowartościowania tego, co jest fundamentem kobiecości«; »dziś kładzie się nacisk na fakt, że kobieta rodzi się kobietą i nikt lepiej od niej nie wykona zadań, które powierzyło jej życie."

72 | Ebd.: »akceptacji dla własnej biologiczności«. 
geführt wurde « ${ }^{73}$, stellt Iwasiów fest, während Nasiłowska ausführlicher bemerkt: "Die allgemeinen Ansichten schreiben den Frauen einen Mutterinstinkt zu, der bewirke, dass ,jede Frau Kinder haben wilk. Dies bezieht sich aber ausschließlich auf verheiratete Frauen, was nicht aus der Biologie, sondern aus dem sozialen Status resultiert. ${ }^{74}$ Beide Aussagen illustrieren mit Verweis auf die Institutionalisierung der Sexualität und mit der Hinterfragung sozialhierarchischer Strukturen Diskursfelder, die in der feministischen Kritik der 1990er Jahre viel zu selten berücksichtigt wurden und deren Verdrängung zugunsten einer monolithischen Weiblichkeitskonzeption einen der Schwachpunkte feministischer Ansätze dieser Zeit ausmacht. So verschob etwa der katholisch-konservative pro-life Diskurs den Fokus zwar von "jede Frau will Mutter werden « hin zu »jedes empfangene `Kind will leben « ${ }^{75}$ der Geburtszwang auch unehelicher Kinder ging jedoch mit einer noch stärkeren Diffamierung ramoralischer Lebensweisen - etwa des Konkubinats - einher. Während also katholisch-konservative Kreise das Phänomen außerehelicher Sexualität zu bekämpfen versuchten, auferlegten sie mit dem teilweisen Abtreibungsverbot von 1993 gleichzeitig den Zwang zum Gebären unter sozial und finanziell instabilen Verhältnissen.

»Die gebärende Kuh soll man nicht mit dem Stock schlagen, zerren, treten noch über den Bauch peitschen. Entgegen der Erwartungen beschleunigt das die Niederkunft nicht. Diese Praktiken kann man damit vergleichen, wie die Frauen unter Androhung von Gefängnisstrafe zum Gebären getrieben werden. Die kleinen Neider [mali zawistnicy] möchten über die Schöpferinnen der Welt herrschen und müssen sich doch mit Wutanfällen begnügen. ${ }^{76}$

So karikiert Brach-Czaina 1992 den normativ-politischen Geburtszwang, während sie mit ihrer Rhetorik gleichzeitig eine Verharmlosung des Problems vornimmt. In ihrer Auslegung lassen sich die "Schöpferinnen der Welt« kraft ihrer Majestätik nicht von den letztlich hilflosen »kleinen Neidern« befehligen. Diese Mystifizierung der Frau lenkt die Aufmerksamkeit weg von den sehr konkret anstehenden Schwierigkeiten im Falle einer unerwünschten Schwangerschaft. Während es sich hier um ein vor die Installierung des Abtreibungsverbots fallendes Zitat handelt, tendiert der in den 1990er und auch 2000er Jahren anzusiedelnde feministische Fokus auf Mutterschaft und snatürlicheく Weiblichkeit zu einer Art Eskapismus oder Resignation. Kraskowska zufolge wird diese Haltung »Neoweiblichkeit‘ (new femininity) genannt, häufiger aber Postfeminismus, und stellt einen Bestandteil der postmodernen New-Age-Atmosphäre des ausgehen-

73 I Iwasiów: Kresy, S. 110: »Rzekomo sświęte macierzyństwo jest święte, jeśli dokonało się za sprawą legalnego pożycia."

74 I Nasiłowska: Natura, S. 189.

75 I Vgl. Matuchniak-Krasuska: Kategorie i reguły; dies.: Czym była dyskusja, S. 202-206.

76 | Brach-Czaina: Szczeliny, S. 34. 
den 20. Jahrhunderts dar. ${ }^{77}$ In diesem Bereich gebe es Kraskowska zufolge »keinen Raum mehr für den Geschlechterkampf, fehlende Akzeptanz des eigenen Geschlechts, das Dogma der Gleichberechtigung (was hier mit einem einfachen Gleichheitsgefühl ersetzt wird) oder das Lächerlichmachen traditioneller weiblicher Rollen. ${ }^{78}$ Die Fokalpunkte feministischer Kritik stehen in dieser Auslegung somit zum Teil nicht unweit des konservativen Mainstreams oder stellen sich diesem jedenfalls nicht in den Weg. Gleiches gilt für das feministische >Überschreiben` von Klassengegensätzen am Beispiel des Haushaltsalltags, auf das ich nun näher eingehe.

\subsubsection{Krzątactwo und Klassenblindheit}

»Was ist das für eine Heldin, die sich in den letzten lichten Momenten dafür interessiert, was in der Küche vor sich geht? ${ }^{79}$, fragt Kraskowska in gespielter Entrüstung aus der Perspektive der >männlichen` Literaturkonvention in Bezug auf die thematische Ausrichtung weiblicher Literatur und stellt fest: "Zusammen mit dem Schaffen von Frauen ging das `krzatactwo in die Literatur ein ${ }^{80}$. Krzątactwo, das Herumhantieren und -wirtschaften, fasse alles zusammen, was in ebendieser Küche und allgemeiner im Haushaltsalltag geschehe. Krzątactwo sei das Gegenteil des außergewöhnlichen Ereignisses. Diesen Neologismus popularisierte Brach-Czaina 1992 als Oberbegriff der in der Regel ohne große Achtsamkeit erledigten, in der Materialität verankerten Alltagshandlung. »Das Herumhantieren ruft aus dem Nichts das delikate, anfällige Gewebe der alltäglichen Existenz hervor, das [...] zu einem flüchtigen Dasein verdammt ist ${ }^{81}$, schreibt Brach-Czaina. Krzątactwo als Herstellungsprozess der »existentiellen Ordnung« müsse ständig aufrechterhalten werden, denn es »vernichtet sich selbst. Jede Aktivität annihiliert ihre eigene Handlung, um der Erneuerungsmöglichkeit Raum zu machen. Die Alltäglichkeit ist aus verschwindenden Gesten gebaut, [...] die ihre Bedeutung verlieren, sobald sie ausgeführt sind. ${ }^{82}$ Das Herumwerken im Haushalt stelle somit die Basis des Daseins überhaupt dar, da es den Alltag performativ erzeuge und ihm

77 | Kraskowska: Piórem niewieścim, S. 157: »nazywany jest sneokobiecością‘ (new femininity), częściej - postfeminizmem, a stanowi część składową postmodernistycznej atmosfery New Age końca XX wieku."

78 । Ebd.: »nie ma już miejsca na walkę płci, brak akceptacji dla własnej biologiczności, dogmat równouprawnienia (tu zastąpiony zwykłym poczuciem równości) czy ośmieszanie tradycyjnych ról kobiecych."

79 । Ebd., S. 98: „[C]óż to za heroina, która w końcowych przebłyskach świadomości interesuje się tym, co dzieje się w kuchni?«

80 । Ebd.: »Wraz z twórczością kobiet weszło do literatury ’krzątactwo«".

81 I Brach-Czaina: Szczeliny, S. 97.

82 | Ebd., S. 103. 
eine Sinnstruktur verleihe. ${ }^{83}$ Von besonderer Bedeutung erweist sich die Materialität: Die Realität entspringe der in sich selbst zusammenfallenden Interaktion mit den $»$ Bröseln des Daseins ${ }^{84}{ }^{4}$ wie etwa dem Staubwischen mit einem Lappen. ${ }^{85}$

In der Fokussierung auf den Alltag richtet die Literatur den Blick auf die Mikrostruktur des Daseins. Besonders die Ansätze von Kraskowska und Kłosińska interessieren sich für die iterative Alltagshandlung als Zentrum der weiblichen Erfahrungswelt. Sie interpretieren die Literarisierung des Alltags, die »Geschichte der Belanglosigkeiten ${ }^{86}$, als thematische Quintessenz weiblichen Schreibens. Besonders relevant wird die sich selbst auslöschende Wirkung der Alltagshandlung, in der das weibliche Ich sich sowohl konstruiert wie auch seine Spuren verwischt: Laut Kłosińska artikuliere das Dienstmädchen Kaśka in Zapolskas Kaśka Kariatyda das

»Wesen ihres Daseins in der Welt, das auf Unterwürfigkeit basiert und dem Verbot untergeordnet ist, 'Spuren ‘ zu hinterlassen. Die Unterschrift, das Ich-Zeichen halten das Dasein fest, die Tätigkeiten der Bediensteten spült das Wasser weg und verwischt der Lappen. So verschwindet auch die Frau: ohne Notiz, ohne Signatur, ohne 'Spur« « 87

Kłosińska zieht eine Parallele zwischen der Haushaltstätigkeit und dem weiblichen Dasein: beides vergehe im patriarchalen System spurlos. Krzątactwo versinnbildliche somit geradezu das weibliche Dasein und stehe für dessen Flüchtigkeit in der männlich dominierten Gesellschaft und Geschichtsschreibung. ${ }^{88}$

83 I Vgl. auch McClintocks (Imperial Leather, S. 170) Hervorhebung der Haushaltsarbeiten als »a semiotics of boundary maintenance. Cleaning is not inherently meaningful; it creates meaning through the demarcation of boundaries."

84 I Brach-Czaina: Szczeliny, S. 10.

85 । Vgl. ebd., S. $170 f$.

86 | Kłosińska: Ciało, S. 19: »historię błahostek«.

87 | Ebd., S. 67: »istotę swego bycia w świecie, sprowadzonego do uległości i podporząadkowanego zakazowi pozostawiania sśladów<. Podpis - znak Ja utrwala bycie, czynności służącej zmywa woda i zmazuje ścierka. Także kobieta znika: bez zapisu, bez sygnatury, bez sśladus."

$\mathbf{8 8}$ । Vgl. als Gegenbeispiel Róża in Kuncewiczowas Cudzoziemka (Die Fremde, 1936), die als Schwiegermutter der Hausherrin ihre Spur auf dem staubigen Klavier gerade als Protest gegen die sschlecht aufrechterhaltene Altagsordnung hinterlässt und damit ihre soziale Position kundtut: "[Róża] schaute irgendwo hinter den Wänden auf die schutzlosen Objekte, auf die schlafenden Kinder, auf die noch warmen Spuren des vergangenen Tages [...] Irgendwie kamen im Verlauf des Tages die Effekte der morgendlichen Inspektion zum Vorschein: Im Staub auf dem Klavier prangte eine Zickzacklinie, ein aufgerissenes Kinderhemd oder ein dreckiges Handtuch hingen an einem Ehrenplatz, der verschimmelte Käse brillierte mitten auf dem Tisch."Kuncewiczowa, Maria: Cudzoziemka, Warszawa 1973, S. 86: »[Róża] gdzieś za ścianami patrzyła na bezbronne przedmioty, na uśpione dzieci, na cieple jeszcze ślady minionego dnia [...] Jakoż w ciągu dnia wychodziły na jaw skutki porannych inspekcyj: w kurzu na desce fortepianu widniał zygzak, rozpruta koszulka 
Krzątactwo ist an die Materialität der Haushaltsgegenstände gebunden, die durch den intimen Umgang die weibliche »Spur« ebenso konservieren wie verhüllen. Gleiches gilt gemäß Kłosińska für die Tradierung weiblicher Schriftlichkeit, die als fragmentarische Stücke im Verborgenen von »Schreibtisch [...], Schatullen und Skapulieren ${ }^{89}{ }^{8}$ überdauert. Materialität und Intimität der Schriftstücke und Erfahrungen impliziert bei deren Weiterreichung eine Nähe zwischen Senderin und Empfängerin. So finde auch in Zapolskas Kaśka Kariatyda die Weitergabe weiblicher Schriftlichkeit durch den persönlichen Kontakt statt: Die Bedienstete erhält von der Hausherrin Pani Budrowska einen Brief und ein Buch, die beide "eine Geschichte der Tränen [so der Titel des Buches, Anm. d. V.] enthalten, eine Niederschrift weiblichen Leidens«. Doch obwohl die Schriftstücke »beide inmitten der Wäsche ruhen, beide in intimer Nähe zum Körper der Protagonistin«, funktioniere in diesem Beispiel die Weitergabe und Tradierung weiblichen Schreibens und weiblichen Wissens gerade nicht, und »beide bleiben ungelesen ${ }^{90}$.

Der Status quo wird in Kaśka Kariatyda im Spezifischen von der mehrheitlich apathischen Pani Budrowska aufrechterhalten. Obwohl sie ihre Angestellte zeitweise »mit den mütterlichen Worten: ^mein Kind « ${ }^{91}$ anspricht und ihr die genannte Lektüre anvertraut, zeigt sich die Dysfunktionalität dieser >matri<linearen Tradierung schon nur darin, dass sich die Hausdame für die beiden Schriftstücke, die sie ihrer Bediensteten übergibt, selbst nicht interessiert. Sie entzieht sie sich der Solidarität, die sich aus der verbindenden Geschlechterrolle ergeben könnte, womit die `pathologische` Kondition beider Frauen versinnbildlicht wird. Kłosińska geht an dieser Stelle nicht darauf ein, dass der Bruch in der weiblichen Tradierung letztlich von einem Klassengefälle geprägt ist: Während Pani Budrowska die emanzipatorische Geschichte der Tränen aus Desinteresse oder Lethargie verschmäht, scheitert Kaśka in der versuchten Lektüre an ihrem Semialphabetismus. Pani Budrowska verkörpert in Kaśka Kariatyda eine fast willenlose Passivität, und ihre stille Solidarität mit Kaśka hört dort auf, wo sie eine Haltung gegenüber ihrem Gatten offenbaren müsste. Indem sie Kaśka mit dem Arrangieren der heimlichen Treffen mit ihrem Liebhaber beauftragt, besiegelt die Hausherrin in ihrer auch affektiv ausgeübten Machtposition Kaśkas Unglück. ${ }^{92}$ Überhaupt scheint die litera-

dziecinna albo brudny ręcznik wisiały na honorowych miejscach, spleśniały kawał sera brylował pośrodku stołu."

89 | Kłosińska: Ciało, S. 26: »Biurko [...] w szkatułkach i szkaplerzach«.

90 । Ebd., S. 62: »zawierają Historię łzy, zapis kobiecego cierpienia«; »0bydwa spoczywają pośród bielizny, obydwa pozostają w intymnej bliskości z ciałem bohaterki«; »obydwa pozostają nie przeczytane«.

91 । Ebd.: »macierzyńskimi słowami: ’moje dziecko«".

92 I Die Klassenstruktur wird gerade durch Budrowskas mütterliche Ansprache »mein Kind!« zwischen den beiden Frauen installiert: »Dieses Wort erfüllte Kaśkas Herz mit unbegrenzter Wonne und umschloss ihre kräftige Figur mit der unzerstörbaren Kette des Gehorsams. In diesem kurzen Moment verlor Kaśka ihren Willen und wurde zu einem Apparat in den Fingern ihrer Herrin." 
rische Nachverfolgung des Werdegangs Kaśkas quer durch die niedersten Schichten des Lembergs des ausgehenden 19. Jahrhunderts gleichsam eine Kritik an der Klassenstruktur wie an der Geschlechterordnung zu transportieren.

Kłosińska übergeht diese klassenkritisch lesbare Seite von Kaśka Kariatyda, obwohl sich gerade so der Bruch in der weiblichen Tradierung schlüssig analysieren ließe. Das Erleben Kaśkas steht bei Kłosińska als weibliches Erleben im Zentrum, und die Erfahrung der harten Haushaltsarbeit gerinnt zum weiblichen Schicksal. Das Paradox von Kaśkas krzątactwo besteht darin, dass der Effekt desselben sichtbar sein muss, gleichzeitig aber die eigentliche Arbeit verhüllt bleiben soll. Kaśka ist es nicht gestattet, im von ihr selbst aufrechterhaltenen Dasein zu existieren was hier meines Erachtens mehr noch als eine geschlechtliche eine klassistische Verdrängung bedeutet. Krzatactwo ist als Reproduktionsarbeit genauso an die Klasse wie an das Geschlecht gebunden. Kłosińska sieht jedoch keinen Gegensatz in diesem $>$ Kampf $\triangleleft$ mit dem Alltag, in dem sich Kaśka die Finger wundscheuert ${ }^{93}$ und anderen `weiblichen ^ Alltagshandlungen wie »Kaffeetrinken, Bäder[n] und Spaziergänge[n] « oder gar dem »dem eigenen Körper Sorgetragen ${ }^{94}$.

Besonders auffällig ist das `Abdrängen` der Klassenfrage in der Monographie Kraskowskas, die mit den weiblichen Texten der Zwischenkriegszeit ein für soziale Fragen empfängliches Material untersucht. Beispielhaft zeigt sich dies am von Kraskowska als Prototyp des »integrativen « weiblichen Schreibens bezeichneten Roman Boguszewskas Całe życie Sabiny. Sabina reflektiert im Verlauf ihres Lebens nicht nur ihr eigenes Schicksal, sondern kontrastiert dieses auch kritisch mit der Situation der Hausangestellten. Dennoch weist sie die sozialistische Broschüre der Bediensteten Stasia in einer Art selbstgefälligen Verteidigungshaltung zurück, die ihr die letztlich privilegierte Position eines geruhsamen Sterbebetts in der Wohnung ihrer Schwester erlaubt. ${ }^{95}$ Das Motiv der Klassendifferenzen und die Frage, wer eigentlich in der Küche hantiert und den Herd einheizt, werden jedoch von Kraskowska in ihrer Thematisierung des krzatactwo völlig außer Acht gelassen. Kraskowska `überliest`subtilere Intonationen, etwa die immer wieder aufscheinende latente Ironisierung der Hauptfigur durch die Erzählstimme oder die Verdoppelung des Bewusstseins der Hauptfigur kurz vor ihrem Ableben, wobei das von Kraskowska in den Vordergrund gestellte Interesse daran, »was in der Küche vor sich geht ${ }^{96}$, eher eine inkorporierte, automatisierte Reaktion auf die Umwelt darzustellen scheint als ihr eigenes Bedürfnis: »Was hackt Stasia in der Küche? Fleisch für die Omeletten? - hört Sabina plötzlich ihre eigene Stimme, als ob sie

Zapolska, Gabriela: Kaśka Kariatyda, Lublin u.a. 1922, S. 24: „To słowo przepełniło serce Kaśki rozkoszą nieokreśloną i skuło jej silną postać nierozerwalnym łańcuchem posłuszeństwa. W tej krótkiej chwili Kaśka straciła swą wolę i stała się maszynką w palcach swej pani.«

93 I Vgl. ebd., S. 38.

94 I Kłosińska: Ciało, S. 18: »picie kawy, kąpiel i spacery«; »dbałość o własne ciało«.

95 I Vgl. Boguszewska, Helena: Całe życie Sabiny, Warszawa 1967, S. 174f.

96 | Kraskowska: Piórem niewieścim, S. 98: »co dzieje się w kuchni«. 
von einer langen Reise zurückgekehrt sei [...].« ${ }^{97}$ Diese Passage illustriert m. E. vor allem ein Einbrechen des Habitus einer Hausherrin in das gedankliche Abdriften der Sterbenden und weniger deren versöhnende Reidentifikation mit ihren ınatürlichen $\ll$ weiblichen Interessensfeldern.

An anderen Stellen in Kraskowskas Monographie lassen sich hingegen Verweise auf eine nach Klassen organisierten Gesellschaft finden, etwa am Beispiel von Kuncewiczowas Przymierze z dzieckiem. Kraskowska kritisiert die Lebenshaltung der Hauptfigur als modische Erscheinung. Eine Schwangerschaft lasse sich, so die Worte Kraskowskas, wenig damit vereinbaren, »den Vormittag auf dem Tennisplatz, den Nachmittag im Café und den Abend im Dancing zu verbringen «" ${ }^{98}$. Die Konstruktion des Gegensatzes von »verformter« Wäscherin und modischer Frau, deren Körper Quell ihres "narzisstischen Interesses «"9 darstelle, betrachtet Kraskowska kritisch. Dennoch geht es ihr weniger um eine Klassenkritik als um eine Kritik an Teresas Weiblichkeit. Die Wäscherin interessiert Kraskowska tatsächlich wenig, doch mit Genugtuung hält sie Teresa die Universalität einer naturalisierten Weiblichkeit vor, vor der es kein Entkommen gibt. ${ }^{100}$

Klar wird bei Kraskowska, dass sie wie Kłosińska auf klassenkritische Spuren, die in den untersuchten Texten ausgelegt sind, grundsätzlich nicht oder höchstens flüchtig eingeht. Dies ist insofern aus feministischer Perspektive nachvollziehbar, als die Klassenfrage die Frage nach der Geschlechterordnung genauso verdrängen kann wie die von Borkowska verbannte patriotische Auslegung weiblicher Handlungsfähigkeit, die ich unter 6.2.4 noch besprechen werde. Dennoch reduziert eine solche Auslegung der weiblichen Texte diese auf ihre >Geschlechtlichkeit` allein und beraubt sie damit ihrer soziopolitischen Polyvalenz. Die Geschlechterordnung bleibt so als einzige, metahistorische Konstante zurück, die im Verständnis Kraskowskas zudem nicht geringfügig naturalisiert wird.

97 । Boguszewska: Całe życie, S. 265: »- Co Stasia sieka w kuchni? Mięso na naleśniki? - słyszy Sabina nagle swój własny głos, jakby wróciła z jakiejś podróży«.

98 । Kraskowska: Piórem niewieścim, S. 153: "spędzenia przedpołudnia na korcie, popołudnia w kawiarni, a wieczoru na dancingu«.

99 । Ebd., S. 154: »jej narcystycznego zainteresowania«.

100 | Vgl. ebd., S. 156. Klassenkritischer analysiert Kuncewiczowas Roman übrigens Nasiłowska, die der Figur Teresa die selbstgefällige Naivität ihrer Klasse vorhält: „Arme Teresa! Sie begriff nicht, wie glücklich sie war. Die Geburt fand nicht unter Fließbandbedingungen statt, und wie unwiderlegbar aus der Beschreibung hervorgeht, kümmerte sich das medizinische Personal um sie, überließ sie nicht ihrem Schicksal. Die Windeln wusch sie nicht eigenhändig, und sogar der Kleider nahm sich sjemand an, wenn sie verbreitert werden mussten, wie aus der unpersönlichen grammatischen Form hervorgeht. Es ist eine weitere Person ohne Vor- und Nachnamen in diesem Text, eine funktionale Person, ohne Gesicht«, schreibt Nasiłowska zu Teresas Ignoranz gegenüber sozialen Hierarchien und ‘Arbeitsteilung‘. Nasiłowska: Natura, S. 194. Vgl. auch Gajewska: Macierzyństwo, S. 263. 
Die Nicht-Berücksichtigung sozialer Hierarchien jenseits der geschlechtlichen in der feministischen Kritik der 1990er Jahre kann als Versuch der \Depolitisierung` gelesen werden, also als Loslösung der Geschlechterfrage von einer von Klassenrhetorik geprägten sozialistischen Geschlechterpolitik. Betont wird deshalb das gemeinsame Los der Frauen, das sich über andere Differenzen und soziale Grenzen hinwegsetzt - allen voran das biologische Los der Mutterschaft. Historische Marker hingegen wie die spezifische Gesellschaftsform (Stände-, Klassengesellschaft; Feudalismus, Demokratie usw.) werden zugunsten einer übergeordneten Fokussierung auf >das Patriarchat`vernachlässigt (siehe 6.2.4). Die feministischen Texte verlieren so teilweise ihre lokalhistorische Dimension und gerinnen zu Untersuchungen einer als universal verstandenen bürgerlichen Kultur der vergeschlechtlichen Sphärentrennung, innerhalb derer eine positive weibliche Identität etabliert werden müsse. Solche Strategien der wissenschaftlichen und sozialen Einbettung, die sich vom (sozialistischen) `Zwang zum Politischen abwendet, bilden den Schwerpunkt des folgenden Unterkapitels.

\subsection{Politisches und Apolitisches}

Das Diskursfeld des Politischen muss in Bezug auf seine für das postsozialistische Polen spezifischen Vorzeichen problematisiert werden. Der Begriff des Politischen stellte in Polen seit der Volksrepublik, besonders aber seit den 1980er Jahren und der oppositionellen Bewegung gegen das sozialistische System einen Problembegriff dar. Bis heute definiert sich der Begriff des Politischen enger auf eine links-rechts-Dichotomie, auf parteipolitische Angelegenheiten sowie auf die 'gro-

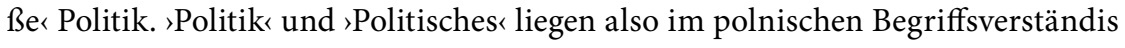
näher beieinander als in westlichen Ländern, wobei der `Politik«-Begriff in Polen eine stärkere Färbung des »Korrumpierten $\aleph^{101}$ trägt. Soziopolitisch engagierte zivilgesellschaftliche Initiativen ziehen es oftmals vor, den Begriff des Politischen zu vermeiden.

Die Zivilgesellschaft als politische Öffentlichkeit gewann in den 1990er Jahren ihre rechtliche Verankerung; gleichzeitig rückte sie als kollektive Kraft im sozialen und politischen Diskurs in gewisser Weise in den Hintergrund. Dies hängt damit zusammen, dass das übergeordnete System des Sozialismus beseitigt wurde, womit die direkte Reibungsfläche der zivilen Gesellschaft in der öffentlichen Sphäre wegfiel. Dieses Wegfallen des `Zwangs zum Politischen (oder, wie ich noch erläutere, zum »Antipolitischen«) zog eine Zuwendung zum Privaten und Individuellen mit sich, das bereits als Desiderat formuliert wurde. Diese Tendenz wurde unterstützt durch die kapitalistische Umstrukturierung, die die Individuen auf sich selbst zurückwarf und viele Institutionen der staatssozialistischen Planung

101 I Vgl. Fuszara: Feminizm i my, S. 14; Snitow: Przyszłość feminizmu, S. 8; Świda-Ziemba: Człowiek wewnętrznie zniewolony, S. 365-369. 
erodierte. Das Streben zum Individuellen und Privaten habe ich für die feministische Kritik bereits festgestellt; im Folgenden soll nun nachgezeichnet werden, wie sich diese Tendenzen in die Dynamiken der 1990er Jahre einschreiben.

Die Differenzierung von Politischem und Privatem ist für das politische Selbstverständnis der feministischen Kritik in Polen von tragender Bedeutung. Besonders der wissenschaftliche Zweig der Geschlechterdebatte zeigt eine mitunter scharfe Abspaltung vom feministisch-politischen Aktivismus. Ich möchte deshalb kurz auf das Phänomen der »Antipolitik« der 1980er Jahre zu sprechen kommen, um die relevanten diskursiven Voreinstellungen der 1990er Jahre einzuführen; anschließend sollen vor diesem Hintergrund die politischen respektive apolitischen Aussagen der feministischen Kritikerinnen in ihren Texten untersucht und dabei gefragt werden, inwiefern hier unter Berücksichtigung der erwähnten postsozialistischen Abgrenzungen von einem politischen Phänomen gesprochen werden kann.

In Polen nahm der Bereich, den Habermas die öffentliche Sphäre nennt, ${ }^{102}$ historisch eine besondere Funktion ein. Die polnische halbprivate Öffentlichkeit war getrennt vom übergeordneten Staatsapparat, der sowohl während der Teilungszeit im 19. Jahrhundert wie auch in der Volksrepublik als sfremdbestimmt galt. Die 'Imagination der polnischen Nation als eine ideell und kulturell zusammengehörige Gemeinschaft ${ }^{103}$ fand innerhalb dieser halbprivaten Sphäre statt. Die Zivilgesellschaft übernahm somit über lange Zeit in Abwesenheit einer spolnischen Staatsführung und einer `öffentlichen`Sphäre die Funktion übergeordneter Gemeinschaftlichkeit; für die Volksrepublik gilt diese Feststellung vor allem ab 1980 und der Verschärfung oppositioneller Bestrebungen. ${ }^{104}$

In den frühen Jahren der Volksrepublik hingegen fand eine spezifische Ver-Öffentlichung des aus bürgerlicher Sicht privaten Raums statt. Das sozialistische System zeichnete sich - am deutlichsten in seiner stalinistischen, totalitären Ausprägung - durch eine politisch-ideologische Durchstrukturierung sämtlicher Lebensbereiche aus. Somit unterlagen gerade auch die sprivaten<, persönlichen Beziehungen einer Formalisierung, die auf eine ideale Gesellschaft mithilfe politischer Regelungen und Kontrollmechanismen abzielte. ${ }^{105}$ Das sozialistische System rekonfigurierte dabei auch die Geschlechterordnung und löste die geschlechtliche

102 | Vgl. Habermas, Jürgen: Strukturwandel der Öffentlichkeit. Untersuchungen zu einer Kategorie der bürgerlichen Gesellschaft (= Politica. Abhandlungen und Texte zur politischen Wissenschaft, Band 4), Neuwied 1962.

103 | Vgl. allg. zur Nationsbildung resp. »-imaginierung « Anderson, Benedict: Imagined Communities. Reflections on the Origin and Spread of Nationalism. Revised Edition, London, New York 1983 (2006); Yuval-Davis: Geschlecht und Nation.

104 I Vgl. Fuchs: Zivilgesellschaft, S. 27-32 für Überlegungen zur Zivilgesellschaft allgemein und deren Funktion in der Transformation.

105 I Vgl. Gal, Susan: "A Semiotics of the Public/Private Distinction«, in: Scott/Keates, Going Public (2004), S. 261-277, hier S. 270. 
Trennung von Heim- und Lohnarbeit (als Prototypen privater bzw. öffentlicher Arbeitsbereiche) zumindest nominell auf. ${ }^{106}$ Gleichsam war es gerade der private Bereich des familiären Zusammenlebens, der nach Ende der stalinistischen Phase am deutlichsten der staatlichen Kontrolle entglitt (siehe Kapitel 2.3). In den real existierenden sozialistischen Staaten entstand - anstelle einer konzeptuellen Selbstauflösung des Privaten im Kollektiven - eine Diskrepanz zwischen privaten, individuellen Absichten ${ }^{107}$ und dem parteilich geformten Kollektivwillen.

Die bewusste Gegenbewegung gegen das `Politische`als Politik des Staats lässt sich gemäß Hanna Świda-Ziemba auf das letzte Jahrzehnt der Volksrepublik datieren. Die Soziologin stellte fest, dass die Ereignisse um den Julistreik von 1980, das Entstehen der NSZZ »Solidarność und der Kriegszustand von 1981 zur psychosozialen Bewusstwerdung des sozialistischen Paradoxons führten: Die Polinnen und Polen stellten fest, dass trotz angeblicher Volksherrschaft (ludowładztwo) »die Bevölkerung über nichts entscheiden konnte «108. So kam es zur endgültigen Entzweiung von Zivilgesellschaft und Regime in "wir und sie« (»my i oni«), wobei diese antagonistische Position ab 1980 von der Opposition gezielt inszeniert und gefördert wurde. Der Politik des Systems und politischen Reglementierungen stellten die Dissidenten die "Antipolitik« des gelebten Alltags und einer privaten Individualität entgegen. ${ }^{109}$ Das Private offenbarte sich als Lücke im System und zugleich als Desiderat der Zivilgesellschaft. Die private Öffentlichkeit der Zivilgesellschaft war jedoch in sich stark von normierenden Narrativen geprägt und bildete einen kollektiven »Individualisierungsdruck« heraus. ${ }^{110}$ Ähnlich galt für die Untergrundliteratur, den sogenannten drugi obieg (zweiten Umlauf), ab Ende der 1970er Jahre eine durch ihre ,Unöffentlichkeit bedingte Norm zum politischen Schreiben. ${ }^{111}$

Die Ablehnung der sozialistischen Politik manifestierte sich vor allem auf einer passiven Ebene, durch eine demonstrative Nicht-Teilnahme am politischen Geschehen. ${ }^{112}$ Der politischen Durchstrukturierung des Lebens sollte nicht eine

106 I Vgl. Godzic, Wiesław: [N.N.], in: Drozdowski/Krajewski, Prywatnie o publicznym (2007), S. 16-18, hier S. 16.

107 | Vgl. Drozdowski, Rafał: [N.N.], in: Drozdowski/Krajewski, Prywatnie o publicznym (2007), S. 19-23, hier S. 20.

108 I Świda-Ziemba: Człowiek wewnętrznie zniewolony, S. $295 f$.

109 । Vgl. Gal: Public/Private Distinction, S. 272; Szacki: Liberalizm po komunizmie, S. $95 f$.

110 । Vgl. Szacki: Liberalizm po komunizmie, S. 105f.; Środa: Kobieta, S. $11 f$.

111 | Vgl. Czerniawski: Poetical Political, S. 22; Eile, Stanislaw: »Introduction«, in: Eile/Phillips, New Perspectives (1992), S. 1-5, hier S. 3; ders.: »Between Absurdity and Apocalypse: Contemporary Poland in Drama and Fiction, 1977-87«, in: Eile/Phillips, New Perspectives (1992), S. 180-200, hier S. 182f.; Iwasiów: Powieść w obiegach, S. 135, 141f.; Pirie, Donald P. A.: »Internal Exile in a Free Society? New Poetry in Poland in the 1980s and Early 1990s «, in: Eile/Phillips, New Perspectives (1992), S. 201-229, hier S. 204f., 211.

112 I Vgl. Świda-Ziemba: Człowiek wewnętrznie zniewolony, S. 353. 
weitere politische Vision entgegengestellt werden, sondern deren radikale Inversion. Die »Antipolitik« war eine Abkehr vom >Politischen<, das als Eindringen des Staates in die Freiheit des Individuums und als Inbegriff ideologischer Überformung wahrgenommen wurde. ${ }^{113}$ Doch die "antipolitische" Strategie hatte trotz gegenteiliger Beteuerungen einen offensichtlichen politischen Charakter. Szacki führt aus, dass "Antipolitik nicht Neutralität in politischen Belangen« hieß, sondern die Frage aufwarf, "wie sich die Leute verhalten sollten, die einer schlechten Führung unterworfen sind und diese im Moment nicht zu ändern vermögen. «14 $^{14}$ Im Zentrum stand somit nicht die staatliche Politik an sich, sondern das politische Moment zivilen Handelns, womit dem Alltag und der Privatsphäre eine performative Relevanz im Rahmen dissidenten Verhaltens zugeschrieben wurde.

Während die oppositionellen Narrative die private Sphäre und die Zivilgesellschaft hochhielten, lösten sie das `Private gleichzeitig in Kollektives und Politisches auf: »only a collective response could offer the prospect of resistance «115, wie der Polonist Donald Pirie schreibt. Damit wird klar, dass das >Private eine ebenso politische und kollektive Sphäre war wie die kritisierte offizielle `Politik«. Was somit verblieb, war die nominelle Abwehr gegen das `Politische $<$ resp. den `Politik«-Begriff als (Selbst)Zuschreibung sowie eine Verunglimpfung der Formen institutionalisierter Politik. Dies zeigt sich in der marginalen politischen Beteiligung der postsozialistischen Bevölkerung, die zudem von politischen Entscheidungsträgern zusätzlich demotiviert wurde. Markantestes Beispiel für die postsozialistische Privatisierung der Politik und den wiederholten Ausschluss der Gesellschaft aus der Entscheidungsfindung ist die Durchsetzung des Balcerowicz-Plans, der das Land der ökonomischen Schocktherapie unterwarf. ${ }^{116}$

\subsubsection{Geschlechterordnung und (anti)politischer Diskurs}

Im Vordergrund der »antipolitischen« Oppositionspolitik stand die - habituelle wie letztlich auch systemische - Loslösung des Individuums und der Bevölkerung als gesamte vom sozialistischen System. Die "Antipolitik« forderte eine Minimierung der staatlichen Strukturierung der Lebensbereiche, darunter insbesondere eine Liberalisierung der `Privatsphäre ‘. Obwohl die »Antipolitik« beim Privatleben ansetzte, thematisierte sie die Geschlechterordnung nicht direkt. Diese könnte somit als $>z u$ privater Privatbereich gelten, ${ }^{117}$ als dass er (anti)politisch eingesetzt würde. Die »antipolitische« Politik konzentrierte sich darauf, »dass die ১Solidar-

113 | Vgl. Szacki: Liberalizm po komunizmie, S. 93.

114 | Ebd., S. 100.

115 | Pirie: Internal Exile, S. 204.

116 | Vgl. Szatlach: Dylematy Polek, S. 161; Świda-Ziemba: Człowiek wewnętrznie zniewolony, S. 344-347.

117 | Vgl. zu den Überlegungen zum fraktalen Charakter von privaten und öffentlichen Bereichen Gal: Public/Private Distinction, S. 265ff. 
ność‘ zuerst die Unabhängigkeit und Demokratie für die ganze Gesellschaft erkämpfen muss «118, die Geschlechterfrage hingegen wurde als sekundär eingestuft. Im Folgenden untersuche ich, wie sich die feministischen Kritikerinnen zu diesem "antipolitischen « Politikzwang der 1980er Jahre verhalten und wie sie dabei die Frage nach der Geschlechterordnung einbringen. Diese Fragen lassen sich nur bei Borkowska und Janion direkt beantworten, da die drei anderen Polonistinnen auf diesen Kontext nicht eingehen. Ich beleuchte deshalb die Texte Janions und Borkowskas hinsichtlich ihrer Verortung des "antipolitischen « Diskurses und diskutiere, wie sie sich zu diesem positionieren. Erst im folgenden Unterkapitel stelle ich die Frage wieder an alle untersuchten Texte, inwiefern sie feministische Kritik als politische Handlung und deren Gegenstand als politisch verhandelbar verstehen.

Borkowska kritisiert in der Geschichtswissenschaft der 1980er und 1990er Jahre die Fokussierung auf die "politische« Dimension in der Untersuchung weiblicher Handlungsfähigkeit im 19. Jahrhundert. Dabei handelt es sich um eine Strategie zur Re-Patriotisierung der Geschichtsschreibung, die das Element des kollektiven polnischen Widerstands gegen die Obrigkeit reinszeniert und damit auch antisozialistische Züge aufweist. »Man untersucht und zeichnet jenes Verhalten aus, das eine patriotische Aussage hat, mit dem Kampf um die Unabhängigkeit verbunden ist. ${ }^{119}$ Das Politische stellt Borkowska ganz in den Kontext der patriotischen Handlung zur Erreichung der Unabhängigkeit. »In der Regel nimmt man an, dass wohltätige Aktivitäten [von Frauen] die illegale politische Aktivität decken mussten [...]. ${ }^{120}$ Sie versucht nun, weibliches Handeln aus diesem Kontext zu lösen und »von Natur aus unpolitische Handlungen ${ }^{121}$ als solche zu würdigen. Damit konstruiert sie weibliches Handeln sowohl im öffentlichen wie im privaten Raum als eine rein persönliche (individuelle, private) Erweiterung der Handlungsfähigkeit.

Borkowskas Beschreibung emanzipatorischen Verhaltens begreift sich als Abkehr von einem vereinnahmenden Politikzwang. Ihre Rhetorik zeigt Ähnlichkeiten mit dem "antipolitischen" Narrativ der 1980er Jahre, das sich ebenfalls gegen ein als aufoktroyiert verstandenes Politisches wendet. Doch während sich das "antipolitische" Narrativ gegen den sozialistischen Staatsapparat stellt, versteht Borkowska das "patriotisch-martyriologische « ${ }^{122}$ Narrativ als vereinnahmenden politischen Diskurs und kritisiert damit Stoßrichtungen der »Antipolitik» selbst. Borkowska sieht das patriotische Narrativ als diskursiven Oppressor der weib-

118 | Janion: Kobiety, S. 326: "Że 'Solidarność‘ musi najpierw wywalczyć niepodległość i demokrację dla całego społeczeństwa«.

119 | Borkowska: Cudzoziemki, S. 34: „Bada się i premiuje te zachowania, które mają wydźwięk patriotyczny, związany z walką o niepodległość."

120 । Ebd.: "Z reguły zakłada się, że działalność dobroczynna musiała kryć nielegalną działalność polityczną [...].«

121 I Ebd., S. 36: »działań z natury niepolitycznych«.

122 | Ebd., S. 34: »patriotyczno-martyrologiczny«. 
lich-privaten Sphäre und der Auseinandersetzung mit derselben. Die Kritik des Politischen zeigt jedoch auch bei Borkowska Tendenzen zu einer rhetorischen Gemeinschaftsbildung: Während das "antipolitische« Narrativ eine in der Opposition diskursiv vereinte Zivilgesellschaft als >private`, kollektive Gegenkraft zum sozialistischen System inszeniert, fasst Borkowska das Weibliche als eine ebenso private und kollektive Kategorie, deren Essenz das Persönliche und Intime ist.

Borkowska wirft dem "patriotischen « Historiker vor, dass »in seinen Augen das Politische wichtiger ist als das Unpolitische. ${ }^{123}$ Damit impliziert Borkowska, dass sie in ihrer Arbeit das "Unpolitische" als relevanten historischen und literaturwissenschaftlichen Forschungsbereich aufwertet, das hier - darin dem »Antipolitischen« ähnlich - die performative Ausweitung der Handlungsfähigkeit von Frauen zum Selbstzweck betrifft. Borkowska stellt das »Politische«, Kollektive in einen deproblematisierten Gegensatz zum »Unpolitischen«, Individuellen/Privaten. Insofern scheint sie auch ihre eigene Arbeit als im Grunde »unpolitischen« Bereich zu definieren, was sich mit ihrer latent essentialistischen Auffassung von Weiblichkeit überschneidet. Es lässt sich jedoch nicht abstreiten, dass Borkowska gerade durch ihr kontroverses Aufgreifen der Frage nach weiblicher Handlungsfähigkeit und Weiblichkeitsvorstellungen diese zum Diskussionsgegenstand und somit zum Politikum erhebt, wobei sie ein dem »antipolitischen« Narrativ ähnliches rhetorisches Verfahren einsetzt. Die Forderung nach der diskursiven Befreiung des »Unpolitischen« kann somit gleichzeitig als kryptopolitische Aussage gelesen werden, die (sich) dies selbst nicht eingesteht.

Obwohl Janion sich ähnlich kritisch zum >patriotisch-politischen ‘ Diskurs äußert, der in den 1980er Jahren herrschte, zielen ihre Aussagen über die Kategorie des Geschlechts als Politikum in eine andere Richtung. Dies wird ersichtlich, wenn Janion schreibt:

»In der Opposition der 1970er und 1980er Jahre herrschte die Denkweise, dass der Kampf um die Unabhängigkeit wichtig sei, unwichtig aber - der Kampf um Frauenrechte. Aktivisten der Unabhängigkeit werden politisch verfolgt, während die von Frauen empfundene Repression und Kontrolle deren Privatsache ist.«124

Janion zeigt auf, dass der oppositionelle Diskurs der `Frauenfrage Charakter zuschrieb und als eine vom Politischen gesonderte Sphäre betrachtete. Obwohl die Feststellungen von Janion und Borkowska ähnlich sind - weiblicher Aktivismus wird nur als nationaler Widerstand wertgeschätzt -, nehmen ihre Rhetoriken unterschiedliche Vektoren an. Mit ihrer Kritik legt Janion den Grund-

123 | Ebd., S. 36: „W jego oczach to, co polityczne, jest ważniejsze od tego, co niepolityczne."

124 I Janion: Kobiety, S. 326: "Poważna, taki górował sposób myślenia w opozycji lat 70-tych i 80-tych, jest walka o niepodległość, niepoważna zaś - walka o prawa kobiet. Prześladowania polityczne dotyczą działaczy niepodległościowych, natomiast odczucie represji i kontroli kobiet jest ich sprawą prywatną." 
stein für eine Politisierung der Geschlechterordnung, die keinen Umweg über eine >Privatisierung`der Weiblichkeit einschlägt, wie sie Borkowska projektiert. Janion appelliert für eine Öffnung der Privatsphäre für die gesellschaftlich-politische Verhandlung - gerade weil die Diskussion über die Geschlechterrollen trotz aller Formalitäten weder in der sozialistischen Praxis noch in der demokratischen Opposition >privat und unangetastet geblieben sei. ${ }^{125}$

Borkowskas Ineinssetzung von Weiblichkeit und Privatheit nähert sich hingegen rhetorisch dem neotraditionalistischen Narrativ der Transformationszeit an. Von diesem unterscheidet sie sich jedoch in ihrer Betonung weiblicher Selbstständigkeit und geistiger Unabhängigkeit, das sie in der Abhandlung zu Żmichowska und den Entuzjastki formuliert. ${ }^{126}$ Das Loslösen der Weiblichkeit aus einem sozialen Utilitarismus kann vor dem Hintergrund des Neotraditionalismus der 1990er Jahre als politische Aussage gelten, bedient jedoch auch die Politikmüdigkeit und Individualisierungstendenzen weiter Teile der Gesellschaft. Innerhalb der partikularisierten, auf sich selbst gestellten und politisch ebenso >unerfahrenen « wie übergangenen Gesellschaft der 1990er Jahre stellt sich die politische Frage für Frauen nochmals anders. ${ }^{127} \mathrm{Zu}$ dieser Problematik schreibt Brach-Czaina 1995, dass sich polnische Frauen angesichts der Herausforderungen der Transformationszeit das Recht auf einen depolitisierten Alltag herausnehmen. Diese apolitische Einstellung lasse sich »auf die Überzeugung der Frauen zurückführen, dass >das Leben in etwas anderem liegt $\iota$, nicht in der Machtausübung, im Besetzen von Posten oder in politischen Kämpfen. [...] Existentielle Probleme und Alltagsorganisation, das ist das richtige Leben. ${ }^{128}$ Vor dem Hintergrund eines solchen Diskurses scheint es für die feministische Kritik wenig aussichtsreich, eine weitere, feministische Ebene des >Politikzwangs` einzuführen. In gewisser Weise beschränken sich die Ansätze von Borkowska, Kraskowska und Kłosińska darauf, dieser Politikentsagung entgegenzukommen und Weiblichkeit als apolitische Kondition zu beschreiben, die als Konstante des Patriarchats ungeachtet gesellschaftlicher und politischer Einflüsse weitgehend stabil sei. Janion und Iwasiów hingegen versuchen, das Geschlecht als politischen Faktor in die Gesamtgesellschaft miteinzubeziehen und stehen damit näher an einem politischen Aktivismus. Diese unterschiedlichen Positionierungen betrachte ich im Folgenden genauer.

\subsubsection{Feministische Ideologie}

Die Einstellung der einzelnen Forscherinnen respektive ihrer Texte zum Feminismus als politische Bewegung wurde bislang höchstens am Rande thematisiert. Ich

125 I Vgl. auch Kulawik, Teresa/Ingbrant, Renata: »Maria Janion. A Tree Spreading Seeds«, in: Baltic Worlds 4 (2011), S. 4-12, hier S. 8.

126 । Vgl. Borkowska: Cudzoziemki, S. $71 f$.

127 | Vgl. Fuszara: Feminizm i my, S. 15; Snitow: Przyszłość feminizmu, S. 12.

128 | Brach-Czaina: Progi, S. 354. 
untersuche deshalb nun entlang von unterschiedlich aufgefassten Begrifflichkei-

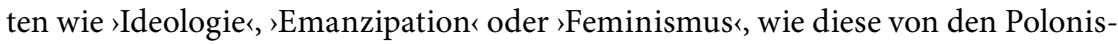
tinnen eingesetzt werden und in welchen Bezug dazu sie die feministische Kritik als 'wissenschaftliches` Instrument stellen. Eine Aufspaltung feministischer Kritik in »ideologische" und »methodische« Ansätze bemerkt Iwasiów bereits 1994, wobei sie die »ideologischen « als vorrangig sieht. ${ }^{129}$ Diese Feststellung lässt sich für die feministische Kritik in der Polonistik der 1990er Jahre nicht bestätigen. Neben einer allgemeinen Politikskepsis lässt sich bei Borkowska und Kraskowska eine Abwehrhaltung gegenüber einer potentiell politischen Komponente der feministischen Kritik beobachten. Dies zeigt sich nicht nur in der Einschreibung der Weiblichkeit in einen persönlich-privaten Bereich, der vom Politischen losgelöst sein sollte. Ersichtlich wird bei ihnen auch eine Trennung von Feminismus und feministischer Kritik; während die feministische Kritik als apolitische Methode verstanden wird, drängen beide Forscherinnen den Feminismus in eine ideologische und zugleich realitätsfremde Form. Im folgenden Zitat aus einem Artikel von Kraskowska aus dem Jahr 1993 kommt diese Zweiteilung feministischer Bestrebungen gut zur Geltung:

»Der Begriff >Feminismus muss auf zweierlei Weise verstanden werden: erstens - als allgemeines Interesse an den Problemen der Frauen, in der Kunst wie auch in den sozialen Wissenschaften, und zweitens - als Bewegung zur Gleichberechtigung der Frauen, die gewöhnlich Elemente der Aggression gegen das andere Geschlecht enthält. « ${ }^{130}$

Kraskowska diskreditiert mit dieser Aussage die politisch-aktivistische Strömung des Feminismus, die sie primär als Aggressionshaltung gegenüber dem männlichen Geschlecht definiert. Auch in ihrer Monographie Piórem niewieścim umschreibt Kraskowska die politische Variante des Feminismus als »sehr tendenziös« und "von Natur aus eher stereotyp ${ }^{131}$. Kraskowska bezeichnet sie als Ideologie, die sich nicht scheue, »Instrumente feministischer Indoktrination ${ }^{132}$ einzusetzen. Befördert werde diese Form des Feminismus durch die »Doktrin der political correctness, die in den meisten demokratischen Gesellschaften Karriere gemacht hat. ${ }^{133}$ In der Verwendung der Signalwörter Ideologie, Doktrin und Indoktrinati-

129 | Vgl. Iwasiów: Kresy, S. 21.

130 | Kraskowska: Kilka uwag, S. 261f.: »Sam termin sfeminizmく trzeba rozumieć dwojako: po pierwsze - ogólne zainteresowanie problemami kobiet, tak w sztuce, jak i w naukach społecznych, a po drugie - ruch mający na celu równouprawnienie kobiet, zwykle zawierający w sobie elementy agresji wobec płci przeciwnej."

131 I Kraskowska: Piórem niewieścim, S. 205: »bardzo tendencyjnym«; »z natury raczej stereotypowych".

132 | Ebd., S. 8: »narzędzi feministycznej indoktrynacji«.

133 | Ebd., S. 205: „doktryny political correctness, która robiła karierę w większości społeczeństw demokratycznych." 
on suggeriert Kraskowska die ideelle Nähe des Feminismus zum Kommunismus, an den diese Signalwörter konnotativ gebunden sind. Mithilfe dieser Signalwörter wirft Kraskowska dem Feminismus soziale Kurzsichtigkeit und festgefahrene Positionen vor, die ohne Rücksicht auf tatsächliche Problemstellungen verfolgt würden. Damit markiert sie den politischen Feminismus rhetorisch als etwas zu Überwindendes. ${ }^{134}$ Gleichzeitig konstruiert sich Kraskowska selbst als in Distanz zu diesem »Feminismus« stehend, insofern als sie ihn aus einer externen Position beurteile (verurteile).

Auch bei Borkowska lassen sich Aussagen finden, die sich implizit gegen einen politischen Feminismus stellen. Dies zeigt sich in den Ausführungen zu den Entuzjastki, deren Aktivitäten Borkowska als habituelle Ausdehnung der »Sphäre der öffentlichen und individuellen Freiheit ${ }^{135}$ versteht. »Es ist zu beachten, dass der diesem Programm eingeschriebene Feminismus nicht Ziel der Aktivitäten ist, sondern deren Ableitung. Die Entuzjastki denken nicht an das Erlangen einer bequemen Position oder das Erkämpfen bestimmter Rechte [...].« ${ }^{136}$ Borkowska suggeriert im Umkehrschluss, dass es auch einen Feminismus gäbe, der sich als Selbstzweck verstehe und allein darin bestehe, eine »bequeme Position « und »bestimmte Rechte« zu erreichen. Stärker noch macht Borkowska diese Gegenüberstellung am Beispiel Żmichowskas:

"Żmichowska ist klug; sie versteht, dass die Emanzipation, die oft als publizistisches Thema, als Mode, als Splitter der Ambition begriffen wird, nicht immer das Feld der Freiheit verbreitert; sie kann es auch verengen. Damit das nicht eintrifft, muss sie Wahl bleiben - eine reine, überlegte und ungezwungene Wahl. «137

Borkowska wertet deutlich die individuell unternommene `Selbstemanzipierung Żmichowskas gegenüber einer Emanzipierung als Mode oder Zwang auf. Obwohl Borkowska eine Situation des 19. Jahrhunderts bespricht, erfüllt sie damit eine Reihe populärer Stereotypen gegenüber einem als `fehlgeleitet inszenierten politischen Feminismus (siehe Kapitel 2.4.1). Dem politischen Feminismus setzen Borkowska und Kraskowska eine `natürliche` Weiblichkeit entgegen, wie dieses Zitat von Kraskowska verdeutlicht: »[D]er Unterschied besteht darin, dass die Weib-

134 I Vgl. auch Kraskowska: Kilka uwag, S. 261, wo sie feststellt, dass der Feminismus in den westlichen Gesellschaften bereits überwunden sei.

135 I Borkowska: Cudzoziemki, S. 50: „sfera wolności publicznej i indywidualnej«.

136 | Ebd., S. 49: „Warto zauważyć, że wpisany w ten program feminizm nie jest celem działania, lecz jego pochodną. Entuzjastki nie myślą o zdobyciu wygodnej pozycji czy wywalczeniu określonych praw $[\ldots] . \ll$

137 | Ebd., S. 146: "Żmichowska jest mądra; rozumie, że emancypacja, pojmowana często jako temat publicystyczny, jako moda, jako odprysk ambicji, nie zawsze poszerza pole wolności; może je także ścieśniać. Żeby się tak nie stało musi pozostać wyborem - czystym, rozważnym i nieskrępowanym." 
lichkeit existiert und sich offenbart, der Feminismus aber überredet. ${ }^{138}$ Während der politische Feminismus als ideologisch-dogmatisches Konstrukt erscheint, konstruiert Kraskowska eine ontologische Weiblichkeit, die jenseits politischer Diskussion stehe. Als solche wird Weiblichkeit zum Objekt einer ebenso apolitischen feministischen Kritik, die Kraskowska wie bereits erwähnt als »allgemeines Interesse an den Problemen der Frauen, in der Kunst wie auch in den sozialen Wissenschaften ${ }^{139}$ definiert. Damit reiht sich Kraskowska in eine laut Węgierek in den 1980er Jahren einsetzende Tradition »feminologischer « Arbeiten ein, die sich "mit immer größerer Sorge [...] um die Aideologizität « ${ }^{140}$ ihrer Forschung bemühen. Die ‘feministische`Kritik Kraskowskas erscheint in diesem Sinne stärker als Teil der Women's Studies. So schreibt Kraskowska über die feministische Kritik wie die Women's Studies affirmativ, dass sich diese »zum Großteil vom Feminismus losreißen konnten und heute völlig autonom funktionieren. ${ }^{141}$ Ungeachtet der vordergründigen Apolitizität von Kraskowskas Arbeit offenbart sich darin aber ein Ideologem, das von ihrem Weiblichkeitskonzept abweichende Entwürfe rhetorisch abstraft.

Die hierarchische Trennung von feministischer Kritik und politischem Feminismus, die Kraskowska und - weniger deutlich - Borkowska vornehmen, widerspiegelt den feminismusfeindlichen Diskurs der 1990er Jahre und versucht die feministische Kritik als neutrales wissenschaftliches Instrument aus diesem Zusammenhang herauszulösen. Komplexer präsentiert sich demgegenüber die Monographie Kłosińskas. Analytisch erschwerend erweist sich die Vermengung des Narrativs von Kłosińska mit dem von ihr untersuchten Ideologem Zapolskas. Kłosińska schält die in den Romanen angesiedelte `Haltung Zapolskas` mithilfe psychoanalytischer Instrumente heraus und argumentiert sehr nahe am literarischen Text, ohne dabei - wie Borkowska oder Kraskowska - über diesen zu urteilen. Der Text Zapolskas überlagert die Intonation Kłosińskas vielerorts. Dies kann man als methodologisches `Stimme geben`verstehen, wobei Zapolska anders als in der von Kłosińska bisher festgestellten Rezeption endlich selbst zu Wort kommen soll.

An einzelnen Stellen resultiert Kłosińskas overreading der Texte Zapolskas jedoch in Nachfragen und Zuspitzungen, wie dieses Zitat zeigt: »Wenn man die Frage nach der Frauenemanzipation zu stellen versucht, die der Roman nicht stellt, müsste man sagen, dass sich die Frau hin zu den Wonnen der Mutterschaft eman-

138 | Kraskowska: Piórem niewieścim, S. 209: »różnica polega na tym, że kobiecość istnieje i się przejawia, feminizm zaś perswaduje."

139 | Kraskowska: Kilka uwag, S. 261: "ogólne zainteresowanie problemami kobiet, tak w sztuce, jak i w naukach społecznych «.

140 | Węgierek: Przegląd, S. 419.

141 I Kraskowska: Piórem niewieścim, S. 8: »w więkżości zdołały się od feminizmu oderwać i dzisiaj funkcjonują w pełni autonomicznie.« 
zipieren sollte. ${ }^{142}$ Gerade an dieser Stelle wird deutlich, dass es auch hier um eine Form einer seigentlichen Weiblichkeit geht, wie sie Borkowska und Kraskowska anvisieren. Ähnlich verhält es sich mit der folgenden Aussage: »[D]ie weibliche Signatur bleibt im Prinzip ambivalent, eher subversiv gegenüber dem Patriarchat als in den Aufbau einer neuen Ideologie engagiert. ${ }^{143}$ Die Subversion, die hier im Gegensatz zum »Aufbau einer neuen Ideologie» steht, erscheint demzufolge als apolitische Handlung; in Zusammenstellung mit einer weiteren Metaaussage Kłosińskas über Zapolska kann sie aber in den Kontext eines proto-performativen Geschlechterverständnisses gestellt werden: "Zapolska verwischt die Grenzen zwischen den Geschlechtern nicht, aber sie situiert sie auch nicht in einer unumstößlichen Opposition. «144 In eine ähnliche Richtung argumentiert auch Kłosińska selbst, wenn sie in der Einleitung festhält, dass das »weibliche Ich ein Produkt der patriarchalen Ideologie ${ }^{145}$ sei. In Kłosińskas Monographie lassen sich somit Hinweise darauf finden, dass die Kategorie des Geschlechts jenseits eines ‘feminologischen Essentialismus angesiedelt wird; als sozial konstituierte Kategorie wird sie damit auch stärker politisch verhandelbar. Das Narrativ schwenkt jedoch immer wieder darauf zurück, dass

»die Schriftstellerin mehr daran interessiert ist, der Frau das ihr hinterlistig entrissene Recht auf glückliche Mutterschaft zurückzugeben, als biologische und gesellschaftliche Unterschiede zwischen den Geschlechtern zu beseitigen. Die Rückgabe dieses Rechts ist vielleicht der erste Schritt zu einer erfolgreichen Emanzipation der Frau. ${ }^{146}$

Inwiefern ein solches Recht auf "glückliche Mutterschaft« im gesellschaftlichen Kontext der 1990er Jahre als politisch subversives oder konformistisches Element gelten kann, hängt dabei von der jeweiligen Perspektive ab, aus der man auf die komplexe und von einer Doppelmoral geprägte Gemengelage des polnischen Mutterschaftsdiskurses blickt (siehe 6.1.1). Es lässt sich auf jeden Fall festhalten, dass Kłosińska weder explizite noch implizite Abwertungen eines politischen Feminismus in ihr Narrativ einbaut; dieser scheint sie neben einer kulturalistisch ausge-

142 I Kłosińska: Ciało, S. 206: »Gdyby spróbować zadać pytanie, którego powieść nie stawia, 0 emancypację kobiety, to należałoby powiedzieć, że powinna się ona emancypować ku rozkoszy macierzyństwa."

143 | Ebd., S. 76: "sygnatura kobieca w gruncie rzeczy pozostaje ambiwalentna, raczej subwersywna wobec patriarchatu niż zaangażowana w budowanie nowej ideologii.«

144 । Ebd., S. 210: »Zapolska nie zaciera różnic pomiędzy płciami, choć także nie sytuuje ich w jakiejś niepodważalnej opozycji.«

145 | Ebd., S. 17: »kobiece Ja - produkt patriarchalnej ideologii«.

146 | Ebd., S. 210: "pisarka bardziej jest zainteresowana zwróceniem kobiecie wydartego jej podstępem prawa do szczęśliwego macierzyństwa niż zacieraniem biologicznych i społecznych różnic między płciami. Zwrot owego prawa jest być może pierwszym krokiem ku udanej emancypacji kobiety.« 
richteten feministischen Kritik aber auch nicht primär als Phänomen mit lokalem politischem Gegenwartsbezug zu interessieren.

Ähnlich ambivalent, jedoch stärker an einem politischen Einsatz interessiert, zeigt sich Janion. Während sie ihr Vorgehen nur stellenweise als feministische Kritik bezeichnet, stellt sie sich in einem Gespräch von 1997 hinter den Begriff des Feminismus.

"[E]s geht um die Notwendigkeit, dass Frauen ihre eigenen Empfindungen definieren. Man kann sagen, dass das eine frühe und ziemlich milde Form des Feminismus sei. Sie entspricht mir aber am meisten. [...] Ich habe auch mehrfach davon gesprochen, dass sowohl Frauen wie Männer im Leben immer einer Unterdrückung unterworfen sind, aber Frauen auf eine spezielle, zusätzliche Weise. Der feministische Standpunkt besteht darin, diese zusätzliche Unterdrückung zu beschreiben. « $" 147$

Janion spricht nicht explizit von einem politischen Aktivismus; der >Feminismus` erschöpft sich hier im Aufdecken, Definieren und Beschreiben der Unterdrückung und überlagert sich somit größtenteils mit der feministischen Kritik als Analysewerkzeug. Gleichzeitig verbietet sich Janion, vom Feminismus als von einer Ideologie zu sprechen: »Nein, das ist keine Ideologie. Es ist eine Idee! Die übrigens überhaupt nicht neu ist. Feminismus ist nur eine neue Bezeichnung für diese Idee. ${ }^{148}$ Ähnlich argumentiert Janion in Bezug auf die Ideologie-Vorwürfe gegenüber Filipiaks Absolutna amnezja. Janion bezieht sich hier auf Dunin, die "zu Recht bemerkt, dass in diesem Fall das, was `spezifisch` ist, als >ideologisch angesehen wird. ${ }^{149}$ Obwohl Janion die Klassifizierung des Romans oder einzelner Ebenen davon als »ideologisch« bestreitet, versteht sie das Werk als feministische Aussage in einem ganzheitlichen, auch politischen Sinne. "So wird es auch unmöglich, >ideologische` und `nicht-ideologische Schichten voneinander zu trennen. ${ }^{150}$ Als problematisch sieht Janion in diesem Fall wohl vor allem den Begriff des Ideologischen an, der mit Dogmatismus assoziiert wird. Die dezidiert feminis-

147 | Janion: Kuferek Harpagona, S. 206: „chodzi o konieczność zdefiniowania własnych doznań przez kobiety. Ktoś może powiedzieć, że to wczesna i dość łagodna postać feminizmu. Ale to mi najbardziej odpowiada. [...] Mówiłam też wielokrotnie o tym, że żyjąc i kobiety, i mężczyźni podlegają zawsze opresji, ale kobiety w sposób szczególny, dodatkowy. Feministyczy punkt widzenia polega na tym, żeby opisać tę dodatkową opresję."

148 | Ebd.: "Nie, to nie jest ideologia. To jest idea! Wcale zresztą nie nowa. Feminizm to tylko nowy wyraz dla tej idei."

149 | Janion: Kobiety, S. 328: "słusznie uważa, że w tym wypadku to, co sszczególneく uznane zostaje za sideologicznes."

150 | Ebd., S. 329: „Toteż niemożliwością staje się wyróżnienie jakichś warstw sideologicznych i >nie-ideologicznych،." 
tische Gewichtung mit politischer Aussage begrüßt Janion an Absolutna amnezja jedoch. ${ }^{151}$

Keine Berührungsängste mit dem Begriff des Ideologischen zeigt hingegen Iwasiów: »Denn ich - eine Frau - lese und realisiere im Artikulieren der Interpretation meine ex definitione ideologischen Ziele. ${ }^{152}$ In ihrer Auslegung ist die spezifisch weibliche Gewichtung unzweifelhaft ideologisch, als hier eine bestimmte, bewusste Perspektivenverschiebung gegenüber einer ’konventionellen` Betrachtungsweise geschieht. Deshalb ist auch der Feminismus für sie »zuerst und am meisten Ideologie. Seine anthropologischen Begründungen verweisen auf den kulturellen Charakter der Geschlechterrollen. ${ }^{153}$ Gleichzeitig besteht Iwasiów darauf, dass es überhaupt keine aideologischen Aussagen geben könne, da jegliche Äußerung bereits derartig vorgeformt sei. ${ }^{154}$ Es geht ihr also primär darum, die patriarchale Ideologie durch ihre eigene, ebenso ideologische Perspektive zu dezentrieren.

Dennoch findet sich auch bei Iwasiów eine Formulierung, die auf den Suggestivcharakter des Feminismus verweist. Sie schreibt, dass die Polonistik »selten den ideologischen Suggestionen [des Feminismus] unterliegt ${ }^{155}$. Mit den Begriffen »Suggestionen« und "unterliegen" (ulegać) impliziert Iwasiów ein (zumindest versuchtes) aktives Eingreifen eines von außen kommenden Feminismus in das Bewusstsein der polnischen Akademiker/innen. Der Prozess des Theorietransfers kann hier als eine Invasion einer diskursiven Macht aufgeschlüsselt werden, während die einzige aktive Tätigkeit der polnischen Seite gemäß Iwasiów das »Berichten" (relacjonować) über die westlichen Feminismen sei. Mit Blick auf Iwasióws allgemeine Argumentation muss diese Passage aber so gelesen werden, dass Iwasiów eine größere Empfänglichkeit oder eben ein »Unterliegen« der polnischen Wissenschaft begrüßen würde.

\subsubsection{The Personal is (not) Political}

Die angesprochenen Distanzierungen von und Anbindungen an Begriffe wie 'Ideologie oder `Politik« in der feministischen Kritik der polnischen 1990er Jahre möchte ich nun im Kontext des postsozialistischen Diskurses betrachten. Innerhalb einer allgemeinen Politikmüdigkeit und Ideologiefeindlichkeit positionieren

151 | Vgl. auch Fuszara: Feminizm i my, S. 20, die für den polnischen Feminismus feststellt: »[E]r wird sich selbst vor der Ideologisierung in Acht nehmen und muss nicht als ideologische Bewegung verstanden werden."

152 I Iwasiów: Kresy, S. 21: „Czytam bowiem ja - kobieta - i realizuję poprzez artykułowanie interpretacji swoje, ideologiczne ex definitione, cele."

153 | Ebd.: "najpierw i najbardziej ideologią. Jego antropologiczne uzasadnienia wskazują na kulturowy charakter ról płciowych.«

154 | Vgl. ebd., S. 32.

155 | Ebd., S. 21: »rzadko ulegającym sugestiom ideologicznym«. 
sich feministische Argumentationen als politisches Projekt schlecht. Dies trifft auch auf den akademischen Bereich zu, der sich gerade einer epistemologischen Öffnung unterzieht und dabei den Versuch unternimmt, das Politische aus seinen methodischen und theoretischen Ansätzen zu verbannen. Obwohl dies, wie Iwasiów feststellt, einen utopischen oder fehlgeleiteten Ansatz darstellt, versucht auch die feministische Kritik teilweise, ihr Subjekt aus einer bisher dominanten politischen Vereinnahmung zu lösen. Damit passt sie sich - absichtlich oder nicht - dem Dogma der >Apolitizität an und distanziert sich von politisch-aktivistischen Grundlagen feministischer Ansätze. Dies kann als pragmatischer Versuch der feministischen Kritikerinnen gelesen werden, ihr Feld trotz dessen nicht geringer Kontroversität in den wissenschaftlichen und gesellschaftlichen Diskurs einzubetten.

In diesem Kontext müssen auch die Konstruktionen der Weiblichkeit als privat, intim und individuell gesehen werden. Mit der Personalisierung der Weiblichkeit und der räumlichen Beschränkung ihres primären Tätigkeitsfelds wird ein Desinteresse an übergeordneten politischen Dynamiken signalisiert: Die Weiblichkeit respektive die einzelne Frau erscheint als vollauf mit sich selbst beschäftigt. Indem ihr Verständnis von Weiblichkeit alternative weibliche Identitätsentwürfe aus >der Weiblichkeit ausschließt, verhält sich diese `feministische Kritik in ihrer postulierten Apolitizität und Rückwendung auf eine gesellschaftlich isolierte, (pseudo)individuelle Privatsphäre jedoch genau nach demselben Muster, das sie dem politischen Feminismus vorwirft: Nämlich dem ideologischen Festhalten an einem bestimmten Weiblichkeitsbild und dessen Generalisierung für alle Frauen. Die Individualisierung und Depolitisierung geht zudem einher mit einer normativen Vorstellung von weiblicher Identität, die sich - abgesehen vom Ablehnen sozialutilitaristischer Funktionen - genau nach dem Vorbild konservativer und von der katholischen Kirche politisch vorangetriebener Geschlechtervorstellungen konstruiert: ${ }^{156}$ Im Zentrum stehen die Mutterschaft und ein auf das Private beschränkter Aktionsradius. Diese Tendenzen treffen vor allem auf Borkowska und Kraskowska zu, mit einigen Vorbehalten auch auf Kłosińska und - kaum mehr auf Iwasiów; am wenigsten normativ erscheinen die Ansätze Janions, die mitunter in diametral andere Richtungen weisen als jene der `feminologischen ` Identitätskonzepte Borkowskas und Kraskowskas.

Trotz der unterschiedlichen Positionen der untersuchten Texte erscheint die feministische Kritik im Polen der 1990er Jahre derjenigen der Zweiten Welle des Feminismus im Westen ähnlich, auf die sie sich vorwiegend beruft; ihre Vorzei-

156 | Vgl. Korbonski: Poland ten years after, S. 126ff.; Marody, Mira/Giza-Poleszczuk, Anna: »Changing Images of Identity in Poland: From the Self-Sacrificing to the Self-Investing Woman?«, in: Gal/Kligman, Reproducing Gender (2000), S. 151-175, hier S. 151f.; Mishtal, Joanna Z.: »How the Church Became the State. The Catholic Regime and Reproductive Rights in State Socialist Poland«, in: Penn, Shana/Massino, Jill (Hg.), Gender Politics and Everyday Life in State Socialist Eastern and Central Europe, New York 2009, S. 133-149, hier S. 143ff. 
chen sind jedoch teilweise grundlegend anders. Besonders augenfällig wird dies am populären Slogan, der die Zweite Welle des Feminismus in den USA prägte: »The personal is political«, wie Carol Hanisch 1969 formulierte. ${ }^{157}$ Damit versuchten US-amerikanische Feministinnen, das politische Augenmerk auf die geschlechtlichen Ungleichheiten zu lenken, die sich jenseits von juridischer Gleichberechtigung im Bereich gesellschaftlicher und familiärer Beziehungen äußerten und den Frauen vor allem die private Sphäre als alleinigen Wirkungsbereich zuordneten. Initiantinnen dieser Forderung waren, so wird jedenfalls retrospektiv festgestellt, vor allem Hausfrauen des weißen Mittelstands, deren Perspektive und Begehren von partikularen Interessen und einem privilegierten Sozialstatus geleitet waren; ${ }^{158}$ der universalgültige Anspruch dieser Losung wurde somit bereits dekonstruiert.

So stellt auch die polnische Feministin Fuszara 1994/95 fest: »In den USA machten sich die Frauen bewusst, dass das, was in ihren Häusern vor sich ging, auch als Politik bezeichnet werden kann. Auf Polnisch tönt das wie ein Missklang $[z g r z y t] \ll^{159}$. Anders als in den USA der 1960er und 1970er Jahre erschien vielen polnischen Frauen der 1990er Jahre die Beschränkung auf die Heim- und Familiensphäre geradezu als begehrenswert. Dies scheint vor dem Hintergrund oftmaliger Doppelbelastung mit Lohn- und Haushaltsarbeit in der Volksrepublik und der ökonomisch äußerst schwierigen Transformationszeit nachvollziehbar. Das Heim wurde in Polen - wenn auch nicht für alle Frauen - zum neuen Realisierungsort individuellen Erfolgs und Selbstverwirklichung in Abgrenzung von der vorherigen politischen und wirtschaftlichen Verpflichtung zur außerhäuslichen Arbeit. ${ }^{160}$ Das Modell geschlechtlich geteilter Arbeitssphären fand so in den 1990er Jahren in Polen zu erneuter und verstärkter Umsetzung. Seine Begehrlichkeit stieg nur noch dadurch, dass es sich hierbei um das seit Jahrzehnten in den westlichen bürgerlichen Gesellschaften praktizierte Modell der Sphärenteilung handelte, das in der polnischen Gesellschaft eine phantasmatische Funktion übernommen hatte. Im Rahmen des Aufholungsnarrativs gegenüber dem Westen wurde die neue Privatsphäre erst installiert, die als Grundlage des kapitalistischen Konsumismus dienen sollte. ${ }^{161}$

Der dem westlichen Feminismus implizite Slogan the personal is political erwies sich somit für die postsozialistische Gesellschaft als höchst problematisch,

157 | Vgl. Hanisch, Carol: »The Personal Is Political. The Women's Liberation Movement Classic with a New Explanatory Introduction «, 1969 (2009).

158 | Vgl. hooks, bell: »Sisterhood. Political Solidarity between Women«, in: Weiss, Penny A./Friedman, Marilyn (Hg.), Feminism and Community, Philadelphia 1995, S. 293-315, hier S. 293f., 296.

159 | Fuszara: Feminizm i my, S. 17. Dieses Urteil Fuszaras trifft aber auf die Ansätze Janions beispielsweise nicht zu.

160 । Vgl. Walczewska: Damy, rycerze i feministki, S. 89.

161 I Vgl. Desperak: Kobiety, S. 179, 182; Marody/Giza-Poleszczuk: Changing Images, S. 166, 173; Nowakowska: Wprowadzenie, S. 6. 
da eine $\mathrm{zu}$ >persönliche` Privatsphäre diskursiv noch gar nicht existierte. ${ }^{162}$ Wenn Hanisch 1969 schreibt: »One of the first things we discover [...] is that personal problems are political problems. There are no personal solutions at this time. There is only collective action for a collective solution ${ }^{163}$, so zeigt dies bereits, wie quer eine solche Aussage in der diskursiven Realität Polens liegt. Die Forderung nach kollektiver Aktion war vielleicht gerade noch für das Stürzen des sozialistischen Apparats zulässig, wurde aber auch hier als individuelle Inszenierungen einer "Antipolitik" getarnt. Die Frage nach "personal problems« stellte sich als öffentliches Thema gar nicht erst. Das Kollektive sollte vorerst in ein Individualisiertes, das Politische in ein Privates oder eben »Persönliches« (und damit Deproblematisiertes) aufgelöst werden. ${ }^{164}$ Während feministische Ansätze der Zweiten Welle in den USA oder Frankreich sich von linken, marxistischen Ideen inspirieren ließen, ${ }^{165}$ floh der polnische Diskurs der 1990er Jahre demonstrativ von diesen weg.

Damit geriet die politische feministische Bewegung in Polen in einen Zwiespalt: Während sie Autonomie für Frauen forderte und damit den Rückzug der Politik und ökonomischer Zwänge aus deren Lebensentscheidungen begrüßte, beförderte das politisch-rechtliche wie auch gesellschaftlich-habituelle Dereglement der privaten Sphäre die Rückkehr zu stärker hierarchisch organisierten Geschlechterrollen und verminderte den staatlichen Schutz vor dem sozialen Umfeld, womit etwa häusliche Gewalt schwieriger $\mathrm{zu}$ ahnden wurde. ${ }^{166}$ Die Frage stellte sich, ob die Familie als private oder öffentliche Institution zu behandeln sei; auch die Frage nach der Teilnahme von Frauen an der politischen Macht wurde aufgeworfen. ${ }^{167}$ Daraus resultierte die komplexe Lage polnischer Fraueninitiativen, die oft versuchten, beide Strömungen - Privatisierung und Politisierung - gleichermaßen zu bedienen. Hinzu kam komplizierend die habituell machtvolle Position im "Hausmatriarchat ", die durch eine Restrukturierung der privaten Sphäre ebenfalls in Frage gestellt würde. Dybel schreibt deshalb über die Herausforderung an die polnische Feministin:

"Wenn sie z. B. dagegen kämpft, dass die Rolle der Frau auf die einer ’Hausfrau< reduziert wird, so sollte sie in Rechnung stellen, dass diese Rolle in Polen nicht allein bedeutet, mit Haushaltspflichten belastet zu sein, sondern auch, die entscheidende Stimme in den sogenannten 'Familienangelegenheiten zu besitzen. Dieses bedeutet: Der wahre Kopf der Familie zu sein, verantwortlich für

162 | Vgl. Fuszara: Feminizm i my, S. 17; Snitow: Przyszłość feminizmu, S. 7.

163 I Hanisch: Personal Is Political.

164 | Vgl. Fuszara, Małgorzata: "New Gender Relations in Poland in the 1990s«, in: Gal/Kligman, Reproducing Gender (2000), S. 259-285, hier S. 261; Marody/Giza-Poleszczuk: Changing Images, S. 167.

165 | Vgl. Greer: Der weibliche Eunuch, S. 11, 22.

166 | Vgl. Drozdowski: N.N., S. 20; Scott, Joan W./Keates, Debra: »Preface«, in: dies., Going Public (2004), S. ix-xv, hier S. x, xii.

167 | Vgl. Fuszara: Feminizm i my, S. 15; dies.: New Gender Relations. 
ihr Wohlergehen sowie die Verwaltung der Finanzen - der Mann nimmt währenddessen meist eine sehr passive, verteidigende Haltung ein. Er erscheint vollkommen an die Seite gestellt und handelt nur, wenn es ihm von einer Frau befohlen wird. « ${ }^{168}$

Die weibliche Konzentrierung auf die Privatsphäre in den polnischen 1990er Jahren kann deshalb auch als ein Versuch gelesen werden, die Kernkompetenzen und den Machtbereich polnischer Frauen zu festigen und so eine gewisse Stabilisierung der gesellschaftlichen Dynamiken zu erreichen. Außer Acht bleibt bei einer solchen Perspektive, dass der Privatbereich bereits von konservativer Seite politisch neu überschrieben wird, die diesen nun nach sittlich restriktiveren und traditionelleren Idealen zu strukturieren und zu kontrollieren versucht. ${ }^{169}$

Der Fokus einiger feministischer Kritikerinnen auf die Depolitisierung von Privatsphäre einerseits und Weiblichkeit andererseits kann damit als eigentliches Problem des polnischen Feminismus gelten. Der gesellschaftliche Diskurs drängt zu einem Bekenntnis zum verbürgerlichten Modell einer stabilen, `natürlichen Geschlechterordnung und zum Verbannen des Politischen aus dem Alltag, der privaten Sphäre und dem Familienleben. Der omnipräsente Staat solle einer individualisierten Freiheit weichen, so der transformationale Konsens. ${ }^{170}$ Dabei wird übergangen, dass durch die Hintertür bereits wieder eine Politik mit invertierten Vorzeichen in das Private Einzug gehalten hat. Ebensowenig wird thematisiert, dass die Privatsphäre mit der Übernahme durch die neoliberale Wirtschaft vielleicht noch stärker als zuvor der Potenz der freien Entscheidung beraubt wird und sich nunmehr vor allem nach Gesichtspunkten der ökonomischen Machbarkeit und Rentabilität organisiert. Die feministische Kritik löst ihre >depolitisierenden Versprechen durch Ausblenden bestimmter Problematiken ein und konzentriert sich vor allem auf den relativ unverfänglichen Bereich kultureller Aufwertung des ,Weiblichen ${ }^{171}$

Dennoch muss auch gesagt sein, dass trotz einiger eingrenzender und essentialisierender Haltungen in der feministischen Kritik diese doch dazu beitrug, das Geschlecht als Bereich einer kryptopolitischen Diskussion zu verstehen und explizit in der Lektüre historischer oder gegenwärtiger Literatur nach dieser Kategorie zu fragen. Grundsätzlich dringt die feministische Kritik somit durch die Thematisierung des Geschlechts in einen auch soziopolitisch relevanten Bereich vor; das Ansprechen der Geschlechtlichkeit an sich kann also als politische Handlung gelesen werden, was einige der Texte jedoch dezidiert verhüllen. Abstrahiert

168 | Dybel: Psychoanalyse in Polen, S. 293. Zu einem ähnlichen Schluss kommen auch Marody und Giza-Poleszczuk (Changing Images, S. 162f.).

169 | Vgl. Korbonski: Poland ten years after, bes. S. 138-141.

170 | Vgl. Szacki: Liberalizm po komunizmie sowie Landes, Joan B.: »Introduction«, in: dies. (Hg.), Feminism, the Public and the Private (= 0xford Readings in Feminism), 0xford, New York 1998, S. 1-17, hier S. 2.

171 | Vgl. Ghodsee: Feminism-by-Design, S. 328. 
man bei Kraskowska etwa von ihrer zum Teil »monologischen « ${ }^{172}$ Intonation, hat sie in der Aufarbeitung der bis dahin wenig rezipierten und in Vergessenheit geratenen weiblichen Perspektive der Literatur der Zwischenkriegszeit einen guten Überblick geliefert und somit vielleicht die Aufmerksamkeit für gewisse Themen und weitergehende Forschung geschärft. Gleichzeitig bietet sie mit ihren Anfeindungen gegen den politischen Feminismus genügend Angriffsfläche für potentiell fruchtbare Polemisierungen. Bedeutend interessanter erweisen sich jedoch die Arbeiten Janions, von denen etliche auch nach Jahren ihre Aktualität nicht verloren haben oder gerade durch den Miteinbezug des lokalen sphantasmatischen texts immer wieder zurückgewinnen (siehe Schlussteil). Die anhaltende Relevanz dieser Arbeiten lässt sich auch auf deren produktive Ambivalenz zurückführen, die grundsätzlich mehr Problemfelder aufwirft, als sie Fragen zu beantworten sucht. Die feministischen Kritikerinnen nehmen also sehr unterschiedliche Positionen ein, wobei die dominanteren und vielleicht einfacheren essentialisierenden Geschlechtervorstellungen mit einer nominell depolitisierenden Haltung einhergehen, während intersektionell und performativ ausgerichtete Ansätze eher das politische Moment feministischer Kritik bejahen.

\subsubsection{Abschied vom polnischen Gemeinschaftsnarrativ}

In den 1990er Jahren überwiegt eine `konservative` Einstellung zum (weiblichen) Geschlecht, die ein solches erst konzeptualisieren will. Grundsätzliche Feststellung aller feministischer Kritikerinnen ist, dass die weibliche Erfahrungswelt nicht mit einer allgemeingesellschaftlichen, d. h. männlichen kongruent sei. Die Gesellschaftsordnung bedinge einen spezifischen Zusammenhang unter Frauen, versuche diesen aber zu verhüllen und zu verwischen. Diese Grunderkenntnisse feministischer Theorien müssen in den polnischen 1990er Jahren im Kontext von gesellschaftlicher Öffnung, Pluralisierung und Individualisierung gesehen werden, die durch den Wegfall des sozialistischen Regimes als Gegenpart in der normativen Binarisierung von "wir und sie« ermöglicht wird. Im Folgenden will ich deshalb untersuchen, welche Rolle die polnische Gesellschaft in der feministischen Kritik spielt und wie sich die feministischen Kritikerinnen gegenüber dem polnischen Gemeinschaftsnarrativ als bislang geltende politische Norm positionieren, welches interne Differenzierungen weitgehend verunmöglichte.

Im einführenden Kapitel 2 der vorliegenden Arbeit wurde auf die enge Verknüpfung von nationaler Gemeinschaft und Geschlechterordnung im 19. Jahrhundert hingewiesen. Der Nationaldiskurs, der die »Funktion des >öffentlichen

172 I Siehe Kristevas (Sèméiotikè, S. 159) Umschreibung des Monologischen als »begrenzt durch die absolute Sicht eines Erzählers, der mit dem Ganzen eines Gotts oder einer Gemeinschaft zusammenfällt«, und als eine Art »Verbot, [...] eine Zensur« (S. 158), was m. E. für das Narrativ Kraskowskas und dessen zum Teil zurechtweisende Intonation zutrifft. 
Schlüsselnarrativs « ${ }^{173}$ übernahm, ordnete den Geschlechtern spezifische Rollen innerhalb dieses `Polentums`zu. Zentral war das Aufopferungsnarrativ, das beide Geschlechter betraf und private, individuelle Bedürfnisse stets dem gemeinsamen Anliegen der Unabhängigkeitsbewegung unterordnete. ${ }^{174}$ Der Diskurs des Polentums als kollektive, in sich geschlossene und entlang spezifischer Aufopferungsrollen geordnete Einheit hatte auch im 20. Jahrhundert noch bindende Kraft und zog sich über die sozialistische Epoche bis hin in die Transformationszeit, wie etwa die Feministinnen Środa und Graff feststellen. ${ }^{175}$ Oppositionelle Aktivitäten von Frauen wie Männern in den 1980er Jahren wurden als Aufopferung für die polnische Gemeinschaft in den Vordergrund gestellt; ähnliches gilt für die Rolle der sich für die Familie aufopfernden Frau, die dieser in der Volksrepublik eine gewisse Selbstnobilitierung und Machtstellung ermöglichte, weshalb ein solches Rollenangebot von Frauen aktiv angenommen, inszeniert und als Teil ihres sozialen Geschlechtsverständnisses verteidigt wurde. ${ }^{176} »$ In der Folge der romantischen Gebote gewöhnte sich die polnische Frau daran, die Lasten des Familien- und öffentlichen Lebens im Schatten und im Schweigen zu tragen, damit sich das Opfer bloß erfülle « ${ }^{177}$, schreibt Janion über die Selbstinszenierung weiblicher Opferrollen.

$\mathrm{Zu}$ Beginn der Transformation kann das Aufopferungsnarrativ für die Gemeinschaft deshalb aus weiblicher Sicht als »soziologischer Tatbestand « im durkheimschen Sinne verstanden werden, als kollektiver Zustand und Zwang, der außerhalb der betroffenen Individuen siedelt, ${ }^{178}$ sowie als Teil des sozialen Geschlechtsverständnisses von Frauen. Mit der Thematisierung und Hinterfragung des Aufopferungsnarrativs zielen die feministischen Kritikerinnen somit einerseits gegen eine vereinnahmende Gesellschaft-als-Gemeinschaft, die die Weiblichkeit zu ihren Zwecken zu überformen sucht; andererseits aber gegen inkorporierte weibliche Habitus, ${ }^{179}$ welche die feministische Perpektive als Mechanismen der

173 | Ostrowska: Matki Polki, S. 227.

174 | Vgl. Janion: Tam gdzie rojsty, S. 106.

175 । Vgl. Graff: Feminizm ryzyka; Środa: Kobieta.

176 | Vgl. Domański: Zadowolony niewolnik, S. 140f.; Marody/Giza-Poleszczuk: Changing Images, S. 162f.; Rosner: Czy istnieje, S. 35.

177 । Janion: Kobiety, S. 99: »W efekcie romantycznych nakazów kobieta polska przyzwyczaiła się do dźwigania ciężarów życia rodzinnego i publicznego w cieniu i w milczeniu, byle spełniła się ofiara."

178 | Vgl. Durkheim, Emile: Die Regeln der soziologischen Methode (= Soziologische Texte, Band 3), Neuwied, Berlin 1961 (1965), S. 109-112, besonders 111f.: »Ein soziales Phänomen ist an der äußerlich verbindlichen Macht zu erkennen, die es über die Einzelnen ausübt oder auszuüben imstande ist; und das Vorhandensein dieser Macht zeigt sich wiederum entweder durch das Dasein einer bestimmten Sanktion oder durch den Widerstand, den das Phänomen jedem Beginnen des Einzelnen entgegensetzt, das inn zu verletzen geneigt ist."

179 | Vgl. zum Habituskonzept Bourdieu, Pierre: Entwurf einer Theorie der Praxis auf der ethnologischen Grundlage der kabylischen Gesellschaft, Frankfurt a/M. 1979 (2012), S. $164 f$. 
Selbstdiskriminierung dekonstruiert. ${ }^{180}$ Beide Ebenen rücken die kollektive Verpflichtung in den Vordergrund, womit sich die polnische Gemeinschaft als normative Referenzstruktur erweist.

Unter den untersuchten Polonistinnen positioniert sich Janion am deutlichsten zu dieser Problematik im Rahmen der gesellschaftlichen Umformungen der Transformation. Sie stellt fest, dass die neue demokratische Ordnung »die Frauen in ihre traditionelle Lebensweise [...] als $>$ Familienwesen ${ }^{2}$ zurückschickt $^{181}$. Eine Auflehnung gegen diese Retraditionalisierung und gegen die Weiblichkeit vereinnahmenden gesellschaftlichen Diskurse sieht Janion in Filipiaks Roman Absolutna amnezja. Dieser stelle die weibliche Aufopferung für die Sache des ,Volkes im Kontext der Opposition der 1980er Jahre in Frage und kontrastiere diese mit spezifisch weiblichen Bedürfnissen und Sichtweisen: »[Filipiak] lässt sich keine allgemeinen - patriotischen oder demokratischen - Ziele einreden, die die konkrete Frau und ihre ausschließlich aus der Geschlechtszugehörigkeit resultierende soziale Beeinträchtigung aus dem Sichtfeld drängen würden. ${ }^{182}$ Der Konflikt zwischen der weiblichen Inkorporation des Gemeinschaftsnarrativs und einer feministischen Aneignung der Weiblichkeit manifestiere sich in Absolutna amnezja an der Mutter-Tochter-Beziehung. Die Mutter sei eine »ewig verschwörerische Nationalheldin, die sich für das Vaterland aufopfert und dem eigenen Kind gegenüber gleichgültig ist, die scheinbar selbstlos opferbereit ist und sich doch in Wahrheit am Dünkel ihrer ungebrochenen Haltung ergötzt« «183, stellt Janion fest. Das von der Mutter realisierte Phantasma der sich (angeblich) selbst aufopfernden Matka Polka resultiere in der Vernachlässigung der eigenen Tochter. Janion wie auch Filipiak sehen jedoch die Notwendigkeit einer Bindung zwischen den beiden Frauen, zwischen Mutter und Tochter, als vorrangig und als Bedingung für eine weniger entfremdete weibliche Existenz. Das politische Aufopferungsnarrativ, das an Filipiaks Romanfigur der Mutter ins Extrem getrieben ist, erscheint dabei als Zerstörung jeglicher persönlicher Bindung.

Auch Borkowska argumentiert gegen das Narrativ der gemeinschaftlichen Aufopferung. Sie sieht dieses jedoch primär als Forschungsparadigma, welches historische Phänomene verzerre und diese allein über den Schlüssel patriotischen Engagements lese. Damit widerspricht sie den oben angeführten Feststellungen, dass der polnische Gesellschaftsdiskurs schon seit dem 19. Jahrhundert stark kol-

180 I Vgl. Brach-Czaina: Progi, S. 354.

181 । Janion: Kobiety, S. 326: »odsyłając kobiety do ich tradycyjnego sposobu życia [...] jako ,istot rodzinnych «

182 । Ebd., S. 327: »[Filipiak n]ie daje sobie wmówić żadnych ogólnych celów - patriotycznych czy demokratycznych, które by usuwały z pola widzenia konkretną kobietę i jej społeczne upośledzenie, wynikające wyłącznie z przynależności płciowej.«

183 | Ebd., S. 330: »to wiecznie konspirująca bohaterka narodowa, poświęcająca się dla ojczyzny i obojętna wobec własnego dziecka, niby to bezinteresownie ofiarna, a w istocie sycąca się pychą z powodu swej niezłomnej postawy.« 
lektiv ausgerichtet gewesen sei. ${ }^{184}$ Sie sieht die Norm einer politischen Gemeinschaft weniger als historische Dimension denn als neuerer, wissenschaftlich-sozialer Ansatz einer (einseitigen) Geschichtsschreibung. ${ }^{185}$ Borkowska bricht diesen Diskurs auf, indem sie am Beispiel Żmichowskas argumentiert, dass auch das 19. Jahrhundert individualistische Lebensentwürfe aufzuweisen vermöge, die sich nicht über das Kollektive definierten und die entsprechend anders gelesen werden müssen. Gleichzeitig streitet sie jedoch nicht ab, dass die Emanzipierungsbestrebungen der Entuzjastki auf starken Widerstand in einer Gesellschaft stießen, die neben einer geschlechtlichen Ordnung teilweise auch eine romantische Widerstandsverklärung kultivierte.

Borkowska weist darauf hin, dass der historische Geschlechterdiskurs in den 1980er und 1990er Jahren von einer patriotischen Interpretation überlagert wird. Ins Zentrum rückt die Frage nach der Rahmung weiblicher agency, wobei Borkowska die Ausweitung weiblicher Handlungsfähigkeit als intrinsisch motiviert versteht. Obwohl sie sich dabei zu Recht kritisch gegenüber einer vorschnellen Auslegung und Reduktion sozialer und künstlerischer Praktiken auf den politischen Aufopferungsdiskurs äußert, zeigt sie selbst eine Tendenz zur voreingenommen depolitisierenden, d. h. depatriotisierenden Lesart, wovon bereits oben die Rede war. Borkowskas Begriff des Politischen bezieht sich primär auf eine patriotisch-aufständische Rahmung, während sie das soziopolitische Moment der Ausweitung weiblicher Handlungsfähigkeit beispielsweise im Rahmen der »Strategie der Biene « nicht als politisches fasst. ${ }^{186}$ Borkowska fokussiert primär auf die einzelne Person und deren Handeln als sprivate Einheit, wobei sie die »Feminisierung" (feminizacja) in der Literatur als einen Prozess der Verschiebung, der »Intimisierung gesellschaftlicher Konflikte oder öffentlicher Angelegenheiten « ${ }^{187}$, also als ein Herunterbrechen des historischen Ereignisses auf eine individuelle Perspektive sieht.

Borkowska begrüßt etwa am Beispiel Żmichowskas die weibliche Verwirklichung von familien- und reproduktionsunabhängigen Lebensentwürfen, die eine Absage an die traditionellen Geschlechterrollen im Gemeinschaftsnarrativ bedeuten. Doch auch die Konzepte von Mutterschaft oder Matrilinearität, wie sie Kraskowska oder Kłosińska entwerfen und wie sie oben auch am Beispiel von Janions Auseinandersetzung mit Absolutna amnezja antönen, lassen sich nicht in einen sozialutilitaristischen Dienst an der Gesellschaft einordnen, sondern dienen in der feministischen Kritik allein als Funktion einer eigenständigen Weiblichkeit. Das Gemeinschaftsnarrativ des Polentums als patriotisches Kollektiv entfällt somit in der feministischen Kritik als positiver Referenzrahmen. Es wird aufgrund seines inhärenten Aufopferungszwangs von Janion und Borkowska eher als zu dekon-

184 | Vgl. Borkowska: Cudzoziemki, S. 38.

185 | Vgl. ebd., S. 34.

186 | Vgl. ebd., S. $70 f$.

187 | Ebd., S. 202: »intymizacji konfliktów społecznych czy spraw publicznych«. 
struierende Größe und als Hindernis einer geschlechtergerechteren Gesellschaft gesehen. ${ }^{188}$ In den beiden späteren Arbeiten von Kraskowska und Kłosińska hingegen findet das polnisch-politische Kollektivum als Referenzgröße neben einem metanational verstandenen Patriarchat kaum oder gar keine Erwähnung.

Als referenzielle Mischform von polnischem »antithetischem" Wertsystem und patriarchaler Substruktur erweist sich hingegen die Archetypensuche Iwasióws, die die Geschlechterordnung vom nationalen Aufopferungsnarrativ hin zu einem patriarchal organisierten Gesellschaftssystem überführt. Entlang von Odojewskis Roman Zasypie wszystko, zawieje... (Katharina oder Alles verwehen wird der Schnee, 1973) zeigt Iwasiów auf, wie die Protagonistin Katarzyna als Gegenspielerin der Nation inszeniert wird. Die männlichen Protagonisten Paweł und Piotr müssten sich zwischen diesen beiden Polen entscheiden, was Iwasiów als Grundformel des von Janion herausgearbeiteten antithetischen Wertsystems der polnischen Literatur skizziert. ${ }^{189}$ Die Frauenfigur werde als Verkörperung des Privaten, als Kehrseite der Nation, der "äußeren Welt, dieser >öffentlichen<, 'nationalen`, ‘tyrtäischen « ${ }^{190}$, eingesetzt. Anders als im herkömmlichen martyriologischen Narrativ werde hier die Frau nicht in die patriotische Mission eingespannt, sondern als Kontrast dazu inszeniert. Allerdings bilde dies erst die oberflächliche Lektüre von Zasypie wszystko, zawieje... und der Figur Katarzynas, wie Iwasiów schreibt:

»Die Analyse des Katarzyna-Strangs deckt auf, dass sich das Drama der Wahl im podolischen Zyklus nur oberflächlich auf die romantische 0pposition bezieht. Während die Helden die Frau verwerfen, sie in den Hintergrund drängen, bleiben sie doch auf tragische Art mit ihr verbunden. [...] Die Wahl des einen wie des anderen ist sowohl private wie auch öffentliche Angelegenheit. « ${ }^{191}$

So interessiert denn Iwasiów an der Figurenkonstellation in Zasypie wszystko, zawieje... jene Verbindung der Geschlechter, die noch tiefer als das romantische patriotische Narrativ liege und mit der Verteilung von aktiven und passiven Elementen zusammenhänge: »In gewissem Sinne diagnostiziert Odojewski somit klinisch (im Rahmen einer künstlich geschaffenen Welt) die Kondition der Frau als Tauschmünze, Zeichen, als notwendiges, aber passives Element der Opposition

188 I So münde etwa die verstärkte Einbindung der Weiblichkeit in das (oppositionelle) patriotische Kollektiv in den 1980er Jahren laut Janion in einen 'Verrat an den Frauen in den 1990er Jahren.

189 | Vgl. Janion: Tam gdzie rojsty, S. 106.

190 I Iwasiów: Kresy, S. 100: "zewnętrzny świat, ten >publiczny«, ’narodowy«, styrtejski««.

191 । Ebd.: »Analiza wątku Katarzyny ujawnia, iż dramat wyboru w cyklu podolskim powierzchniowo tylko odwołuje się do romantycznej opozycji. Odrzucając kobietę, spychając ją na plan dalszy, bohaterowie pozostają do niej tragicznie przywiązani. [...] Wybór jednego z nich jest tak sprawą prywatną, jak publiczną. « 
von privat und öffentlich. «192 Die Funktion der Frau könne deshalb nicht mehr als antithetisch zur öffentlichen Gesellschaft und als Verkörperung des Privaten konstruiert werden. In ihrer Funktion als Tauschwährung stelle die Frau im Gegenteil den Motor >öffentlicher` Beziehungen dar, da sie als Grundfigur jeglicher Transaktionen diene. ${ }^{193}$

Die phantasmatischen Beziehungen der Figuren untereinander würden laut Iwasiów einerseits über das Begehren aufgespannt und andererseits mit der normativen Rollenzuschreibung (aktiv/passiv) konfrontiert, die sich in der Pflicht gegenüber der Nation äußert. Allerdings wird der Kernkonflikt, der die Romanhandlung in Gang halte, in der Interpretation Iwasióws nicht auf die nationale Dimension reduziert, sondern gewinnt einen universalen gesellschaftlichen Charakter. Iwasiów rekonstruiert in ihren Ausführungen eine (als allgemeingültig verstandene) Geschichte der Rollenverschiebung zwischen den Geschlechtern, in der das Männliche die aktive Rolle vom Weiblichen übernommen habe und so das $\mathrm{Pa}$ triarchat installiert wurde; diesen »Stand der Dinge« wiederum würde der gesellschaftliche Diskurs retrospektiv zu naturalisieren und legitimieren versuchen. ${ }^{194}$

Damit verweist Iwasiów auf den sekundären Charakter der Narrative zur Geschlechterordnung und lädt ihre Leser/innen ein, diese kritisch zu hinterfragen und mit der gesellschaftlichen Realität abzugleichen. Als >Wahrheit betrachtet Iwasiów die tatsächlich existierenden Mechanismen der Macht, die das Verhältnis der Geschlechter strukturieren. In ihrer Auslegung ist es möglich und notwendig, zu einer `Essenz $\triangleleft$ der patriarchalen Geschlechterordnung zu gelangen, die von anthropologischen Narrativen verschleiert werde. ${ }^{195}$ Damit wendet sie sich auch gegen die im Gemeinschaftsnarrativ enthaltenen Versprechen einer symbolischen Gleichstellung durch Aufopferung, da diese als Verschleierungstaktik der patriarchal-hierarchischen Realität auszulegen sei. Iwasiów schreibt dazu: »Die Verehrung der Frau, wie etwa in der Ritterkultur, erfüllte immer die Funktion der unumgänglichen Tarnung, der sseidenen Peitsche`, die die Kontrolle vereinfachte [...].«196 Während Iwasiów besonders die untergeordnete Rolle der Frauen in der patriarchalen Ordnung kritisiert, identifiziert sie diese Ordnung aber als für beide

192 । Ebd., S. 99: »W pewnym więc sensie Odojewski klinicznie (w obrębie sztucznie stworzonego świata) diagnozuje kondycję kobiety jako monety wymiennej, znaku, koniecznego, lecz biernego składnika opozycji prywatne-publiczne."

193 । Vgl. ebd., S. 102, 107.

194 | Vgl. ebd., S. $101 \mathrm{ff}$.

195 I Es geht Iwasiów um einen der gesellschaflichen Strukturierung zugrunde liegenden Diskurs, der durch wandelbare Narrative unsichtbar gemacht wird. Dieser patriarchale Diskurs kann, anders als eine naturalistische Vorstellung der Geschlechterordnung, dekonstruiert und verändert werden (so wie auch ein Wandel von der matriarchalen zur patriarchalen Ordnung stattfand, vgl. ebd., S. 100f.).

196 | Ebd., S. 101: »Uwielbienie dla kobiety, jak na przykład w kulturze rycerskiej, pełniło zawsze funkcję niezbędnego kamuflażu, ,jedwabnego bata ułatwiającego sprawowanie kontroli [...].« 
Geschlechter geltende Normvorschreibungen: «Das ist das Korsett der Kultur, das gleich eng für alle ist. ${ }^{197}$

Iwasiów geht in ihren Ausführungen zwar von einer lokal eingebetteten Lektüre aus, kontextualisiert diese aber in einer kulturenübergreifenden patriarchalen Ordnung. Insofern schließt sie von dieser als universal angenommenen, archetypischen Grundstruktur auf bestimmte lokale Ausprägungen patriarchaler Narrative zurück. In diesem Sinne wird bei Iwasiów der nationale Diskurs der Aufopferung zu einer Ausformung des Patriarchats und diesem zugeordnet. Bei den Untersuchungen von Kraskowska und Kłosińska hingegen tritt das polnische Gemeinschaftsmotiv oder dessen patriotisch-aufständische Ausformung völlig in den Hintergrund. Dies hat ohne Zweifel auch damit zu tun, dass in den von ihnen untersuchten Texten patriotische Motive nicht oder nur am Rande verhandelt werden und somit bei beiden Arbeiten von 1999 das Element des Polentums abgeschwächt ist. Gleichzeitig kann es auch als eine methodologische Aussage gelesen werden, die sich nationalen Rahmungen entzieht, indem sie diese als mögliche Bestimmungsgrößen zugunsten transnationaler kultureller Deutungsmuster ausschließt.

Kłosińska betont wie Iwasiów das Moment des wirtschaftlichen Austausches in einer patriarchalen Gesellschaft, die die Herrschaft über die Frau übernimmt: »Die irreführende Überzeugung, dass die Frau ihren Körper, ihr Hymen selbst besitzt, tritt gegenüber dem ökonomischen Recht des Warenumlaufs zurück. «198 Kłosińska sieht aber in der historischen Entwicklung der Zivilisation keine Euphemisierungen dieses Tauschgeschäfts, sondern - am Beispiel von Zapolskas Kaśka Kariatyda - eine Radikalisierung, die mit den europäischen Industriegesellschaften ihren vorläufigen Höhepunkt erreicht habe:

"Zapolska notiert ungewöhnlich detailliert, wie der soziale Strukturwandel über die Statusdegradation der Frau entscheidet: In der industriellen Welt wird diese nicht mehr getauscht oder objektiviert, sondern unterworfen und vergewaltigt. Wenn der Frauentausch die soziale Ordnung garantierte, so ist das von Zapolska beschriebene Versagen dieses Austausches unbestrittener Ausdruck des Degenerationsprozesses der Gesellschaft. «"199

Die so beschriebene degenerierende Gesellschaft erscheint als transeuropäisches Kontinuum, in der Kłosińska das Geschlecht als die deutlichste Struktu-

197 | Ebd., S. 103: „To gorset kultury - równie ciasny dla wszystkich."

198 I Kłosińska: Ciało, S. 115: "Złudne przeświadczenie, że kobieta posiada na własność swoje ciała, swój hymen, ustępuje wobec ekonomicznego prawa obiegu towarów.«

199 । Ebd., S. 117: "Zapolska niezwykle wnikliwie zapisuje, jak zmiana struktury społecznej decyduje o degradacji statusu kobiety: w świecie industrialnym nie wymienia się już jej, nie reifikuje, ale podbija i gwałci. Jeśli wymiana kobiet gwarantowała porządek społeczny, to opisane przez Zapolska załamywanie się owej wymiany jest niewątpliwym objawem procesu degeneracji społeczeństwa.« 
rierungs- und Diskriminierungsachse darstellt. ${ }^{200}$ Kłosińska hebt das Problem der gesellschaftlichen Unterwerfung der Frauen auf eine metanationale Stufe. Die entscheidenden Strukturen sind für sie die eines universalen Patriarchats, während eine kulturelle Verankerung im lokalen Kontext diesbezüglich überflüssig erscheint.

Ähnlich wie bei Kłosińska spielt das spezifisch Polnische in der Monographie Kraskowskas kaum eine Rolle in der Verhandlung der untersuchten Texte. Kraskowska geht es gerade um die Herausarbeitung und Aufwertung einer sweiblichen< Welt, die sich größtenteils auf kleinräumige Umkreise der Protagonistinnen beschränkt. Mit der differenzfeministischen Ausrichtung geht eine Missachtung der Relevanz nationaler Diskurse für die weibliche Erfahrungswelt einher: Kraskowska, so könnte man aus ihren Ausführungen herauslesen, stuft nationalpolitische und makrogesellschaftliche Diskurse als für Frauen relativ irrelevant ein. ${ }^{201}$

Die Abwesenheit spezifischer Lokalität und polnischer Gemeinschaftsnarrative bei Kraskowska und Kłosińska liegt zwar zu großen Teilen im analysierten Material begründet, kann jedoch auch im Kontext postsozialistischer Diskurse gelesen werden. Das polnische »wir« als Kollektivum wird in der Systemtransformation durch politisch-ökonomische Prozesse aufgelöst und individualisiert. Zudem wirft der Wegfall des sozialistischen Regimes als die Außengrenze definierende Gegengruppe die polnische Gesellschaft ohne >direktes` Gegenüber auf sich selbst zurück, womit neue Trennungen in der Gesellschaft stattfinden (können). ${ }^{202}$ Eine solche Trennung bildet in der feministischen Kritik die soziale Geschlechterdifferenz, die in den Monographien von Kraskowska und Kłosińska als Hauptstrukturierungsachse der polnischen Gesellschaft erscheint. Damit wird die polnische zu einer patriarchalen Gesellschaft unter vielen, und lokale Unterschiede verwischen sich gerade zugunsten einer besseren Konzeptualisierung der Weiblichkeit oder des Frau-Seins. Während also der Blick ins Innere der Gesellschaft gelenkt wird, gleitet er auch über dieses hinaus ins Metanationale. Das Patriarchat substituiert in den Arbeiten von Kraskowska, Kłosińska und letztlich auch Iwasiów endgültig das Polentum als repressives Referenzsystem; auch Janion macht mit ihren transnationalen Parallelziehungen darauf aufmerksam, dass sich die Erfahrung von ,Weiblichkeit in vielen Gesellschaften überlagert. Die Nivellierung lokaler kultureller Differenzen entproblematisiert die weitgehende Einordnung der polnischen feministischen Literaturwissenschaft in einen transnationalen Kultur- und Wissenschaftskontext. Die konzeptuelle Anknüpfung an das patriarchale System er-

200 I Der Roman Zapolskas hält weitere Strukturierungsachsen bereit, etwa entlang sozialer Klassen oder ethnischer Gruppierungen. Diese blendet Kłosińska größtenteils aus. Siehe dazu auch 6.1.3.

201 I Vgl. Kraskowska: Piórem niewieścim, S. 87-100.

202 I Dies zeigt etwa auch das Verhalten der katholischen Kirche nach 1989, die das Wegfallen des Feindbilds des sozialistischen Regimes durch neue Feindkonstruktionen zu ersetzen sucht. Vgl. Korbonski: Poland ten years after, S. $124 f$. 
laubt somit gleichsam im Zirkelschluss, auch die feministische Polonistik als Teil eines globalen feministischen Kontinuums zu sehen.

Die feministische Neuaufteilung läuft somit quer durch die polnische Gesellschaft und zerreibt den nationalen Gemeinschaftsdiskurs. Diese Teilung zieht die Formulierung eines neuen feministischen »wir» nach sich, das in den polnischen 1990er Jahren primär als Gemeinschaft der Frauen gesetzt wird. Dieses friedet nominell alle Frauen ein und schreibt ihnen damit auch eine bestimmte Identität zu; die Stelle des »sie« bleibt jedoch grundsätzlich unbesetzt. Die feministischen Kritikerinnen der polnischen 1990er Jahre sind umsichtig genug, diese Funktion nicht den Männern zuzuschreiben. Eher stellt sich ihnen die Aufgabe, eine weibliche Gemeinschaft innerhalb und in Abgrenzung von einer inkorporierten, habitualisierten Machtstruktur zu konstruieren. Dies zieht die Notwendigkeit mit sich, ein neues Gemeinschaftsnarrativ zu entwerfen. Ich will deshalb die untersuchten Texte danach befragen, wie sie Gemeinschaft konstruieren und welche Form diese annimmt. Dabei dient mir die intertextuelle Transposition von Lesen/Schreiben wiederum als Ort, an dem meine Analyse ansetzt und wo meines Erachtens Gemeinschaft entstehen kann. Die feministisch-literaturwissenschaftliche Lektüre, in dem sich die Polonistin auf den (weiblichen) Text einlässt, soll deshalb als affektiver Prozess verstanden werden. Der polonistische Text wird gleichzeitig als ebenso affektives Angebot für seine Leser/innen betrachtet, in dem Ein- und Ausschlüsse als gemeinschaftsbildende Mechanismen untersucht werden.

\subsection{Gemeinsam einsam}

Im Vordergrund der feministischen Kritik steht somit die Weiblichkeit als verbindender Faktor, der die Funktion des Referenzrahmens übernimmt. Diese referentielle Verschiebung trifft jedoch auf Widerstände in der polnischen Gesellschaft. Wie bereits festgestellt, bilden insbesondere auch polnische Frauen einen Teil dieses Widerstands, da sie das Geschlecht selten als primäre Strukturierung der Gesellschaft verstehen. Gegenüber tradierten und inkorporierten Grenzziehungen wie jene des Polentums oder sozial-ontologischer Gruppierungen wie Arbeitsbelegschaften oder der familiären Verwandtschaft ${ }^{203}$ findet die Vorstellung einer weiblichen Gemeinschaft im Bewusstsein der angesprochenen polnischen Frauen kaum Raum. Dies hängt damit zusammen, dass die Weiblichkeit oder das Frau-Sein als "einfache" Gemeinschaft konzipiert wird: Sie setzt sich direkt aus nicht mehr weiter unterteilbaren Einheiten, den einzelnen Frauen, zusammen. ${ }^{204}$ Dies bedeutet, dass sie - besonders wenn Weiblichkeit als universales Phänomen

203 | Vgl. Domański: Zadowolony niewolnik, S. 137-141; Rosner: Czy istnieje, S. 35.

204 I Das Konzept der »einfachen Gesellschaften«, das Durkheim (Regeln, S. 170) entwirft, adaptiere ich hier für die weibliche Gemeinschaft, da mir seine Überlegungen in diesem Zusammenhang die Problematik erhellend erscheinen. 
verstanden wird - in ihrer Serialität einen unüberblickbaren Umfang aufweist und auf einer abstrakten Ebene siedelt. Umgekehrt bleibt die einzelne Frau innerhalb der Gemeinschaft als solche isoliert, ${ }^{205}$ da diese "unmittelbar in Individuen zerfällt. Die letzteren bilden innerhalb der Gesamtgruppe keine engeren von jener unterschiedenen Gruppierungen; sie sind einander wie Atome nebengeordnet. ${ }^{206} \mathrm{Mit}$ der Gleichschaltung und Atomisierung sind meines Erachtens Grundprobleme des Konstrukts einer verbindenden Weiblichkeit angesprochen, die sich über jegliche andere Strukturierungs- und Gruppierungsmöglichkeiten zu stellen versucht.

Die Problematik einer solchen »einfachen« Gemeinschaft möchte ich am Beispiel eines Zitats aus Cudzoziemki skizzieren. Borkowska verweist hier auf transnationale feministische Ansätze, die eine Gemeinschaftsbildung anstreben und dabei Unterschiede und Untergruppen berücksichtigen:

"Die zeitgenössischen Forscherinnen bauen ein Feld der Gemeinschaft zwischen Frauen von unterschiedlichem Bildungsniveau, verschiedener Herkunft, Hautfarbe oder sexueller Vorlieben. Unabhängig von diesen offensichtlichen Unterschieden unterstreichen sie das wichtigste Element der Gemeinschaft - das Geschlecht und die damit verbundenen existentiellen und axiologischen Ähnlichkeiten: Erhaltung des Lebens, Pazifismus, Widerstand gegen Brutalität und Gewalt.«207

Borkowska betont, dass es trotz »offensichtlicher Unterschiede« zwischen Frauen möglich sei, eine übergeordnete Gemeinschaft zu bilden. Sie schreibt jedoch - in Anlehnung an die "zeitgenössischen Forscherinnen « -, dass diese Gemeinschaft auf einem Grundelement basiere, nämlich auf jenem der »existentiellen und axiologischen Ähnlichkeiten«. Hier liegt auch die Problematik dieser Aussage, denn die folgende Aufzählung birgt eine normative Vorstellung über Frauen im Allgemeinen. Frauen würden im Rahmen ihrer >Weiblichkeit` über spezifische Charaktermerkmale verfügen, die ihnen allen gleich eigen seien. Zudem drängt sich hier auf, dass diese Grundhaltungen in einem Kontrastverhältnis zur >Männlichkeit skizziert werden. Wenn Frauen »gegen Brutalität und Gewalt« seien, so müssten letztere unweigerlich »axiologische« Charakterzüge des Männlichen sein. Neben die Dichotomisierung der geschlechtlichen Eigenschaften tritt so eine Hierarchisierung, die das "pazifistische« Weibliche über das Zerstörung bringende Männliche stellt.

205 | Als Beispiel einer solchen Isolierung kann die Argumentation Iwasióws in Gender dla średnio zaawansowanych gelten (S. 82), vgl. ansatzweise Seiler: Geschlechterfragen, S. 60f. sowie dies.: Brüche im Kontinuum, S. $103 \mathrm{f}$.

206 | Durkheim: Regeln, S. 170, Hervorh. v. d. Verf.

207 | Borkowska: Cudzoziemki, S. 17: »Współczesne badaczki budują pole wspólnoty pomiędzy kobietami o różnym poziomie wykształcenia, o odmiennym pochodzeniu, kolorze skóry, inklinacjach seksualnych. Bez względu na te oczywiste różnice podkreślają najistotniejszy element wspólnotowy - płeć i związane z nią podobieństwa egzystencjalne i aksjologiczne: podtrzymywanie życia, pacyfizm, sprzeciw wobec brutalności i przemocy." 
Diese idyllische Vorstellung einer allen Frauen gemeinsamen, positiven Weiblichkeit ist, wie intersektionelle Kritiken des Feminismus herausgestellt haben, utopisch und repressiv zugleich. >Weiblichkeit s wird als essentieller Charakterzug aller Frauen konstruiert, der einzelnen weiblichen Identitäten zuwiderlaufen kann. ${ }^{208}$ Eine so verstandene >Weiblichkeit hat deshalb einen normativen Charakter, der sich individuelle Weiblichkeitsentwürfe unterordnet oder bei Nicht-Anpassung ausschließt. Diese normierenden Verfahren werde ich am Beispiel von Borkowska und ihrer Auseinandersetzung mit Orzeszkowa noch verhandeln.

Die Frage bleibt bestehen, wie eine sweibliche`Gemeinschaft geschaffen werden kann, ohne dabei universalisierende und repressive Annahmen zu treffen. Für eine Verankerung feministischer Argumentationen und eine letztliche Vorantreibung feministischer Politiken scheint es unumgänglich, besonders auch unter Frauen ein Bewusstsein für vergeschlechtlichte Ungleichheiten zu schaffen und dabei Zusammenhänge zwischen Betroffenen herzustellen. ${ }^{209}$ Diese Frage stellt sich auch Iwasiów in Gender dla średnio zaawansowanych von 2004. Während sie für den polnischen Kontext die Notwendigkeit der Konstruktion einer weiblichen Gruppenidentität feststellt, verwirft sie dies gleichzeitig im Hinblick auf den 'performativen`Stand ‘führender`Geschlechtertheorien: eine Gruppenidentität müsste zugleich konstruiert wie dekonstruiert werden. Dies stellt für Iwasiów ein unlösbares, aber >irgendwie` zu überwindendes Paradox der postsozialistischen Situation dar: »Vielleicht gelingt es uns, mehrere Hindernisse auf einmal zu überwinden. Wir haben die anderswo ausgearbeitete Theorie und unsere Wirklichkeit, die nicht allzu euphorisch stimmt. ${ }^{210}$

Was Iwasiów hier als polnisches Problem einer `verspäteten` Liberalisierung oder gar einer Retraditionalisierung der Geschlechterordnung sieht, gilt jedoch generell für die Frage nach der Kategorie des Geschlechts. ${ }^{211}$ Das Paradox der gleichzeitigen Identifizierung mit einer Geschlechtszuschreibung und deren Hinterfragung etwa durch subversives Performieren hat Spivak in der Formulierung des »strategischen Essentialismus « zu lösen versucht. Spivak versteht damit eine vergeschlechtlichte Gemeinschaft nicht als über bestimmte geschlechtliche Charaktereigenschaften oder gemeinsame Identitäten definiert, sondern als temporärer und volitionaler Zusammenschluss aufgrund gemeinsamer Anliegen oder ähnlicher Erfahrungen. Die gemeinsame Komponente liegt dabei nicht in der >Identität ‘ der einzelnen Mitglieder selbst, sondern in der Relation des Diskurses von Wissen und Macht zum Individuum. ${ }^{212}$ Die Bestrebungen eines consciousness

208 | Siehe dazu hooks: Sisterhood, S. 294f.

209 | Vgl. bspw. Rosner: Czy istnieje, S. 36, 39.

210 I Iwasiów: Gender, S. 82: »Może uda nam się przeskoczyć przez kilka przeszkód naraz, mamy wypracowaną gdzie indziej teorię i naszą, nienastrającą zbyt ekstatycznie, rzeczywistość. Siehe dazu auch den Schlussteil.

211 I Vgl. hooks: Sisterhood, S. 296-304.

212 I Vgl. Spivak: Subaltern Studies, S. 205. 
raisings, wie es etwa der Feminismus Zweiter Welle in den USA popularisierte, ${ }^{213}$ sollten deshalb nicht in der Bewusstwerdung einer gemeinsamen Identität oder einzelner Charakterzüge liegen, sondern in der Bewusstwerdung von Machtstrukturen und deren Mechanismen, die sich nicht nur über die Achse des Geschlechts bemerkbar machen. Eine solche Strategie schlägt etwa bell hooks mit ihrem Konzept des bondings zur Erlangung einer intersektionellen politischen Solidarität vor. ${ }^{214}$

Die Herausforderungen einer sneuen` Gemeinschaftsbildung gelten auch für die feministische Kritik in Polen, deren Strategien ich in einer Analyse der Mechanismen der Gemeinschaftskonstruktion in den polonistischen Texten nachzuvollziehen versuche. ${ }^{215}$ Im Hinblick auf dieses Vorgehen möchte ich hier zwei Vorbemerkungen anbringen. Einen Teil der analytischen Aufmerksamkeit werde ich darauf aufwenden, die Frage nach einer affektiven Dynamik an die Texte heranzutragen. Ich gehe nämlich davon aus, dass die Gemeinschaftsbildung neben einer logisch-argumentativen Dimension insbesondere auch auf der Ebene affektiver Prozesse wirksam wird. ${ }^{216}$ Diesbezüglich wird die Körperlichkeit in den folgenden Auseinandersetzungen eine gewisse Rolle spielen. ${ }^{217}$ Die zweite Vorbemerkung betrifft die Annahme, dass der Text als Plattform der Gemeinschaftskonstituierung eingesetzt wird und so zu einer Art »virtual plaza ${ }^{218}$ wird. Der feministische Text kann damit ähnliche Funktionen wie eine consciousness raising group übernehmen und - insbesondere über den affektiven Miteinbezug der Leserin/des Lesers - zu einem Instrument des (feministischen) bondings werden.

Die polnischen Feministinnen verweisen darauf, dass über das Element des Schreibens historisch bereits ein weibliches Gemeinschaftsgefühl bestehen könne. Dies betrifft etwa die unter 5.3 untersuchten Formen des (matrilinearen) Tradierens weiblicher Schriftlichkeit und weiblicher Figuren in der Literatur. So argu-

213 I Vgl. Hogeland, Lisa Maria: Feminism and Its Fictions. The Consciousness-Raising Novel and the Women's Liberation Movement, Philadelphia 1998; Shreve, Anita: Women Together, Women Alone. The Legacy of the Consciousness-Raising Movement, New York 1989, S. 5-15.

214 । Vgl. hooks: Sisterhood.

215 | Vgl. dazu auch Markowski, Michał Paweł: »Emocje. Hasło encyklopedyczne w trzech częściach i dwudziestu trzech rozdziałach (nie licząc motta)«, in: Budrewicz et al., Pamięć i afekty (2014), S. 345-366, hier S. 353, der in Anlehnung an Aristoteles die Rhetorik als Mittel der Schaffung und Verankerung eines Gemeinschaftsempfindens sieht, wobei er auch die Funktion von Emotionen im Prozess der »Vereinigung von Bündnispartnern in gemeinsamer Sache « festhält. 216 । Vgl. Leys: The Turn to Affect, S. 436; Tabaszewska, Justyna: „Afektywne interpretacje. Afekt w koncepcjach Jill Bennett oraz Valerie Walkerdine«, in: Budrewicz et al., Pamięć i afekty (2014), S. 215-226, hier S. 217f.

217 | Vgl. hooks: Sisterhood, S. 306, die das "learning one another's cultural codes « als Grundprinzip des bonding beschreibt, wozu eben auch eine somatische Dimension gehört (Körpersprache, Redelautstärke usw.).

218 | Ahmed: Collective Feelings, S. 38. 
mentiert Kłosińska, dass sich durch den Text geknüpfte Verbindungen auch über die textuelle Ebene hinaus auswirken würden: "Gerade das weibliche Schreiben bildet die matrilinearen Beziehungen heraus..$^{219}$ Kraskowska hingegen sieht diese Verbindung stärker textgebunden, als eine Art publizistische Gemeinschaftlichkeit. Sie stellt über die schreibenden Frauen der Zwischenkriegszeit fest, dass in der Literatur und Kunst »Solidarität und gemeinsame Unterstützung die ungeschriebene Regel ist, sogar wenn private Animositäten vorkommen..${ }^{220}$ Kraskowska postuliert damit die besondere Stellung der Textualität, des Schreibens, in dem das Gruppenbewusstsein höher sei und besser hergestellt werden könne als im alltäglichen Leben. Beide Polonistinnen gehen darin einig, dass die Textualität eine grundlegende Funktion weiblicher Gemeinschaft bilde und imstande sei, durch den Prozess weiblichen Schreibens und Lesens eine Verbindung zwischen Frauen herzustellen.

Eine Komponente dieser Verbindung sei die Ausgrenzung aus dem ımännlichen Paradigma, notiert Kłosińska: »[D]ie den schreibenden Frauen allgemein vorgeworfene Inkompetenz (Widerstand gegen die Konvention?) kann das weibliche Ich bekunden - als Produkt der patriarchalen Ideologie. ${ }^{221}$ Ausschluss und Marginalisierung können als verstärkendes Element eines Gemeinschaftsgefühls wirken. Wenn Kłosińska in Bezug auf das weibliche Schreiben von einem »weiblichen Untergrund« spricht, kann folglich für diesen eine ähnliche Feststellung wie für den drugi obieg als konspirative Literatur gelten: Diese sei »a risky, exciting act that also leant a sense of danger and urgency to the act of reading; it brought a feeling of complicity between poet and reader. ${ }^{222}$ Entlang dieser Argumentation wird der weibliche Text durch seine Entstehungsumstände zu einem sintimen` und 'nahen'; die virtual plaza des weiblichen Texts wäre in dieser Auslegung gleichzeitig ein Privatraum. Im Oszillieren zwischen Enthüllen und Verhüllen, zwischen Offenlegung und Intimisierung nimmt der affektive Gehalt des Textes insofern zu, als seine Transpositionen vom und in den sozialen und historischen Kontext von einer Prekarität und Dringlichkeit gekennzeichnet sind.

\subsubsection{Affektierte Körper}

Wie Kraskowska zu Beginn ihrer Monographie schreibt, stellt das subjektive Erkenntnisinteresse der Wissenschaftlerin am Thema der weiblichen Literatur einen konstitutiven Teil ihrer Auseinandersetzung dar. Der erste Schritt Kraskowskas in Richtung feministischer Kritik war, wie sie notiert, dass weibliche Texte »mich

219 | Kłosińska: Ciało, S. 27: »Matrylinearne związki buduje właśnie pisanie kobiet.»

220 I Kraskowska: Piórem niewieścim, S. 29: „niepisaną regułą jest solidarność i wzajemne się popieranie, nawet jeśli prywatnie zdarza się animozja.«

221 । Kłosińska: Ciało, S. 17: »powszechnie zarzucana kobietom piszącym niekompetencja (sprzeciw wobec konwencji?) może manifestowac kobiece Ja - produkt patriarchalnej ideologii."

222 | Pirie: Internal Exile, S. 202. 
in der Sprache meiner eigenen Erfahrung [ansprachen] «223. So äußert sich der affektive Gehalt des Textes, der die (wissenschaftliche) Leserin über das Verfahren der Ähnlichkeit einbindet. Mit der persönlichen Einbindung der Analytikerin gewinnt das subjektive Empfinden in der feministischen Kritik an wissenschaftlicher Bedeutung, das als abrufbares Set affektiver Grundstimmungen ${ }^{224}$ eines kollektiven weiblichen Erfahrungsrepertoires konzeptualisiert wird. Anzumerken ist hier, dass zur Vorstellung von universalen weiblichen Charaktereigenschaften, wie sie die (nicht nur) polnische feministische Kritik verhandelt, auch eine erhöhte Empathiefähigkeit oder eben Affektivität gehört. ${ }^{225}$ Damit gerät die Intersektion von Körper und Text, an der sich die affektive Transposition des Schreibens/Lesens äußert, stärker in den Fokus des Interesses. Diese Intersektion möchte ich nun am Beispiel von Borkowskas Analysen exemplarisch untersuchen. Diese Auswahl drängt sich auf, weil Borkowska zu ihren `Untersuchungsobjekten Żmichowska und Orzeszkowa sehr unterschiedliche Beziehungen aufbaut. Während in der Auseinandersetzung mit Żmichowska Nähe über das Körperliche hergestellt wird, kehrt sich dies bei Orzeszkowa in eine Distanznahme um. Damit wendet Borkowska das in Orzeszkowas Texten festgestellte Verfahren emotionaler Distanz gleichsam auf ihre eigene Analyse an.

Als Beispiel zur Untersuchung, mit welchen Verfahren Borkowska die Verbindung zu Żmichowska aufbaut, dient mir der bereits erwähnte (5.2.3) publizistische Streit zwischen Żmichowska und der Autorin von Erziehungs- und Jugendliteratur Hoffmanowa, den Borkowska rekonstruiert. Borkowska ergreift dabei die Partei Żmichowskas, indem sie diese als die stärker unter den Animositäten leidende Figur darstellt. Borkowska referiert auf einen körperlichen Schmerz der Schriftstellerin, der durch deren künstlerische Empfindsamkeit erhöht werde: »Auf jeden Fall herrschten zwischen den Heldinnen unseres Essays unausgesprochene Animositäten, bestimmt leichter als morgendlicher Nebel, für Narcyza aber mit Sicherheit schmerzhaft, denn die Haut von Künstlern ist außerordentlich anfällig für solche Kühle. ${ }^{226}$ Auffallend ist hier Borkowskas körperliche Inszenierung dieses Streits, der die Schriftstellerin an ihrer Außengrenze - der Haut - physisch

223 I Kraskowska: Piórem niewieścim, S. 7: "przemówiły do mnie językiem mego własnego doświadczenia«.

224 । Vgl. dazu Ahmed: Collective Feelings, S. 27; Shouse: Feeling, 0. S.

225 । Vgl. Filipowicz: Przeciw >literaturze kobiecej‘, S. 254; Janion: Kobiety, S. 83; Kraskowska: Piórem niewieścim, S. 90, 137ff.; Tabaszewska: Afektywne interpretacje, S. 217f. Siehe dazu auch Tomkins Überlegungen zu Ideologie, Affekt und Geschlechterdifferenzierungen im historischen Kontext, Tomkins, Silvan S.: »Ideology and Affect«, in: ders., Exploring Affect. The Selected Writings of Silvan S. Tomkins (= Studies in Emotion and Social Interaction), Cambridge, Paris 1995, S. 109-167, hier 160-163.

226 I Borkowska: Cudzoziemki, S. 62f.: »W każdym razie były między bohaterkami naszego eseju jakieś niewysłowione animozje, Iżejsze pewnie od porannej mgły, a dla Narcyzy z pewnością bolesne, bowiem skóra artystów jest wyjątkowo podatna na takie chłody.« 
angreife. Ihre Figur tritt somit als abgeschlossene Einheit eines Körpers hervor, wobei die Haut Grenze und Kontaktpunkt zur Außenwelt darstellt. Hier entstehen die Prozesse des Austausches und der gegenseitigen Beeinflussung.

Borkowska positioniert sich nun aber nicht außerhalb dieser abgeschlossenen Einheit, sondern im Innern: Sie interpretiert die Gefühlswelt Żmichowskas, als hätte sie Einblick in deren Psyche. Die Formulierung »für Narcyza mit Sicherheit schmerzhaft" suggeriert eine personelle Nähe, als ob Borkowska über eine Freundin sprechen würde. Dies legt auch die Verwendung des Vornamens Żmichowskas nahe. Es bleibt zu vermuten, dass sich diese Nähe und das Hineinschlüpfen in die Autorinnenfigur für Borkowska durch die Lektüre von Żmichowskas Texten und zusätzlichen biographischen Informationen hergestellt hat. Dies wiederum suggeriert die deproblematisierte Möglichkeit eines fließenden Übergangs vom Text zur Psyche der Schriftstellerin, in der sich diese der empathischen Leserin als >offenes Buch anbietet. Bemerkenswert ist überdies die poetische Ausformung des obigen Zitats, was eine Annäherung von Forscherin und Schriftstellerin auf einer weiteren, formellen Ebene darstellt.

Die »unausgesprochenen Animositäten« zwischen den beiden schreibenden Frauen Żmichowska und Hoffmanowa, die Borkowska hier bespricht, ${ }^{227}$ gliedern sich in die »Regel der weiblichen Solidarität« insofern ein, als, wie Kraskowska nahelegt, Antipathien nicht direkt ausgetragen werden. Darauf macht Borkowska aufmerksam, wenn sie die Kritik Żmichowskas an Hoffmanowa als gut im Text verhüllt bezeichnet: «Nur in einigen Rezensionen bemerkte man, dass der Essay Żmichowskas zu kritisch gegenüber den Büchern Hoffmanowas ist. Aber das eigentliche Verbrechen der Autoritätsanfechtung blieb unbemerkt. Wie ein perfektes Verbrechen. $\ll^{228}$ Es sei erst die feministische Lektüre und das Sich-Einlassen auf die Gesamtheit von Autorin und Text, die die Entdeckung des "perfekten Verbrechens« möglich mache. Dieses sei überdies affektiv verhüllt: Żmichowska »markierte [den Text] mit ihrem Sarkasmus, stempelte [ihn] mit Ironie und Hohn « ${ }^{229}$, wie Borkowska schreibt. Durch die psychologische Annäherung an Żmichowska inszeniert sich Borkowska im Gegensatz zu anderen Rezipierenden in einer Sonderstellung, die von einer Empfänglichkeit für die affektive Sendung der schreibenden Instanz geprägt ist. Borkowska scheint deshalb zu wissen, welche Intentionen Żmichowska während des Schreibprozesses leiteten: Żmichowska »zählte

227 | Vgl. Walczewska: Damy, rycerze i feministki, S. 118f., die wie erwähnt die Meinung nicht teilt, dass Żmichowska Hoffmanowa gegenüber sehr kritisch eingestellt war.

228 । Borkowska: Cudzoziemki, S. 60. "Zaledwie w kilku recenzjach zauważono, że esej Żmichowskiej jest nazbyt krytyczny wobec książek Hoffmanowej. Ale sama zbrodnia podważenia autorytetu pozostała nieodkryta. Jak zbrodnia doskonała."

229 | Ebd.: "naznaczyła je swoim sarkazmem, ostemplowała ironią i drwiną". An anderer Stelle schreibt Borkowska, dass Żmichowska "spottet«, und: „Żmichowska ist sehr scharfzüngig, und ihr Stachel steckt ohne Mitleid.«Ebd., S. 70: „zakpić«; S. 71: „Bardzo uszczypliwa jest Żmichowska, a jej żądło tkwi bez litości.» 
auf die Reaktion des scharfsinnigen, intelligenten Lesers ${ }^{230}$. Borkowska positioniert sich im Umkehrschluss als ebenjener "scharfsinnige, intelligente Leser", den Żmichowska als intellektuellen Verbündeten anzupeilen scheint. Damit verstärkt sich die persönliche Bindung: Borkowska - als die von Żmichowska erhoffte Leseinstanz - scheint somit bereits in den Schreibprozess eingebunden, und ihre Lektüre füllt diese bislang leere Funktion des Textes nach über einem Jahrhundert endlich aus.

Auf die Komponente einer körperlich-psychischen Annäherung oder einer sinnlichen Affektion über die Textlektüre verweist Borkowska an anderer Stelle mit dem Schlagwort des plaisir du texte. ${ }^{231}$ Borkowska verwehrt sich jedoch gegen ein Abrutschen in ungewollte Tiefen der Sinnlichkeit (»Perversität ${ }^{232}$ ) und gegen eine erotische Interpretation ihrer Lektüreerfahrung. Sie versucht, diese auf einer Ebene der unverfänglichen Sympathiebekundung gegenüber »»meinen Schriftstellerinnen ${ }^{233}$ zu verankern. In diesen Abgrenzungsrhetoriken zu »radikaleren« Ansätzen der feministischen Kritik wie hier jene Felmans ${ }^{234}$ zeigen sich Borkowskas Bemühungen, ihre eigene `feministische Kritikı sittlich eher konservativ zu halten.

Als symptomatisch kann jedoch auch die Formulierung ")meine Schriftstellerinnen« gelesen werden. Denn implizit nimmt Borkowska die untersuchten Schriftstellerinnen - allen voran Żmichowska - in Beschlag und monopolisiert den Zugang zu ihnen. Dies zeigt sich nicht nur auf der Ebene der historisch-körperlichen Autorinnen, als deren engste Vertraute sich Borkowska inszeniert. Obwohl Borkowska die affektive Kraft der Texte Żmichowskas als deren Beitrag zur weiblichen Literatur und damit einer emanzipatorischen Stoßrichtung benennt, verläuft der dargestellte Prozess der Affektierung vorwiegend über die Instanz Borkowskas selbst. Borkowskas Lektüre erst öffnet diesen Zugang und vermittelt die Nähe zu Text und Autorin. Dies heißt aber auch, dass die feministische Lektüre hier keine egalitäre ist, sondern auf qualifizierte Entschlüsselungsinstanzen setzt und damit zu einem regulierten System der Wissensvermittlung wird, das nur nominell eine subjektive und selbstermächtigende Leseform in den Vordergrund stellt. In gewisser Weise illustriert dieses Beispiel auch den ratomisierenden Effekt, den Versuche von (nicht nur) weiblicher Gemeinschaftsbildung haben können: Während Borkowska eine intime Beziehung zu Żmichowska aufbaut, bindet ihr Text seine/n Leser/in nicht in diesen Prozess ein. Der feministische Text Borkowskas reduziert den/die Leser/in damit auf die voyeuristische Position des Zuschauens, die letztlich jene eines distanzierten Konsumierens ist.

230 । Ebd., S. 70: »licząc na reakcję ze strony domyślnego, inteligentnego czytelnika«.

231 | Vgl. Barthes, Roland: Le plaisir du texte, Paris 1973.

232 । Borkowska: Cudzoziemki, S. 20: »perwersyjności«.

233 | Ebd.: "swoje pisarki«.

234 | Vgl. Felman: Le Scandale. 


\subsubsection{Ausgrenzungen}

Während Borkowska in den Abschnitten zu Żmichowska ein Verhältnis der Nähe zwischen sich und der Schriftstellerin als Figur konstruiert, kehrt sie dieses Verfahren in der Analyse von Orzeszkowas Werk um in einen kritischen und distanzierten Ton. ${ }^{235}$ Bei Żmichowska als schriftstellerische Freiheit ausgelegte literarische Auslassungen oder Verformungen (auto)biographischer Ereignisse interpretiert Borkowska bei Orzeszkowa als übermäßige Bedachtsamkeit und Geheimhaltung ihrer Privatsphäre und letztlich als "nicht wirklich echt ${ }^{236}$. Borkowska wirft Orzeszkowa eine stete Pauschalisierung und fehlenden persönlichen Einsatz vor, indem sie sich selbst als fühlendes und vergeschlechtlichtes Wesen aus dem Text "herausschneide «. ${ }^{237}$ Im Besonderen macht Borkowska darauf aufmerksam, dass die von Orzeszkowa angewandte "Strategie der Mimikry« als Selbstverhüllung im Grunde der Weiblichkeit zuwiderlaufe. Orzeszkowas emanzipatorisches Projekt inszeniere sich als "Befreiung vom Druck biologischer Bedingungen" und, wie Borkowska kritisch anmerkt, als Emanzipation der Frau »von sich selbst, von ihren Wünschen, von erweckten erotischen Bedürfnissen und von den Privilegien, die sich aus ihrer Mutterfunktion ergeben. ${ }^{238}$ Diese Verdrängung der Geschlechtlichkeit und spezifisch weiblicher Bedürfnisse steht Borkowskas eigenem Projekt der `Intimisierung der Weiblichkeit diametral entgegen. Ein Gutheißen von Orzeszkowas "Selbstbegrenzungsmodell « ${ }^{239} \mathrm{kommt}$ deshalb für Borkowska nicht infrage. Sie sieht bei Orzeszkowa im Gegenteil ein »Unvermögen zuzugeben, dass das Gefühl des persönlichen Glücks und Unglücks zu einem riesigen Teil von der emotional-erotischen Sphäre abhängt. « ${ }^{240}$

Damit transportiert Borkowskas Text eine essentialisierte Wahrheit über die Weiblichkeit, welche er an Orzeszkowa heranträgt. Borkowska lässt die in Orzeszkowas Texten vorgestellte Perspektive nicht als authentisch gelten, sondern identifiziert diese als »falsch", als "gestellt«. Entsprechende Markierungen finden sich auch in Borkowskas Analysen von Orzeszkowas Romanen und Erzählungen, wie hier am Beispiel von Rodzina Brochwiczów (Die Familie Brochwicz, 1876): „Es ist schwierig, die Brutalität zu akzeptieren, mit der Stefan die Entscheidung zur

235 | Allein die Wende in Orzeszkowas Schaffen zu Ende ihres Lebens vermag der Forscherin ein versöhnlicheres Urteil zu entlocken.

236 I Borkowska: Cudzoziemki, S. 164: »nie jest do końca prawdziwe«.

237 | Vgl. ebd..

238 | Ebd., S. 180f.: »wyzwalania się od presji uwarunkowań biologicznych«; »od samej siebie, od swych pragnień, od rozbudzonych potrzeb erotycznych i od przywilejów, jakie wynikają z jej funkcji macierzyńskich."

239 | Ebd., S. 160: "model samoograniczający«.

240 | Ebd., S. 164: "nieumiejętność przyznania, że poczucie osobistego szczęścia i nieszczęścia zależy w ogromnym stopniu od sfery uczuciowo-erotycznej.« 
Trennung trifft. Er ist kalt, steif, zynisch, akkurat « ${ }^{241}$, urteilt Borkowska. Als »nicht überzeugend « und »seltsam $\aleph^{242}$ empfindet sie an anderer Stelle den Verlauf der Handlung und das Verhalten der literarischen Figuren.

Borkowska geht so weit, die literarische Unterschlagung affektiver Bindungen in Orzeszkowas Texten als "psychologische Blockade» der Schriftstellerin zu bezeichnen, die mit »einer Furcht vor dem Aufdecken schmerzhafter Verletzungen $\aleph^{243}$ zusammenhänge. Borkowskas Kritik richtet sich gegen die postulierte Gefühlskälte Orzeszkowas primär als einen sunweiblichen`Charakterzug, wobei die Dimension der Spür- oder Erfahrbarkeit der Schriftstellerin als affektierte Person fehle. Deshalb, so kann man Borkowska folgend schließen, funktionieren die Texte Orzeszkowas nicht affektiv, vermögen also ihre Leser/innen nicht emotional zu bewegen und zu überzeugen, sondern würden rein intellektuell operieren. Orzeszkowas Methode orientiere sich an männlicher Rationalität. Dies illustriert Borkowska mit der Bezeichnung der "Strategie der Mimikry«, die »eine Manifestierung einer scheinbaren Kraft [ist], die das sich camouflierende Subjekt im Grunde nicht besitzt. ${ }^{244}$ Was Orzeszkowa Borkowska zufolge als »Kraft" der Texte inszeniere, richte sich letztlich gegen sie selbst, da sie weibliche Leserinnen so zu nichts »bewegen ${ }^{245}$ könne.

Folgt man Borkowskas Ansatz, so ist ein Merkmal weiblicher Literatur das In-Bewegung-Setzen einer subrationalen Ebene, ein unterschwelliges Ansprechen der Leserin als Frau im somatischen und identitären Sinne. Auf diese Weise funktioniere auch die weibliche (literarische) Gegenwelt, die die Leserin als Betroffene `stimme . Bei Orzeszkowa hingegen sei der Zugang zu dieser `Stimmung verwehrt, die Gegenwelt abgeschnitten vom Text, aber, so suggeriert Borkowska, >in Orzeszkowa dennoch vorhanden, auch wenn sie diese nicht als vertextlichte Emotion nach außen, in den Text dringen lasse. Diese Verweigerung Orzeszkowas ruft den Widerstand Borkowskas hervor. Während Borkowska Żmichowskas Texten >glaubt‘, ist das Verhältnis zu Orzeszkowa und deren Schriften von Misstrauen, ideologischer Ablehnung und gezieltem Lesen gegen den Strich geprägt. Die Ideologeme der Texte Orzeszkowas und Borkowskas stehen in starkem Kontrast, weshalb Borkowska über die Hintertür psychologisierender Lektüre das in den Texten Orzeszkowas vermisste >Gefühl als in der biographischen Figur Orzeszkowas selbst versiegelt verortet.

Einen ähnlichen Fall des Verstoßes gegen die weibliche Empfindung ১behandelt « auch Kraskowska. Wie erwähnt geht sie von einer Art »ungeschriebenen Re-

241 | Ebd., S. 167: »Trudno zaakceptować brutalność, z jaką Stefan podejmuje decyzję o zerwaniu. Jest zimny, sztywny, cyniczny, dosłowny."

242 । Ebd., S. 168 resp. 169: »nieprzekonujące«; »dziwne«.

243 | Ebd., S. 164: »blokada psychologiczna«; »lęk przed odkrywaniem bolesnych urazów«.

244 । Ebd., S. 180: »manifestacją pozornej siły, której w gruncie rzeczy kamuflujący się osobnik nie posiada."

245 | Ebd., S. 176: »nakłania«. 
gel [der] Solidarität und gemeinsamen Unterstützung « ${ }^{246}$ unter weiblichen Schriftstellerinnen und Publizistinnen aus. Als abweichendes Beispiel nennt sie Irena Krzywicka, die die Vorzeigeweiblichkeit ihrer Kolleginnen vom Fach kritisierte. Die rantiweiblicher Haltung Krzywickas ahndet Kraskowska, indem sie ihr niedere Motive und fehlendes literarisches Talent vorwirft: In ihrer »Boshaftigkeit einer bekannten Publizistin und Prosaikerin nicht allzu hoher Flüge« »schmiede« Krzywicka einen »kümmerlichen Neologismus« und »spotte « ${ }^{247}$ so über andere Autorinnen. Die Argumentation Kraskowskas disqualifiziert die Aussagen und Urteile Krzywickas mittels affektiver textueller Verfahren, die einen ebenso aggressiven Gehalt aufweisen wie die postulierte Boshaftigkeit von Krzywickas Kritik und die diese aus einer `weiblichen` Perspektive ausgrenzen.

Für Borkowska wie Kraskowska gilt somit eine Form der Gemeinschaftskonstruierung nicht nur über gemeinsame Faktoren, sondern auch über die Abgrenzung von gegen die »Regel« der Gemeinschaft verstoßenden Figuren/Texten: von Frauenfiguren, deren Haltung sich nicht in die Weiblichkeitsentwürfe der Forscherinnen integrieren lässt. ${ }^{248}$ In der normativ begründeten Exklusion divergierender Haltungen mithilfe affektiver Rhetoriken arbeiten beide Polonistinnen mit einer metonymischen Verschiebung der Strategien der von ihnen kritisierten Texte, wobei sie deren Hierarchisierungen invertieren und Weiblichkeitskonzepte gegeneinander ausspielen. Mit dieser Engführung von Weiblichkeit ziehen die beiden feministischen Kritikerinnen Grenzen um ihre Definition und verteidigen diese mit rhetorischen Mitteln gegen ein anders-weibliches Außen. Deutlicher noch, aber auch motivischer, wird bei Kraskowska die Abgrenzung zum Männlichen. Ich ziehe hier erneut die Untersuchung von Całe życie Sabiny bei, die in Kraskowskas textuellem Ideologem eine Schlüsselposition einnimmt. An diesem Beispiel erklärt Kraskowska die Differenz weiblicher und männlicher Literatur als einfache affektive Segregation, der das vergeschlechtlichte lesende Subjekt ausgesetzt sei: »Männer mögen Całe życie Sabiny nicht. Dieser Roman ist für sie schlicht uninteressant. ${ }^{249}$ Die Formulierungen "mögen nicht" (nie lubia) und »schlicht» (po prostu) entbinden rhetorisch von einer rationalen Begründung der $\mathrm{Zu}$ - oder

246 | Kraskowska: Piórem niewieścim, S. 29: »niepisaną regułą jest solidarność i wzajemne się popieranie, nawet jeśli prywatnie zdarza się animozja."

247 | Ebd., S. 19: "złośliwości znanej publicystki i nie najwyższych lotów prozaiczki«; »ukuwa marny neologizm «; »szydzi«.

248 । Dies beschreibt hooks: Sisterhood, S. 296 als typische Strategie auch feministischer Gruppierungen, die durch diese Ein- und Ausschlüsse das eigene Gemeinschaftsgefühl stärken: »Bonding between a chosen circle of women who strengthen their ties by excluding and devaluing women outside their group «, was letztlich einem feministischen Engagement einer politischen "Sisterhood « zuwiderlaufe und sich in die Strukturen des Patriarchats einfüge.

249 | Kraskowska: Piórem niewieścim, S. 98: »Mężczyźni nie lubią Całego życia Sabiny. Ta powieść jest dla nich po prostu nieciekawa.« 
Abneigung. Diese wird von Kraskowska vielmehr als intuitive ${ }^{250}$ Reaktion interpretiert. Eine Kompatibilität weiblicher Literatur mit einem männlichen Leser wird so als essentiell unmöglich ausgeschlossen.

Damit lenkt Kraskowska den Fokus auf eine unüberwindbare geschlechtliche Differenz, die sich stereotyper Charakterzuschreibungen bedient und deren Transgression sie nicht in Betracht zieht: »Geben wir aber ehrlich zu, dass für uns Frauen die Beschreibungen vom Karabinerputzen, vom tödlichen Ringen mit einem Schwertfisch oder vom Leben auf einem Walfangboot genauso wenig interessant sein können. ${ }^{251}$ Kraskowskas `Gemeinschaftsbildung^operiert somit auch appellativ, indem sie die Leserinnen als inklusive Gruppe (»wir«, »uns«) aufruft, sich ihrer eigentlichen Gefühle bewusst zu werden und diese als geschlechtliche Differenz zu konzeptualisieren. Implizit suggeriert Kraskowska, dass »wir Frauen« »uns« bisher dahingehend verstellt hätten, auch an `männlichen ‘ literarischen Topoi Gefallen zu finden. Von diesem Zwang befreit Kraskowska »uns« nun. Abgemildert wird dieses Aussage jedoch durch die Formulierung "genauso wenig interessant sein können «, womit hier die Möglichkeit des Abweichens von diesem >weiblichen Empfinden zumindest gegeben ist.

\subsubsection{Geschlossene und offene Apelle}

Während bislang die Rede war von Widerständen, die die feministischen Kritikerinnen in ihren Lektüren entwickeln und die sie in ihren Texte affektiv zu vermitteln suchen, möchte ich die Aufmerksamkeit nun auf Widerstände lenken, die sich aus der feministischen Argumentation selbst entwickeln können. Bereits habe ich mit Kraskowskas affektiven Lektüren die "Appellstruktur ${ }^{252}$ auch wissenschaftlicher Texte angesprochen und so den Fokus auf das Lesen feministischer Kritik als Transpositionsprozess verschoben, in den der/die Leser/in eingebunden ist, und innerhalb dessen Widerstände entstehen können. Dazu schreibt Wolfgang Iser, dass die Erzählinstanz durch ihre Kommentare die Leerstellen im Text soweit reduzieren kann, dass »bestenfalls noch die Möglichkeit [besteht], einer solchen Auffassung zu widersprechen ${ }^{253}$. Iser bezieht sich konkret auf Erzähltexte, meines Erachtens gilt jedoch diese Feststellung unterschiedlicher >Offenheit` der Argumentationsführung auch für das wissenschaftliche Schreiben. Im Folgenden gehe ich diesbezüglich auf die teilweise geschlossenen Argumentationen Kłosińskas

250 | An anderer Stelle verweist Kraskowska darauf, dass sie die Meinung Szemplińskas, Frauen und Kinder hätten eine größere Tendenz zur `Vertierlichung von Gegenständen, »intuitiv teile«. Ebd., S. 139: "[i]ntuicyjnie podzielam«.

251 । Ebd., S. 98f.: »Przyznajmy jednak szczerze, że dla nas, kobiet, równie mało interesujące mogą być opisy czyszczenia karabinu, śmiertelnych zmagań z marlinem czy życia na statku wielorybniczym.«

252 I Iser: Appellstruktur, S. 228.

253 | Ebd., S. 238. 
ein, um diese anschließend mit offeneren, ironischen und sich entziehenden Rhetoriken Janions zu kontrastieren.

Wie auch bei Kraskowska lässt sich bei Kłosińska beobachten, dass sie teilweise mit einer sintuitiven Zustimmung zu bestimmten Phänomenen arbeitet. So notiert Kłosińska zum weiblichen Schreiben: »Man kann sich an dieser Stelle nur schwer der unfreiwilligen Assoziation widersetzen, die diese nicht-schaffende und doch mit dem Innern ihres Körpers schreibende Frau mit der Spinne in Verbindung bringt. « $^{254}$ Die Affektionsmacht erscheint in diesem Beispiel sogar noch größer als bei Kraskowska, als die Anerkennung der vorgestellten These in einem explizit "unfreiwilligen" Prozess stattfindet, dem man sich laut Kłosińska kaum entziehen kann. Zwar benennt Kłosińska die Möglichkeit eines Widerstands gegen die Intuition in Form der "unfreiwilligen Assoziation", indem sie diesen mit der Formulierung "sich widersetzen" (oprzeć się) andeutet; gleichzeitig sieht sie die Kapitulation als beinahe unausweichlich. In eine ähnliche Richtung weist auch Kłosińskas Feststellung in Bezug auf das Kreuzchen, mit dem das Dienstmädchen Kaśka in Zapolskas Kaśka Kariatyda das Hausinventar unterzeichnet und dabei das Papier nicht nur zeichnet, sondern in ihrer Ungeschicktheit gar aufreißt. »Die Wunde, von der eine Zeichen-Narbe hinterbleibt, gebietet an eine gewisse matriarchale Ursprünglichkeit zu denken, die sich in der sschwarzen` Narbe irgendwie widerspiegeln sollte. ${ }^{255}$ Mit dem Begriff »gebieten « (kazać) ist in die Argumentation Kłosińskas wiederum ein Element der Gewalt eingebaut, das von Unausweichlichkeit und Entmündigung zeugt. Dieses steht hier in Kontrast zu den Unbestimmtheitsmarkern "gewisse (pewna) und »irgendwie« (jakoś) - diese weisen auf eine unterdrückte `Leerstelle hin, womit der vertragsartige Charakter der Argumentation noch verstärkt wird.

Die feministische Theorie, die die Verbindung von schreibender Frau und Spinne herstellt oder das Kreuzchen mit der matriarchalen Ursprünglichkeit verknüpft, wird somit in der Rhetorik Kłosińskas als unanfechtbar dargestellt, als kontextunabhängig existierende Tatsache, der es trotz Unsicherheiten zu folgen gelte. ${ }^{256}$ Die Verbindungen von schreibender Frau und Spinne, von zerrissenem Papier und ursprünglichem Matriarchat erfahren so eine Naturalisierung. Wer dieser Argumentation nicht folgen kann oder will - wer sich dem Zusammenhang von Spinne und weiblich-körperlichem Schreiben widersetzt -, wird von Kłosińskas Aussagen aus der Textlogik ausgeschlossen. Das rhetorische Ausradieren eines abweichenden Standpunktes bringt Skeptiker/innen in eine Position, die im Text

254 । Kłosińska: Ciało, S. 23: »Trudno oprzeć się w tym miejscu mimowolnemu skojarzeniu owej, nietwórczej, a jednak piszącej wnętrzem swego ciała, kobiety z pająkiem."

255 । Ebd., S. 68: »Rana, po której pozostaje znak-blizna, każe myśleć o pewnej matriarchalnej pierwotności, którą 'czarna‘ blizna miałaby jakoś odbijać."

256 | Dazu schreibt Łebkowska, dass die feministisch-psychoanalytische »Interpretation manchmal in ihrer demagogischen Eindeutigkeit irritiert«. Łebkowska: Czy ’płeć‘ może uwieść poetykę, S. 92. 
keinen Raum findet und diesem nurmehr eine entgegengesetzte sein kann. Das argumentative Korsett der Psychoanalyse, wie es Kłosińska in den obigen beiden Beispielen einsetzte, kann zu einem Widerstand gegen das zugrundeliegende Interpretationsmodell im weiteren Kontext führen, also in diesem Fall etwa - ausgehend von einzelnen Wörtern oder argumentativen Formulierungen des ıZwangs - gegen die feministisch-psychoanalytische Auslegung von Zapolskas Werken im Allgemeinen.

Hier möchte ich nun als letztes Beispiel Janion einbringen, deren affektive Rhetorik sowohl in Bezug auf Weiblichkeitskonzepte wie auch auf textuelle Mechanismen der Ein- oder Ausgrenzung zu derjenigen Borowskas, Kraskowskas und Kłosińskas in gewissem Gegensatz steht. Insgesamt lässt sich feststellen, dass Janions persönlicher Einsatz im Text zurückhaltend ist; ihre subjektive Haltung offenbart sich am ehesten in der subversiven Ironie. Meistens jedoch lässt Janion Andere (sogenannte »Spezialistenmeinungen ${ }^{257}$ ) zu Wort kommen und gibt dabei nur ihr Einverständnis dazu - etwa im Fall der Besprechung von Filipiaks Roman Absolutna amnezja, wo sie der pro-feministischen Argumentation Dunins »Recht" gibt (słusznie uważa). ${ }^{258}$ Janions eigene Rolle reduziert sich auf die Bewertung der Interpretationsansätze, was als indirekte Markierung ihrer Haltung erscheint. Ein solches Vorgehen scheint weniger auf eine eindeutige Lesart zu zielen, als dies wie oben herausgearbeitet bei Borkowska und Kraskowska, aber auch Kłosińskas psychoanalytischen Auslegungen der Fall ist. Janion engagiert den literarischen und literaturkritischen Diskurs zur hermeneutischen Introspektion; sie selbst fungiert primär als Moderatorin. Diesbezüglich aufschlussreich ist Janions Rhetorik in der Besprechung von Badinters $X Y$, de l'identité masculine, die ich bereits als vielschichtig beschrieben habe (siehe Kapitel 4.1.1).

Obwohl Janion hofft, dass $X Y$ als Auslöser einer in Polen längst überfälligen Debatte über das Geschlecht dienen könnte, ${ }^{259}$ positioniert sie den Ansatz Badinters in einem Spannungsverhältnis, indem sie diesen mit gegenteiligen Aussagen kontrastiert. Wenn Janion in ihrem Text die Argumentation Badinters nachvollzieht, hat dies vor allem den Rang eines Gedankenexperiments, zu dem sie die Leser/innen einlädt: »Es wäre unehrlich, die Leser nicht darüber zu informieren, dass [ein] Rezensent [...] ihre Suggestion für sehr strittig hält [...] Aber kehren wir zur Denkweise Badinters zurück « ${ }^{260}$, schreibt Janion. Zum Aufbrechen festgefahrener Denkmuster eignen sich die provokativen oder eben »strittigen« (dyskusyjne) Thesen Badinters besonders gut, wobei hier nicht zwingend nötig ist, diesen Thesen zuzustimmen. Janion resümiert Badinters Ansatz folgendermaßen:

257 | Vgl. Janion: Kobiety, S. 228.

258 | Vgl. ebd., S. 328.

259 | Vgl. ebd., S. 179.

260 | Ebd., S. 180: „Byłoby jednak nieuczciwością niepoinformowanie czytelników, że recenzent [...] uznał za wielce dyskusyjną jej sugestię [...] Ale wróćmy do stylu myślenia Badinter.« 
"Gegen Ende des Buches zieht sie Gott auf inre Seite und korrigiert die Bibel auf erstaunliche Weise. Die von ihr privilegierte Frau verkörpert das Glück einer versöhnten Menschheit. >Gott wurde zum Komplizen Evas, entgegen der Geschichte ihrer Verdammnis. Er nahm nicht nur Adam die Prokreationskraft, um sie Eva zu geben, sondern sprach den Frauen auch das Privileg zu, aus dem Bauch des selben Geschlechts geboren zu werden. [...] Das Gebären ist nun kein Fluch mehr, und die Frau wurde besonders ausgezeichnet, da sie das Prinzip der Harmonie in sich hat!«261

Janion ironisiert die Argumentation Badinters, indem sie deren Vorgehen überspitzt: Sie verleiht Badinter eine Gott ebenbürtige Position der Deutungs- und Zuweisungshoheit (jej nadanie) sowie eine übermenschliche Überzeugungskraft: sie »zieht Gott auf ihre Seite«. Janions überspitztes Nachzeichnen der Thesen Badinters weist in die Richtung einer subversiven Affirmation, also der Unterwanderung der Argumentation durch deren allzu >offensichtliche` Bestätigung. ${ }^{262}$ Janions Strategie funktioniert aber deutlicher ironisch, etwa durch die Verwendung des Ausrufezeichens. Gleichzeitig durchflicht Janion das mimetisch-übertriebene Nachzeichnen der Argumentation mit einer Metaposition, aus der heraus sie Badinters Thesen als solche entlarvt. ${ }^{263}$

Aus dieser Position >spricht $<$ Janion auch zu ihrem Publikum, das sie mit ihrem Gedankenexperiment gleichsam aus einer gewissen Distanz die Argumentation Badinters durchspielen lässt. Der Einsatz der Ironie dient Janion dabei einerseits zur `Leser/innenführung`, nimmt also eine Art indexikalische Funktion ein. Andererseits wird die Ironie zum Ort der intellektuellen Übereinkunft von Schreibender und Lesender/Lesendem. Hier werden die Grenzen eines gemeinsamen Weltverständnisses oder Ideologems ausgelotet; die Grenze zwischen Ironie und ,Wortsinn ist deshalb von der jeweiligen Transposition im Leseprozess abhängig. Voraussetzung für ein Funktionieren ironischer Einschübe ist ein zumindest par-

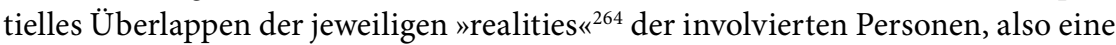
weltanschauliche Annäherung und ähnliche Weisen der Auslegung bestimmter Phänomene.

261 | Ebd.: "Pod koniec książki przeciąga ona na swoją stronę Boga i osobliwie koryguje Biblię. Z jej nadania uprzywilejowana kobieta uosabia szczęście pogodzonej ludzkości. >Bóg stał się wspólnikiem Ewy, wbrew historii o jej potępieniu. Nie tylko odebrał Adamowi moc prokreacji, by dać ją Ewie, ale zarazem przyznał kobietom przywilej rodzenia się z brzucha tej samej płci.< [...] Rodzenie nie jest już przekleństwem, a kobieta została szczególnie wyróżniona, gdyż ma w sobie zasadę harmonii!«

262 | Vgl. zu subversiver Affirmation Arns, Inke/Sasse, Sylvia: "Subversive Affirmation: On Mimesis as a Strategy of Resistance«, in: IRWIN (Hg.), East Art Map. Contemporary Art and Eastern Europe, Cambridge 2006, S. 444-455, hier S. 445.

263 | Vgl. auch Barańczak, Stanislaw: "Zbigniew Herbert and the Notion of Virtue«, in: Eile/Phillips, New Perspectives (1992), S. 105-118, hier S. 110; Eile: Introduction, S. 5.

264 | Vgl. Shweders: Divergent Rationalities. 
Deutlicher wird der affektive Einsatz von Ironie am Beispiel der Gegenüberstellung von Komornicka und dem Arzt Oszacki, respektive von Oszacki und Janion. Janion kommentiert Oszackis Verdikt über Komornicka folgendermaßen: »Und so gelangen wir schließlich auf den Pfad der Erlösung - durch die Unterordnung unter die repressiven Systeme, vor denen Komornicka das ganze Leben so konsequent floh! ${ }^{265}$ Als deutlichste Marker der Ironie können hier die Verwendung des Wortes "Erlösung« (zbawienie) sowie des Ausrufezeichens gelten; mit dem Begriff »repressiv« signalisiert Janion ihren Widerstand gegen Oszackis Urteil am wörtlichsten. Janion appelliert an das Freiheits- und Selbstbestimmungsverständnis der Leserin/des Lesers, ihrer hier nur implizit ausgesprochenen Kritik zu folgen und das Urteil Oszackis als unhaltbar zu interpretieren. Der hier vorgestellte Textmechanismus der Ironie hängt also auch damit zusammen, dass die lesende Person vom Begriff der Repression affektiert und somit eine reflexartige Abwehrhaltung gegen Oszackis Vorschlag der Unterordnung ausgelöst wird. Die Einnahme des ironisch kritisierten Standpunktes Oszackis wird hingegen affektiv erschwert und kann höchstens mit einer Art Trotz verteidigt werden. ${ }^{266}$

Indem Janion mit ironischen Mitteln arbeitet, um bestimmte Positionen für oder gegen die vorgestellten Thesen einzunehmen, entzieht sie sich gerade aufgrund der schwierig zu definierenden Grenzen solcher Ironie einer eindeutigen Festlegung. Ihre Rhetorik befördert deshalb eine Lektüre, die sich auf keine ‘fixen Tatsachen stützen kann, nicht einmal auf ein kohärentes Ideologem der schreibenden Instanz. Bis auf wenige Ausnahmen, in denen Janion eine Haltung im Text direkt und unvermittelt einnimmt - am nächsten kommt dem wohl die Passage zu Filipiak und der weiblichen Erfahrung ${ }^{267}$-, setzt Janion somit ihre Methodik der $»$ Hermeneutik der Verdachte ${ }^{268}$ auch auf rhetorischer und affektiver Ebene ein. Ihre Gemeinschaftsbildung funktioniert stärker über die »Leerstelle«, ${ }^{269}$ an der die Lektüre offen und polyvalent wird und in der Transposition selbst sentscheiden`muss, welchen interpretativen Weg sie einschlägt. Dabei spielt auch das Geschlecht der schreibenden/lesenden Person eine untergeordnete Rolle.

Die untersuchten Beispiele affektiver Textmechanismen zeigen einige Strategien der Gemeinschaftsbildung auf, die sich in der feministischen Kritik der 1990er Jahre finden lassen. Dabei habe ich die für mich prägnantesten Beispiele zusammengestellt, die jedoch keinen repräsentativen Charakter haben und die Gestalt

265 । Janion: Kobiety, S. 223: »| tak wreszcie dobrnęliśmy do drogi zbawienia - przez podporządkowanie się tym systemom represyjnym, przed którymi Komornicka przez całe życie tak konsekwentnie uciekała!«

266 I Vgl. dazu auch Hemmings, Clare: »Invoking Affect. Cultural theory and the ontological turn «, in: Cultural Studies 19/5 (2005), S. 548-567, hier S. 556, die ähnliche Phänomene beschreibt.

267 I Vgl. Janion: Kobiety, S. 328 sowie Kapitel 5.2.2.

268 | Vgl. Janion: Droga, S. 15 sowie Kapitel 3.2.2.

269 । Vgl. Iser: Appellstruktur, S. 235. 
der einzelnen untersuchten Texte auch nur teilweise mitbestimmen. Dennoch scheint die Analyse dieser Verfahren einige Gemeinsamkeiten, aber insbesondere auch Differenzen zwischen den Texten und deren >Arbeitsweisen hervorzuheben, die für den untersuchten Bereich der feministischen Kritik der 1990er Jahre aufschlussreich sind.

So unterscheiden sich beispielsweise die einzelnen Polonistinnen im textuellen Einsatz >ihrer selbstı, wobei Borkowska die vielleicht am offensichtlichsten spersönliche Stimme (und Körper) bildet; ihre intime Verbindung zur untersuchten Żmichowska lässt hingegen die Leser/innen in der Gemeinschaftskonstruktion außen vor. Kraskowska inszeniert am konsequentesten eine skonventionelle Weiblichkeit, was besonders im Vergleich mit den Ideologemen des von ihr untersuchten Materials auffällt. Kraskowska geht im Gegensatz zu Borkowska keine direkte Beziehung zu den untersuchten Schriftstellerinnen ein; ihre Position ist diejenige einer übergeordneten Instanz, womit sie sich von den Autorinnen distanziert. Kłosińska wiederum ist in ihrem Text nicht deutlich als urteilende Instanz wahrzunehmen, wohingegen ihr interpretatives Instrumentarium das engmaschigste Netz knüpft. Janions Kobiety $i$ duch inności entzieht sich einer gesamthaften Beurteilung größtenteils und weist in sich die deutlichsten Brüche auf, die von keiner durchgehenden `Erzählstimme`zusammengehalten werden. Auch Iwasiów - die ich in den obigen Ausführungen vernachlässigt habe, im Gegenzug aber im Schlusswort unter ähnlichen Aspekten berücksichtige - manifestiert sich in ihrer Dissertation nicht als affektierte oder körperliche Instanz, trotz der anfänglichen Betonung ihrer `weiblichen< Lesart. ${ }^{270}$

Infolge der obigen Ausführungen kann man für das potentielle Projekt einer ıneuen Gemeinschaft، festhalten, dass es neben Ansätzen der positiven Inkludierung in den feministischen Texten der Polonistik auch etliche Stellen gibt, die bestimmte Weiblichkeiten ausschließen und so Widerstand hervorrufen können. Vorwiegend wird - von Borkowska, Kraskowska und Kłosińska - die weibliche Gemeinschaft eingegrenzt und abgesteckt. Die Polonistinnen fungieren dabei als Schaltstellen der >richtigen urteilung anhand literarischer Ausarbeitung. Wie das Beispiel Borkowskas zeigt, finden dabei auch Prozesse der gewaltvollen Überschreibung von Weiblichkeiten statt, die das konventionelle Weiblichkeitsbild der empathischen, somatischen und auf den privaten Bereich konzentrierten Frau nicht erfüllen (wollen). Auf der textuellen Ebene wirkt sich dies in affektiven Verfahren aus, die die Leserin auf diese eng definierte Weiblichkeit sstimmen`. Wieweit dabei Widerstände gegen solche textuellen Verfahren vor allem aus einer distanzierten und retrospektiven Lektüre wie der meinigen (siehe Einleitung) zustande kommen, lässt sich aus den Texten allein nicht beantworten. Fest steht jedoch, dass die Ideologeme der feministischen Kritikerinnen bestimmte Ausschlussverfahren in den Text einbauen, die man begrüßen oder auch ablehnen kann. Die Integrierung in die textuelle 
Gemeinschaft kann so nur unter bestimmten Vorzeichen der Einwilligung geschehen. Dies trifft auch für die Lektüre der Arbeiten Janions zu, deren Gemeinschaftskonstruktionen sich allerdings weniger über feste Definitionsrahmen des (weiblichen) Geschlechts bilden als über die Einwilligung, Kategorien und Definitionen zu hinterfragen und so auch in der eigenen Weltsicht zu destabilisieren.

Die feministische Kritik der polnischen 1990er Jahre zeigt sich aufgrund der hier untersuchten fünf Monographien als eine disparate. Dies lässt sich auf unterschiedliche Anbindungen und Inspirationen aus der transnationalen feministischen Kritik zurückführen und hat auch mit den jeweils untersuchten literarischen Texten zu tun. Gerade hier muss aber festgestellt werden, dass die feministischen Kritikerinnen gegenüber den analysierten Texten ambivalente Haltungen einnehmen, was wiederum als Effekt bestimmter Vorannahmen gelesen werden muss. Diese Vorannahmen, die an die Texte herangetragen werden, betreffen zumeist die Frage nach der Weiblichkeit, die oft als Set bestimmter Eigenschaften verstanden wird und so eine spezifische weibliche Identität und Erfahrungswelt konstruiert. Hinzu kommt, dass die Kritikerinnen mit wenigen Ausnahmen keinen Bezug zu den Arbeiten der jeweils anderen feministischen Polonistinnen herstellen, womit auch hier von einer Art >Atomisierung und somit einer schwachen Grundlage für eine feministische Gemeinschaftsbildung gesprochen werden kann. Das Projekt feministischer Kritik der 1990er Jahre erscheint so eher als eine jeweils individuelle Inszenierung des eigenen Ideologems, das sich durch die postsozialistische Öffnung im gesellschaftlichen wie wissenschaftlichen Bereich neu verortet. 



\section{Schlusswort}

In der vorliegenden Arbeit habe ich die feministische Kritik in der Polonistik der 1990er Jahre anhand von fünf Monographien untersucht. Dabei lag mir daran, die Texte als intertextuelles Geflecht in ihren Anbindungen an transnationale Theorieströmungen, die polnische Literatur(geschichte) und den lokalen sozialen und historischen Diskurs zu verstehen. Ich interpretierte die Monographien als (Er)Zeugnisse ihrer Zeit und als Beitrag zu einer postsozialistischen Gesellschaft und Wissenschaft, weshalb ich besonders auch die Diskursbildung rund um das Jahr 1989 mit berücksichtigt habe. Mithilfe der drei in der Einleitung genannten methodologischen Orientierungsrahmen der Intertextualität, der Intonation und des Ideologems möchte ich nun die wichtigsten Einsichten der Textanalyse auf den Punkt bringen. Dabei stelle ich gewisse verallgemeinerbare Tendenzen in den Vordergrund, wo mir dies sinnvoll und vertretbar erscheint. Abschließend rekapituliere ich zentrale Dynamiken der polnischen postsozialistischen Gesellschaft anhand von einigen Textbeispielen, die den Blick auf das 21. Jahrhundert öffnen und so die Konsequenzen der Weichenstellungen der feministischen Kritik aufzeigen.

Bei diesen letzten Textbeispielen handelt es sich wie in der gesamten Arbeit um eine motivierte, aber gleichsam persönliche wie materialgeleitete Auswahl. Wohl konnte ich in den Monographien der 1990er Jahre zum Teil Ansätze feststellen, die sich in mehreren Arbeiten oder mit Vorbehalten sogar bei allen fünf Kritikerinnen wiederfinden ließen. Bei einzelnen Texten bin ich jedoch analytischen Stoßrichtungen gefolgt, die mir bei anderen als wenig sinnvoll erschienen. Dies resultierte in einer unterschiedlichen Gewichtung der einzelnen Monographien oder bestimmter Textpassagen in den jeweiligen Kapiteln und Unterkapiteln. Gewisse Argumentationsstrategien ließen sich gegenüberstellen oder parallelisieren, aber eine konsequente Kategorisierung nach einzelnen Merkmalen erschien mir in Anbetracht der in vielerlei Hinsicht unterschiedlichen Texte nicht grundsätzlich angebracht.

Das in der vorliegenden Arbeit vorgestellte `Narrativ beruht zu großen Teilen auf meiner Sichtweise, aufgrund derer mir bestimmte Anhaltspunkte auffielen oder sich spezifische Lesarten aufdrängten. In gewisser Weise verhält sich meine 
Analysepraxis wie Zygmunt Baumans »Schwarm«: Bei Bedarf ballten sich die Texte zusammen, standen in einer flüchtigen Relation, um sich gleich darauf wieder $\mathrm{zu}$ verschieben, neu zu gruppieren oder auseinanderzustieben. ${ }^{1}$ Dieses Vorgehen ist, wenn man sich eines weiteren Bilds postmoderner Theorie bedienen will, auch der rhizomatischen Verstrickung des untersuchten Diskursfelds geschuldet, dem ich mich untergeordnet habe. Damit hoffe ich der jeweiligen Spezifik der untersuchten Texte gerecht geworden zu sein.

\subsection{Positionierungen feministischer Kritik der 1990er Jahre}

Das vielleicht zentralste Konzept meiner Arbeit ist jenes der Intertextualität. Es bildete das `Netz`, mit dem ich die von mir untersuchten Texte mit ihrem literarischen, theoretischen und soziopolitischen Kontext verknüpfen konnte. Es ermöglichte die Erkenntnis, dass sich die feministische Kritik in den 1990er Jahren nicht in einem luftleeren Raum ansiedelte, sondern etwa die polnische sweiblicher Literatur als Teil der feministischen Anbindung beizog und diese auf Weiblichkeitskonzepte oder die Relation der Geschlechter in der Gesellschaft befragte. Transferbewegungen fanden synchron und diachron wie auch transnational und lokal statt und können nicht allein als Übernahme westlicher Konzepte verstanden werden. Die Verortung im gesellschaftlichen Kontext der postsozialistischen Umformungen hingegen fällt bei den einzelnen Arbeiten der feministischen Kritik unterschiedlich aus. Die Positionierungen gegenüber der Retraditionalisierung und Verbürgerlichung der Geschlechterrollen reichen von explizit kritisch bis implizit befürwortend; bei der Untersuchung nicht-zeitgenössischer Literatur wird der aktuelle geschlechterpolitische Kontext jedoch meist weitgehend ausgeblendet und nurmehr implizit im Text angelegt.

Dass sich die feministische Kritik in der Polonistik oder den Literaturwissenschaften allgemein erst ab den 1990er Jahren herausbildete, während die Kategorie des Geschlechts beispielsweise in der Soziologie bereits in der Volksrepublik immer wieder (und unterschiedlich kritisch) thematisiert wurde ${ }^{2}$ kann im Kontext der Verhandlung einer neuen polnischen Identität nach 1989 gesehen werden. Das Interesse am historischen `Polentum dessen unerforschten oder verdrängten Rändern verstärkte sich in den 1990er Jahren. Dies gilt auch für die Rekonstruktion einer polnischen Weiblichkeit, die sich von der angeblichen sozialistischen `Neutralisierung absetzen sollte und deshalb vorwiegend die Vorkriegszeit als Referenzpunkt setzte. In den feministischen Texten der 1990er Jahre lassen sich Versuche erkennen, eine marginalisierte matrili-

1 I Vgl. Bauman, Zygmunt: Gemeinschaften. Auf der Suche nach Sicherheit in einer bedrohlichen Welt, Frankfurt a/M. 2009, S. 15.

2 I Vgl. Czerwiński: Przemiany obyczaju; Domański: Zadowolony niewolnik; Sokołowska: The Woman Image. 
neare Tradierung der $>$ Weiblichkeit $\triangleleft$ über die Literatur zu (re)konstruieren, womit der literarische Diskurs der Vorkriegszeit mit der postsozialistischen Situation verknüpft wird.

Die - zwar bescheidenen - Ansätze der Geschlechterforschung und des Geschlechterdiskurses in der PRL blendet die feministische Polonistik vorwiegend aus. Hingegen haben meine Nachforschungen zur sozialistischen Epoche ergeben, dass die Tendenz zur Privatisierung, Depolitisierung und Retraditionalisierung der Geschlechterrollen bereits in der Volksrepublik einsetzte und so für die Entwicklung der Transformation richtungsweisend wurde. Ein Zusammendenken der 1990er Jahre mit den vorausgehenden Jahren erscheint mir deshalb für das Verständnis feministischer Entwicklungen als unumgänglich. Dies habe ich am Beispiel Janions zu zeigen versucht, deren Forschung eine ‘feministischer Konstante mit einer Zuspitzung in den 1990er Jahren aufweist. Ihre Ansätze erscheinen zugleich weniger normativ als diejenigen einiger ihrer jüngeren Kolleginnen und sind auch für eine differenzierte und intersektionelle Gesellschaftskritik immer noch prägend.

Die Auseinandersetzung mit der direkten (auch wissenschaftlichen) Vergangenheit wird in der Mehrzahl der untersuchten feministischen Texte verdrängt, indem stattdessen eine Anbindung an eine internationale feministische Theoriebildung stattfindet. $\mathrm{Zu}$ beobachten ist insgesamt eine relativ breite Rezeption, bei der vor allem Showalter, Miller, Irigaray sowie Gilbert und Gubar mehrfach genannt werden; Cixous ist primär durch ihr Konzept der écriture féminine vertreten. Auffallend ist, dass sich die Polonistinnen vorwiegend an jenen Ansätzen orientieren, die in der Regel der Zweiten Welle westlicher Feminismen zugerechnet werden und bereits ab den 1980er Jahren zunehmend für ihre zum Teil essentialistischen und hegemonialen Geschlechtervorstellungen kritisiert werden. An diesem theoretischen Hintergrund zeigt sich das Bedürfnis der polnischen feministischen Kritikerinnen, eine Weiblichkeit zu (re)konstruieren, wobei deren kritische Dekonstruktion als bereits überwunden oder als für den polnischen Kontext hinderlich betrachtet wird.

In dieser theoretisch-intertextuellen Anbindung weichen Janion und Iwasiów in ihren Arbeiten vom Miteinbezug westlicher feministischer Kritik ab. Obwohl auch in ihren Texten vereinzelte Hinweise auf feministische Theorien zu finden sind, kann bei ihnen eher von einer Parallelentwicklung des eigenen sfeministischen Standpunkts gesprochen werden. Für Janion gilt dies seit den 1970er Jahren, womit hier eine historische Parallele festzustellen ist. Iwasiów unternimmt den Akt einer verdichteten Parallelentwicklung in ihrer Dissertation, wobei das feministische Element nahe am strukturalistischen und poststrukturalistischen Theoriefeld bleibt. Der intertextuelle Bezug ist bei beiden Polonistinnen geprägt von einer metaphorischen Ähnlichkeit der herausgearbeiteten Standpunkte mit vergleichbaren Ansätzen der westlichen feministischen Kritik. Besonders eindrucksvoll zeigt sich dies an Janions Interesse an der Intersektion von Geschlecht und psychopathologischen Ausgrenzungen. 
Mit dem Konzept der Intonation als methodologischem Orientierungsrahmen habe ich versucht, die Frage nach der Subjektivität des Schreibens/Lesens nicht aus dem analytischen Blick zu verlieren. Die Intonation sollte helfen, innerhalb eines intertextuellen Bezugsnetzes die Spezifika der untersuchten Texte zu ergründen und dabei auch die Transposition analytisch zu berücksichtigen, die im Prozess der Lektüre stattfindet. Die Frage nach der Intonation bezieht sich somit zu großen Teilen auf die Beziehung, die sich zwischen schreibendem/lesendem Subjekt und Text etabliert. Einerseits sah ich die sfeministischen Polonistinnen als sprechende Instanzen in den Texten, die mitverantwortlich zeichnen für dessen Ideologem und die sich selbst teilweise als empathische, affektierte Einheiten in den Text einbringen. Andererseits interessierte mich die Intonation als affektiver Textmechanismus, der das lesende Subjekt im Lektüreprozess miteinbezieht.

Das Konzept der Intonation führte mich stärker auf die poetologischen Aspekte der untersuchten Texte hin und zu Mikroanalysen bestimmter Textpassagen. Dies erlaubte mir, in der Analyse jene Elemente des Texts hervorzuheben, die als Ein- oder Abgrenzungsmechanismen aktiv werden können. Für die feministische Kritik sind solche Mechanismen insofern besonders relevant, als sie versucht, ein weibliches Bewusstsein für vergeschlechtlichte Ungleichheiten in der Gesellschaft zu schaffen und so eine zumindest virtuelle Gruppenbildung der Frauen über den literarischen und wissenschaftlichen Text zu erreichen. Dies zieht jedoch je nach textuellem Ideologem oder methodischer Engführung auch bestimmte Ausschlüsse sowohl gegenüber dem untersuchten Material wie auch potentiellen Lesern und Leserinnen nach sich.

Die Intonation hat aber auch damit zu tun, wie sich die Stimme der Schreibenden des wissenschaftlichen Texts zu denjenigen der untersuchten Literatur verhält. Hierbei lassen sich wiederum sehr unterschiedliche Intonationsstile feststellen. So gibt es einerseits ein eher dialogisches Modell, bei dem sich die Stimmen überlagern und die `Erzählstimme` des wissenschaftlichen Texts nicht (immer) als distinkte hervortritt - wie etwa bei Kłosińskas Überlagerung mit `Zapolska` und bei Janion als polyphone Multiplizierung. Borkowska, Kraskowska und Iwasiów stützen sich dagegen stärker auf ein monologisches Modell, in dem ihre Stimmen deutlicher hervortreten und die Narration offen bestimmen. ${ }^{3}$ Dennoch sind auch die hier zusammen gruppierten Texte intonativ nicht gleichzusetzen. Iwasiów beispielsweise radiert >Odojewski< fast vollständig aus und ersetzt den `Schreiber als Instanz durch die Rekonstruktion von durch den Text dringenden Archetypen. Radikal entgegengesetzt ist dem der psychologisierende Ansatz Borkowskas, der sich für die Texte primär als Ausdruck der Psyche der im Zentrum stehenden

3 I Ich stütze mich hier auf die Herausarbeitung des Dialogischen und Monologischen durch Kristeva: Sèméiotikè, S. 158-171. Die Begriffssetzung soll hier vor allem als Vereinfachung gelten; eine detaillierte Beschreibung der feministischen Texte nach monologischem resp. dialogischem Prinzip habe ich jedoch unterlassen. 
Schriftstellerinnen interessiert. Dies führt zu einem innertextuellen Ringen der Ideologeme, als Borkowska ihre Subjektivität den untersuchten Texten überwirft. Kraskowskas Text wiederum, der ebenfalls ein dominantes Ideologem aufweist, wahrt zu den Schriftstellerinnen größtenteils eine `wissenschaftliche` Distanz, die nur punktuell durch Verfahren des metaphorischen Schlagabtauschs durchbrochen wird.

Diese unterschiedlichen Intonationen sind es auch - neben den unterschiedlichen Ideologemen -, die die feministischen Arbeiten der Polonistik als Einzelarbeiten herausstellen. Trotz Rhetoriken einer weiblichen Gemeinschaft zeigen sich starke Tendenzen einer Individualisierung und zum Teil exklusiven Aneignung feministischer Narrative. Die Texte treten untereinander kaum in Dialog, auch wenn sie sich in gewissen Aspekten überschneiden. Dies hat nicht nur damit zu tun, dass sie nominell wenig Bezug aufeinander nehmen. Die Texte scheinen teilweise darauf bedacht, ihre narrative Machtposition zu bewahren und die wissenschaftliche Souveränität als individuellen Akt zu konstruieren, statt die Wissensproduktion und -hinterfragung einer inkludierenden feministischen Perspektive zu überantworten. Hierzu muss allerdings angefügt werden, dass letzteres vielleicht ein ohnehin utopisches Unterfangen darstellt, ${ }^{4}$ und die in den feministischen Texten konstruierte Subjektivität als Akt der weiblichen `Stimmnahme` verstanden werden kann.

Mit der Untersuchung der Ideologeme der feministischen Arbeiten als implizit greifbare Position und Verortung im intertextuellen Zusammenhang ließen sich deren Differenzen in Bezug auf ihre Positionierung als >feministische Gemeinsam ist den Arbeiten die Überzeugung, dass das `Weibliche in der Gesellschaft einer spezifischen Überformung unterliegt, wobei diese als repressiv und im Verhältnis zum >Männlichen ‘ als untergeordnet verstanden wird. Unterschiede zeigen sich jedoch bereits in der Frage, ob eine `weibliche` Identität als solche konsolidiert oder hinterfragt werden sollte. Arbeiten wie jene Janions oder Kłosińskas weisen darauf hin, dass >Weiblichkeit` primär als Produkt des herrschenden patriarchalen Systems zu verstehen und eine darüber hinausgehende Bestimmung des >Weiblichen im Prinzip unmöglich sei. Dahingegen sehen die Texte Kraskowskas und Borkowskas die >Weiblichkeit` in relativ klar umrissenen Grenzen, die sie performativ nachziehen und verstärken.

Im Zusammenhang damit stellt sich die Frage, inwiefern die Kategorie des Geschlechts als politische zu formulieren sei. Die Antworten der einzelnen feministischen Monographien können vor dem Hintergrund des Narrativs der >Depolitisierung gelesen werden, das den soziopolitischen Diskurs der 1990er Jahre mitbestimmte. Die ,feministischen • Positionen reichen hier von einer impliziten Übernahme depolitisierender Forderungen und einer identitären Einschreibung

4 । Vgl. aber die Erwähnung Borkowskas der »Kunst als Kontaktraum« (Borkowska: Cudzoziemki, S. 16: "sztuka jako przestrzeń kontaktu«) sowie Janions Verweis auf eine »geistige Kollegialität«« unter Frauen (Janion: Kobiety, S. 259: »koleżeństwa umysłowego«). 
des Weiblichen in das Private, Intime und Apolitische, bis hin zu teilweise scharfer Kritik an politikfeindlichen postsozialistischen Gesellschaftsdynamiken.

Insgesamt ist der Versuch zu beobachten, Frauen aus einer sozial-utilitaristischen Rahmung zu befreien; gleichzeitig will die feministische Kritik sich nicht als rideologische $<$ verstehen oder verweist alternativ darauf, dass auch das patriarchale System trotz vordergründiger `Natürlichkeit eine zutiefst ideologische Struktur sei. Während also beispielsweise Iwasiów darauf aufmerksam macht, dass die Wissenschaft stets auf axiologischen Annahmen beruhe, versucht Kraskowska im Gegenteil die feministische Kritik als `reine etablieren. Zudem fällt auf, dass gerade die beiden sspätesten` Arbeiten die Frage nach dem lokalen Zusammenhang am deutlichsten aus ihrem Narrativ drängen und mit der »Weiblichkeit» (Kraskowska) und dem »Patriarchat" (Kłosińska) als zentrale Begriffe mit einem universalisierenden Vokabular operieren.

Das Paradox der feministischen Kritik der 1990er Jahre liegt in einer impliziten Politisierung der Geschlechterfrage bei gleichzeitiger Absage an das Politische, in der versuchten Gemeinschaftsbildung unter Frauen bei gleichzeitigem Fokus auf das Individuelle und in der geschlechtlichen Essentialisierung bei gleichzeitiger Dekonstruktion (neo)traditioneller Geschlechterrollen. Diese sich zuwiderlaufenden Tendenzen, die sich zwischen den einzelnen Arbeiten, aber auch innerhalb derselben manifestieren, erwirken sschizoide Positionen des Dazwischen in der feministischen Verortung und Argumentation, die sich auf einen von widersprüchlichen Narrativen geprägten gesellschaftlichen Diskurs zurückführen lassen. Darauf möchte ich nun abschließend und vorausblickend eingehen.

\subsection{Von Spalten zu Spaltungen. Ausblick auf das 21. Jahrhundert}

Mit der Ablösung vom sozialistischen System verschiebt sich das Verhältnis von Individuum und Gesamtgesellschaft. Verstärkt auftretende Probleme sozialer Art wie das Abrutschen in Arbeitslosigkeit und Armut oder die stärkere Auffächerung in soziale Schichten bilden kein Kernpolitikum der Dritten Polnischen Republik. Das Abwälzen der Verantwortung auf die/den Einzelne/n im Zug neoliberaler Umformung kann als gesellschaftliche Liberalisierung und insbesondere als Bestreben der `Entkommunisierung`gelesen werden, das Klassenrhetoriken und Argumente für eine soziale Gerechtigkeit vermeidet. Das Ressentiment ${ }^{5}$ gegen den sozialistischen Kollektivismus und die Betonung der >Befreiung` des Individuums vom Joch des `Gemeinwohls« steht einerseits im Kontext des Begehrens einer Gesellschaft im Wandel, die den Anschluss an (neo)liberale und postindustriel-

5 | Vgl. Scheler, Max: Das Ressentiment im Aufbau der Moralen (= Klostermann Texte: Philosophie), Frankfurt a/M. 1978, S. 5-9; Szacki: Liberalizm po komunizmie, S. 91f. Siehe auch Jameson: The Political Unconscious, S. 200-205, der ebenfalls mit dem Ressentiment-Begriff arbeitet. 
le Gesellschaften im `Westen sucht. Der Druck westlicher Politiken zu radikaler Liberalisierung besonders im ökonomischen Bereich verstärkt den Fokus auf individuelle Selbstbestimmung und Unabhängigkeit noch. Andererseits weist das antikollektivistische Ressentiment seinerseits kollektive Züge auf. Szacki spricht hier gar von einem "kollektivistischen Individualismus « (kolektywistyczny indywidualizm), der sich mit dem oppositionellen Diskurs der 1980er Jahre herausbildete: die "Manifestation der Autonomie des Individuums« sei mit dem Willen einhergegangen, "an der Gemeinschaft teilzunehmen « und »so zu sein wie andere, die sich dem Diktat [des Staats] nicht unterordneten. ${ }^{6}$ In den dissidenten Kreisen der 1980er Jahre habe damit ein normativer Druck zur Anpassung an die oppositionellen Verhaltensweisen geherrscht. Der Gemeinschaftscharakter beruhte zugleich auf einer Exklusivität, welche zum einen die spolnischen Werte von Katholizismus und einer antikommunistischen Haltung betraf und zum anderen historisch durch den konspirativen, auf persönlichen Beziehungen beruhenden Charakter der Foren der Opposition bestimmt wurde, die Prozesse der Elitarisierung und Privatisierung ausgelöst hatten. ${ }^{7}$

Damit finden sich die 1990er Jahre im Spannungsfeld von Individualisierungsdruck und einem diesem zuwiderlaufenden Gemeinschaftsnarrativ, ${ }^{8}$ was zu einer Spaltung von sozialer Realität und gesellschaftlicher Erzählung führte. Der Wegfall sozialistischer Politik und Wirtschaftsführung zog de facto die Privatisierung ökonomischer und sozialer Probleme nach sich, und der Transformationsdiskurs propagierte die selbstbestimmte, fortschrittsmotivierte Individualgesellschaft. Das Narrativ der 'polnischen Werter suggerierte demgegenüber einen sozialen Zusammenhalt, der das Auseinanderdriften von Individuen und sozialen Klassen verhüllte, und bot insbesondere denjenigen, die zunehmend zu einem wirtschaftlich abfallenden »Polen B « wurden, den ideologischen Strohhalm der moralischen Integrität und Überlegenheit gegenüber dem dekadenten "Polen A«, den urbanen, gebildeten und ökonomisch erfolgreichen Schichten. ${ }^{9}$ Für die tatsächlichen Schwierigkeiten, Unzufriedenheiten und Fehlschläge blieb im neoliberal-progressiven wie auch im konservativ-patriotischen Narrativ wenig Platz: Im Fokus stand die Neuausrichtung der Zuschreibungen von "wir und sie«.

Die Aufwertung der Familie im Zuge der Demokratisierung Polens ist unumstritten und kann ebenfalls als Effekt verstärkter Individualisierung und Privatisierung gesehen werden. Die Charakteristika von Familie und Privatsphäre werden jedoch unterschiedlich definiert. Aus katholisch-konservativer Sicht stellt die Familie das natürliche und in seiner geschlechtlichen Rollenaufteilung genau definierte Fundament der Gesellschaft dar. Die Privatsphäre bildet so einen Teil

6। Szacki: Liberalizm po komunizmie, S. 105.

7 I Vgl. Świda-Ziemba: Człowiek wewnętrznie zniewolony, S. $356 f$.

8 I Vgl. Owczarski, Wojciech: »Poradnik dla Czytelnika«, in: ders., Colloquia gdańskie (2008), S. 5-10, hier S. 7.

9 । Vgl. Janion: Niesamowita słowiańszczyzna, S. 12. 
der übergeordneten Gesellschaftsstruktur und ist notwendig, um deren Stabilität zu garantieren - sie wird zu einer sozialen Pflicht. Liberale und auch emanzipatorische Ansichten vertreten hingegen ein eher freiheitliches Konzept, welches die Privatsphäre - Familie und Freizeit - als Feld der Unabhängigkeit und Selbstverwirklichung begreift. Hier lassen sich auch die feministischen Ideologeme einordnen, die ich in der vorliegenden Arbeit untersucht habe.

Das Interesse der feministischen Kritik an den skleinen Geschichten tet eine Zuwendung zum Partikularen, zum Individuellen, Intimen und Privaten - im Gegensatz zur ‘großen`, weltgeschichtlich als relevant diskursivierten >männlichen` Geschichte. Die Frage nach der Funktion der Privatsphäre in der Gesellschaft wird zugunsten einer Nutzenbetonung für das Individuum in den Hintergrund gedrängt. >Politische`Argumente werden weitgehend ausgeblendet, und die feministische Polonistik schweigt auch zum Thema Religion. ${ }^{10}$ Obwohl die Religion eine für die habituelle Ausgestaltung der polnischen Gesellschaft zentrale Rolle spielt, finden sich in den polonistischen feministischen Texten nur an einigen wenigen Stellen überhaupt Verweise auf eine Religiosität in der Gesellschaft. ${ }^{11}$ Der Fokus auf die individuelle weibliche Erfahrung lenkt die Aufmerksamkeit weg von der politischen Annektion der Frau als Mutter.

Diese Ausrichtung, die ein weibliches Empowerment in der Selbstaufwertung 'weiblicher Rollen sieht, kann im Zusammenhang mit der nahen Vergangenheit des Sozialismus gesehen werden. Aus der feministischen Perspektive der 1990er Jahre bestand die Diskriminierung der Frauen im Sozialismus darin, dass das ,Weibliche` ausradiert und Frauen in eine sa-geschlechtliche` Rolle gedrängt worden waren. Die Betonung der "Neuen Weiblichkeit« in der postsozialistischen Zeit kann als ein Prozess der Verbürgerlichung der Gesellschaft gesehen werden, der die vergeschlechtlichten Sphären reetabliert. Hier werden transnationale Verschiebungen besonders offensichtlich, als sich etwa die US-amerikanische feministische Stoßrichtung um 1970 mit dem Slogan the private is political deutlich von derjenigen im polnischen postsozialistischen Kontext unterscheidet. Solche Inkongruenzen bei gleichzeitiger argumentativer Anbindung befördern eine innere Spannung feministischer Rhetoriken, was die Atomisierung der als Gemeinschaft intendierten polnischen Frauen durch fehlende soziale Zusammenhänge oder gemeinsame Anliegen weiter vorantreibt.

Ich möchte nun an einem Beispiel nachvollziehen, inwiefern die Divergenzen der polnischen Gesellschaft die paradoxe Situation feministischer Kritik in Polen

10 I Anders als der politische Feminismus, der auf die Relevanz der katholischen Kirche in der Retraditionalisierung der Geschlechterrollen verweist und diese damit auch kritisiert. Vgl. bspw. Fuszara: Feminizm i my, S. 20; Środa: Kobieta. Siehe auch Korbonski: Poland ten years after sowie Mishtal: How the Church.

11 I Etwa in Kraskowskas Heilsterminologie am Beispiel der Sabina aus Całe życie Sabiny, oder bei Kłosińskas Verweis auf die >Heiligsprechung der außerehelichen Schwangerschaft durch Zapolska in Kaśka Kariatyda. Vgl. Kraskowska: Piórem niewieścim, S. 98; Kłosińska: Ciało, S. 76. 
deutlich machen. Ich ziehe hierzu einen Ausschnitt aus Iwasióws Gender dla średnio zaawansowanych bei, in dem die intertextuellen Bezüge von feministischer Theorie und polnisch-lokalem sozialem Kontext gegeneinander ausgespielt werden. Deutlich wird dabei Iwasióws Bewusstsein, dass in der polnischen feministischen Debatte eine Verknotung verschiedener Zeitlichkeiten stattfindet und diese zu einer paradoxen Positionierung führt.

»Uns, den Frauen der neuen Welt, sollte an einer Öffnung der Gesellschaft liegen. Wir müssen keine Selbsthilfegruppe gründen und in deren Rahmen unsere Körper lernen. [...] Seht ihr? Nein? Die Welt vor dem Fenster weiß noch nicht, dass Weiblichkeit etwas anderes ist, als Mahlzeiten zuzubereiten? Ich weiß es nicht. Vielleicht gelingt es uns, mehrere Hindernisse auf einmal zu überwinden. Wir haben die anderswo ausgearbeitete Theorie und unsere Wirklichkeit, die nicht allzu euphorisch stimmt. « ${ }^{12}$

Iwasiów verweist darauf, dass identitäre Bestrebungen des Feminismus bereits überwunden seien und sich die zeitgenössische feministische Ausrichtung auf Dekonstruktionen stütze. Gleichzeitig inszeniert sie ein Abprallen insbesondere der postfeministischen Theorien an der Realität, wie sie den Frauen in Polen entgegentrete.

Iwasiów verwendet in ihrer Narration ein Ein- und Ausschlussverfahren, um die polnische gesellschaftliche Realität zu konzipieren. Sie schafft eine Gemeinschaft feministisch interessierter Leserinnen/Zuhörerinnen, denen sie ihre Inhalte vermittelt. Diese Gemeinschaft verortet sie räumlich in der polnischen Gesellschaft, die über den Körper und soziale Normen auf das weibliche Subjekt repressiven Einfluss nimmt. Mit dem Konflikt zwischen weiblichem Subjekt und den gesellschaftlichen Normen und Anforderungen an dieses inszeniert Iwasiów eine Abgrenzung und Spaltung zwischen sozialer Realität und ideeller Selbstdefinition des feministischen Subjekts: Zwischen körperlicher und ideeller Verortung tut sich eine Spalte auf. ${ }^{13}$ Gleichzeitig lassen sich diese Normen der polnischen Gesellschaft vorerst nur auf einer virtuellen Ebene, über den ideellen Anschluss an die globale feministische Theorie, umgehen.

Doch auch hier zeigt sich eine Spaltung, die durch die Verortung im lokalen sozialen Kontext bedingt ist und zwischen feministischem Projekt in Polen und feministischer Theorie im Allgemeinen stattfindet. Mit dem Verweis auf die soziale Realität stellt Iwasiów nämlich fest, dass die feministischen Ansätze für Polen ızu

12। Iwasiów: Gender, S. 82: „Nam, kobietom nowego świata, powinno zależeć na otwarciu społeczeństwa, nie musimy więc tworzyć grup wsparcia i uczyć się w ich ramach swoich ciał. [...] Widzicie? Nie? Świat za oknem jeszcze nie wie, że kobiecość to coś innego od przygotowywania posiłków? Nie wiem. Może uda nam się przeskoczyć przez kilka przeszkód naraz, mamy wypracowaną gdzie indziej teorię i naszą, nienastrającą zbyt ekstatycznie, rzeczywistość."

13 I Vgl. auch Łebkowska: Kobieta czytająca, S. 187 zum »literaturwissenschaftlichen Dilemma zwischen Skepsis und Faszination gegenüber dem Neuen, zwischen Zweifel und Öffnung «, das sie für die feministische Kritik in Polen feststellt. 
fortschrittlich seien; die Anbindung an den raktuellen` Theoriestand wird durch die vorgefundene Realität vereitelt, eine Synchronisierung erscheint unmöglich. Iwasiów entwirft eine Lage der feministischen Kritik in Polen, die suggeriert, man müsste eigentlich schon längst >dort` sein, stecke aber noch mitten im >hier . Statt der neueren Ansätze des Queering und performativer Geschlechtssubversion erscheint `hier eher eine Identitätspolitik und ein Feminismus der Differenz vonnöten. ${ }^{14}$ Die Parallelität und Verknotung von Hier und Dort und das Bedürfnis nach der Gleichzeitigkeit beider Strategien löst bei Iwasiów eine Art Lähmung aus, ${ }^{15}$ die sich primär in der Formulierung "an die Arbeit, liebe Frauen ${ }^{16}$ erschöpft.

Damit geraten feministische Überlegungen in Polen in einen schizoiden $\mathrm{Zu}$ stand $^{17}$ der gleichzeitigen Ungleichzeitigkeit und der Abspaltung epistemischer Ebenen, der, so suggeriert Iwasióws Auslassung des sozialen Kontextes in den westlichen Gesellschaften, ‘anderswo « nicht existiert. Die feministischen Kritikerinnen finden sich so in einem Dazwischen, das als Effekt des Auseinanderdriftens globaler Theorieansätze und Gesellschaftsentwürfe einerseits und dem Versuch, nationale Spezifika zu bewahren und durch normative Festschreibung gegen Außen abzugrenzen, andererseits gesehen werden muss. Indem das Textbeispiel die Inkongruenz von postfeministischen Ansätzen und sozialer Realität nur für den polnischen Kontext erwähnt, erweckt es den Eindruck, westliche Gesellschaften würden nurmehr fließende Geschlechtsperformanzen hervorbringen, womit die Kategorie des Geschlechts >dort ‘ gar keine soziale Rolle mehr spiele.

Mit dieser impliziten Utopisierung des `Dorts` spielt Iwasiów gleichzeitig einer kulturkritischen und antifeministischen Auslegung in die Hände: Es ist genau dieses Bild einer geschlechtlich entgrenzten Gesellschaft, das die katholische Kirche als Schreckgespenst der »Gender-Ideologie« inszeniert. Das dekonstruktive Element der Gender Studies, das auf die Hinterfragung kultureller (und biologischer) Geschlechtsidentitäten als feste Einheiten zielt, bildet die Grundlage für den katholischen Angriff auf die »Gender-Ideologie ${ }^{18}$ Die Umdeutung von Begrifflichkeiten, die die Anti-Gender-Kampagne der 2010er Jahre vornimmt, ${ }^{19}$ hat jedoch

14 I Iwasiów verweist für letztere auf Eve Kosofsky Sedgwick, Adrienne Rich und Butler, vgl. Sedgwick, Eve Kosofsky: Epistemology of the Closet, Berkeley 1990; Rich, Adrienne: „Compulsory Heterosexuality and Lesbian Existence«, in: Signs 5/4 (1980), S. 631-660; Butler: Gender Trouble. 15 I Janion meint zu den neuen Herausforderungen der Geisteswissenschaften nach 1989: "[W]ir stehen innen völlig hilflos, kraftlos und ratlos gegenüber«. Janion: Morze zjawisk, S. $115 f$.

16 I Iwasiów: Gender, S. 82: »do pracy, drogie panie«.

17 I Iwasiów operiert in ihrer Dissertation an einem anderen Beispiel mit dem Begriff der Schizophrenie(nähe), der die »emotionale Kondition des Protagonisten « beschreibt, welcher »von Imagination und Wirklichkeit gleichzeitig lebt«. Iwasiów: Kresy, S. 79: »Kondycja emocjonalna tegoż bohatera bliska jest schizofrenii: żyje on przecież w imaginacji i rzeczywistości zarazem [...]."

18 । Siehe bspw. Oko: Gender, S. 40.

19 | Vgl. allgemein den Band Gender. Przewodnik Krytyki Politycznej (Gender. Handbuch Krytyka Polityczna, 2014) zur Kontextualisierung der Gender Studies und der »Attacke auf die >Gen- 
wenig mit den tatsächlichen Ansätzen der Gender Studies zu tun. Es handelt sich dabei um gezieltes und bedeutungsverschiebendes Misreading, das umso griffiger wird, als Gendertheorien komplex sind und mit einem gewissen Grad von Abstraktion arbeiten. Dahingegen bieten konservative Misreadings plastischere Auslegungen, wie sie für den Populismus gängig sind. ${ }^{20}$ Ein extremes Beispiel hierfür ist die Verschiebung des Begriffs Gender von der Bezeichnung der Kategorie des sozialen Geschlechts (die ohnehin nicht akzeptiert wird) über die Benennung einer ideologischen Haltung hin zu einer Personifizierung des »Genders", das als Schreckgespenst die Bevölkerung heimsuche. ${ }^{21}$

Für solche Misreadings können die Leerstellen fruchtbar gemacht werden, die sich in geschlechtsanalytischen Texten unweigerlich auffinden lassen. Als Beispiel dafür kann die oben angeführte Auslassung Iwasióws in Bezug auf den westlichen Gesellschaftskontext dienen, was ungehinderte Projektionen auf diesen ermöglicht. Als weiteres Beispiel möchte ich hier auf die "geheimen Zeichen« eingehen, auf die Ritz 1997 in seinen gender-Lektüren aufmerksam macht. Gemäß Ritz zeigen die Gender Studies die Konstruiertheit des «männlichen (heterosexuellen) Diskurses «22 durch das Vorhalten des Andersseins weiblicher und homosexueller Diskurse auf. Die Kategorie gender sei eine »historische Kategorie, [...] auch auf der Ebene ihres literarischen Ausdrucks« und beziehe sich auf das »weibliche und homosexuelle Anderssein « gleichsam als "poetologische Kategorie « ${ }^{23}$. Die gender-Lektüre stellt als demzufolge zweifache Lektüre eine gewisse Herausforderung dar und richtet sich dabei auch "gezielt gegen den Text ${ }^{24}$, wie der Polonist erläutert. Dies zeigt sich besonders an Ritz' Untersuchung der »geheimen Zeichen im gender-Code«. Er erwähnt die »Rätselhaftigkeit« (enigmatyczność) dieser Zeichen, die eine »Form äsopischer Sprache ${ }^{25}$ seien. Diese entschlüsselt der Genderforscher und ıüberführt ‘ damit den Text in Bezug auf unwillentliche Spuren der Sublimierung. Er macht darauf aufmerksam, dass sich in der poetisch geformten

der-Ideologie der polnischen Kirchenhierarchen« (Graczyk, Ewa: »Tego się nie robi temu narodowi«, in: Gender. Przewodnik Krytyki Politycznej (= Przewodniki Krytyki Politycznej, Band 38), Warszawa 2014, S. 405-410, hier S. 408) in der polnischen Gesellschaft.

20 | Als hervorragendes Beispiel hierfür dient das katholisch-fundamentale Internetportal Fronda. pl, das immer wieder 'Schreckgeschichten ‘ aus dem Bereich von Identität, Geschlecht und Sexualität in schrillen Tönen aufbereitet.

21 । Was in den Medien mit der Darstellung des "Gender-Monsters « in Gestalt eines Yetis aufgegriffen wurde, der angeblich in der Nähe der westlichen Landesgrenze gesehen wurde. Vgl. Dziennik.pl Rozrywka, 31.12. 2013.

22 । Ritz: Niewypowiadalne pożądanie, S. 43: »dyskurs męski (heteroseksualny)«.

23 I Ebd., S. 44: »jest kategorią historyczną, [...] także na poziomie swego wyrazu literackiego«; »nność kobieca i homoseksualna«; »kategoria poetologiczna«.

24 । Ritz: Neue Welt, S. 272.

25 | Ritz: Niewypowiadalne pożądanie, S. 55: »tajnych znaków w kodzie gender«; »formą mowy ezopowej«. 
Sprache Verweise auf die heteronormative Machtstruktur und deren Subversion finden lassen, die »sich dem Bewusstsein des Erzählers [...] entziehen ${ }^{26}$.

Der Verweis auf die äsopische Sprache wird hier relevant; die gender-Lektüre kann nämlich ebenso als eine Art äsopische Sprache wahrgenommen werden, die sich erst für den/die entsprechend eingeweihte/n und informierte/n Leser/in entschlüsselt und nachvollziehbar wird. Ansonsten verbleibt der Einsatz der Kategorie gender als eine konzeptuelle Undurchdringlichkeit, als Leerstelle im wissenschaftlichen Text. Die gender-Lektüre kann so selbst zu einem enigmatischen Un-Heimlichen werden, das über die »Spalten " geheimer Zeichen in den Text und dessen >Psyche < eindringt. Dieses Bild ist es wohl, was bei einem auf die heteronormative Machterhaltung bedachten Publikum Unbehagen auslöst: Die (polnische) integre Identität erscheint von einer unwillentlichen, fremdkontrollierten Selbstentblößung bedroht. `Gender`, das sich als epistemologische Kategorie einem ontologischen Zugriff entzieht, muss deshalb `festgemacht`, ’gefasst $`$ werden, indem es sich in ein fast materiell greifbares `Etwas` mit ausländischem Namen verwandelt.

Mit den Beispielen von Iwasiów und Ritz will ich hier aufzeigen, wie konservative Misreadings von feministischen und gender-Texten Bedeutungen verschieben und durch Verkürzungen >Bedrohungen in einen Text oder einen Diskurs hineinkonstruieren können. Durch semantische Abspaltungen und eine vereinfachend-verdrehende Aneignung geschlechtertheoretischer Überlegungen können sich konservativ-fundamentalistische Kreise ganze rhetorische >Arsenale zusammenstellen, gegen deren Rhetorik es schwerfällt, aus einer differenzierteren Perspektive zu argumentieren. Die Argumentationen feministischer oder liberaler Positionen und die Rhetorik konservativer Haltungen zielen so völlig aneinander vorbei, dass hier nicht nur von antagonistischen Positionen, sondern gar von »divergierenden Realitäten " gesprochen werden muss. ${ }^{27}$

Zur Problematik divergierender Realitäten in einem schizoiden Diskursfeld möchte ich abschließend einige Überlegungen Janions beiziehen, die sich in Niesamowita słowiańszczyzna (Unheimliches Slaventum, 2006) über die polnische "postkoloniale Mentalität« äußert. Diese bestehe in einem »Gefühl der Ohnmacht [...], der Minderwertigkeit und Marginalität des Landes und seiner Erzählungen« gegenüber dem Westen. Diesem Gefühl werde »ein messianistischer Stolz in Gestalt der Narration von unseren besonderen Leiden und Verdiensten, von unserer Größe und Überlegenheit über den unmoralischen >Westen« « entgegengestellt. ${ }^{28}$

26 I Ebd.: »wymykających się świadomości narratora«. Spezifisch ist hier die aktive Formulierung: die Signale entziehen sich, leisten Widerstand, sgehorchen der textuellen Instanz nicht.

27 | Vgl. zum Begriff der divergierenden Rationalitäten Shweders: Divergent Rationalities; außerdem Mouffe, Chantal: Agonistik. Die Welt politisch denken, Berlin 2014, S. 12f. zu antagonistischen Positionen als ontologische Dimension des Politischen.

28 I Janion: Niesamowita słowiańszczyzna, S. 12: "poczuciu bezsilności [...], niższości i peryferyjności kraju oraz jego opowieści«; »mesjanistyczna duma w postaci narracji o naszych wyjąt- 
Der messianistische Diskurs, der sich in den über zehn Jahren seit dem Erscheinen von Janions Buch nur noch verstärkt hat, wirke sich als narrativer Teufelskreis lähmend auf die Imagination der polnischen Gesellschaft aus. Diese bleibe somit gefangen in der Position der Selbsterhöhung und gleichzeitigen Vorannahme der eigenen Minderwertigkeit, was wenig Spielraum für ein kreatives Ausloten von Freiräumen und abweichenden Lebensentwürfen lässt. »Die nationale Megalomanie«, schreibt Janion, „verunmöglicht die Distanznahme gegenüber sich selbst, behindert das Verzichten auf Herrschaftsansprüche und auf die Verachtung und Geringschätzung >Anderer $«{ }^{29}$

Im Kontext der postsozialistischen Öffnung bleibt die Frage nach dem Zweck und der Verortung des >Polentums` weitgehend unbeantwortet - umso stärker dienen die tradierten und wiederbelebten Muster allerdings zur Orientierung in einer zunehmend desorganisierten und liquiden Gesellschaft. ${ }^{30}$ Diese diskursive Schließung der Gesellschaft kann jedoch nicht, wie Janion bereits vor über zwanzig Jahren deutlich festhielt, »in einer Gesellschaft funktionieren, die zu einer demokratischen werden soll, das heißt zu einer differenzierten und dezentralisierten, die auch kulturell verschiedenste Bedürfnisse zeitigt. ${ }^{31}$ Das Problem liegt darin, dass sich die Demokratie in Polen nicht zu einer integrativen und dialogischen entwickelt hat, sondern die 1990er Jahre vielmehr als Ausgangspunkt sich vertiefender sozialer Spaltungen zu verstehen sind, die mit der Betonung einer seinheitlichen Kultur zu übertünchen versucht werden. ${ }^{32}$

Zu Beginn der 2010er Jahre machen sich diese Spaltungen wiederholt am Beispiel der Geschlechtsauffassung fest, wobei das Divergieren der Rationalitäten endgültig offensichtlich wird. Die Argumentationen des katholisch-konservativen Lagers und feministisch-queerer Bewegungen haben sich soweit voneinander entfremdet, dass sich ihre Bezugspunkte kaum mehr überschneiden. Diese

kowych cierpieniach i zasługach, o naszej wielkości i wyższości nad ’niemoralnym< Zachodem«. Deutsche Übersetzung angelehnt an Janion, Maria: Die Polen und ihre Vampire. Studien zur Kritik kultureller Phantasmen, Frankfurt a/M. 2014, S. 60.

29 । Janion: Niesamowita słowiańszczyzna, S. 329: »megalomanii narodowej [...] uniemożliwia zdobycie dystansu wobec siebie, przeszkadza w rezygnacji z pretensji do dominacji, z pogardy i lekceważenia sinnych «."

30 | Vgl. Janion, Maria: »Zmierzch paradygmatu«, in: dies., »Czy będziesz wiedział, co przeżyłeś« (= Stanowiska/Interpretacje, Band 1), Warszawa 1996, S. 5-23, hier S. 15; dies.: Morze zjawisk, S. 115f. Zur liquiden Gesellschaft vgl. Bauman, Zygmunt: Liquid Modernity, Cambridge 2000.

31 I Janion: Zmierzch paradygmatu, S. 15: »funkcjonować w społeczeństwie, które ma stać się demokratyczne, to znaczy zróżnicowane i zdecentralizowane, objawiające rozmaite potrzeby, również kulturalne."

32 I Vgl. auch die Überlegungen Bhabhas zum »inner split“ einer Nation: »the subject of cultural discourse - the agency of a people - is split in the discursive ambivalence that emerges in the contest of narrative authority between the pedagogical and the performative." Bhabha: Location of Culture, S. 148. 
grundlegende Divergenz der Denk- und Argumentationsmuster führt dazu, dass die Aussagen der Gegenseite nurmehr als Absurdum verstanden werden können oder vollkommen unlesbar werden. Der konstruktive antagonistische Dialog wird begraben und macht einer gegenseitigen Karnevalisierung Platz. Dies illustrieren etwa die Formulierungen des Priesters Oko für die eine und diejenige der Feministin Graff für die andere Seite. ${ }^{33}$ Angesichts dieses innerlich gebrochenen und dysfunktionalen Diskursfelds stellt sich die Frage, wie sich eine feministische Kritik zu diesem verhalten kann.

Janion versteht die Literaturhistorik und Kulturwissenschaft als Korrektiv erstarrender nationalkonservativer Diskurse, welche die tatsächlichen Dynamiken der polnischen Gesellschaft in ein phantasmatisches Korsett zwängen. ${ }^{34}$ Sie entlässt ihr Publikum 2006 mit den Worten: »[E]s gilt, eine andere Narration herauszubilden, eine sandere Geschichte` zu erzählen « ${ }^{35}$, die eine integrative und zukunftsgerichtete Ausrichtung haben soll. Doch eine solche hat seit Mitte der 2010er Jahre einen zunehmend schweren Stand.

33 I Vgl. Oko: Gender; Graff: Feminizm ryzyka, S. 20f.; dies.: Świat bez kobiet, S. 23; siehe auch Snitow: Przyszłość feminizmu, S. 11.

34 । Vgl. Janion: Niesamowita słowiańszczyzna, S. 20; dies.: Morze zjawisk, S. 115f.; dies.: »Mesjanizm to przekleństwo. List Marii Janion do Kongresu Kultury«, 2016.

35 I Janion: Niesamowita słowiańszczyzna, S. 329: „trzeba stworzyć inną narrację, trzeba opowiedzieć sinną historię«. 


\section{Literaturverzeichnis}

Ahmed, Sara: "Collective Feelings. Or, The Impressions Left by Others", in:

Theory, Culture \& Society 21/2 (2004), S. 25-42.

https://doi.org/10.1177/0263276404042133

Alexander, Manfred: Kleine Geschichte Polens, Stuttgart 2003 (2008).

Amnesty International, Warszawska Grupa (Hg.), Prawa człowieka prawem kobiet, Warszawa 1995.

Anderson, Benedict: Imagined Communities. Reflections on the Origin and

Spread of Nationalism. Revised Edition, London, New York 1983 (2006).

Arns, Inke/Sasse, Sylvia: "Subversive Affirmation: On Mimesis as a Strategy of

Resistance«, in: IRWIN (Hg.), East Art Map. Contemporary Art and Eastern

Europe, Cambridge 2006, S. 444-455.

B.L./T.O.: »Wstęp«, in: Spotkania feministyczne (1994/1995), S. 4-5.

Bachtin, Michail: Probleme der Poetik Dostoevskijs (= Literatur als Kunst), München 1971.

Bachtin, Michail M.: Die Ästhetik des Wortes, Frankfurt a/M. 1979.

Bachtin, Michail M.: Sobranie sočinenij v semi tomach. Tom 1. Filosofskaja èstetika 1920-ch godov, Moskva 2003.

Bachtin, Michail M.: Autor und Held in der ästhetischen Tätigkeit, Frankfurt a/M. 2008.

Badinter, Elisabeth: XY - tożsamość mężczyzny, Warszawa 1993.

Bal, Mieke: Travelling concepts in the humanities. A rough guide, Toronto u.a. 2002.

Baranowska, Agnieszka: Kraj modernistycznego cierpienia, Warszawa 1981.

Baranowska, Małgorzata: »Anamorfoza i tożsamość«, in: Janion/Rosiek, Maski II (1986), S. 333-340.

Barańczak, Stanislaw: "Zbigniew Herbert and the Notion of Virtue«, in: Eile/ Phillips, New Perspectives (1992), S. 105-118.

Barthes, Roland: »L'Effet de réel«, in: Communications 11/1 (1968), S. 84-89.

https://doi.org/10.3406/comm.1968.1158

Barthes, Roland: S/Z. Essai (= Tel Quel), Paris 1970.

Barthes, Roland: Le plaisir du texte, Paris 1973.

Barthes, Roland: »Ultra-płeć«, in: Janion/Rosiek, Maski I (1986), S. 139-141. 
Barthes, Roland: »Der Tod des Autors«, in: Jannidis et al., Theorie der Autorschaft (2000), S. 185-193.

Bator, Joanna: Wizerunek kobiety w reklamie telewizyjnej, Warszawa 1998.

Bator, Joanna: Wizerunek kobiety w polskiej debacie politycznej. Perspektywa feministyczna, Warszawa 1999.

Bator, Joanna: Feminizm, postmodernizm, psychoanaliza. Filozoficzne dylematy feministek >drugiej fali`, Gdańsk 2001.

Bauman, Zygmunt: Liquid Modernity, Cambridge 2000.

Bauman, Zygmunt: Gemeinschaften. Auf der Suche nach Sicherheit in einer bedrohlichen Welt, Frankfurt a/M. 2009.

Beauvoir, Simone de: Le Deuxième sexe. Volume 1. Les Faits et les mythes. Volume 2. L’expérience vécue, Paris 1949.

Beauvoir, Simone de: Druga płeć. Tom I. Fakty i mity. Tom II. Kształtowanie się kobiety, sytuacja, usprawiedliwienia i ku wyzwoleniu, Kraków 1972.

Beskid, Lidia: »Bezrobocie kobiet«, in: Sikorska, Kobiety i ich mężowie (1996), S. 101-116.

Bettelheim, Bruno: Symbolic Wounds. Puberty Rites and the Envious Male, Glencoe, Ill. 1954.

Bhabha, Homi K.: The Location of Culture, London, New York 1994.

Biedrzycka, Jadwiga: [Vorwort], in: Konecka, Elżbieta (Hg.), Kobiety polskie, Warszawa 1986, S. 5.

Blagojevic, Marina: »Creators, Transmitters and Users: Women's Scientific Excellence at the Semi-Periphery of Europe«, in: European Commission Community Research (Hg.), Gender and Excellence in the Making, Brüssel 2004, S. 135-145.

Bloom, Harold: The Anxiety of Influence. A Theory of Poetry, New York 1973.

Bloom, Harold: A Map of Misreading, New York 1975.

Boguszewska, Helena: Całe życie Sabiny, Warszawa 1967.

Boniecki, Edward: Modernistyczny dramat ciała. Maria Komornicka, Warszawa 1998.

Borkowska, Grażyna: Dialog powieściowy i jego konteksty (na podstawie twórczości Elizy Orzeszkowej) (= Z Dziejów Form Artystycznych w Literaturze Polskiej, Band 72), Wrocław 1988.

Borkowska, Grażyna: »Wstań, siostro! Wstań! - polska proza kobieca (18401918)«, in: Rocznik Towarzystwa Literackiego imienia Adama Mickiewicza 26-27 (1991/1992), S. 51-61.

Borkowska, Grażyna: „Córki Miltona. (O krytyce feministycznej ostatnich piętnastu lat)«, in: Nycz, Po strukturalizmie (1992), S. 71-92.

Borkowska, Grażyna: »Komandosiく, hippisi, feministki (I)«, in: Kresy 16 (1993), S. 239-241.

Borkowska, Grażyna: »Emigrantki (2)«, in: Kresy 17 (1994), S. 182-184.

Borkowska, Grażyna: »Metafora drożdży. Co to jest literatura/poezja kobieca«, in: Teksty Drugie, Feminizm po polsku (1995), S. 31-44. 
Borkowska, Grażyna: Cudzoziemki. Studia o polskiej prozie kobiecej, Warszawa 1996.

Borkowska, Grażyna: »Płeć jako skaza: Przybyszewski i Nałkowska«, in: Ritz et al., Nowa świadomość płci (2000), S. 77-87.

Borkowska, Grażyna: »Feminizacja kultury: głębia i powierzchnia. Literatura kobieca w latach 1900-1945«, in: Borkowska et al., Pisarki polskie (2000), S. 87-116.

Borkowska, Grażyna: Interview [unveröffentlicht], Warszawa 2013.

Borkowska, Grażyna et al. (Hg.), Pisarki polskie od średniowiecza do współczesności. Przewodnik, Gdańsk 2000.

Borkowska, Grażyna/Sikorska, Liliana (Hg.), Krytyka feministyczna. Siostra teorii i historii literatury, Warszawa 2000.

Bourdieu, Pierre: Entwurf einer Theorie der Praxis auf der ethnologischen Grundlage der kabylischen Gesellschaft, Frankfurt a/M. 1979 (2012).

Bourdieu, Pierre: Die männliche Herrschaft, Frankfurt a/M. 2005.

Brach-Czaina, Jolanta: Szczeliny istnienia, Warszawa 1992.

Brach-Czaina, Jolanta: »Progi polskiego feminizmu«, in: Kwartalnik Pedagogiczny 155-156/1-2 (1995), S. 343-357.

Brach-Czaina, Jolanta (Hg.), Od kobiety do mężczyzny i z powrotem. Rozważania o płci w kulturze, Białystok 1997.

Bronfen, Elisabeth: Over Her Dead Body. Death, Femininity and the Aesthetic, Manchester 1992.

brulion: »Feminizm. Magia chaosu. Sadomasochizm«, 19B (1992).

Brzozowski, Stanisław: Współczesna powieść i krytyka, Kraków 1984.

Buchbinder, David/Milech, Barbara H.: Contemporary Literary Theory and the Reading of Poetry, Melbourne 1991.

https://doi.org/10.1007/978-1-349-12843-3

Budrewicz, Zofia et al. (Hg.), Pamięć i afekty (= Nowa Humanistyka, Band 13), Warszawa 2014.

Budrowska, Kamila: »Wykluczanie tradycji. Cenzurowanie międzywojennej literatury kobiecej w latach czterdziestych i pięćdziesiątych XX wieku (na przykładzie twórczości Zofii Nałkowskiej)«, in: Sztuka Edycji 7 (2015), S. 49-57.

Bujwid, Andrzej (Hg.), Kobieta polska lat osiemdziesiątych, Warszawa 1988.

Butler, Judith: Gender Trouble. Feminism and the subversion of identity, New York, London 1990.

Butler, Judith: Bodies That Matter. On the Discursive Limits of 'Sexı, New York 1993.

Butler, Judith: »Podmioty płci / płciowość / pragnienia«, in: Spotkania feministyczne (1994/1995), S. 58-67.

Butler, Judith: Uwikłani w płeć. Feminizm i polityka tożsamości, Warszawa 2008. Chańska, Weronika/Ulicka, Danuta (Hg.), Polskie oblicza feminizmu. Materiały z konferencji »Polskie oblicza feminizmu«, Uniwersytet Warszawski 8 marca 1999 roku, Warszawa 2000. 
Chodorow, Nancy: The Reproduction of Mothering, Berkeley 1978.

Chołuj, Bożena: »Tożsamość płci - natura czy kultura? /kulturowe aspekty kobiecości, różnica płci nie istnieje; postfeminizm/«, in: Spotkania feministyczne (1994/1995), S. 68-73.

Chołuj, Bożena: »Women’s und Gender Studies in Polen«, in: Die Philosophin. Forum für feministische Theorie und Philosophie 17 (1998), S. 121-124.

Chołuj, Bożena: »Różnica między women’s studies i gender studies«, in: Katedra 1 (2001), S. 26-33.

Chołuj, Bożena: Interview [unveröffentlicht], Zürich 2013.

Chutnik, Sylwia: »Transformers, czyli przemiany w Polsce po 1989 roku w oczach trzydziestolatki«, in: Grzybek/Mrozik, Kobiety w czasach przełomu (2009), S. 37-50.

Ciechomska, Maria: „Feminizm a macierzyństwo«, in: brulion, Feminizm (1992), S. 249-254.

Ciechomska, Maria: Od matriarchatu do feminizmu, Poznań 1996.

Cixous, Hélène: »Le Rire de la Méduse«, in: L’Arc 61 (1975), S. 39-54.

Cixous, Hélène: „Śmiech Meduzy«, in: Teksty Drugie, Śmiech feministek (1993), S. 147-166.

Clayton, Jay/Rothstein, Eric (Hg.), Influence and Intertextuality in Literary History, Wisconsin 1991.

Culler, Jonathan D.: On Deconstruction. Theory and Criticism after Structuralism, Ithaca, New York 1982.

Czerniawski, Adam: »A Poetical Political History«, in: Eile/Phillips, New Perspectives (1992), S. 6-27. https://doi.org/10.1007/978-1-349-12331-5_2

Czerwiński, Marcin: Przemiany obyczaju, Warszawa 1969.

Czyżewski, Marek et al. (Hg.), Cudze problemy. O ważności tego, co nieważne. Analiza dyskursu publicznego w Polsce (= Biblioteka Dyskursu Publicznego. Kultura, Retoryka, Demokracja), Warszawa 1991 (2010).

Dajnowicz, Małgorzata: »Działalność publiczna kobiet polskich na pograniczu ziem północno-wschodniej Polski (od końca XIX wieku do 1939 roku)«, in: Pudłocki, Tomasz/Sierakowska, Katarzyna (Hg.), Aktywność publiczna kobiet na ziemiach polskich. Wybrane zagadnienia, Warszawa 2013, S. 69-83.

Darska, Bernadetta: Głosy kobiet. Prasa feministyczna po roku 1989 wobec tożsamości i dyskursu, Olsztyn 2009.

Decottignies, Jean: Physiologie et mythologie du feminin, Lille 1989.

Deleuze, Gilles: Le Pli. Leibniz et le baroque, Paris 1988.

Deleuze, Gilles/Guattari, Félix: Rhizome, Paris 1976.

Deleuze, Gilles/Guattari, Félix: »1440 - le lisse et le strié«, in: dies., Mille plateaux. Capitalisme et schizophrénie tome 2, Paris 1980, S. 592-625.

Dernałowicz, Maria: »Piotr Odmieniec Włast«, in: Twórczość 3 (1977), S. 75-78.

Desperak, Izabela: »Kobiety - wielkie przegrane polskiej transformacji«, in: Michalczyk, Tadeusz et al. (Hg.), Problemy społeczne w okresie transformacji ustrojowej (= Zeszyty Naukowe Instytutu Filozofii i Socjologii oraz Instytu- 
tu Agrobiznesu z Informatyką Stosowaną Filii Akademii Świętokrzyskiej im. Jana Kochanowskiego, Band 1), Piotrków Trybunalski 2004, S. 175-184.

Domański, Henryk: Zadowolony niewolnik? Studium o nierównościach między mężczyznami i kobietami w Polsce, Warszawa 1992.

Domański, Henryk et al.: Polska jedna czy wiele? (= Seria z rekomendacją), Warszawa 2005.

Drozdowski, Rafał: [N.N.], in: Drozdowski/Krajewski, Prywatnie o publicznym (2007), S. 19-23.

Drozdowski, Rafał/Krajewski, Marek (Hg.), Prywatnie o publicznym/publicznie o prywatnym (= Uniwersytet im. Adama Mickiewicza w Poznaniu, Seria Socjologia, Band 50), Poznań 2007.

Duch-Krzystoszek, Danuta: »Relacje między pracą domową i zawodowąu, in: Sikorska, Kobiety i ich mężowie (1996), S. 85-99.

Dunin, Kinga: »Polska policja menstrualna«, in: Ex Libris 80 (1995), S. 6-7.

Dunin, Kinga: Tao gospodyni domowej, Warszawa 1996.

Durkheim, Emile: Die Regeln der soziologischen Methode (= Soziologische Texte, Band 3), Neuwied, Berlin 1961 (1965).

Dybel, Paweł: Ziemscy, słowni, cieleśni. Eseje i szkice, Warszawa 1988.

Dybel, Paweł: Dialog i represja. Antynomie psychoanalizy Zygmunta Freuda, Warszawa 1995.

Dybel, Paweł: Freuda sen o kulturze, Warszawa 1996.

Dybel, Paweł: »Psychoanalyse in Polen - Herausforderung für Bräuche und Tradition?«, in: Krasnodębski, Zdzisław et al. (Hg.), Kulturelle Identität und sozialer Wandel in Osteuropa: das Beispiel Polen (= Beiträge zur Osteuropaforschung, Band 3), Hamburg 1999, S. 283-295.

Dybel, Paweł: Urwane ścieżki. Przybyszewski - Freud - Lacan, Kraków 2000.

Dybel, Paweł: Zagadka »drugiej płci«. Spory wokół różnicy seksualnej w psychoanalizie i w feminizmie, Kraków 2012.

Dybel, Paweł: »Die Idee des Ödipuskomplexes«, in: Kowalewicz, Michel Henri (Hg.), Formen der Ideengeschichte (= Vestigia Idearum Historica. Beiträge zur Ideengeschichte Europas, Band 2), Münster 2014, S. 217-237.

Dybel, Paweł: Psychoanaliza - ziemia obiecana? Z dziejów psychoanalizy w Polsce 1900-1989. Część I. Okres burzy i naporu. Początki psychoanalizy na ziemiach polskich okresu rozbiorów 1900-1918 (= Dzieje psychoanalizy w Polsce), Kraków 2016.

Dyczewski, Leon: Rodzina polska i kierunki jej przemian, Warszawa 1981.

Dziennik.pl Rozrywka, 31.12.2013. http://rozrywka.dziennik.pl/hity-internetu/ zdjecia/446988,3,galeria-memow-o-leku-przed-gender.html (08.03.2017).

Dziurdzikowska, Renata: »Maria Janion. Samotność humanisty«, in: Twój Styl 30/1 (1993), S. 14-19.

Ebert, Teresa L.: »Alexandra Kollontai und die Rote Liebe», in: Sozialistische Zeitung 4 (2002), S. 24. http://www.vsp-vernetzt.de/soz/020424.htm (24.01.2017). Eile, Stanislaw: »Introduction«, in: Eile/Phillips, New Perspectives (1992), S. 1-5. 
Eile, Stanislaw: »Between Absurdity and Apocalypse: Contemporary Poland in Drama and Fiction, 1977-87«, in: Eile/Phillips, New Perspectives (1992), S. 180-200.

Eile, Stanislaw/Phillips, Ursula (Hg.), New Perspectives in Twentieth-Century Polish Literature. Flight from Martyrology (= Studies in Russia and East Europe), Basingstoke, London 1992. https://doi.org/10.1007/978-1-349-12331-5

Faliszek, Krystyna et al. (Hg.), Kobiety wobec przemian okresu transformacji, Katowice 1997.

Faludi, Susan: Backlash. The Undeclared War against Women, London 1993.

Felman, Shoshana: Le Scandale du corps parlant. Don Juan avec Austin ou la séduction en deux langues, Paris 1980.

Feyerabend, Paul: Wider den Methodenzwang. Skizze einer anarchistischen Erkenntnistheorie, Frankfurt a/M. 1976.

Fidelis, Malgorzata: Women, Communism and Industrialization in Postwar Poland, Cambridge 2010.

Fidelis, Małgorzata: „Szukając traktorzystki - kobiety i komunizm«, in: Znak 10 (2012), S. 42-49.

Filipiak, Izabela: »W.+M. = M.W.«, in: Ritz et al., Nowa świadomość płci (2000), S. 111-140.

Filipowicz, Halina: »Przeciw >literaturze kobiecej««, in: Teksty Drugie, Śmiech feministek (1993), S. 245-258.

Foucault, Michel: »Z ^Historii seksualności««, in: Janion/Majchrowski, Odmieńcy (1982), S. 392-396.

Foucault, Michel: CEeuvres. Volume II (= Bibliothèque de la Pléiade, Band 608), Paris 2015.

Frąckowiak-Sochańska, Monika: »Aksjologiczny wymiar tożsamości polskich kobiet - obszary ciągłości i zmiany«, in: Frąckowiak-Sochańska/Królikowska, Kobiety w polskiej transformacji (2010), S. 347-377.

Frąckowiak-Sochańska, Monika/Królikowska, Sabina (Hg.), Kobiety w polskiej transformacji 1989-2009. Podsumowania, interpretacje, prognozy, Toruń 2010.

Freud, Sigmund: „Einige psychologische Folgen des anatomischen Geschlechtsunterschieds«, in: Internationale Zeitschrift für Psychoanalyse 11/4 (1925), S. 401-410.

Freud, Sigmund: »Über die Psychogenese eines Falles von weiblicher Homosexualität«, in: ders., Werke aus den Jahren 1917-1920. Gesammelte Werke. Zwölfter Band, Frankfurt a/M. 1947, S. 269-302.

Freud, Sigmund: Totem und Tabu. Einige Übereinstimmungen im Seelenleben der Wilden und der Neurotiker. Gesammelte Werke. Neunter Band, Frankfurt a/M. 1973.

Friedrichsmeyer, Sara/Clausen, Jeanette: »What's Missing in New Historicism or the >Poetics` of Feminist Literary Criticism«, in: Women in German Yearbook 9 (1993), S. 253-258. 
Frieske, Kazimierz W.: "Poza stereotypami: między Matką Polką a Kobietą Nierządną«, in: Faliszek et al., Kobiety wobec przemian (1997), S. 198-202.

Fronda.pl. Portal poświęcony. http://www.fronda.pl/ (08.03.2017).

Fuchs, Gesine: Die Zivilgesellschaft mitgestalten. Frauenorganisationen im polnischen Demokratisierungsprozess (= Politik der Geschlechterverhältnisse, Band 21), Frankfurt a/M., New York 2003.

Furia Pierwsza 1-8 (1997-2000).

Fuszara, Małgorzata: „Feminizm i my - dyskusja nad tekstem Ann Snitow«, in: Spotkania feministyczne (1994/1995), S. 14-21.

Fuszara, Małgorzata: "New Gender Relations in Poland in the 1990s«, in: Gal/ Kligman, Reproducing Gender (2000), S. 259-285.

Gadomska, Barbara et al. (Hg.), Kobiety w Polsce w latach 90. Raport Centrum Praw Kobiet, Warszawa 2000.

Gajewska, Agnieszka: „»Macierzyństwo « - prezentacja pojęcia w dyskursie feministycznym w Polsce«, in: Radkiewicz, Gender (2004), S. 253-272.

Gajewska, Agnieszka: »Feministyczne rozrachunki z PRL-em«, in: FrąckowiakSochańska/Królikowska, Kobiety w polskiej transformacji (2010), S. 463-478.

Gal, Susan: »A Semiotics of the Public/Private Distinction«, in: Scott/Keates, Going Public (2004), S. 261-277.

Gal, Susan/Kligman, Gail (Hg.), Reproducing Gender. Politics, Publics, and Everyday Life after Socialism, Princeton, New Jersey 2000.

Gallop, Jane: »Keys to Dora», in: Bernheimer, Charles/Kahane, Claire (Hg.), In Dora's Case. Freud, Hysteria, Feminism (= Gender and culture), New York 1985, S. 200-220.

Genz, Stéphanie/Brabon, Benjamin A.: »Introduction. Postfeminist Contexts», in: dies. (Hg.), Postfeminism. Cultural Texts and Theories, Edinburgh 2009, S. $1-50$.

Ghodsee, Kristen: »Feminism-by-Design. Emerging Capitalisms, Cultural Feminism, and Women's Nongovernmental Organizations in Postsocialist Eastern Europe«, in: Signs 29/3 (2004), S. 727-753.

https://doi.org/10.1086/380631

Gilbert, Sandra M./Gubar, Susan: The Madwoman in the Attic. The Woman Writer and the Nineteenth-Century Literary Imagination, New Haven 1979.

Gill, Rosalind/Scharff, Christina: »Introduction«, in: dies. (Hg.), New Femininities. Postfeminism, Neoliberalism and Subjectivity, Basingstoke 2011, S. 1-17.

Godzic, Wiesław: [N.N.], in: Drozdowski/Krajewski, Prywatnie o publicznym (2007), S. 16-18.

Goffman, Erving: Frame Analysis. An Essay on the Organization of Experience, Cambridge, Mass. 1974.

Górnicka-Boratyńska, Aneta: Chcemy całego życia. Antologia polskich tekstów feministycznych z lat 1870-1939, Warszawa 1999.

Górnicka-Boratyńska, Aneta: »Idea emancypacji w literaturze polskiej XIX i XX wieku«, in: Ritz et al., Nowa świadomość płci (2000), S. 13-31. 
Grabowska, Genowefa: »Kobiety w prawie międzynarodowym«, in: Faliszek et al., Kobiety wobec przemian (1997), S. 98-108.

Graczyk, Ewa: »Być kobietą?«, in: Gosk, Hanna/Karwowska, Bożena (Hg.), (Nie) Przezroczystość normalności w literaturze polskiej XX i XXI wieku (= Seria Prac Zakładu Literatury Polskiej XX Wieku Instytutu Literatury Polskiej Uniwersytetu Warszawskiego), Warszawa 2014, S. 225-243.

Graczyk, Ewa: »Tego się nie robi temu narodowi«, in: Gender. Przewodnik Krytyki Politycznej (= Przewodniki Krytyki Politycznej, Band 38), Warszawa 2014, S. 405-410.

Graff, Agnieszka: »Feminizm ryzyka - i dlaczego w Polsce go nie ma«, in: Pełnym głosem 4 (1996), S. 19-23.

Graff, Agnieszka: »Patriarchat po seksmisji«, in: Gazeta Wyborcza 141 (19.06.1999), S. 20 .

Graff, Agnieszka: Świat bez kobiet. Płeć w polskim życiu publicznym, Warszawa 2001.

Graff, Agnieszka: »Warum Frauen in Polen ınicht stören«", in: Jahrbuch Polen 17 (2006), S. 34-44.

Graff, Agnieszka: »Gender Studies in Poland. A View from Within«, in: aspasia. The International Yearbook of Central, Eastern and Southeastern European Women's and Gender History 4 (2010), S. 167-176.

Greer, Germaine: Der weibliche Eunuch. Aufruf zur Befreiung der Frau, Frankfurt a/M. 1971.

Grotowska-Leder, Jolanta/Warzywoda-Kruszyńska, Wielisława: »Feminizacja katowickiej biedy?«, in: Faliszek et al., Kobiety wobec przemian (1997), S. 203-224.

Grzebalska, Weronika: Płeć powstania warszawskiego (= Lupa Obscura), Warszawa 2013.

Grzybek, Agnieszka/Mrozik, Agnieszka (Hg.), Kobiety w czasach przełomu 19892009. Polska, Czechy, Słowacja, Niemcy Wschodnie, Ukraina, Warszawa 2009.

Habermas, Jürgen: Strukturwandel der Öffentlichkeit. Untersuchungen zu einer Kategorie der bürgerlichen Gesellschaft (= Politica. Abhandlungen und Texte zur politischen Wissenschaft, Band 4), Neuwied 1962.

Hadaczek, Bolesław: Kresy w literaturze polskiej XX wieku. Szkice, Szczecin 1993. Hanisch, Carol: »The Personal Is Political. The Women's Liberation Movement Classic with a New Explanatory Introduction«, 1969 (2009). http://www.carolhanisch.org/CHwritings/PIP.html (25.07.2016)

Haraway, Donna: »A Cyborg Manifesto: Science, Technology, and Socialist-Feminism in the Late Twentieth Century«, in: dies., Simians, Cyborgs, and Women. The Reinvention of Nature, New York 1991, S. 149-181.

Haraway, Donna: „Situiertes Wissen. Die Wissenschaftsfrage im Feminismus und das Privileg einer partialen Perspektive«, in: dies., Die Neuerfindung der Natur. Primaten, Cyborgs und Frauen, Frankfurt a/M., New York 1995, S. 73-97.

Harding, Sandra: Is Science Multicultural? Postcolonialisms, Feminisms, and Epistemologies, Bloomington, Indianapolis 1998. 
Harding, Sandra: »Introduction: Standpoint Theory as a Site of Political, Philosophic, and Scientific Debate«, in: dies. (Hg.), The Feminist Standpoint Theory Reader. Intellectual and Political Controversies, New York, London 2004, S. 1-15.

Heim, Edgar: Die Welt der Psychotherapie. Entwicklungen und Persönlichkeiten, Stuttgart 2009.

Helbig-Mischewski, Brigitta: »Guru przełomu tysiąclecia. Dyskurs Nowej Ery w pracach Marii Janion«, in: Teksty Drugie 43-44/1-2 (1997), S. 165-192.

Helbig-Mischewski, Brigitta: Ein Mantel aus Sternenstaub. Geschlechtstransgress und Wahnsinn bei Maria Komornicka, Norderstedt 2005.

Helbig-Mischewski, Brigitta: Strącona bogini. Rzecz o Marii Komornickiej (= Polonica Leguntur. Literatura polska w krajach języka niemieckiego, Band 11), Kraków 2010.

Heller, Włodzimierz (Hg.), Humanistyka i płeć. Tom III. Publiczna przestrzeń kobiet. Obrazy dawne i nowe, Poznań 1999.

Hemmings, Clare: »Invoking Affect. Cultural theory and the ontological turn«, in: Cultural Studies 19/5 (2005), S. 548-567.

https://doi.org/10.1080/09502380500365473

Hemmings, Clare: Why Stories Matter. The Political Grammar of Feminist Theory (= Next Wave: New Directions in Women's Studies), Durham, London 2011.

Hogeland, Lisa Maria: Feminism and Its Fictions. The Consciousness-Raising Novel and the Women's Liberation Movement, Philadelphia 1998.

https://doi.org/10.9783/9781512804157

Hołówka, Teresa: Delicje ciotki Dee, Warszawa 1988.

Hołówka, Teresa (Hg.), Nikt nie rodzi się kobietą, Warszawa 1982.

hooks, bell: »Sisterhood. Political Solidarity between Women«, in: Weiss, Penny A./Friedman, Marilyn (Hg.), Feminism and Community, Philadelphia 1995, S. 293-315.

Hornung, Magdalena et al. (Hg.), Ciało, płeć, literatura. Prace ofiarowane profesorowi Germanowi Ritzowi w pięćdziesiątą rocznicę urodzin, Warszawa 2001.

Humm, Maggie: Słownik teorii feminizmu, Warszawa 1993.

Irigaray, Luce: Ce Sexe qui n'en est pas un, Paris 1977.

Irigaray, Luce: Le Corps-à-corps avec la mère, Montréal 1981.

Irigaray, Luce: Je, tu, nous. Pour une culture de la différence, Paris 1990.

Iser, Wolfgang: »Die Appellstruktur der Texte«, in: Warning, Rainer (Hg.), Rezeptionsästhetik. Theorie und Praxis, München 1975, S. 228-252.

Iwasiów, Inga: Kresy w twórczości Włodzimierza Odojewskiego. Próba feministyczna, Szczecin 1994.

Iwasiów, Inga: »Ślady porządków represywnych«, in: Pełnym głosem 2 (1994), S. 101-111.

Iwasiów, Inga: Gender dla średnio zaawansowanych. Wykłady szczecińskie, Warszawa 2004.

Iwasiów, Inga: »Powieść w obiegach. Lata osiemdziesiąte i kontynuacje», in: Iwasiów, Prywatne/publiczne (2008), S. 131-192. 
Iwasiów, Inga: Interview [unveröffentlicht], Szczecin 2013.

Iwasiów, Inga (Hg.), Prywatne/publiczne. Gatunki pisarstwa kobiecego (= Uniwersytet Szczeciński. Rozprawy i studia, Band 723), Szczecin 2008.

Iwasiów, Inga/Galant, Arleta (Hg.), Pisarstwo kobiet pomiędzy dwoma dwudziestoleciami, Kraków 2011.

Jabłonowska, Zofia: »Rodzina w XIX i na początku XX wieku«, in: Komorowska, Przemiany rodziny polskiej (1975), S. 52-71.

Jameson, Fredric: The Political Unconscious. Narrative as a Socially Symbolic Act, London 1981.

Janion, Maria: Romantyzm, rewolucja, marksizm. Colloquia gdańskie, Gdańsk 1972.

Janion, Maria: Odnawianie znaczeń, Kraków 1980.

Janion, Maria [et al.]: »Ciało skolonizowanych«, in: Janion/Rosiek, Galernicy wrażliwości (1981), S. 215-235.

Janion, Maria [et al.]: »Rozmowa druga: o współczesnej mediokracji«, in: Janion/ Rosiek, Galernicy wrażliwości (1981), S. 371-401.

Janion, Maria: Humanistyka: poznanie i terapia, Warszawa 1982.

Janion, Maria [et al.]: »Fałszywy paszport Adeli H.«, in: Janion/Majchrowski, Odmieńcy (1982), S. 113-126.

Janion, Maria: »)Gdzie jest Lemańska?!«, in: Janion/Majchrowski, Odmieńcy (1982), S. 152-199.

Janion, Maria [et al.]: »Przekroczenie stało się faktem«, in: Janion/Majchrowski, Odmieńcy (1982), S. 285-328.

Janion, Maria: »Tam gdzie rojsty«, in: Twórczość 4 (1983), S. 93-110.

Janion, Maria: »Przybyszewska pragnie stworzyć osobowość mentalną rewolucji«, in: Janion/Rosiek, Osoby (1984), S. 161-172.

Janion, Maria [et al.]: »Komentarze 1«, in: Janion/Rosiek, Osoby (1984), S. 345-353. Janion, Maria [et al.]: »Komentarze 3«, in: Janion/Rosiek, Osoby (1984), S. 391-449. Janion, Maria: »Zbroje Grażyny«, in: Janion/Rosiek, Maski I (1986), S. 148-159.

Janion, Maria: Projekt krytyki fantazmatycznej. Szkice o egzystencjach ludzi i duchów, Warszawa 1991.

Janion, Maria: »Niańka i kowboy«, in: Badinter, XY (1993), S. 9-15.

Janion, Maria: »Zmierzch paradygmatu«, in: dies., „Czy będziesz wiedział, co przeżyłeś« (= Stanowiska/Interpretacje, Band 1), Warszawa 1996, S. 5-23.

Janion, Maria: Kobiety i duch inności (= Stanowiska/Interpretacje, Band 3), Warszawa 1996.

Janion, Maria: »Kuferek Harpagona. Z profesor Marią Janion rozmawiają Anna Nasiłowska i Marta Zielińska«, in: Teksty Drugie 43-44/1-2 (1997), S. 199-217. Janion, Maria: »Droga«, in: Borkowska/Sikorska, Krytyka feministyczna (2000), S. 11-19.

Janion, Maria: »Postscriptum: reprywatyzacja życia prywatnego«, in: dies., Tragizm, historia, prywatność. Prace wybrane. Tom 2 (= Klasycy Współczesnej Polskiej Myśli Humanistycznej), Kraków 2000, S. 446-448. 
Janion, Maria: Niesamowita słowiańszczyzna. Fantazmaty literatury, Kraków 2006.

Janion, Maria: »Polonia powielona«, in: Gabryś, Monika et al. (Hg.), Polka. Medium. Cień. Wyobrażenie, Warszawa 2006, S. 19-31.

Janion, Maria: »Morze zjawisk i okruchy egzystencji. Rozmowa Zbigniewa Majchrowskiego z Marią Janion«, in: Owczarski, Colloquia gdańskie (2008), S. 103-136.

Janion, Maria: Die Polen und ihre Vampire. Studien zur Kritik kultureller Phantasmen, Frankfurt a/M. 2014.

Janion, Maria: »Mesjanizm to przekleństwo. List Marii Janion do Kongresu Kultury«, 2016.

http://wyborcza.pl/7,75410,20813344,mesjanizm-to-przeklenstwo-list-marii -janion-do-kongresu-kultury.html?disableRedirects=true (1.11.2016)

Janion, Maria/Szczuka, Kazimiera: Janion. Rozmawia Kazimiera Szczuka. Transe, traumy, transgresje. Tom 1. Niedobre dziecię (= Seria z Różą), Warszawa 2012. Janion, Maria/Szczuka, Kazimiera: Janion. Rozmawia Kazimiera Szczuka. Transe, traumy, transgresje. Tom 2. Profesor Misia (= Seria z Różą), Warszawa 2014. Janion, Maria/Żmigrodzka, Maria: Romantyzm i historia, Warszawa 1978. Janion, Maria/Chwin, Stefan (Hg.), Dzieci (= Transgresje, Band 5), Gdańsk 1988. Janion, Maria/Majchrowski, Zbigniew (Hg.), Odmieńcy (= Transgresje, Band 2), Gdańsk 1982.

Janion, Maria/Rosiek, Stanisław (Hg.), Galernicy wrażliwości (= Transgresje, Band 1), Gdańsk 1981.

Janion, Maria/Rosiek, Stanisław (Hg.), Osoby (= Transgresje, Band 3), Gdańsk 1984. Janion, Maria/Rosiek, Stanisław (Hg.), Maski. Tom I i II (= Transgresje, Band 4), Gdańsk 1986.

Jannidis, Fotis et al. (Hg.), Texte zur Theorie der Autorschaft, Stuttgart 2000. Jaruzelski, Wojciech: Przemówienia 1981-1982, Warszawa 1983.

Kaliściak, Tomasz/Nęcka, Agnieszka: »Lesbijka w Safonie czy Safona w lesbijce? O jednej powieści Anny Kowalskiej«, in: Iwasiów/Galant, Pisarstwo kobiet (2011), S. 113-123.

Kałwa, Dobrochna: »Between Emancipation and Traditionalism - The Situation of Women and the Gender Order in Poland after 1945«, in: Hering, Sabine (Hg.), Social Care under State Socialism (1945-1989). Ambitions, Ambiguities, and Mismanagement, Opladen, Farmington Hills, MI. 2009, S. 175-187.

Kałwa, Dobrochna: »Historia kobiet versus studia gender - o potrzebie interdyscyplinarnego dialogu«, in: Domańska, Ewa et al. (Hg.), Historia - dziś. Teoretyczne problemy wiedzy o przeszłości, Kraków 2014, S. 115-125.

Kampichler, Martina: »Reflexionen zum Potential des 'Reisens ‘ feministisch motivierter Theoriebildung «, in: Hüchtker, Dietlind/Kliems, Alfrun (Hg.), Überbringen - Überformen - Überblenden. Theorietransfer im 20. Jahrhundert, Köln 2011, S. 149-160.

https://doi.org/10.7788/boehlau.9783412213688.149 
Karkowski, Czesław: »Świat według Paglii«, in: Teksty Drugie, Śmiech feministek (1993), S. 206-212.

Keff-Umińska, Bożena: »Odzyskać traktory«, in: Grzybek/Mrozik, Kobiety w czasach przełomu (2009), S. 14-26.

Keinz, Anika: Polens Andere. Verhandlungen von Geschlecht und Sexualität in Polen nach 1989, Bielefeld 2008. https://doi.org/10.14361/9783839410110

Kemlein, Sophia (Hg.), Geschlecht und Nationalismus in Mittel- und Osteuropa 1848 - 1918 (= Einzelveröffentlichungen des Deutschen Historischen Instituts Warschau, Band 4), Osnabrück 2000.

Kenney, Padraic: »Pojęcie `Matki-Polki< w języku opozycji i władzy«, in: Szarota, Tomasz (Hg.), Komunizm. Ideologia - system - ludzie, Warszawa 2001, S. 338-351.

Kijowski, Andrzej: Arcydzieło nieznane, Kraków 1964.

Kłosińska, Krystyna: Powieści w »wieku nerwowym«, Katowice 1988.

Kłosińska, Krystyna: »Jestem wszędzie i nigdzie mnie nie ma. Miejsce kobiety w dyskursie współczesnym«, in: Piętkowa, Eros, psyche, seks (1993), S. 17-22.

Kłosińska, Krystyna: Ciało, pożądanie, ubranie. O wczesnych powieściach Gabrieli Zapolskiej (= Kobieta, Kultura, Krytyka), Kraków 1999.

Knothe, Maria Anna: „Kobiety i praca. Problemy polskiego rynku pracy dla kobiet w okresie przejścia do gospodarki rynkowej«, in: Faliszek et al., Kobiety wobec przemian (1997), S. 10-18.

Komorowska, Jadwiga (Hg.), Przemiany rodziny polskiej, Warszawa 1975.

Korbonski, Andrzej: »Poland ten years after: the church«, in: Communist and Post-Communist Studies 33 (2000), S. 123-146.

https://doi.org/10.1016/S0967-067X(99)00028-8

Kowalczyk, Izabela: Ciało i władza. Polska sztuka krytyczna lat 90, Warszawa 2002.

Kraft, Claudia: »Paradoxien der Emanzipation. Regime, Opposition und Geschlechterordnungen im Staatssozialismus seit den späten 1960er-Jahren «, in: Zeithistorische Forschungen/Studies in Contemporary History 3 (2006), S. 381-400.

Kralkowska-Gątkowska, Krystyna: „Dziwne miasto Eropolis. Obrazy i funkcje erotyki w tekstach Marii Komornickiej«, in: Piętkowa, Eros, psyche, seks (1993), S. 27-34.

Kralkowska-Gątkowska, Krystyna: Cień twarzy. Szkice o twórczości Marii Komornickiej, Katowice 2002.

Kraskowska, Ewa: Twórczość Stefana Themersona: dwujęzyczność a literatura (= Rozprawy literackie, Band 65), Wrocław 1989.

Kraskowska, Ewa: »Kilka uwag na temat powieści kobiecej«, in: Teksty Drugie, Śmiech feministek (1993), S. 259-273.

Kraskowska, Ewa: Piórem niewieścim. Z problemów prozy kobiecej dwudziestolecia międzywojennego (= Filologia Polska, Band 60), Poznań 1999.

Kraskowska, Ewa: »Czytelnik jako kobieta«, in: Zacharska, Jadwiga/Kochanowski, Marek (Hg.), Wiek kobiet w literaturze, Białystok 2002, S. 15-31. 
Kraskowska, Ewa: »Maria Dąbrowska i Anna Kowalska«, in: Iwasiów/Galant, Pisarstwo kobiet (2011), S. 81-97.

Krasuska, Karolina: Płeć i naród: Trans/lokacje. Maria Komornicka/Piotr Odmieniec Włast, Else Lasker-Schüler, Mina Loy (= Lupa obscura), Warszawa 2012.

Kreiswirth, Martin: »Merely Telling Stories? Narrative and Knowledge in the Human Sciences«, in: Poetics Today 21/2 (2000), S. 293-318.

https://doi.org/10.1215/03335372-21-2-293

Kristeva, Julia: Sèméiotikè. Recherches pour une sémanalyse. Essais (= Collection Tel Quel), Paris 1969.

Kristeva, Julia: Le Texte du roman. Approche sémiologique d'une structure discursive transformationelle (= Approaches to Semiotics, Band 6), Den Haag, Paris 1970.

Kristeva, Julia: La Révolution du langage poétique. L'avant-garde à la fin du XIXe siècle: Lautréamont et Mallarmé, Paris 1974.

Kristeva, Julia: »Le Vréel«, in: Kristeva, Julia/Ribettes, Jean-Michel (Hg.), Folle vérité. Vérité et vraisemblance du texte psychotique (= Tel Quel), Paris 1979, S. 11-35.

Kristeva, Julia: Pouvoirs de l'horreur. Essai sur l'abjection, Paris 1980.

Krzyżanowska, Natalia: Kobiety w (polskiej) sferze publicznej, Toruń 2012.

Kuchowicz, Zbigniew: Żywoty niepospolitych kobiet polskiego baroku, Łódź 1989.

Kulawik, Teresa/Ingbrant, Renata: »Maria Janion. A Tree Spreading Seeds«, in: Baltic Worlds 4 (2011), S. 4-12.

Kulpa, Robert/Mizielińska, Joanna: »Contemporary Peripheries`: Queer Studies, Circulation of Knowledge and East/West Divide«, in: dies., De-Centring Western Sexualities (2011), S. 11-26.

Kulpa, Robert/Mizielińska, Joanna (Hg.), De-Centring Western Sexualities. Central and Eastern European Perspectives, Farnham 2011.

Kuncewiczowa, Maria: Cudzoziemka, Warszawa 1973.

Kurkowska, Mirella: »Narcyza Żmichowska w środowisku warszawskim lat czterdziestych XIX w.«, in: Żarnowska/Szwarc, Kobieta i świat polityki (1994), S. 235-244.

Lachmann, Renate: Gedächtnis und Literatur. Intertextualität in der russischen Moderne, Frankfurt a/M. 1990.

Landes, Joan B.: »Introduction«, in: dies. (Hg.), Feminism, the Public and the Private (= Oxford Readings in Feminism), Oxford, New York 1998, S. 1-17.

Leitch, Vincent B.: American Literary Criticism from the Thirties to the Eighties, New York 1988.

Lem, Stanisław: Maska, Kraków 1976.

Lemoine-Luccioni, Eugénie: Partage des femmes (= Le Champ freudien), Paris 1976.

Lennox, Sara: "Feminism and New Historicism», in: Monatshefte 48/2 (1992), S. 159-170.

Leszkowicz, Paweł: Nagi mężczyzna. Akt męski w sztuce polskiej po 1945 roku, Poznań 2012. 
Lévi-Strauss, Claude: Das wilde Denken, Frankfurt a/M. 1968.

Leys, Ruth: "The Turn to Affect. A Critique«, in: Critical Inquiry 37/3 (2011), S. 434-472. https://doi.org/10.1086/659353

Limanowska, Barbara: »Dlaczego w Polsce nie ma feminizmu«, in: Pełnym głosem 1 (1993), S. 3-24.

Limanowska, Barbara: »Backlash, czyli kontratak», in: Spotkania feministyczne (1994/1995), S. 34-39.

Limanowska, Barbara: „Pytania zadawane w cieniu pomnika«, in: Petnym głosem 5 (1997), S. 42-46.

Lindhoff, Lena: Einführung in die feministische Literaturtheorie, Stuttgart 1995. https://doi.org/10.1007/978-3-476-03982-8

Lipowska-Teutsch, Anna: „Śmiech i gniew«, in: Walczewska, Feministki (2005), S. 53-74.

Loseff, Lev: On the Beneficience of Censorship. Aesopian Language in Modern Russian Literature (= Arbeiten und Texte zur Slavistik, Band 31), München 1984.

Lubamersky, Lynn: »The >Wild Woman in the Culture of the Polish-Lithuanian Commonwealth«, in: Shifrin, Susan (Hg.), Women as Sites of Culture. Women's Roles in Cultural Formation from the Renaissance to the Twentieth Century, Hampshire 2002, S. 183-193.

Lyotard, Jean-François: La Condition postmoderne. Rapport sur le savoir, Paris 1979.

Łaciak, Beata: »Wzór osobowy współczesnej Polki«, in: Titkow/Domański, Co to znaczy (1995), S. 233-244.

Łebkowska, Anna: ")Kobieta czytająca jak kobieta czytająca jak kobieta...«", in: Teksty Drugie, Feminizm po polsku (1995), S. 180-187.

Łebkowska, Anna: »Czy >płeć« może uwieść poetykę?«, in: Bolecki, Włodzimierz/ Tomasik, Wojciech (Hg.), Poetyka bez granic (= Z dziejów form artystycznych w literaturze polskiej), Warszawa 1995, S. 78-93.

Łebkowska, Anna: Empatia. O literackich narracjach przełomu XX i XXI wieku (= Modernizm w Polsce, Band 22), Kraków 2008.

Łoziński, Władysław: Życie polskie w dawnych wiekach, Kraków 1958.

MacIntyre, Alasdair: Whose Justice? Which Rationality? Notre Dame, Indiana 1988.

Magnone, Lena: „Die polnischen Gender Studies«, in: Die Welt der Slaven. Internationale Halbjahresschrift für Slavistik 61/2 (2016), S. 371-398.

Magnone, Lena: Emisariusze Freuda. Transfer kulturowy psychoanalizy do polskich sfer inteligenckich przed drugą wojną światową. Tom 1 i 2 (= Horyzonty Nowoczesności, Band 120), Kraków 2016.

Magnone, Lena (Hg.), Psychoanaliza w Polsce 1909-1946. Tom 1 i 2 (= Klasycy Polskiej Nowoczesności), Warszawa 2016. 
Majbroda, Katarzyna: Feministyczna krytyka literatury w Polsce po 1989 roku. Tekst, dyskurs, poznanie z odmiennej perspektywy (= Modernizm w Polsce, Band 41), Kraków 2012.

Malinowska, Ewa: »Dwa oblicza uczestnictwa kobiet we współczesnych przemianach społeczeństwa polskiego «, in: Faliszek et al., Kobiety wobec przemian (1997), S. 159-175.

Malinowska, Ewa: Feminizm europejski demokracja parytetowa a polski ruch kobiet. Socjologiczna analiza walki o równouprawnienie płci, Łódź 2000.

Markowski, Michał Paweł: »Emocje. Hasło encyklopedyczne w trzech częściach i dwudziestu trzech rozdziałach (nie licząc motta) «, in: Budrewicz et al., Pamięć i afekty (2014), S. 345-366.

Marody, Mira/Giza-Poleszczuk, Anna: »Changing Images of Identity in Poland: From the Self-Sacrificing to the Self-Investing Woman?", in: Gal/Kligman, Reproducing Gender (2000), S. 151-175.

Marszałek, Magdalena: »eszcze raz o mózgu, płci, biologii i polityce«, in: Pełnym głosem 4 (1996), S. 41-47.

Martinez, Matías/Scheffel, Michael: Einführung in die Erzähltheorie, München 2005.

Massumi, Brian: »Notes on the Translation and Acknowledgements«, in: Deleuze, Gilles/Guattari, Félix, A Thousand Plateaus. Capitalism and Schizophrenia, Minneapolis, London 1987, S. xvi-xix.

Matuchniak-Krasuska, Anna: »Kategorie i reguły polskiego dyskursu o aborcji«, in: Czyżewski et al., Cudze problemy (1991), S. 129-156.

Matuchniak-Krasuska, Anna: „Czym była dyskusja o aborcji«, in: Titkow/Domański, Co to znaczy (1995), S. 189-212.

Matuchniak-Krasuska, Anna: »Ruch feministyczny i kobiecy w Polsce. Interwencja socjologiczna 1994/95«, in: Acta Universitatis Lodziensis. Folia Sociologica 27 (1998), S. 123-150.

McClintock, Anne: Imperial Leather. Race, Gender and Sexuality in the Colonial Contest, New York, London 1995.

Merfeld, Mechthild: Die Emanzipation der Frau in der sozialistischen Theorie und Praxis, Reinbek bei Hamburg 1972.

Michalik, Józef: »Prawdziwa miłość dotyka nieskończoności«, Hirtenbrief vom 16.10.2013, Wrocław. http://wiadomosci.gazeta.pl/wiadomosci/1,114871,1479 5597,_Ideologia_gender_budzi_sluszny_niepokoj Zadna.html (29.1.2017).

Michnik, Adam: »Nationalism«, in: Social Research 58/4 (1991), S. 757-763.

Miller, Nancy K.: Subject to Change. Reading Feminist Writing, New York 1988. Millett, Kate: Sexual Politics, New York 1970.

Miluska, Jolanta/Pakszys, Elżbieta (Hg.), Humanistyka i płeć. Tom I. Studia kobiece z psychologii, filozofii i historii, Poznań 1995.

Miłosz, Czesław: »W stronę kobiet«, in: Teksty Drugie, Śmiech feministek (1993), S. 7-14. 
Mishtal, Joanna Z.: »How the Church Became the State. The Catholic Regime and Reproductive Rights in State Socialist Poland «, in: Penn, Shana/Massino, Jill (Hg.), Gender Politics and Everyday Life in State Socialist Eastern and Central Europe, New York 2009, S. 133-149. https://doi.org/10.1057/9780230101579_9

Mizielińska, Joanna: Płeć Ciało Seksualność. Od feminizmu do teorii queer, Kraków 2006.

Moi, Toril: Sexual/Textual Politics. Feminist Literary Theory (= New Accents), London 1985.

Moir, Anne/Jessel, David: Płeć mózgu. O prawdziwej różnicy między mężczyzną a kobietą, Warszawa 1993.

Monczka-Ciechomska, Magda: »Mit kobiety w polskiej kulturze«, in: Walczewska, Głos mają kobiety (1992), S. 95-101.

Money, John: »Hermaphroditism, Gender and Precocity in Hyperadrenocorticism. Psychologic Findings«, in: Bulletin of the Johns Hopkins Hospital 96 (1955), S. 253-264.

Moser, Jeannie: »Poetologien | Rhetoriken des Wissens. Einleitung«, in: Höcker, Arne et al. (Hg.), Wissen. Erzählen. Narrative der Humanwissenschaften, Bielefeld 2006, S. 11-16.

Mosse, George L.: The Image of Man. The Creation of Modern Masculinity (= Studies in the History of Sexuality), New York, Oxford 1996.

Mouffe, Chantal: Agonistik. Die Welt politisch denken, Berlin 2014.

Mrozik, Agnieszka: Akuszerki transformacji. Kobiety, literatura i władza w Polsce po 1989 roku, Warszawa 2012.

Nasiłowska, Anna: »Drażliwe pytania?», in: Teksty Drugie, Śmiech feministek (1993), S. 1-6.

Nasiłowska, Anna: »Natura jako źródło cierpień«, in: Teksty Drugie, Śmiech feministek (1993), S. 189-194.

Nasiłowska, Anna: Domino. Traktat o narodzinach, Warszawa 1995.

Nasiłowska, Anna: »Feminizm i psychoanaliza - ucieczka od opozycji«, in: Teksty Drugie, Feminizm po polsku (1995), S. 132-141.

Nasiłowska, Anna: Jean Paul Sartre i Simone de Beauvoir (= Pary), Kraków 2006.

Nasiłowska, Anna: »Literatura lat osiemdziesiątych - czy warto o niej pamiętać?», in: Gosk, Hanna/Karwowska, Bożena (Hg.), (Nie)Obecność. Pominięcia i przemilczenia w narracjach XX wieku (= Seria Prac Zakładu Literatury Polskiej XX Wieku Instytutu Literatury Polskiej Uniwersytetu Warszawskiego), Warszawa 2008, S. 424-434.

Newton, Judith: »History as Usual? Feminism and the `New Historicism««, in: Cultural Critique 9 (1988), S. 87-121. https://doi.org/10.2307/1354235

Newton, Judith: »Family Fortunes: `New History` and `New Historicism«", in: Radical History Review 43 (1989), S. 5-22. https://doi.org/10.1215/01636545-1989-43-5

Nietyksza, Maria: „Tradycyjne i nowe formy aktywności publicznej kobiet w warunkach zaborów«, in: Żarnowska/Szwarc, Kobieta i świat polityki (1994), S. 83-98. 
Nowakowska, Urszula: »Wprowadzenie«, in: Gadomska et al., Kobiety w Polsce (2000), S. 5-7.

Nowakowska, Urszula/Korzeniewska, Maja: »Prawa kobiet w sferze prokreacji«, in: Gadomska et al., Kobiety w Polsce (2000), S. 225-256.

Nycz, Ryszard: »Od redaktora«, in: Nycz, Po strukturalizmie (1992), S. 7-8.

Nycz, Ryszard (Hg.), Po strukturalizmie. Współczesne badania teoretycznoliterackie, Wrocław 1992.

Odojewski, Włodzimierz: Zasypie wszystko, zawieje..., Warszawa 1990.

Oko, Dariusz: "Gender - ideologia totalitarna. Interview: Anna Cichobłazińska«, in: Niedziela. Tygodnik Katolicki 24 (2013), S. 40-43. http://www.niedziela.pl/ artykul/106423/nd/Gender---ideologia-totalitarna (9.12.2013).

Orzeszkowa, Eliza: »Kilka słów o kobietach«, in: Tygodnik Mód i Powieści (1870). https://pl.wikisource.org/wiki/Kilka_s\%C5\%82\%C3\%B3w_o_kobietach_(1873) (29.2. 2016).

Ostrowska, Elżbieta: »Matki Polki i ich synowie. Kilka uwag o genezie obrazów kobiecości i męskości kulturze polskiej«, in: Radkiewicz, Gender (2004), S. 215-227.

Oszacki, Aleksander: »Spowiedź niedorodzonej. Kilka uwag lekarza o psychice Marii Komornickiej«, in: Pigoń, Miscellanea (1964), S. 342-349.

OŚKa. Pismo Ośrodka Informacji Środowisk Kobiecych 1-18 (1997-2002).

Owczarski, Wojciech: »Poradnik dla Czytelnika«, in: ders., Colloquia gdańskie (2008), S. 5-10.

Owczarski, Wojciech (Hg.), Colloquia gdańskie, Gdańsk 2008.

Paczoska, Ewa: »Na strychu i po kątach. Pisarki czasu międzywojnia w cieniu i blasku PRLu (Rekonesans) «, in: Gosk, Hanna (Hg.), (Nie)Ciekawa epoka? Literatura i PRL (= Seria Prac Zakładu Literatury Polskiej XX Wieku Instytutu Literatury Polskiej Uniwersytetu Warszawskiego), Warszawa 2008, S. 198-220. Pakszys, Elżbieta/Sikorska, Liliana (Hg.), Humanistyka i płeć. Tom IV. Duchowość i religijność kobiet, dawniej i dziś, Poznań 2000.

Pakszys, Elżbieta/Sobczyńska, Danuta (Hg.), Humanistyka i płeć. Tom II. Kobiety w poznaniu naukowym, wczoraj i dziś, Poznań 1997.

Partyka, Joanna: »Żona wyćwiczona«. Kobieta pisząca w literaturze XVI i XVII wieku (= Rozprawy Literackie, Band 82), Warszawa 2004.

Pawlicki, Aleksander: »Sonderwege der Zensurpolitik in der Volksrepublik Polen«, in: Bock, Ivo (Hg.), Scharf überwachte Kommunikation. Zensursysteme in Ost(mittel)europa (1960er - 1980er Jahre) (= Das andere Osteuropa. Dissens in Politik und Gesellschaft, Alternativen in der Kultur (1960er - 1980er Jahre). Beiträge zu einer vergleichenden Zeitgeschichte, Band 1), Berlin 2011, S. 209-361.

Pawlik, Wojciech: »Spór o aborcję, czyli sztuka parlamentarnej erystyki«, in: Czyżewski et al., Cudze problemy (1991), S. 157-189.

Pełnym głosem 1-5 (1993-1997).

Penn, Shana: Solidarity's Secret. The Women Who Defeated Communism in Poland, Ann Arbor 2006. 
Piętkowa, Romualda (Hg.), Eros, psyche, seks. Materiały z konferencji »Język a erotyka« zorganizowanej przez koło naukowe językoznawców Uniwersytetu Śląskiego, Katowice 1993.

Pietrow-Ennker, Bianka: »Frau und Nation im geteilten Polen«, in: Kemlein, Geschlecht und Nationalismus (2000), S. 125-142.

Pietruczuk, Władysława: „Słowo wstępne«, in: Fiszerowa, Maria/Pietruczuk-Kurkiewiczowa, Władysława (Hg.), Mojego domu radości i troski. Kobiety o sobie, Warszawa 1978, S. 5-13.

Pigoń, Stanisław (Hg.), Miscellanea z pogranicza XIX i XX wieku (= Archiwum Literackie, Band 8), Wrocław u.a. 1964.

Piotrowski, Jerzy: »Badania nad pozycją społeczną kobiet w Polsce Ludowej i wynikające stąd potrzeby społeczne«, in: Wrochno, Krystyna (Hg.), Kobieta, praca, dom. Problemy pracy zawodowej kobiet i rodziny współczesnej. Materiały z konferencji naukowej zorganizowanej przez Zarząd Główny Ligi Kobiet w dniach 25-27 marca 1965 r., Warszawa 1967, S. 10-25.

Piotrowski, Piotr: Art and Democracy in Post-Communist Europe, London 2012. Pirie, Donald P. A.: »Internal Exile in a Free Society? New Poetry in Poland in the 1980s and Early 1990s«, in: Eile/Phillips, New Perspectives (1992), S. 201-229.

Podraza-Kwiatkowska, Maria: »Tragiczna wolność. O Marii Komornickiej«, in: dies., Młodopolskie harmonie i dysonanse, Warszawa 1969, S. 137-168.

Podraza-Kwiatkowska, Maria: »Salome i Androgyna. Mizoginizm a emancypacja«, in: dies., Symbolizm i symbolika w poezji Młodej Polski. Teoria i praktyka, Kraków 1975, S. 363-384.

Podraza-Kwiatkowska, Maria: „Schopenhauer i chuć«, in: dies., Somnambulicy dekadenci - herosi. Studia i eseje o literaturze Młodej Polski, Kraków, Wrocław 1985, S. 162-172.

Podraza-Kwiatkowska, Maria: »Młodopolska femina. Garść uwag«, in: Teksty Drugie, Śmiech feministek (1993), S. 36-53.

Pollock, Griselda: Vision and Difference. Femininity, Feminism, and the Histories of Art, London 1988.

Popiel, Magdalena: »'Powieści w >wieku nerwowym‘, Krystyna Kłosińska, Katowice 1988: [recenzja]«, in: Pamiętnik Literacki 81/2 (1990), S. 388-392.

Pstrong, Krzysztof: »Próba niezupełnie feministyczna«, in: Teksty Drugie, Feminizm po polsku (1995), S. 187-195.

Rachwał, Tadeusz/Sławek, Tadeusz: Maszyna do pisania. O dekonstruktywistycznej teorii literatury Jaquesa Derridy, Warszawa 1992.

Radkiewicz, Małgorzata (Hg.), Gender. Konteksty, Kraków 2004.

Rajan, Tilottama: »Intertextuality and the Subject of Reading/Writing«, in: Clayton/Rothstein, Influence and Intertextuality (1991), S. 61-74.

Rattner, Josef/Danzer, Gerhard: Sozialismus und Psychoanalyse. Studienausgabe (= Enzyklopädie der Psychoanalyse, Band 4), Würzburg 2009.

Regulska, Joanna/Grabowska, Magdalena: »Post-1989 Women's Activism in Poland«, in: Regulska, Joanna/Smith, Bonnie G. (Hg.), Women and Gender in 
Postwar Europe. From Cold War to European Union, London, New York 2012, S. 212-230.

Res Publica Nowa: »Kobiety, feminizm i coś jeszcze«, 108/9 (1997).

Reszke, Irena: Prestiż społeczny a płeć. Kryteria prestiżu zawodów i osób, Wrocław 1984.

Reszke, Irena: Nierówności płci w teoriach: teoretyczne wyjaśnienia nierówności płci w sferze pracy zawodowej, Warszawa 1991.

Rich, Adrienne: „Compulsory Heterosexuality and Lesbian Existence«, in: Signs 5/4 (1980), S. 631-660. https://doi.org/10.1086/493756

Ritz, German: „Eros i sublimacja u Jarosława Iwaszkiewicza«, in: Teksty Drugie 25/1 (1994), S. 29-48.

Ritz, German: »Niewypowiadalne pożądanie a poetyka narracji«, in: Teksty Drugie 45/3 (1997), S. 43-60.

Ritz, German: „Nowy świat i dawny wizerunek kobiety. Polska awangarda po 1918 roku a kulturowe aspekty płci«, in: Kresy 31/3 (1997), S. 11-26.

Ritz, German: "Neue Welt und altes Frauenbild. Ein Gender-Blick auf die polnische Avantgarde nach 1918«, in: Die Welt der Slaven 42 (1997), S. 272-290.

Ritz, German: »Literatura w labiryncie pożądania. Homoseksualność a literatura polska«, in: Pogranicza 1 (1998), S. 92-99.

Ritz, German: »Transgresja płciowa jako forma krytyki spod znaku gender i transformacja dyskursu«, in: Ritz et al., Nowa świadomość płci (2000), S. 89-110.

Ritz, German: »Maria Komornicka: Die gefährdete Autorschaft in den Wirren des Geschlechts. Die widerständige Identität der Transvestitin«, in: Frank, Susi et al. (Hg.), Mystifikation - Autorschaft - Original, Tübingen 2001, S. 135-161.

Ritz, German: „Młoda Polska a transgresja płciowa«, in: ders., Nić w labiryncie pożądania. Gender i płeć w literaturze polskiej od romantyzmu do postmodernizmu, Warszawa 2002, S. 111-136.

Ritz, German: »Kanon i historia literatury widziane z zewnątrz«, in: Iwasiów, Inga/Czerska, Tatiana (Hg.), Kanon i obrzeża, Kraków 2005, S. 29-40.

Ritz, German: »Gender studies dziś. Budowanie teorii i wędrowanie teorii«, in: Teksty Drugie 113/5 (2008), S. 9-15.

Ritz, German et al. (Hg.), Nowa świadomość płci w modernizmie. Studia spod znaku gender w kulturze polskiej i rosyjskiej u schyłku stulecia, Kraków 2000.

Rosner, Katarzyna: »Czy istnieje w Polsce ruch feministyczny? «, in: Pełnym głosem 5 (1997), S. 34-41.

Rühling, Lutz: »Fiktionalität und Poetizität«, in: Arnold, Heinz Ludwig/Detering, Heinrich (Hg.), Grundzüge der Literaturwissenschaft, München 1996 (2011), S. 25-51.

Said, Edward W.: Orientalism, New York 1979.

Said, Edward W.: »Traveling Theory«, in: ders., The World, the Text and the Critic, Cambridge, Mass. 1983, S. 226-247.

Sapkowska, Agata: „Feminizm - wyzwanie czy zagrożenie dla Kościoła?», in: Chańska/Ulicka, Polskie oblicza feminizmu (2000), S. 137-150. 
Sasse, Sylvia: Michail Bachtin zur Einführung, Hamburg 2010.

Schahadat, Schamma: »Intertextualität: Lektüre - Text - Intertext«, in: Pechlivanos, Miltos et al. (Hg.), Einführung in die Literaturwissenschaft, Stuttgart, Weimar 1995, S. 366-377.

Schahadat, Schamma: „Szalone kobiety, nerwowi mężczyźni: histeria i gender na przełomie wieków«, in: Ritz et al., Nowa świadomość płci (2000), S. 245-268.

Scheler, Max: Das Ressentiment im Aufbau der Moralen (= Klostermann Texte: Philosophie), Frankfurt a/M. 1978.

Scott, Joan W.: »Gender: A Useful Category of Historical Analysis«, in: The American Historical Review 91/5 (1986), S. 1053-1075. https://doi.org/10.2307/1864376 Scott, Joan W./Keates, Debra: »Preface«, in: dies., Going Public (2004), S. ix-xv. Scott, Joan W./Keates, Debra (Hg.), Going Public. Feminism and the Shifting Boundaries of the Private Sphere, Urbana, Champaign 2004.

Sedgwick, Eve Kosofsky: Epistemology of the Closet, Berkeley 1990.

Seiler, Nina: »Geschlechterfragen an der Schnittstelle. Verortungen feministischer Polonistik im postsozialistischen Gesellschaftsdiskurs", in: Femina Politica 24/2 (2015), S. 54-67. https://doi.org/10.3224/feminapolitica.v24i2.20976

Seiler, Nina: ">To Overcome the Hurdles«: Locating Feminist Literary Research in 1990s' Poland«, in: Kadin/Woman 2000. Journal for Women's Studies 16/2 (2015), S. 23-43.

Seiler, Nina: »Gipfeltreffen. Polens bergiges Fenster zur Welt«, in: Frölicher, Gianna et al. (Hg.), »Dieser Mont Blanc verdeckt doch die ganze Aussicht!« Der literarische Blick auf Alpen, Tatra und Kaukasus, Zürich 2016, S. 207-220.

Seiler, Nina: »Brüche im Kontinuum. Feministische Kritik im Spannungsfeld polnischer Identitätssuche«, in: Traverse. Zeitschrift für Geschichte 23/2 (2016), S. 97-107.

Shouse, Eric: »Feeling, Emotion, Affect«, in: M/C Journal 8/6 (2005). http://journal. media-culture.org.au/0512/03-shouse.php (18.05.2016).

Showalter, Elaine: »Toward a Feminist Poetics«, in: Jacobus, Mary (Hg.), Women Writing and Writing About Women (= The Oxford Women's Series, Band 3), London 1979, S. 22-41.

Showalter, Elaine: »Feminist Criticism in the Wilderness«, in: Critical Inquiry 8/2 (1981), S. 179-205. https://doi.org/10.1086/448150

Showalter, Elaine: »Hysteria, Feminism, and Gender«, in: Gilman, Sander L./Showalter, Elaine (Hg.), Hysteria Beyond Freud, Berkeley 1993, S. 286-335.

Shreve, Anita: Women Together, Women Alone. The Legacy of the Consciousness-Raising Movement, New York 1989.

Shweders, Richard A.: »Divergent Rationalities«, in: Fiske, Donald W./Shweder, Richard A. (Hg.), Metatheory in Social Science. Pluralisms and Subjectivities, Chicago, London 1986, S. 163-196.

Siemieńska, Renata: Płeć, zawód, polityka. Kobiety w życiu publicznym w Polsce, Warszawa 1990. 
Siemieńska, Renata: »To ona sprowadziła gender do Polski. Prof. Siemieńska u Kublik«, in: Gazeta Wyborcza Studio TV, 07.01.2014.

http://wyborcza.pl/12,82983,15235048,To_ona_sprowadzila_gender_do_ Polski__Prof__Siemienska.html?disableRedirects=true (16.03.2016).

Siemieńska, Renata (Hg.), Wokół problemów zawodowego równouprawnienia kobiet i mężczyzn, Warszawa 1997.

Sierakowska, Katarzyna: "Aspiracje polityczne Związku Równouprawnienia Kobiet Polskich«, in: Żarnowska/Szwarc, Kobieta i świat polityki (1994), S. 245-253.

Sikorska, Joanna (Hg.), Kobiety i ich mężowie. Studium porównawcze, Warszawa 1996.

Siwicka, Dorota: »Ojczyzna intymna«, in: Res Publica Nowa 58-59/7-8 (1993), S. 70-72.

Snitow, Ann: »Przyszłość feminizmu w krajach postkomunistycznych«, in: Spotkania feministyczne (1994/1995), S. 6-13.

Sobczyńska, Danuta: »Macierzyństwo: wartości i dylematy«, in: Miluska/Pakszys, Humanistyka i płeć I (1995), S. 69-84.

Sokołowska, Magdalena: Kobieta pracująca. Socjomedyczna charakterystyka pracy kobiet (= Sygnały), Warszawa 1963.

Sokołowska, Magdalena: »Płeć a przemiany obyczaju«, in: Komorowska, Przemiany rodziny polskiej (1975), S. 164-172.

Sokołowska, Magdalena: »The Woman Image in the Awareness of Contemporary Polish Society«, in: The Polish Sociological Bulletin 35/3 (1976), S. 41-50.

Sokołowska, Magdalena (Hg.), Kobieta współczesna. Z badań socjologów, lekarzy, ekonomistów, pedagogów i psychologów. Materiały z seminarium pracy kobiet IFiS PAN (= Biblioteka Nauki o Pracy), Warszawa 1966.

Sosnowski, Jerzy: »Każdy był małą dziewczynką«, in: Ex Libris 80 (1995), S. 4-5.

Spivak, Gayatri Chakravorty: „Subaltern Studies: Deconstructing Historiography«, in: Guha, Ranajit/Spivak, Gayatri Chakravorty (Hg.), In Other Worlds. Essays in Cultural Politics, Oxford 1988, S. 197-221.

Spotkania feministyczne, Warszawa (1994/1995).

Stańczak-Wiślicz, Katarzyna: »Traktorzystka - o potędze wizerunku«, in: Teksty Drugie 141/3 (2013), S. 150-163.

Stanford Friedman, Susan: »Weavings: Intertextuality and the (Re)Birth of the Author«, in: Clayton/Rothstein, Influence and Intertextuality (1991), S. 146-180.

Stark, David: »Path Dependence and Privatization Strategies in East Central Europe«, in: East European Politics and Societies 6/1 (1991), S. 17-54.

Stegmann, Natali: »'Wie die Soldaten im Feld : Der widersprüchliche Kampf polnischer Frauen für >Vaterland Kemlein, Geschlecht und Nationalismus (2000), S. 197-216.

Stegmann, Natali: »Paradygmaty nauk przyrodniczych, ruch kobiecy i kategoria ‘sexı: o ustaleniu ról płciowych w polskim ruchu na rzecz moralności w 
przededniu pierwszej wojny światowej«, in: Ritz et al., Nowa świadomość płci (2000), S. 33-49.

Stoller, Robert J.: Sex and Gender. Volume I. The Development of Masculinity and Femininity, London 1968 (1984).

Szacki, Jerzy: »Polish Democracy: Dreams and Reality«, in: Social Research 58/4 (1991), S. 711-722.

Szacki, Jerzy: Liberalizm po komunizmie (= Demokracja. Filozofia i praktyka), Kraków 1994.

Szatlach, Maria Ewa: „Dylematy Polek na rynku pracy - aspekty teoretycznoprawne a rzeczywistość społeczna«, in: Pierzchalski, Filip et al. (Hg.), Feminizm po polsku, Warszawa 2011, S. 129-181.

Szczuka, Kazimiera: „Czy feministki wybić się mogą na mit?«, in: Res Publica Nowa, Kobiety, feminizm (1997), S. 38-43.

Szczuka, Kazimiera: Kopciuszek, Frankenstein i inne. Feminizm wobec mitu, Kraków 2001.

Szczuka, Kazimiera: Milczenie owieczek. Rzecz o aborcji, Warszawa 2004.

Szpakowska, Małgorzata: Chcieć i mieć. Samowiedza obyczajowa w Polsce czasu przemian (= Seria z Wagą), Warszawa 2003.

Ślęczka, Kazimierz: »Rola kobiet we współczesnych transformacjach społecznych (w zwierciadle feminizmu)«, in: Faliszek et al., Kobiety wobec przemian (1997), S. 129-141.

Ślęczka, Kazimierz: Feminizm. Ideologie i koncepcje społeczne współczesnego feminizmu, Katowice 1999.

Środa, Magda: »Kobieta: wychowanie, role, tożsamość«, in: Walczewska, Głos mają kobiety (1992), S. 9-17.

Świątkiewicz, Wojciech: »Rodzina wobec kryzysu wartości«, in: Faliszek et al., Kobiety wobec przemian (1997), S. 178-186.

Świda-Ziemba, Hanna: Człowiek wewnętrznie zniewolony. Mechanizmy i konsekwencje minionej formacji - analiza psychosocjologiczna, Warszawa 1997.

Tabaszewska, Justyna: »Afektywne interpretacje. Afekt w koncepcjach Jill Bennett oraz Valerie Walkerdine«, in: Budrewicz et al., Pamięć i afekty (2014), S. 215-226.

Tacke, Charlotte: »Geschlecht und Nation«, in: Kemlein, Geschlecht und Nationalismus (2000), S. 15-32.

Taperek, Marta: »Szztuka sławiańskaく w wybranych pismach teoretycznych architekta Jana Sasa-Zubrzyckiego«, Unveröffentlichte Skizze, Warszawa 2016.

Teksty Drugie: »Śmiech feministek«, 22-24/4-6 (1993).

Teksty Drugie: »Feminizm po polsku«, 33-34/3-4 (1995).

Tischner, Józef: Etyka solidarności oraz Homo sovieticus, Kraków 1992.

Titkow, Anna: »Kobiety pod presją? Proces kształtowania się tożsamości«, in: Titkow/Domański, Co to znaczy (1995), S. 9-39.

Titkow, Anna/Domański, Henryk (Hg.), Co to znaczy być kobietą w Polsce, Warszawa 1995. 
Tomaševskij, Boris: »Literatur und Biographie«, in: Jannidis et al., Theorie der Autorschaft (2000), S. 49-61.

Tomkins, Silvan S.: »Ideology and Affect«, in: ders., Exploring Affect. The Selected Writings of Silvan S. Tomkins (= Studies in Emotion and Social Interaction), Cambridge, Paris 1995, S. 109-167.

Truszkiewicz-Budziło, Ewa: „Dyskusja feminizmu z freudyzmem«, in: Pełnym głosem 4 (1996), S. 48-56.

Turner, Victor: The Ritual Process. Structure and Anti-Structure, Ithaca, New York 1969.

Valéry, Paul: Schlimme Gedanken und andere, Frankfurt a/M. 1963.

Vatter, Theresa: Die Rezeption der Gender Studies in der polnischen Literaturwissenschaft, Unveröffentlichte Diplomarbeit, Passau 2009.

Vogl, Joseph: »Für eine Poetologie des Wissens«, in: Richter, Karl et al. (Hg.), Die Literatur und die Wissenschaften 1770-1930, Stuttgart 1997, S. 107-127. https://doi.org/10.1007/978-3-476-04286-6_5

Vogl, Joseph: »Einleitung«, in: ders. (Hg.), Poetologien des Wissens um 1800, München 1999, S. 7-16.

Walczewska, Sławomira: »Czy kobietom w Polsce potrzebny jest feminizm?«, in: Titkow/Domański, Co to znaczy (1995), S. 245-256.

Walczewska, Sławomira: »Feminizm? - jest!«, in: Pełnym głosem 4 (1996), S. 25-26. Walczewska, Sławomira: Damy, rycerze i feministki. Kobiecy dyskurs emancypacyjny w Polsce (= Kobieta, Kultura, Krytyka), Kraków 1999 (2000).

Walczewska, Sławomira: »Dwie dekady feminizmu«, in: dies., Feministki (2005), S. 5-20.

Walczewska, Sławomira (Hg.), Głos mają kobiety. Teksty feministyczne, Kraków 1992.

Walczewska, Sławomira (Hg.), Feministki - własnym głosem o sobie, Kraków 2005.

Walicka-Hueckel, Małgorzata: „Feminizm jest polityczny. Rozmowa z Toril Moi«, in: Teksty Drugie, Śmiech feministek (1993), S. 97-114.

Watson, Peggy: "Eastern Europe’s Silent Revolution: Gender«, in: Sociology 27/3 (1993), S. 471-487. https://doi.org/10.1177/0038038593027003008

Wawrzykowska-Wierciochowa, Dionizja: »Kobieta polska w zaraniu ruchu wyzwoleńczego«, in: Wiedza i Życie 3 (1954), S. 152-157.

Wawrzykowska-Wierciochowa, Dionizja: Z dziejów kobiety wiejskiej. Szkice historyczne 1861-1945, Warszawa 1961.

Wawrzykowska-Wierciochowa, Dionizja: Od prządki do astronautki. Z dziejów kobiety polskiej, jej pracy i osiągnięć, Warszawa 1963.

Wawrzykowska-Wierciochowa, Dionizja: Rycerki i samarytanki, Warszawa 1988. Weedon, Chris: Feminist Practice and Poststructuralist Theory. Second Edition, Oxford 1987 (1997).

Weininger, Otto: Geschlecht und Charakter. Eine prinzipielle Untersuchung, Wien 1919. 
Węgierek, Monika: „Wybrane katolickie i protestanckie elementy płci kulturowej (gender) w stereotypie roli kobiety«, in: Kwartalnik Pedagogiczny 155-156/1-2 (1995), S. 179-197.

Węgierek, Monika: »Przegląd ważniejszych polskich publikacji feminologicznych po roku 1980«, in: Kwartalnik Pedagogiczny 155-156/1-2 (1995), S. 417-449.

Węgierek, Monika: »Polski feminizm - jest czy go nie ma?», in: Pełnym głosem 4 (1996), S. 3-6.

White, Hayden: Metahistory. The Historical Imagination in Nineteenth-Century Europe, Baltimore, London 1973.

White, Hayden: Tropics of Discourse. Essays in Cultural Criticism, Baltimore, London 1978.

Wiarda, Howard J.: »Southern Europe, Eastern Europe, and Comparative Politics: >Transitology and The Need for New Theory«, in: East European Politics and Societies 15 (2001), S. 485-501. https://doi.org/10.1177/0888325401015003001

Wierzbicki, Andrzej: Wschód-Zachód w koncepcjach dziejów Polski. Z dziejów

polskiej myśli historycznej w dobie porozbiorowej, Warszawa 1984.

Więź: »Miejsce kobiety w Kościele i społeczeństwie«, 411/1 (1993).

Więź: »Nowy feminizm?«, 471/1 (1998).

Wisłobocki, Tomasz: Obywatelki. Kobiety w przestrzeni publicznej we Francji przełomu wieków XVIII i XIX, Kraków 2014.

Wolff, Larry: Inventing Eastern Europe. The Map of Civilization on the Mind of the Enlightenment, Stanford, California 1994.

Woolf, Virginia: A Room of One's Own, London 1929.

Woolf, Virginia: Własny pokój, Warszawa 1997.

Wrochno, Krystyna: Kobiety w Polsce, Warszawa 1969.

Yuval-Davis, Nira: Geschlecht und Nation, Emmendingen 2001.

Zadra 1- (1999-).

Zapolska, Gabriela: Kaśka Kariatyda, Lublin u.a. 1922.

http://wolnelektury.pl/katalog/lektura/zapolska-kaska-kariatyda/ (04.03.2017)

Zawiszewska, Agata: »Międzywojenna felietonistyka kobieca. Casus: Irena Krzywicka«, in: Iwasiów, Prywatne/publiczne (2008), S. 13-79.

Zielińska, Eleonora: »Between Ideology, Politics, and Common Sense: The Discourse of Reproductive Rights in Poland «, in: Gal/Kligman, Reproducing Gender (2000), S. 23-57.

Zimand, Roman: »Klucze do Marii P.O.W.«, in: ders., Wojna i spokój. Szkice trzecie, London 1984, S. 123-143.

Żarnowska, Anna: »Prywatna sfera życia rodzinnego i zewnętrzny świat życia publicznego - bariery i przenikanie (przełom XIX i XX wieku)«, in: Żarnowska/ Szwarc, Kobieta i świat polityki (1994), S. 5-28.

Żarnowska, Anna/Szwarc, Andrzej (Hg.), Kobieta i społeczeństwo na ziemiach polskich w XIX wieku, Warszawa 1990.

Żarnowska, Anna/Szwarc, Andrzej (Hg.), Kobieta i edukacja na ziemiach polskich w XIX i XX wieku. Tom I i II, Warszawa 1992. 
Żarnowska, Anna/Szwarc, Andrzej (Hg.), Kobieta i świat polityki. Polska na tle porównawczym w XIX i w początkach XX wieku, Warszawa 1994.

Żarnowska, Anna/Szwarc, Andrzej (Hg.), Kobieta i kultura. Kobiety wśród twórców kultury intelektualnej i artystycznej w dobie rozbiorów i w niepodległym państwie polskim, Warszawa 1996.

Żarnowska, Anna/Szwarc, Andrzej (Hg.), Kobieta i świat polityki w niepodległej Polsce 1918-1939, Warszawa 1996.

Żarnowska, Anna/Szwarc, Andrzej (Hg.), Kobieta i kultura życia codziennego. Wiek XIX i XX, Warszawa 1997.

Żarnowska, Anna/Szwarc, Andrzej (Hg.), Kobieta i praca. Wiek XIX i XX, Warszawa 2000.

Żarnowska, Anna/Szwarc, Andrzej (Hg.), Kobieta i kultura czasu wolnego, Warszawa 2001.

Żarnowska, Anna/Szwarc, Andrzej (Hg.), Kobieta i małżeństwo. Społeczno-kulturowe aspekty seksualności. Wiek XIX i XX, Warszawa 2004.

Żarnowska, Anna/Szwarc, Andrzej (Hg.), Kobieta i rewolucja obyczajowa. Społeczno-kulturowe aspekty seksualności. Wiek XIX i XX, Warszawa 2006.

Żmichowska, Narcyza: »Słowo przedwstępne do dzieł dydaktycznych pani Hoffmanowej«, in: dies. (Hg.), Dzieła Klementyny z Tańskich Hoffmanowa. Tom 8, Warszawa 1876, S. 207-297. 



\section{Begriffs- und Titelverzeichnis}

\section{Begriffe und Bezeichnungen}

drugi obieg

Untergrundliteratur in der Volksrepublik in den 1980er Jahren

Entuzjastki

Die »Enthusiastinnen«, ein sich lose um die Schriftstellerin Narcyza Żmichowska gruppierender informeller Frauenbund. Kresy

Die »Grenzländer«, die ehemaligen Ostgebiete der Republik Polen-Litauen, die heute in Litauen, Weißrussland und der Ukraine liegen.

krzatactwo

Das Herumwirtschaften und -hantieren, 1992 von Jolanta Brach-Czaina eingeführt

Liga Kobiet

Frauenbund, sozialistisch aktive »Frauengewerkschaft" ab 1945 und in geringerem Maße auch nach 1989. Anfang der 1980er wurde die Organisation in Bund Polnischer Frauen umbenannt (Liga Kobiet Polskich).

Matka Polka

Mutter Polin, das romantische Ideal der polnischen patriotischen Mutter Młoda Polska

Junges Polen, die künstlerische Strömung des Modernismus in polnischen Gebieten um die Wende zum 20. Jahrhundert

Niezależny Samorządny Związek Zawodowy (NSZZ) »Solidarność«

Unabhängige Selbstverwaltete Gewerkschaft "Solidarität», treibende Kraft hinter den oppositionellen Bestrebungen der 1980er Jahre. Im Zuge des Kriegszustands von 1981 wurde die NSZZ »Solidarność « verboten.

Polska Rzeczpospolita Ludowa (PRL)

Polnische Volksrepublik, 1949-1989 


\section{Mehrfach genannte Titel}

\section{Absolutna amnezja}

Absolute Amnesie | Izabela Filipiak, 1995

Archiwum Literackie

Literarisches Archiv| Reihe

Titel des genannten Bandes: Miscellanea z pogranicza XIX i XX wieku

Miszellaneen von der Wende des 19. zum 20. Jahrhundert| Stanisław Pigoń, 1964

Całe zycie Sabiny

Das ganze Leben Sabinas | Helena Boguszewska, 1934

Ciało, pożądanie, ubranie. O wczesnych powieściach Gabrieli Zapolskiej

Körper, Begehren, Kleidung. Die frühen Romane Gabriela Zapolskas | Krystyna Kłosińska, 1999

Cudzoziemki. Studia o polskiej prozie kobiecej

Ausländerinnen. Studien zur polnischen weiblichen Prosa | Grażyna Borkowska, 1996

Domino. Traktat o narodzinach

Traktat über die Geburt | Anna Nasiłowska, 1995

Gender dla średnio zaawansowanych

Gender für fortgeschrittene Anfänger | Inga Iwasiów, 2004

»Gdzie jest Lemańska?!»

»Wo ist Lemańska?!«| Maria Janion, 1979

Kaśka Kariatyda

Käthe, die Karyatide | Gabriela Zapolska, 1888

Kobiety i duch inności

Frauen und der Geist des Andersseins | Maria Janion, 1996

Kresy w twórczości Włodzimierza Odojewskiego. Próba feministyczna

Die Kresy im Schaffen Włodzimierz Odojewskis. Ein feministischer Versuch |

Inga Iwasiów, 1994

Książka pamiątek

Buch der Andenken | Narcyza Żmichowska, 1847-48/1885

Maria Komornicka, in memoriam

Maria Komornicka, in memoriam | Maria Janion, 1996

Pełnym głosem

Mit voller Stimme | feministische Zeitschrift | Fundacja eFKa, 1993-1997

Piórem niewieścim. Z problemów prozy kobiecej dwudziestolecia międzywojennego

Mit weiblicher Feder. Problemstellungen der weiblichen Prosa der Zwischen-

kriegszeit | Ewa Kraskowska, 1999

Przedpiekle

Die Hölle der Jungfrauen [Vorhölle] | Gabriela Zapolska, 1889

Przymierze $z$ dzieckiem

Allianz mit dem Kind | Maria Kuncewiczowa, 1927 
Przyszłość feminizmu w krajach postkomunistycznych

Die Zukunft des Feminismus in den postkommunistischen Staaten | Ann Snitow, 1994/1995 (1993)

Spotkania feministyczne

Feministische Treffen | Sammelband, 1994/1995

Szczeliny istnienia

Spalten im Sein | Jolanta Brach-Czaina, 1992

Smiech feministek

Das Lachen der Feministinnen | Sonderband der Teksty Drugie, 1993

Teksty Drugie

Zweite Texte | literaturwissenschaftliche Zeitschrift

Transgresje

Transgressionen | Reihe | Maria Janion et al. (Hg.), 1981-1988

W strone kobiet

Auf die Seite der Frauen | Czesław Miłosz, 1993

W Grabowie podczas wojny. Xiega poezji idyllicznej

In Grabów während des Kriegs. Buch der idyllischen Poesie | Piotr »Odmieniec« Włast, 1917-1927

$X Y$, de l'identité masculine

XY - Die Identität des Mannes | Élisabeth Badinter, 1992

Zasypie wszystko, zawieje...

Katharina oder Alles verwehen wird der Schnee | Włodzimierz Odojewski, 1973 


\section{Kulturwissenschaft}

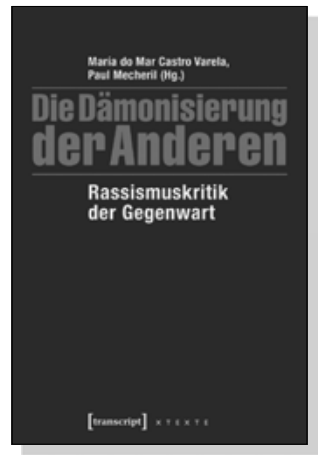

María do Mar Castro Varela, Paul Mecheril (Hg.)

Die Dämonisierung der Anderen

Rassismuskritik der Gegenwart

2016, 208 S., kart.

$17,99 €(D E), 978-3-8376-3638-3$

E-Book

PDF: $15,99 €(D E)$, ISBN 978-3-8394-3638-7

EPUB: $15,99 €(D E)$, ISBN 978-3-7328-3638-3

Fatima El-Tayeb

Undeutsch

Die Konstruktion des Anderen

in der postmigrantischen Gesellschaft

2016, 256 S., kart.

$19,99 €(D E), 978-3-8376-3074-9$

E-Book: 17,99 € (DE), ISBN 978-3-8394-3074-3

$[$ ramoripen $\cdots \cdots \cdots$

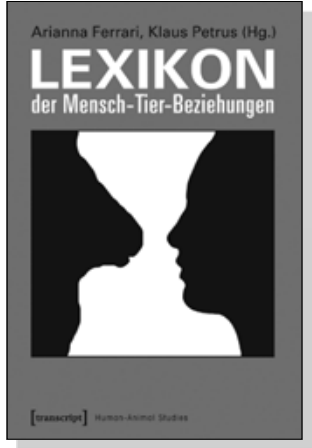

Arianna Ferrari, Klaus Petrus (Hg.)

Lexikon der Mensch-Tier-Beziehungen

2015, 482 S., kart.

$29,99 €(D E), 978-3-8376-2232-4$

E-Book: 26,99 € (DE), ISBN 978-3-8394-2232-8 


\section{Kulturwissenschaft}

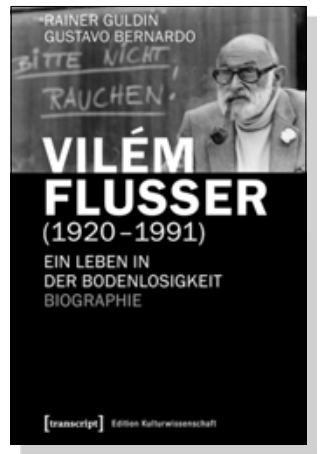

Rainer Guldin, Gustavo Bernardo

Vilém Flusser (1920-1991)

Ein Leben in der Bodenlosigkeit. Biographie

September 2017, 424 S., kart., zahlr. Abb.

$34,99 €(D E), 978-3-8376-4064-9$

E-Book: 34,99 € (DE), ISBN 978-3-8394-4064-3

\section{POP}

Thomas Hecken, Moritz Baßler, Robin Curtis, Heinz Drügh, Mascha Jacobs, Nicolas Pethes, Katja Sabisch (Hg.)

\section{POP}

Kultur \& Kritik (Jg. 6, 2/2017)

Oktober 2017, 176 S., kart., zahlr. Abb.

$16,80 €(D E), 978-3-8376-3807-3$

E-Book: $16,80 €(D E)$, ISBN 978-3-8394-3807-7

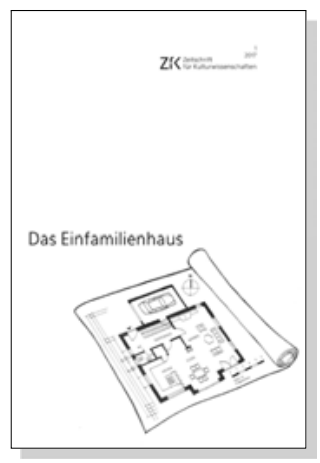

Sonja Hnilica, Elisabeth Timm (Hg.)

\section{Das Einfamilienhaus}

Zeitschrift für Kulturwissenschaften, Heft 1/2017

Juli 2017, 176 S., kart.

$14,99 €(D E), 978-3-8376-3809-7$

E-Book: 14,99 € (DE), ISBN 978-3-8394-3809-1 
